


\section{HARVARD UNIVERSITY.}

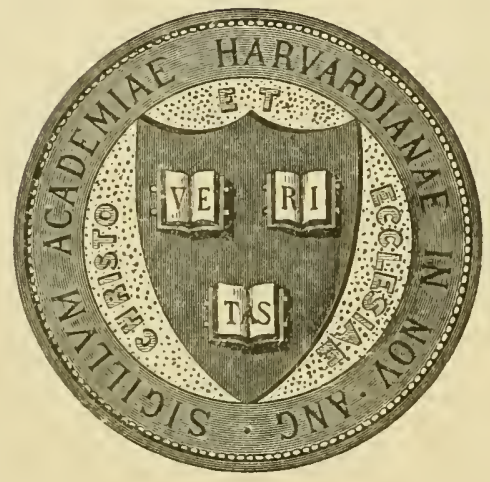

L I B R A R Y

OF THE

MUSEUM OF COMPARATIVE ZOÖLOGY

$\underline{36,557}$

LIBRARY OF

SAMUEL GARMAN

September 1. 1928 . 



FISHES, LIVING AND FOSSIL 


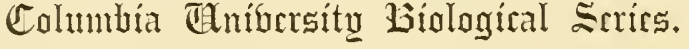

\author{
EDITED BY \\ HENRY FAIRFIELD OSBORN.
}

1 FROM THE GREEKS TO DARWIN.

By Henry Fairfield Osborn. Sc.D Princeton.

2. AMPHIOXUS AND THE ANCESTRY OF THE VERTEBRATES.

By Arthur Willey, B.Sc. Lond. Univ.

3. FISHES, LIVING AND FOSSIL. An Introductory Study

By Bashford Dean. Ph.D. Columbia.

4. THE CELL IN DEVELOPMENT AND INHERITANCE

By Edmund B. Wilson, Ph.D. J.H.U. 


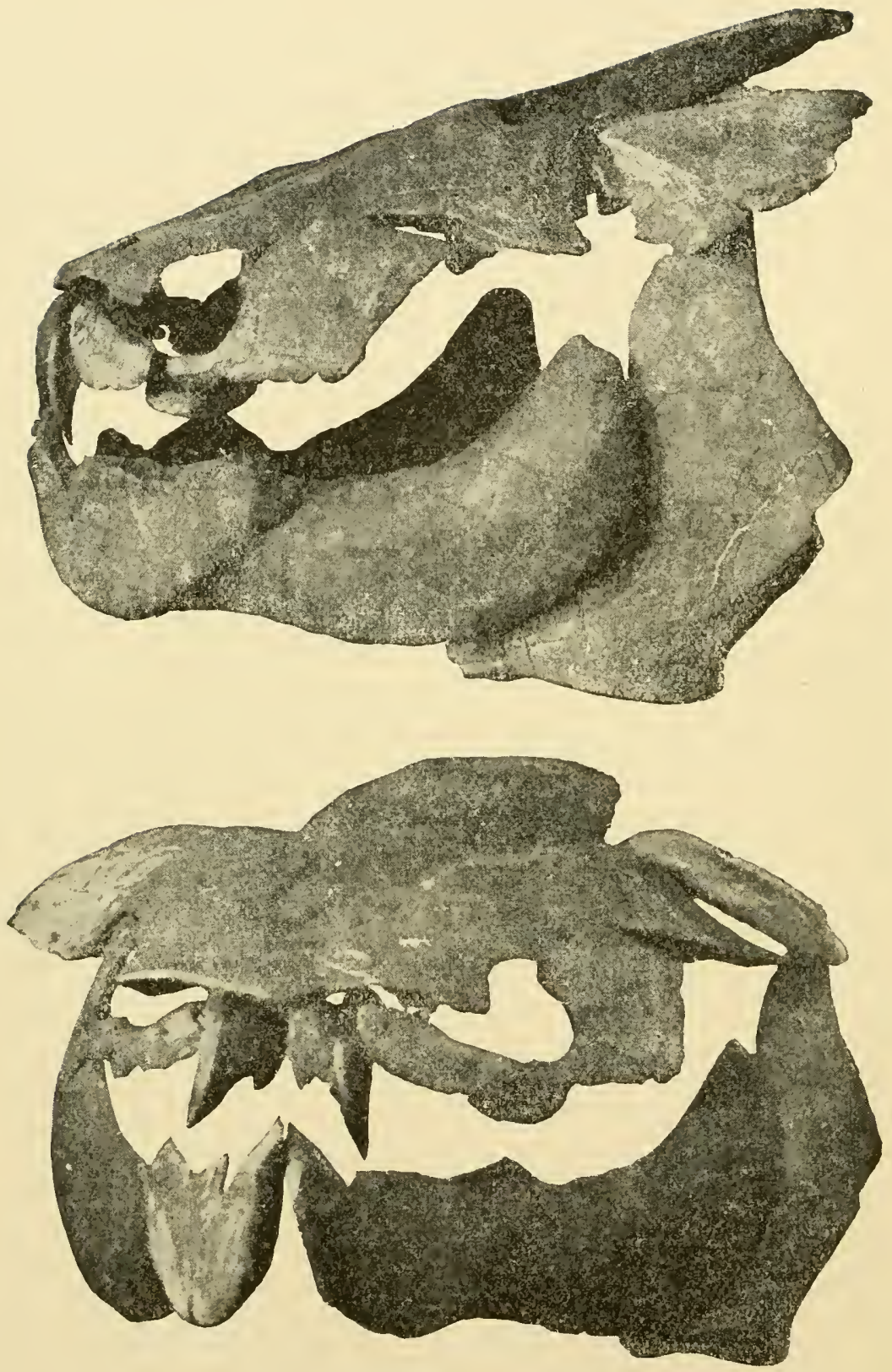

Frontisprece.- - Head of Dinichthys INTERMEDIUS, NEIVBERRY, in front and side viers. $\times \frac{1}{10}$. From photograph of specimen collected by Dr. William Clark, in the Waverly (Lower Carboniferous) of Ohio, now in the collection of Columbia College, New York. (V.p. I33.) 


\title{
Fishes, Living ANd Fossil
}

\author{
AN OUTLINE OF THEIR FORMS AND \\ PROBABLE RELATIONSHIPS
}

BY

\author{
BASHFORD DEAN, Ph.D. \\ instructor in Biology, Columbia College, New York City
}

Now 19 ark

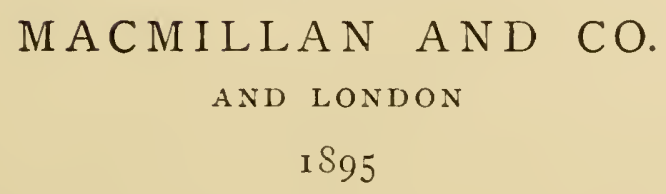


Copyright, 1895,

By MACMILLAN AND CO.

Norbood 扔ess

J. S. Cushing \& Co. - Berwick \& Smith Norwood Mass. U.S.A. 


\section{$\pi$}

MY FRIEND AND TEACHER

\section{JOHN STRONG NEWBERRY}

LATE PROFESSOR OF GEOLOGY IN

COLUMBIA COLLEGE 


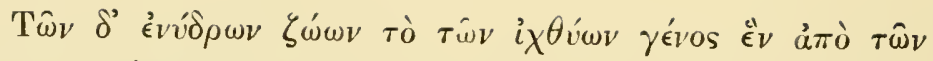

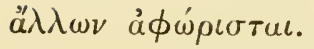

Aristotle, De Animalibus Historiae, Lib. II., cap. xiii. 


\section{P R E F A C E}

A knowledge of Fishes, living and fossil, is not to be included readily within the limits of an introductory study. In preparing the present volume it has nevertheless been my object to enable the reader to obtain a convenient review of the most important forms of fishes, and of their structural and developmental characters. I have also endeavoured to keep constantly in view the problems of their evolution.

At the end of the book a series of tables affords more definite contrasts of the anatomy and embryology of the different groups of fishes. And as an aid to further study has been added a summarized bibliography, including especially the works of the more recent investigators.

My sincere thanks are due to my friend and colleague, Professor Henry Fairfield Osborn, for many suggestions during the early preparation of the book, and for the care with which he has later revised the proof. I must also express my indebtedness to Mr. Arthur Smith Woodward of the British Museum for his personal kindnesses in aiding my studies. My thanks are also due to my father, William Dean, for the preparation of the index.

The figures, unless otherwise stated, are from my original pen drawings.

B. D.

Biological laboratory of Columbia College,

May, I 895. 



\section{CONTENTS}

I

PAGE

Introductory. The form and movement of Fishes. Their classification; geological distribution; mode of evolution. The survival of generalized forms

The Evolution of Structures characteristic of Fishes; e.g. (I) gills, (2) skin defences, teeth, (3) fins, and (4) sense organs . . . . 14

\section{III}

The Lampreys and their Allies. Their structures and probable relationships. The Ostracoderms and Palæospondylus . . . . . . . 57

The Sharks. Their plan of structure; prominent forms, living and extinct; their interrelationships.

The Chimæroids. Their characteristic structures; their representatives and relationships

The Lung-fishes. Their structures. Extinct and recent forms. The evolution of the group . . . . . . . . . . . II6 


\section{VII}

The Teleostomes (i.e. Ganoids and Teleosts). Typical members; their structures and interrelationships; their probable descent . . . . 139

\section{VIII}

The Groups of Fishes contrasted from the Standpoint of Embryology. Their eggs and breeding habits. Outlines of the development of Lamprey, Shark, Lung-fish, Ganoid, and Teleost. Their larval development

\section{EXPLANATORY TABLES :}

I. Classification of Fishes . . . . . . . . . . $S$

II. Distribution of Fishes in Geological Time . . . . . 9

III. Phylogeny of Sharks, Chimæroids, Dipnoans . • . . 98

IV. Phylogeny of Teleostomes . . . . . . . . . 166

V. Characters of Vertebræ, Fins, Skull (Figs. 310-315) . . 252

VI. Relations of Jaws and Branchial Arches (Figs. 310-315) . 256

VII. Heart (Figs. 316-325) . . . . . . . . . 260

VIII. Gills, Spiracle, Gill rakers (Figs. 9-12, 326-33I) . . . 260

IX. Digestive Tract (Figs. 326-33I) . . . . . . . 263

X. Swim-Bladder (Figs. 13-19) . . . . . . . . 264

XI. Genital System (Figs. 331-337) . . . . . . . . 266

XII. Plan of Circulation in Fishes (Fig. 338) . . . . . . 269

XIII. Excretory System (Figs. 33I-337) . . . . . . . 270

XIV. Abdominal Pores (Figs. 33I-337) . . . . . . . 271

XV. Central Nervous System (Figs. 339-344) . . . . . . 274

XVI. Sense Organs . . . . . . . . . . . . 276

XVII. Integument, Lateral line . . . . . . . . 278

XVIII. Developmental Characters . . . . . . . . 280

XIX. Comparison of Phylogenetic Tables of Authors . . . 282 


\section{LIST OF FIGURES}

Frontispiece. Head of Dinichthys. FIG.

I, 2. Moving fishes, shark and eel

3. Spanish mackerel . . .

4. Front view of Spanish mackerel . . . . . 4

5-S. Numerical lines of fishes . 5

9-1 2. Gills of fishes . . . 17, 259

I3-19. Air-bladder . . . . 22, 265

20-3I. Teeth and scales . . . 24

$32-3 \delta$. Fin spines . . . . 29

39-43. Unpaired fins . . . 32, 33

44-48. Caudal fin . . . . 37

49-54. Paired fins . . . . . 42

55-60. Barbels and sense organs 47

6I-68. Nucous canals . . . 50

69. General anatomy of Cyclostome . . . . . 58

69 A. Slieleton of lamprey . . 58

70-72 A-D. Bdellostoma, Myxine, Petromyzon . . 60, 6I

73. Palæospondỵlus . . . . . 65

74. Pteraspis . . . . . . 66

75. Palreaspis . . . . . 66

76, 77. Plates of Pteraspis . . . 66

78, 79. Cephalaspis . . . . . 66

So-S2. Pterichthys . . . . . 68

83. General anatomy of shark . 73

84. Skeleton of shark . . . 75, 255

85. Vertebræe of shark . . . . 706

S6, 86 A. Cladoselache . . . . 79

86 B. Teeth of Cladoselache . . So

S7. Acanthodes . . . . . . SI

8S. Acanthodes, shagreen . . . I I $_{\mathbf{I}}$

88 A. Acanthodes, teeth . . . 82

89. Climatius
FIG. PAGE

9o. Pleuracanthus . . . . $S_{3}$

go A. Teeth of Pleuracanthus . $S_{4}$

$90 \mathrm{~B}$. Head roof of Pleuracanthus $S_{4}$

91. Cestracion . . . . . $S_{5}$

92. Chlamydoselache . . . $S_{7}$

93. Heptanchus , . . . . 88

94. Squalus . . . . . . S9

95. Alopias . . . . . . S9

96. Lamna . . . . . . 90

96 A. Cetorhinus . . . . . 90

96 в. Læmargus . . . . . 91

97. Squatina . . . . . 9 I

98, 98 A. Pristis . . . . 92

99. Pristiophorus . . . . . 93

I00. Rhinobatis . . . . . 93

IOI. Raja . . . . . . . . 94

I02. Torpedo. . . . . . . 95

IO2 A. Dicerobatis (Cephaloptera). . . . . 96

I03. Shark phỵlogeny . . . 98

104. General anatomy of Chimæra IOO

105. Skeleton of Chimæra . . 102

$105 \mathrm{~A}$. Ischyodus . . . . 104

I06. Myriacanthus . . . . 105

I06 A. Squaloraja . . . . I05

I06 B, C. Derm plates of Myria-

canthus . . . . . 105

107-I I2. Dental plates of Chimeroids. . . . . 106

I 3-116A. Spines and claspers of Chimieruids . . . 107

I 7 . Harriotta . . . . . IoS

I I \&. Callorhynchus . . . . . 109

I I9. Chimara . . . . . . I Io

I 20. Chimera, young . . . I I I

I 21. General anatomy of lung-fish I I $7_{7}$ xiii 
FIG.

PAGE

I22. Skeleton of lung-fish .

FIG.

PAGE

I 22 A. Jaws and skull of Protopterus . . . . . I 20

I23. Dipterus . . . . . . . 121

124. Derm bones of head of Dipterus . . . . . . I $2 \mathbf{I}$

I 25, I 25 A. Jaws of Dipterus . . 12I

I26. Phaneropleuron . . . . 122

I 27. Ceratodus . . . . . . I 23

128. Skeleton of Ceratodus . . 123

I 28 A. Skull of Ceratodus . . . I24

I 29. Lepidosiren . . . . . I25

I 29 A. Protopterus . . . . . I26

I3O. Coccosteus . . . . . I I3I

I3I. Coccosteus, dorsal view . . I32

I32. Coccosteus, ventral . . . 132

133. Dinichthys . . . . • .133

I34-137. Dinichthys, dorsal view 134

$13^{8-144}$. Mandibles of Arthrodirans . . . . . . 137

145. General anatomy of Teleost I 40 146. Skeleton of Teleost . . . I42

I47. Skeleton of Ganoid . . . 144

I4S. Polypterus . . . . . I 4 S

I49. Polypterus, head of young . $14 \delta$

I 50. Calamoichthys . . . . 150

I5I. Gyroptychius . . . . I5I

I52. Osteolepis . . . . . I5I

I53. Holoptychius . . . . . I5I

I54. Eusthenopteron . . . I52

I55. Colacanthus . . . . I53

I 56. Diplurus . . . . . . I54

I56 A. Undina . . . . . . I54

I57. Lepidosteus . . . . I55

I58. Elonichthys . . . . I56

159. Eurynotus . . . . . . 156

I60. Cheirodus . . . . . I 157

I6I. Semionotus . . . . I I57

I62. Aspidorhynchus . . . I $5^{8}$

I63. Microdon . . . . . $15^{8}$

I64. Palæoniscus . . . . . I59

165. Acipenser . . . . . . I60

I65 A. Chondrosteus . . . I6I

166. Scaphirhynchus . . . . I62

I66 A. Psephurus . . . . . I62

I66 B. Polyodon . . . . . I63

167. Amia. . . . . . . . 163

I68. Amia, gular region . . . I64

I69. Caturus . . . . . . . 164

I 70. Leptolepis . . . . . . 165

I7 I. Megalurus . . . . . . I65

I 7 A. Phylogeny of the Teleostomes . . . . . I66

I72-I 74. Deep-sea fishes . . I68

I75. Fierasfer . . . . . . I69

I 76. Carassius . . . . . . I70

I77. Amiurus . . . . . . I7 I

I 78. Callichthys . . . . . . 172

I 79. Mormyrus . . . . . I 172

I So. Anguilla . . . . . . . 173

I81. Perca . . . . . . . 173

I 2 . Gadus . . . . . . . I74

I $S_{3}$. Pseudopleuronectes . . I 75

I 84 . Chilomycterus . . . . I 76

I84 A. Lagocephalus . . . I I76

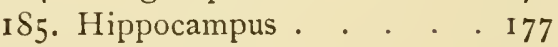

I $\delta_{5}$ A. Syngnathus . . . . I 78

I 86-I 99. Eggs of fishes . . I I

200-215. Development of lam-

prey . . . . . . I 89

2r6-230. Development of shark . 194

23I-24S. Development of lung-

fish . . . . I99, 201

249-268. Development of Ganoid 203

269-283. Development of Teleost 208

284-289. Larval sharks . . . 216

290-295. Larval lung-fishes . . 219

296-302. Larval sturgeons. . . 222

303-309. Larval Teleosts . . . 224

310-3I5. Skulls, jaws, and branchial arches . . . 254

316-325. Heart and conus arteriosus . . . . . 258

326-331. Digestive tracts . . 262

332-337. Urinogenital ducts and openings. . . . . 267

338. Blood-vessels of shark . . 268

339-344. Brain . . . . . 272 


\section{FISHES IN GENERAL}

\section{INTRODUCTION}

Fishes, defined in a popular way, are back-boned animals, gill-breathing, cold-blooded, and provided with fins. It is in their conditions of living that they have differed widely from the remaining groups of vertebrates. Aquatic life has stamped them in a common mould and has prescribed the laws which direct and limit their evolution; it has compressed their head, trunk, and tail into a spindlelike form; it has given them an easy and rapid motion, enabling them to cleave the water like a rounded wedge. It has made their mode of movement one of undulation, causing the sides of the fish to contract rhythmically, thrusting the animal forward. A clear idea of this mode of motion is to be obtained from a series of photographs of a swimming fish (Figs. I-2) taken at successive instants: thus in the case of the shark (Fig. I) the undulation of the body may be traced from the head region backward, passing along the sides of the body, and may be seen to actually disappear at the tip of the tail. It is the pressure of the fish's body against the water enclosed in these incurved places which causes the forward movement.

The density of the living medium of fishes exerts upon them a mechanical influence; they are, so to say, balanced in water, free to proceed in all planes of direction, poised 
with the utmost accuracy, enabled to rise to the surface or sink readily into deep water. A special organ, the 'air-,' or 'swim-bladder,' has even been acquired by the majority of living fishes, which, whatever may have been its origin or accessory functions (v. p. 2I), has certainly to an extraor-

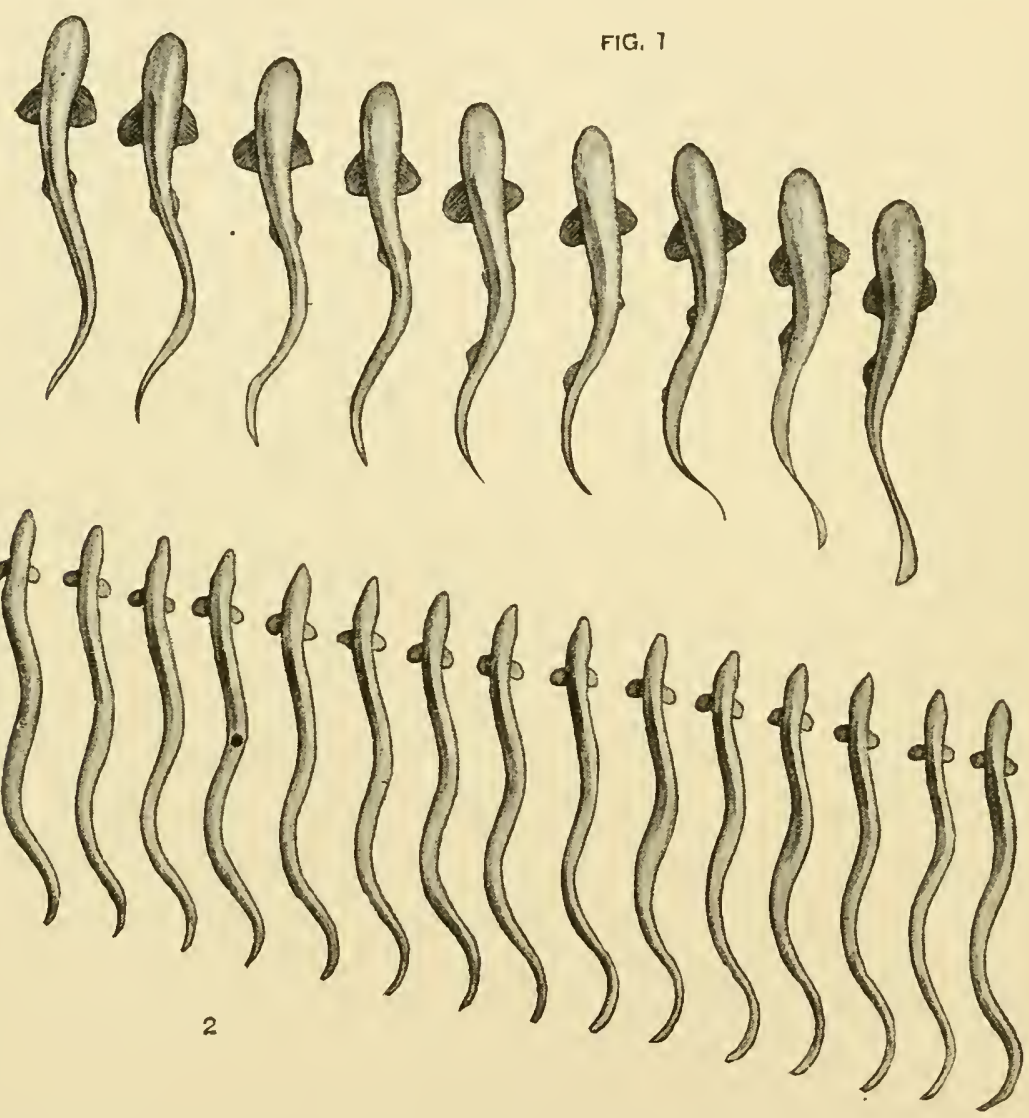

Figs. I and 2. - Movement of fishes, - shark and eel. (After MAREY.)

dinary degree the power of rendering the specific gravity of the fish the same as that of the surrounding water.

In an example of a swift-swimming fish some of the most striking peculiarities of the aquatic form may be seen. The Spanish mackerel, Scomberomonus (Fig. 3), shows admirably a stout spindle-like outline; its entire sur- 
face is accurately rounded, and there appear no irregular points which could retard the forward motion of the fish. Even in the wedge-shaped head the conical surface has been made more perfect by the tightly fitting rims of the jaws, by the smoothly closed gill shields, and by the eyes' accurate adjustment to the head's curvature. Viewed from in front (Fig. 4) the fish's outline appears as a perfect ellipse, and seems surprisingly small in size : the fins, which appear so prominent a feature in profile, can now be hardly distinguished; above and below they form keels, sharp and thin. In side view the vertical or unpaired fins are seen surrounding the hinder region of the body: they resolve themselves into dorsal $(D)$, anal $(A)$, and caudal $(C)$ elements; the former are low and stout, elastic in

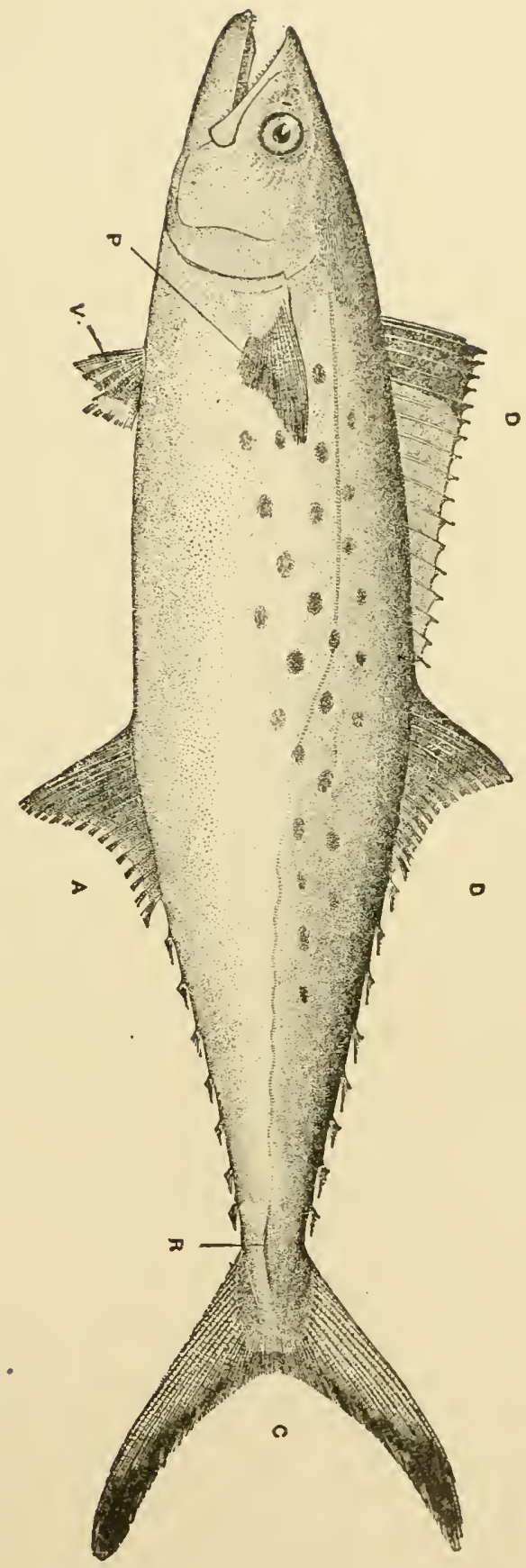

Fig. 3. - Type of swift swimming fish, their firm cutwater margin, Spanish mackerel, Scomberomorns maculadeeply notched and inter- in U.S.F. C.) \& G. $\times \frac{1}{9}$. (After Goodf 
rupted posteriorly, where useless elements have been discarded; the caudal is broadly forked, stout in its supporting rays, strong in power of propulsion. At its sides a remarkable ridge has been developed, functioning as a horizontal keel $(R)$ and preventing the stroke of the cau-

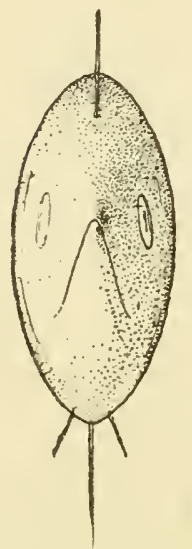

Fig. 4. - Front view of Spanish mackerel. dal from varying from the vertical plane. The lateral, or paired fins, pectoral and ventral $(P$ and $V)$, may rotate outward and arrange themselves in the line of the fish's motion, so that in a somewhat horizontal plane they may, like the unpaired fins, function as keels. When thus erected, the paired fins present a firm anterior margin which serves as a cutwater. While thus somewhat similar in function to the vertical fins, the ventrals and especially the pectorals may acquire additional uses : they may serve as delicate balancers, or may aid in guiding or arresting the fish's motions.

In further conformity to aquatic needs, the entire surface of the fish is notably slime covered, and although perfectly armoured by plates and scales, yet presents no point of resistance to forward motion. An internal balance, moreover, has been effected between the supporting, visceral and muscular parts : the firm vertebral axis acquires its central position, and at its anterior end the head structures form a compact, wedge-like mass: the body muscles which give the fish its form-contour thin away on the ventral side, permitting in the region between the head and the anal fin the space occupied by the closely compacted viscera: respiratory organs occupy a restricted space on either side of the gullet; the heart and its arterial trunk are implanted closely in the throat in the median ventral 
line; the dorsal blood-vessel takes its position immediately below the vertebral axis, and the air-bladder in the most dorsal part of the abdominal cavity.
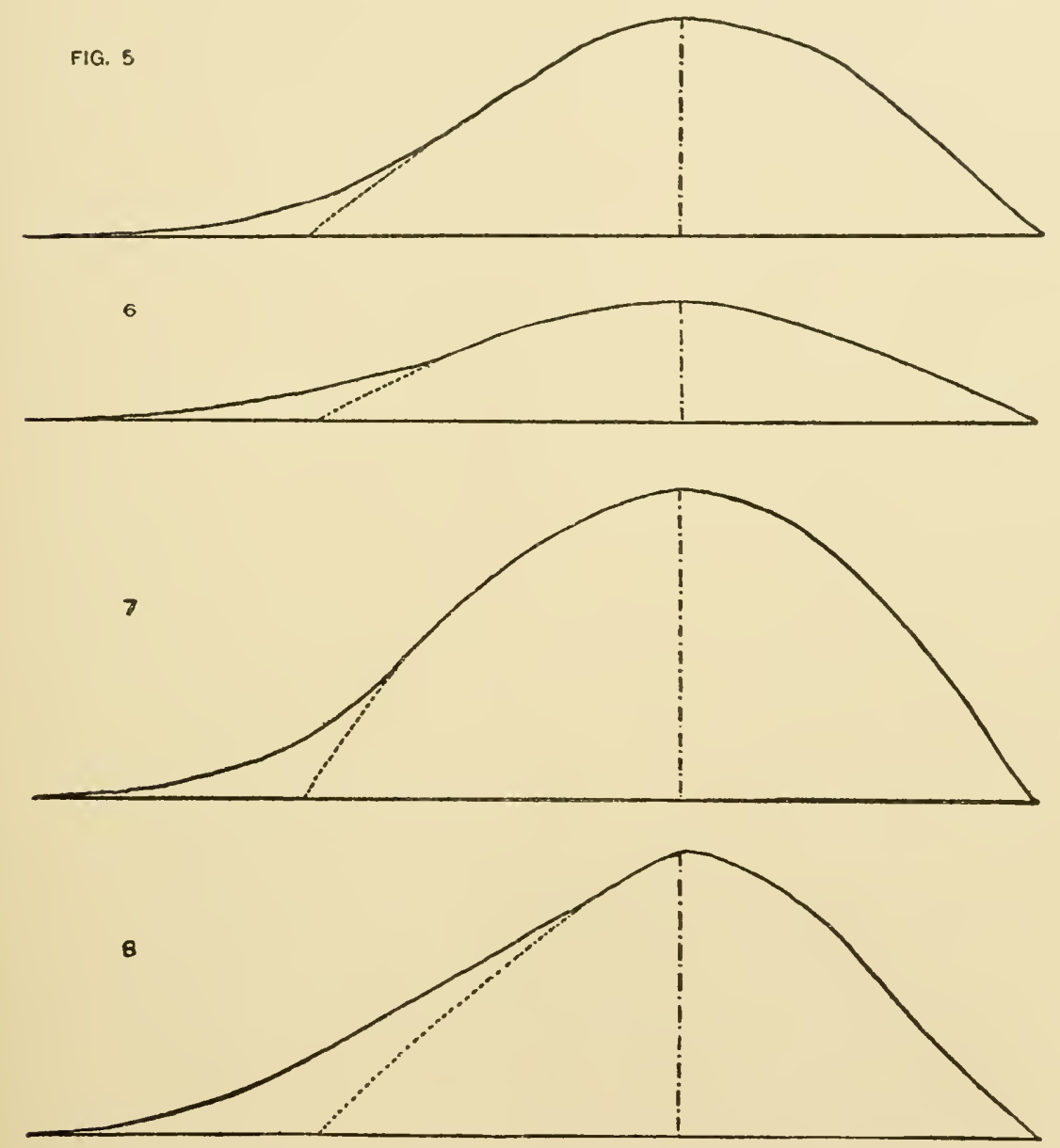

Figs. 5-8. - Numerical lines of fishes and cetaceans. The "entering angle" begins at the snout-tip at the right, and extends as far as the vertical dotted line ( $36 \%$, about, of the entire length); the "run" then begins and is continued to the body terminal. 5. Striped porpoise, Phocaena lineata. 6. Spanish mackerel (Cuban), Scomberomorus cavalla. 7. Humpback whale, Megaptera'longimana. 8. Striped bass, Labrax lineatus. (All figures after PARSONS.)

In acquiring this perfect outward symmetry it is interesting to note that the forms of fishes may be said to have actually evolved the practical solution of the most theoretical problems of curves and displacement in relation to sub- 
marine motion. A study of the "lines" of typical fishes by naval engineers * has led to some most interesting results as to the uniformity of their mathematical "normals." It is found, for example, that the "entering angles" of many and very different fishes are surprisingly similar (Figs. 6 and 8): they thus terminate regularly (at the plane of the greatest cross-section of the body) at 36 per cent of the fish's total length; and the curves of the "run" (i.e. of the hinder part of the trunk, from the plane of the greatest cross-section to the body terminal), similar for all, are smooth hollow curves, which in the forward motion of the fish permit the passage of the displaced water.

It would be unreasonable to doubt that the fish form is adapted to the mechanical needs of its environment, even if there existed no further evidence than that of the metamorphoses of aquatic mammals. Many of these have shown so complete an adaptation to water-living that it is scarcely remarkable that they were early included among fishes. And it is of further interest that there exist transitional forms between the land-living mammals on the one hand and the cetaceans on the other. In the Seal it is but the initial step in the transformation that has taken place; the head and body have become bluntly tapering, the hind legs displaced backward, the foot and hand webbed, the hair adapted to submerged locomotion. A further stage in the acquisition of the fish-like form is shown in the Dugong and Manatee. And finally in the Dolphin and Whale (Figs. 5 and 7) have been actually attained the mumerical lines of fishes (cf. Figs. 6 and 8). In these cases, the mechanical conditions of aquatic living have produced their result only at the greatest cost, -

* 's8. Parsons, Displacement and Area Curves of Fishes, Trans. Am. Soc. Mech. Engineers. 
enormous structural and physiological changes had of necessity to have been attained. The frame of the head and trunk has become moulded as in the fish's form, contours have been elaborately filled out and rounded, median dermal keels developed, vein valves lost, and the legs transformed into fin-like appendages.

The form of the fish is accordingly to be looked upon as cast in a more or less common mould by its environment. Its internal structures, as in the cetacean, are also observed to be modified in accordance with its external form. This is a factor in the evolution of fishes which appears in every group and sub-group. And it has ever stood in the way of classifying them satisfactorily according to their kinships.

"Fishes," used as a popular term, may include Lampreys, Sharks, Chimæroids, Lung-fishes, and "Modern Fishes" (Teleostomes), - the major groups to be discussed in the present book. But the relative position of each of these divisions must at present remain more or less doubtful. The group of the Lampreys is certainly widely removed from the remaining ones, standing midway between the simplest chordate, Amphioxus, and the true fishes: it is usually given a rank co-ordinate with either of these, and, in fact, with all other groups of vertebrates, taken collectively. Sharks, Chimæroids, Teleostomes, may be taken to represent true fishes; and each might be assigned co-ordinate rank, although genetically the Chimæroids are certainly far more closely allied to the Sharks than are the Teleostomes. The Lung-fishes, as a widely divergent group, appear, as W. N. Parker has suggested, to be reasonably entitled to a rank equivalent to that of the three groups of true fishes taken together. 
The present writer has, however, retained in the main the classification of Smith Woodward, in which Fishes (Pisces) is looked upon as a class, and is made to include as sub-classes, (I.) Sharks, (II.) Chimæroids, (III.) Lungfishes, and (IV.) Teleostomes. A tabular grouping of the fishes is shown below. And on the opposite page their geological distribution is indicated.

\section{TABLE I}

\section{A CLASSIFICATION OF FISHES}

\section{Type: CHORDATA (VERTEBRATES).}

Class: Marsipobranchii, Lampreys, Palcospondylus, Hag, Lamprey, Ostracoderms.

Class: Pisces (True Fishes).

I. Sub-class: Elasmobraxchir, Sharks and Rays.

Order: Pleuropterygii (Dean), Cladoselachids (Dean).

‘Ichthyotomi (Cope). Pleuracanthids.

6. Selachii, Sharks and Rays.

II. Sub-class: Holocephali, Chimæroids, Spook-fishes.

Order: Chimaroidei, Squaloraiids, Myriacanthids, Chimærids.

III. Sub-class: Dipxor, Lung-fishes.

Order: Sirenoidei, Dipterids, Phaneropleurids, Ctenodonts, Lepidosirenids.

.. ? Arthrodira, Coccosteids, Mylostomids.

IV. Sub-class: Teleostom, Ganoids and Bony Fishes (Teleosts).

Order: Crossopterygii, Holoptychiids, Osteolepids, Onychodonts, Calacanthids.

6. Actinopterygii,

Sub-order: Chondrostei (Ganoids), Palaoniscoids, Sturgeons, Garpikes, Amioids.

"Teleocephali, recent Bony Fishes (Teleosts).

NotE. - The groups italicized are represented only in fossil forms. The derivations of the scientific names are given on pp. 227-230. 


\section{TABLE II}

THE DISTRIBUTION OF FISHES IN GEOLOGICAL TIME

The geological distribution of the prominent groups of fishes as here shown is in the main as given by Zittel (Palæontologie: $F$ ische). The varying thickness of the lines denotes approximately increase or diminution in the number of existing genera.

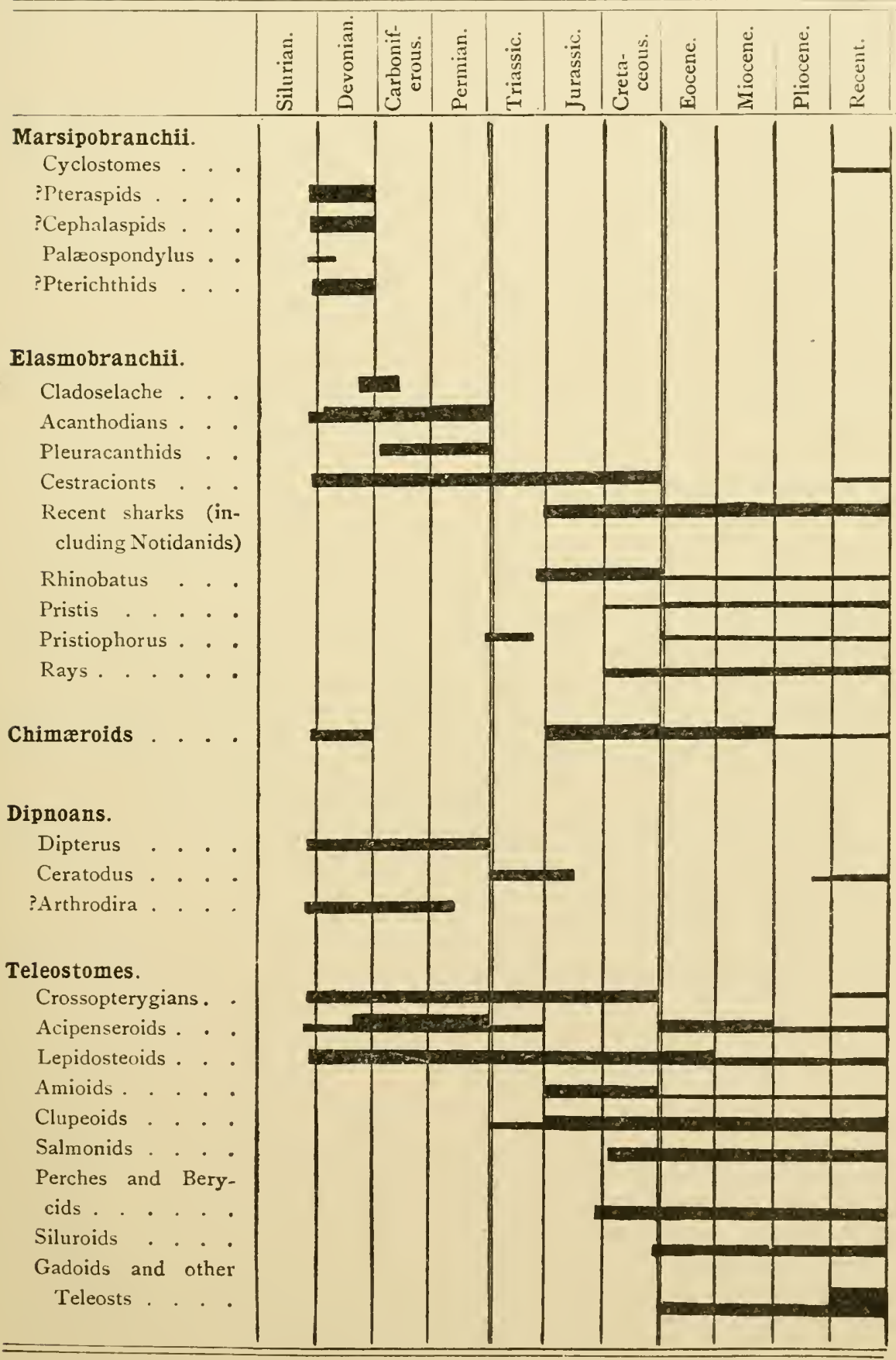


Fishes hold an important place in the history of backboned animals : their group is the largest and most widely distributed: its fossil members are by far the earliest of known chordates; and among its living representatives are forms which are believed to closely resemble the ancestral vertebrate.

The different groups of fishes appear especially favourable for comparative study. Their recent forms are generally well understood, both structurally and developmentally; while a vast number of extinct fishes has been preserved to serve as a check, as well as an aid, to theoretical investigation.

The remarkable permanence of the different types of fishes seems a striking proof of how unchanging must have ever been the conditions of aquatic living. From as early as the Devonian times there have been living members of the four sub-classes of existing fishes, - Sharks, Chimæroids, Dipnoans, and Teleostomes. Even their ancient sub-groups (orders and sub-orders) usually present surviving members; while, on the other hand, there is but a single group of any structural importance that has been evolved during the lapse of ages, - the sub-order of Bony Fishes. There are many instances in which even the very types of living fishes are known to be of remarkable antiquity: thus the genus of the Port Jackson Shark, Cestracion (Fig. 9I), is known to have been represented early in the Mesozoic; the Australian Lung-fish, Ceratodus (Fig. I27), dates back to Liassic times; * the Frilled Shark, Chlamydoselache (Fig. 92), though not of a palæozoic genus, as formerly supposed (Cope), must at least be regarded as closely akin to the Sharks of the Silurian.

* Cf., however, Smith Woodward, The Fossil Fishes of the Hazukesbury Series at Gosford. Memoirs of the Geol. Surv. of N. S. IV. Pal. No. 4, ISgo. 
The evolution of groups of fishes must, accordingly, have taken place during only the longest periods of time. Their aquatic life has evidently been unfavourable to deepseated structural changes, or at least has not permitted these to be perpetuated. Recent fishes have diverged in but minor regards from their ancestors of the Coal Measures. Within the same duration of time, on the other hand, terrestrial vertebrates have not only arisen, but have been widely differentiated. Among land-living forms the amphibians, reptiles, birds, and mammals have been evolved, and have given rise to more than sixty orders.

The evolution of fishes has been confined to a noteworthy degree within rigid and unshifting bounds; their living medium, with its mechanical effects upon fish-like forms and structures, has for ages been almost constant in its conditions; its changes of temperature and density and currents have rarely been more than of local importance, and have influenced but little the survival of genera and species widely distributed; its changes, moreover, in the normal supply of food organisms, cannot be looked upon as noteworthy. Aquatic life has built few of the direct barriers to survival, within which the terrestrial forms appear to have been evolved by the keenest competition.

It is not, accordingly, remarkable that in their descent fishes are known to have retained their tribal features, and to have varied from each other only in details of structure. Their evolution is to be traced in diverging characters that prove rarely more than of family value; one form, as an example, may have become adapted for an active and predatory life, evolving stronger organs of progression, stouter armouring, and more trenchant teeth; another, closely akin in general structures, may have acquired more 
sluggish habits, larger or greatly diminished size, and degenerate characters in its dermal investiture, teeth, and organs of sense or progression. The flowering out of a series of fish families seems to have characterized every geological age, leaving its clearest imprint on the forms which were then most abundant. The variety that to-day maintains among the families of Bony Fishes is thus known to have been paralleled among the Carboniferous Sharks, the Mesozoic Chimæroids, and the Palæozoic Lung-fishes and Teleostomes. Their environment has retained their general characters, while modelling them anew into forms armoured or scaleless, predatory or defenceless, great, small, heavy, stout, sluggish, light, slender, blunt, tapering, depressed.

When members of any group of fishes became extinct, those appear to have been the first to perish which were the possessors of the greatest number of widely modified or specialized structures. Those, for example, whose teeth were adapted for a particular kind of food, or whose motions were hampered by ponderous size or weighty armouring, were the first to perish in the struggle for existence; on the other hand, the forms that most nearly retained the ancestral or tribal characters - that is, those whose structures were in every way least extreme-were naturally the best fitted to survive. Thus generalised fishes should be considered those of medium size, medium defences, medium powers of progression, omnivorous feeding habits, and wide distribution: and these might be regarded as having provided the staples of survival in every branch of descent.

Aquatic living has not demanded wide divergence from the ancestral stem, and the divergent forms which may culminate in a profusion of families, genera, and species, 
do not appear to be again productive of more generalized groups. In all lines of descent specialized forms do not appear to regain by regression or degeneration the potential characters of their ancestral condition. A generalized form is like potter's clay, plastic in the hands of nature, readily to be converted into a needed kind of cup or vase; but when thus specialized may never resume unaltered its ancestral condition: the clay survives; the cup perishes. 
THE EVOLUTION OF STRUCTURES CHARACTERISTIC OF FISHES

IT will be the object of the present chapter to review the gradations which occur in some of the characteristic structures of fishes and to follow in some degree the mode of their evolution. We may thus review the conditions of the (I) gills, (2) skin defences (including teeth), (3) fins, and (4) sense organs.

The structures of the immediate ancestor of the fishes cannot be definitely inferred: the form, however, must have been elongate and transversely jointed, for this condition seems to have existed remotely before fishes - in the broadest sense — had become evolved. This segmentation, or metamerism, of the vertebrate body is best shown among water-living forms, sometimes indeed in so perfect a way as to suggest the jointed condition of an earth-worm.

The segmented body of the eel-shaped Lamprey, shown in section in Fig. 69, illustrates an interesting condition of vertebrate metamerism. Its entire body, from the head region to the base of the tail, is composed of drumlike segments which closely correspond to one another in size and in component structures. Each segment thus resembles its neighbours in its equal portions of the vertebral column, digestive tract, nerve tube, muscle plates and blood canal, and in the arrangement of these parts with reference to bilateral symmetry. Motion in this form requires no more of each segment than that its 
sides contract alternately to produce a rhythmical wave passing along the entire series of segments and giving the trunk an undulatory movement.

Should this elongate body now acquire a more fish-like form, in attaining, for example, the power of more rapid movement, it is obvious that this simple type of metamerism would undergo a series of changes. Every change of outward form would be reflected on the parts not only of each, but of all segments in their common relationships. To perform more perfectly the functions of their location, adjacent segments might become enlarged, folded, or blended, and cause the most puzzling complications of their component structures. One region of the body might thus appear to develop at the expense of another, as in the evolution of fin structures (cf. pp. 32-44), where a vertical fin fold, representing the sum of the dorsal and ventral outgrowths of the hinder body segments, becomes reduced to the lappet-like dorsal and ventral fins; the intervening substance of the fin web becoming drawn to the points where greater rigidity is required.

The simple metameral character of the lamprey acquires an especial interest when the different groups of fishes are examined; for it is found that all exhibit clearly body segments and segmental structures in the most varied stages of complexity. To trace metamerism seems, accordingly, a mode of determining to what degree the different groups have diverged from a common stem; and to compare the sums of the archaic metameral characters in the different types of fishes may perhaps be looked upon as one of the safest aids in determining their genetic position. From the conditions of segmentation the lampreys must certainly be given a lowly rank; even with due allowance for degeneration of structures they are clearly more 
primitive than the most archaic sharks: while, on the other hand, to the metameral type of the sharks may the structures of the remaining groups of fishes be best referred.

\section{AQUATIC BREATHING}

Respiration in fishes is developed on the primitive chordate plan of ejecting water through gill slits perforating the throat wall. The water taken in by the mouth is rich in absorbed air, and, as it passes out, is well calculated to oxygenate the blood suffusing the sides of the gill slits.

Among the earliest chordates there seems evidence that the gill openings of the gullet were arranged with reference to some form of primitive segmentation. Perhaps they occurred as well in the region of the mid-digestive tract, before their location became restricted to the gullet. There has been as yet, however, little satisfactory evidence $^{*}$ as to the number or conditions of the gill slits in very primitive forms. In Amphioxus the gill arrangement seems clearly a most specialized one: its adult condition presents an atrium and an elaborate branchial basket, $\uparrow$ which could hardly have occurred in the lowly ancestral chordate. Its early larva, however, is known to possess (but in a condition of assymmetry) but a few gill slits (seven to nine) from which the many openings of the adult branchial basket take their origin, - a developmental stage which most closely and most interestingly suggests the conditions of higher forms.

* It has generally been inferred that the immediate ancestors of fishes had not many gill slits, probably not more than eight or nine. A Liassic shark, a Cestraciont, Hybodus (p. 85), is known to have had but five; a Permian Pleuracanthid, as in the recent Heptanchus, seven (p. 88); the Lower Carboniferous Cladoselache probably seven.

$+C f$. Vol. II, of this series. Willey, Amphioxus and Other Ancestors of the Chordates. 

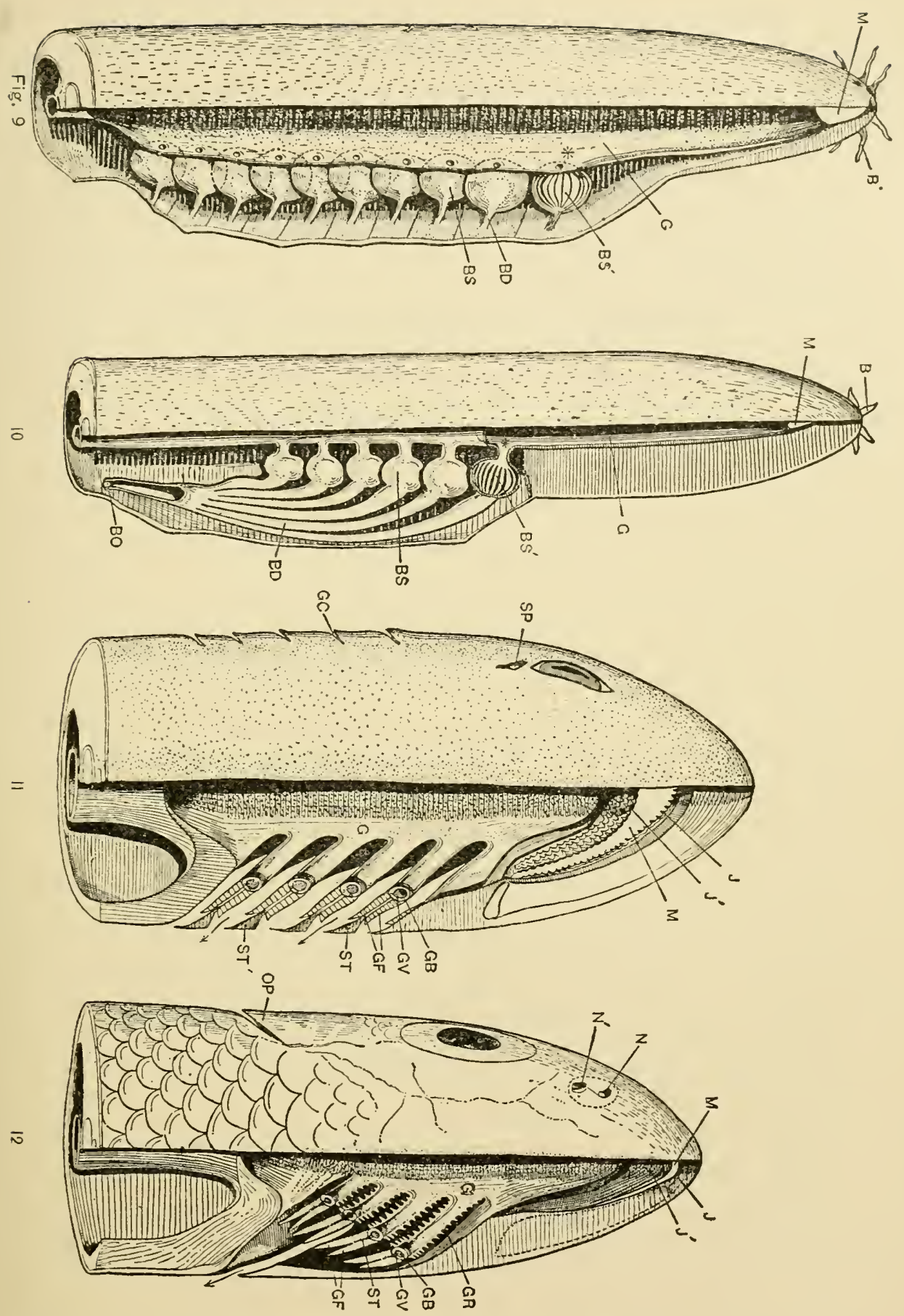

Figs. 9-I2. - Arrangement of gills of Bdellostoma (9), Myxine (Io), Shark (II), and Teleost (I2). In each figure the surface of the head region is shown at the left.

$B$. Barbels. $B D$. Outer duct from gill chamber, $B S . B O$. Common opening of outer ducts from gill chambers. $B . S$. Branchial sac, or gill chamber. $B S^{\prime \prime}$. Branchial sac, sectioned so as to show the folds of its lining membrane. $G$. Lining membrane of gullet. $G B$. Gill bar, supporting vessels and filaments of gills. $G C$. Outer opening of gill cleft. $G F$. Gill filament. $G R$. Gill rakers. $G V$. Vessels of gill. $7, \mathcal{F}^{\prime}$. Upper and lower jaw. $M$. Mouth opening. $N, N^{\prime}$. Anterior and posterior opening of nasal chamber. $O P$. Operculum. SP. Spiracle. $S T$. Tendinous septum between anterior and posterior gill filaments. * Denotes the inner branchial opening; $\rightarrow$, the direction of the water current. 
In the singular group of lampreys and slime eels (Marsipobranchs, v. p. 57), the segmental arrangement of the gills seems of a primitive pattern. In the Californian Myxinoid (p. 59) the slits are as numerous as thirteen and fourteen on either side, each opening directly from the gullet to the neck surface (Fig. 9, $G$, * $B S^{\prime}, B D$ ). In the lamprey the conditions are similar, but the number of gill slits is reduced to seven. In Myxine (Fig. Io, $G, B S^{\prime}, B D$, $B O)$ the outer portions of the canals becoming produced tail-ward have merged in a single pore (Fig. 7 I *). In these forms each gill canal has become dilated at one point of its course, and in this sac-like portion the blood-suffused tissues have grouped themselves into leaf-like plates (gill filaments, or lamellæ, $B S^{\prime}$ ) to increase their surface of contact with the out-passing water. The dilating power of this gill sac has then become specialized so that even should the animal's mouth be closed, water for respiration could be drawn in through the canal's outer opening: from this acquired function the elaboration of branchial muscles and a supporting framework of cartilage (branchial basket, Fig. $69 A, B B$ ) may have taken its origin.

Among fishes proper many stages in the evolution of gill organs are represented. They show altogether a marked advance over the conditions of Fig. 9. There has been a general tendency to press closely together the gill pouches and to elaborate into thinner and larger lamellæ the blood-suffused tissue. In this process the gill chamber has become slit-like, bearing gill lamellæ only on its front and rear margins; its supporting tissue has consolidated into stout vertical gill bars, the gill structures in general, becoming more highly perfected, tending to recede from the surface. These conditions may best be illustrated 
by contrasting the highly modified gill apparatus of a bony fish with the more archaic type of the shark.

In the sharks (p. 73) the gill slits pierce separately the throat wall, as in the lamprey, and thus retain their primitive segmental arrangement (Fig. II). Their number is usually five on either side, but in an archaic form (Heptanchus, p. 8S) may be increased to seven. Above and in front of the line of gill slits occurs a small opening leading into the gullet, the spiracle $(S P)$. This, though at present possessing but few gill lamellæ, and therefore of little respiratory value, was doubtless quite like its neighbours before its gill-supporting tissue became of value in suspending the lower jaw. It may now aid the mouth opening in admitting water to the gills. At the left of the figure (Fig. II), the narrow slit-like openings of the gill clefts are seen at $G C$ : at the right, where the upper portion of the head has been removed, the gill lamellae are shown at $G F$; the tissue intervening between the gill pouches is reduced to a thin tendinous septum, ST, at whose inner rim is the cartilaginous gill arch or bar, $G B$, supporting the branchial vessels, $G V$.

In the gill region of a bony fish (Fig. I2) a number of modified characters are now evident: the spiracle has become obliterated; the number of gill bars reduced in one form but two on either side remaining. These have become closely pressed together, and bent backward, receding from the surface of the head: their gill lamellæ have become larger and more numerous, their intervening septum, $S T$, reduced in size. The gills no longer open separately at the surface, but into an outer branchial chamber formed and protected by a large overlapping scale, or opercle, $O P$. This shield-like organ is hinged at its anterior margin and opens or shuts rhythmically as 
the throat muscles draw in or eject the water used in respiration. On the gullet wall, the gill bars, now seen to be closely drawn together, have acquired marginal outgrowths, or gill rakers, $G R$, which form an interlocking screen across the gill openings and prevent the escape of food organisms. So perfect may this apparatus become that the opening and closing gill bars may retain even microscopic life.**

Between the conditions of Figs. I I and I 2 there occur many transitional forms.

To protect the gill region, specialized devices are known to have been evolved early in the history of fishes, the more early if, as Garman has supposed, the gill filaments in primitive sharks protruded at the sides of the head. $f$ There are thus the gill-encasing derm frills of the archaic sharks, Cladoselache, Chlamydoselache, and Acanthodes (pp. 78-83), or of Chimaroids (p. Ioo). These protective structures, the writer believes, may well have originated independently even within the limits of subgroups. They have certainly no direct relation to the opercle of bony fishes.

Modes of respiration by gill filaments have been found in endless variety among fishes, clearly dependent in the majority of cases upon environment. Thus fishes that require a temporary existence out of water will be found to have specialized spongy gill filaments and a closely fitting gill cover to keep moistened the respiratory organs (e.g. Callichthys, p. I 72).

* Thus in many bony fishes, e.g. mullet or Brevoortia (menhaden), the inner margins of the gill bars are fringed with what appears like the finest gauze, each gill raker giving off primary, secondary, and tertiary branches. A somewhat similar condition occurs in the shark, Selache (p. 90).

+ This condition appears to have been possessed by the Lower Carboniferous Cladoselache. 
To live a longer time out of water has been rendered possible only by the appearance of a lung-like organ. Such a structure, however, would have been of too great importance in the living economy of terrestrial vertebrates to have had a sudden origin: it may most reasonably have been derived from a similar structure occurring very generally among fishes. The lungs certainly resemble the swimbladder of fishes in so many important characters that it seems difficult to regard these organs as morphologically distinct. In itself the swim-bladder must be looked upon as an ancient and essentially a generalized structure, for within the groups of fishes it has already acquired a variety of modified characters: appearing in a lowly condition in sharks, it acquires a balancing function in the majority of bony fishes; in some forms (carp, siluroids) its function connects it with the auditory organ, often by a highly elaborated apparatus: while in other forms (Amia, Garpike, Dipnoans), it is unquestionably of respiratory value. The wide range in the characters of the air-bladder (cf. Figs. I3-19, and Table, p. 264), even among recent fishes, would naturally favour its homology with the lungs : it may thus be paired or unpaired, attached by its duct to either the dorsal, lateral, or ventral wall of the gullet: it may present the most varied characters in its lining membrane or in its vascular supply. When, moreover, it becomes of respiratory value (e.g. Dipnoans, Polypterus), the gills are known to become in part degenerate. The larval history of amphibians, presenting so perfect a transition between gill-breathing and terrestrial vertebrates, should alone seem to render more than probable the general homology of airbladder and lung - an homology which a closer knowledge of the conditions of the lungs of the lower urodeles (e.g. Necturus may well be expected to establish definitely. 
FIG. 13
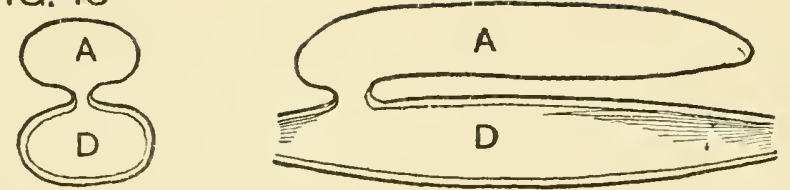

STURGEON

AND MANY

TELEOSTS

14
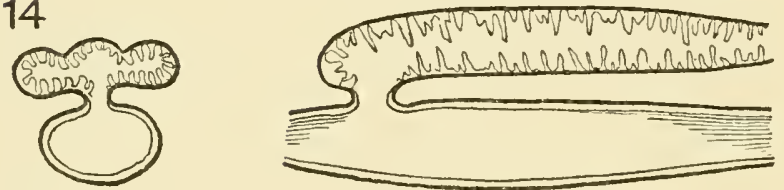

LEPIDOSTEUS

AND

AMIA

15
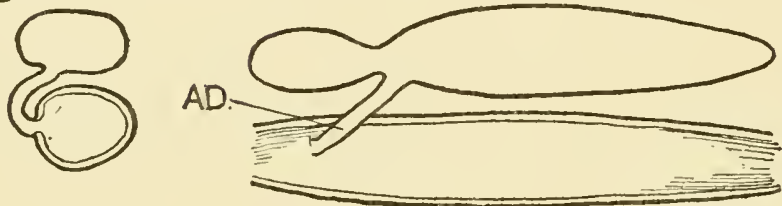

ERYTHIRINUS
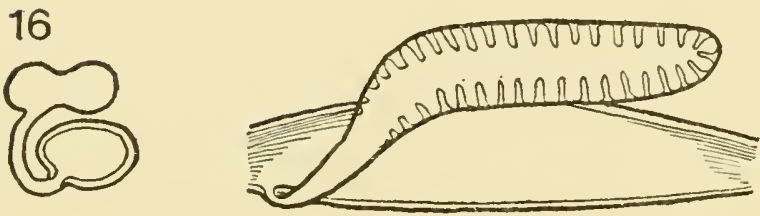

CERATODUS
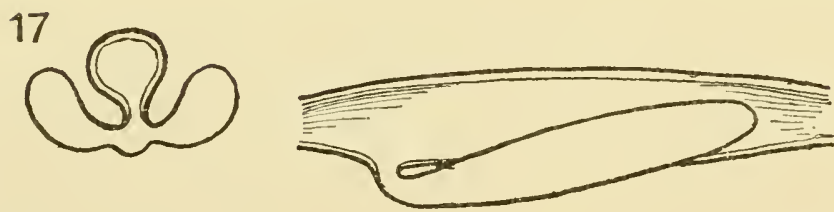

POLYPTERUS

AND

CALAMOICHTHYS
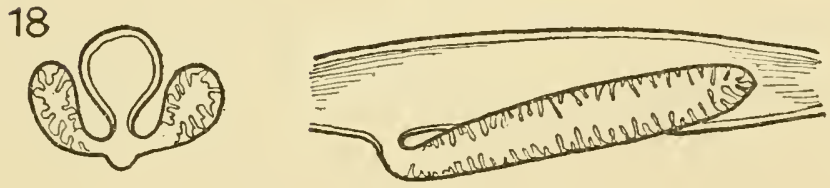

\section{LEPIDOSIREN \\ AND \\ PROTOPTERUS}
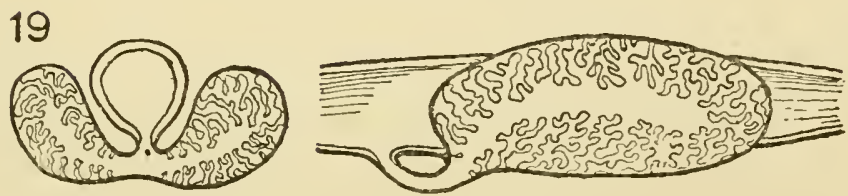

REPTILES

BIROS

MAMMALS

Figs. 13-19. - Air-bladder of fishes, shown from the front and sides. Cf. p. 264. - A. Air-or swim-bladder. $A D$. Air duct. $D$. Digestive tube. (After Wilder.) 13. Sturgeon and many Teleosts. I4. Amia and Lepidosteus. I5. Erythrinus, a Cyprinoid Teleost. I6. Ceratodus. I7. Polypterus and Calamoichthys. I8. Lepidosiren and Protopterus. 19. Reptiles, birds, and mammals. The diagrams illustrate the paired or unpaired character of the organ, its varied mode of attachment to the digestive tube, and the smooth or convoluted condition of its lining membrane. 
The mode of origin of the lungs as an unpaired cliverticulum of the gullet is in every sense similar to that of the air-bladder.

\section{THE DERMAL DEFENCES OF FISHES}

The dermal defences of fishes include scales, spines, fin rays, armour plates, and teeth, presenting in all a wide range of calcified structures. They have usually an outer, or surface layer of hard enamel-like texture and an inner substance heavy, stout, and bone-like. The former is derived from the outer layer of the skin (epidermis), the latter from the derma. The relation of these structural parts may be well seen in a section of shark skin which passes through one of its minute limy cusps, or dermal denticles (Fig. 20). The outer skin layer, $E^{\prime}$, originally covered the denticle, which grew outward, papilla-like, beneath it; its inner surface, in contact with the outgrowing papilla, secreted the enamel, $E$, and is known as the enamel organ, EO: at the cusp, however, the epidermis is early worn away. The bone-like substance of the tooth is clearly formed in the lower (dermal) layer of the skin, $D^{\prime}$ : it is formed by the calcification of the outer layers of the tip and base of the dermal papilla, leaving a vascular cavity, $P C$, within. This limy substance, "dentine," $D$, presents microscopically a columnar "cancellated" structure; in this and in its lack of bone cells it differs structurally from true (cartilage) bone.

The dermal denticle of the shark is certainly the simplest form of a calcified skin defence: it appears to represent the ancestral condition of the various scales, teeth, or bone plates which have been evolved in the groups of fishes. It is usually of minute size, and studs closely the entire surface of the skin, forming shagreen. In many 

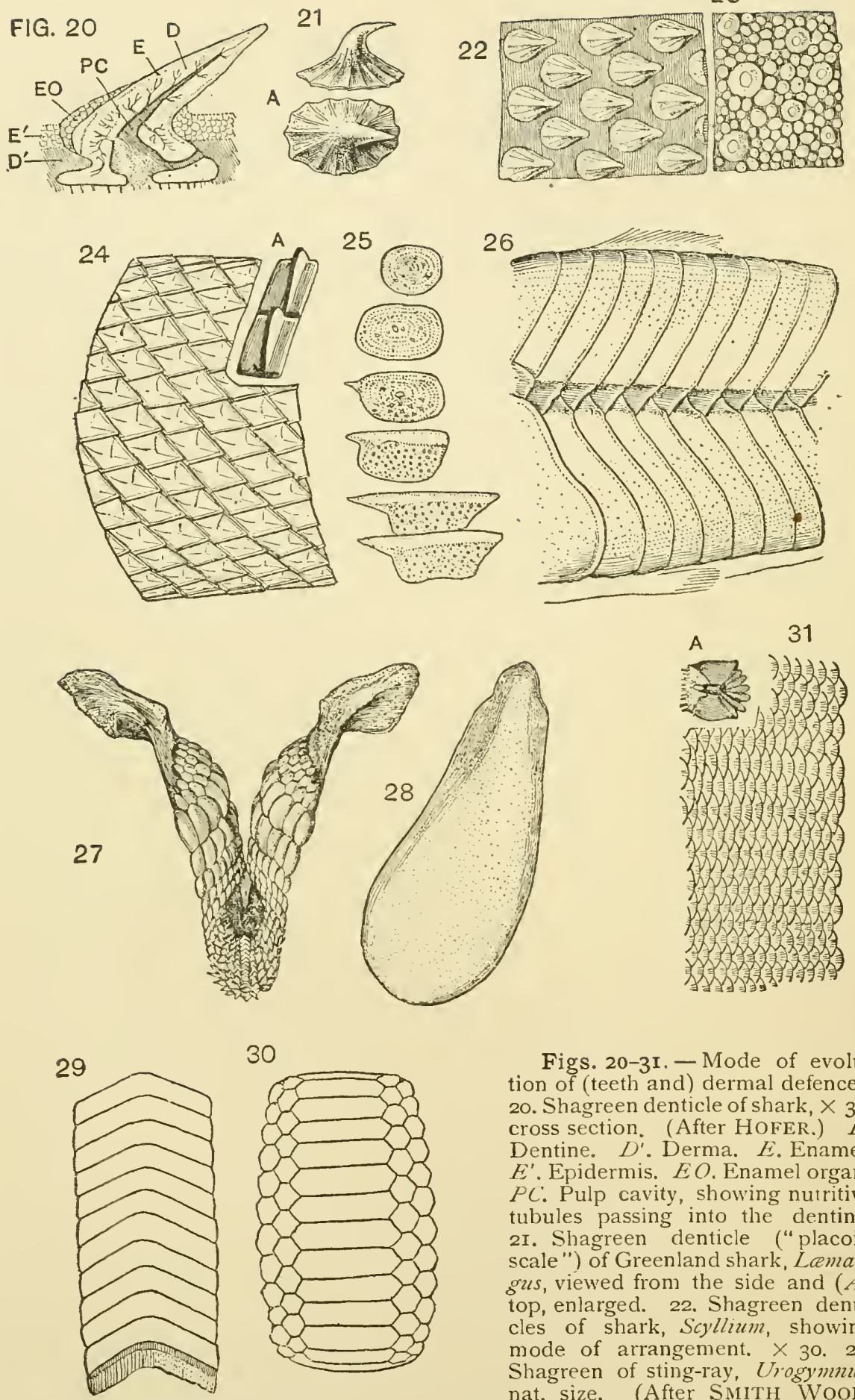

30

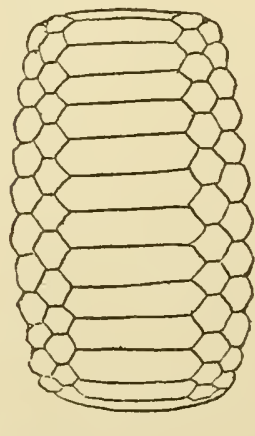

Figs. 20-3I. - Mode of evolution of (teeth and) dermal defences. 20. Shagreen denticle of shark, $\times 30$, cross section. (After HOFER.) $D$. Dentine. $D^{\prime}$. Derma. E. Enamel. $E^{\prime}$. Epidermis. EO. Enamel organ. $P C$ : Pulp cavity, showing nutritive tubules passing into the dentine. 2I. Shagreen denticle ("placoid scale ") of Greenland shark, Lcemargus, viewed from the side and $(A)$ top, enlarged. 22. Shagreen denticles of shark, Scyllium, showing mode of arrangement. $\times 30.23$. Shagreen of sting-ray, Urogymmus, nat. size. (After SMITH WooDWARD.) 24. Ganoid dermal plates of Lepidosteus. A. Inner face of ganoid plates, showing tile-like device of interlocking. 25. Variation of ganoid plates in Aetheolepis. (After SMITH WOODWARD.) Plates from different regions vary in outline from circular to lozenge shape. 26. Coalesced ganoid plates of the siluroid Callichthys. 27. Jaw of Port Jackson shark, Cestracion. 28. Dental plate of extinct cestraciont (?), Sandalodus, 29. Dental plates of jaw of sting-ray, Trygon (?). 30. Dental plates of eagle-ray, Mlyliobatis. 3т. Scales of Teleost. A. A single scale enlarged. 
members of the shark group the denticles are scattered over the body without traces of metameral arrangement (Fig. 23); in others they acquire a segmental position (Fig. 22). Usually the denticles possess very definite shapes and regional characters; their basal portion, where implanted in the skin, may thus become of enlarged size and regular outline (Fig. 2 I $A$ ), their projecting cusps tapering, blunted (Fig. 23), or branched. Sometimes the fusion of contiguous denticles may occur (as in the enlarged blunted denticles of Fig. 23).

The evolution of the more perfect body armouring of fishes from shagreen denticles has not been followed in minor details. It appears, however, that the calcification of the skin which occurs superficially in the dermal papillæ of the shark may in other fishes be traced occurring in deeper and deeper layers of the derma: the papillæ at the surface accordingly lose their functional importance, and tend to disappear, while the calcified tissue of the derma - representing morphologically the basal region of the denticles - is coming to occupy more and more definite tracts. These processes have already taken their origin within the group of sharks.

An interesting condition in the subsequent evolution of the dermal armouring is illustrated in Fig. 25, and has been described by Smith Woodward. The circular bone plate of the figure is a calcified dermal tract which still retains, scattered generally over its surface, traces of shagreen tubercles: from this shark-like condition a well-marked gradation in the form of the derm plates may be traced in different body regions of the same fish: according to metameral needs there are acquired rectangular or lozenge-shaped outlines. In Fig. 24 these bone or "ganoid" plates are seen to constitute a com- 
plete but flexible body armouring, made additionally strong by an interlocking articulation of its elements (24 A).

In this form the enamel-like surface layer ("ganoine") of the ganoid plates is believed to be derived from the dentine substance, and not deposited by the epidermis: they bear numerous shagreen denticles during an early period of life.

The most complete encasement of a fish's body by dermal plates is shown in Fig. 26, v. p. I72. The metameral conditions have here permitted extended fusions, a single dermal plate enclosing the upper, or lower division of the muscle-plate of either side.

The thin horn-like scales of the majority of recent fishes, e.g. carp or perch (Fig. 3 I $A$ ) are probably derived from a condition not widely different from that of Fig. 24. They take their origin, however, in a deeper layer of the derma, thence grow outward, arising as if from deep and flattened pockets. Their substance becomes horn-like, rather than limy, and they enlarge in outline, rather than in thickness. Their hinder margins, often crenulate, overlap widely the neighbouring scales; their arrangement is in direct relation to the underlying metameres, and their surface is densely slime-coated. The dermal armouring they thus constitute is both light, tough, and flexible.

Degeneration of scales is shown to occur in many types. In some forms their size may become microscopic (eel), in others enormously enlarged (mirror carp). In cases they may entirely disappear (leather carp). The fusions of the dermal plates of the trunk-fish or of the sea-horse (p. I77) are probably degenerate. 


\section{Teet/}

Teeth have long been known to represent the dermal defences of the mouth rim. In this region they have become of especial value in the living economy of vertebrates - seizing, holding, cutting, or crushing the foodmaterial. They have here accordingly been retained and specialized. In the sharks the dermal denticles of the mouth rim are often identical in shape and pattern with those of the entire body surface: they differ only in their larger size. Their arrangement in many rows still presents clearly their metameral character.

The forms of teeth acquired among the different groups of fishes suggest closely the evolution of the more modified dermal defences. In general, they are found to vary widely according to their function or location; those nearest the dermal margin of the mouth usually retaining the cusp-like and more primitive features. Thus in the jaw of Port Jackson. shark (Fig. 27, v. p. 85), the teeth of the symphysial region clearly represent shagreen denticles; while those deeper in the mouth, large and blunt, serve as crushing or "pavement" teeth. These must evidently be looked upon as standing in the same relation to the anterior cusps, as do the bone plates of Fig. 25 to the derm denticles of Fig. 23 ; the fused crushing teeth have still retained their metameral arrangement. The dental plates (Fig. 30) of a ray, Myliobatis (p. 96) show more perfect conditions for crushing; they are uniform in size, tightly set, and present a smooth, mosaic-like surface. A still more perfect fusion of the dental elements occurs in a ray, closely akin to Myliobatis; all lateral elements have here been fused, but their metameral sequence has been retained (Fig. 29). In Fig. 28 is shown a dental plate of a 
fossil shark (?), Sandalodus, which probably represents a condition of complete fusion; it would accordingly correspond to the sum of the dental elements of half of the jaw of Fig. 27.

In more highly modified fishes the tooth-producing region has become greatly extended; teeth are present not only on the jaw rims, but deep in the mouth cavity, studding its floor and roof, and occurring even on the tongue, gill bars, and pharynx.

\section{Fin Spines}

Primitive dermal defences appear to have played a prominent part in the formation of fin spines. The clustering of dermal cusps on the exposed margin of a fin may have been an important initial step toward the formation of a rigid cutwater. The anterior margin of the fin of Fig. 49 is whitened with a fusion of dermal tubercles which must have formed a firm encrusting support; the extension of the calcification of the bases of the tubercles would accordingly be the mode of origin of a fin spine. In Fig. 32 is shown a spine that appears largely of this origin. A similar spine (Fig. 33) shows its dermal tubercles not only at its sides, but in a most marked way at its hinder margins. In Fig. 34, representing the "sting" of the sting ray, a series of dermal spines, bearing rows of minute denticles are seen to arise in a metameral succession. A condition somewhat similar is known in the Carboniferous shark, Edestus (Fig. 35), whose spine, often of gigantic size, is of special interest, since it shows how important a part in spine-formation may be taken by the dermal defences of many successive metameres. The spine is clearly segmented, and as its separate elements (Fig. 37) are bilaterally symmetrical (Figs. 36 and 38), its 
position was probably in the median line of the body. The well-marked, backward curve of the spine suggests
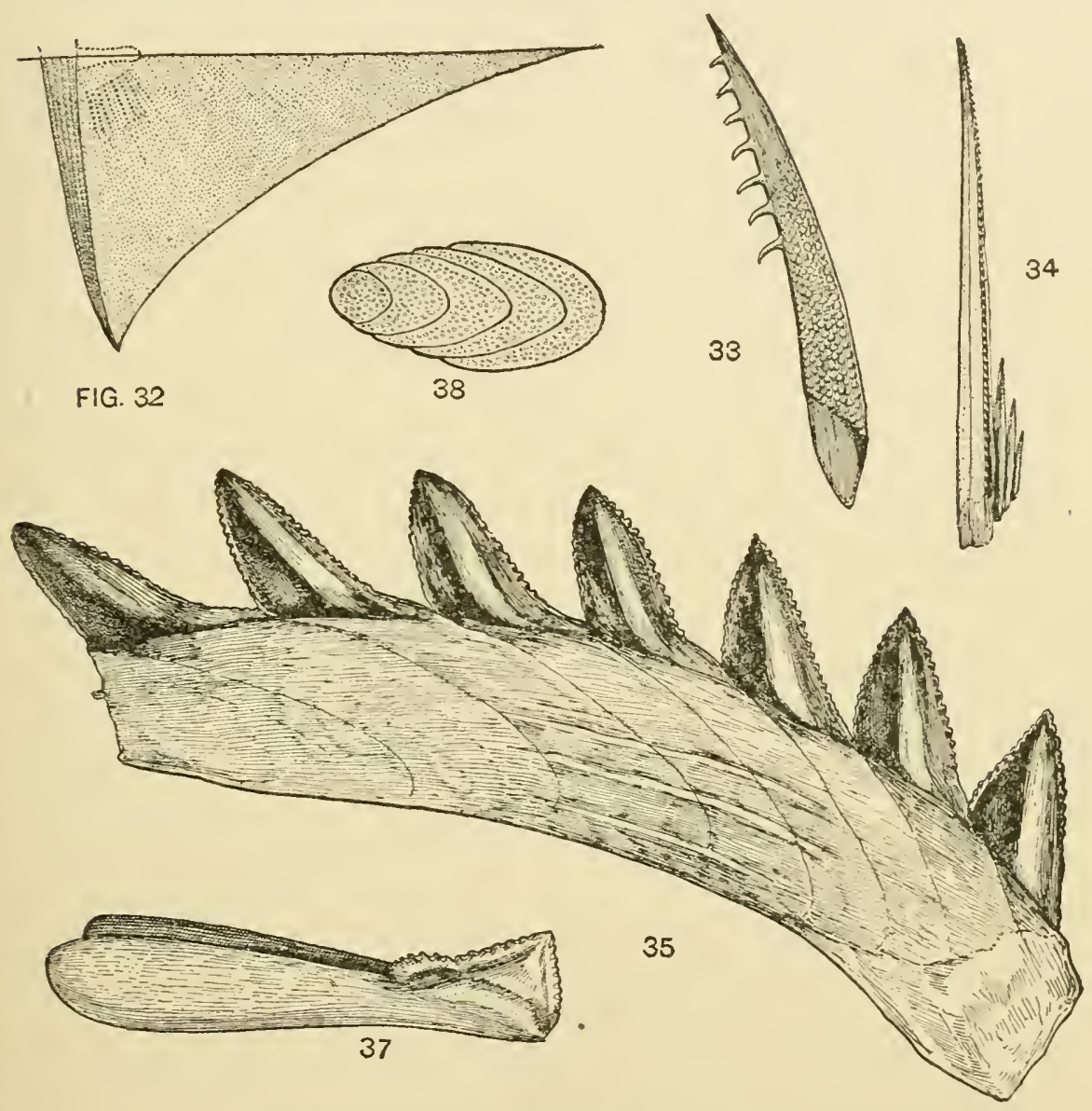

36

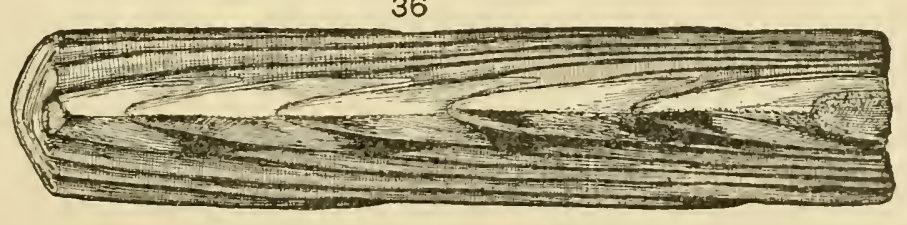

Figs. 32-38. - Fin spines. 32. Fin spine and pectoral fin of Acanthodian. 33. Hybodus (cestraciont shark). 34. Sting-ray, Trygon. 35. Edestus heinrichsii (Carboniferous shark, known only from its spine), side view of spine. $\times \frac{1}{3}$. 36 , $37,3^{8}$. Dorsal view, separated element and transverse section of Edestus spine.

that fin structures could not well have existed behind it. Each separate element has an elongated basal portion, 
which apparently was imbedded in the integument; its gouge-like form (Figs. 37 and 38) permitted it to be firmly apposed to its anterior and posterior neighbours. Each median enamelled cusp represents apparently the sum of the shagreen papillæ, occurring in the median-dorsal region of each metamere, its gouge-like underlying portion the metameral calcification of the bases of the denticles.

What has been the mode of origin of the primitive derm cusps is a puzzling question. It is significant, perhaps, that they occur in primitive forms (sharks) in connection with the sense organs of the lateral line (p. 50), and that they are in this region retained in a number of archaic forms (Polypterus, p. 148, Callichthys, p. I72), which have in all other body parts evolved protective derm plates. It is certain that for the sensory groove of the lateral line, no more simple, protective devices could have arisen than conical elevations of skin. Arising in this region, they may have extended their protective functions over the entire body surface.

\section{THE EVOLUTION OF FINS}

Fins are the organs of progression adapted to the needs of aquatic living. A fish, balanced in its living medium, acquires, as has been seen, a boat-like form, enabling it to pierce the water in the least resisting manner. Its appendages, when they come to arise, must reasonably be looked to to fulfil the mechanical conditions of aquatic motion in order to propel to the best advantage the lightly balanced and boat-shaped mass. Fins might thus be expected to arise as keel-like struct-

* In the sensory canals of the head of Chimæra, the presence of scattered bony plates, protective in function, v. p. I I4, would suggest the concentration of the marginal cusp elements for more perfect protection. 
ures, i.e. as ridges in the direction of the fish's axis or line of motion.

Fish fins have long been distinguished as vertical (median, or unpaired) or lateral (paired), the former functioning both as keel and means of propulsion, the latter as accessory and specialized balancing organs.

\section{Median Fins}

Median fins are unquestionably the older. They exist in the simplest condition in those fishes whose axis is long and whose motion is undulating. Indeed, the sole swimming requisite is here the continuous dermal keel which passes clown the back from the head to the body terminal, and extends thence forward on the ventral side. The undulatory motion of the body is well transmitted to the surrounding medium by the exaggerated undulation of this long, waving fin web. This condition was probably the ancestral one in the evolution of fishes. It represents the simplest metamerism; it occurs as the adult condition in the lampreys (p. 57), and as the embryonic or larval stage in all fishes, appearing before any traces of paired fins are known; it is even adverse to their specialization: should life habits require undulatory motion, paired fins must inevitably tend to disappear (eel, p. I73; Calamoichthys, p. I 50).

From this condition the further evolution of the unpaired fins may thus be theoretically outlined.

The primitive continuous dermal fin could have been of little value in active movement: its more rapid undulations could not have greatly increased the rate of motion, since its web, lacking in supports, would not have retained its rigidity. As the simplest means of strengthening the fin fold, "actinotrichia" (Ryder), appear to have been early 
evolved (Fig. 39, T) ; these are slender, unjointed fin supports, passing from the body wall to the margin of the

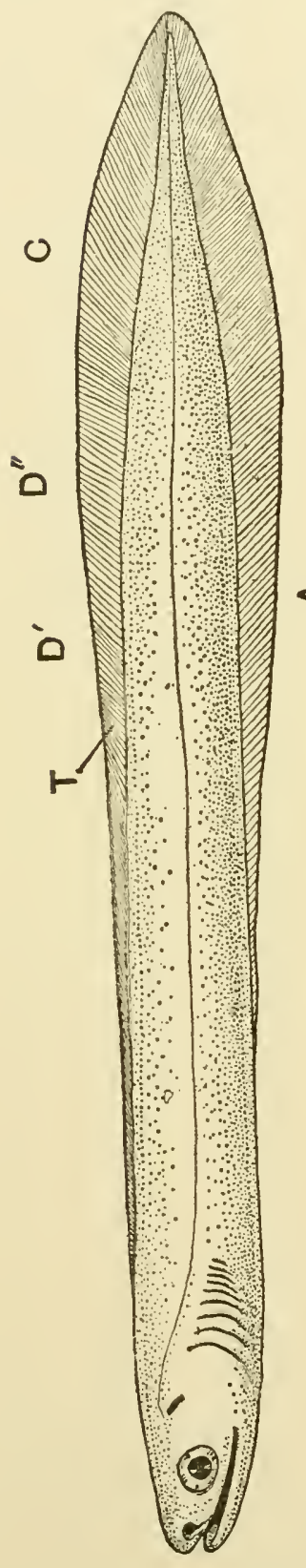

Fig. 39. - Hypothetical ancestral shark. Letters as on p. 33 . fin, appearing to arise without relation to the underlying body segments. The more rapid undulations of the continuous fin would next cause nodes to arise; and at other points the greatest mechanical stress would occur. The्se portions of the fin web would accordingly become prominent, while the intervening or useless parts would diminish in width and tend to disappear. The body terminal (tail, caudal fin) has now become the seat of propulsion: dorsal and ventral fins arise as lobate elements of the fin fold, functioning as vertical keels in the region of the body where mechanical stress demands them (v. Fig. 40), increasing in size as the intervening portions of the web gradually disappear. Their rate of growth is doubtless affected by the appearance of the paired fins; for even at an early period of development these are known to have an important function in balancing the fish.

The lappet-shaped fins (Fig. 40) next acquire more rigid supports. Cartilaginous rod-like elements arise within the fin web, arranged in metameral sequence, representing, perhaps, fusions of actinotrichia. As shown in Fig. 40, these cartilaginous "radials," $R$, appear to be largest and stoutest in the widest por- 
tions, of the fin lobe, and thence to taper in size toward the nodal points of the web. Each radial appears shortly to segment off a proximal joint, or "basal" cartilage, $B$, to secure a more perfect attachment with the wall of the body.

The subsequent evolution of the fins appears to have been determined by two modifications of growth, - the clustering of the radial and basal elements, and the encroachment of newly formed marginal (distal) rays

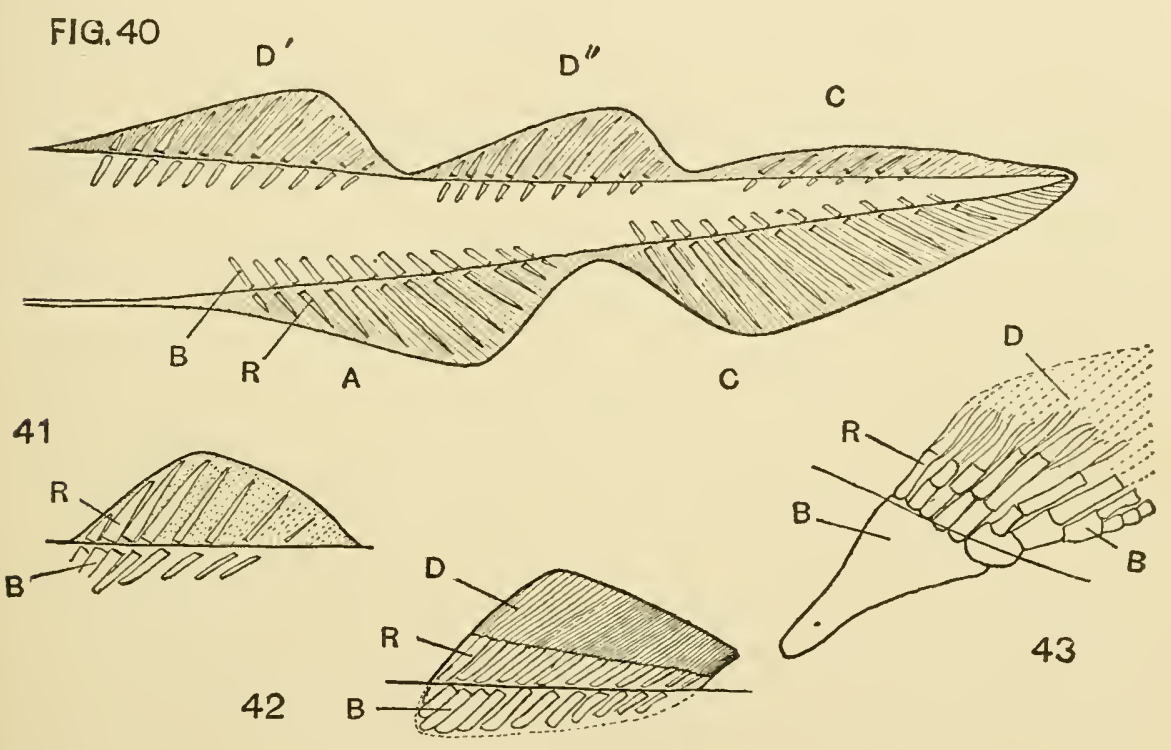

Figs. 40-43. - Evolution of unpaired fins. 40. Plan of reduction of vertical fin web into its dorsal, anal, and caudal elements. 4I. Arrangement of fin supports in primitive fin (Cladoselache). 42. Plan of archaic unpaired fin in (larval) shark. 43. Unpaired fin of fossil Crossopterygian, Holoptychizs. (After SMith WoodWARD.)

$A$. Anal fin. $B$. Cartilaginous basal (fin support). C. Caudal fin. D. Dermal margin of fin. $D^{\prime}$. Anterior and $D^{\prime \prime}$. Posterior dorsal fin. $R$. Cartilaginous radial (fin support). $T$. Actinotrichia.

upon the functions of the older fin supports. Three stages in this metamorphosis will be seen in Figs. $4 \mathrm{I}-43$. The first illustrates the dorsal fin of an arient shark (Cladoselache, p. 79), and will at once be seen to present most primitive conditions: it closely resembles the theo- 
retical dorsal fin, $D^{\prime}$ or $D^{\prime \prime}$ of Fig. 40. The form of the fin suggests the lobate constriction of the continuous fin web; its radial supports, $R$, extend from the body wall to the margin of the fin, and between them traces of actinotrichia are to be seen. The anterior margin of the fin must now function as a strong cutwater, its supporting elements, both radial and basal, tightly clustering. A fin of this character could evidently have possessed a greater freedom of lateral movement in its hinder than in its anterior part; and thus the clustering of the fin supports becomes of especial significance. The region of movement, restricting itself to the hinder part of the fin, permits extensive fusions of the supporting cartilages anteriorly, and leads ultimately to exceedingly complex conditions. The dorsal fin of a Coal Measures fish (Holoptychius, p. I 5 I) has thus (Fig. 43) specialized the power of lateral movement in the highest degree. The length of the fin has, in the first place, become greatly compressed, a process which seems to have resulted in implanting the anterior basals, $B$, deeply into the integument and in fusing them: the posterior basals then appear to have been everted from the surface of the body. Here they still retain their segmental arrangement, but are irregular in shape and reduce in size distally.

An important part is taken by the dermal margin of the fin in modifying the size of the older fin supports. The simplest form of a dorsal fin of a recent shark (Fig. 42) has thus more than half of its functional area of a dermal origin, although in other regards it resembles closely the conditions of Fig. 4I. The dermal margin of the fin has apparently increased to the detriment and consequent reduction of the cartilaginous elements; it produces in its secondary structures light flexible horn- 
like rays, which prove stronger and more serviceable than the heavier radials; it seems more capable of adapting the fin for special uses.

Accordingly, in many forms of recent fishes, notably bony fishes, the entire fin is found to become of dermal origin; the radio-basals, greatly reduced in number and size, extend no further outward than the base of the fin; they are usually small and irregular, and are often deeply sunken within the body wall.

After this glimpse at the mode of origin of the vertical fins, i.e. dorsals and anals, the history of the final vertical fin, the tail, and of the paired fins may next be reviewed.

\section{The Candal Fin}

The tail, or caudal fin, is the main organ of aquatic propulsion, and it is doubtless on this account that it presents so wide a range in its structure and outward form. From the earliest times there are found fishes of all groups whose tail shapes are tapering (diphyccrcal, Fig. 47), unsymmetrical (heterocercal, Figs. 45, 46), or squarely truncate (homocercal, Fig. 48), as the mechanical needs in swimming may have demanded.

The following summary of the mode of evolution of the caudal fin seems to be warranted by study of fossil and embryonic forms. The vertical fin fold of the ancestral fish was probably carried around the body terminal and strengthened by constant actinotrichia (Fig. 39 C), a condition similar to that (Fig. 44) of an early larval stage of living fishes (protocercy). This caudal structure, however, could have proven of value only in sluggish undulatory motion. The functional needs, which gave rise to radials anteriorly, have in the tail region produced firmer and stouter fin supports. These appear both on the 
dorsal and ventral sides, but, unlike the radials of the anal or dorsal fins, do not segment off basal elements. They first occur in the region of the base of the caudal, as in the embryonic stage (Fig. 44, R), since, perhaps, it is in this region that the greatest stress occurs in propulsion. It is not until a later stage that their metameral sequence is extended backward to the tip of the vertebral axis (Fig. 40, C).

With the origin of cartilaginous supports there seems to have arisen a mechanical need for enlarging the ventral lobe of the caudal; it is here certainly that in the majority of early forms the radials appear longer and stouter, giving rise to the condition of heterocercy of Figs. 45 and 46. The greater functional importance of the radials of the ventral region, $R+H$, is acquired contemporaneously with the upturning of the end of the vertebral axis. In the tail of a Lower Carboniferous shark (Fig. 46, v. p. 79), an extreme degree of heterocercy has been acquired before the radials of the lower lobe have extended themselves in the hindmost region of the vertebral axis ; the ventral web of the upper tail lobe, accordingly, is still strengthened by minute (dermal) rays, which the writer believes homologous with actinotrichia; on the fin's dorsal side the radials have been abruptly upturned with the notochord, and are fused into a compact cutwater.

The plan of structure of the shark's caudal fin (Fig. 45) may in its most primitive form prove to be the ancestral one of fishes; if this is the case it would give rise to the types of caudal fins of Figs. 47 and 48. That it has given rise to the latter form cannot be doubted, for even in the adult condition of the fin the notochord, $N$, may be seen passing to the upper lobe of the tail; the essential outward form of this truncated, or homocercal, tail had already 
FIG. 44
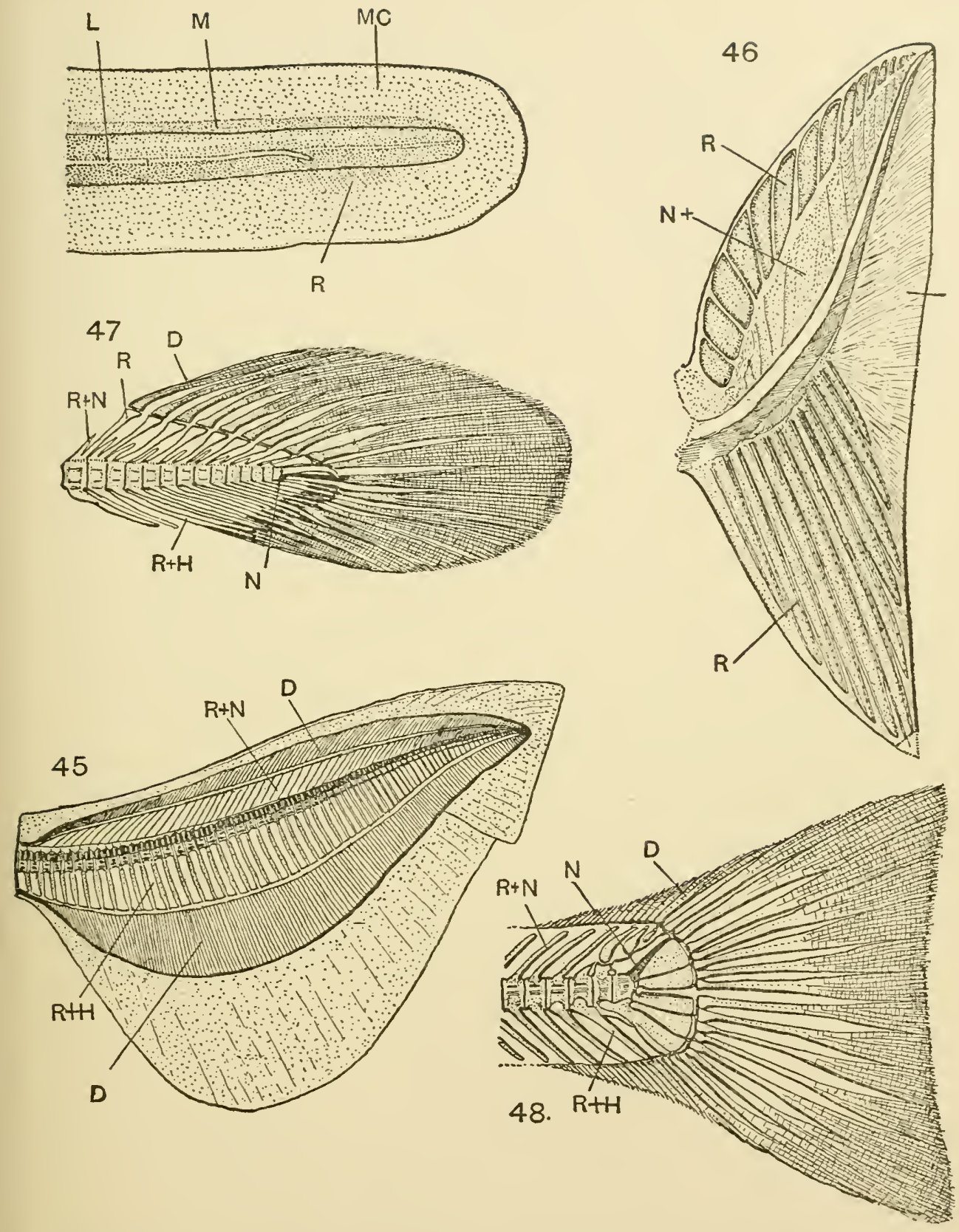

Figs. 44-48. - Evolution of caudal fin. 44. Embryonic caudal of Amia. 45. Heterocercal caudal of shark, Cestracion. 46. Heterocercal caudal of Cladoselache. 47. Diphycercal caudal of Polypterus. (After L. AgAssiz.) 48. Homocercal caudal of Teleost. (After RYDER.)

$D$. Dermal fin supports. L. Lateral line. $M$. Spinal cord. $M C$. Membranous caudal. $N$. Notochord. $N+$, and $R+N$. Neural spines, including probably radial and basal elements. $R$. Radials. $R+H$. Hæmal arch and spine; includes as well, probably, radial and basal elements. 
been acquired in ancient sharks (Fig. 46). The fin of Fig. 47 , however, has not generally been looked upon as derived from shark-like conditions; it has, on the other hand, been thought to be most nearly of the ancestral form. The vertebral axis does not appear to be upturned, and the ventral and dorsal lobes of the fin remain nearly symmetrical, or diphycercal. This form of the caudal fin, on the other hand, has been noted to present many degenerate characters, and to the writer * it seems more reasonable to regard the diphycercal condition as in many cases directly descended from the heterocercal. This might be effected by the terminal portion of the vertebral rod aborting (as in Fig. 47, N), and the upper and lower lobes of the tail becoming pressed backward until their hinder margins appose in the axial line. $t$ The form of diphycercy which is seen in Fig. I I9 is unquestionably of little morphological value; it occurs commonly in deep-sea fishes of every group, and must be looked upon as a degenerate condition resulting from impeded motion under the conditions of bathybial, or deep-sea living.

The cartilaginous supports of the caudal, like those of other unpaired fins, become greatly reduced in size by the encroachment of dermal rays. In the tail of the fossil shark (Fig. 46) the cartilaginous supports, $R$, extend to the very margin of the fin: in the modern shark (Fig. 45) a large part of the functional fin area has become of secondary, or dermal origin, $D$. In the caudals of Figs. 47 and 48 , distinct dermal rays, $D$, are seen, extending from the body wall to the fin margin, splitting and segmenting distally in becoming more perfectly specialized in function. The cartilaginous supports, $R+N$ and $R+H$, must now be

* Fournal of Morphology, IX, I, IS94.

$\uparrow$ Gephyrocercy of Ryder. 
looked upon as including the elements of both the radials and the hæmal or neural processes and spines.

\section{The Paired Fins}

The paired fins of fishes claim an especial interest as the precursors of the limbs of the land-living vertebrates. In this light they have been widely studied, and many schemes have been devised for the comparison of the parts of the five-fingered extremity, or cheiropterygium, of the amphibian with the fin structures of many fishes. The unsatisfactory character of these homologies, however, is felt at the present time more generally than ever, and many morphologists believe with Dr. Mollier* that the ancestral form of the terrestrial limb cannot be found in any of the known types of paired fins.

Among fishes, on the other hand, there appears to be a well-marked unity of plan in the varied forms of the paired fins; and there exists so perfect a gradation in structural characters in the different forms that it seems impossible to doubt their genetic kinship. Which fin, however, must be looked upon as the ancestral type is still disputed. Professor Gegenbaur has long maintained that the fin of Fig. 54 (or, better, the pectoral fin of Fig. $147 \dagger$ ) is to be looked upon as the most primitive form, or Archipterygium. It is a leaf-shaped fin, whose principal cartilaginous supports are arranged in a row from base to tip in the position of a mid-rib: and whose minor fin supports are grouped more or less symmetrically on either side of this axis (cf. Figs. 53, 54, I21, 123, I26). The archipterygium is believed by Gegenbaur to have had a centrifugal origin : it arose behind the gill region, representing in its

* SB. Gesell. f. Morph. Mïnchen, r894, p. I7.

+ Gegenbaur, Das Flossenskelet der Crossopterygier. Cf. Morph. 7B, r894. 
supporting substance the fusion of the cartilages of the hindmost gill bars; in its outward growth the median axis of the fin was first produced, the minor supports then arranging themselves on both anterior and posterior margins. The fin of Fig. 52 was believed to represent a specially evolved (or "monoserial") form of the archipterygium: the hindmost of its elements, $B$, was homologized with the primitive fin stem, along whose posterior (post-axial) margin the elements, $R$, no longer occurred. The structures of Fig. 53 were adduced as a transitional stage in the differentiation of the biserial archipterygium (Fig. 54) into the monoserial form of Fig. 52.

The theory of Gegenbaur as to the origin and evolution of the paired fins cannot be said to be in any way generally supported at the present time. The opposing view, that of their derivation from a continuous lateral dermal fin fold, based on the work of Thacher, Balfour, Mivart, Dohrn, Wiedersheim, and others, is widely accepted, and continues to gain supporting evidence on the sides both of embryology and palæontology.

In the following discussion of the paired fins the writer has mainly followed the recent studies of Wiedersheim.*

The paired fins are believed to have arisen as balancing organs, accessory in function to the vertical fins. They probably occurred early in the line of descent as a response to a need for balancing the fish's body, at the time when the vertical fin was separated into caudal, dorsal, and anal elements. There can be little doubt that they first arose in the line of the fish's motion, and are known primitively (Figs. 49, 50), as a pair of keel-like lateral lappets arising somewhat ventrally, and directed outward and downward.

* Das Gliedmassenskelet der Wirbelthiere, 1893. 
The foremost pair appears anteriorly not far behind the gill region : from its position it has certainly the more important mechanical function in balancing the fish's length - on this account becoming more widely modified in form and function as the pectoral fins. The hinder pair, or ventral fins, though in the plane of the pectorals, has a more ventral position, the hinder borders converging in the region of the anus. The ventral fins are certainly placed in the most motionless region of the fish: they are little affected by either the lateral or upward movements of the body; and remain accordingly smaller in size and simpler in structure than the pectoral fins. That there may have existed in primitive fishes a third (post-ventral) pair of fins is by no means improbable (cf. T. J. Parker, Rcf. p. 244), although its presence has not as yet been satisfactorily demonstrated.

The paired fins thus appear to have been derived from a continuous dermal fold, similar in every way to that giving rise to the vertical fins. They appear, moreover, to have undergone the same mode of evolution in their structures as have the dorsal or anal fins. The unpaired fin fold as it passed forward on the ventral side of the body may primitively have forked in the anal region, and given rise on either side to a lateral fold. In these might next appear an anterior and posterior pair of lappets, - pectoral and ventral fins, - whose positions would be determined by mechanical needs, and whose size would increase as the intervening and useless portion of the dermal fold disappeared. In the subsequent history of pectoral and ventral fins, supporting elements, actinotrichia, radials, and basals, would arise in the same way as in the unpaired fins, and a similar metamorphosis of the fin form would take place, owing to the concrescence of these elements and to the 
FIG. 49

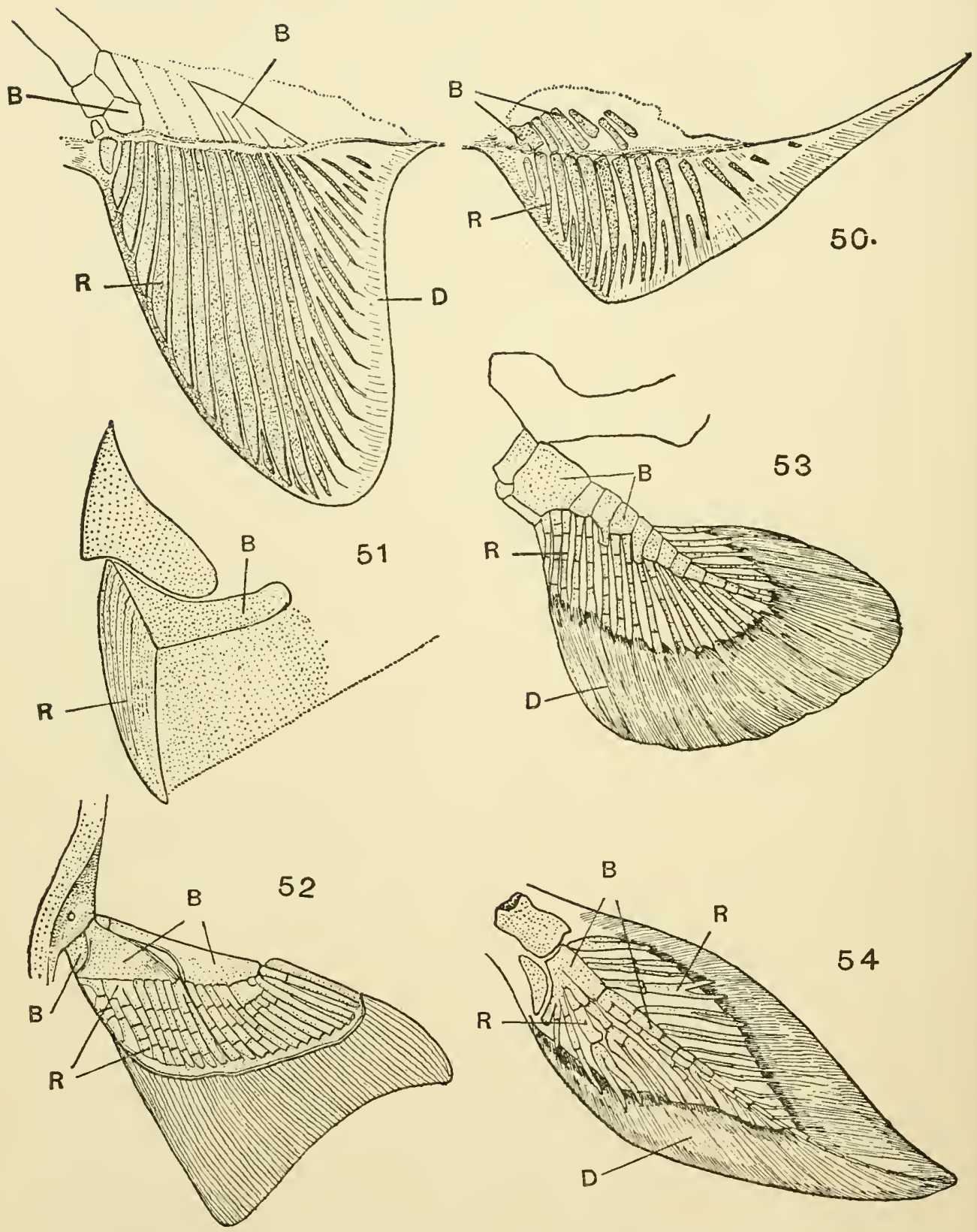

Figs. 49-54. - Evolution of paired fins. 49-50. Pectoral and ventral fins of Cladoselache. $\times \frac{1}{3}$. 51. Pectoral fin of Acanthodian, Parexus. (After SMithi Woodward.) 52. Pectoral fin of Heptanchus. (After Gegenbaur.) 53. Pectoral fin of Xenacanthus (Pleuracanthus.) (After A. FritsCh.) 5+. "Archipterygial" pectoral fin of Ceratodus. (After HOWEs.)

B. Basal. D. Dermal. R. Radial. 
subsequent encroachment of the dermal fin margin. These conditions may be briefly illustrated. The paired fins of a primitive shark (Figs. 49, 50, v. p. 79) appear as the actual lappet-shaped remnants of a continuous dermal fold. The ventral fins (Fig. 50) have clearly retained even the outward shape of the fin fold; the supporting elements are arranged in metameral order ; the radials, $R$, are unjointed, extending from body wall to fin margin; the basals, agreeing in number with the radials, are uniform in size, and as yet unfused. The pectorals, acquiring more special functions (Fig. 49), are enlarged in size, their basals, $B$, becoming compressed and obscure. In these fins the effect of concrescence is admirably marked; the anterior fin margins, pressed tail-iward in their plane of growth, become firm and rigid, their elements stout and compact; the basals, responding to this outward need, cluster more firmly together, are compressed and fused, their anterior elements, largest and stoutest, become inturned, their posterior elements, slightest and most clearly metameral.*

The next stage in the evolution of the paired fins is clearly comparable to that already noted as occurring in the dorsal fin of Holoptychius (Fig. 43), where the line of basals, fusing compactly into a plate-like mass, had inturned its anterior, and protruded its posterior tip; a change apparently slight, but great in functional importance. Up to this stage the fin has been firmly implanted in the body wall; its motion, probably slight upward or downward, served but to balance the fish, its fin rays, tending to concentrate anteriorly, functioned as an efficient cutwater. This process of concentration in the anterior fin margin may have resulted, the writer believes, in the

* The effect of the enlarged and clustering dermal denticles in strengthen ing the cutwater margin of the fin has already been noted (p. 28). 
formation of fin spine, as in Acanthodian* (Figs. 32, $5 \mathrm{I}$, and p. $8 \mathrm{I}$ ). But the protrusion of the line of the.basals must have brought with it a new use in the economy of fish motion. The plane of the fin could now be directed upward or downward; the fin would become a direct aid in propulsion; it would acquire a paddle-like function; it could also be extended sideways as a check to motion. Under these circumstances it is not unnatural that the region of the concrescence of the fin rays should now be transferred from the fin's anterior to the more useful posterior (now distal) margin, and that the fin rays, as well as the line of basals, should acquire a more jointed structure, suited to flexible motions. The course of the differentiation of fin structures may be traced from this point onward, as Wiedersheim has shown, by means of a series of gradational stages: from the conditions of Fig. 49 we may in the present figures pass to those of Fig. 52, thence to those of Figs. 53 and 54. In the pectoral fin of a modern shark (Fig. 52) the basal cartilages, $B$, may still be compared with those in the older form (Fig. $49 B$ ) ; their distal element $(B$, at the right of the figure), however, protrudes from the body wall and is becoming surrounded by clustered radials, $R$; the cartilaginous elements, it is here noted, have been placed in competition with the dermal elements, and have already yielded them over half of the fin area. In the next stage of the evolution, as in the pectoral fin of a Permian shark (Pleuracanthus, p. 83, Fig. 53), the line of the basals is seen to boldly protrude from the body wall and to have become distinctly jointed; the radials have surrounded its distal end, and taken a position

* This homology proposed by the writer has not been accepted by Smith Woodward; the spine is unquestionably encased outwardly by dermal denticles. 
along the outer half of the hinder margin of the fin stem; the dermal region of the fin, $D$, has notably increased. Indeed, the fin area in the modern bony fishes (Fig I45, $P F)$ may become entirely dermal, and the basal supports greatly reduced and metamorphosed. In a final type of fin (Fig. 54) the line of the basals has become widely specialized, and the characters of the archipterygium have been attained: the fin stem is long, tapering, jointed; the radials occur as clearly along the hinder as along the anterior margin; and, as in Figs. 52, 53, dermal rays contribute largely to the fin area. This form of fin may be noted as most closely approximating in function the limb type of land-living vertebrates.

It has recently been urged that the lateral fold origin of the paired fins as thus described is not confirmed by developmental studies, — the especial ground for this belief being that in sharks these fins appear, even in very early stages, as paired lappet-like outgrowths, destitute of intervening fin membrane. The perfected fin fold is therefore claimed to represent nothing more than a specialization to bottom-living, since this condition is known to maintain in earlier stages and in more primitive metamerism in the development of skates: and as skates (p. 93) are well known to represent a comparatively recent offshoot from the stem of the sharks, it is accordingly inferred that the chief proof of the lateral fold doctrine is destroyed.

Since these objections, however, were raised, the structural conditions of the ancient shark of Figs. 49 and 50 have been described, and may be looked upon as the weightiest evidence of the origin of paired fins from lateral folds. Nor does it seem to the present writer that the early character of the fin-fold metamerism of skates is to be looked upon as an unexpected condition. Their 
broad longitudinal fins, specialized to bottom-living, become fashioned in an ancestral mould; and it seems not unnatural that they tend to reacquire their latent primitive form at an early period. On the other hand, the fin-fold condition of the shark might be less perfectly shown on account of processes of accelerated development.

4. THE CHARACTERS OF THE SENSE ORGANS OF FISHES

It has already been seen that the conditions of aquatic living have caused fishes to evolve adaptive structural characters, such as body form, specialized metamerism, organs of progression, and dermal investiture. It is not, accordingly, unnatural to expect that, from the same causes, the condition of the sense organs may have been strikingly modified.

The sense of "feeling" - using the word in its general meaning - has been of especial value in fishes, and tactile organs appear to be independently developed in all fish groups whose living habits clemand them. In the form of barbels they thus occur in members of the various divisions of bony fishes, as cod (cusk, Ophidium) (Fig. 55), drum-fish, Pogonias (Fig. 56), or sculpin, Hemitripterns (Fig. 57). Their form may be lobate, thread-like, or villose ; they are often surprisingly similar in size, position, and innervation; they usually appear on the inferior head surface, most often in the anterior throat region, in the position most exposed to tactile impressions. The threadlike barbels of the catfishes (Fig. 58, p. I7I) are arranged in pairs about the margin of the mouth ; the longest lateral pair is connected with the marginal bone (maxillary) of the upper jaw and directed at will. In other mud-living forms, sturgeons (Fig. I6o), the barbels have arisen on the under side of the shovel-like snout, directly in advance of 

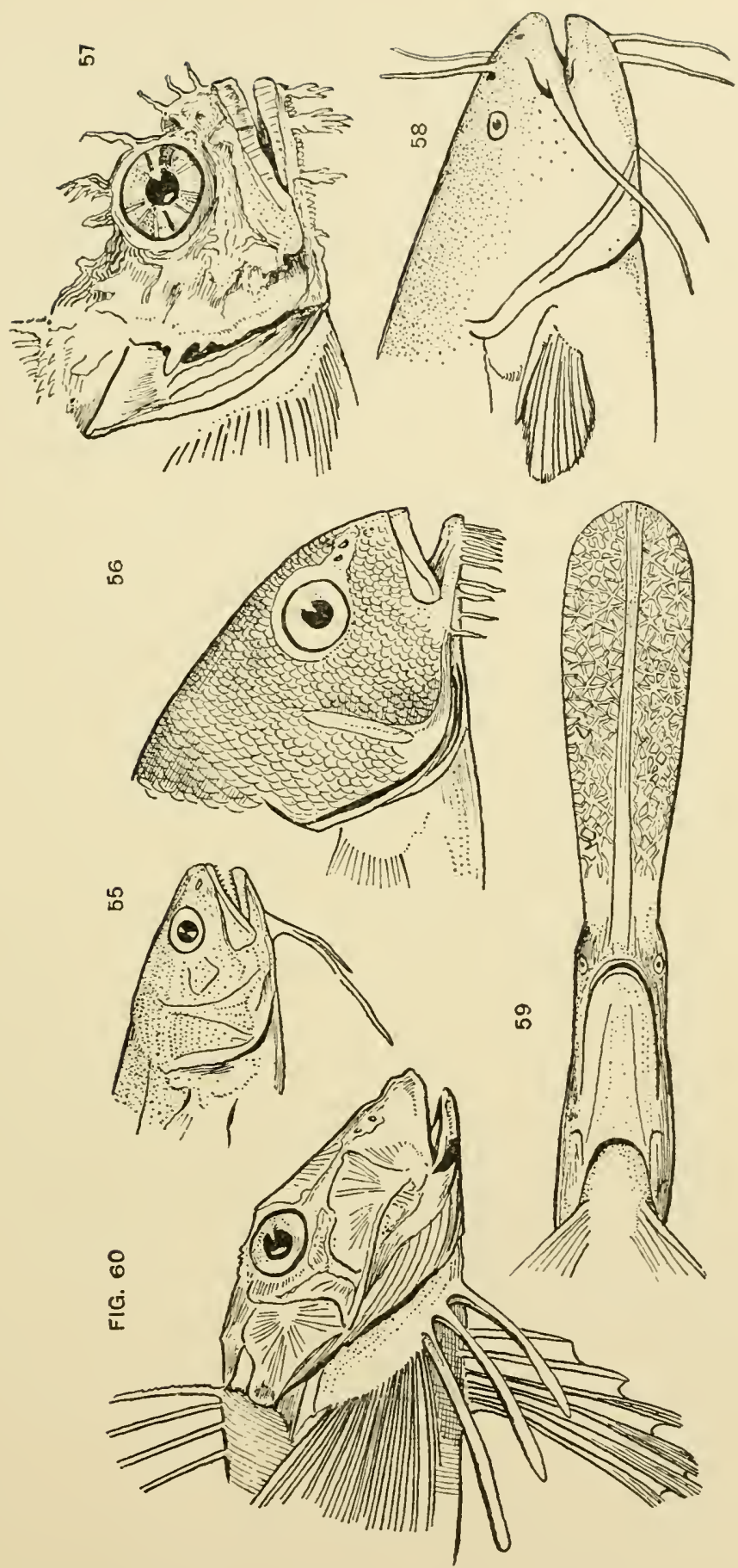

Figs. 55-60. - Barbels and tactile sense organs. (After GoODE in U. S. F. C.) 55. Cusk, Ophidium. 56. Drum-fish, Pogonias. 57. Sea-raven, Hemitripterus. 58. Catfish, Amiurus. 59. Spoon-bill sturgeon, Polyodon (ventral view of snout). 6o. Sea-robin (Gurnard), Prionotus. 
the protractile sucking mouth. There can be little doubt that the most aberrant tactile organ in fishes is the long spatulate rostrum of the paddle-fish (Polyodon) of the Mississippi (Fig. 59): the sense organs are here known to be most highly specialized, although their intimate structure is as yet not understood. Tactile organs are often to be found upon fin structures, especially those of the anterior body region. In the sea-robin, Prionotus (Fig. 60), the sensory structures are borne by three anterior fin rays; these are greatly enlarged, lose their connecting fin web, and can be moved at will in a variety of ways. In all cases the barbels appear to be true and highly specialized organs of touch, and the end organs are comparable apparently with the touch papilla of higher forms. Of their extreme sensitivity there can be no doubt, and as far as can be judged from their innervation, it would appear that their function is tactile rather than gustatory, as has been suggested. The limits of these processes, however, are no doubt poorly defined in aquatic living.

\section{The Lateral Line}

The sense organs, generally known as the lateral line, or mucous canal system, are looked upon as essentially peculiar to fishes. In the form of a 'lateral line,' they are arranged more or less segmentally along the median line of either side of the body and form a conspicuous feature in the outward appearance of the fish (Figs. 87, I04, LL, I 2 I, LL, I 45, LL). Often by striking coloration, the lateral line is rendered even more prominent, passing from the head to the tail as a pale or brightly coloured band, against the dusky side of the fish. In the region of the head, however, this sensory structure is, as a rule, no longer conspicuous: it dips below the skin sur- 
face and becomes a series of interconnecting tubes, which pass along the most exposed ridges of forehead, cheek, orbit, and jaw rim. Here in different regions, these sensory mucous tubes may become dilated, constricted, or ramose, and may communicate with the surface by occasional or numerous pores.

The mucous canal system has long been a subject of study and investigation. It is looked upon generally as a sensory organ, adapted to the conditions of aquatic living, but its function has not been definitely established. How it was acquired, or how its ancestral conditions have been modified in the present groups of fishes, must at present be looked upon as in many ways doubtful.

The simplest conditions of the mucous canal system appear to exist in primitive sharks: and to these the writer believes that the modified sense canals in other fishes may best be referred.

The ancestral condition of the lateral line of sharks appears to have been represented in an open continuous groove,* lined with ciliated sense cells, and protected only by an overcropping margin of shagreen denticles (Fig. 6I). In this condition it at least exists in the ancient sharks of Figs. 86, 87, 92, and in the Chimæra (Fig. 104). That the canals of the head region were also primitively of this character appears exceedingly probable: they are thus retained in the adult Chimæra (Fig. I04, M.C) $\dagger$

In the modern forms of sharks the condition of the

* It is to be noted that this condition occurs in deep-sea fishes: it here is evidently an adaptation to their peculiar environment, which causes an early ontogenetic stage to be permanently retained.

† In Callorhynchus this condition has been largely lost: the outer margins of the sensory groove have sealed over. 
FIG. 61
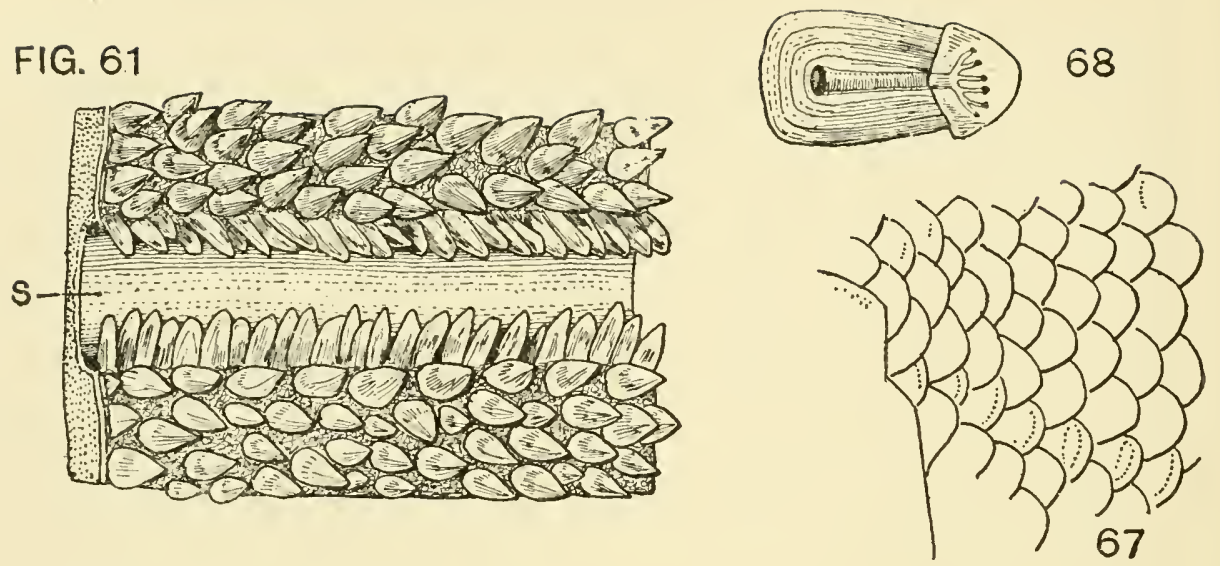

62

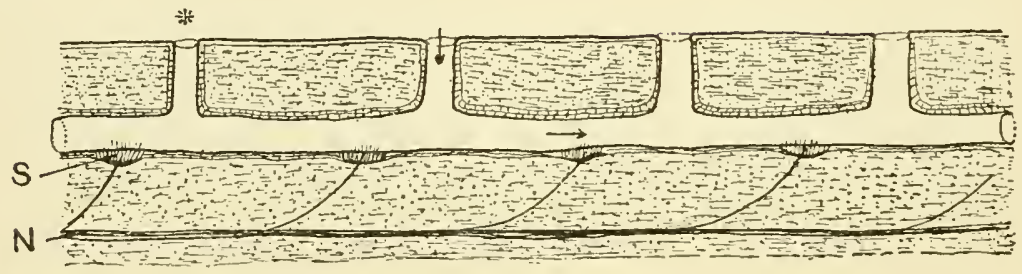

63
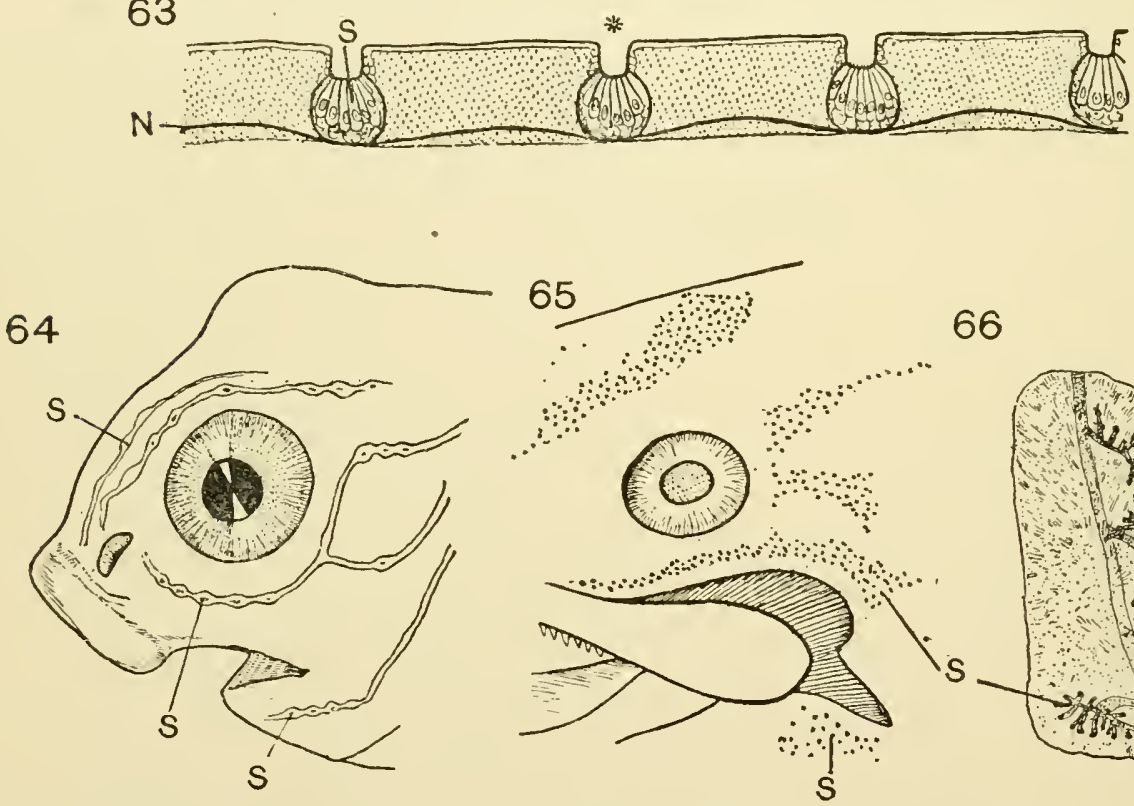

66

Figs. 6r-68. - Mucous canals (lateral-line organs). 6r. Chlamydoselache, groove-like lateral line. (After GARMAN.) 62. Plan of lateral line of sharks, longitudinal section. 63. Plan of sensory end buds (lateral line). 64. Sensory tracts of head of larval Amja. 65. Surface openings of tubules of sensory tracts of head of adult Amia. 66. Ramification of sensory tubules in dermal plate of Amia. 67. Cycloid scales of Amia, showing the openings of the tubules of the lateral line. 68. Cycloid scale of the lateral line of Amia, showing the course of the sensory tubule. (Figs, $64-68$ after ALLIS.)

$N$. Nerve supply. S. Sensory tissue. * Denotes an outer opening; $\rightarrow$ the direction of an incoming stimulus. 
sensory canals suggests the modifications to which the open sensory groove has been subjected. There are thus forms in which the canal becomes more and more deeply sunken in the integument, and acquires a tubular character by the fusing together of its outer margins. The section of the lateral line of the Greenland shark, Leemargus (Fig. 62, v. p. 90), shows the tube-like sensory canal well sunken from the surface, but retaining metameral openings at the points. The sensory cells, $S$, are no longer, as in Fig. 6r, scattered evenly along the floor of the canal; they now occur in metameral masses supplied with a distinct nerve branch, $N$, located in the region immediately below the external tubules. When sunken in the integument, the sensory canal is known to have acquired supporting structures to enable its tubular character to be maintained; in the Cretaceous shark, Mesiteia, an elaborate series of surrounding calcified rings * were thus evolved.

Further changes in the mucous canal are often accompanied by the subdivision of the external apertures; each of the openings of Fig. 62 might by this process give rise to a series of minute surface pores, as at $S$ in Fig. 65, or enlarged, showing the collecting mucous canals in Fig. 66. This ramose mode of termination of the external tubules has been admirably described by Allis $\uparrow$ in the untogeny of a ganoid; in a larval stage (Fig. $64, S, S, S$ ), the condition of the sensory canals is seen to differ little from those shown in section in Fig. 62; although imbedded in the integument, occasional pores are seen, $S, S$, to open to the surface; these subsequently by repeated subdivision give rise to the great number of minute open-

* A condition somewhat similar has been noted (Leydig) in Chimæra.

+ On the Lateral Line System of Amia calva. F. of Morph., I \$89. 
ings already noted in Fig. 65. A process of this kind is carried to great lengths among the fishes which develop horn-like scales, as Amia, herring, or cod: in the scales of the lateral line region the distal tubules appear at the surface as a cluster of pores, as shown in Fig. 67 , or in the detached scale of Fig. 66.

The organs of the lateral line (of a bony fish) shown in section in Fig. 63 are regarded by the writer as of a highly modified character. They appear to have been derived from the conditions of Fig. 62 ; the end organ, $S$, corresponds with that, $S$, of the preceding figure; its size, however, has greatly increased, and the intervening sensory tube has been lost; its metameral opening at the surface corresponds with that of Fig. 62 ; the nerve supply, $N$, is now seen to have secured a more perfect relation to the end organs.

The original significance of the lateral line system as yet remains undetermined. As far as can be judged from its development, it appears intimately, if not genetically related to the sense organs of the head and gill region of the ancestral fish: in response to special aquatic needs, it may thence have extended further and further backward along the median line of the trunk, and in its later differentiation acquired its metameral characters.

A significant feature of its development is its peculiar innervation. Its lateral tract is innervated by a specially evolved root of the vago-glossopharyngeal group, but its head region is supplied by a similar root of the facial nerve (perhaps also by the trigeminus; cf. Collinge, Ref. p. 248).

In view of this innervation, the precise function of this entire system of end organs becomes especially difficult to determine. Feeling, in its broadest sense, has safely been 
admitted as its possible use. Its close genetic relationship with the hearing organ suggests the kindred function of determining waves of vibration. These are transmitted in so favourable a way in the aquatic living medium, that from the side of theory a system of hyper-sensitive end organs may well have been specialized. The sensory tracts along the sides of the body are certainly well situated to determine the direction of the approach of friend, enemy or prey.

\section{The Pineal Eye}

The presence or absence in fishes of the pineal end organ, the "unpaired median eye of chordates," may finally be noted, since the condition of the epiplyysis and its associated structures in fishes has an important bearing on general vertebrate morphology.

It is well known that in many forms of reptiles there exists, at the distal end of the epiphysis, a well-defined sensory capsule, whose structure shows unquestionably its optic function. It has seemed to many, therefore, that throughout the chordates the epiphysis has been primitively associated with a median eye, which has degenerated as the paired eyes became better evolved. That it has been retained in an almost perfect condition in reptiles has accordingly been looked upon as an outcome of a life habit which concealed the animal in sand or mud, and allowed the forehead surface alone to protrude:the median eye thus preserving its ancestral value in enabling the animal to look directly upward and backward.

If this view as to the presence of a parietal eye in the ancestral vertebrate is to be generally accepted, one would naturally suggest that the organ should be present, at all events to a recognizable degree, in some of the varied forms 
of the lowest vertebrates extant, - fishes and amphibia. If there are no suggestions of its visual nature among these forms, one would be inclined to believe with O. Hertwig, that the epiphysis was originally of a different function and that its connection with a median eye may have been altogether of a secondary character.

The evidence as to the presence, primitively, of a median eye in fishes is certainly far from satisfactory: * in all the forms of recent fishes, no structure has been found associated with the epiphysis which, by the broadest interpretation, could be looked upon as suggesting a visual function. It is possible that fishes and amphibia may, in their extant forms, have lost all definite traces of this ancestral organ on account of some peculiar condition of their aquatic living. On this supposition, evidence of its presence might be sought in the pineal structures of the earliest Palæozoic fishes - whose terrestrial kindred, and probable descendants, may alone have retained the living conditions which fostered its functional survival.

It is accordingly of interest to find that in a number of fossil fishes the pineal region retains an out ward median opening, whose shape and position suggest that it may have enclosed an optic capsule. If the median eye existed in these forms, it may well have been passed along in the line of descent through the early amphibia (where substantial traces of a parietal foramen occur, e.g. as in Cricotus) to the ancestral reptiles. This view is greatly strengthened, as Beard has shown, by the presence in the lamprey of a pineal end organ (optic?).

The evidence, however, that the median opening in the head shields of ancient fishes actually enclosed a pineal

* Hertwig (Mark), Handbook of Embryology of Vertebrates, and Cattie, $v$. Ref. p. 250. 
eye, is now felt by the present writer to be more than questionable. The remarkable pineal funnel of the Devonian Dinichthys (Fig. I34) is evidently to be compared with the median foramen of Ctenodus and Paladaphus (=Sirenoids, p. I22); but this can no longer be looked upon as having possessed an optic function, and thus practically renders worthless all the evidence of a median eye presented by fossil fishes. It certainly appeared that in the characters of the pineal foramen of Dinichthys there existed strong grounds for believing that a median visual organ was present: its opening was in the pineal plate, midway between the orbits ( $P N$, Fig. I34). At the surface it was of minute size ( $X$, Fig. I36), but below (Fig. I 37) it flared out into a funnel-like form, shown in longitudinal section in Fig. I37 $A$. The peculiar character of this opening seemed to render it especially fitted for a visual function; the minute external opening forms an image near the plane of the visceral opening of the funnel, without the specialization of a lens, - an image so perfect that it might readily be photographed. It is evident, accordingly, that if an optic capsule were enclosed by this fora: men, it would have enabled its possessor to have looked directly upward and backward; and, without the need of developing lens-like and focussing structures, it could have readily received the images of all outer objects near or remote.

But the function of this pineal foramen, unfortunately for speculation, could not have been optical. It occurs in a fish (Titanichthys) closely related to Dinichthys, and, as the writer * has recently found, is of a distinctly paired

* He is obliged by accumulating evidence to abandon his former view that the pineal foramen of Dinichthys contained a specialized optic capsule ( $N . Y$. Rep. of Fisheries, I891, pp. 310-314). 
character, its visceral and outer openings bearing grooves and ridges which demonstrate that the pineal structures must not only have been paired, but must have entered the opening in a way which precludes the admission of the epiphysis. It is now, therefore, that the pineal foramen which has been described in Siluroids * becomes of especial interest, since its contained structures are apparently connected with the lateral line system of paired nerves.

It must for the present be concluded, accordingly, that the pineal structures of the true fishes do not tend to confirm the theory that the epiphysis of the ancestral vertebrates was connected with a median unpaired eye ; it would appear, on the other hand, that both in their recent and fossil forms, the epiphysis was connected in its median opening with the innervation of the sensory canals of the head. This view, it is now interesting to note, seems essentially confirmed by ontogeny. The fact that three successive pairs of epiphysial outgrowths have been noted in the roof of the thalamencephalon, appears distinctly adverse to the theory of a median eye.

* Dean, N.Y. Rep. of Fisheries, I891, and Klinckowström, Anat. Anz, I893, viii, p. 561. 


\section{THE LAMPREYS AND THEIR ALLIES}

THE relations of the more primitive chordates to the true fishes have not been considered in the present discussion. A brief account, however, must be given of the Cyclostomes, or Marsipobranchii, which are represented in the recent lampreys and hags.

The three prominent forms of Cyclostomes are figured on a following page (Figs. 70-72, $A-D$ ). They are eellike in shape, but are lacking both in paired fins and in an under jaw. Their mouth is of a rounded form, and is suctorial; when closing, its lateral margins draw together. Their skeleton is of the simplest character, membranous rather than cartilaginous; its elements are never more highly differentiated than those shown in the accompanying figure (Fig. 69, $A$ ).

Bdellostoma is shown in surface view in Figs. 70 and $72 A$, and in sagittal section in Fig. 69. It is looked upon as the most archaic form of the living Cyclostomes. Barbel-like structures surround its mouth region; its nasal canal (Fig. 69, $N$ and $C$ ) has a forward opening at the snout, and a hinder one piercing the roof of the pharynx, - a very exceptional character in fishes; its tongue, studded with rows of rasp-like teeth,* may be greatly everted,

* The teeth of Myxinoids are cuticular structures, and may well have been evolved within the limits of the group. Beard has homologized them with the teeth of sharks, but his determination of the presence of true enamel has not been confirmed (Ayers). 


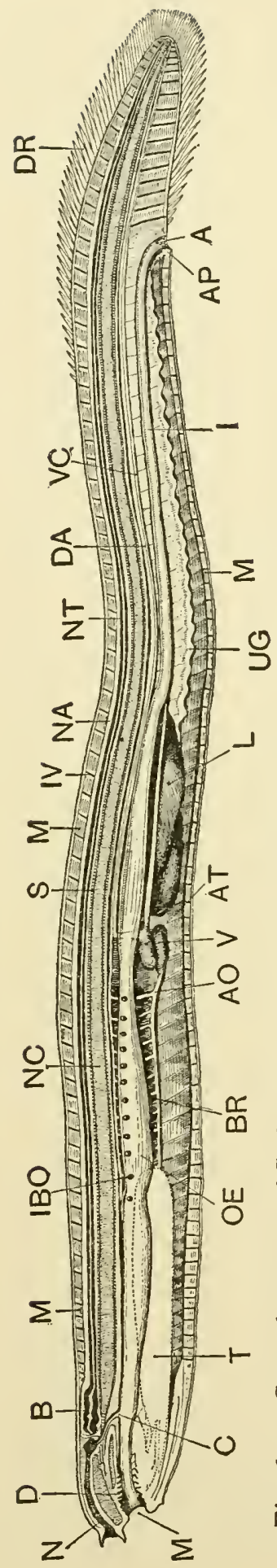

无

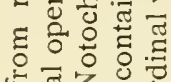

雨文过矛

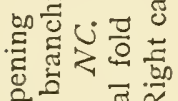

원.

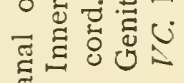

نํ.

풍

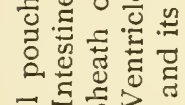

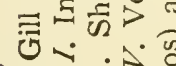

ठำ

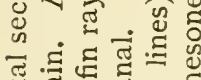

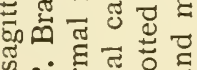

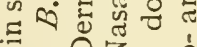

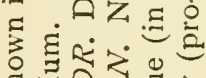

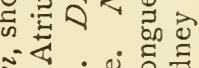

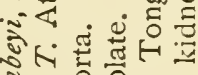

₹ 0 定发

ช ส ฮ

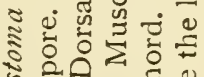

ज्ञ

읨ㅇ

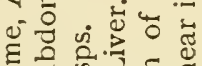

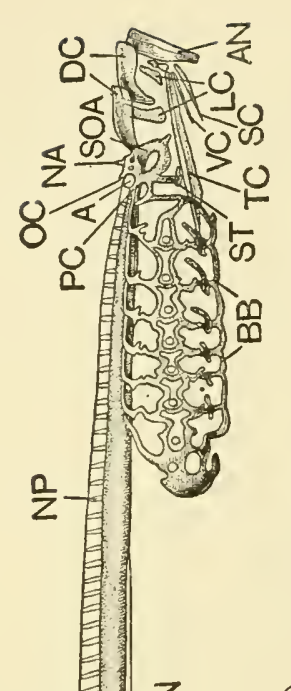

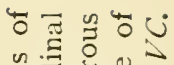

总政

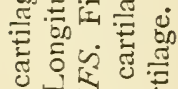

敬焉

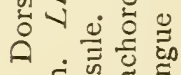

ن. ํํㄹ है

A

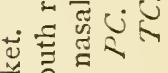

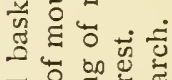

बब

氜

는

०० के के

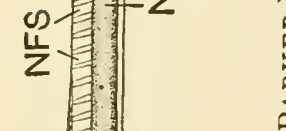

诺

的家

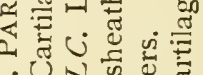

$\therefore \sim$ on

$-\dot{0} \cdot$ ह

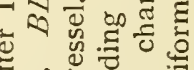

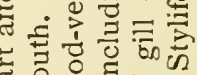

采

풀

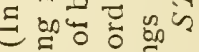

跣

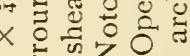

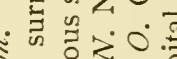

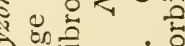

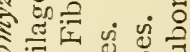

E

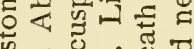

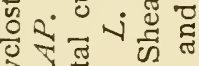

Uे

䜤

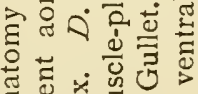

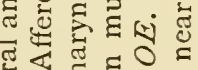

垴.

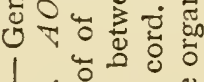

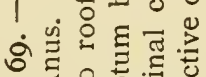

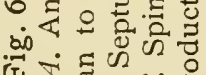

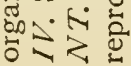

2.

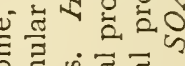

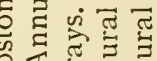

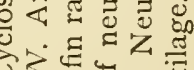

ठै।

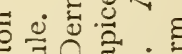

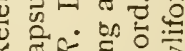

की

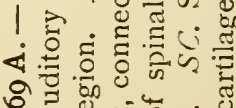

8. 先

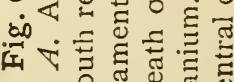

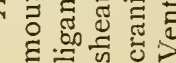


as in Fig. 72, $A$, and then drawn in by stout tongue muscles, $T$ (Fig. 69); its digestive tube is almost straight, terminating at the base of the tail region at $A$; the region of the gullet, $O E$, is pierced by a number of branchial openings, varying from seven to fifteen, often assymmetrical. The body cavity is an extremely large one for the size of the contained viscera. An unpaired fin, supported by delicate, unbranched (dermal) rays is restricted to the hindmost part of the body. Passing down the side is a row of mucous pouches by which a remarkable supply of slime is secreted. The living animal is enabled, by the peculiar character of this slimy secretion, to render a pailful of water jelly-like in consistency.

Bdellostoma occurs plentifully in the bays of the Pacific coast of America, notably at Monterey, California. It is active in its movements, is carnivorous, and is well known to take a baited hook. Its numbers make it an enemy of the fishermen, entangling and sliming their set lines, and destroying the captured fish. It is said to feed at night, although little is yet known of its general habits of living. None but adult specimens have thus far been observed.

The Hagfish, Myxine glutinosa (Fig. $7 \mathrm{I}$, and $72, B$ ), is in many regards similar to Bdellostoma; it differs mainly in the character of its unpaired fin and in its branchial structures (Figs. 9, IO). As already noted, the outer ducts of the gills, instead of opening separately at the surface as in Fig. 70, are drawn together tail-ward, and terminate on either side in a common ventral opening (Fig. 7I, at the point*). The unpaired fin is almost lacking in supports; its ventral origin is even as far forward as the branchial openings; the anus, as a slit-like opening, pierces it in the tail region. As in Bdellostoma, the nasal canal begins at the snout, and at its hinder opening pierces the roof of 

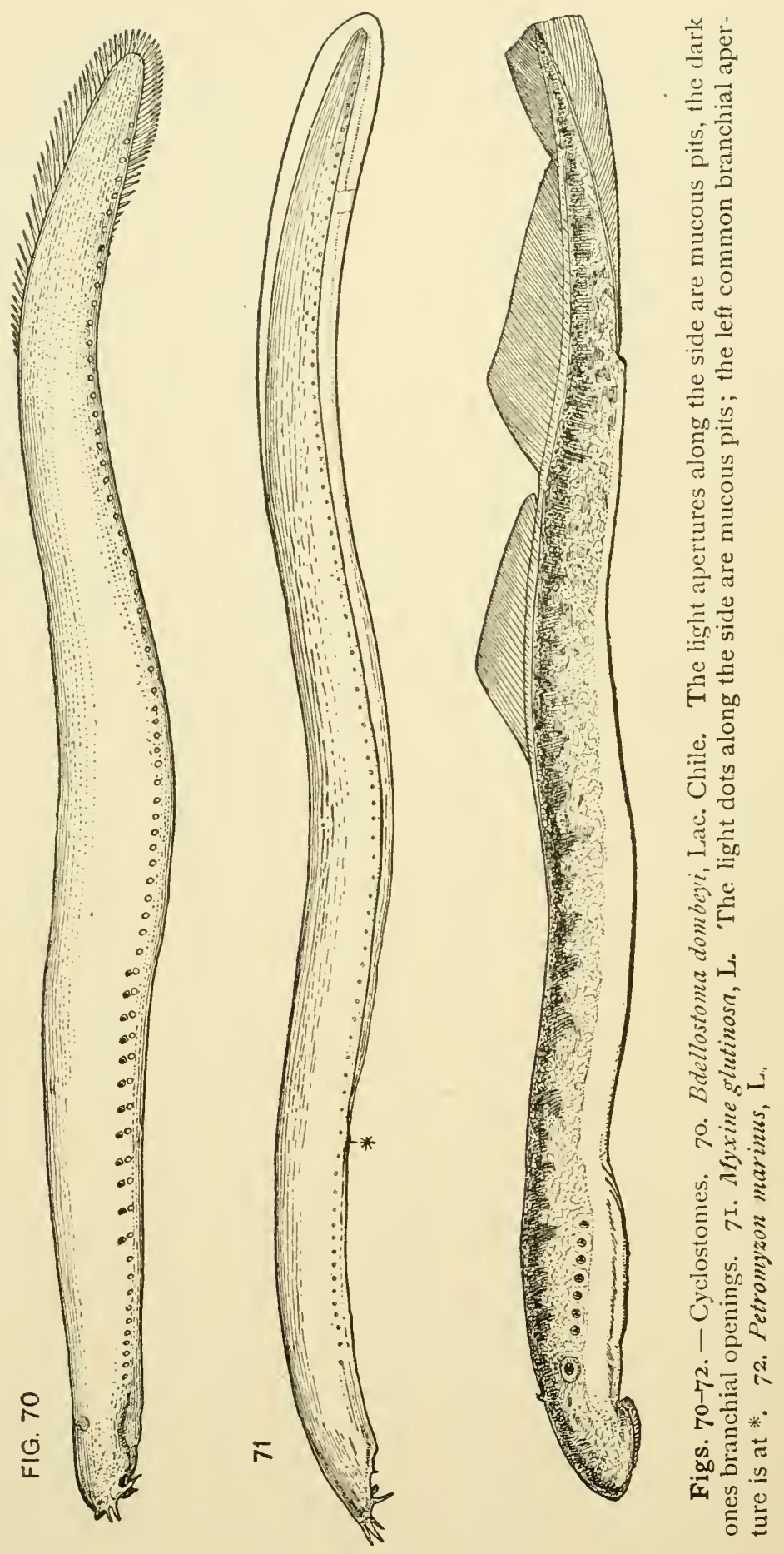

60 
the pharynx; this, with other related conditions, has caused Myxine and Bdellostoma to be included in a sub-group of Cyclostomes, as Myxinoids, or Hyperotretes. * In each genus there is possibly no more than a single valid species.

Myxine is a well-known form : it occurs along the Atlantic coast at moderate depths. It is exclusively carnivorous,
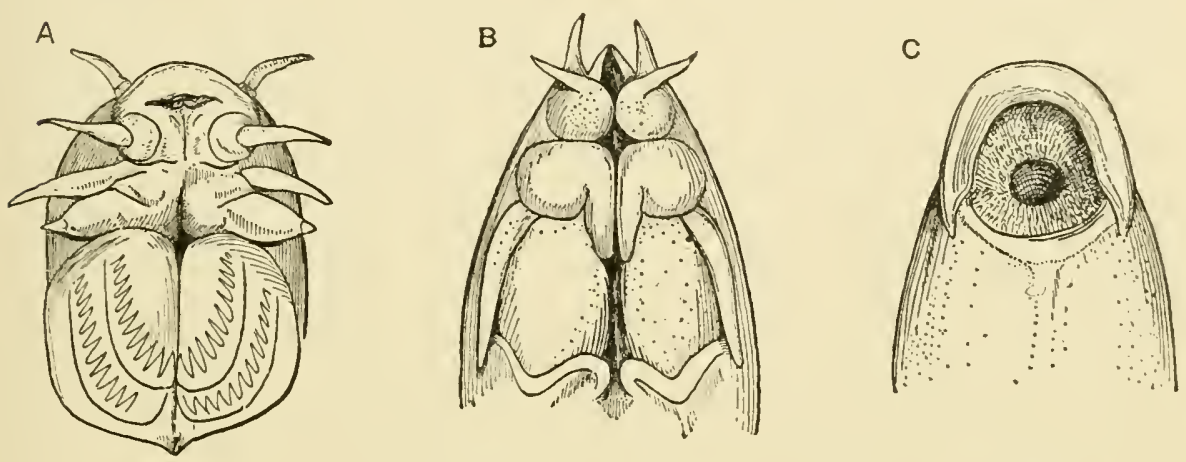

Fig. 72. $-A-D$. Ventral aspects of heads of $(A)$ Bdellostoma (after AYERS); (B) Myxine (after GüNTHER); ( $C$ ) Ammocetes (after Gunthre); (D) Petromyzon (after GÜNTHER).

often boring its way into the abdominal cavity of (diseased or injured) fishes, and with them is brought to market; it is also taken not infrequently by line fishermen. The smallest example that has

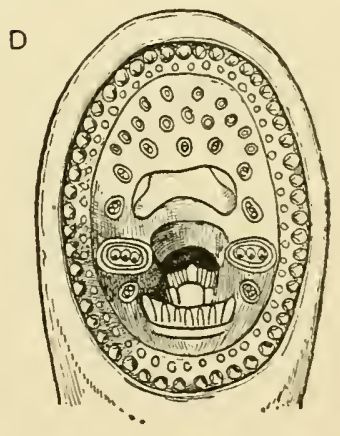
thus far been described is $6 \mathrm{~cm}$. in length; it was recorded by Beard. (V. Ref. p. 239).

The Lamprey, Petromyson, is the most perfectly studied member of the Cyclostomes. Its species are common to the continents of the northern hemisphere; and in South America and Australia there occur very closely allied genera, as Mordacia and Geotria. The largest lamprey, $P$. marinus (Fig. 72 , and $C, D$ ), is known to attain a length of nearly four feet; it occurs in the coast * v. Glossary, p. 228. 
rivers, ascending them in numbers in the springtime (April) on the way to the spawning grounds (v. p. I82). During its adult life it is supposed to be exclusively carnivorous, to some degree, perhaps, parasitic, although many doubt that it is truly parasitic in the sense of entering the bocly cavities of healthy fishes. It certainly is often taken attached to other fishes, as shark, sturgeon, or salmon.

Immature lampreys differ so strikingly from the adults that they were formerly regarded as species of a separate genus, Ammocotes (v. p. 2I5). In feeding habits the ammocote is widely unlike the mature form; it is toothless (Fig. 72, C), and in part mud-eating, i.e. vegetivorous.

Petromyzon must be regarded as the most highly organized of Cyclostomes. Its mouth has no longer the fringing barbels of Myxinoids, - which suggest, according to Pollard, the buccal cirrhi of Amphioxus, - it has acquired stout supporting cartilages and a funnel-shaped form, studded with a series of conical teeth, as shown in Fig. $72, C$. The teeth of the hinder mouth region now appear almost as though they were supported by a mandibular cartilage; the tongue, as in other Cyclostomes, bears the teeth which are probably of the greatest functional importance. The nasal canal of Petromyzon has its outer opening on the dorsal surface of the head; its inner end, however, does not perforate the roof of the mouth, although produced backward as a blind sac, closely apposed to the pharynx. Petromyzonts are, accordingly, arranged as the sub-group Hyperoartia, in contrast to the Myxinoids.

Further structural characters, which the lamprey seems to have derived from simpler conditions, may be noted in its unpaired fin, gill chamber, nervous system, and skeleton. The unpaired fin has subdivided into dorsal and caudal elements, and is now supported by well-marked 
rays, which (sometimes) bifurcate. The branchial region of the adult lamprey's gullet is restricted to a pouch-like diverticulum (v. p. 263 and Fig. 326). A 'sympathetic' nervous system, and a 'lateral line' has appeared: the latter passes down the side in two branches, one above and one below the median lateral plane: its end organs are the pouches of nervous epithelium which in Myxinoids are scattered generally over the body surface. The skeletal structures of the lamprey (Fig. 69, A) indicate well-marked advances: a stouter supporting tissue of cartilage-like character has appeared; the brain case is partly roofed over; neural processes, $N P$, a branchial basket, $B B$, and a series of mouth cartilages are especially noteworthy.

\section{Affinities of the Cyclostomes}

The relations of the group, Cyclostomi, to the earlier chordates, and, on the other hand, to fishes, have been by no means definitely established. Dohrn and others have suggested that the Cyclostomes are greatly degenerate, and are even closely akin to the recent bony fishes, as perch or cod. Their views have been based upon several structural characters, notably vestigial organs, such as the appendages at the sicles of the cloacal opening of Petromyzon which were believed to represent pelvic fins; and there was further taken into consideration the belief that the entire group was one of degenerate life habits. The views of these writers, however, do not appear to be confirmed by later studies, and the belief is becoming more and more general that Cyclostomes represent a very ancient chordate stem whose ancestral form is most nearly exemplified by Bdellostoma. Parasitism has been acquired to a limited degree, but does not appear to have affected the general characters 
of the group. Among its primitive features are to be included : skeleton and muscles, continuous vertical fin, gill characters (p. 260), viscera (p. 263), urino-genital organs (pp. 266, 270), nervous and circulatory systems (pp. 260, 269, and 274). With these must be taken into account: absence of mandible* and of paired fins and girdles; and in addition the remarkable conditions of metamerism (p. I4).

Little more that a vague kinship between lampreys and fishes has been established by the study of living forms. And, on the other hand, it would appear equally impracticable to obtain evidence bearing upon this problem from the side of palaontology. All that is known of the recent Cyclostomes more than suggests that their soft body structures would prove most unfavourable to fossilization. It would be only, therefore, in the event of some of their ancient members possessing calcified structures that palæeontology would be able to offer a clue as to their ancient affinities.

Upon the problem of their descent the evolution of fishes has, however, an undoubted bearing, in suggesting the lines and effects of aquatic evolution and the permanence of generalized types. It certainly tells of the extreme slowness of the evolution of aquatic forms and convinces us that the ancestral Cyclostome could only have occurred in a time stratum exceedingly remote. Palæontology cannot perhaps hope to obtain more than suggestions of the ancestral forms, although these, from their generalized characters, may well have survived during geo-

* The cartilages of the mouth region of Cyclostomes have been homologized with the structures of gnathostomes; Pollard recently (Anat. Anz. ix, pp. 349-359) ascribes a cirrhostomial origin to the mouth parts of a Teleostome (catfish), which the writer cannot believe has been demonstrated; variations in the number, shape, and function of the cartilages of the mouth rim of Cyclostomes might well have occurred within the limits of this ancient group. 
logical ages. It can, however, show that Cyclostomes are not the degenerate descendants of shark-like forms; and - if only by analogies in the evolution of fishes - it may still be able to demonstrate with fair probability their genetic kinships. It may, for example, prove that in the most ancient time there existed undoubted Cyclostomes, and that these in many and most specialized forms were even then branching-off twigs of a great descent tree. In such an event an inference would certainly be the more reasonable which derived the advancing line of fish descent from the genealogical tree of the more primitive Cyclostomes, than that vice versa.

It is now accordingly of especial interest that the fossil remains of what seems undoubtedly a lamprey (Fig. 73) have been discovered in the Devonian; and this, together with a better knowledge of the ancient and curious chordate group, Ostracoderms, may, it is hoped, lead to some solution of the Cyclostome puzzle.

\section{The Ostracoderms}

Fig. $73 \cdot-$ The De-
vonian Cyclostome, Palceospondylus gunni, T. $\times$ 4. (After TRAOstracoderms, as they are called from QUAIR.) Achanarras their shell-like, dorsal and ventral derm quarry, N. Scotland. plates, are certainly the oldest known remains of vertebrates.* In their simpler forms they occur in the Upper Silurian; they flower out in a variety of types in the Devonian, and shortly become extinct. In the present con-

* The earlier (Ordovician) vertebrate remains described by Walcott are as yet uninterpretable. 
FIG. 74

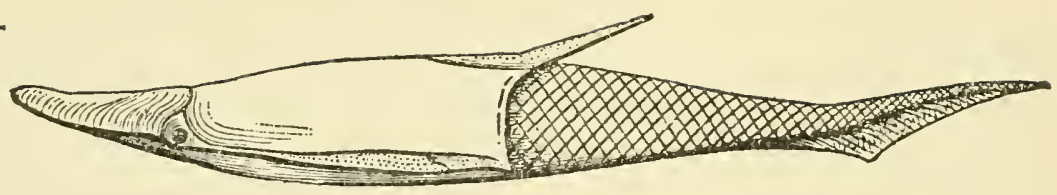

75
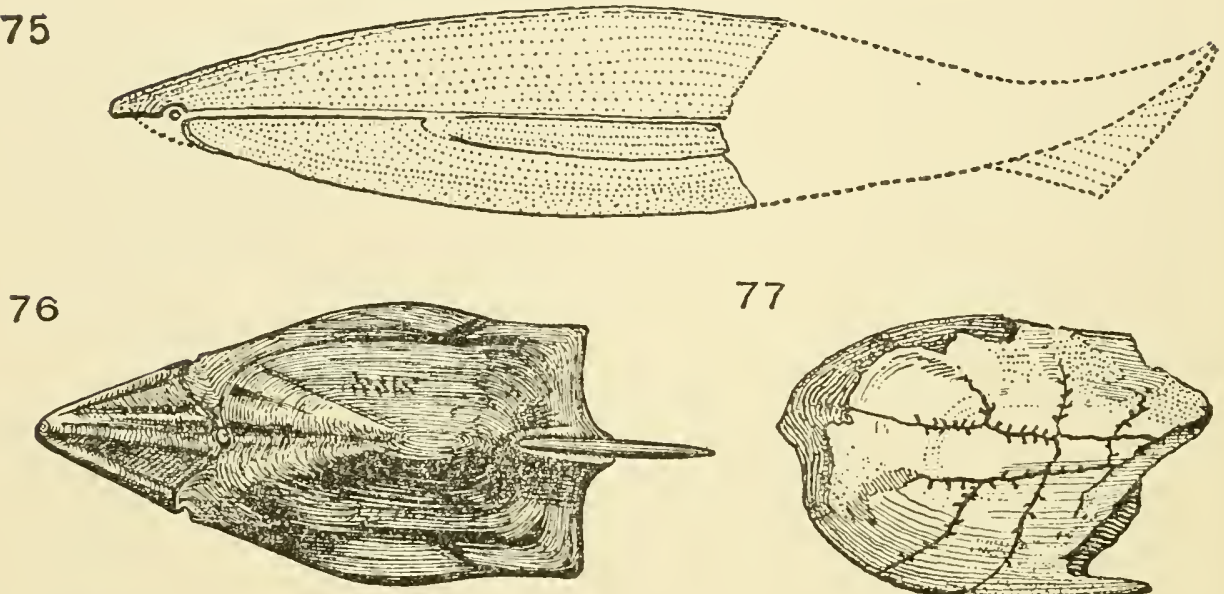

77
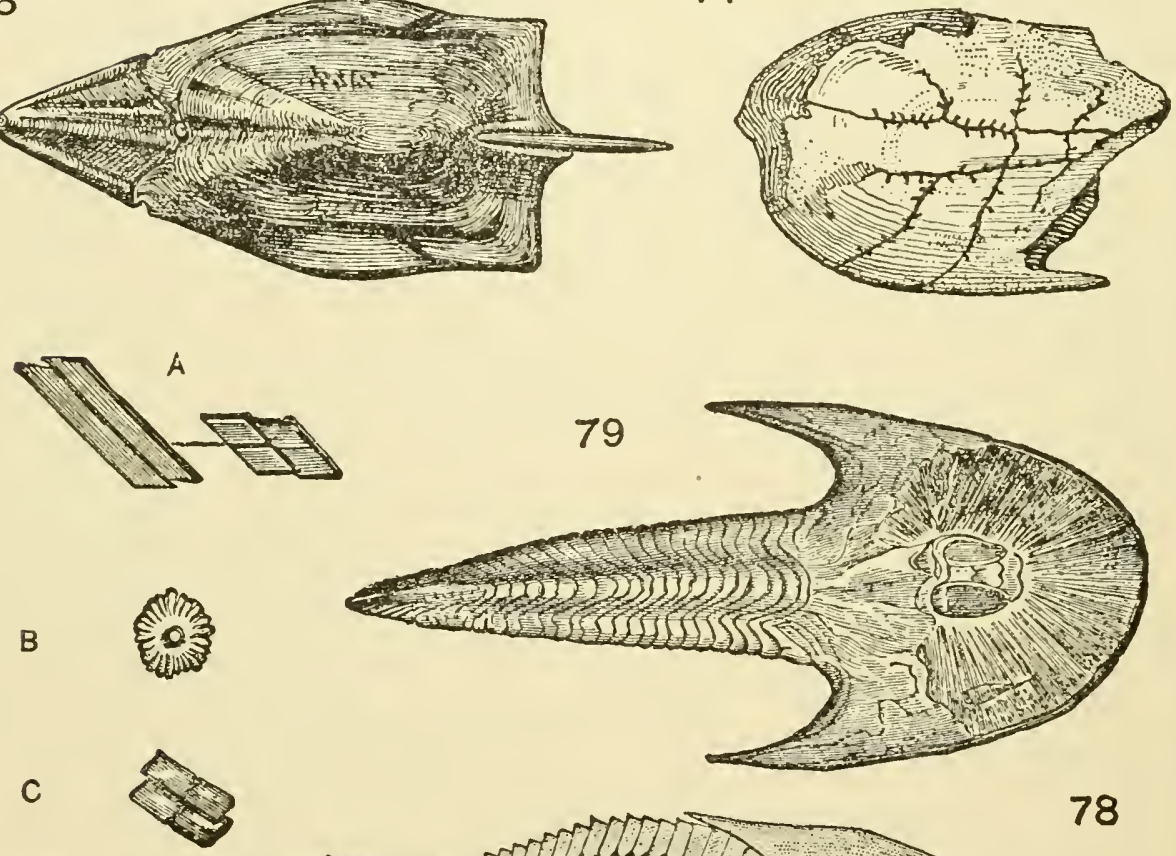

78

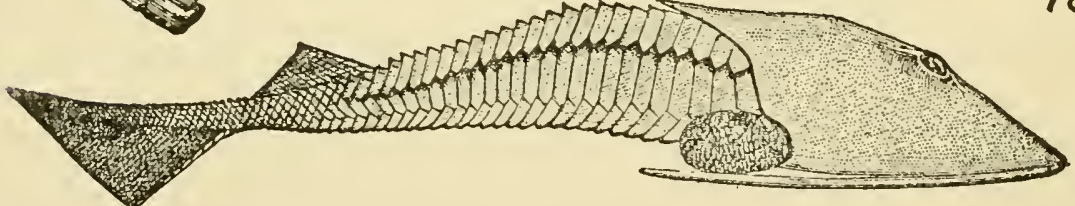

Figs. 74-79. - Pteraspis (restored). $\times \frac{1}{2}$. (After LANkester.) Lower Old Red Sandstone, Herefordshire. 75. Palceaspis americana, Claypole. $\times \frac{3}{4}$. (Restoration after Ci.AyPole, somewhat modified by the writer.) 76. Pteraspis, dorsal shield, slightly restored. (After LANKESTER.) 77. Pteraspis, ventral shield ("Scaphaspis"), showing mucous canals. (After SMiTh WoOdward.) 78. Cephalaspis lyelli, side view. (Restored by LANKESTER.) 79. Cephalaspis lyelli, dorsal aspect. $\times \frac{1}{3}$. (After L. AgAssiz.) Specimen from Old Red Sandstone, Forfarshire. $A C$. Rhomboidal scales from different body regions. $B$. Tessera from middle layer of head shield. 
nection they may be described, if only to indicate that they are in no way closely connected with the ancient shark types (p. 78), and that they are accordingly of but indirect interest in the descent of jaw-bearing vertebrates.

Ostracoderms may readily be reduced to three general types, Pteraspid, Cephalaspid, and Pterichthid. The first, oldest, and probably simplest occurs in the Lower Old Red Sandstone of Herefordshire. It was provided with arched back and breastplate (Figs. 74, 76, 77), from whose anterior lateral notches a pair of eyes protruded; the surface of these plates (Fig. 77) appears to have been grooved for sensory canals. Pteraspis, as seen in the restoration, had a snout plate, a dorsal spine, and a body casing of rhomboidal scales; its mouth was probably in the region immediately below the eyes, in front of the margin of the well-rounded ventral plate; this was generally regarded as the dorsal plate of a kindred genus, "Scaphaspis." Closely related is the American Pteraspid, Palaaspis (Claypole), from the Upper Silurian of Pennsylvania (Fig. 75); this form lacks the dorsal spine of the English species; it has a well-marked lateral plate intervening between those of the back and ventral side, and, according to its discoverer, Professor Claypole, possessed pectoral fins similar to those seen in Fig. I23. Its hinder trunk region is unknown.

Cephalaspis, the second type of Ostracoderm, is from the Old Red Sandstone of Scotland (Figs. 78, 79). It was curiously suggestive of a trilobite, and with little doubt mimicked this ancient crustacean in its life habits. Its most prominent feature is a crescent-shaped head, with sharp rounded margin like a saddler's knife. This is protected clorsally by but a single plate, arching upward and backward; at its summit was a pair of closely apposed eyes, and near its flattened rim were pouch-like sensory 

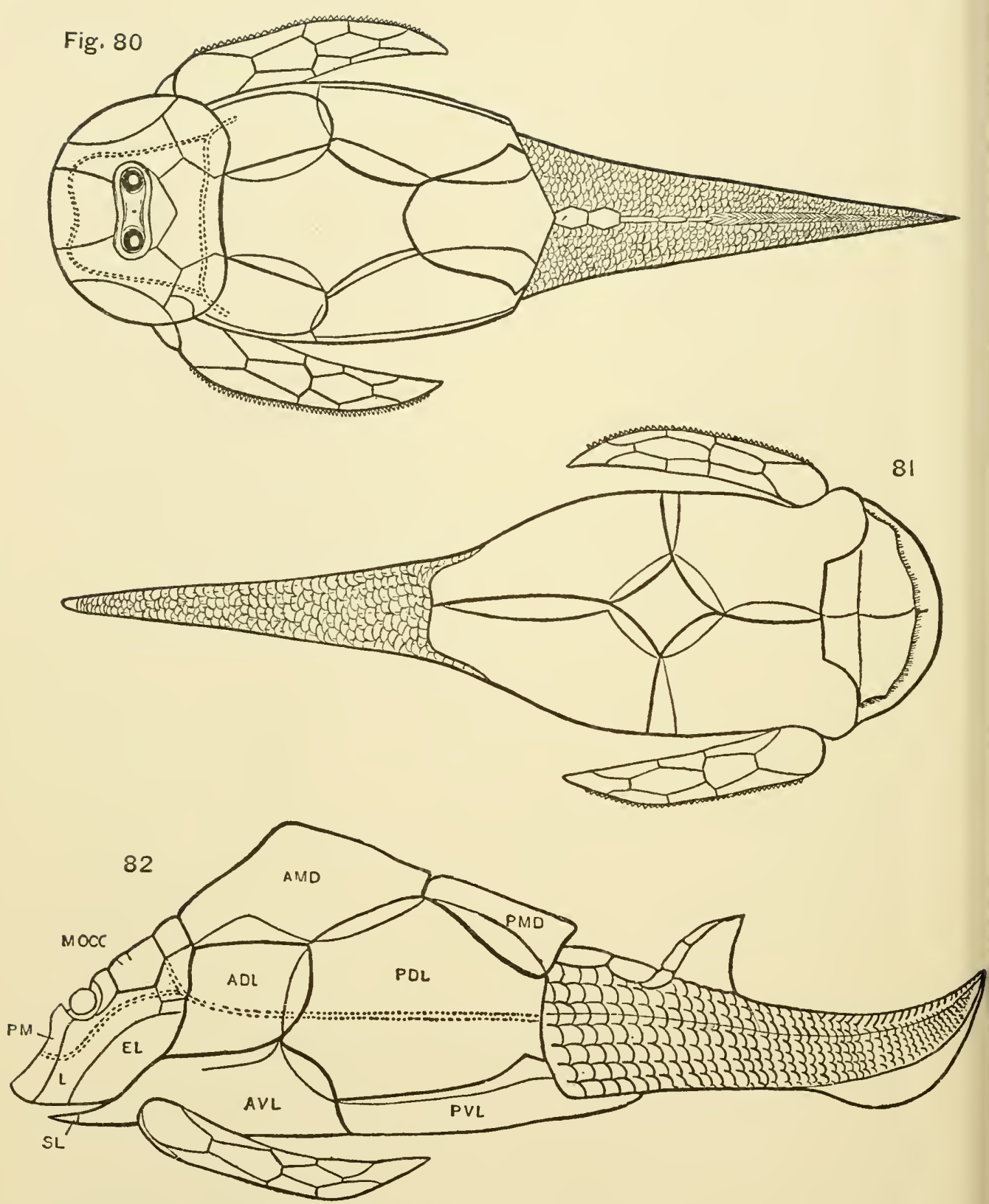

Figs. 80-82. - Pterichthy's testudinarius, Ag.; restored by R. H. TRAQUAIR, from the dorsal aspect (80), ventral aspect (8I), and lateral aspect (82). The double dotted lines indicate the grooves of the sensory canal system; and in the trunk, the thick lines represent the exposed borders of the plate, the thin line showing the extent of the overlap.

$A D L$. Anterior dorso-lateral. $A M D$. Anterior median dorsal. $A V L$. Anterior ventrolateral. EL. Extra-lateral (or operculum). L. Labial. MOCC. Median occipital. PM. Premedian. PDL. Posterior dorso-lateral. PMD. Posterior median dorsal. PVL. Posterior ventro-lateral. SL. Semilunar. (Figure from SMITH WoodwaRD.) 
organs. The angles of the head plate are in some genera produced most acutely, and bear spines which served probably in progression. The body walls were encased in metameral derm plates, which became arched in the median line to serve as a dorsal fin. A heterocercal tail and an anal fin were also present. Problematical opercular flaps protruded at the sides of the head plate, and represented (as is now known) a continuation of the elastic middle layer of the head plate.

Pterichthys must be looked upon as the culminating type of these anomalous forms (Figs. 80-82). As in some Cephalaspids, there are two body regions that are cuirassecl, - head and thorax. The tail portion is encased in dermal plates; it bears a dorsal fin and a clumsy heterocercal tail. In the consolidation of its armoured parts the elements are usually clearly indicated. The curious arm-like jointed appendages at the lateral head angle were formerly regarded as homologous with the opercular flaps of Cephalaspid, but are now known to be nothing more than the lateral head angles produced and specialized (i.e. jointed for locomotion). The strengthening spine of the dorsal fin is also but a prinitive specialization of the body integument; it is formed by a pair of the bent scales of the dorsal ridge, and is not, therefore, homologous with the radial fin cartilages of fishes.

In Cephalaspids and Pterichthids there occurs a pineal plate (or its equivalent) which may have been either movable or fixed. In this are to be found the paired eyes and the socket of a median unpaired eye (?). In all of these singular forms mouth parts ${ }^{*}$ are wanting. In

* Smith Woodward has since described a pair of inturned labial plates in the mouth of Pterichthys. Their position suggests that the sides of the mouth rim might become apposed, as in the Cyclostomes. 
no instance has a trace of endoskeletal parts been observed.

The more that is determined of the structural characters of Ostracoderms, the less is it possible to accept the views as to their affinities with forms other than "fishes," either (Cope) as to their permanent larval-ascidian characters, or (Patten) as to their relationships with arachnids. Their general kinship is certainly to the fishes. According to Smith Woodward, the markings appearing on the visceral surface of head tests indicate the presence of gill pouches; in some forms clearly marked furrows suggest the possession of vertical semicircular canals; fish-like sense organs occur (Fig. 77); and their derm plates, in their cancellated and bone-like characters, cannot well be likened to the exoskeletal parts of invertebrates.

The lamprey-like form, Palaespondylus gumni, Traquair (Fig. 73), in the Lower Devonian is by many looked upon as the actual solution of the Cyclostome, and even of the Ostracoderm puzzle. This interesting fossil was discovered by Dr. Marcus Gunn, in the Lower Old Red Sandstone of Caithness, and was described in several papers by Traquair (Trans. Edin. Soc., I\$92-IS94). It is of very small size, commonly of about an inch in length, but is admirably preserved (Fig. 73). There can be no doubt that Palæospondylus possessed a ring-like mouth surrounded by barbels like those of a Myxinoid, and that it lacked paired fins. But as a Cyclostome it must have highly specialized, having the same relation to the more primitive Cyclostomes of its day, as had the minute Acanthodians (p. 8I) to the existing sharks. It had thus a remarkably large caudal fin with elaborately bifurcating supports; it had evolved stout, ring-like vertebræ, even in the caudal region, which had developed stout neural proc- 
esses. Its skull was highly evolved: in its anterior part were represented, according to Traquair, the palatine cartilages; the brain case was complete, and the auditory capsules were of relatively enormous size. The lateral plates of the neck region are as yet uninterpretable.

From the evidence of Palæospondylus, accordingly, it may reasonably be inferred that lamprey-like forms existed in highly specialized conditions, even at the beginning of Devonian times. If they then existed, it is of course not impossible, and perhaps even not improbable, that their offshoots may have culminated in the Ostracoderms, as Smith Woodward has suggested. These can certainly belong to no gnathostome stem. Their organs, though often highly specialized, were yet of the most primitive order, - lack of paired appendages, * softness of axial parts, lowly sense organs; even the dermal plates, elaborate in their subdivision or ornamentation, or in the special uses, as "opercula," "pectoral fins," or "fin rays," $\dagger$ are yet but primitive specializations of the exoskeleton.

* The presence of paired fins in Palæaspis, as determined by Claypole, has not been confirmed. The present writer, to whom the type specimens were kindly shown by their describer, must regard these structures as elasmobranchian (Chimæroid?) spines, in crushed condition, accidentally associated with the head region of the fossil.

+ It is obvious that these structures are but analogous to the opercular and fin structures of fishes, and would tend to separate, rather than closen, the ties of kinship of these groups. 


\section{IV}

\section{THE SHARKS}

All true fishes may conveniently be grouped into the four sub-classes that have been noted (p. 8) in the introductory chapter. These are now in turn to be considered, and in this review the principal forms, fossil and recent, of each group must be exemplified. From the standpoint of their structural and developmental characters, a general idea of the mutual relationships of the fishes may finally be deduced.

The sub-class Elasmobranchii, which includes the sharks and rays, is usually regarded as representing most nearly the persistent ancestral condition of fishes, and, indeed, of all other jaw-bearing vertebrates. As a group it should certainly be taken first in the present discussion, as a convenient basis of comparison.

Sharks and rays should be looked upon at the beginning as the representatives of the oldest, most widely diffused, and possibly largest group of fishes. In their living forms they suggest but faintly the number and variety of their fossil kindred. It is generally thought that the history of this group, when more perfectly determined, is to furnish the most important evidence as to the general lines of descent of the fishes. 


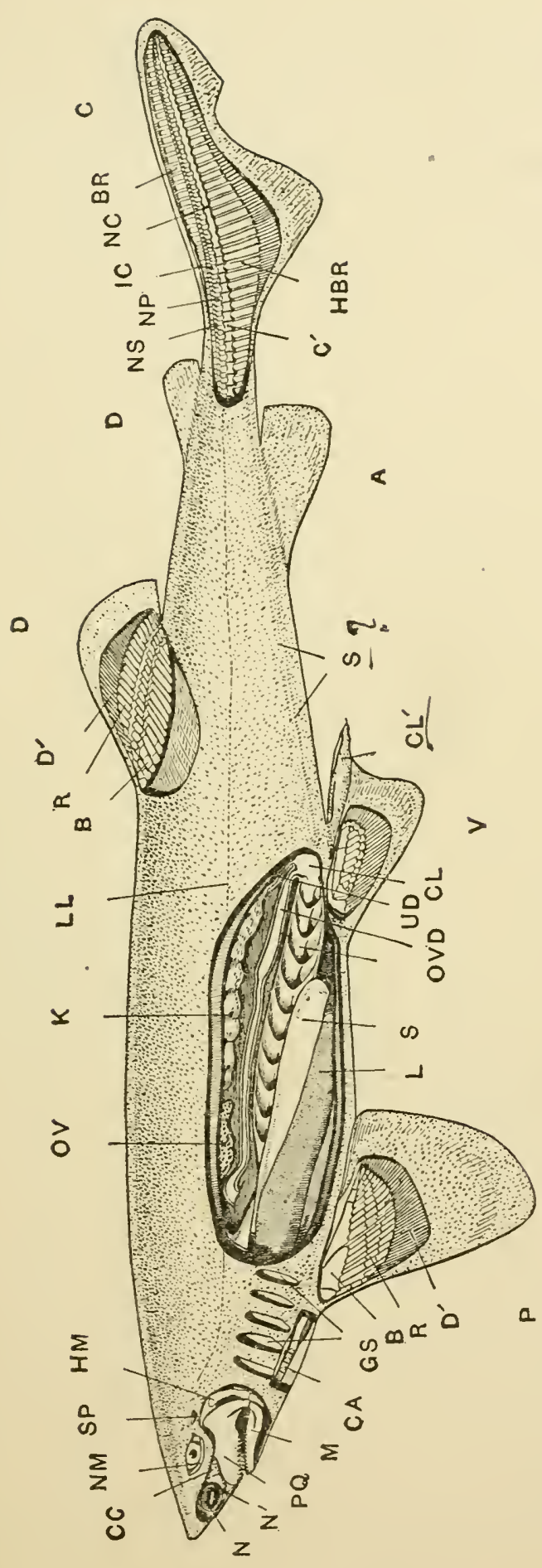

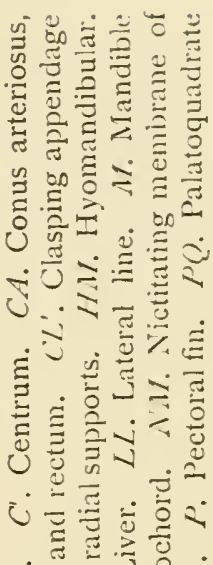

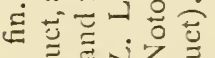

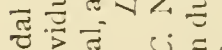

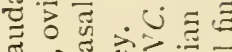

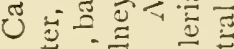

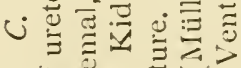

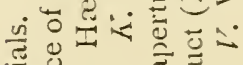

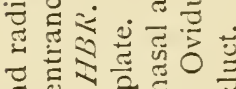

๘) $\cong$.

ก ำ

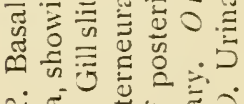

ख

宛

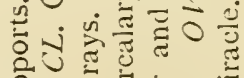

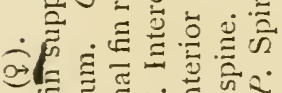

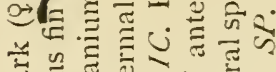

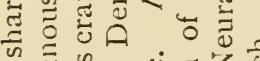

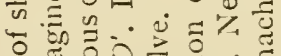

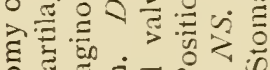

है

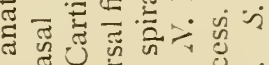

च ल

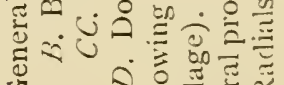

ษ

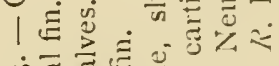

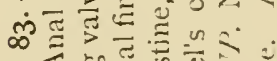

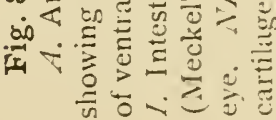




\section{Structural Characters}

The definition of a shark emphasizes its cartilaginous skeleton, investiture of shagreen, uneven (heterocercal) tail, and its separate and slit-like gill openings. Its more definite characters may well be summarized in the accompanying figure (Fig. 83).

I. The skeleton is cartilaginous (cf. Fig. 83,84 , and p. 252), sometimes calcified generally, but always (in recent forms) lacking in dermal bones. Behind the simple, troughlike brain case the vertebral rod, beginning at the occipital condyles, is clearly segmented; the notochord is often retained, especially in the tail region, $N C$, but is encroached upon by the cartilaginous rings, centra, $C$, arising metamerally in its sheath (Fig 85). The vertical supports of each centrum include a well-marked ventral plate, the hæmal arch and spine, $H B R$, - which in the tail region probably represents as well the cartilaginous elements of the fin support, - and a pair of small dorsal plates, the neurals and interneurals, $N P, I C$, each capped by a neural spine, NS. The fin supports compare closely in structure with the vertebral processes; they form a large part of the functional fin, and preserve clearly, both in basal and radial parts, their metameral character. This segmental arrangement is also characteristic of the supporting elements of the cavity of the mouth and throat. These constitute the "visceral arches" (cf. p. 256) which pass backward from the rim of the mouth to the region of the pectoral fin. The first visceral arch strengthens the rim of the mouth ; it is margined with teeth and functions as jaws,*

* The writer believes that the upper element of the mandibular arch is to be regarded as the palatoquadrate cartilage, rather than the pre-spiracular ligament. 


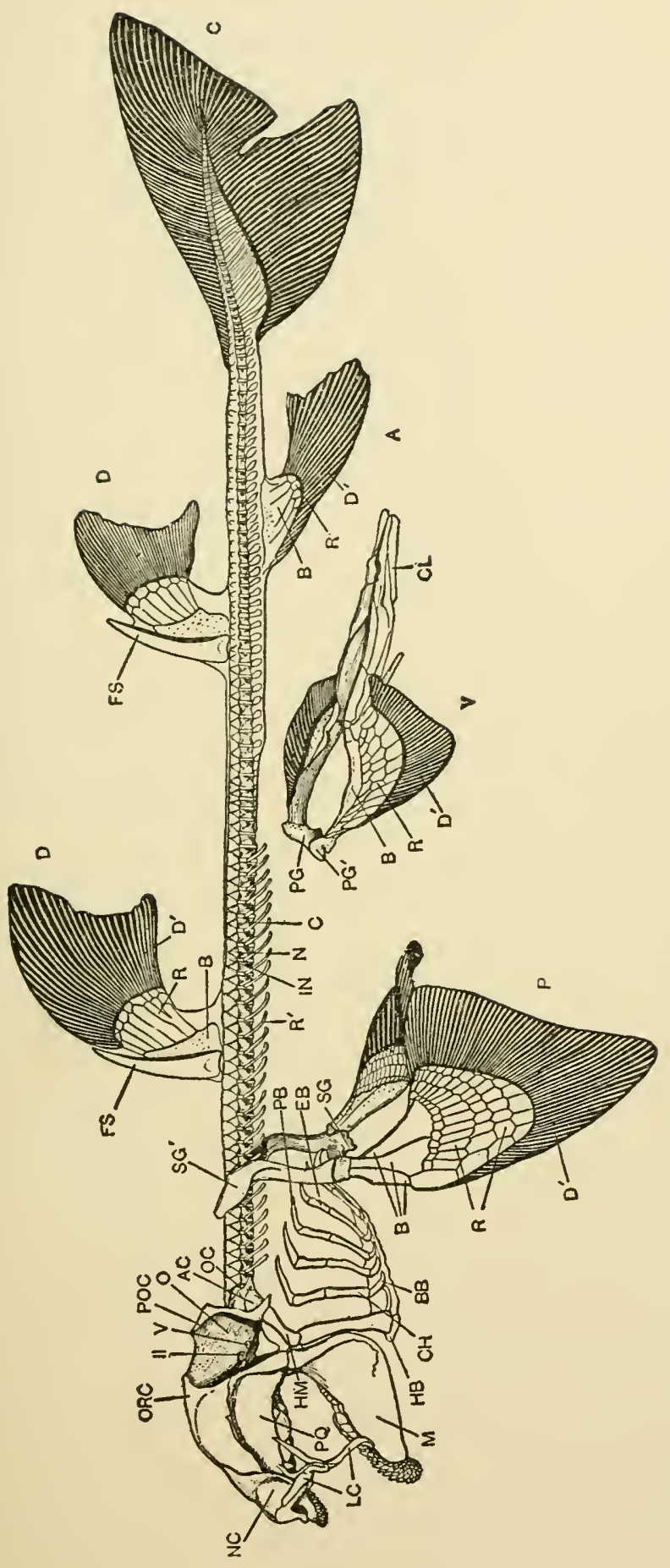

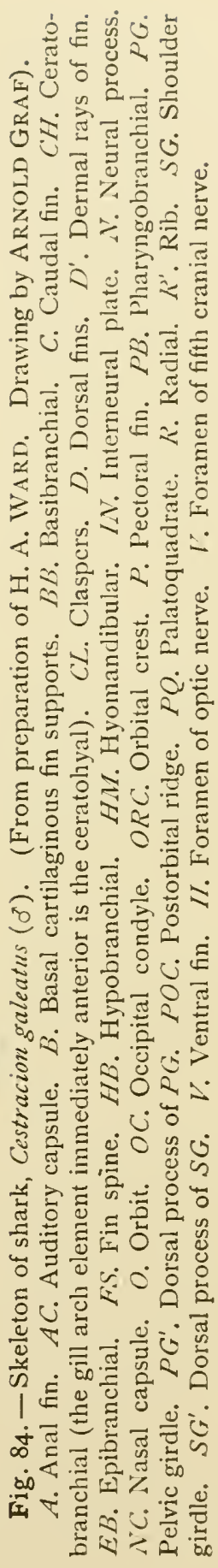


$P$ and $M$. The second arch serves as the principal support of the jaw hinge, $H M$, while holding in position, ventrally, the hinder arches; it also supports the tongue, and forms the hinder border of the spiracle (p. I9). The succeeding arches, usually five in number, are the bearers of the func tional gills, their jointed structure permitting the dilating and contracting movements of breathing.

As a further skeletal element of the Elasmobranchs the sub-notochordal rod is to be mentioned. It is present in the larval stages of sharks, and appears to persist in the adult Cladoselache (p. 79). It is a prominent structure of the hinder body region, passing along, like a second

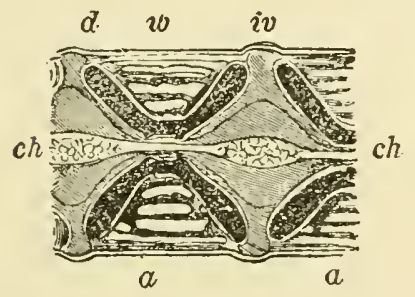

Fig. 85. - Vertebræ of shark (Squatina), longitudinal section. (After ZITTEL.)

$c h$. Notochord. $d$. Calcified rim and anterior surface of centrum. iv. Intervertebral space. $v$. Centrum. notochord, immediately below the vertebral axis. Its significance is unknown.

II. The Integument of the sharks, as has been noted (p. 23), is studded with shagreen denticles, often in metameral arrangement. These have been shown to correspond clearly with the teeth.

The soft structures characteristic of the Elasmobranchs include:--

III. Gills, arranged metamerally (p. ig); the most anterior one partly functional in the spiracle, $S P$.

IV. Sense organs of the lateral line, in some forms in an open sensory groove, in others sunken and constricted in metameral pouches.

V. BRAIN, simple in its segmental characters and cranial nerves (v. p. 274).

VI. NASAl ORgan, EYE AND EAR, as shown on p. 276.

VII. Renal and Reproductive systems (p. 270), abdominal pores (p. 27I). 
VIII. Digestive tube with a single bend, $S$, $I$, the intestine provided with a spiral valve (p. 263), terminating, together with the ducts of the renal and reproductive organs, in a common cloaca, $C L$ (p. 266). Liver, $L$, spleen, and pancreas large; mesenteries simple but greatly fenestrated; air bladder absent.

IX. Heart with a contractile arterial cone, $C A$, containing several rows of valves (p. 260); circulatory system in general as described on p. 269.

X. "Claspers" developed at the hinder margin of the ventral fins as the intromittent organ of the male. They are rudimentary in the female, $C L^{\prime}$. Each clasper is the trough-like hinder rim of the fin, which becomes transformed into the compact, elongated, tube-like sperm canal. Its tip is often studded with elongated shagreen denticles whose recurved cusps retain it in copulo.

\section{Fossil Sharks}

Of all fishes, sharks certainly suggest most closely in their general structures the metameral conditions of the Cyclostome: it should also be noted that they possess the greatest number of body segments, in some instances over three hundred, known among vertebrates. Little is known, however, of the primitive stem of the sharks, and even the lines of descent of the different members of the group can only be generally suggested. The development of the recent forms has yielded few results of undoubted value to the phylogenist: it would appear as if palæontology alone could solve the puzzles of their descent.

The history of fossil sharks has as yet been but imperfectly outlined. The remains of the more ancient forms have usually proven so imperfectly preserved that little could be determined of their structural characters. Spines, 
teeth, shagreen denticles, have proven the antiquity of the shark stem and the wealth and variety of its fossil forms; they have provided the evidence that even in Silurian times there lived sharks whose exoskeletal specializations had progressed further than in their recent kindred: that in the Carbon there occurred the culminating-point in their differentiation, when specialized sharks existed whose varied structures are paralleled only by those of existing bony fishes, - sharks fitted to the most special environment; some minute and delicate; others enormous, heavy, and sluggish, with stout head and fin spines, and elaborate types of dentition.

But the detached fragments of the fossil sharks can give little satisfactory knowledge of their general structures. The simpler the form of the shark, indeed, the less liable is it to become fossilized. The more generalized of the ancient sharks must thus remain structurally unknown until more perfect fossils come to be found. To this event the discoveries of the past few years have certainly yielded most encouraging aid. Several forms of sharks of the Lower Carbon and Permian have been obtained in a condition of admirable preservation, and have already contributed materially to the morphology of Elasmobranchs. Other early forms may be forthcoming which will be found to have retained sufficient of the characters of their ancestors to warrant more definite views as to the general relationships of fishes.

Of the three primitive forms of fossil sharks lately described: the earliest, from the Ohio Waverly (Lower Carbon) is Cladoselachc, Dean; a later and puzzling form, from the Carboniferous, is Chondrenchelys, Traquair; the latest from the Permian and Coal Measures, is Pleuracanthus, Agassiz. The only early shark type that had previ- 
ously been structurally known was that of the aberrant and highly specialized Acanthodian of the Coal Measures.

Cladoselache is the most primitive, as well as the oldest, of these ancient sharks. It is relatively of small size, varying in the length of its species from two to six feet. Its outward form, as restored by the writer, is seen in Fig. 86 , and in ventral view in Fig. $86 A$. The shape is clearly
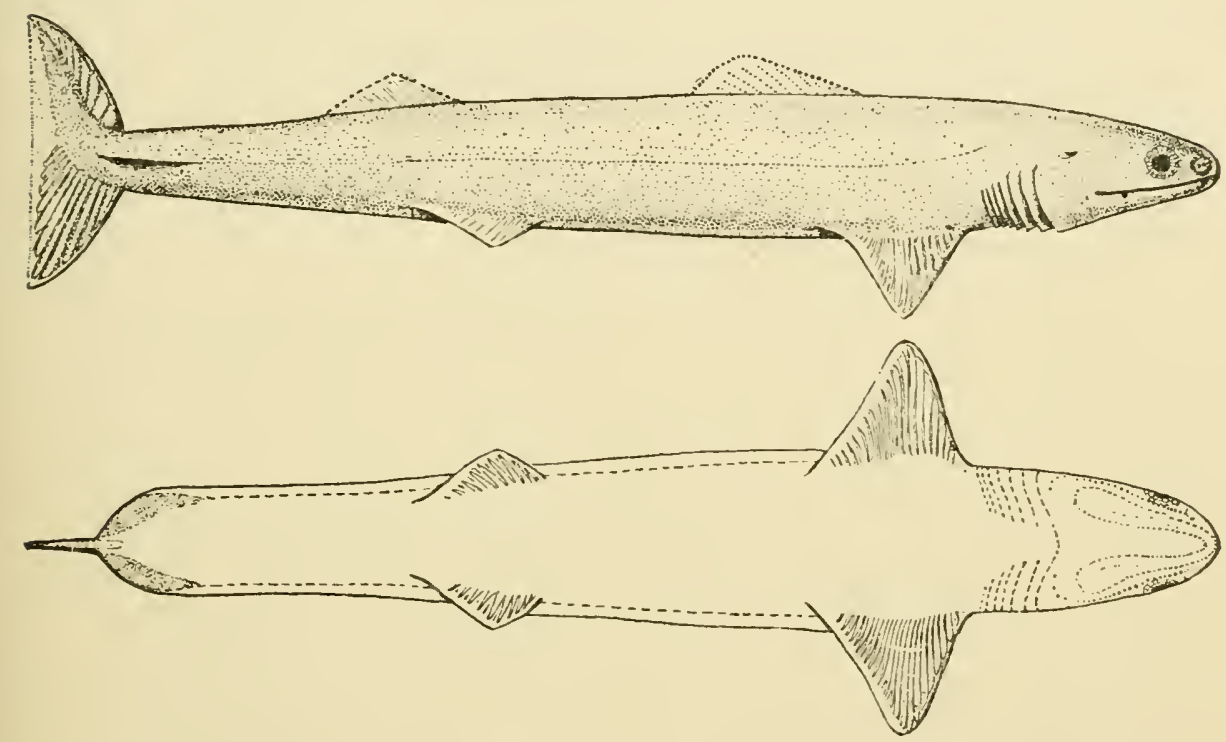

Fig. 86. - Cladoselache fyleri, Newb. $\times \frac{1}{5}$. Restoration by writer. After specimen in the museum of Columbia College from Cleveland shales, Ohio.

Fig. 86 A. - Cladoselache fyleri; ventral aspect.

that of a modern shark; the fins, too, in their size and position, have somewhat of a modern look; and at the base of the tail occurs the small horizontal keel of many living forms. But in spite of these peculiarities, Cladoselache must be looked upon as the most archaic, and, in many ways, the most generalized of known sharks; its paired fins are but the remnants of the lateral fold (p. 43), serving alone as balancers; the tail, curiously specialized, is widely heterocercal, its hinder web lacking supports in the upper lobe (p. 36); the vertebral axis is notochordal; 
and the writer now finds that an exceedingly simple condition existed in the neural and hæmal arches; they prove to be of moderate size and thickness, each a tapering rod of cartilage, forked at its base; each body segment contains a single neural and hæmal spine, closely alike in size. Unlike modern sharks, Cladoselache was without claspers : its eggs must have been fertilized after their deposition, as in the majority of fishes other than Elasmosbranchs. The gill openings, at least seven (probably nine) in number, appear as in the restoration, to have been shielded anteriorly by a dilated dermal flap. A spiracle was probably present. The jaws were slender, and apparently hyostylic (p. 257); * the teeth are of the pattern of shagreen denticles, but occur
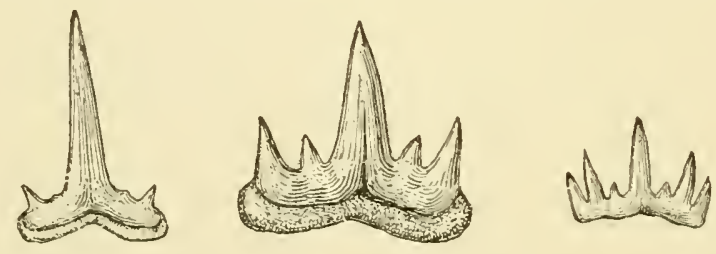

Fig. 86 B. - Teeth of ("Cladodus") Cladoselache. $\times \frac{1}{2}$. The above forms occur in different regions of the mouth.

in clusters ("Cladodus," Fig. 86, B). The mouth was terminal in its position. The nasal capsule was apparently not connected with the mouth by a dermal flap. The eye was protected by several rings of rectangular plates, clearly shagreen-like in character. The integument was finely studded with minute lozenge-shaped denticles, and was everywhere lacking in membrane bones. The lateral line retained its groove-like character.

The shark, Acanthodes (Fig. 87), of the Coal Measures is now to be regarded (Smith Woodward) as a member of a highly specialized Palæozoic group. And its many specialized structures - added to its greatly reduced size-

\footnotetext{
* As Claypole's recent figure seems to demonstrate. Am. Geol., Jan. I895.
} 
may, perhaps, have been the cause of its extinction. The present writer believes that Cladoselache may well have represented the ancestral form of the Acanthodian. The generalized structures of the former have given place to a perfected dermal armouring, and a completed series

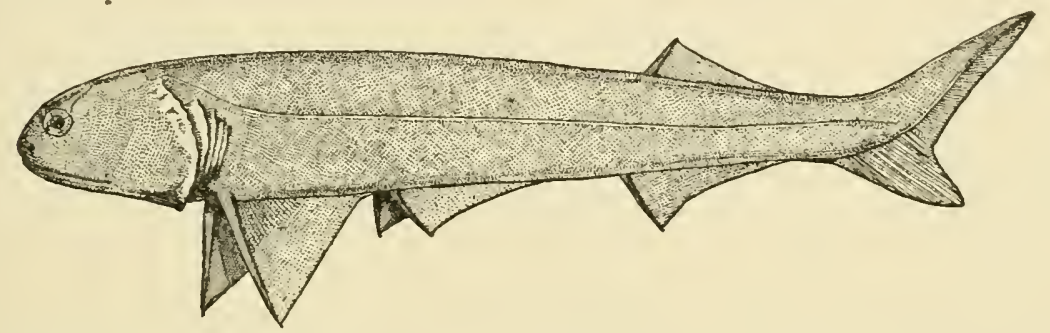

Fig. 87. - Acanthodes wardi, Egert. $\times$ about $\frac{1}{5}$. (Restoration slightly modified after SMITH WOODWARD.) Coal Measures, England.

of balancing fins. In Acanthodes the shagreen denticles have thus become greatly enlarged and thickened, their flattened and enamelled surfaces wedging closely together (Fig. 88); and on the roof of the head and mouth traces of membrane bones have appeared. Around

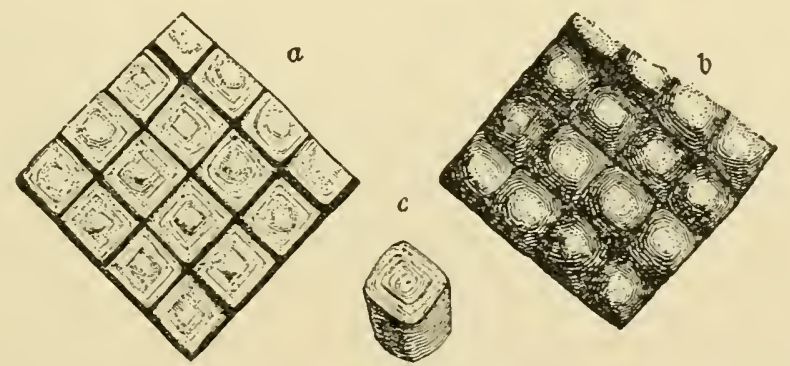

Fig. 88. - Acanthodes gracilis, Beyr. Shagreen. $\times$ about $\frac{1}{10 \sigma}$. (After ZiTTEL.) $a$. Outer face. $b$. Inner face. $c$. Isolated denticle.

the eyes the many shagreen plates of Cladoselache have fused into a group of four. Supporting the dermal gill frills, there have also appeared rows of minute sculptured plates (corresponding, perhaps, to those, BR, of Fig. I45), homologous, apparently, with shagreen denticles. 
Further resemblances to Cladoselache are to be traced in the position of the fins, gill slits, eyes, mouth, nasal capsule, and in the structures of the caudal fin (Kner), and of the lateral line. The teeth, however, are no longer of the derm-denticle pattern; they have become few in number, large, and "degenerate" in their fibrous structure (Fig. $88, A)$. The fins are clearly more per-

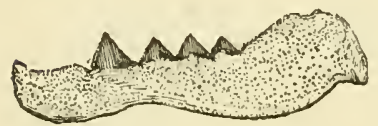

Fig. $88 \mathrm{~A}$. - Teeth of Acanthodopsis wardi. $\times \mathrm{I}$. From sketch after specimen in British Museum. fect balancing organs than those of the older shark; their anterior rim is formed by a stout spine, representing, the present writer believes, the concrescence of the radial fin supports; it is heavily crusted over with the calcifications of shagreen denticles. The functional fin area has thus become dermal, and is lacking in supports, excepting in the pectoral fin. This, as the most highly specialized of all the body fins (p. 4I), appears in some cases to have evolved strengthening (dermal) rays in its proximal portion (as in Figs. 87 and 32 ).

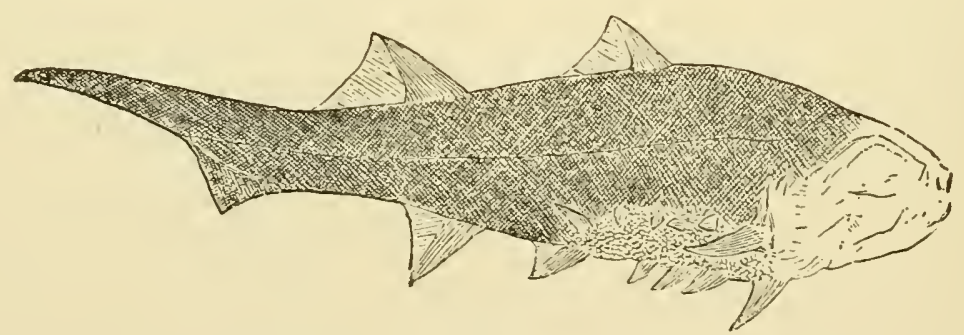

Fig. 89. - Climatius scutiger, Egert. $\times$ I. (From ZITTEL, after PowrIE.) Old Red Sandstone, Forfarshire.

In connection with these fin structures the remarkable Acanthodian, Climatius (Fig. 89), should finally be mentioned. In this form the paired fins are represented by a series of fin spines whose size grades backward from the pectoral region; a series of paired fins appear, therefore, 
to have been present, and suggest strongly continuous fin-fold characters. (V. p. 40.)

Pleuracanthus (Fig. 90), the third of the well-known Palæozoic sharks, is widely different from the Acanthodian: it suggests a transitional form between the generalized Cladoselachian, on the one hand, and the Dipnoan on the other; or, more accurately, it demonstrates that the stems of shark and lung-fish were at one time drawn very closely together. It has thus far occurred only in the Carbon and Permian, but may reasonably be expected in lower horizons as a contemporary of the earliest lungfishes.

Pleuracanthus is in many ways the most interesting and suggestive member of the shark group; for it destroys
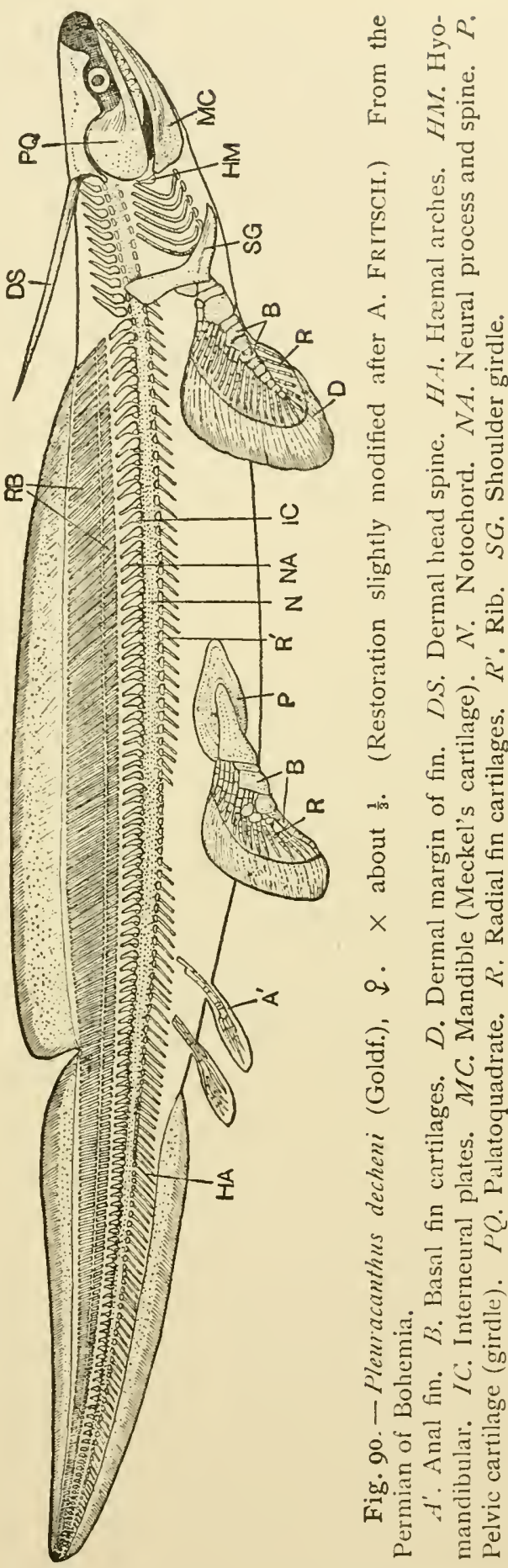
many of our conventional ideas as to the general characters 
essential to sharks. That it was actually a shark cannot be doubted; its gills, six or seven in number, opened separately to the surface; its teeth (Fig. $90 A$ ) were typically shark-like, arranged in many rows on Meckelian and palatoquadrate cartilages; a tuberculated dorsal spine was present; claspers occurred in the male; the vertebral column, although notochordal, $N$, presented intercalary plates, $I C$, and the
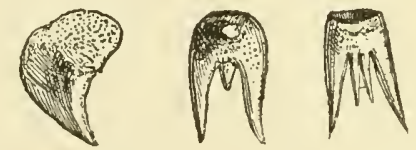

Fig. 90 A. - Teeth of Pleuracanthus. (After DAvis.)

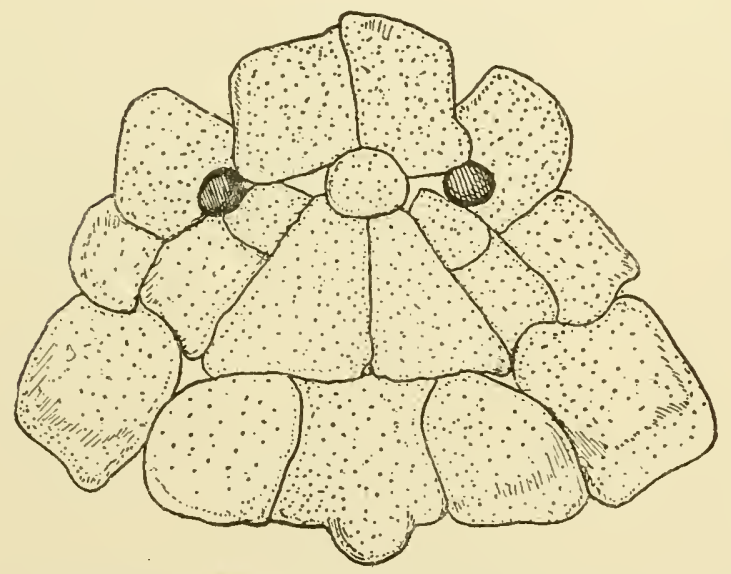

Fig. 90 B. - Dermal bones of the head roof of Pleuracanthus. $\times \frac{1}{3} . \quad$ (After DAvis.) jaw was essentially hyostylic, $H M$. On the other hand, $\times \frac{1}{3}$. many of its structures are clearly transitional to the Dipnoan : the pelvic fins are shark-like, with the radial supports, $R$, arising from but one side of the line of basals, $B$; but the pectoral fin is typically archipterygial, and the caudal diphycercal, as in the lungfishes. In this regard the continuous dorsal fin, with its separate basals and radials, $B$ and $R$, is again noteworthy. But most singular of all the features of this lung-fish-like shark were its integumentary characters; shagreen tubercles had disappeared on the body surface, and derm bones had appeared roofing the head : their arrangement (Fig. $90 \mathrm{~B}$ ) is strikingly similar to that of the lung-fish of Fig. I24. 
The final form of Palaeozoic shark whose structural characters have in any way been described is Chondrenchelys. It appears to have somewhat resembled the Pleuracanthid in its elongate form and tapering tail; but as yet the details of its structure have not been cliscovered. In its vertebral characters it had certainly made a marked advance; the notochord had become greatly constricted; and well-marked centra and arches were present. These appear to have been highly calcified, and show a peculiar

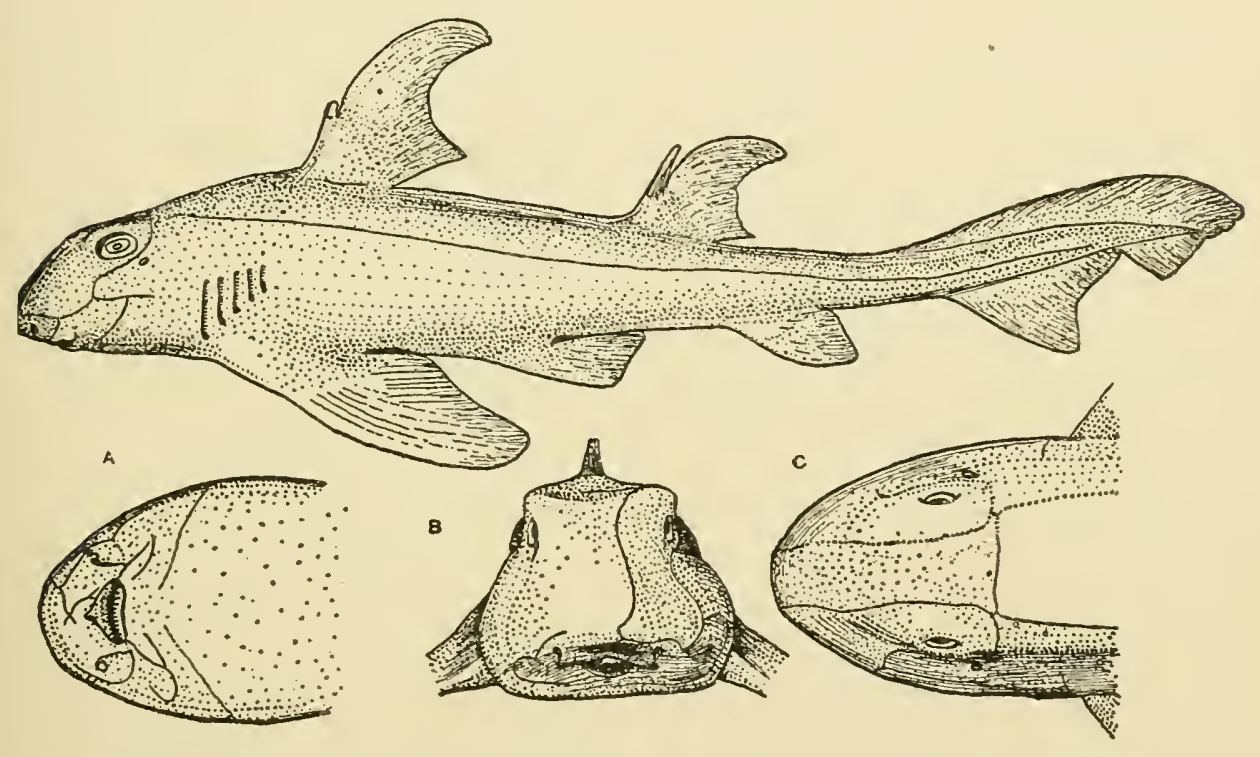

Fig. 91. - Port Jackson shark, Cestracion philippi (\$). $\times \frac{1}{10}$. (After GARMAN.) Australia. $A$. Ventral. $B$. Anterior, and $C$. Dorsal aspect of head.

beaded or fretted structure which in this form is apparently unique.

Other ancient sharks, as far as can be inferred from fragmental structures, appear to have closely resembled forms that are still extant.

Such unquestionably were the Cestracionts, a group of sharks especially abundant in the early Palæozoic seas, judging from the numbers of their fin spines and 
pavement teeth that have been preserved. Their bygone rôle was certainly a long and important one. In some of their forms they could have differed but little from their single survivor, the Port Jackson shark, Cestracion (Heterodontus) (Fig. 9I, $A, B, C$ ). In others, the dentition and dermal defences suggest a wide range in evolution. Their general character appears to have been primitive, but in structural details they were certainly specialized; thus their dentition had become adapted to a shellfish diet, and they had evolved defensive spines at the fin margins, sometimes even at the sides of the head. In some cases the teeth remain as primitive shagreen cusps on the rim of the mouth, but become heavy and blunted behind; in other forms the fusion of tooth clusters may present the widest range in their adaptations for crushing; and the curves and twistings of the tritoral surfaces may have resulted in the most specialized forms of dentition (e.g. Janassas, Petalodonts, Cochliodonts, and Psammodonts of the Coal Measures) which are known to occur not merely in sharks but among all vertebrates. Equally interesting may prove the evolutional details of other cestraciont structures when they come to be known. Ray-like proportions may well have been evolved even among the earliest Palæozoic forms.

The surviving member of this group, Cestracion, suggests in itself the adaptations of a bottom-living form in its greatly enlarged pectorals. Its genus, however, has not been traced earlier than the Mesozoic, although its comparatively generalized dentition (Fig. 27) suggests a far more remote descent.

It is of interest to note that Cladoselache approaches in its dentition the characters of the primitive Cestracionts (e.g. Synechodus). 


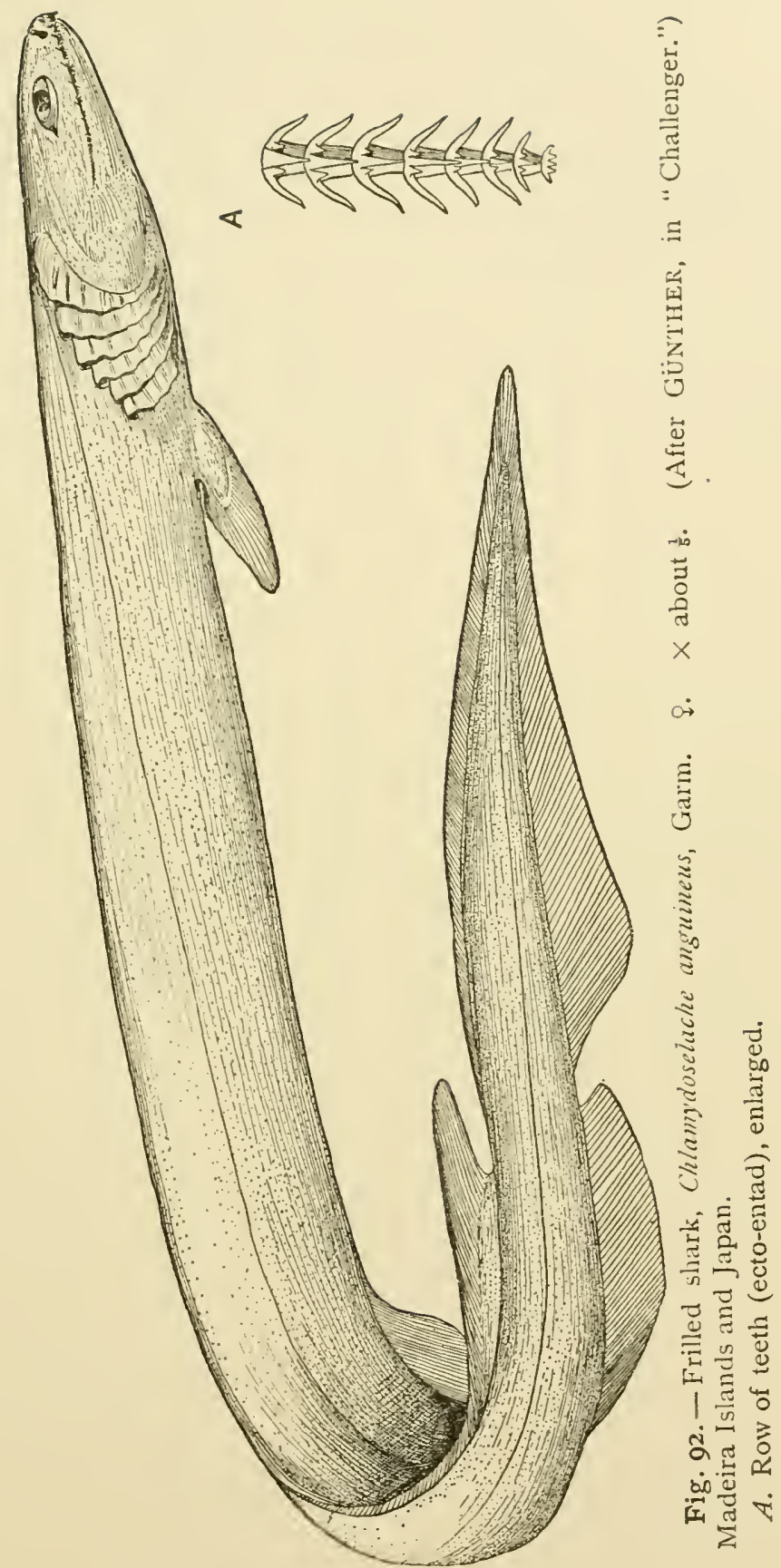




\section{Recent Sharks}

The forms of Sharks and Rays common at the present time are generally looked upon as closely related genetically, although their lineage cannot be definitely traced. As far as palæontological evidence goes, they may well have been derived from a single Palæozoic ancestor.

Perhaps of all recent forms, Chlamydoselache (Fig. 92), and Notidamus (Heptanchus, or Heptabranchias) (Fig. 93), which are universally regarded as "primitive," have inherited most directly the features of this generalized Palæozoic form. But which of these two sharks must be regarded as resembling its remote ancestor the more closely seems to the writer a very doubtful matter. Chlamydoselache derives its great interest from its late discovery (I 884 , Garman), rareness, and Pleuracanthid type of teeth (Fig. 92, $A$ ); but now that it has been taken in numbers - comparatively in deep water, one is inclined to believe that many of its

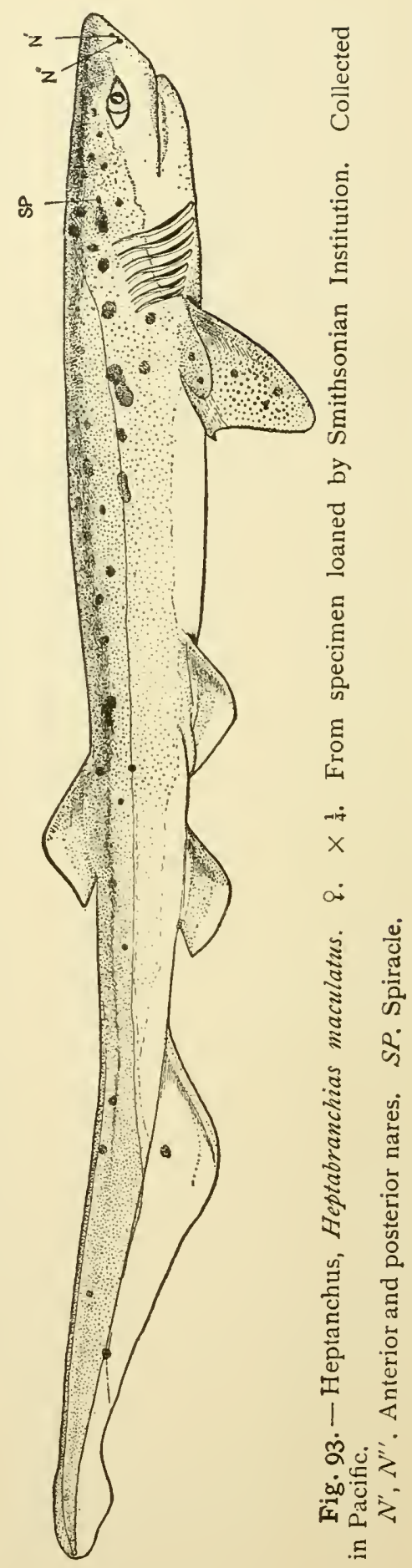


"primitive" features, like its eel-like shape, may partly be due to its environment : its resemblance, moreover, to the Pleuracanth has since been found to be of a superficial character. Notidanus, on the other hand, adds to its primitive characters the presence of no less than seven

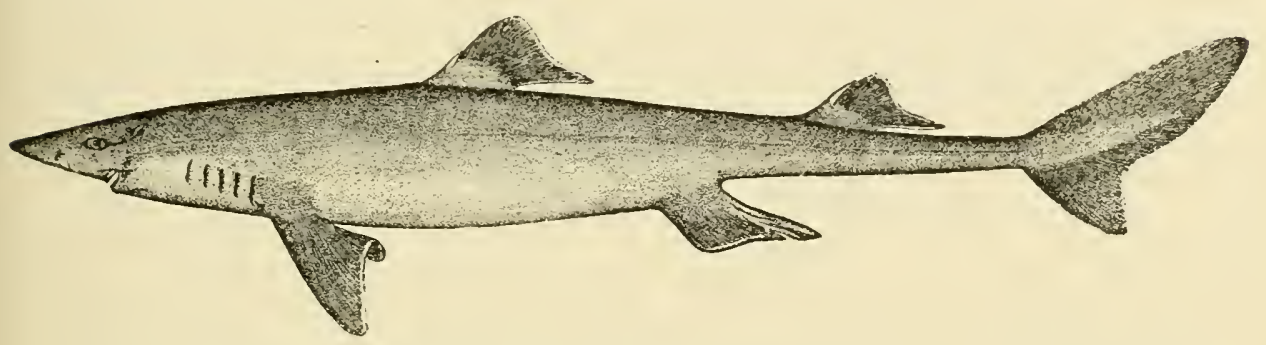

Fig. 94. - The horned dog-fish, Squalus acanthias, L. o'. $\times \frac{1}{8}$. (After GoodE in U.S. F. C.) Atlantic.

gill slits, - a feature which morphologists generally are inclined to regard as of great significance.

The many forms of recent sharks have certainly not diverged widely from the stem of descent which Notidanus may well represent: they retain the sub-cylindrical body form, specializing more or less to environment; in deepsea genera the body length appears proportionally in-

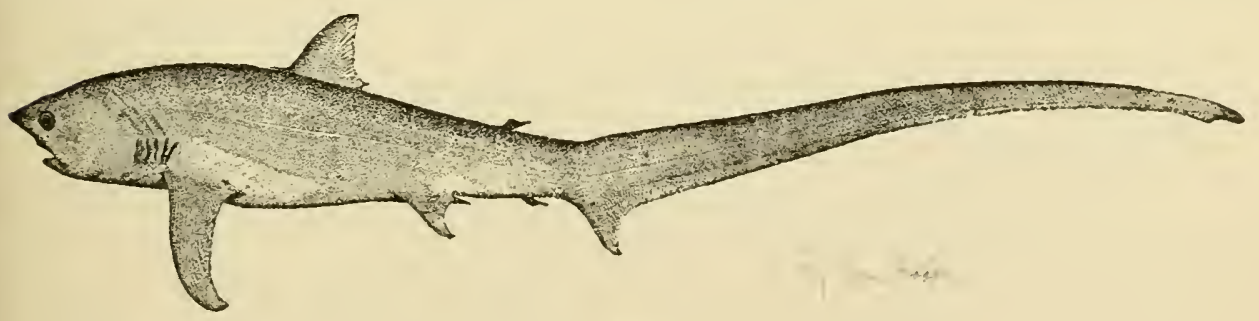

Fig. 95. - The thrasher shark, Alopias vulpes (Gmel.), Bonap. 2. $\times \frac{1}{10}$. Atlantic.

creased : predatory forms, such as Squalus, Alopias, Lamna (Figs. 94, 95, 96), acquire great size and strength, travel great distances, and are enabled to become cosmopolitan. Among the minor details to which their evolution has been carried, may be noted : the pattern, size, and arrange- 
ment of teeth and shagreen denticles; the calcification of the vertebra (great differences sometimes occurring in the same genus, c.g. Scyllizm), the size, disposition, and num-

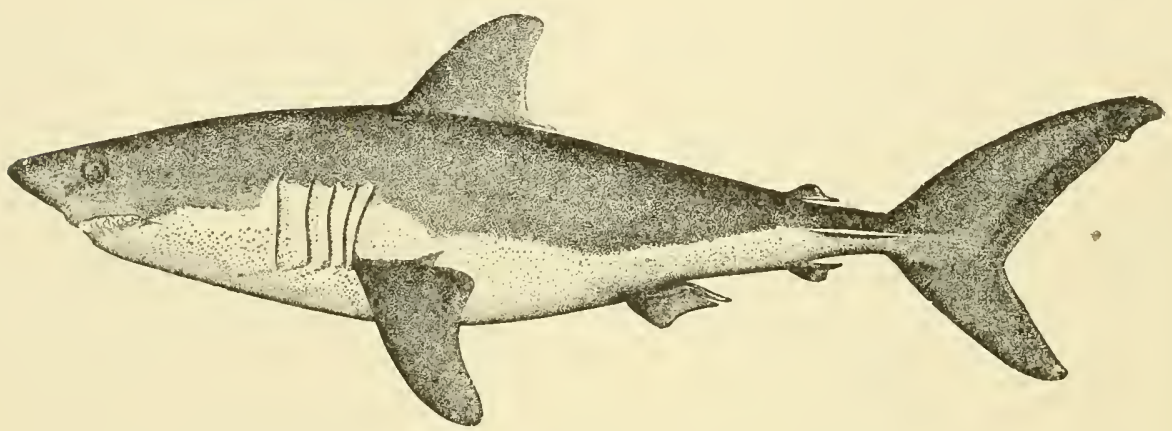

Fig. 96. - The mackerel shark, Lamna cornubica (Gmel.), Fleming. $\times \frac{1}{27}$ North Atlantic.

ber of the fins, the more or less pouch-like character of the sensory canals.

In the basking shark, Cetorkimus (Selache) (Fig. 96 $A$ ), widely specialized conditions occur in the gill rakers, which enable the throat to retain the smallest food organ-

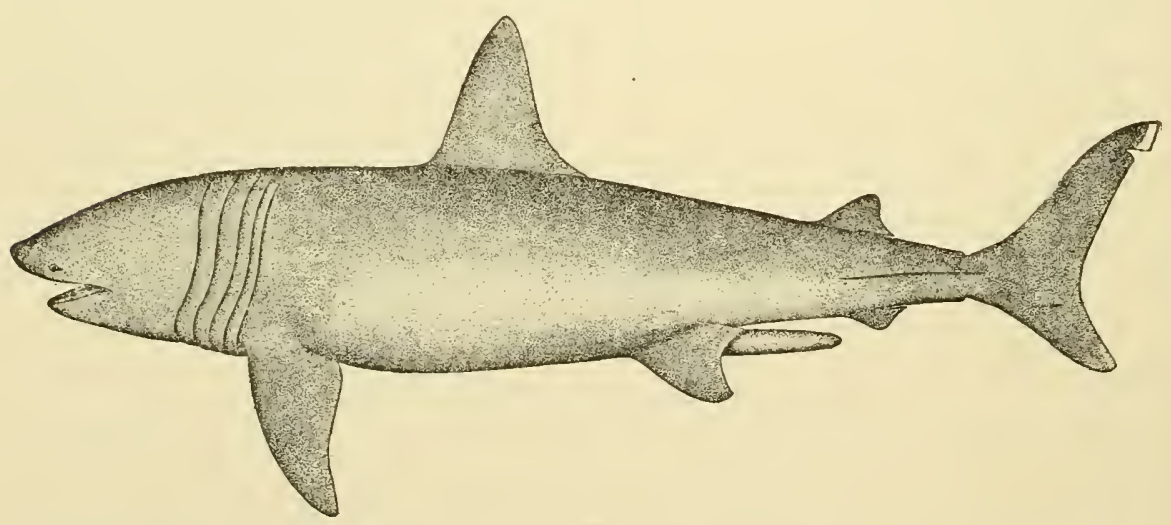

Fig. 96 A. - The basking shark, Cetorhinus maximus, (L.) Blainville. o* $\times \frac{1}{80}$. (After GoodE in U.S. F. C.)

isms. In another shark, Lamargus (Fig. $96 \mathrm{~B}$ ), the eggs are probably fertilized after being deposited, - a condition unique among recent Elasmobranchs. 
The different families of the existing sharks appear to to have been already differentiated during the early Mesozoic times. The ancient shark-like form had then given place to the flattened and rostrated types, adapted to the

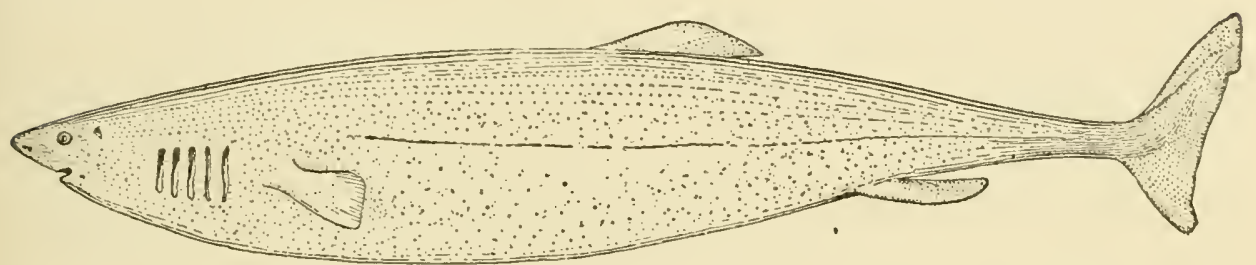

Fig. 96 B. - The Greenland shark, Lemargus borealis, L. $\times \frac{1}{35}$. (After GÜNTHER.) conditions of bottom living and to the special character of their shell-fish or crustacean diet.

One of the earliest offshoots from the main selachian stem appears to have been Squatina (Fig. 97), popularly known as the monk-fish, or angel-fish. As early as the Mesozoic times it was existing, differing but little from the recent species. Its general shape is shark-like, although its

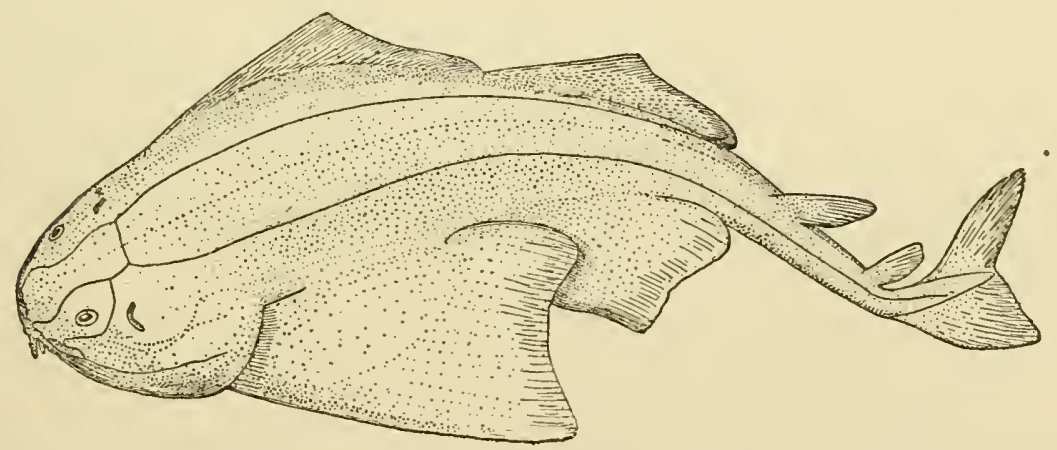

Fig. 97. - The monk-, or angel-fish, Rhina squatina. ․ $\times \frac{1}{12}$. Atlantic, Mediterranean, Pacific.

head and trunk are clearly depressed. This, together with its enlarged pectoral fins, enables it to take a position closer to the bottom.

The recent saw-fish, Pristis (Figs. 98, $98 A$ ), is next to 
be mentioned as a form somewhat transitional from shark to ray. Its body, as may be seen in the figure, has been strikingly flattened, the gill openings changing their position from the lateral to the ventral side, but the fins retaining in general the selachian characters. Its singular rostrum with lateral spike-like teeth is unquestionably a

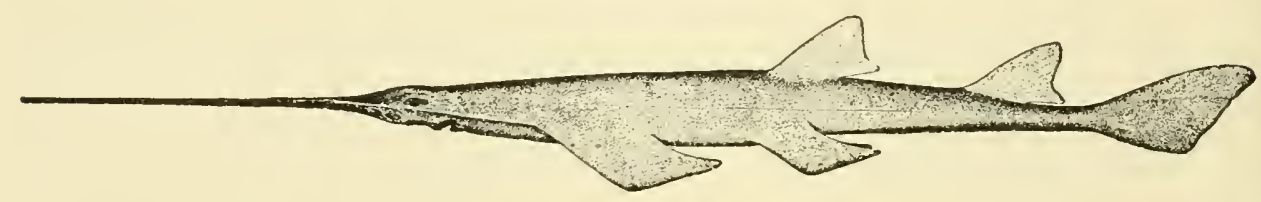

Fig. 98. - The saw-fish. Pristis pectinatus, Latham. Q. $\times \frac{1}{20 .}$ Tropical seas. (After Goode in U. S. F. C.)

highly specialized organ. Pristis is thus far known not earlier than the Eocene, but its close connection geneticaily with the ancient and more generalized Pristiophorus is usually conceded.

Pristiophorus (Fig. 99) is certainly more closely allied to the sharks: its gill slits have not as yet acquired their ventral position, and its rostrum suggests the ancestral

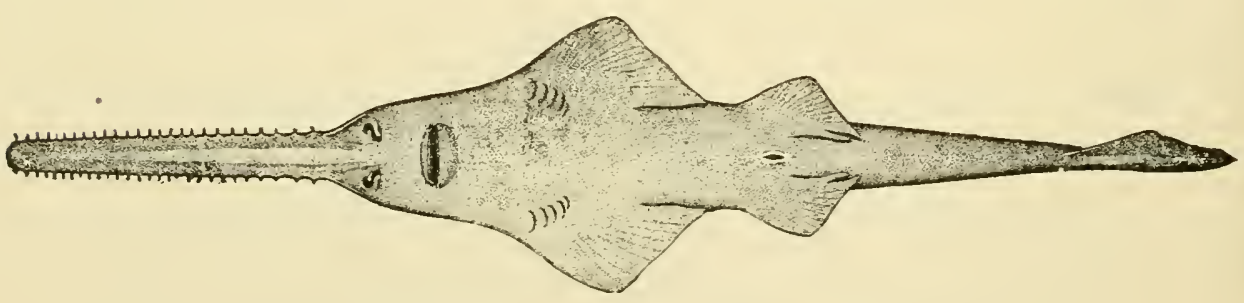

Fig. 98 A. - Saw-fish, ventral view.

conditions of that of Pristis. Its barbel-like structures, however, distinguish this form clearly from all other Elasmobranchs. It is known to have occurred as early as the Jura.

The Skates or Rays are well known to represent the most highly modified survivors of the ancient stem of the 
The body form of the Skate (Fig. IOI) has become admirably adapted to bottom living; it is exceedingly flattened anteriorly, its head and trunk and paired fins fusing so perfectly that from the surface view one could not define their limits; the tail region, on the other hand, has dwindled away to rod-like or whip-like proportions.

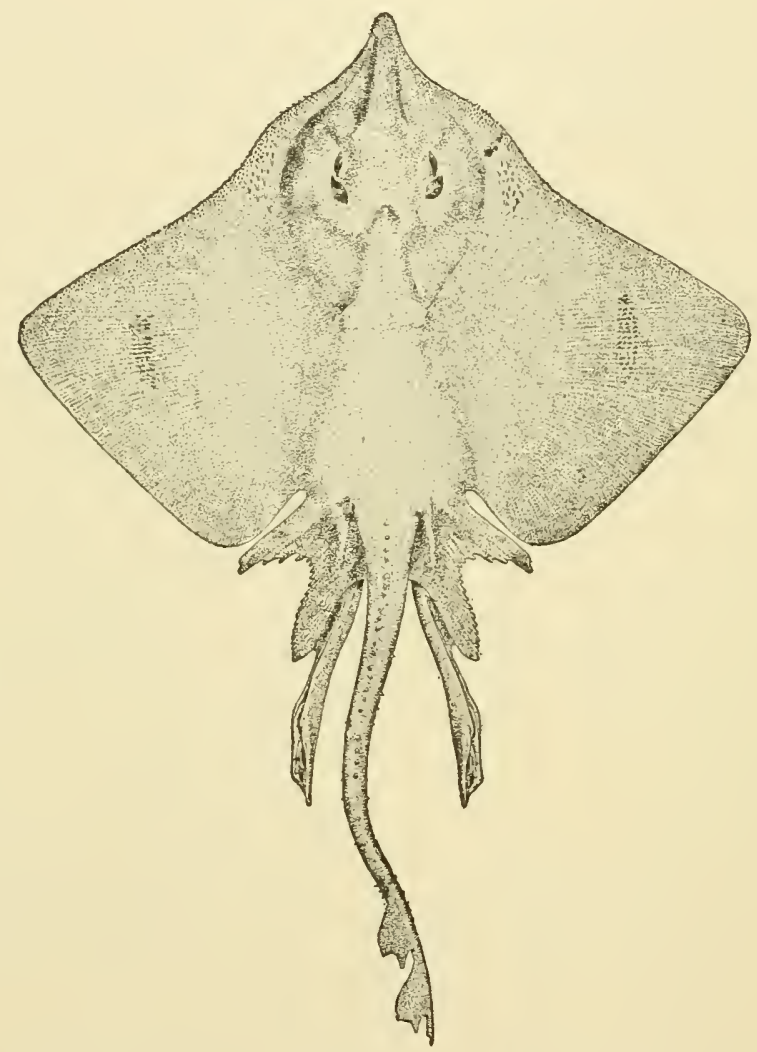

Fig. Ior. - The barn-door skate, Raja lavis, Mitch. $\sigma^{*} \cdot \quad \times \frac{1}{8} . \quad$ (After GoonE in U. S. F. C.)

In the process of flattening; the gill openings take their appearance early in the ventral side of the body, and the pectoral fins, enlarging rapidly, press closely forward at the side of the flattened head, fusing with its tissues. Motion is now accomplished by the gentle undulation of the long horizontal fin margin: and the enlarged 
anterior element of the fin stem, by being raised or depressed, comes to direct the upward or downward motion of the fish. In this mode of movement seems to have been paralleled the undulation of the ancestral fin fold. On the fish's dorsal side colour adaptations have become marked, the ventral aspect becoming deficient or wanting in pigment. In its habits the skate mimics the colour of the bottom and glides along inconspicuously, apparently without movement; when alarmed, it will press its enlarged and flattened fins so closely to the bottom that it appears to adhere, and is to be dislodged only with the greatest efforts.

Two of the aber. rant forms of rays are shown in Figs. ${ }^{O} 2$ and IO2 $A$. The for-

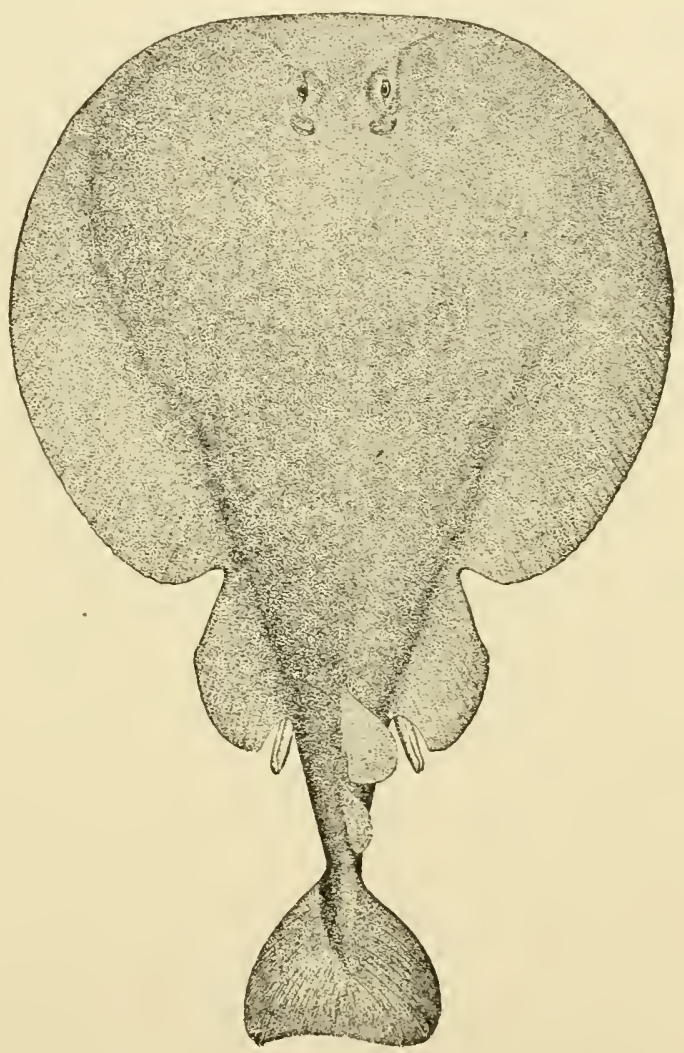

Fig. 102. - The torpedo, Torpedo occidentalis, Storer. $\sigma^{3} . \times \frac{1}{4}$. (After GOODE in U. S. F. C.) mer, the Torpedo, is remarkable on account of its electric organs; the latter, Dicerobatis, on account of the great breadth of its pectorals, and its enormous size. 


\section{Affinities}

In concluding the present chapter, the probable affinities and interrelationships of the Elasmobranchs may be summarized as follows (v. Fig. IO3) :-

I. Of all known stems that of the shark is most nearly ancestral in the line of jaw-bearing vertebrates.

2. A generalized form not unlike Cladoselache might well represent the ancestor of Pleuracanthid, as well as of the primitive Cestraciont, of Acanthodes, and of the modern sharks and rays.

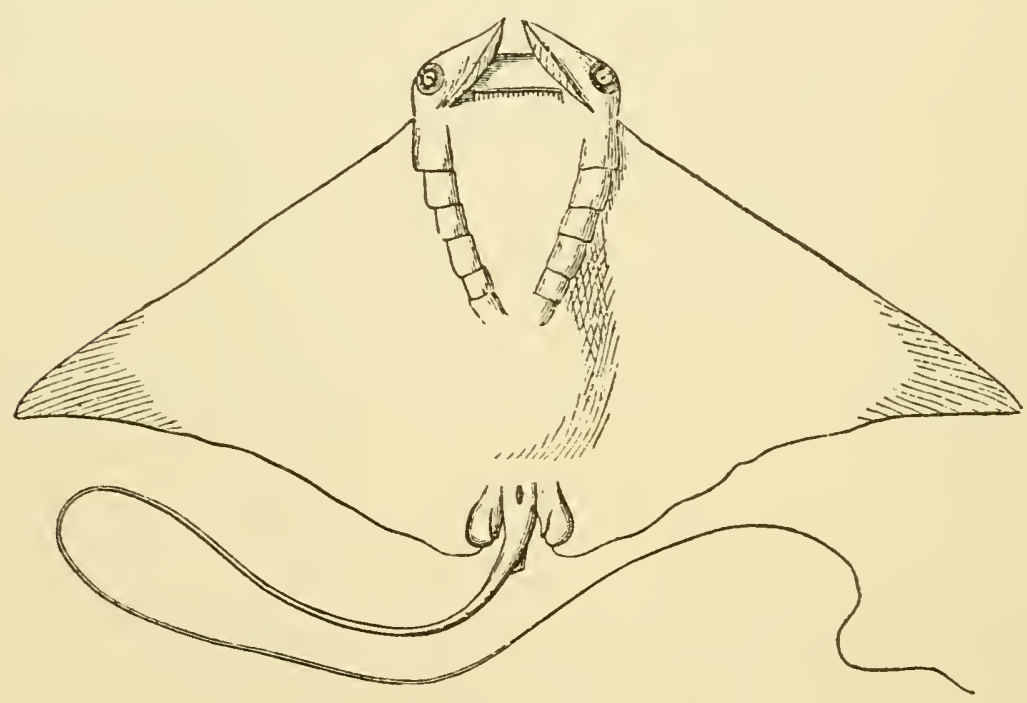

Fig. 102 A. - The mantis, or devil ray, Ciphaloptera (Dicerobatis) draco. $\times \frac{1}{50}$. (After GüNTHER.) Tropical seas.

3. On the evidence of the Permian Pleuracanthids, lung-fishes (Dipnoans) and the earliest bony fishes (Crossopterygians) are to be derived from an advancing shark type.

4. From the ancestral stem of the recent sharks Cestracionts were the most early differentiated: it is one of their more generalized forms, Cestracion, that has alone 
survived among the widely evolved genera and families of Palaeozoic times.

5. The more primitive types of modern sharks, Chlamydoselache, Notidanus, represent in an almost differentiated condition the Palæozoic phylum.

6. The modern rays are derived in early Mesozoic times from the main shark stem, not (in the opinion of the writer) descended from Cestracionts, Pristids, Pristiophorids, or even (?) Rhinids.

7. Chimæroids, next to be discussed, represent the most ancient of known offshoots from the (Pre-Silurian?) sharks : they are not degenerate in their essential structures, nor are they connected with the ancestral phylum of the lungfishes, save through a common descent from early sharklike ancestors.

These results the writer has expressed in the diagram on the following page. The diverging phyla are indicated as they are represented historically; their primitive concurrence with the main line of descent is suggested by dotted lines. 


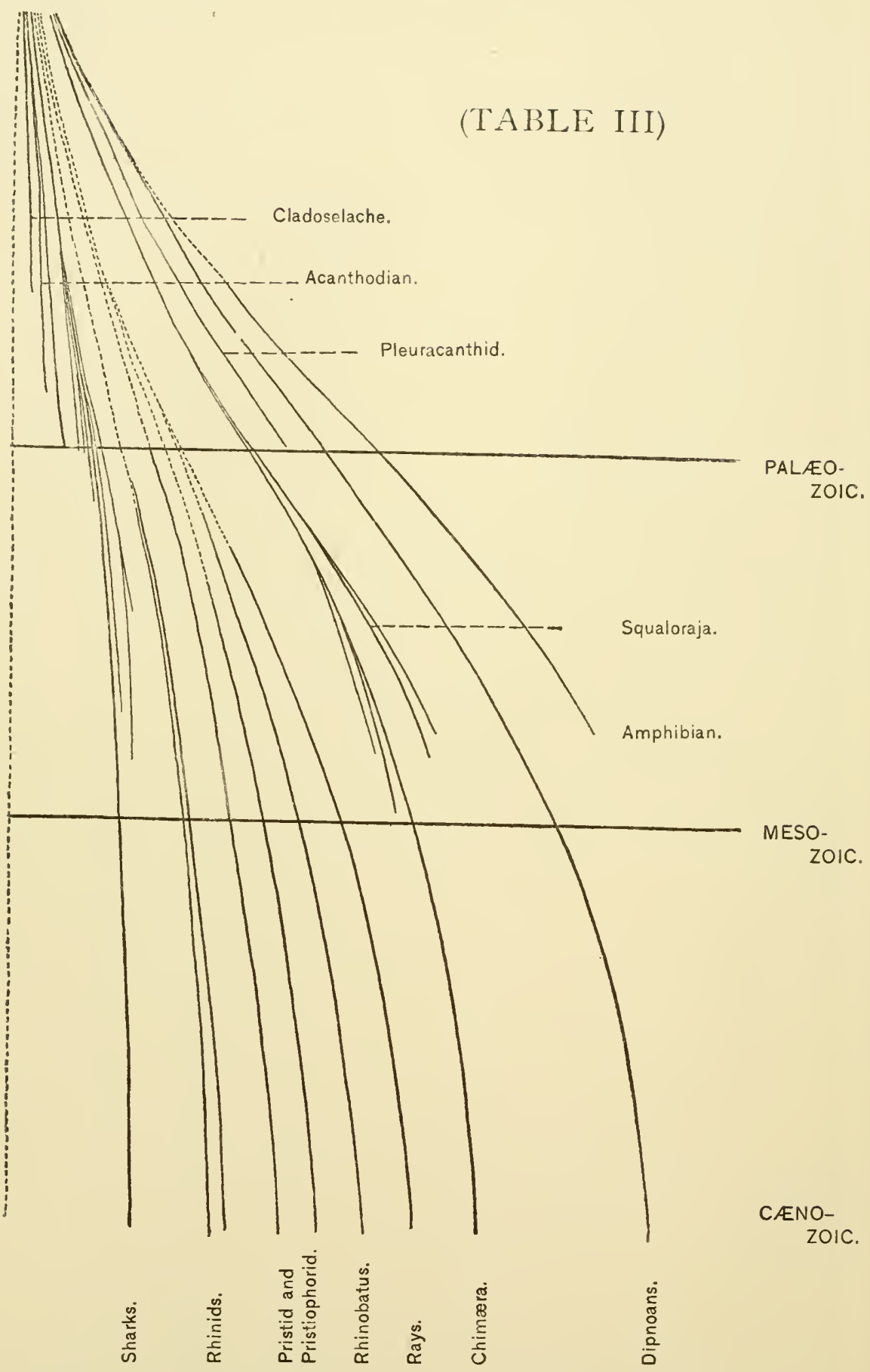

Fig. I03. - Scheme suggesting the interrelationships of Sharks, Chimæroids, and Lung-fishes. 


\section{V \\ THE CHIMÆROIDS}

CHImeroids are shark-like in their general characters, but cannot be looked upon as in any strict sense closely associated with the Elasmobranchs. They constitute the second of the more important groups of fishes. Their typical representative is the Chimæra, spook-fish, or seacat (Fig. I I9).

\section{Structural Characters}

The typical structures of Chimæra are shown in the dissection given in Fig. 104. Its thick, round, and blunted head tapers away gradually to the tip of a diphycercal tail, C. The body surface is generally smooth. The paired fins are somewhat shark-like, but their dermal margins have become greatly enlarged, tapering distally to an acute point ; the foremost dorsal fin provided with an anterior spine folds like a fan and may be depressed into a sheath, $S H$, in the body wall; this fin and the hinder ones are largely dermal, $D^{\prime}$, basal and radial supports existing only at $B^{\prime}, R^{\prime}$. The gill arches, $B A$, may be seen to be closely drawn together; their outer openings are now reduced to the slit-like aperture beneath the dermal flap, $O P$. Teeth exist in the form of dental plates, closely fused with the jaws; as shown in the figure, $D$, three of these occur in each side, a single one on the mandible, an anterior and posterior on 


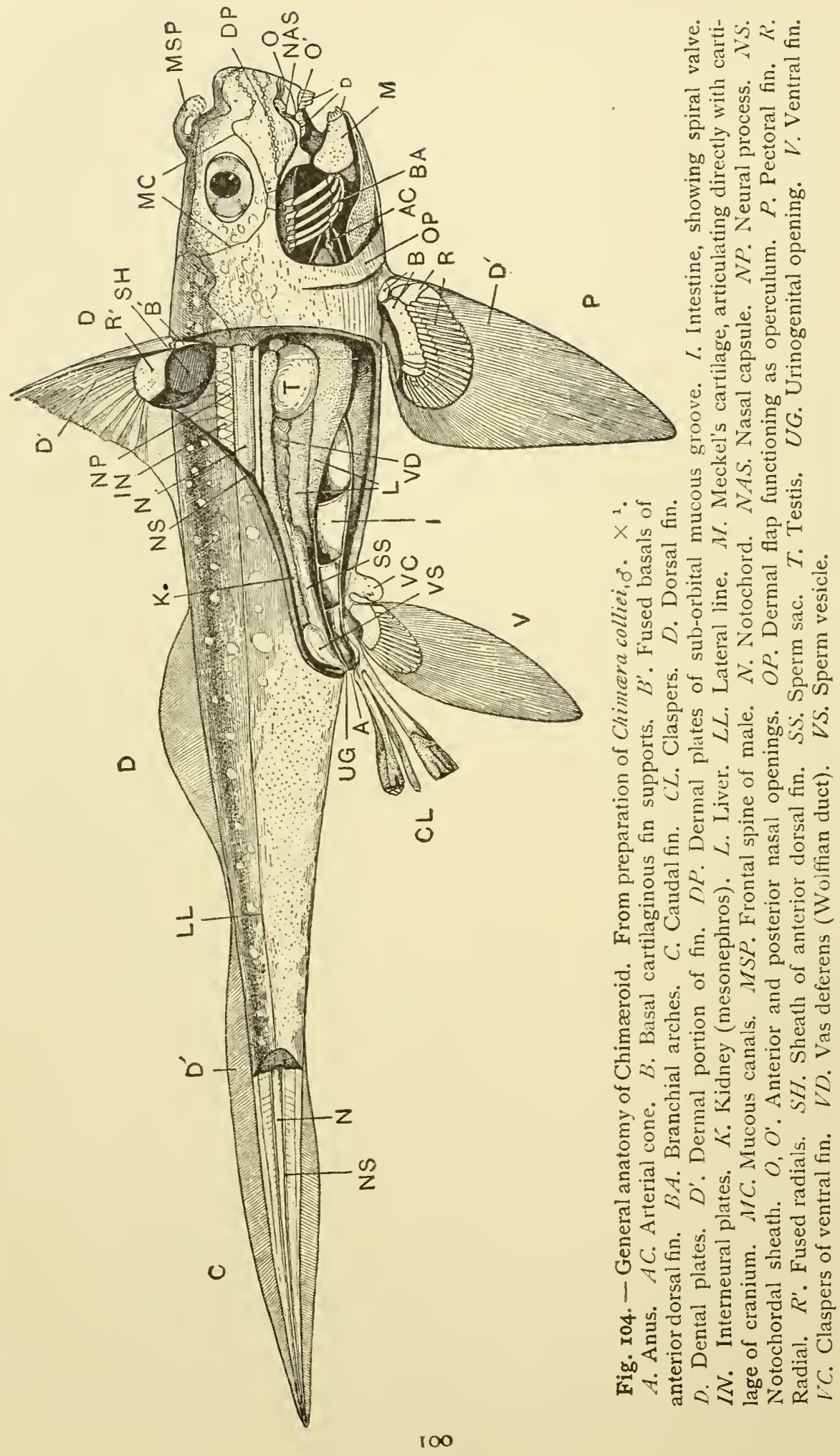


the upper jaw ("premaxillary" and "palatine") ; they are studded with hardened points, or "tritors" (Figs. IOg-I I 2). The sense organs are similar to those of sharks; the nasal capsule, $N A S$, has both an anterior and a posterior opening, $O, O^{\prime}$, the latter within the cavity of the mouth.

The visceral parts are decidedly shark-like; the digestive tube is straight (p. 263); the intestine, $I$, with a spiral valve of three turns; the liver, $L$, is prominent; the kidney, $K$, reproductive organs, $T$, and their ducts, $V D$, $S S, V S$, and abdominal pores are as in sharks; the intestine, however, opens directly to the surface, $A$, separating an anal from a urogenital aperture, $U G$. The mesenteries are string-like.

The male fish is provided with a highly specialized intromittent organ, $C L$; it has a supplemental clasping organ, $V C$, at the front margin of each ventral fin, $V$ (cf. also Fig. I 6 and Fig. I $6 a$ ), and a retractile spine in the region of the forehead, MSP (cf. Figs. I I 3 and I I 5 ).

The skeleton of a Chimæroid is shown in the following figure (Fig. I05). Its structure is cartilaginous. The vertebral axis is notochordal; its sheath, lacking in definite centra, is strengthened anteriorly by a series of calcified rings. In the anterior region of the trunk, neural processes, interneurals, and neural spines. $N P, I N, N S$, together with hæmal processes, occur as in sharks; toward the tail region they fade away, and before joining with the head at the occipital condyles, $O C$, they fuse into a compact mass, joining with the basal supports of the dorsal fin.

The cranium is of a highly compacted structure; its vertical height has been greatly produced; the orbits, $O R$, are of great size and are separated from each other by a membranous septum. The snout region is greatly meta- 


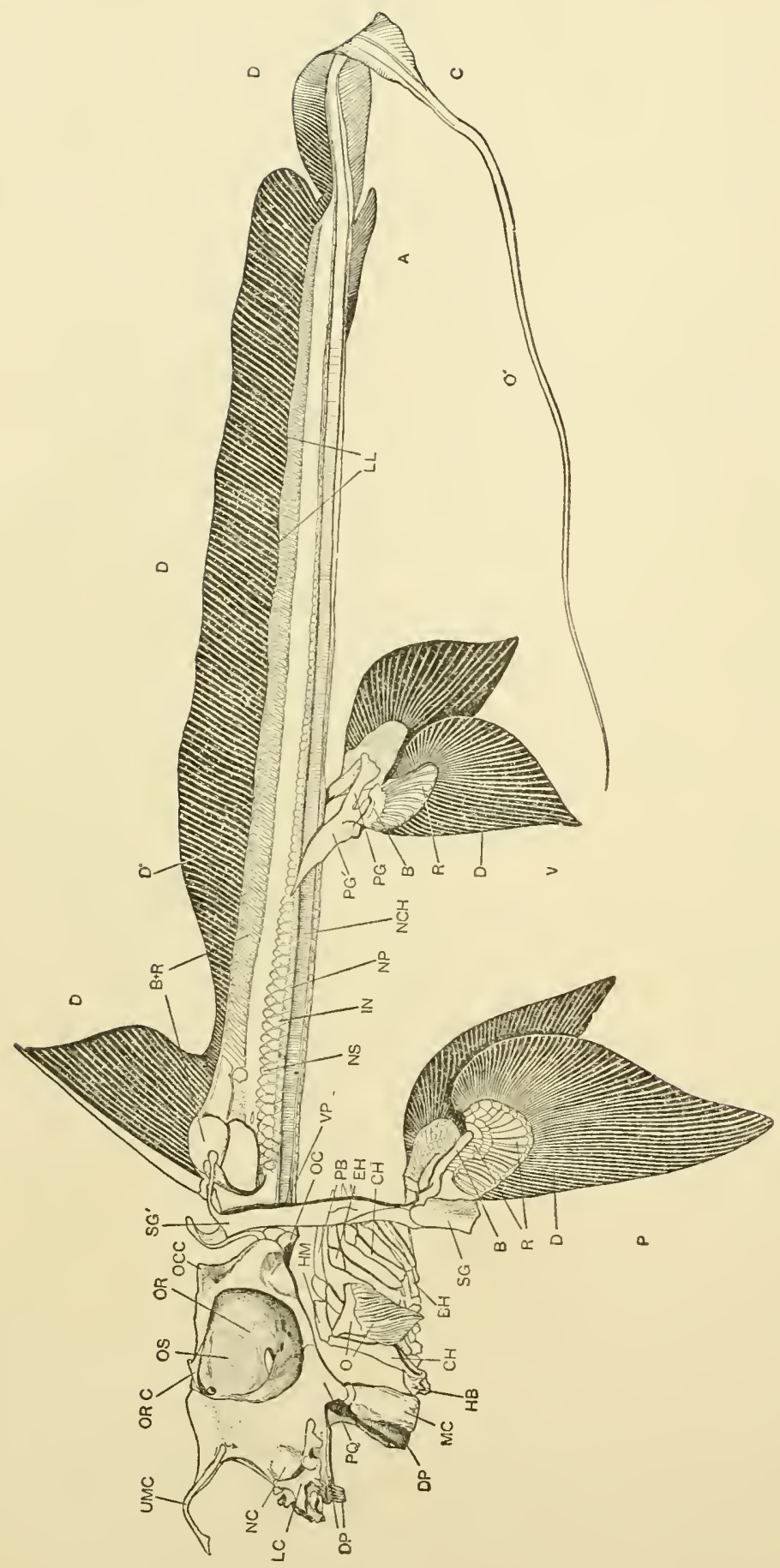

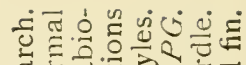

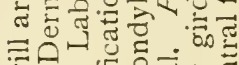
की. U

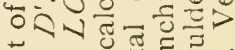
范。

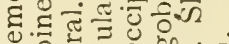

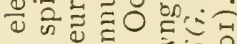
.

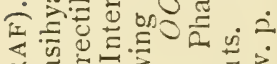
出

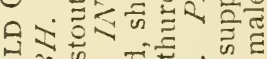

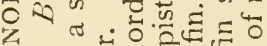
क मे

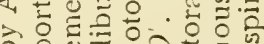
a U क्षे ह क के

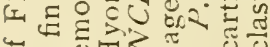
प 0

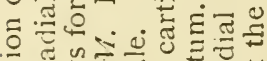
ฮㄴ. ฮี

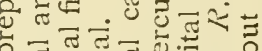

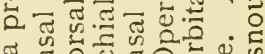
๒

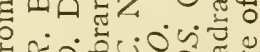

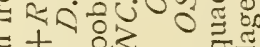

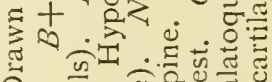

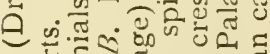
○ ธ के

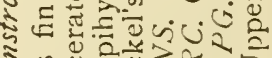
\% 뇌워 ₹

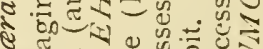
들 츠.

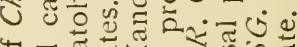

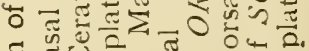
อิ

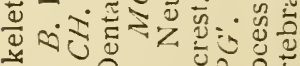
कै 1 घंर्य

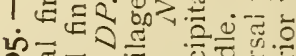

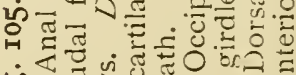

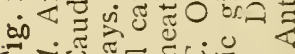

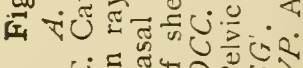

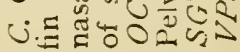


morphosed; the mandible appears to be autostylic, or articulated directly with the skull cartilage, $P Q$. The gill arches are shark-like, but the hyoid arch appears far less modified than in sharks; its upper element, $H M$, is thus unconnected with either the skull or the joint of the jaw ; its distal element, $\mathrm{CH}$, has, however, developed a series of specialized supports for the dermal gill shield, $O P$. The study of the fin supports shows the dorsal elements, $B+R$, representing probably the radial and basal elements together, arranged in a single row margined distally by the longitudinal ligament, $L L$, supporting the dermal functional fin, $D$. The paired fins are readily reduced to the plan of those of Fig. 84; their girdles, however, seem to have acquired more modified characters, their ventral and dorsal elements greatly increasing in size.

Chimæroids as a group have received but a small share of the attention paid to the other fishes; their living forms are few and comparatively rare; their embryology and larval history are unknown; and their life habits have been suggested only in the work of Dr. Günther (Challenger Report). His record of the taking of immature specimens of Chimcera at great depths seems thus far the most important clue as to the conditions of their living and breeding.

\section{Fossil Chimeroids}

Fossil Chimæroids have left behind them very imperfect records of the history of their group. Like the sharks, little more than their dental plates and fin spines have usually been preserved. The structures of some of their ancient members appear to have cliffered little from those just described in the recent Chimæra. In Ischyodus,

* Cf. also Goode and Bean, on Harriotta, P. U. S. Nat. Mus., XVII. 47 I-473. 
a Jurassic form (Fig. I05 $A$ ), the skeletal structures are readily comparable to those of Fig. 105. In the case of two of the Mesozoic genera, however, the evolution of the Chimaroids had evidently attained a high degree of specialization: Myriacanthus and Squaloraja, whose partial restoration has been attempted in Figs. Io6 and Io6 $A$, must be both looked upon as highly modified forms; their snouts and frontal spines are greatly enlarged, and their dental plates (Figs. I07 and IO8) widely divergent from the general Chimæroid type: in Myriacanthus a series of membrane bones occurs in the head region (Fig. Io6, $B, C)$. In Squaloraja a horizontally flattened body shape parallels the development of the ray-like form of sharks.

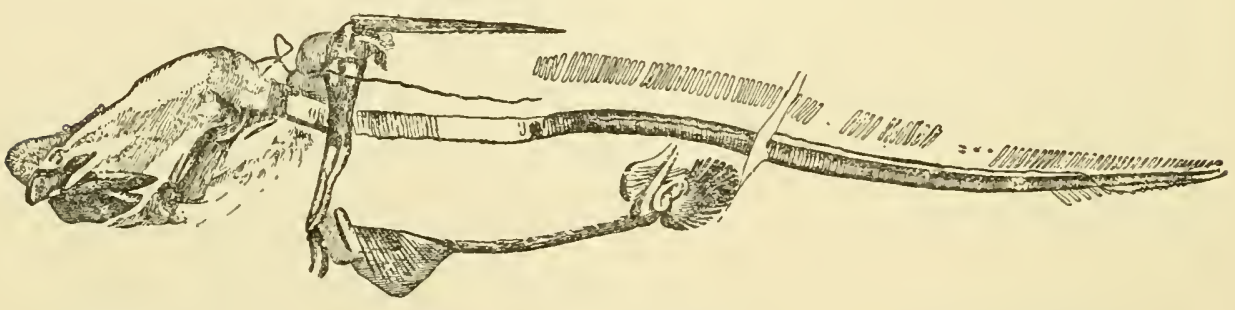

Fig. I05 A. - The Mesozoic Chimæroid Ischyodus. $\times \frac{2}{3}$. (After ZitTEL.)

\section{Living Chimceroids}

The Chimæroids of to-day must be looked upon as the survivors of a group comparatively numerous in Mesozoic times: the few existing forms accordingly, from the palæontological standpoint, acquire an exceptional interest. They have been grouped under three genera, - Harriotta, Callorhynchus, and Chimara. The first of these (Fig. I I $7, A, B, C$ ) has been only recently discovered, and but a few examples have been taken; it merits especial attention, since it is unquestionably the most shark-like of known Chimæroids. In the male it lacks entirely the frontal spine and has its claspers in an exceedingly un- 


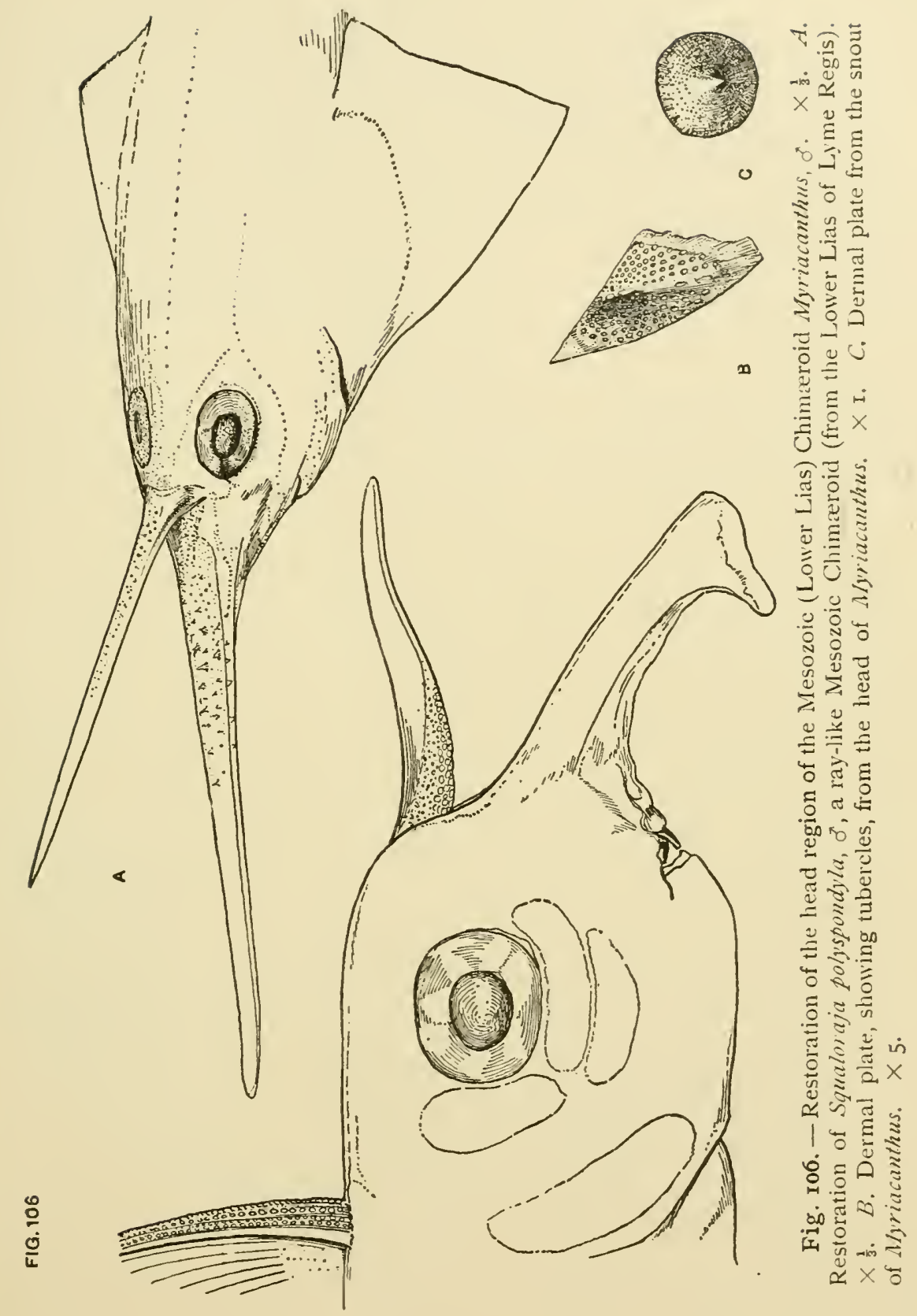

differentiated condition. The eggs are evidently fertilized after they have been extruded.

The second genus, Callorhynchus, is represented by but 


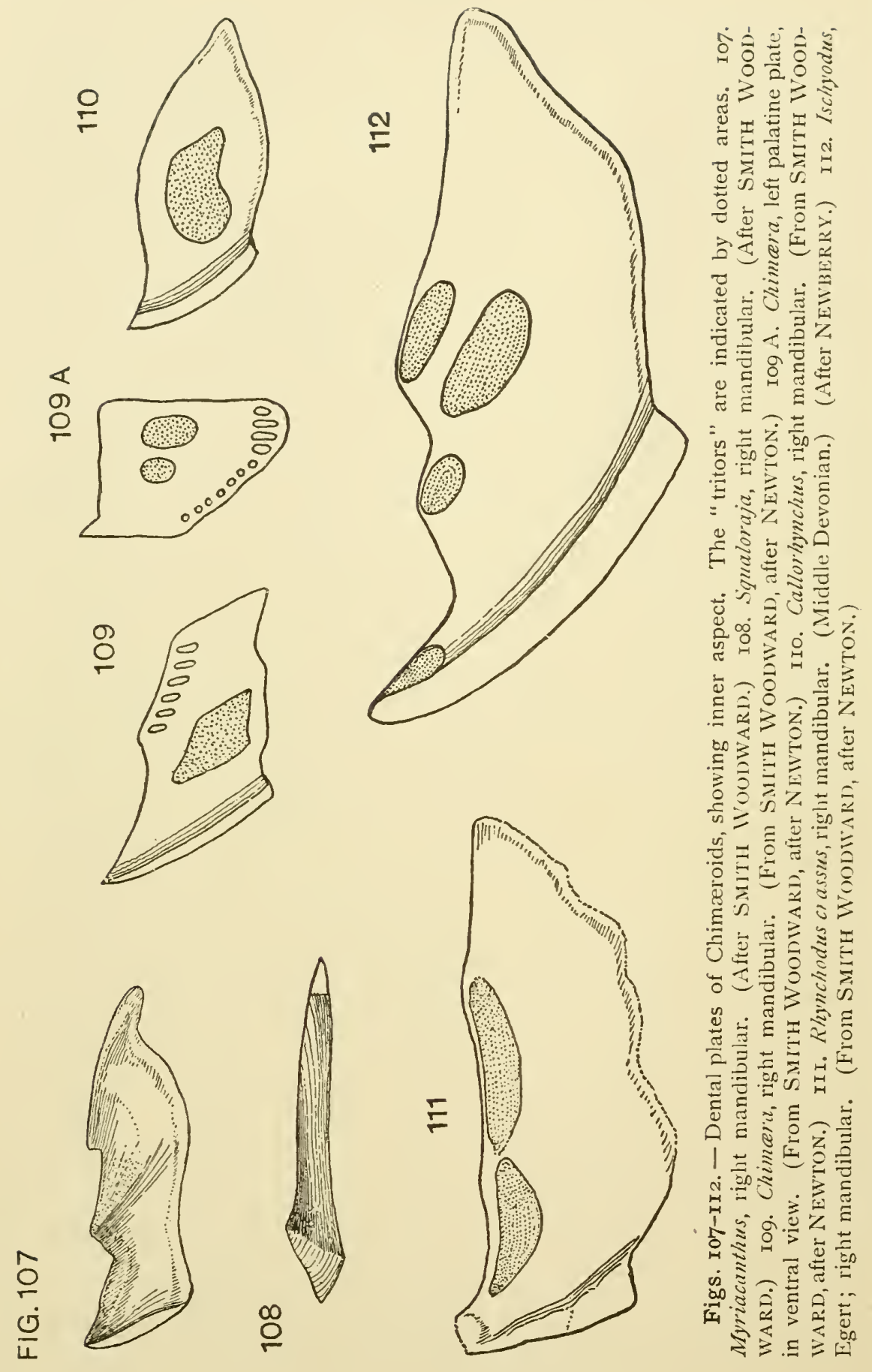




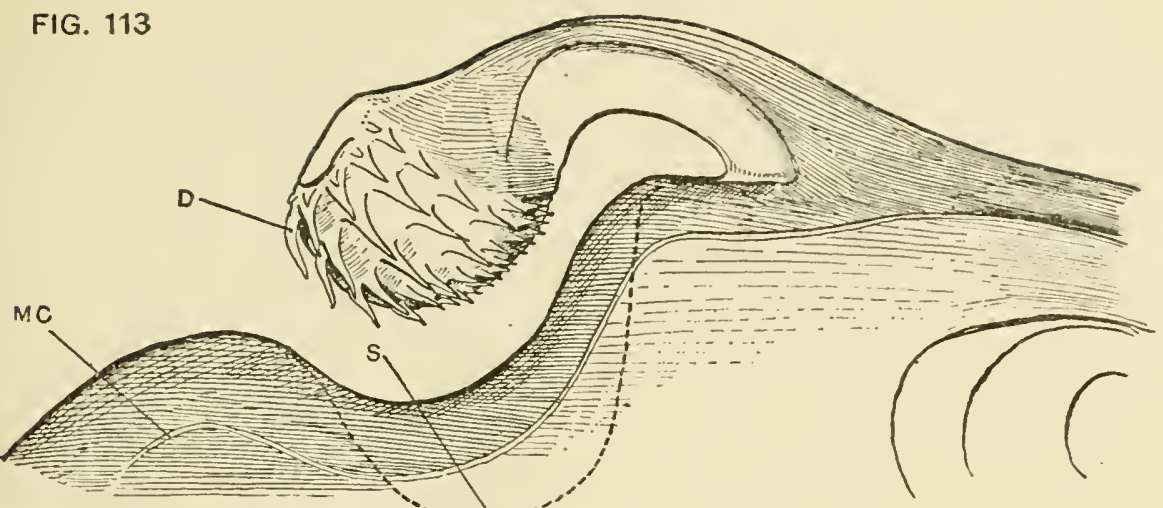

114

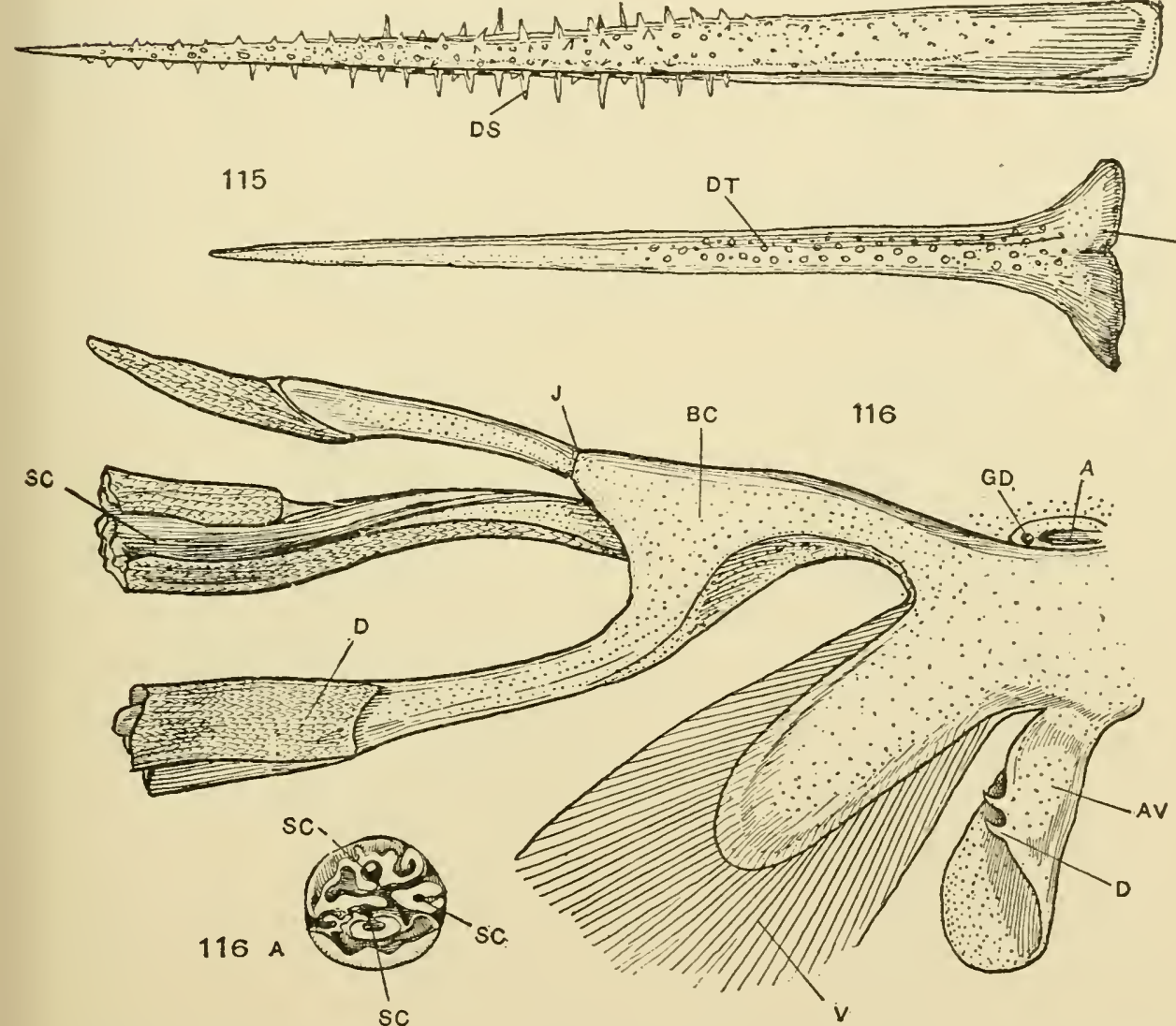

Figs. II3-II6 A. - Spines and clasping organs of Chimæeroids. II3. Clasping spine of the forehead of male Chimara colliei. $\times 6$. IIt. Myriacanthus dorsal spine. (After L. A(rissiz.) II5. Frontal spine of male Squaloraja. (From Surth Woodward.) 116. Ventral fin and clasping organs of male Chimera colliei. $\times$ I. II6 A. View of tip of hinder clasper (intromittent organ), when the three tips are drawn together.

$A$. Anus. $A I$. Anterior rim of ventrai fin, specialized as a clasping organ. $B C$. Body of the posterior clasper (intromittent organ). D. Dermal denticles. DS. Dermal spinelike denticles. DT. Dermal tubercles. GD. Urinogenital aperture. $\mathcal{F}$. Jointed base of inner ventral element of intromittent organ. $M C$. Mucrus canal. $S$. Sheath of frontal spine. $S C$. Sperm groove of inner face of clasper. $V$. Ventral fin. 

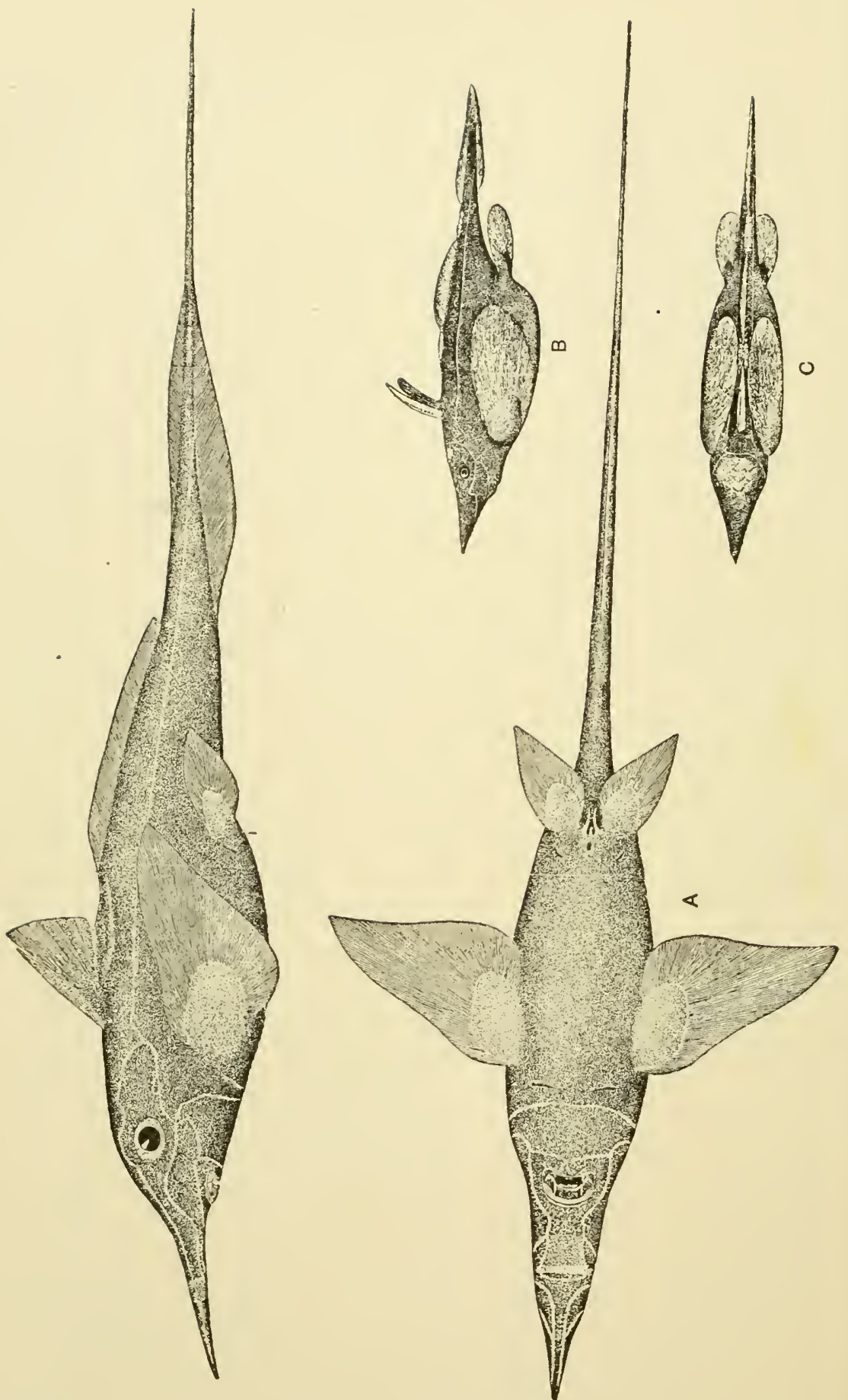

Fig. 117. - Harriotta raleighana, Goode and Bean. $3 \cdot \times \frac{1}{2}$. A new genus of Chimæroid - a bathybial form. A. Ventral view, showing rudimentary claspers. $B, C$. Immature specimens. 
a single species, $C$. antarcticus. It is said to be common in the Straits of Magellan, and is popularly known as the Bottle-nosed Chimæra (Fig. I I $8, A, B$ ). Its remarkable snout is well supplied with sense organs, and its pad-like dilation in front of the mouth is evidently of barbel-like function; it illustrates closely, no doubt, the remarkable snout process of Myriacanthus. Callorhynchus is sharklike in its general shape; and its caudal, dorsal and ventral

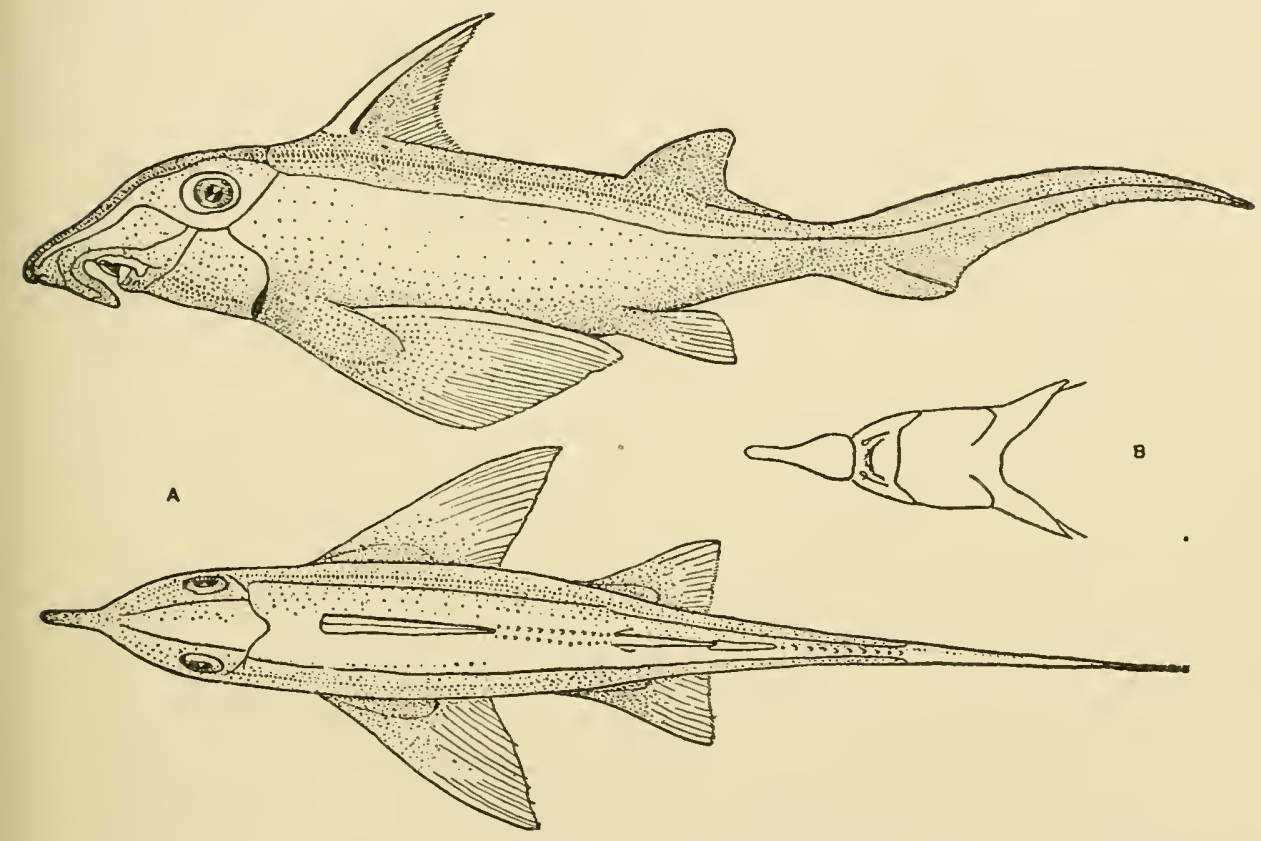

Fig. 118. - The bottle-nose Chimæra, Callorhynchus antarcticus, $9 . \times \frac{1}{6}$. From Magellan Straits. A. Dorsal aspect. B. Ventral view of head. (After GARMAN.)

fins correspond closely in appearance and structure with those of certain sharks; the greatly enlarged pectoral fins have, however, a more highly specialized character; they stand boldly out from the sides of the body, and their bases are rounded and muscular. The mucous canals (Garman) have paralleled the saccular or tubular structures of the majority of sharks. The mandible (Fig. I IO) shows but a single broad tritoral area. 
Chimæra, the third genus of the recent forms, is well represented in the commoner form, C. monstrosa (Fig. I I9, $A, B)$. This species is widely distributed in the Mediterranean and Atlantic, taken usually in deep water; it is the largest of the living species, often attaining a yard in length. Its occurrence is usually erratic: in a favourable locality, as at Messina, months often elapse before one is taken; at other times many will be brought in in the course of a few days. The Portuguese species, C. affinis,

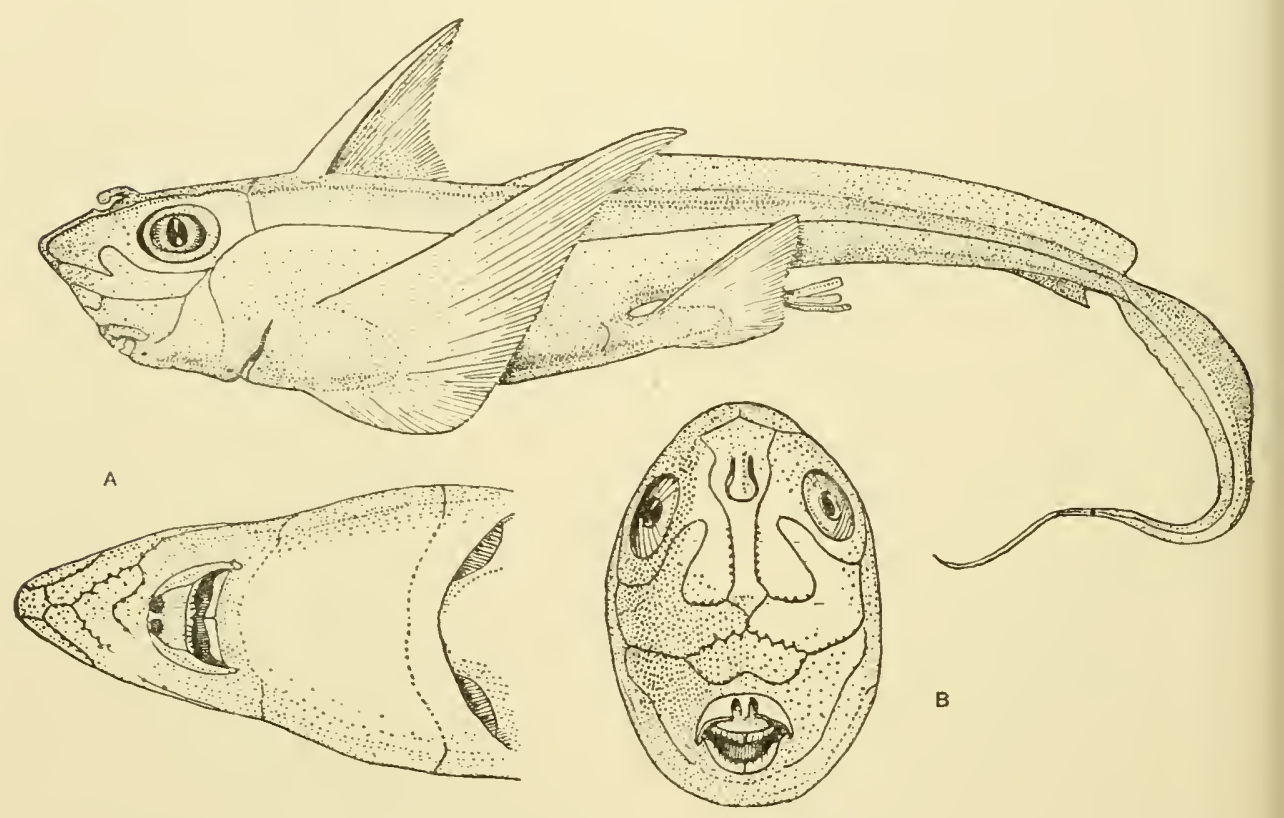

Fig. I19. - The sea-cat, Chimera monstrosa, $\delta . \times \frac{1}{9} . A$. Ventral view of snout. $B$. Front view of head. (After GaRMaN.)

is said to be numerous in the deep fishing grounds; the writer has seen it in the Lisbon market, where from its low price it evidently ranks with the sharks as a food fish. The smaller Pacific C. colliei (Fig. IO4), rarely half a yard in length, differs sharply from the other species, and is therefore often given rank as a distinct genus, Hydrolagus, Gill. The writer learns from his friend Dr. Bean 
that it occurs abundantly in the shallow waters of Vancouver ; it is there well known as the "rat fish," and may often be seen in the neighbourhood of the docks, swimming slowly at the surface.

The shape of the body of Chimæra seems in some regards to have diverged from the more shark-like form of Callorhynchus. Its organs have become concentrated in the pectoral region, and the disturbance in the curve normals of the fish seems to have caused the shortening of the snout, and the sudden dwindling of the hinder trunk region; the tail, with its thread-like terminal, the opisthure (Fig. 120), is accordingly to be looked upon as de-

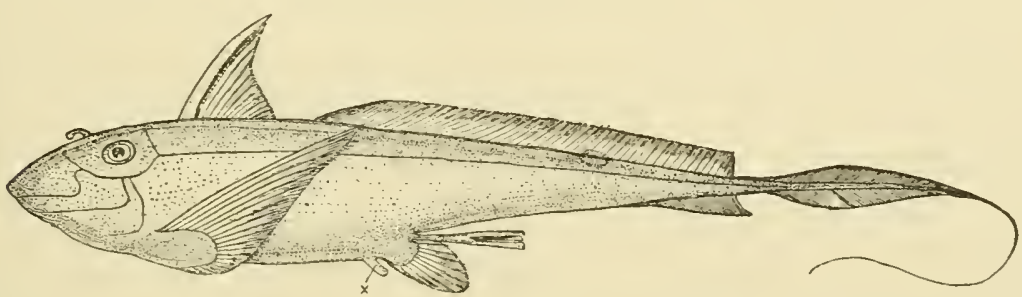

Fig. I20. - Chimara monstrosa, $\sigma^{7}$. Juv. $\times$ about $\frac{2}{3}$. (After L. Agassiz.) The anterior ventral clasper is noted at $X$; the tail terminates in a thread-like opisthure.

generate. In the anterior region, however, a number of what seem to be primitive characters have been retained; the mucous canals are groove-like; and the dental plates (Figs. I09, IO9 $A$ ) exhibit a series of tritoral areas.

\section{Affinities}

All that is known of Chimæroids, living or fossil, gives but little definite knowledge of the kinships or evolution of the group. Their shark-like structures cannot be shown to have taken their origin from shark-like conditions. Thus the dental plates even of the most ancient forms do not suggest their derivation from shagreen cusps; the 
beak-like jaws of the Devonian Rhynchodus (Fig. I I I), of the Devonian Ptyctodus, or of the Mesozoic genera, e.g. Ischyodus (Fig. I I2), differ little in their structures from those of their living kindred (Figs. Io9, $109 A$, I IO). The tritors accordingly are only doubtfully to be clerived from the fusion of the primitive basal substance of the teeth with the tissue of the jaws. But the history of Chimæroids tells of their ancient importance and of the diversity of their forms, and demonstrates that they cannot be connected with other existing forms of fishes. In Liassic times their specialized members bore the same relation to Chimera as did the aberrant Cestracionts of the Coal Measures to the simpler sharks. In their dental evolution they had even reached a more specialized condition than the Cochliodonts (Cestracionts ?). Thus in Myriacanthus and Squaloraja, "all anterior prehensile teeth have disappeared, and the growth of the dental plates, instead of taking place exclusively at the inner border, seems to have sradually extended to the whole of the attached surface. The Chimæridæe exhibit an advance in the circumstance that all the dental plates are thickened, while the hinder upper pair are both closely apposed in the median line and much extended backward" (Smith Woodward). * Squaloraja had certainly attained a high degree of evolution in the calcified vertebral rings, and in its specialized girdles, fins, and clasping organs. Myriacanthus, on the other hand, while retaining its ancient vertebral characters, had evolved a well-marked series of membrane bones.

One cannot deny that the study of Chimæroids as a sroup emphasizes many of their structural affinities to the sharks. They resemble them in their cartilaginous skeleton, fins and girdles, "claspers," integument, and 
sense organs: they present similar visceral characters, spiral intestine, heart, gills, abdominal pores, renal and reproductive organs.

Their more important divergences from the plan of elasmobranchian structure may thus be summarized:-

I. Skull and Mandible (v. pp. 252, 256). The mandible articulates directly with what appears to be the cartilage of the cranium, i.e. without the hyoid-arch element serving as the suspensorium (Autostylic, p. 257).

II. Fins, paired (Wiedersheim) and unpaired (Ryder), and fin defences. The first dorsal, armed with an anterior spine, is so specialized that it folds like a fan, and may be depressed into a receptive sheath. The tail is (secondarily) diphycercal.

III. Skin defences And TeEth. Shagreen tubercles occur in Chimæroids and are in every way shark-like. They are scattered thickly over the entire dorsal region in Menaspis, sparsely in Squaloraja. They occur in the head region and on the spines in Myriacanthus (Figs. Io6 $C$, I I4); and on the head, spine, and clasper tips of recent forms (Figs. I $3 D$, i i6 D). But dermal bones also occur, as in Myriacanthus (Fig. I06 B), which do not outwardly resemble the structures of ancient sharks shown, e.g. in Fig. $90 B$. The dermal plates protecting the suborbital sensory canal of Chimæra (Fig. I O4, DP) must be looked upon as specialized defences, not as degenerate remnants of a complete dermal armouring (Pollard). And the dental plates, as already noted (p. 99), are altogether unshark-like; their tritors are few in number and constant in position, suggesting an origin from more superficial tooth centres, but these in turn, like the toothplates of Cestracionts, may have been evolved from shagreen denticles.

* Jaekel, SB. d. Gesell. nat. Freunde, Berlin, I891, Nr. 7. 
IV. Gill ARches. The gills have become drawn closely together as in the more highly evolved types of fishes (e.g. bony fishes), and are enclosed by a protective dermal flap which fringes the sides of the head. The concentration of the arches and the appearance of the dermal shield suggest, however, the conditions we have seen in ancient sharks (Cladoselache, Chlamydoselache, Acanthodes), and cannot be given significance as the ancestral form of the opercular apparatus of Teleostome. Even the similar conditions of the Chimæroid and ancient shark may well have been evolved independently. It is interesting to note that in Chimæroids the spiracle is absent.

V. Brain. The brain structure is archaic. Its general plan is, however, more shark-like than Dipnoan (Wilder, Ref. p. 244).

VI. LATERAL Line. The sensory canals possess many distinctive features; they retain their groove-like character, but become widely sacculated and dilated, especially in the snout region.

VII. Clasping spine. The forehead clasper of the male has been a well-marked character of Chimæroids from Liassic time. It folds anteriorly into a receptive groove; its distal end, studded with recurved spines, serves in the recent forms for strongest retention. It seems to represent morphologically the anterior spine of a dorsal fin (cf. Pleuracanthus, p. 83).

In spite of these differences, however, the kinships of the Chimæroids seem unquestionably nearer the stem of the sharks than that of other fishes. On existing evidence the Chimæroid could not have been derived from either Teleostome or lung-fish; nor, on the other hand, could any of the larger groups of fishes be reasonably 
derived from its conditions as ancestral. The dentition of Chimæroids alone is so remarkable that no direct process of differentiation could convert it into the structures of lung-fish or Ganoid. A number of archaic features draw fishes together in the lines of their descent, but they cannot be interpreted as linking the Chimæroids with the Dipnoans, or the Dipnoans with the Chimæroids. Autostylism, often adduced to ally these groups, differs widely in its characters in each (p. 254): and the apparent similarities in dental plates and membrane bones are closely paralleled by the sharks. The diphycercal tail of the Chimæroid can be made no standard of comparison, since it is evidently a secondary structure, arising within the limits of the group, as it may well have done among sharks (Pleuracanthus) or Teleostomes (Polypterus, eel).

If the sum of the general characters of Chimæroids be considered, their affinities would clearly be to the most ancient sharks. Their structures are not so widely at variance with those of Elasmobranchs that they cannot reasonably be derived from their more generalized conditions in vertebral characters, cranium, mandible, girdles, fins, membrane bones, gills. Absence of swim-bladder is again strikingly shark-like. Like the ancient sharks, they have been well adapted for survival by evolving but few specialized structures (e.g. dentition, gills). Their ventral clasping organs separate them clearly from the Dipnoans. Until the discovery of Harriotta the frontal clasping spine remained as one of the most distinctive features of Chimaroicls; its high degree of specialization in Liassic times is alone significant of the antiquity of their descent. 


\section{THE LUNG-FISHES}

Lung-Fishes, or Dipnoans, have long been looked upon as the linking type between amphibians and fishes. In some regards of structure they approach the primitive sharks ; in others, they resernble so closely the salamanders that they were recently regarded by W. N. Parker as worthy of a class by themselves, intermediate between fishes and amphibians. As with the Chimæroids, their few surviving members give but a mere suggestion of the former size and importance of the group.

\section{Structural Characters}

The general structural plan of a Dipnoan is shown in the adjoining figure (Fig. I $2 \mathrm{I}$ ), taken from a dissection of the African form, Protopterus. Its thick, spindle-shaped body, enclosed in rounded, horn-like scales, $C S$, terminates in a diphycercal tail, $C F$. The head is salamander-like both in shape and in slimy integument. The paired fins (schematized in the figure, $P F, V F$ ) are archipterygial.

The head region is characterized by a cartilaginous brain case, roofed by dermal bones, $H R$; a mandible, $M A$, directly articulated with the skull (autostylic); an anterior and posterior nares, $N O$, - the former opening under the lip, the latter within the mouth; a row of small, compressed (unsegmented) gill arches, $G A$, whose single outer aperture 


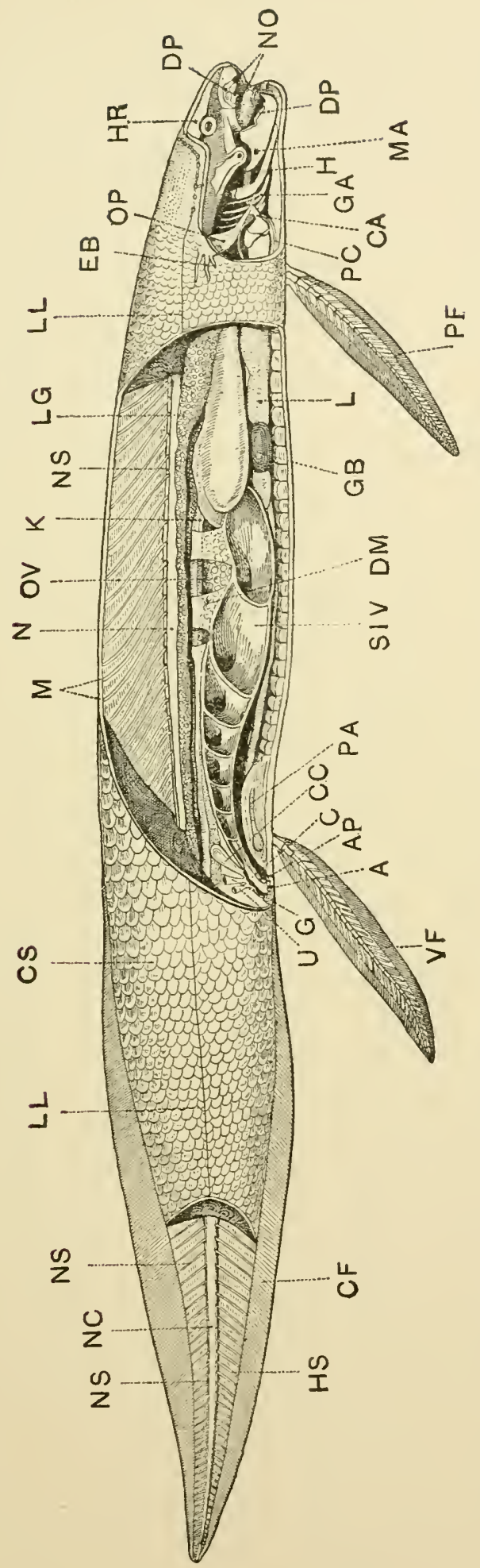

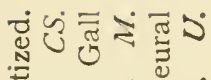

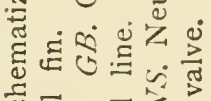

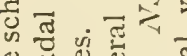
ขु

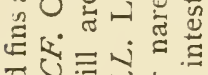

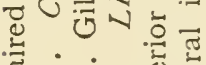

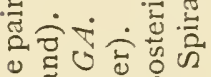
西

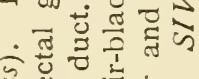
产总焉范

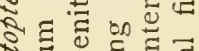

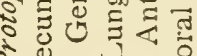
Q O

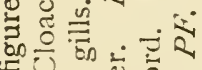

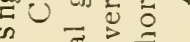

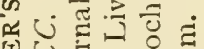

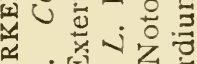

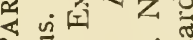

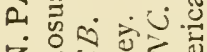

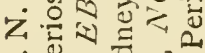

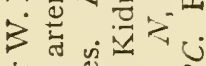
过 त ป气 घं $\overline{0}$.

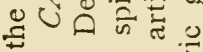
छ

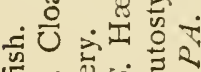

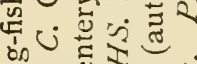

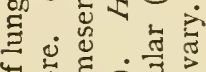
पू है 厄

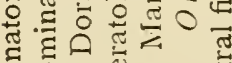

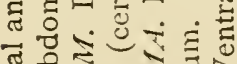

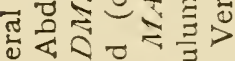
ป บำ

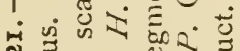

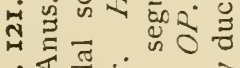

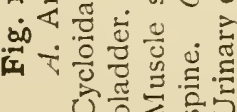


is guarded by an operculum, $O P$. The stunted external gills which here protude, $E B$, are sometimes looked upon as significant of an ancestral condition (Garman, Wiedersheim).

The viscera are somewhat shark-like in their features. They include a short digestive tracr, with well-marked spiral intestinal valve, $S I V$; a fenestrated dorsal mesentery, $D M$; a large, elongate liver, $L$; a heart whose arterial cone, $C A$, contains transverse rows of valves; a cloaca, abdominal pores (or pore), $A$; and a rectal cæcum, $C C$ (v. p. 263). The elongate kidney, $K$, the ovary, $O V$, with its many small eggs, and the long, paired, sacculated air-bladder (lung) may be named as among the least sharklike of its visceral characters.

The skeleton of a Dipnoan (Fig. I22) is almost entirely cartilaginous. A stout notochord, encased in a heavy sheath, $N C H$, passes from the skull to the tip of the tail: vertebral centra encroach upon it only in the caudal region, C. Dorsal and ventral processes, arranged in metameral sequence; extend from the notochordal sheath outward and become distally the cartilaginous supports of the dermal unpaired fin. The proximal elements might thus be regarded as neural, $N, N S$, or hæmal processes and spines, the distal elements as equivalent to the basal and radial fin supports, $B+R$. A stout, longitudinal ligament, $L L$, serves to connect the outer ends of the cartilaginous processes, as well as the proximal ends of the dermal fin rays. The ribs are probably the homologues of the hæmal processes; the most anterior pair, greatly enlarged, extends downward on either side as the occipital ribs, $O R$, specialized in the function of the air-bladder.

The structure of the paired fin is normally of the archipterygial form of Fig. 54. In Protopterus, however, 


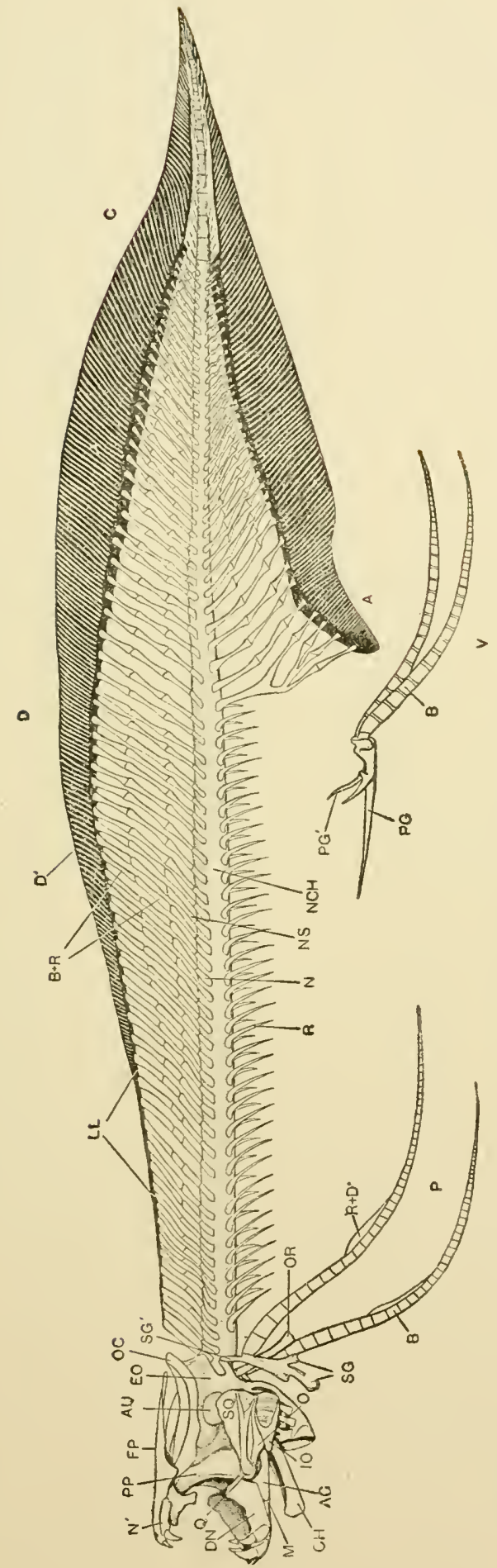

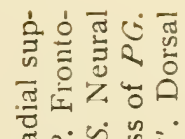

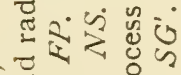

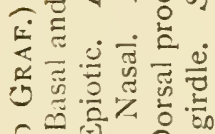

0 0 쇠당ㅎㅇ

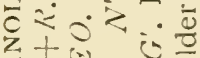

出州的人

$\dot{0} \dot{0} \dot{0}^{\bar{N}}$

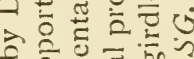

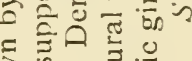

के. 3.0

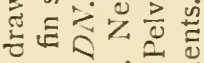

记

顽

项边

을

ट

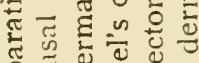

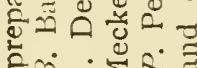

घं

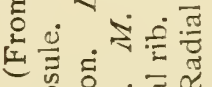

.

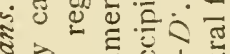

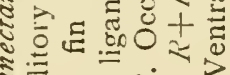

इ

¿

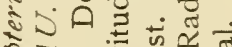

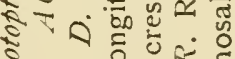

ㄴ.

ร

$=\stackrel{50}{=}$ 닝

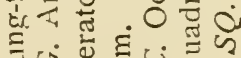

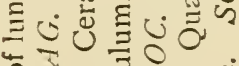

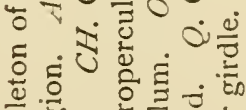

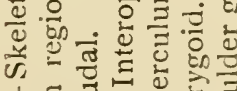

I E

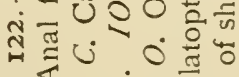

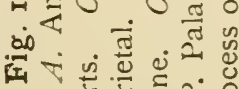
总解 
(Fig. I 22), this plan of structure is somewhat obscured by the rudimentary character of the radial and basal elements, $R+D$, although the fin stem presents a well-marked jointed character, $B$. The pelvic girdle, a solid plate of cartilage, is produced anteriorly into a narrow median outgrowth, $P G$, and laterally into a pair of dorsal spurs, $P G^{\prime}$. The shoulder girdle is composed on either side of a large ventral element, $S G$, which meets its fellow in the median ventral line, and of a short dorsal element, $S G^{\prime}$, which connects it with the skull.

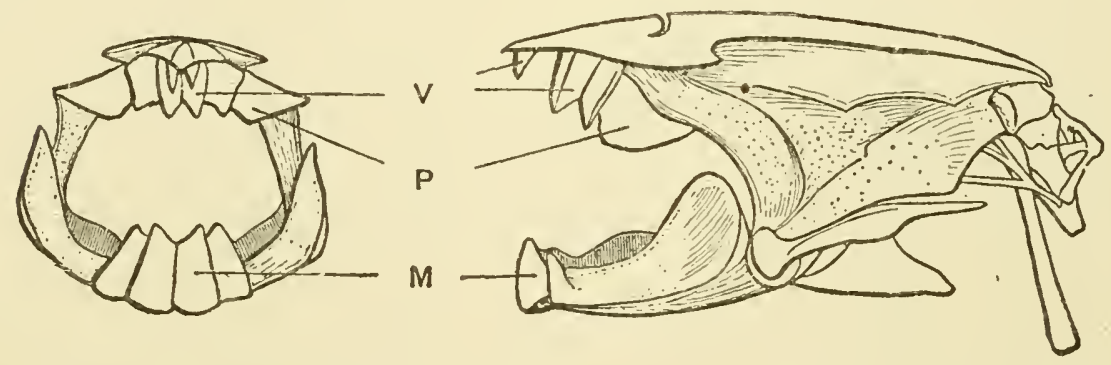

Fig. I22 A. - Jaws and skull of Protopterus annectans, figured in front and side aspects, showing paired dental plates. $\times$ I. (After NEwberRY.)

W. Dental plates of (dentary) mandible; $P$. of palatopterygoid; $V$. of vomer.

In the head region (v. pp. 252,254 ), the brain case is cartilaginous, with, however, a few true bone centres $(e . g$. epiotic) appearing; the roofs of the skull and mouth, together with the mandible, are well sheathed by dermal bones, as FP, N,PP,DN,AG. Paired dental plates fringe the rim of the mandible (Fig. I22 $A, M$ ), the vomerine region $(V)$, and the anterior end of the palatopterygoids $(P)$.

\section{Fossil Lung-fislies}

The structures of the recent Dipnoans can as yet be but imperfectly compared with those of fossil forms. Their ancestral conditions can only be determined when more 

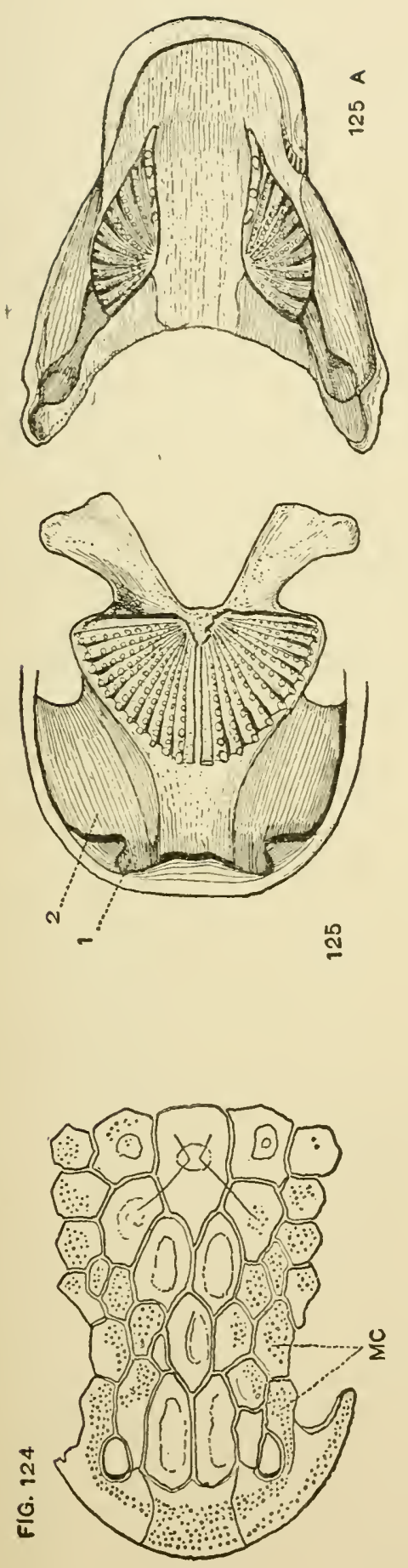

나운

몬

苞言芯

员苛

如公完

总言究

य

这官

政=

志方

छㅇํㅇ

किष

吼

施的

害焉

今

는

证

○气

ㄴ.

$\leqslant \cong$

ธे 웡

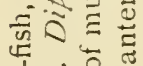

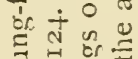

$\Xi$ 일

हี

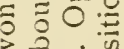

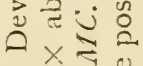

$\cong x$

产突

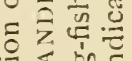

它定.

음

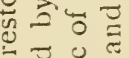

ব

$1=0$

4

和氜

पำ

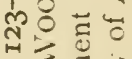

二

的齿

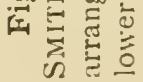


perfect evidence is discovered as to their kinship and the lines of their descent.

In the history of fishes, Dipnoans are known to have been early a dominant group. In some regards, one of their ancient forms bore many resemblances to the Pleuracanthid shark, which, although known at present only in a later period, may well have been its contemporary. But the range in the forms of Dipnoans occurring in the early Palaeozoic indicates the remote antiquity of their origin. They had even then evolved exoskeletal characters which are scarcely less specialized than those of existing forms.

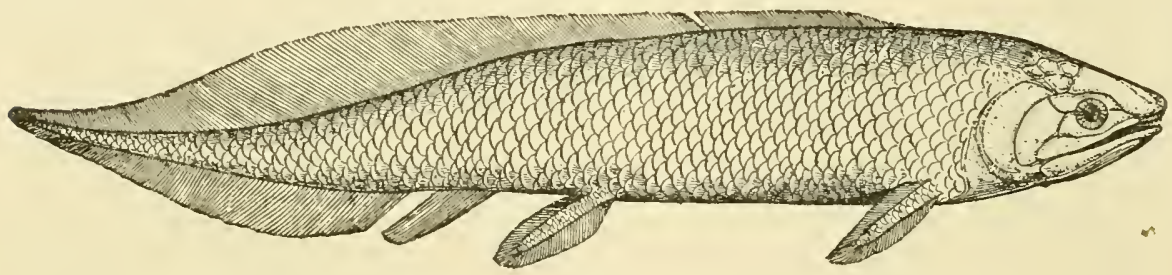

Fig. 126. - A restoration of the Devonian lung-fish, Phaneropleuron. $\times{ }_{6}^{1}$.

Dipterus, of the Old Red Sandstone (Fig. I23), had a complete body armouring of cycloidal scales, a head roofing of dermal plates (Fig. I24), and well-calcified jaw rims (Figs. I 24, I 25, I $25 A$ ). Its fin rays were dermal in structure, its paired fins were archipterygial, its tail and its dorsal fins separate and lobate. Its mucous canals had become elaborately adapted to the body scales (lateral line, Fig. I23) and head plates, piercing the latter with minute pores, as in Figs. 65, 66. Anterior and posterior nares are indicated under the rim of the upper jaw (Fig. I25, I-2). Marginal teeth have disappeared; a pair of elaborate dental plates on the mouth roof (palatine) are apposed by a similar pair in the hinder part of the mandible (splenial).

The Carboniferous Ctenodus was a nearly allied form.

Another Devonian lung-fish, Phaneroplewron (Fig. I26), 

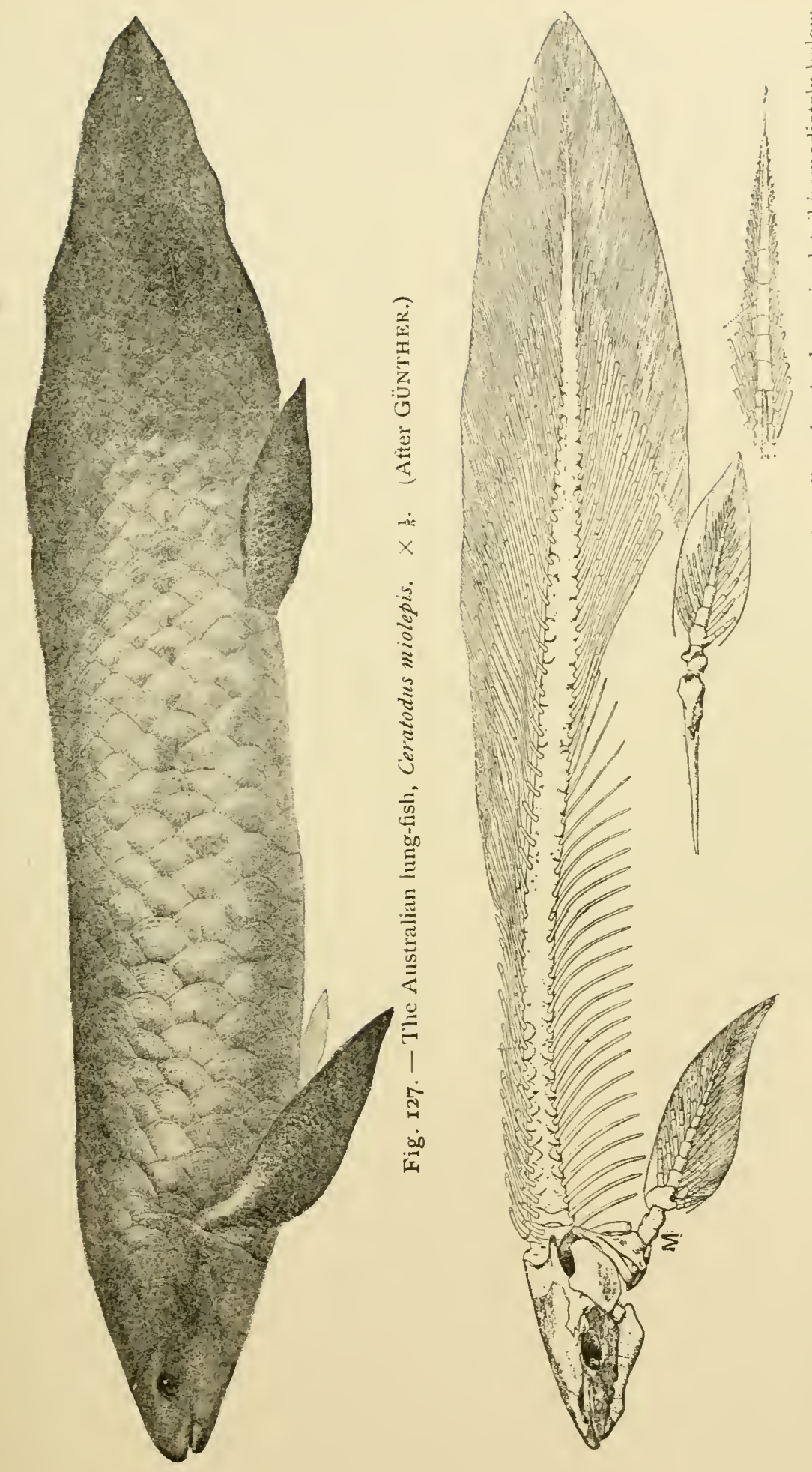

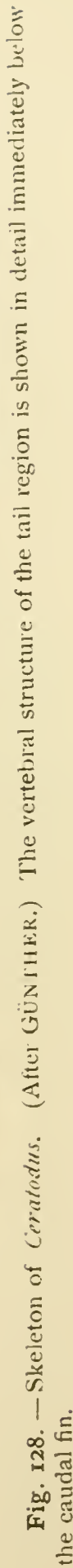


was similar to Dipterus in its skeletal characters. Its elongate diphycercal tail was continuous with the dorsal and anal (?) elements; in this, and in the retention of marginal cusp-like teeth, it resembled the Pleuracanthid sharks.

\section{Living Forms}

The three forms of living lung-fishes may reasonably be looked upon as the survivors of the more generalized Palæozoic forms. Ceratodus, the

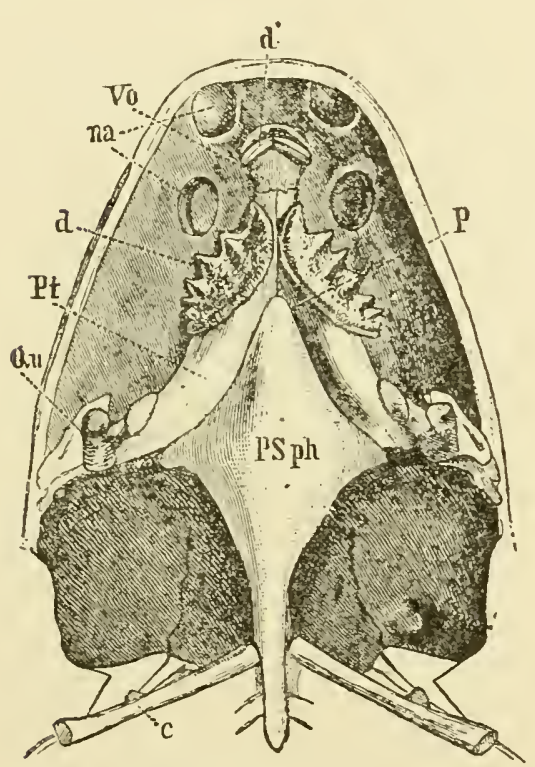

Fig. I28 A. - Skull of Ceratodus. Seen from the ventral side. (After ZiTTEL.)

c. Occipital rib. d. Dental plates. $n a$. Anterior and posterior nares. $P$. Palatine. PSph. Paraspenoid. $P t$. Pterygoid. Qu. Quadrate. I'o. Vomer. Australian genus, appears to have retained most perfectly the ancestral conditions; it has probably remained almost unmodified from the early Mesozoic times, ${ }^{*}$ and presents close affinities to the Coal Measure family, Ctcnodontide, and even to the Devonian Dipterids. Its outward appearance is shown in Fig. I 27, and its skeleton in Fig. I28. The latter is seen to resemble closely the characters of Fig. I 22 ; its paired fins are archipterygial; the mouth is lacking in marginal cutting plates (cf. $V$, Fig. I 22 A). The dental plates of the palatine and splenial regions (Fig. I28 $A$ ) are seen to correspond clearly with those of Figs. I 25, I $25 \mathrm{~A}$.

Ceratodus had long been known to the colonists of

* v. p. Io. The recent genus, according to Dr. Gill, is to be distinguished as Neoceratodus. 
Queensland as a plentiful food-fish, a "salmon" in size and taste, although, curiously enough, it remained undescribed until i 870 (Krefft, and Günther). After this its developmental history was eagerly awaited, in the hope that it would reveal the affinities of the Dipnoans to the sharks, amphibians, and in general to the early chordates. About ten years ago Caldwell was sent to Queensland by the

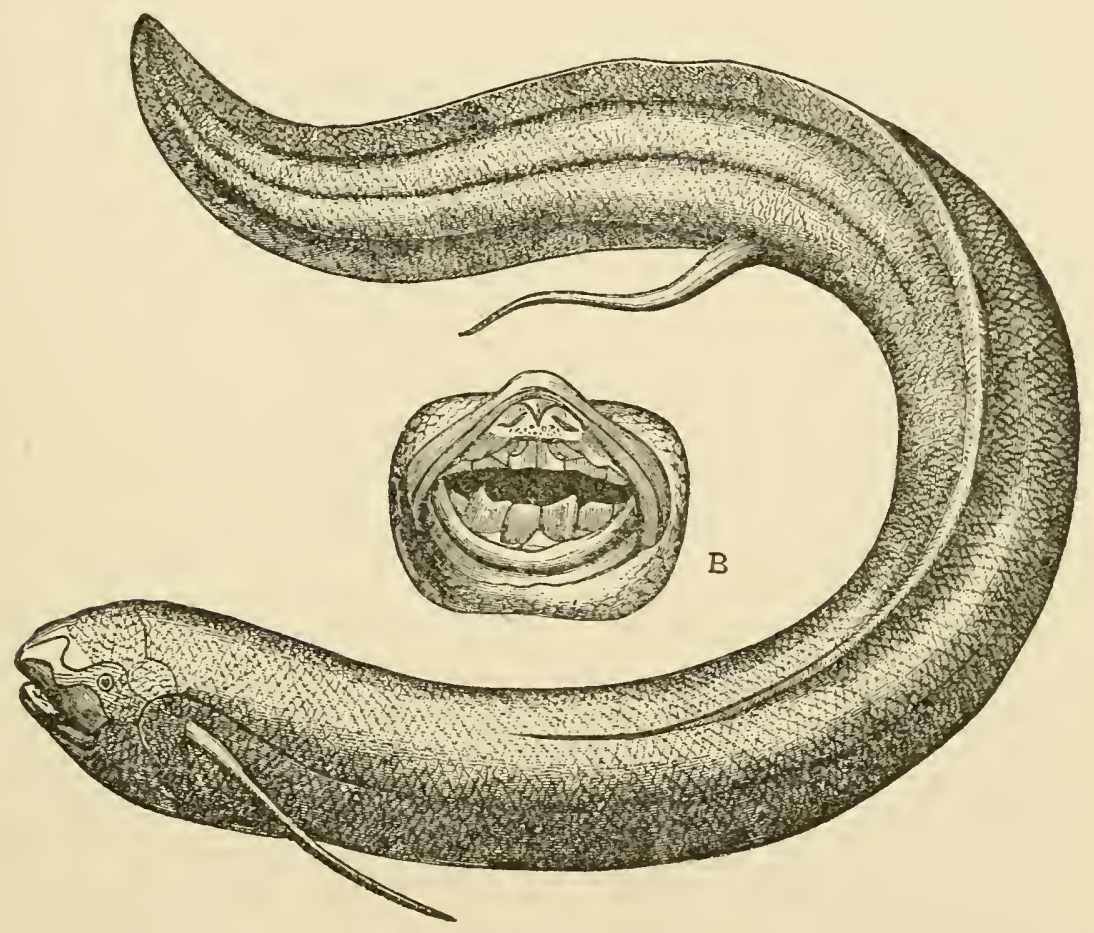

Fig. I29. - The South American lung-fish, Lepidosiren paradova, Natter. $\times \frac{2}{4}$. (From Nicholson, after NATTERER.) A front view of the mouth is shown at $B$.

Royal Society, and succeeded in securing a set of the embryonic stages, but his results still remain unpublished. A second set of embryos was collected in I 89 I by Semon, from whose recent paper a summary is later given (p. I9S). The development of Ceratodus, however, as far as it is at present known, has proven in many ways unsatisfactory to the phylogenist; its abbreviated growth stages cannot be 
looked upon as furnishing clearly the ancestral history of Dipnoans.

The two remaining forms of recent lung-fishes, Lcpi-

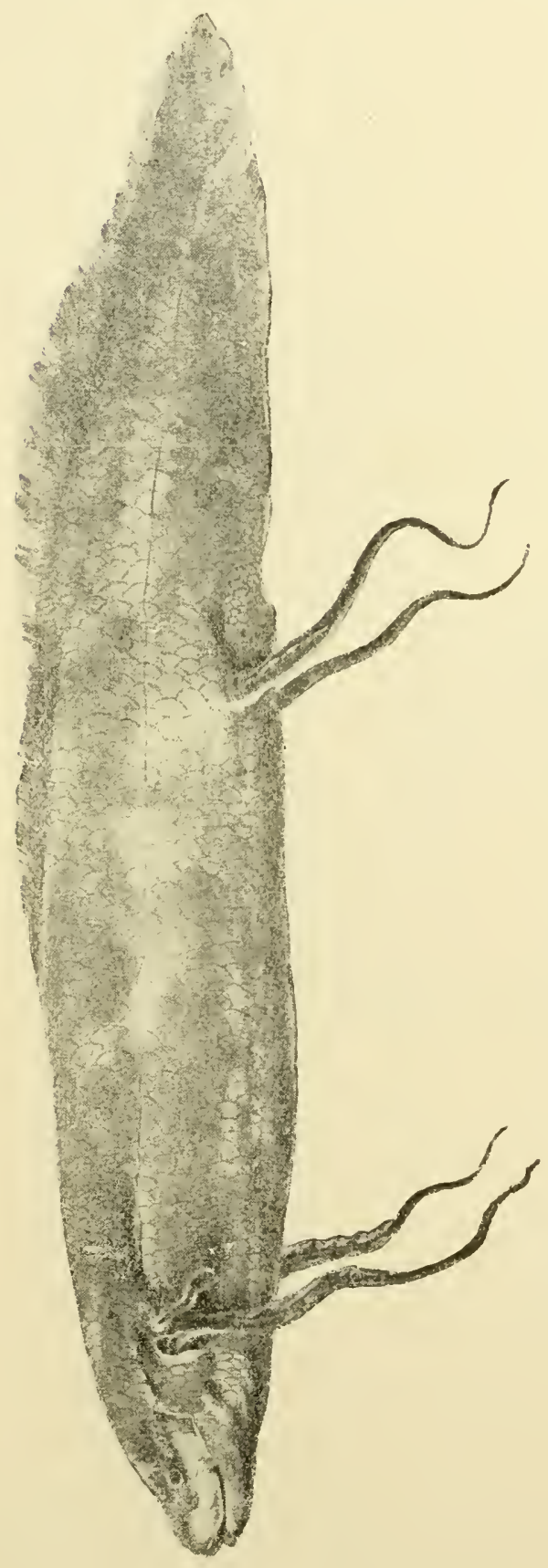
dosiren and Protoptcrus, resemble each other so closely that Ayers has contended that they should be regarded as distinct only specifically. Lepidosiren, the South American form (Fig. I 29), was discovered by $\rightarrow$ its describer, Natterer, in 1837 in the upper Amazon. It then, for many years, succeeded in eluding the collectors, and was known as one of the rarest specimens of foreign museums. In I 887 it was, however, rediscovered in Paraguay, where it appears to have long been known as a food-fish. Its structures are now regarded as entitling it unquestionably to the rank of a distinct genus.

Protopterus, common in the White Nile and Congo (Fig. I $29 A$ ), has long been the "Lepido- 
siren" of dealers, often of museums. It is the best known of Dipnoans, on account, partly, of the ease with which it may be transported alive. In the hardened mud cocoons with which it encases itself during the dry season, it is readily dug out of the stream bed and packed for exportation. When placed in tepid water, the cocoon dissolves and the fish shortly revives.

\section{Relationships}

A review of our knowledge of Dipnoans gives but little satisfactory suggestion as to their relations as a group. They must certainly be looked upon as an advancing phylum from which the amphibia may early have diverged. Their many amphibian characters have been lately emphasized by W. N. Parker. On the other hand, the evidences of the kinship of Dipnoans to the other types of fishes can only be interpreted as the common convergence of the ancient phyla toward the structures of the ancestral form of fish. Thus we find that the types of Devonian lung-fishes can only be distinguished from those of the contemporary Teleostomes by the pattern of arrangement of the plates of the head roof, * a condition which has led Smith Woodward to believe that these groups had already diverged before the appearance of dermal bones.

Lung-fishes have unquestionably many structures which may have been derived from the more generalized conditions of the sharks; and as a group they may not unreasonably be looked upon as descended from the primitive elasmobranchian stem. Their ties of kinship to the sharks

* The present writer regards this distinction as somewhat provisional; median head plates are nominally characteristic of Dipnoans (Fig. 124), but, as in the sturgeons and siluroids, they are also well known among Teleostomes. Protopterus has, moreover, a symmetrical arrangement of the head plates. 
have now been closened by the proof that their paddleshaped fins may be directly deduced from a "monoserial archipterygium," and that their diphycercal caudal, formerly regarded as most primitive in plan, may have been acquired secondarily after a condition of heterocercy (W. N. Parker, Traquair, Dean).

The resemblances of Dipnoans to Elasmobranchs might be summarized in the following structures :-

I. Vertebral axis. Its notochordal condition and simple metameral, neural, and hæmal elements suggest the conditions of Cladoselache (p. 8o); in that ancient form, however, the vertebral processes had not come into relation with the unpaired fins.

II. Skull. The chondrocranium is as yet largely retained; as yet no dentigerous membrane bones of the mouth rim (maxillary and premaxillary) have appeared.

III. Teeth. These are clearly of an elasmobranchian order; the tubercles of the dental plates (Fig. I25) suggest closely a shagreen pattern; in Phaneropleuron, marginal cusps have even been retained. The palatine and splenial plates parallel strikingly some of the forms of Cestraciont dentition.

IV. Brain. Its structures are of an advancing elasmobranchian order, annectent with reptilian (Ceratodus) and amphibian types (Protopterus).*

V. Visceral characters. Heart, gills, digestive tract, vessels, mesenteries.

The closely corresponding characters of Phaneropleuron and Pleuracanthus might be looked upon as independently acquired; but in view of the many nearnesses of their phyla, these characters may reasonably be regarded as proof of genetic kinship. 
The advancing structures of the Dipnoan include, in addition :-

I. Exoskeletal specializations. Head-roofing dermal bones (cf., however, Pleuracanthid) and cycloidal scales. In early forms (Dipterus) these appeared at the surface and were apparently enamelled. In recent forms they are deeply sunken in the integument (Prototerus). They suggest closely the structures of Crossopterygian (p. 149).

II. Articulation of the mandible. This is autostylic, somewhat as in Chimæroid (v. p. 256). Its homology is obscure.

III. Air-bladder. (v. p. 264).

IV. Absence of ventral "claspers" (cf., however, Cladoselache).

V. True posterior Nares (amphibian).

VI. The great size of the cellular elements of all tissues (amphibian); the gLandular structures OF THE EPIDERMIS (amphibian).

ViI. Circulatory characters: the three-chambered heart; aortic arches.

VIII. Limb structure. This, however, is not to be interpreted as in any way directly transitional to cheiropterygium.

\section{The Arthrodiran Lang-fishes}

The Arthrodira, as Smith Woodward has shown, may provisionally be regarded as an order of extinct and highly specialized lung-fishes. They occur geologically among the earliest fishes, and include a number of (Devonian) forms whose peculiar characters and gigantic size must have made them among the most striking members of ancient fauna. The group might be regarded as standing in the same relation to the ancient Dipnoans as Acanthodians to the Cla- 
doselachian sharks. As recently as I 887 its members were associated by Traquair with Pterichthys, but the discovery of jaws, specialized dentition, fin spines, and highly evolved pelvic fins at once separate this group from the lowly Ostracoderms.

American Arthrodirans, described mainly by Newberry and by Claypole, have proven of especial interest. They occur from the Silurian to the Coal Measures. The giant predatory member of this group, Dinichthys (Frontispiece, and Figs. 133-I37), attained a length of ten feet. Titanichthys, less formidable in armour and dentition, may well have been twenty-five feet in length. These forms occur almost exclusively in the Waverly of Ohio. Their discovery has here been due to the efforts of Dr. William Clark of Berea, Rev. William Kepler of New London, and Mr. Jay Terrell of Linton; and most of the type specimens have been preserved in the museum of Columbia College, New York.

The European member of this group is a small, freshwater (?) form, Coccosteus, especially abundant in the Old Red Sandstone of Scotland. It has thus far yielded the most complete material for study, and its structural characters might accordingly be described, since they are probably common to all members of the group.

The lateral view of Coccosteus is shown in Fig. I 30 , the dorsal aspect of the anterior region in Fig. I 3 I, and the ventral view of the visceral region in Fig. I32. It will accordingly be seen that the general shape of the body of this Arthrodiran was somewhat depressed; that the head, shoulder, and stomach regions were protected by bony plates; and that the trunk region was lacking in armouring, and short in relative length. In well-preserved fossils the space occupied by the notochord, $N$, is seen to 
pass from the region of hinder plates of the body armour to that of the tip of the tail. This is seen to be bordered by neural and hæmal processes, $N, H$, which in size and character are somewhat comparable with those of Protopterus or Pleuracanthus. The dorsal fin presents a metameral series of supporting cartilages (radial and basal, $D R$, $D B$ ). The basal supports of each pelvic fin have become compressed into a flattened plate, $V B$. Pelvic fins were present, but there have as yet been found no traces of pectoral appendages. In Dinichthys Newberry believed that a pectoral fin spine was present, and that this fin was

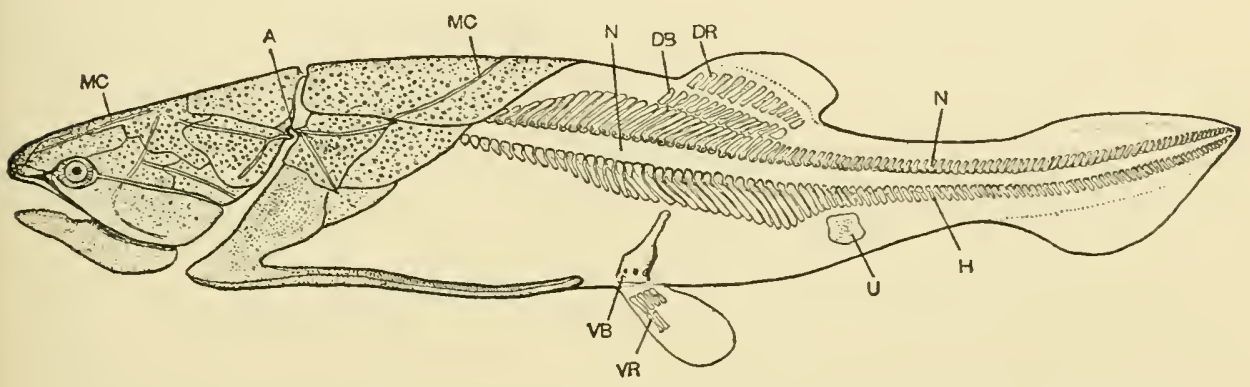

Fig. I30. - The Devonian Arthrodiran, Coccosteus decipiens, Ag. $\times \frac{1}{1}$. Old Red Sandstone, Scotland. (Side view, restored; slightly modified, after SMITH IVooDWARD.)

$A$. Articulation of head with trunk. $D B$. Cartilaginous basals of dorsal fin. $D R$. Cartilaginous radials of dorsal fin. $H$. Hæmal arch and spine. $M C$. Mucous canals. $N$. Neural arch and spine. $U$. Median unpaired plate of hinder ventral region. $V B$. Basals of ventral fin. $V R$. Radials of ventral fin.

probably Siluroid-like (p. I7I), but this view has not been confirmed.

The head of Coccosteus was clearly flattened, with orbits and nasal openings near its anterior margin; it was roofed by a stout buckler of closely fitted dermal plates (Fig. I3I), whose outer surface was tuberculate, enamelled, and furrowed by sensory grooves, $M T C$. The arrangement of the dermal plates of Coccosteus was early (I86I) compared by Huxley with that of recent Siluroids, 
an analogy afterward supported by Newberry, Dean, and recently, on account of the similar characters of the sensory canals, by Pollard. In their conclusions, however, fundamental characters of structure seem to have been overlooked in the unlikeness of Arthrodiran to Teleostome. The inner structure of the cranium of Arthro-
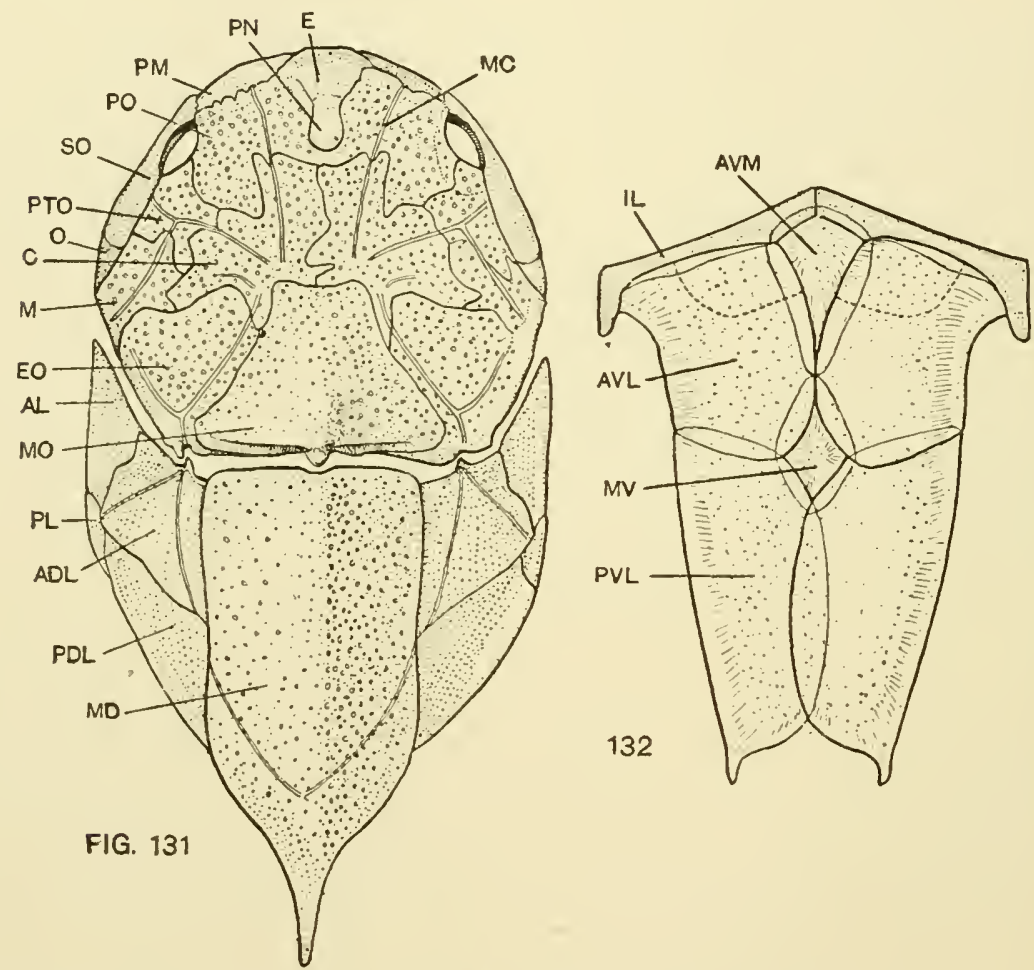

Figs. 131, 132. - Coccosteus decipiens. Dorsal view of dermal armouring. $\times \frac{1}{3}$. (After Traquair.) I32. Ventral plates. (After TRAQUaik.)

$A D L$. Antero-dorso-laterai. $A L$. Anterolateral. $A V M$. Antero-ventro-lateral. C. Central. E. Ethmoid. EO. Epiotic. IL. Inferior lateral. M. Marginal. MC. Mucous canals. MD. Median dorsal. MO. Median occipital. MV. Median ventral. $O$. Opercular. $P D L$. Postero-dorso-lateral. PL. Posterior lateral. PM. Premaxillary. P.V. Pineal. PO. Preorbital. PTO. Postorbital. PII. Postero-ventro-lateral. SO. Suborbital.

dira was evidently entirely cartilaginous; in a Russian Coccosteid, according to Smith Woodward, the base of the brain case (parachordal cartilages) has been preserved and shows a "tubular canal originally occupied by the anterior 
extremity of the notochord." Gill arches and opercula are not definitely known. The mandible was attached directly to the skull (autostylic). The jaws were shear-like, their margins usually with pointed teeth, whose bases fuse with the tissue of the jaw and constitute dental plates. In all forms, as in Dinichthys (Frontispiece), there appear to have been three pairs of these "plates," those forming the rim of the manclible below, and those of the vomerine and palatine regions ("premaxillary" and "maxillary") above.* This arrangement of the dental plates somewhat resembles the Dipnoan's. Those of the Arthrodiran, however, appear to have been movable, and suggest a dental condition elsewhere unknown among vertebrates.

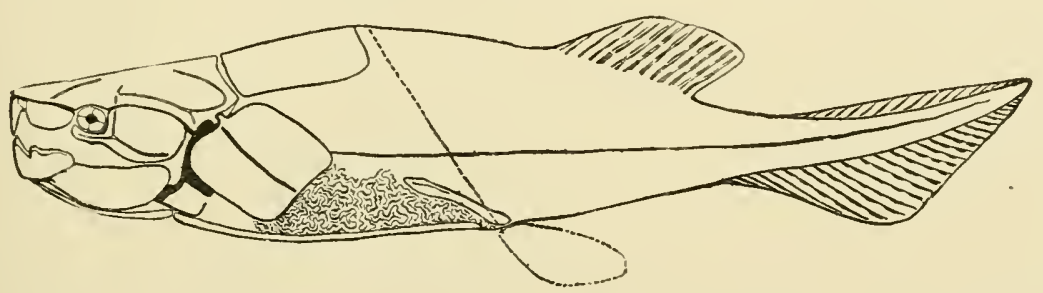

Fig. 133. - Restoration of Dinichthys intermedius, Newb. $\times \frac{1}{24}$. Cleveland Shaies, Ohio.

The body armouring of dermal plates is characteristic of the group. A carapace, cape-like in shape, begins at the head angle and broadens out backward and dorsally towards the median line. It consists of a single median spade-shaped element, which forms the strong ridge of the back, and a flanking of lateral plates, all compactly joined. The rigid shield that is thus formed is movably connected with the head; an elaborate joint, formed on either side between the anterolateral dorsal plate, Fig. I 3 I, $A D L$, and the "epiotic," $E O$, - whence the name Arthrodira, - must

* According to Dr. Clark, an additional symphysial pair of dental plates was present in both upper and lower jaw (Dinichthys). 
have permitted the head to be thrown backward to a degree which suggests the thoracic joint of an Elater. On the ventral side of the trunk there occurs a flattened plastron (Fig. I 32) : its dermal elements are connected by overlapping margins; they are lighter, and in some forms (Fig. I35) lack the tuberculate surface of the dorsal plates. Dorsal and ventral shields are connected by stout lateral elements (Fig. I32, IL), which, passing ventrally,

FIG. 135

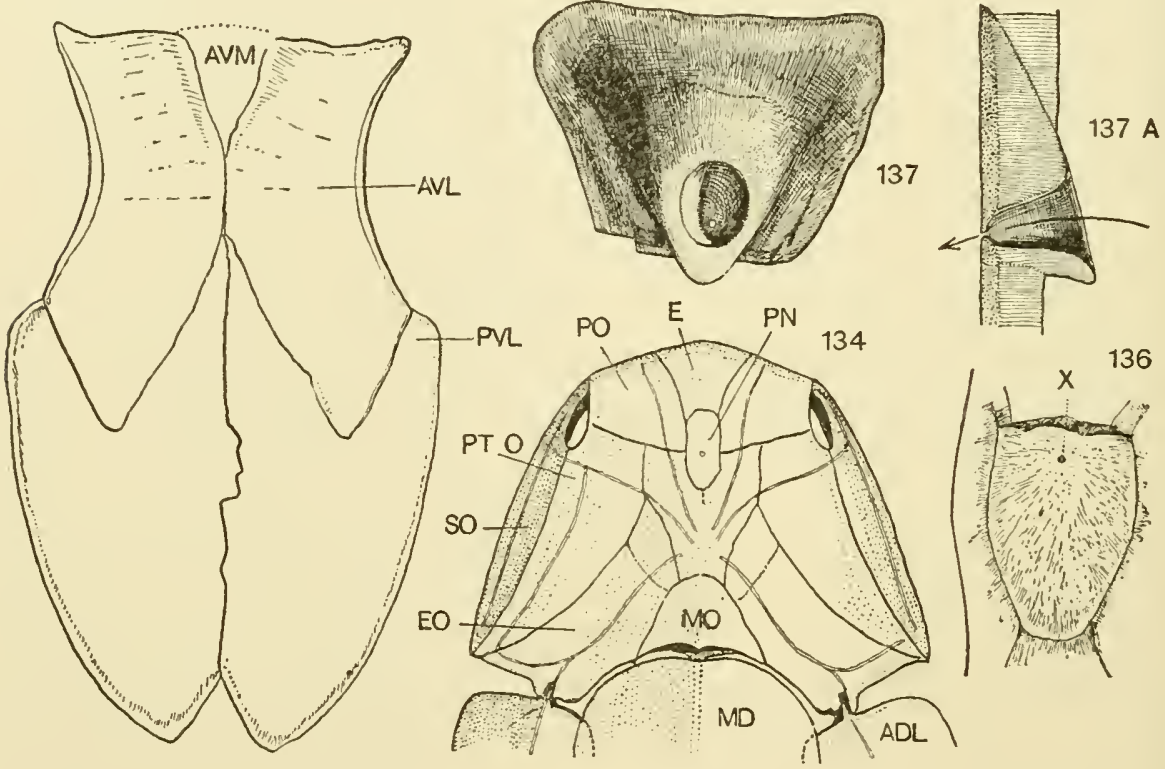

Figs. 134-137. - Dermal plates of Dinichthys. I34. Associated plates of head and shoulders. I35. Plates of ventral armouring. (After A. A. WRIGHT). I36. Pineal plate of Dinichthy's intermedius, surface view. I37. Pineal plate of Dinichthys terrelli, visceral aspect. I37 A. Pineal plate, in sagittal section.

$A D L$. Antero-dorso-lateral. $A V L$. Antero-ventro-lateral. $A V M$. Anteroventro-median. E. Ethmoid. EO. Epiotic. MO. Median occipital. $P N$. Pineal. PO. Preorbital. PTO. Postorbital. PVL. Postero-ventro-lateral. SO. Suborbital. $X$. External aperture, and $\rightarrow$, the axis of the pineal funnel.

meet in the median line, and become the anterior supporting rim of the plastron. By some writers these have been homologized as "clavicles."

In further detail little is known of the anatomy of 
Arthrodirans. Sensory canals have been clescribed channelling the surface of the dermal plates of the dorsal side. In the body region of Coccosteus evidence of a lateral line occurs (Smith Woodward) in a white calcified band fossilized in the region of the space of the notochord. In this form, too, an endoskeletal plate is known, (Fig. I 30, $U$ ) occurring in the median line in the region of the vent, which must be regarded as "suggesting an internal element of support occurring in the vertical septum between the right and left halves of some paired organ (S. $W$.)." The character of the dermal investiture of the trunk has apparently not been described; it may therefore be of interest to note that the museum of Columbia College has recently acquired two of the hincler dorsal plates of Dinichthys which clearly indicate the presence of integument. The plates are covered by a crinkled epidermis, whose irregular surface traceries resemble the roughened finish of Turkey morocco. This leather-like surface is seen to have been continued over the margin of the plates along the side of the trunk; traces of scales or tubercles are altogether lacking, and its appearance suggests that it may have been degenerate in structure.

Among Arthrodirans there occurs a series of most interestingly evolved forms; and it is found more and more evident that they, with other lung-fishes, may have represented the dominant group in the Devonian period, as were the sharks in the Carboniferous, or as are the Teleosts in modern times. There were forms which, like Coccosteus, had eyes at the notches of the head buckler; others, as Macropetalichthys, in which orbits were well centralized; some, like Dinichthys and Titanichthys, with the pineal foramen present; some with pectoral spines (?); some with elaborately sculptured derm 
plates. Among their forms appear to have been those whose shape was apparently sub-cylindrical, adapted for swift swimming; others (Mylostoma) whose trunk was depressed to almost ray-like proportions. In size they varied between that of a perch and that of a basking shark. In dentition (Figs. I38-144) they presented the widest range in variation, from the formidable shear-like jaws of Dinichthys to the lip-like mandibles of Titanichthys, the tearing teeth of Trachosteus, the wonderfully forked, tooth-bearing jaw tips of Diplognathus, to the Cestraciont type, Mylostoma. The latter form has hitherto been known only from its dentition, but now proves to be, as Newberry and Smith Woodward suggested, a typical Arthrodiran.

The puzzling characters of the Arthrodirans * do not seem to be lessened with a more definite knowledge of their different forms. The tendency, as already noted, seems to be at present to regard the group provisionally as a widely modified offshoot of the primitive Dipnoans, basing this view upon their general structural characters, dermal plates, dentition, autostylism. But only in the latter regard could they have differed more widely from the primitive Elasmobranch or Teleostome, if it be admitted that in the matter of dermal structures they may clearly be separated from the Chimæroid. It certainly is difficult to believe that the articulation of the head of Arthrodirans could have been evolved after dermal bones had come to be formed, or that a Dipnoan could become so metamorphosed as to lose not only its body armouring

* The writer believes that the Arthrodirans may as well be referred to the sharks as to the lung-fishes; as far as existing evidence goes, they certainly differed more widely from the lung-fishes than did the lung-fishes from the ancient sharlss. They may, perhaps, be ultimately regarded as worthy of rank as a class. 

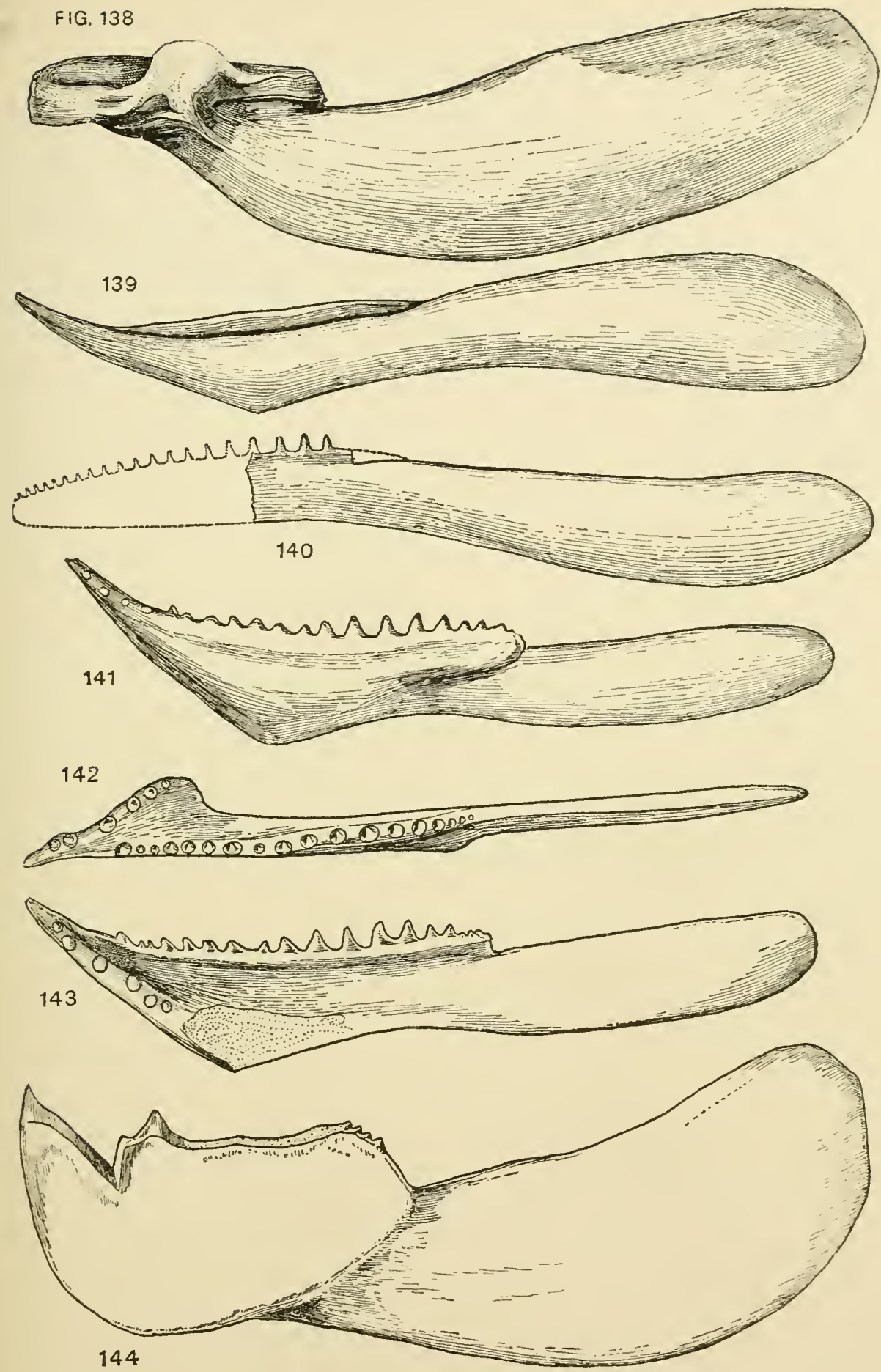

Figs. 138-144. - Mandibles of Arthrodirans: Cleveland Shale, Ohio. I38. Mylostoma variabilis, Newb., visceral aspect. I39. Titanichthys clarki, Newb., visceral aspect. $\times \frac{1}{3}$. I fo. Trachosteus, Newb., outer aspect. $\times \frac{1}{3}$. IfI. Diplognathus, Newb., outer aspect. $\times \frac{1}{3}$. I 42 . Diplognathus, seen from dorsal side. I+3. Diplognathus, visceral aspect. If+. Dinichthys intermedius, outer aspect. $\times \frac{1}{2}$. 
but its pectoral appendages as well. The size of the pectoral girdle is, of course, little proof that an anterior pair of fins must have existed, since this may well have been evolved in relation to the muscular supports of plastron, carapace, trunk, and head. The inter-movement of the dental plates, seen especially in Dinichthys, is a further difficulty in accepting their direct descent from the Dipnoans. 


\section{VII}

\section{THE TELEOSTOMES}

All fishes not to be grouped among Sharks, Chimæroids or Lung-fishes, have been included in the fourth sub-class, Teleostomi. In this are to be merged the two time-honoured groups, Ganoids* and Teleosts, since it is now found that there are absolutely no structures of the one group that are not possessed by members of the other. The terms, therefore, "Ganoid" and "Teleost," must be used in a popular and convenient, rather than in an accurate sense ; the former to denote the "old-fashioned" Teleostome, with its rhombic bony body plates, and cartilaginous endoskeleton; the latter, the modern "bony fish," with rounded, horn-like scales and its calcified endoskeleton.

Teleostomes present so wide a range of variation that it becomes exceedingly difficult to include in a single definition their minor structural characters.

As a basis for the comparison of the Teleostomes, the characteristic structures of a single type, e.g. the Perch, might conveniently be taken. From these conditions, typical of a modern and highly specialized form, the simple structures of the ancient, more primitive, and ancestral Ganoids may afterward be readily unclerstood.

* The term Ganoid, as here used (as far as p. 147), includes the Crossopterygians as well. 


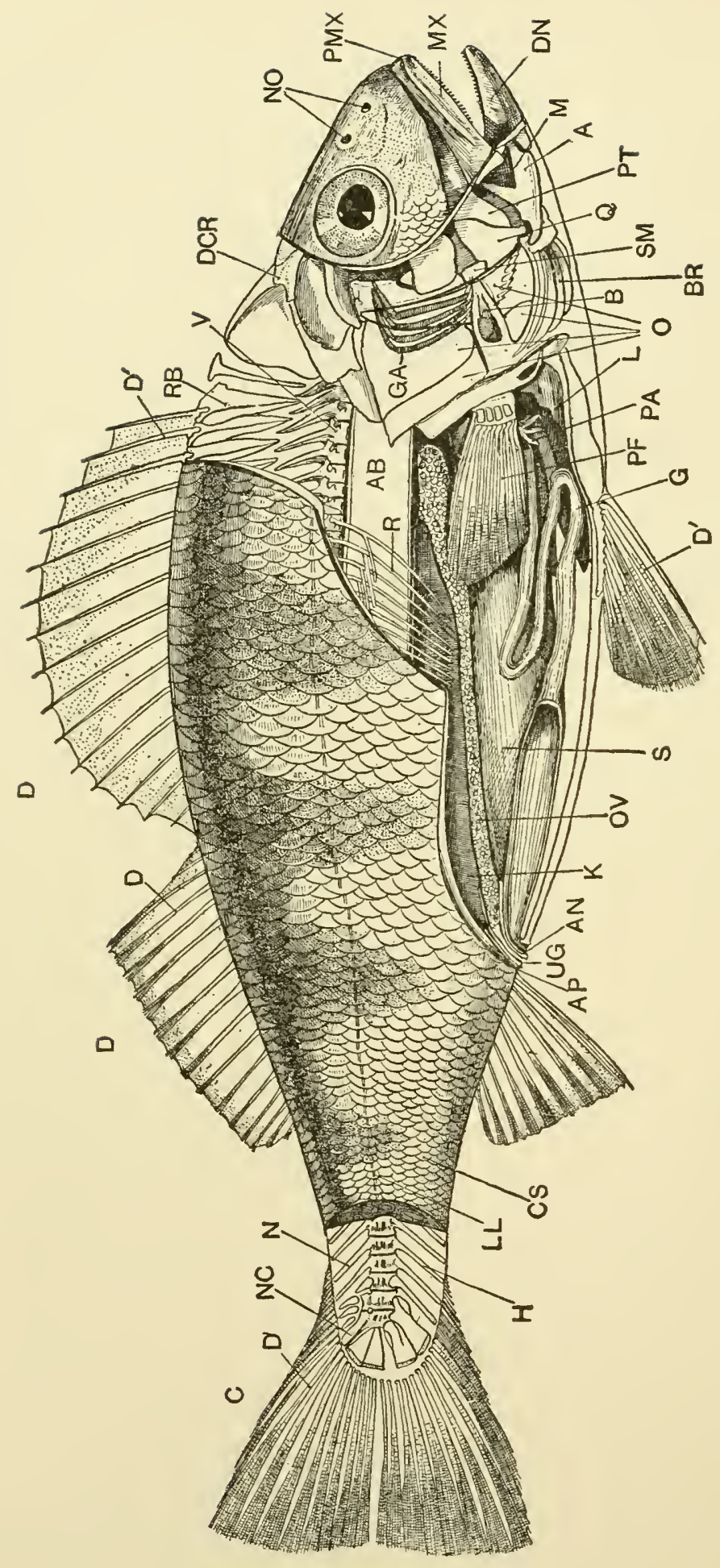

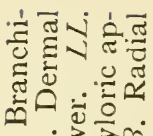

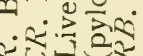
ด๐: \ิن்

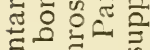
कर

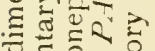

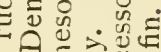

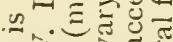
जदें ¿ छ心 记氠了放 运 政 कू पं एं का

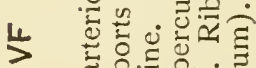
ง हैं ตี ฮี ฮูำ

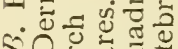

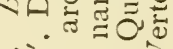
نำ ฉ.

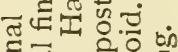

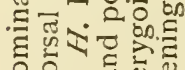

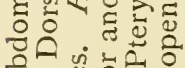
दे.

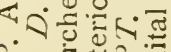
Q. ن के ज्ञ हैत्र ๘๐ ๘๐

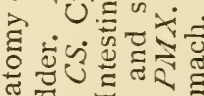
สี

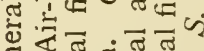

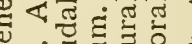

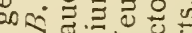

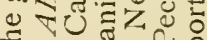
$=\ldots$. 1 过吸范

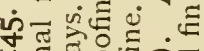
ษ

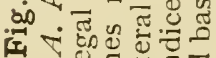

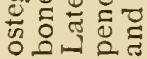




\section{General Anatomy}

In the Teleost (Fig. I45) the shortened and muscular body appears admirably adapted to the conditions of aquatic motion. Anteriorly it is broad and deep, its trunk muscles firmly attached to the bony prongs of the enlarged base of the skull, $D C R$, and to the solid, compact, calcified vertebra, $V$, and their stout processes. The fish's tapering sides are encased in horn-like cycloidal scales, CS, a light, flexible armour, whose elements overlap, defending every point, and whose smooth and slimecoated surface provides the least possible resistance to motion. The fins, $D, C, A, P F, V F$, are light and strong, erectile and depressible; their rays are thin, narrow, spinelike, strong; they are entirely dermal, their cartilaginous supports sinking within the body wall, $R B$. The caudal is large and fan-shaped (homocercal), its crowded rays providing admirably its needed strength; its stout basal supports, compacted beneath the tip of the notochord, $N C$, show that its form is modified heterocercy. The pectoral fin, $P F$, has now taken its position high in the side of the body; its basi-radial supporting elements are reduced to a proximal row of a few small irregular plates.

The skeleton is completely calcified. The vertebral axis has undergone entire segmentation, the notochord persisting only between the cup-shaped faces of the centra; the vertebral arches and processes have merged with the centra, and those of the hinder region, $\Lambda^{\top}, H$, with probably the basal fin supports as well. Ribs, $R$, usually with intersupporting processes, strengthen the walls of the visceral cavity, and represent calcifications of the myocommata, rather than transverse processes of the vertebræ. The skull is formed of compact bony elements; its carti- 


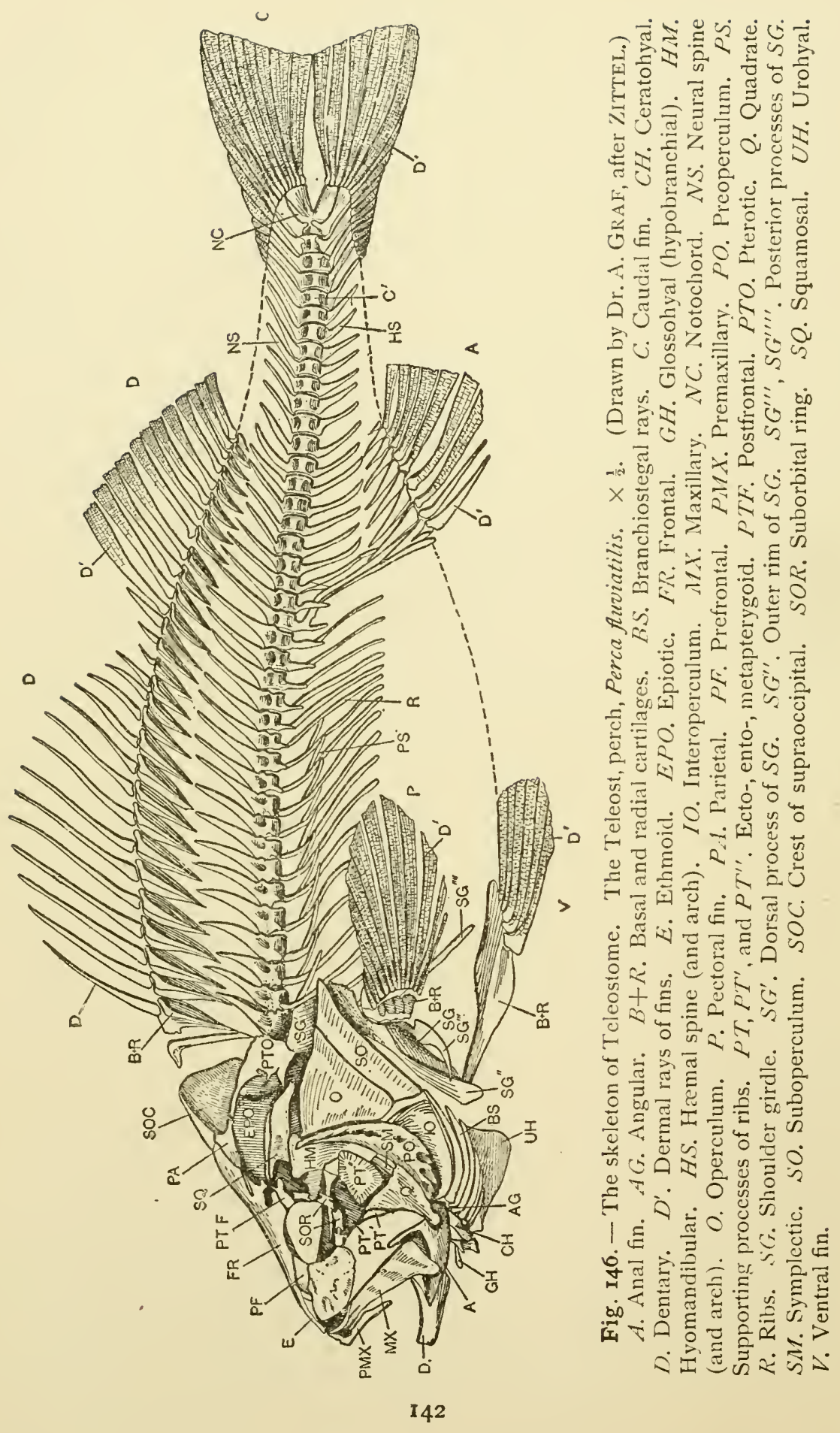


laginous brain case is replaced by many definite osseous elements. The floor and roof of the skull, the face region, jaws, gill arches, and their protecting parts, are all encased by an elaborate series of membrane bones; these, however, must be noted as deeply embedded in the body tissue, $D C R, D N, A, Q, P T, S M, B R, O$. The membrane bones of the jaw rim - maxillary, premaxillary, and dentary, $M X$, $P M X, D N$ - bear teeth, and are especially characteristic of the Teleostomes; those overlapping and protecting the gill arches $(G A), O, I O, P O, S O$, usually four in number, are also characteristic of the group. The skull is hyostylic.

As to the visceral parts. The gill arches, $G A$, are reduced in number, usually widely bent backward, and closely crowded together; their gill filaments are enlarged and specialized. The heart lacks the arterial cone with its transverse series of valves; in its place a stout bulbus, $B$, forms the base of the aorta. The digestive tract is tubular, long, and coiled; its intestine, $G$, lacks a spiral valve, and terminates at the body surface, $A N$, not in a cloaca; its glands include a series, often great in number, of pyloric cæca (pancreas). An air-bladder, $A B$, is present, which may, or may not, retain its communication with the gullet. The ovary, with its many small eggs, and the kidney, dorsal to it, have often a common external opening in a urinogenital papilla, $U G$, in either side of which abdominal pores may occur. The nervous system and sense organs (pp. 275, 277) have many peculiarities: the roof of the fore brain is non-nervous; the nasal openings appear in the dorsal side of the head, NO, and are separate; the eye has specialized a vascular, nutritive structure, the processus falciformis, projecting from the region of the entrance of the optic nerve into the vitreous cavity of the capsule; the optic nerves cross in passing to the eyes, but their fibres do not fuse. 


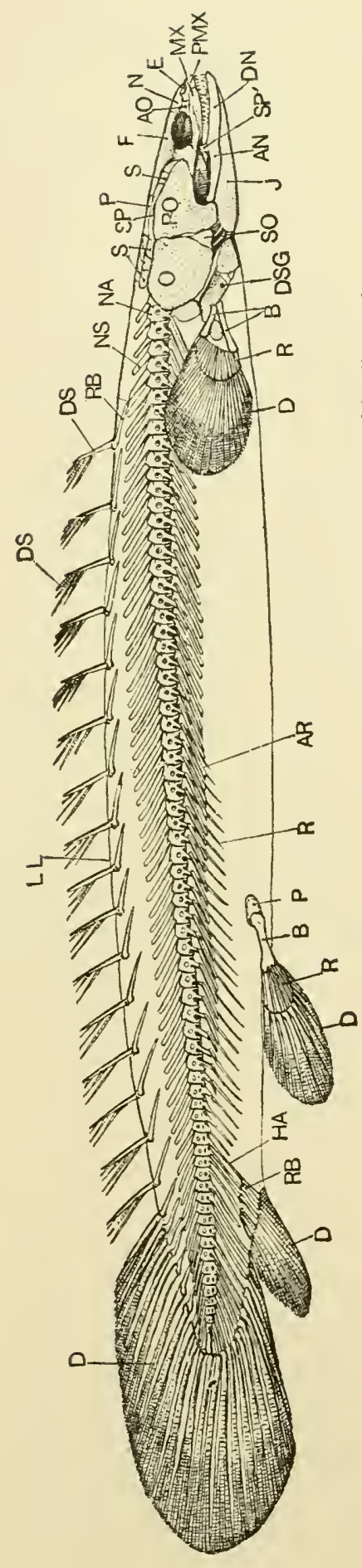

is 政

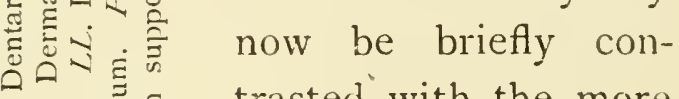

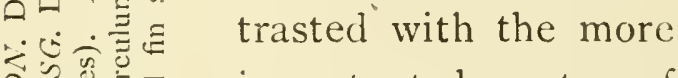

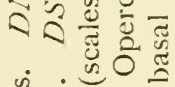

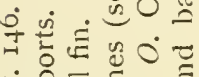
的鲾

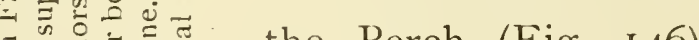

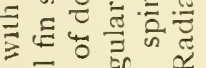
可

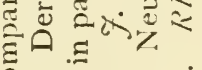
$\dot{0}=0$

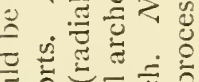

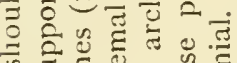

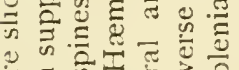

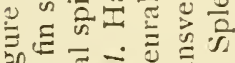
然元

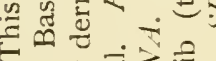
s

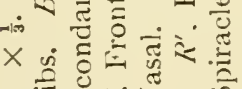

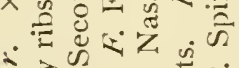

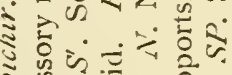

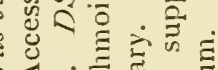

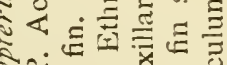

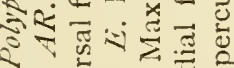

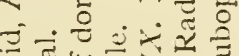
כั

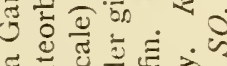

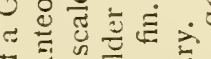

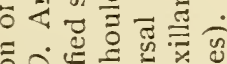

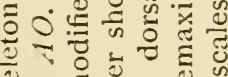

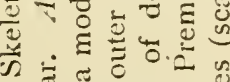

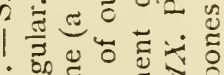

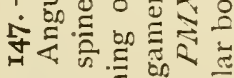

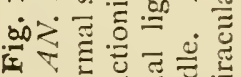
important characters of the Ganoids.

In skeletal structures the Perch (Fig. I46) may be strikingly contrasted with the most nearly ancestral form of Ganoid (Fig. 147). In this, Polypterus (p. I48), the skeleton retains a semi-calcified condition. Its vertebral centra are practically separate from the arches; its ribs, $R$, are equivalent to the transverse processes; its accessory ribs, $A R$, to the "ribs" of Teleosts. The cartilaginous brain case is notably retained; the membrane, or dermal bones, of the head roof, as $F, P, S P$, $P O, O$, are clearly scale-like, with an enamelled surface, similar in character to 
those of Dipterus. The shoulder girdle includes outer dermal elements, $D S G$. The external parts of the unpaired fins are dermal; but their cartilaginous supports are retained, $R B$, even in the tail region. The caudal fin may be regarded as either diphycercal or heterocercal. The exposed parts of the paired fins, it is especially interesting to note, are only in part dermal ; the two rows of cartilaginous supports are retained in a condition very similar to that of sharks, $R B$; * two of the basal elements of the pectoral fin, however, have retained the rod-like form in strengthening the front and hinder margin of the fin.

In visceral structures the Ganoids exhibit the following noteworthy characters: a greater number of gill arches; a spiracle; a short and almost straight digestive tube, with spiral valved intestine; a shark-like pancreas; an arterial cone, with many rows of valves; a cellular airbladder, like that of a Dipnoan; primitive conditions in the urinogenital apparatus; shark-like characters in the nervous system and sense organs; a chiasma of the optic nerves, (pp. 260-279).

\section{Relationships and Descent}

Johannes Müller, when separating Ganoids from Teleosts, recognized clearly even at that early date (I844) that the majority of the structural differences of these forms were bridged over in exceptional instances; there were thus Teleosts with bony body plates, as well as, it was afterwards found, a Ganoid (Amia, p. 163) with herringlike cycloidal scales. But he believed that three structural characters of the Ganoids separated them constantly from all Teleosts, and warranted the integrity of the groups.

* Contrast Gegenbaur's view that this fin represents the simplest known condition of the archipterygium. Ref. on p. 248 . 
These distinguishing characters were :-

I. A contractile arterial cone, containing rows of valves.

II. An intestinal spiral valve.

III. The interfusion (chiasma) of the optic nerve.

It was not until these differences were shown to be of little morphological importance that the two groups were merged in that of Teleostomi (Owen, I 866). Thus transitional characters in the arterial cone of Butrinus (p. 258) were discovered by Boas: the Teleost Cheirocentrus was found to present ganoidean intestinal characters; and the optic chiasma, as Wiedersheim * demonstrated, could no longer be regarded as of taxonomic or morphological value.

The descent of the Teleostomes, like that of the other groups, has long been a matter of speculation. Their affinities with the Dipnoans are generally admitted (Günther, Gegenbaur, Haeckel, Smith Woodward). Rabl derives them directly from a selachian stem, regarding the Dipnoans as later evolved ganoidean forms. Beard, on the other hand, even goes so far as to entirely separate the Teleostome stem from that of the shark, lung-fish, and amphibian, deriving it with a close kinship to Petromyzonts, from the earliest vertebrates. Palæontology, however, has lately been giving rich contributions to this disputed problem, and there can at present be little doubt that the conditions in fossil fishes have demonstrated that in most ancient times Dipnoan and Teleostome were closely approximated. Although even in the earliest fossils they may be distinguished $(e . g$. by the arrangement of the head-roofing derm bones, v. p. I 27), yet, as Smith Woodward has noted, forms occur too clearly transitional to indicate anything less

* One form of lizard was shown to possess a chiasma of the optic nerves; in its neighbouring genus the nerves were found to cross without fusion. 
than genetic kinship. The Crossopterygian, whose ancient structure is well known, may well have been derived from an ancestor common to the Ctenodont (Dipnoan) and Holoptychian (Fig. I 53) ; so that the gradual nearing of the Teleostome stem to that more fixed, of the Dipnoan, is a strong suggestion as to its derivation. The later descent of the Ganoids from an ancestor closely akin to, if not identical with the Crossopterygian, is usually conceded. Teleosts first occurring in Cretaceous are by evidence of fossils the almost undoubted survivors of an extensive group of transitional Mesozoic Ganoids (p. 165). But whether all Teleosts are to be deduced from a single ganoidean phylum can at present hardly be established. Thus catfishes, or Siluroids, appear in many structural regards closely akin to the sturgeon (p. I6o); but as their fossil remains are lacking before the Eocene-when, however, they appear to have been in every way as highly evolved as in recent forms - little clue has been given to their descent.

Teleostomes may, in the present connection, be briefly characterized under their two principal subdivisions.

I. Crossopterygian, the more archaic group, uniting characters of shark, lung-fish, and Ganoid, retaining the ancient cartilaginous fin bases, radials, and basals in their lobate fins; in some forms (Holoptychius, Fig. I 53), the concrescence of the basal parts of unpaired fins passing through the same evolution as those of paired fins. Represented in the surviving Polypterus ("Bichir" of the White Nile, Fig. I48), and in the slender Polypteroid Calamoichthys (of Calabar), and in the extinct Holoptychius, Undina, Diplurus, and Colacanthus.

II. Actinopteryglan, the spine-finned Teleostomes. Fins supported by dermal rays; ancient fin support greatly 


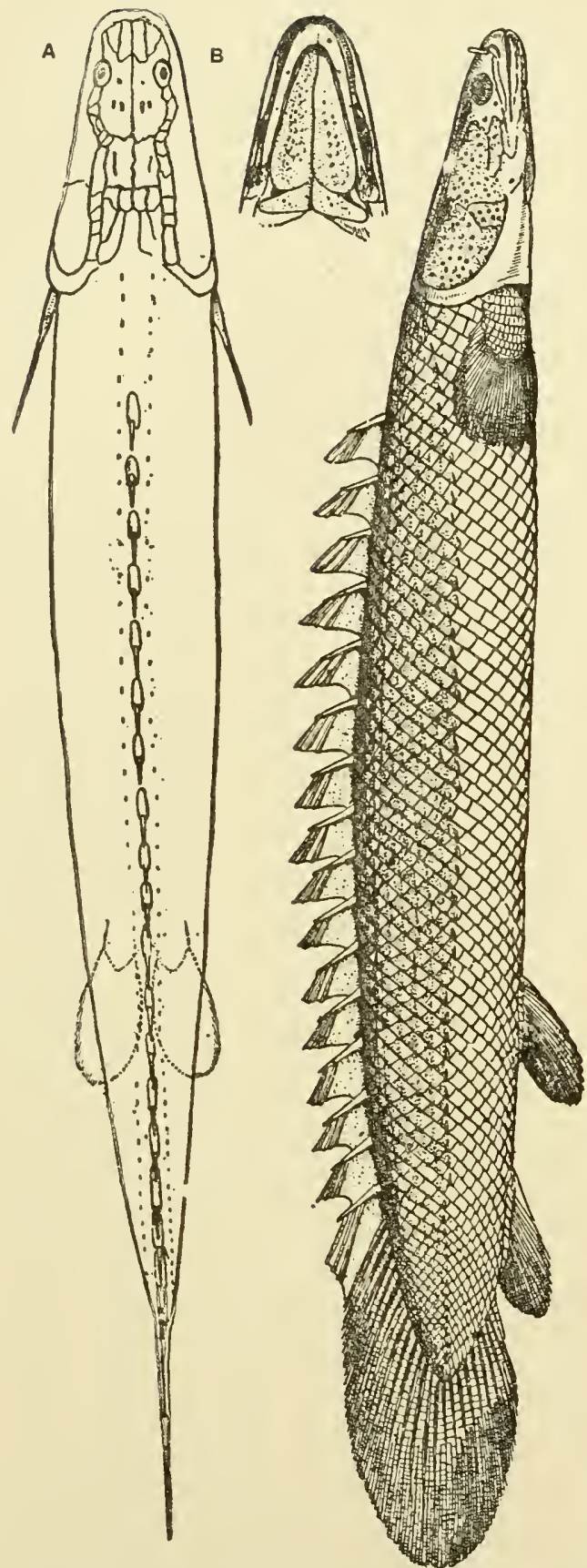

Fig. 148. - The Nile bichir, Polypterus bichir. $\times \frac{1}{3}$. White Nile. (Modified after L. Agassiz.)

$A$. Dorsal aspect. $B$. View of throat region, showing jugular (gular) plates and ventral elements of the dermal shoulder girdle. reduced, implanted within body wall. Includes Chondrosteans ("Ganoids") and Teleocephali ("Teleosts").

\section{CROSSOPTERYGIANS}

The CrossopterygIANS, as palæontology has demonstrated, are the most ancient Teleostomes. In their structural characters - especially in the fins, skeleton, nervous system - they are clearly to be separated from the neighbouring Ganoids. And their transitional characters have not as yet been clearly demonstrated.

Polyptems (Figs. I48, $A, B, \mathrm{I} 49)$ and its kindred ge $11 \mathrm{us}$, Calamoichthys (Fig. I 50), stand alone as the survivors of the Crossopterygian group. They have diverged but little from their Devonian kindred, and demonstrate in the most interesting way the persistent survival of fishes. From 
their isolated position, these recent forms become of extreme interest to the morphologist, and from the side of their development, when this comes to be studied, they are expected to throw the greatest light on the relations of the primitive Teleostome to the sharks and Dipnoans, on the one hand, and to the Ganoids on the other.

I'olypterus * presents the exoskeletal characters of the ancient Crossopterygians, and the typical conditions of their lobate pectoral fins; the dermal plates of its head region are tuberculate as in Dipnoans, but, unlike these, their arrangement, as in all Teleostomes, is dis-

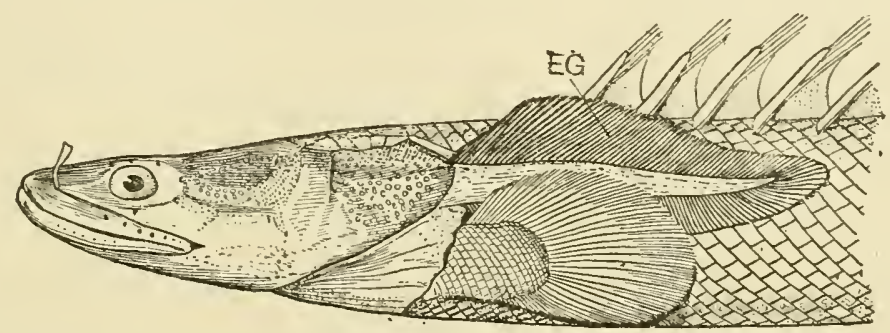

Fig. I49.- Polypterus lapradei. (After STEINDAChNer.) Head region of well-grown larva showing external gill, $E G$.

tinctly paired, i.e. "ethmoids," frontals, parietals, occipitals (Fig. I $48 A$ ), including a pair of gular plates in the throat region, $B . \dagger$ Among the structures peculiar to the

* Polypterus occurs in the Nile, but is rarely taken below the Cataract. It was noted, however, from near Cairo in the Description d'Egvpte, and a specimen in the possession of Professor Innes of the College of Medicine, Cairo, was taken near Boûlak a few years ago. It is known by the Arabs near Assuan, and is here occasionally taken in the fykes at the beginning of the floodingseason. The remarkable series of Polypterus in the Vienna collection was collected in the White Nile, although some of these specimens, Dr. Steinlachner has stated personally to the writer, were taken in Middle Egypt. It seems evident to the writer, from the results of his collecting-trip from Cairo to Assuan, April and May, I892, that abundant material of Polypterus is not readily securer below the Second Cataract. Until, therefore, the interior of Egvpt is marle more accessible to foreigners, developmental stages can hardly be hoperl for.

$t$. Is in some of the fossil lung-fishes. 


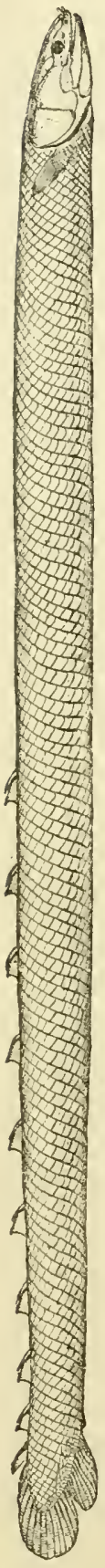

recent forms may be included the fringing dorsal fin, the tubular nasal opening (Fig. I49), and an external gill in Polypterus (Steindachner), $E G$, in the late larval stages.

Calamoichthys is unquestionably a divergent member of the stem of Polypterus; its form, becoming elongated, has acquired a general undulatory movement ; the paired fins have accordingly diminished in relative size, the ventral fins finally disappearing.

Little is known of either the living or breeding habits of Crossopterygians: in these they might naturally be expected to resemble the Ganoids.

\section{Fossil Crossopterygians}

A number of the fossil kindred of Polypterus are shown in the succeeding figures (Figs. I5 II $56 \mathrm{~A}$ ).

Gyroptychius and Osteolepis, Devonian genera (Figs. I5I, I52), are certainly most nearly in the ancestral line of the recent forms. Like many sharks and fossil Dipnoans, they present a heterocercal tail, a single anal fin, and a pair of dorsals. The pectoral fin of Osteolepis is becoming a typical archipterygium.

Holoptychius, another Devonian form (Fig. I53), approaches even more closely the dipnoan types: the scales are cycloidal; its paired fins are distinctly archipterygial; and the caudal region, reduced in length, is becoming metamorphosed into the typical diphycercal form by the tendency of the second dorsal and anal fin to coalesce with 
the caudal. In these forms a number of paired gular plates may occur.

In a closely related genus, Eusthenopteron, also of

Fig. 151
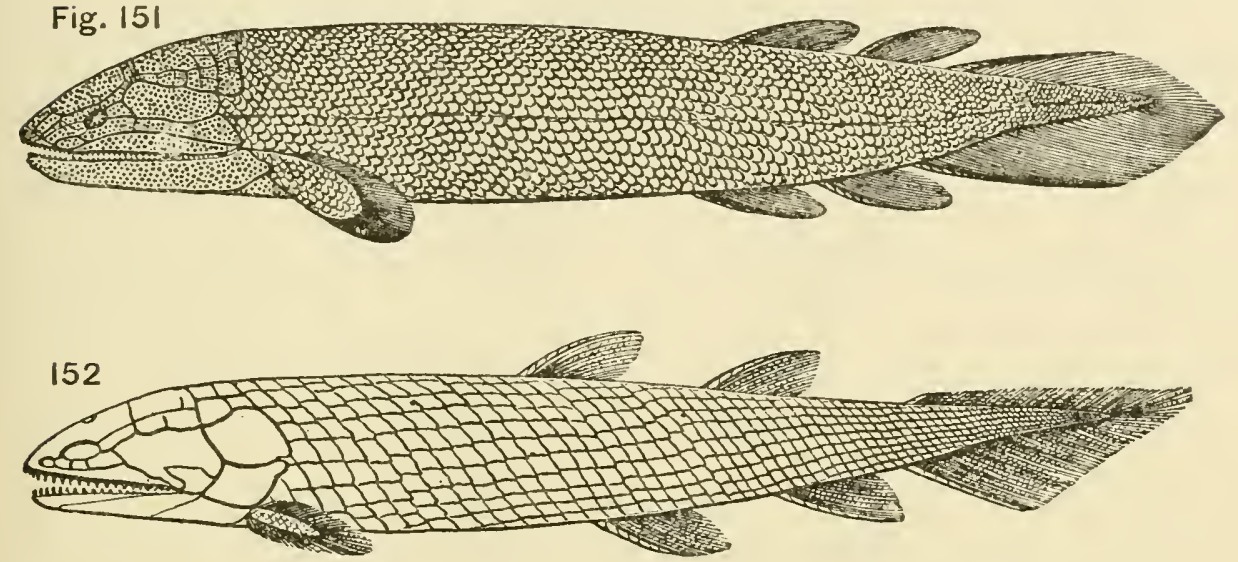

Fig. 151. - Gyroptychius. $\times \frac{1}{4}$. Old Red Sandstone, Scotland. (After SMITH WOODWARD.)

Fig. 152.- Osteolepis. $\times$.. Old Red Sandstone, Scotland. (Restoration from SMITH WOODWARD, after PANDER.)

Devonian age (Fig. I 54, $A, B$ ), the structure of the basal parts of the unpaired fins is exceedingly interesting; the radial supports are unfused, while the basals, merged in a

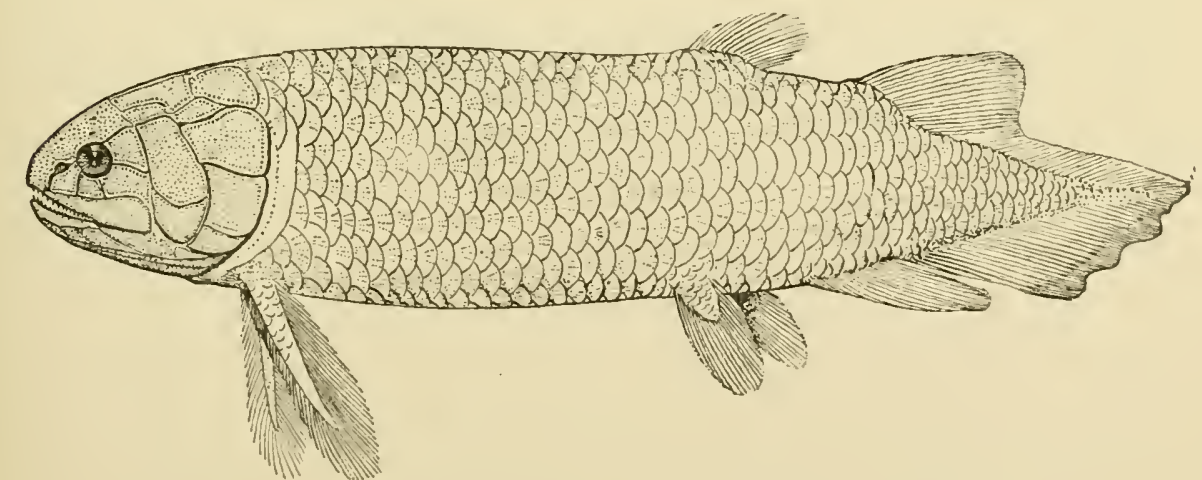

Fig. 153. - Holoptychius andersoni. Old Red Sandstone, Scotland.

single plate, have come into especial relation with the axial skeleton; the subsequent stage of their differentia- 


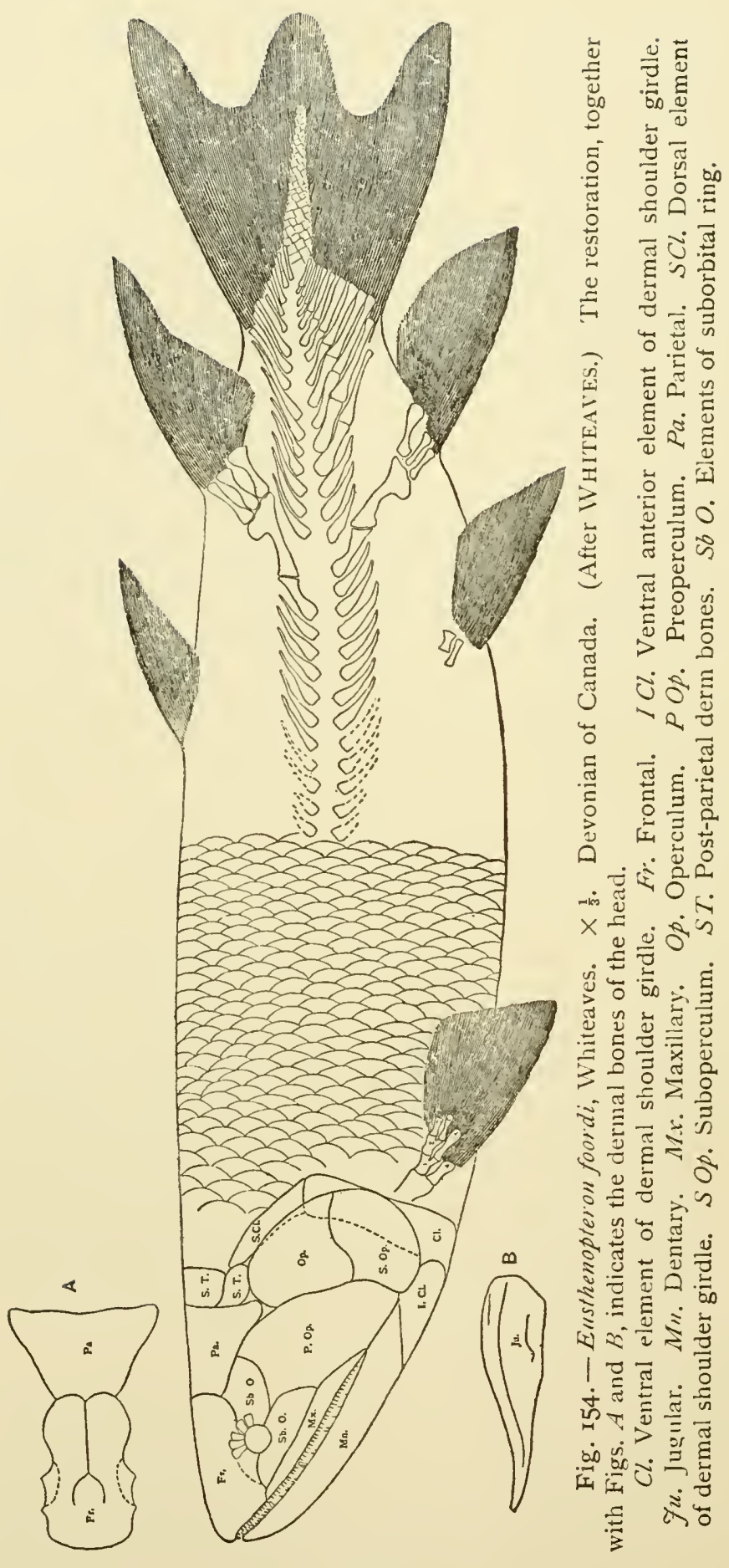

152 
tion has been noticed in Fig. 43. The condition of the caudal fin of Eusthenopteron is also worthy of note; the tip of the notochord is retained although the functional portion of the fin is derived from the more anterior body region. The vertebral arches are here clearly suggestive of the conditions of the Dipnoan.

Calacanthus, common in the Coal Measures (Fig. I 55), is the most specialized of the Crossopterygians; it has retained all of the archaic structures of its kindred, yet has concealed them under the outward appearance of a recent bony fish; the gencral contours of its head, trunk, scales and fins resemble strikingly those of a dace or

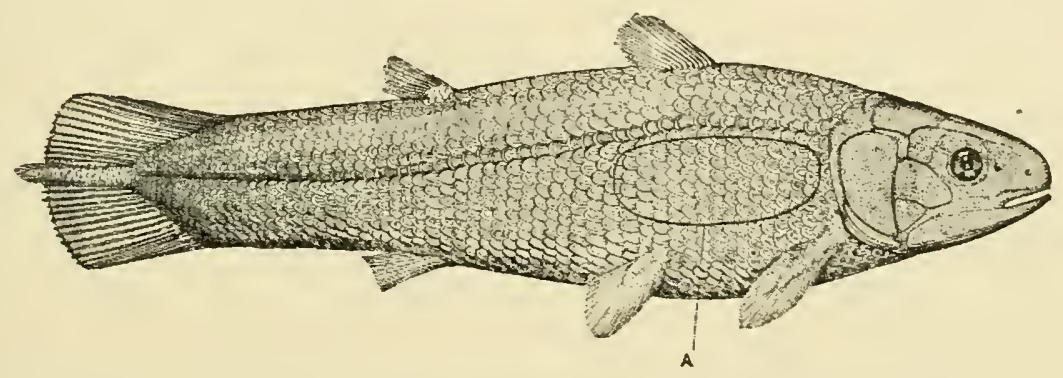

Fig. I55. - Colacanthus elegans, Newb. $\times \frac{3}{4}$. Coal Measures, Ohio. $A$. Position of calcified swim-bladder.

chub; but on closer view the paired fins are found to be archipterygial, the scales enamelled and sculptured, the true caudal fin the degenerate stump of the notochord; the functional caudal has been formed of the enlarged fin rays of the dorsal and anal region. Traces of a calcified air-bladder, $A$, are often preserved.

Diplums and a closely related genus, Undina (Figs I 56, I $56 \mathrm{~A}$ ), may finally be noted among the highly evolved Crossopterygians. They appear in the Mesozoic when the majority of their kindred have disappeared ; they have assumed peculiar characters and have apparently reached the point of differentiation when they shortly become extinct. 
Diplurus has become excessively shortened in its body length; the head is of relatively enormous size; its derm bones are squamous, and appear to have been deeply implanted in the integument; teeth have disappeared;

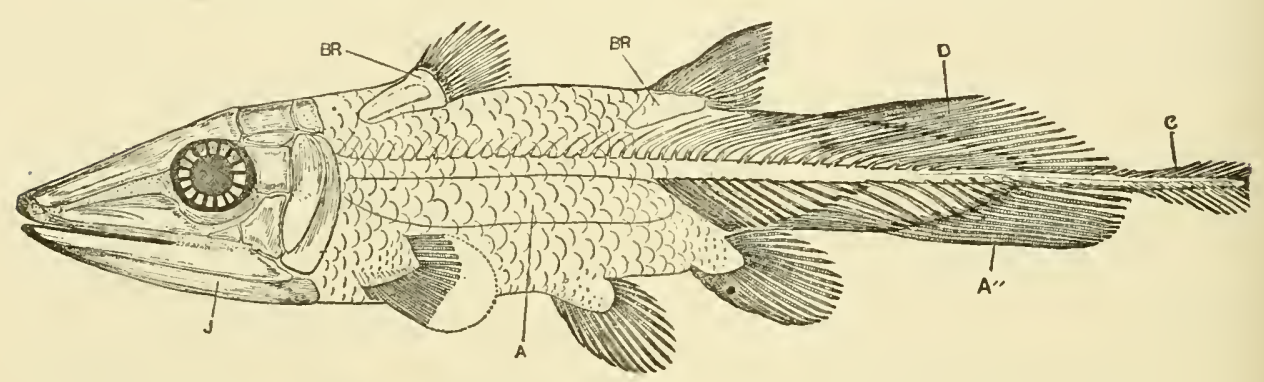

Fig. 156. - Diplurus longicaudatus, Newb. $\times \frac{1}{8}$. Triassic, Boonton, N.J.

$A$. Position of calcified swim-bladder. $A^{\prime \prime}$. Second anal fin (now the ventral portion of the functional caudal). $B R$. Radial and basal fin supports. C. Caudal fin (degenerate). D. Hindmost dorsal fin (now the dorsal portion of the functional caudal). . Jugular.

scales have become exceedingly thin and are rarely preserved. Fin structures are apparently of a degenerate character; their cartilaginous bases, when showing, appear

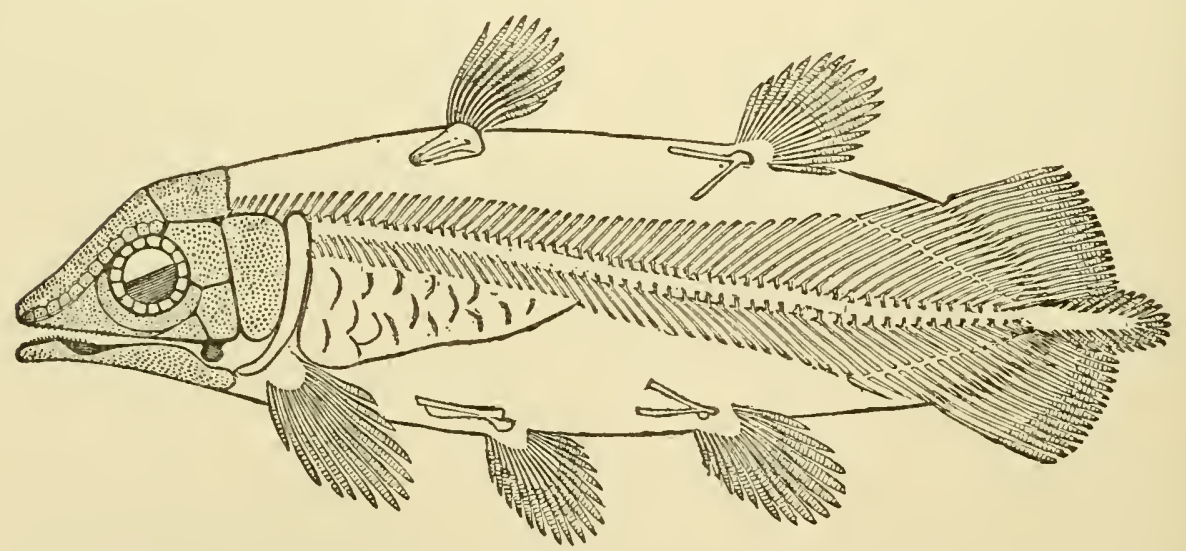

Fig. ${ }_{56}$ A. - Undina gulo, Egert. $\times \frac{1}{3}$. Lower Lias of Lyme Regis. (Restoration after SMITH WOODWARD.)

to have become reduced to single plates, as $B R$; the caudal is the elongate tip of the vertebral axis; the functional caudal, now elongate and diphycercal, is formed 
by dorsal and anal elements, $D, A^{\prime \prime}$, as in Colacanthus. The boundary line of the calcified air-bladder, $A$, is often preserved.

\section{ACTINOPTERYGIANS}

A. Chondrosteans (Ganoids). Ganoids agree with the Crossopterygians in their exoskeletal characters, although usually lacking in gular plates. The most important differences between these groups have been reduced to those of fin structures; the Ganoids have no longer the lobate form of the paired fins; their basal fin supports have become greatly reduced and are usually represented by a single row of a few metamorphosed elements in the

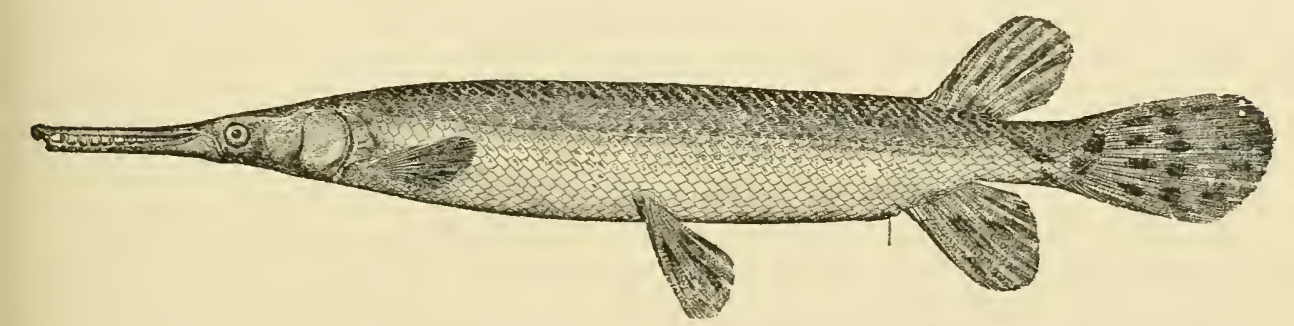

Fig. 157. - The short-nosed gar-pike, Lepidosteus platystomus, Raf. $\times \frac{1}{8}$. Mississippi basin. (After Goode in U. S. F. C.)

most proximal region of the fin. The transitional stages - if they exist - between the lobate and the monoserial fins have not as yet been demonstrated.

\section{Fossil Forms}

From the middle of the Palæozoic period to the end of the Mesozoic there seems to have been a culminating time of forms like the still existing Gar-pike (Fig. I 57); their fossils are generally the most numerous, and, on account partly of their strong body armouring of interlocking rhombic plates, the most perfectly preserved of fossil fishes. They usually exhibit the structural characters 
which Lepidosteus has retained, while diverging widely on all sides in matters of shape, size, special dentition, and

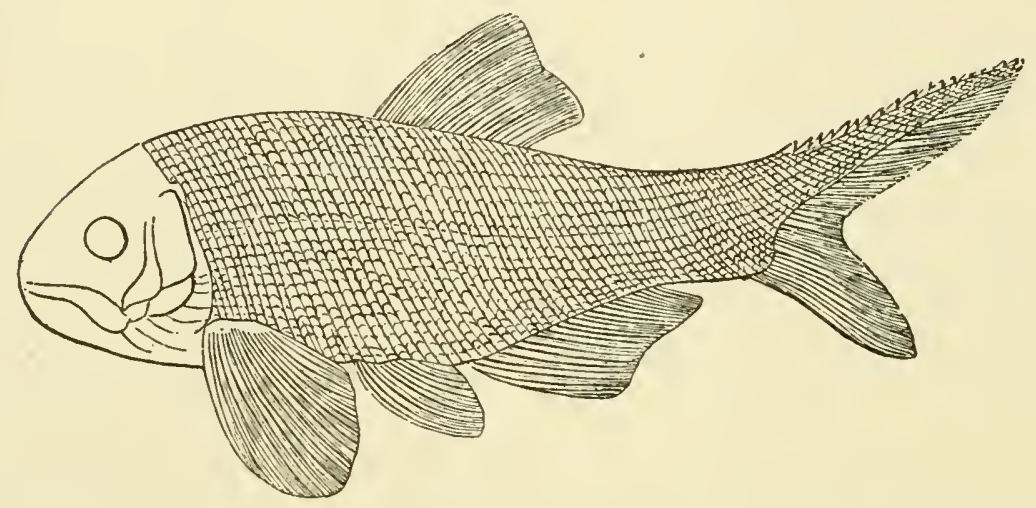

Fig. 158.-Elonichthys (Rhabdolepis) macropterus (Giebel), Bronn. $\times \frac{1}{3}$. (After L. Agassiz.) Lower Permian, Rhenish Prussia.

features of the body.armouring, - characters, apparently, of minor morphological importance. But a few of the characteristic types of the early Ganoids can be noted in the present connection. Some of the more important have been figured in Figs. I $58-164$.

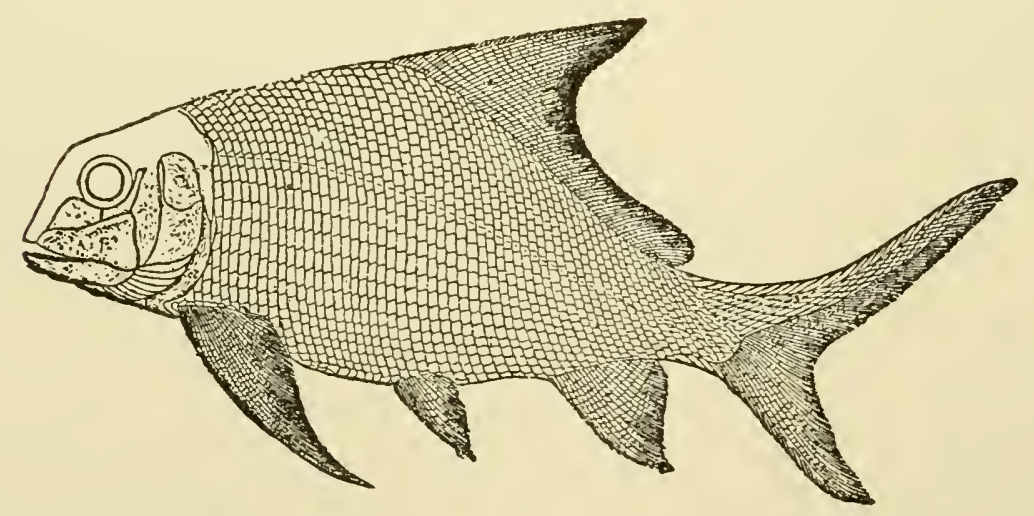

Fig. 159. - Eurynotus crenatus, Agassiz. $\times \frac{1}{3} . \quad$ (After TraquaIr.) Calciferous Limestone, Scotland.

Thus Elonichthys (Fig. I58) was a form which had evolved a small size and narrow sculptured body plates; 
Eurynotus (Fig. I 59) had attained a great depth of body and prominent dorsal fin; Cheirodus (Fig. I60) was distinctly flattened; Semionotus (Fig. I6I) was small, with

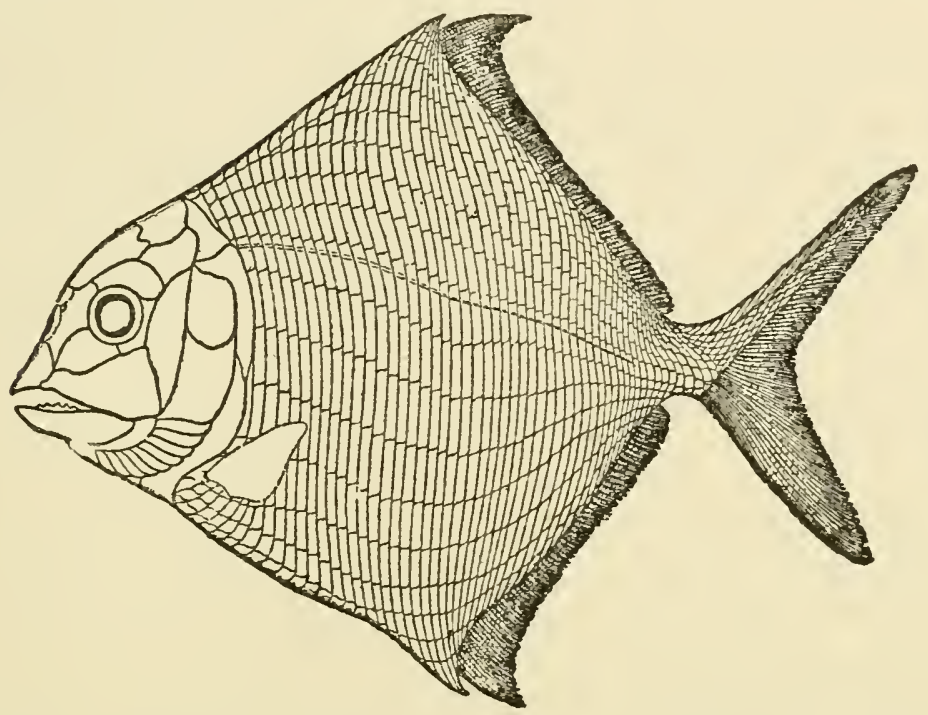

Fig. I60. - Cheirodus granulosus, Young. $\times \frac{1}{2}$. Coal Measures, Scotland. (After TRAQUAIR.)

elaborate fin conditions; Aspidorhynchus (Fig. I62) had a remarkable pointed snout and a reduced number of body

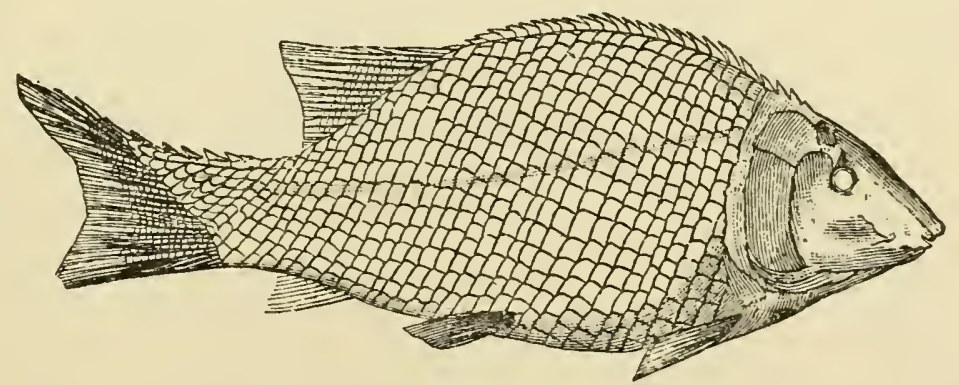

Fig. I6I. - Semionotus kapff, Fraas. $\times \frac{2}{3}$. (From ZirTeL, after FrAAs.) Keuper, Stuttgart.

plates; Microdon (Fig. I63), flattened like Cheirodus, had evolved an admirable series of crushing teeth (-Pycnodont).

And, finally, is to be mentioned Palaoniscus (Fig. I64), a form whose abundance, numerous species, and long sur- 
vival (Palæozoic-Mesozoic) have made it the most widely known of fossil fishes. Of all extinct Ganoids there

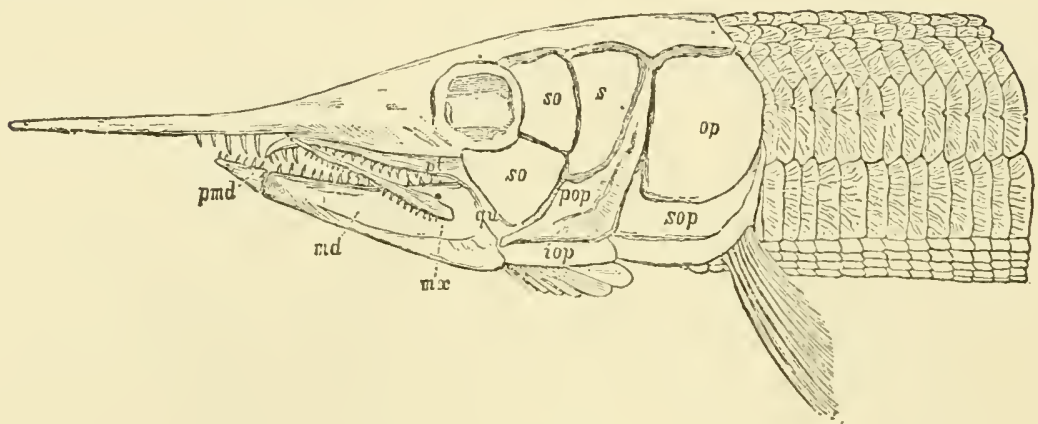

Fig. I62. - Aspidorhynchus acutirostris, Agassiz. $\times \frac{2}{3}$. (After ZITTEL.) Jura, Solenhofen.

appears to attach to Palæoniscus the greatest morphological interest; on the one hand, it seems closely akin to the

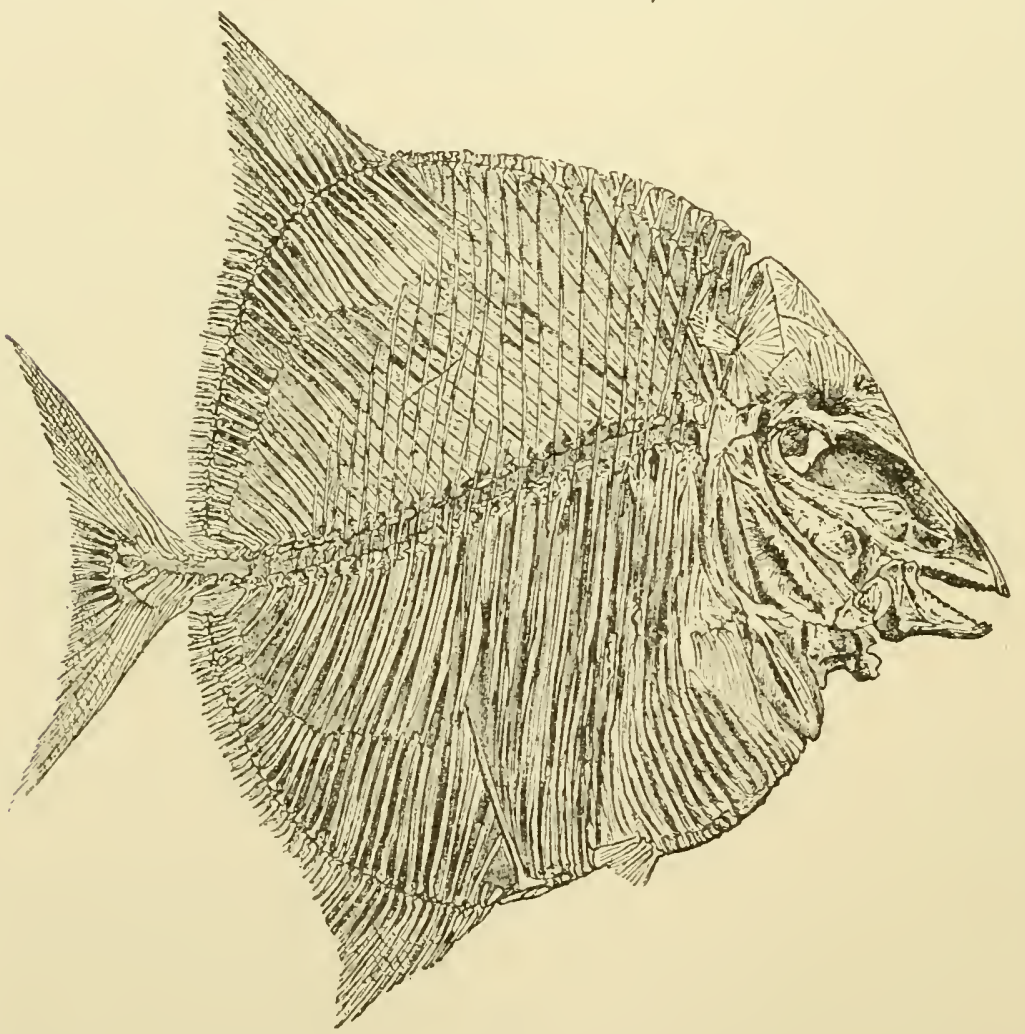

Fig. 163. - Microdon wagneri, Thiolliere. $\times \frac{1}{3}$. (From ZITTEL, after THIOL LIERE.) Jura, Cerin. 
recent gars, and, on the other, even as evidently to the sturgeons; of all fossil kindred of these living forms, it seems most nearly in the ancestral line.

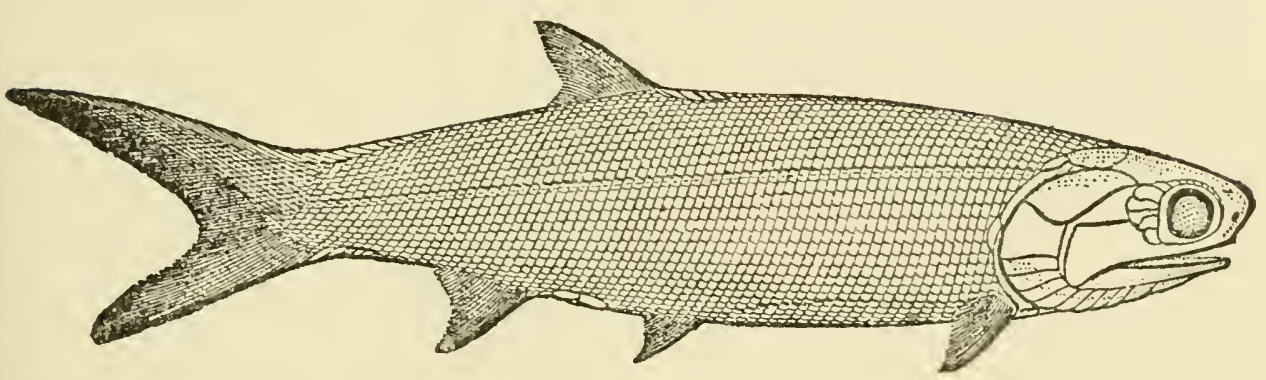

Fig. I64. - Palaoniscus macropomus, Agassiz. $\times \frac{3}{3}$. (After restoration of Traquair.) Upper Permian.

Ganoids certainly outrank the Crossopterygians in the number and variety of their ancient forms. Their few living representatives give but little idea of the importance of the group, and can suggest but faintly the lines of its evolution.

\section{Living Types}

The recent Ganoids include the Gar-pike, the Sturgeons, and Amia. The first is of especial interest in connecting the group most closely with the Crossopterygians, the last as best illustrating the intermediate stage between the Ganoids and Teleosts.

The Gar-pike, Lepidosteus (Fig. I 57), resembles Polypterus in many characters of skeleton and dermal defences. It is a form not uncommon in the fresh waters of North America, and is especially abundant in the Mississippi, Great Lakes, and rivers of the Southern States. In South Carolina the writer has known the gar-pikes to occur in such numbers that they would fill the shad nets, and for many days render this fishery impracticable. They sometimes attain a length of six feet, and are said to become 
as aggressive as sharks. They are remarkably tenacious of life, and their complete armouring of dermal plates renders them practically invulnerable.

In development Lepidosteus has apparently more primitive features than Acipenser (v., p. 207; also Jour. of Morph. XI, No. I).

Of all recent Ganoids, Lepidosteus must certainly be looked upon as retaining most perfectly the structural characters of the most abundant and probably the most generalized Palæozoic and Mesozoic forms. Its genus, it is true, is not known to occur earlier than the Eocene, but its structures - scales, fins, labyrinthine teeth and partially calcified skeleton - are known to have been possessed,

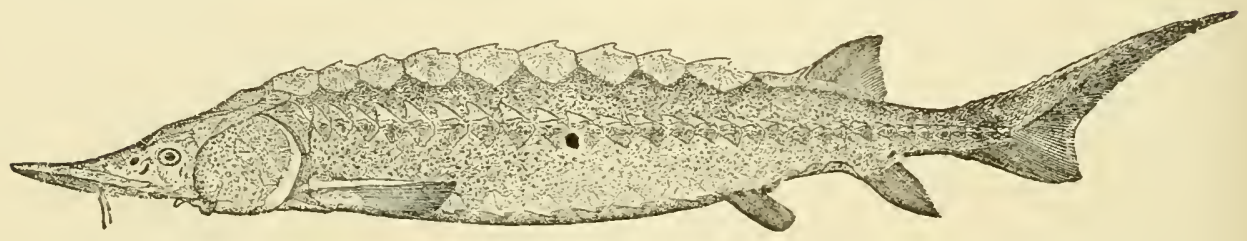

Fig. I65. - The sturgeon, Acipenser sturio, L. $\times \frac{1}{27}$. Streams entering North Atlantic. (After Goone in U. S. F. C.)

even in their details, by a number of the older genera and families.

The Sturgeons, Acipenser, Scaphirhynchus, Pseplumrus, Polyodon, must in many ways be looked upon as of a highly adaptive or even retrogressive character. There is strong evidence that in their descent a large proportion, and, in cases, all of their dermal armouring has been lost, and that their cusp-like ancestral teeth have either disappeared or are retained in a rudimentary condition.

The interrelationships of the four surviving forms of sturgeons have not as yet been definitely suggested ; transitional fossil forms have thus far been lacking, and the relative importance of the different structures in the recent 
genera cannot, therefore, be determined for purpose of comparison.

The genus of the common sturgeon, Acipenser, is the most completely studied of the recent forms. It includes twenty or more "species," varying in length from one (A. brevirostris, of the Eastern United States) to ten yards ( $A$. huso, of Russia), and is altogether one of the most valuable food-fishes of the rivers, lakes, and coasts of the northern hemisphere. It is a sluggish, bottom-feeding fish, common in muddy streams. Its broad and pointed snout, sensory barbels, and greatly protractile jaws are the most striking differences from the Palæoniscoid; its dermal

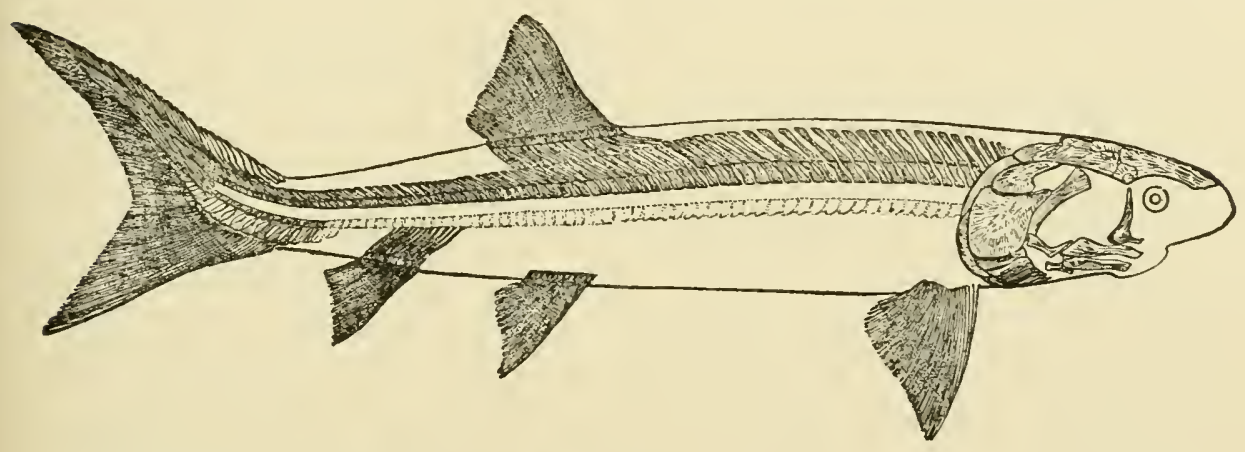

Fig. 165 A. - Chondrostens acipenseroides, $\times \frac{1}{6}$. From Lias of Lyme Regis. (Restoration of skeleton after SMITI IVOODWAKD.)

armouring has become recluced to the five longitudinal bands of body plates, * but is more perfect in the tail region; its skeleton retains an entirely cartilaginous condition. In its larval stage conical teeth are known to be present, and the entire series of dermal plates are much larger in relative size.

A figure of Chondrosteus, a Liassic sturgeon, may here

* It is interesting to note that in Palæoniscoids there is sometimes a noticeable tendency for the five rows of plates, dorsal, and the paired lateral and ventral, to increase in size, suggesting the first steps in the origin of the derm plates of Acipenser. 
parenthetically (Fig. $165 \mathrm{~A}$ ) be inserted; it is of especial interest as suggesting an approximation of the type of the modern sturgeon to that of the Palæoniscoid; its snout is shorter than in Acipenser; its jaws larger, and apparently less protrusible; its dermal plates of the head region, including the branchiostegals, are clearly of the ancient pattern, and the fins, fin supports, and vertebral characters,

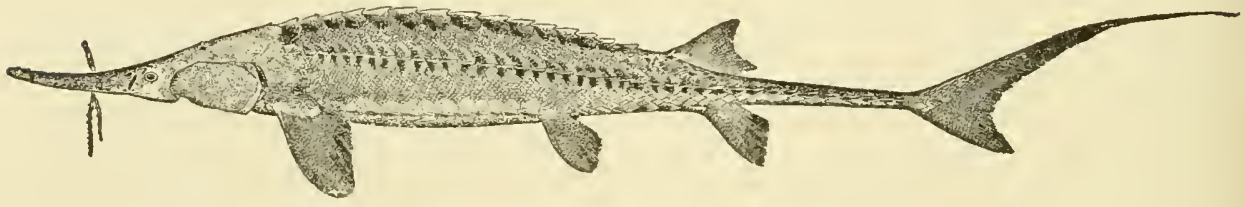

Fig. 166. - The shovel-nose sturgeon, Scaphirhynchus platyrhynchus (Raf.), Gill. $\times \frac{1}{8}$. Mississippi basin. (After Goone in U. S. F. C.)

together with the general small size of the fish, suggest intermediate conditions.

Of the remaining sturgeons, the shovel-nose, Scaphirlynchus (Fig. I66), of the Mississippi and of Central Asia, seems to possess the closest relations to Acipenser; although it is apparently a more modified form, on account of its elongate body shape and flattened snout, it still retains many interesting and archaic features. Among

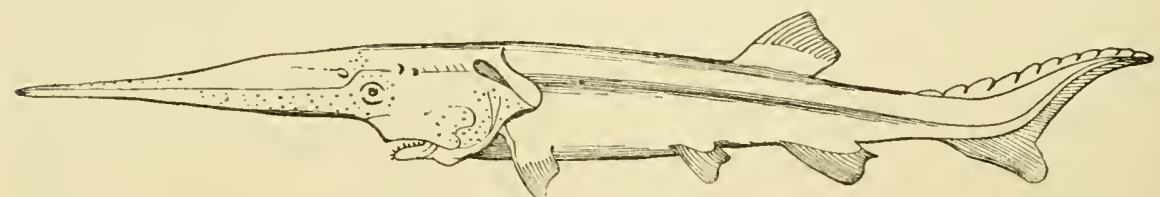

Fig. 166 A. - Psephurus gladius, Gün. $\times \frac{1}{3}$. Rivers of China. (After GüNTHER.)

these it includes the most complete dermal armouring of recent forms, its hinder body region being entirely encased.

Pseplumus (Fig. I66 A), of the Chinese rivers, and Poly. odon, or Spatularia (Fig. I65 B), of the Mississippi, are the other forms of living sturgeons. Their greatly elongate snouts, giving them the popular names of Spoonbills, Paddle-fish, Spear-fish, are among the most remarkable 
sensory appendages of fishes. They have been but little studied, and their relations to Acipenser have never been satisfactorily determined. They have certainly many feat-

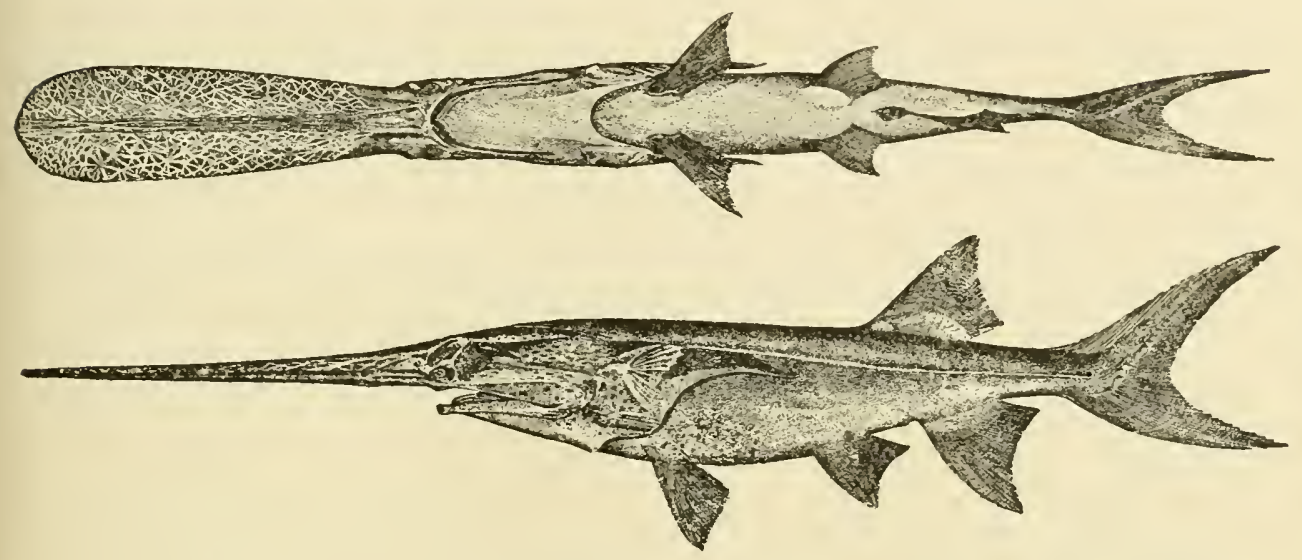

Fig. I66 B. - The spoon-bill sturgeon or paddle-fish, Polyodon spatula (Walb.), J. and G. $\times \frac{1}{3}$. Ventral and side view. Mississippi basin. (After GoodE.)

ures in skeletal parts, fin structures, lateral line organs, jaws, teeth, which can only be looked upon as of primitive character; on the other hand, their highly specialized rostrum, degenerate opercula, and want of dermal amouring would suggest an early divergence from the main stem of the sturgeons. To the writer, Psephurus seems the more generalized of these peculiar forms.

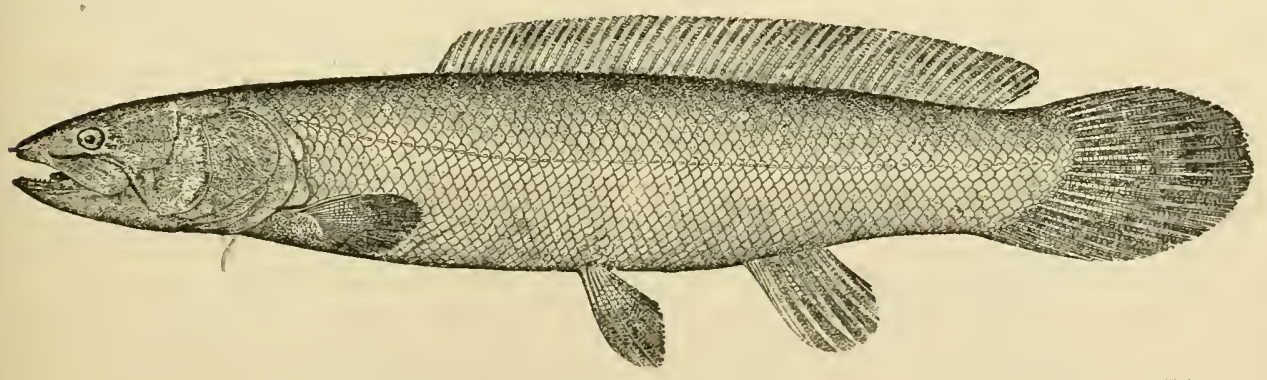

Fig. 167. - The bowfin, Amia calva, I. $\times \frac{1}{4}$ (After Goone in U. S. F. C.) Central and Eastern United States.

Amia calva (Fig. I67) is the last of the recent Ganoids to be noted. Its distribution corresponds closely with that of the gar-pike; it is a common form, worthless as 
a food-fish, but deemed worthy of a host of local names, as: Bowfin, Grindle, Dog-fish, Mud-fish, Sawyer, Joseph Grindle, Lawyer-fish. Its

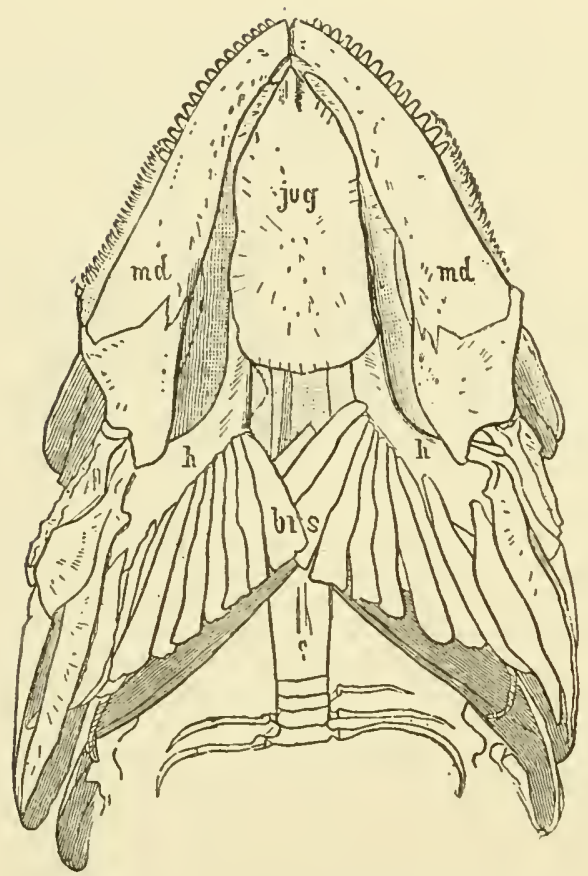

Fig. I68. - Amia. Ventral view of jaw region. $\times I$. (After ZiTTEL).

$b r s$. Branchiostegal rays. $h$. Ceratohyal. jug. Jugular plate. md. Mandible. interest, as already suggested, is in its close kinship to the Teleosts on the one hand, and to the sturgeons and gars on the other. Its cycloidal scales, its fin structure, and calcified skeleton seemed of so modern a character, that it was long included among the members of the herring group; only after a closer examination did its primitive structures become apparent. It is one of the few Ganoids which possess a gular plate (Fig. I68, jug). Like that of Lepidosteus, its air-bladder is cellular, and of respiratory value (Wilder).

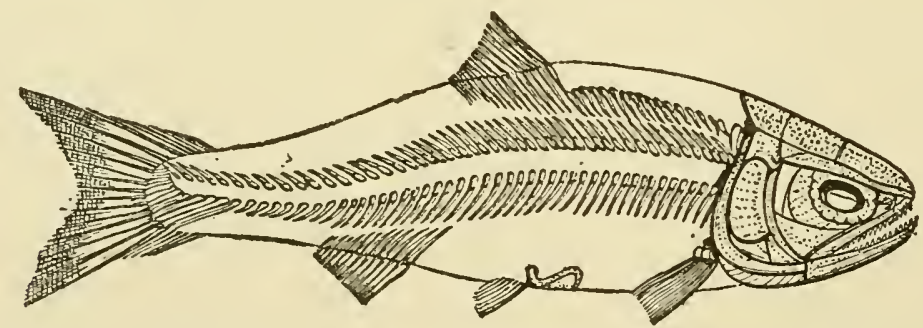

Fig. I69. - Caturus furcatus. $\times \frac{1}{3}$. (From SMITH WOODWARD, after AGASSIZ.) Lithographic stone (Upper White Jura), Solenhofen.

The relations of Amia become of especial interest, in view of the number and range of its fossil kindred. Its 
group is known to have attained its prominence at a later geological time than the other Ganoids; it is doubtless derived, more or less directly, from the main ganoidean stem. Three of the more typical Mesozoic forms are shown in Figs. I69, I70, I7I, in Caturus, Leptolepis, and

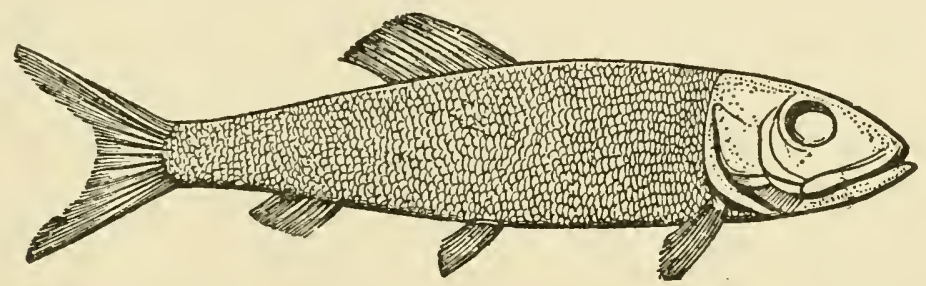

Fig. I70. - Leptolepis sprattiformis. $\times \frac{2}{3}$. (From SMITH WOODWARD.) Lithographic stone, Solenhofen.

Megalums. To these amioid forms the ancestry of the (majority of the) Teleosts is reasonably to be traced.

A general scheme of the phylogeny of the Teleostomes is suggested on the adjoining page (Fig. I7 I $A$ ).

B. Teleocephali (Teleosts.) This group, popularly known as that of the bony fishes, or Teleosts, includes as great a proportion perhaps as 95 per cent of the kinds of fishes

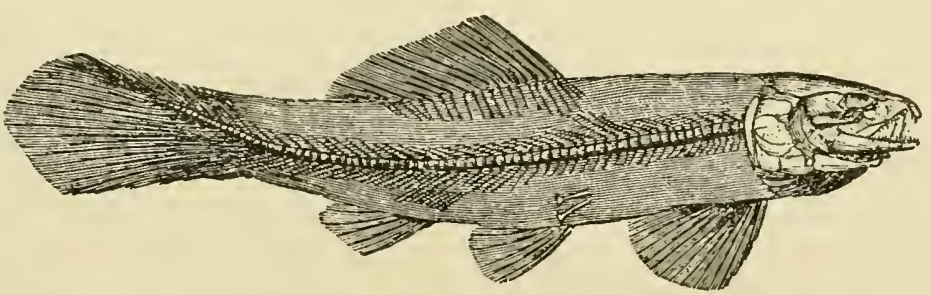

Fig. I7I. - Megalurus elegantissimus, Wagner. $\times \frac{2}{3}$. (After ZITTEL.) Jura, Solenhofen.

living at the present time. The immense number of their genera and species is doubtless suggestive of the form changes which occurred during the flowering periods of the sharks, chimæroids, or lung-fishes.

Teleosts have diverged most widely of all fishes from 
what seem to have been their primitive structural conditions. Their skeleton has become highly calcified, its elements multiplying, fusing, and specializing. The notochord has practically disappeared, owing to the complete formation of bony vertebræ. The derm bones of the head, which in

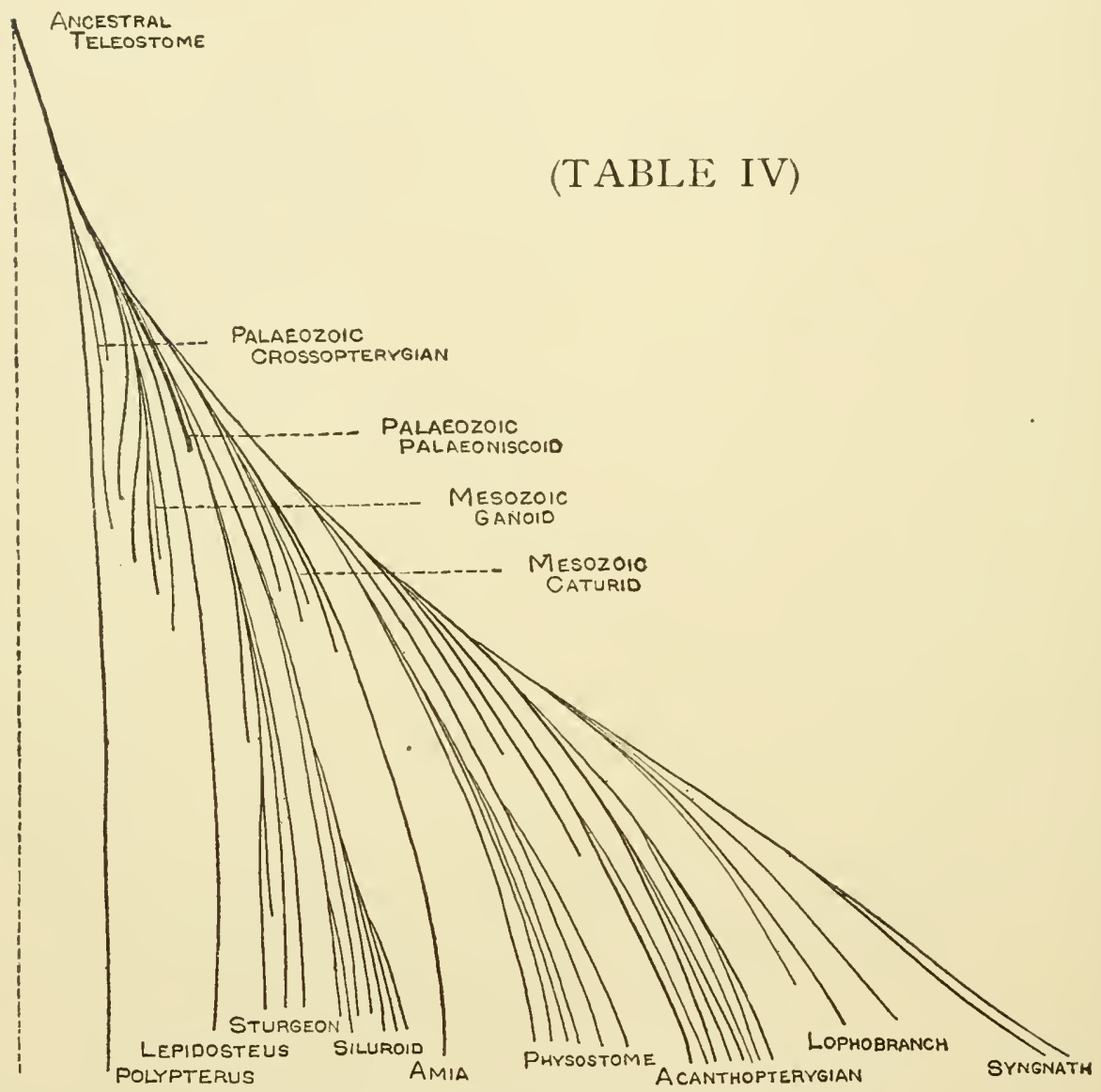

Fig. I7I A. - The Phylogeny of the Teleostomes.

the ancestral Ganoid were at the surface, enamel-coated,* are now deep-seated in the head, resembling true cartilage bones ; their surfaces are usually deeply furrowed or ridged,

* The enamel of Ganoid plates (ganoine) appears to be derived from the underlying bony tissue, not deposited by the overlying epidermis (enamel organ). 
and their character is often squamous. Scales are widely specialized, thin, horn-like, ornate, overlapping their outer margins, their inner rims set deeply but loosely in dermal pockets (Fig. 3I). Fins are dermal structures, their ancient basal supports hardly to be distinguished; the primitive tail structure is so masked by clustered and fused skeletal elements that its heterocercy is scarcely apparent. In short, the most widely modified conditions can be shown to exist in Teleosts in almost every structural character, as in gills, teeth, opercula, circulatory and urinogenital organs, sensory structures, and nervous system. They have evidently been competing keenly in the struggle for survival, for in every detail of form or structure the most varied conditions exist. In addition to these structural adaptations of Teleosts, changes in coloration have been rendered possible by the transparency of their scales; and in their different families these changes have taken place often with striking results: adaptive coloration, brilliant, dull, mottled, inconspicuous, occurs with a range of variation which is not surpassed even by the colours of birds.

It is not remarkable, therefore, that members of the different groups of Teleosts should often parallel each other in structural likenesses, when placed under the same environmental conditions. Each organ, in fact, may become a centre of variation, and confuse the line of the descent of the minor groups; for the keenest judgment cannot select of all these varying structures those which can definitely be made the standards of general comparison. Environment, like a mould, has impressed itself upon forms genetically remote, and in the end has placed them side by side, apparently closely akin, similar in form and structure.

A striking instance of changes due to environment is 
well known in the case of Deep-sea Fishes, in their acquiring a characteristic shape under the conditions of abyssal life. The head region of these forms becomes greatly exaggerated in size, and the trunk tapers suddenly away toward the tip of the pointed tail. The tissues become extremely modified, soft, porous, delicate, often transparent; skeletal parts are deficient in lime, and loosely articulated. Many organs are retained in curiously undeveloped or aborted conditions; the vertebral axis is noto-
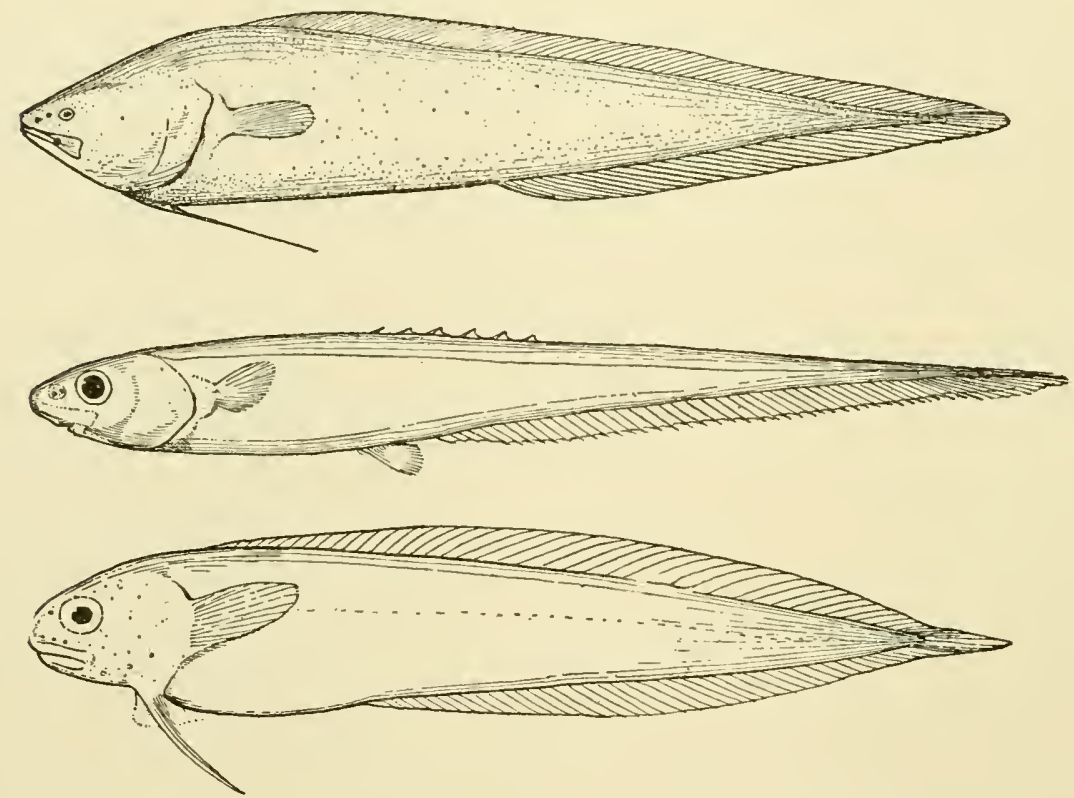

Figs. I72-I74. - Deep-sea fishes. (After Günther.) I72. Paraliparis bathybius. 640 fathoms. 173. Bathyonus compressus. I400 fathoms. 174. Notacanthus sexspinis. 1800 fathoms.

chordal ; gill arches, as many as six (?) in number, may open freely to the surface, never enclosed by opercula; sensory canals remain as open grooves as in the most generalized fishes; paired fins are retained either in an undeveloped condition or are not produced at all. Absence of light has been not without its effects ; body colours are usually dark and meaningless; while, on the other hand, when eyes still 
occur, a widely modified series of integumentary phosphorescent organs are often evolved as lures by predatory forms. It is evident, in the case of deep-sea fishes, that the simple condition of their structures does not separate them widely in point of descent from more specially evolved Teleosts. Intermediate forms, occurring in shallower water, often connect them clearly with different, and widely distinct, groups of bony fishes. In this way the

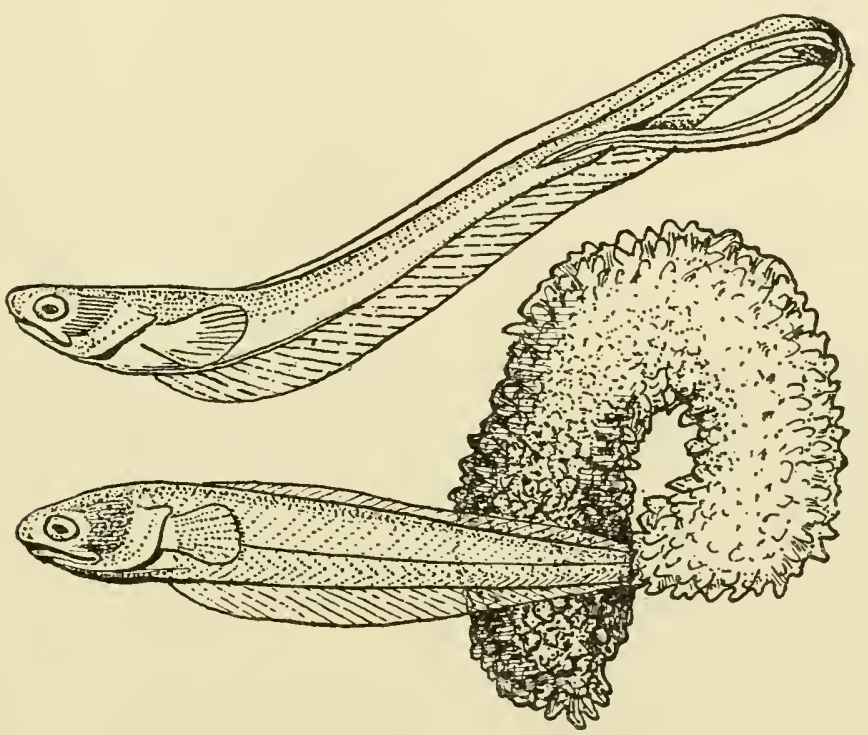

Fig. 175. - Fierasfer acus, Kaup. $\times \frac{2}{3}$. (After EMERY.) Commensal of seacucumber in southern waters.

forms which are shown in Figs. 172, I73, I74 are severally connected with the cottid, the cod and the salmon, although the striking similarity of their outward structures would naturally lead one to regard them as far more intimately related.

Another interesting instance of the modification of a fish's form by its living conditions has often been noted in the case of Fierasfer (Fig. I75). This small Teleost lives as a commensal in the branchial chamber of the sea-cucum- 
ber, and from its peculiar life habit retains permanently a number of its embryonic characters; it has thus its elongated larval form, a functional pronephros, a notochordal skeleton and immature fin conditions (Emery, Ref. p. 249).

To what clegree the structures of fishes may be varied by artificial selection is an interesting question, but one that has as yet received little attention even from those who have made artificialization an especial study. In the instance of the Goldfish it is well known how wide a

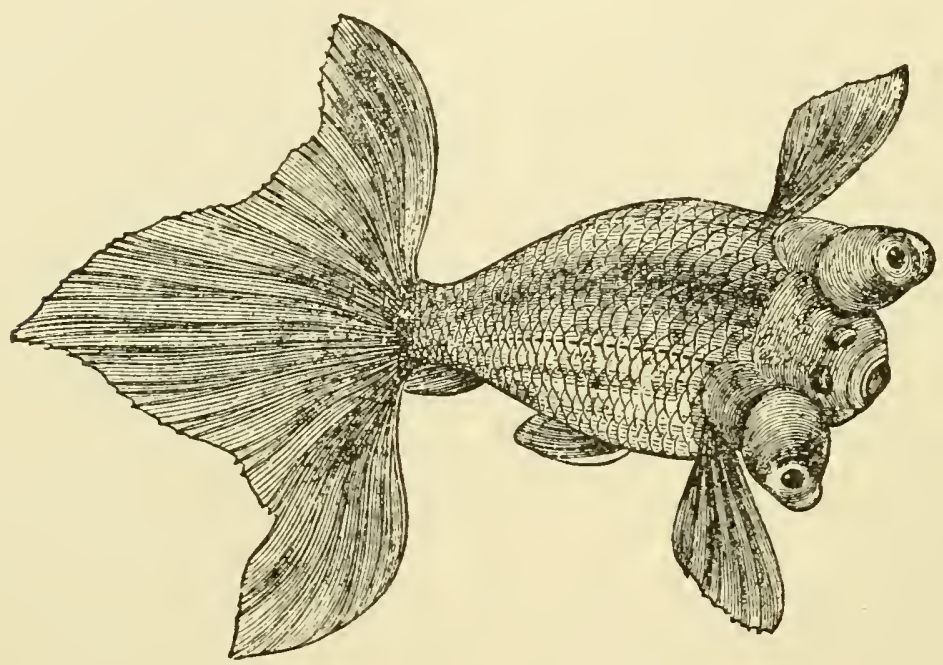

Fig. I76. - Goldfish, Carassius auratus ("Telescope" variety). $\times$ I. (After GüNTHER.) Japan.

variation has been produced in colour, size, and proportions. Fin structures are elaborately developed, long, drooping, lace-like, often to a degree which must render progression both slow and difficult. Even the eyes have been made to become large and protruding (Telescope-fish, Fig. I76). In carp the variation in scale character, due to artificialization, is also to be mentioned. It is natural, perhaps, that artificial selection has been most successfully practised 
among these forms which compete most actively for survival.

To conclude the present chapter, several forms of Teleosts may be briefly discussed as especially characteristic of the group, namely the catfish, Mormyrus, eel, perch, cod, flounder, porcupine-fish, sea-horse.

The catfish, representing the Siluroids, has, as already noted, many structural affinities to the sturgeon, and is, perhaps, a direct descendant of some early type of Mesozoic Palæoniscoid. It is a representative of a large and widespread family, usually of river fishes. Its habits are slug-

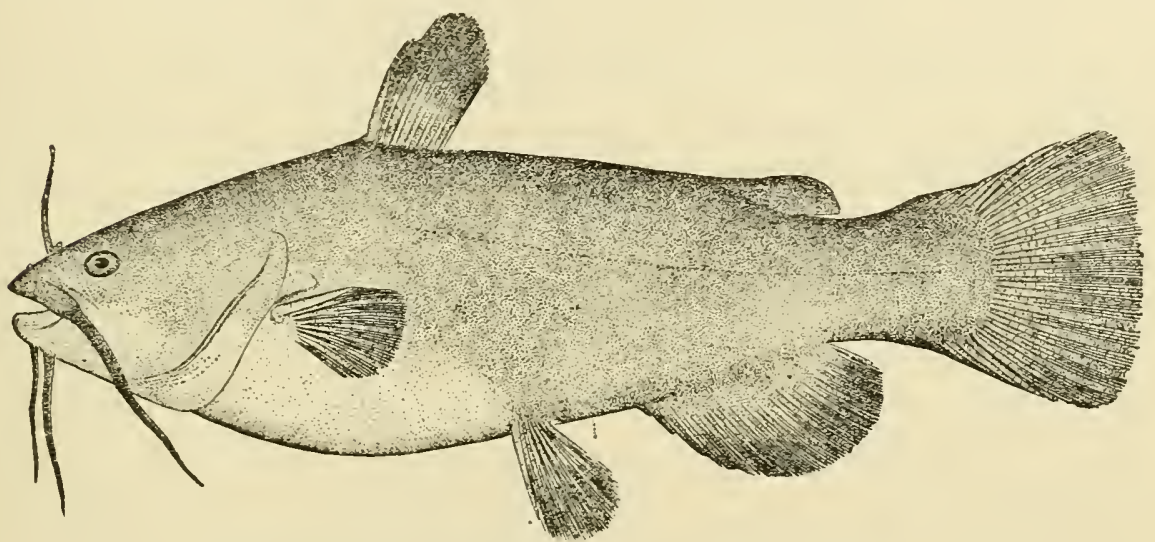

Fig. I77. - The bull-head (catfish), Amiurus melas (Raf.), Jord. and Copeland. $\times \frac{1}{2}$. (After Goode in U. S. F. C.) Eastern North America.

gish and mud-loving. Its trunk is heavy, rounded, and without Teleostean scales; its broad mouth margin is provided with barbels; the fin rays of its dorsal and pectoral fins fuse into a stout, serrate, erectile spine. In North American forms armouring derm plates are developed only on the head roof (Fig. 177). Closely akin to these are the Asiatic genera, and the single European species, Silums glanis, the gigantic Wels of the Danube. The Nile is of interest if only for its forms of catfish to parallel the shapes and structures of the recent Teleosts. 
In South America the catfish is a regnant type, and is remarkable for the variety as well as for the number and size of its forms. Many, completely armoured (Fig. I78), are strongly suggestive of Ganoids. Their armouring is

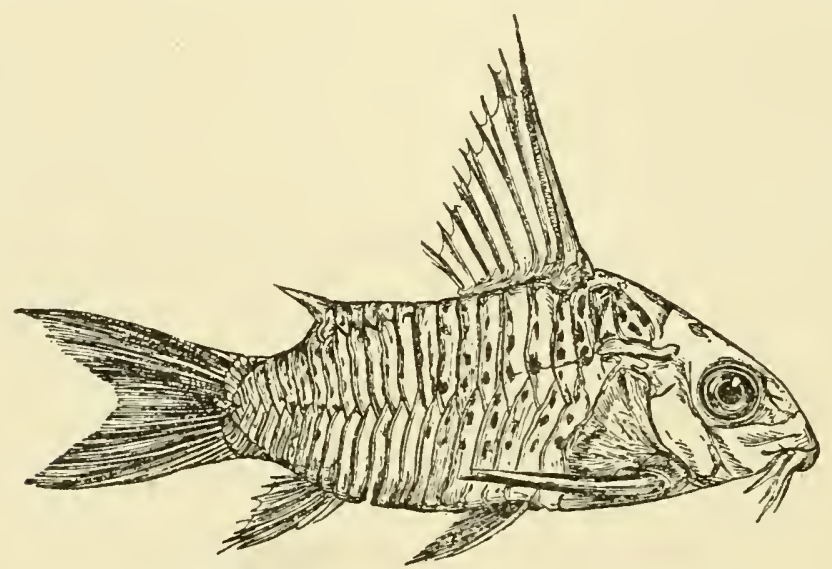

Fig. 178. - South American Siluroid, Callichthy's armatus. $\times$ I. (After GÜNTHER.) Upper Amazon.

metameral and archaic, their sensory canals primitive in structure and arrangement.

Mormyrus, like the catfish, appears to have long been divergent from the main stem of the Teleosts. Its species

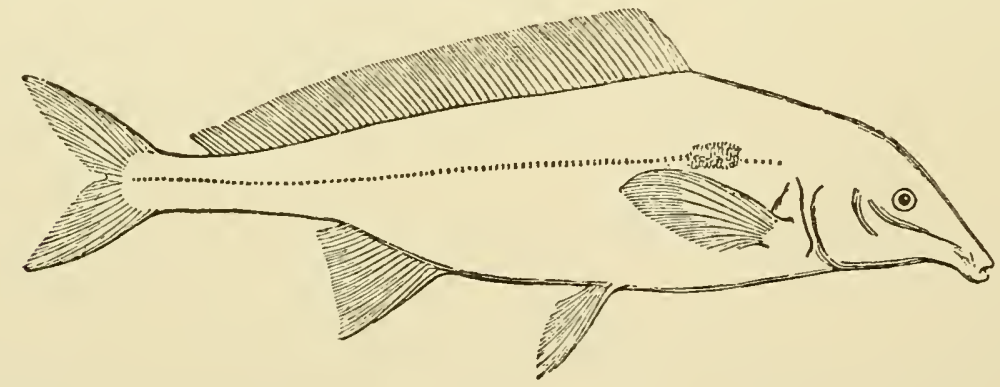

Fig. 179. - Mormyrus oxy'hynchus. $\times \frac{1}{6}$. (After GüNTHFr.) Nile.

are restricted to the Nile, one - the long-nosed M.oxyrhynchus (Fig. 179) - figuring prominently in Egyptian myth. In many of its structures it is archaic, as in axial skeleton, fins, dermal characters, sensory canals; in others, $\epsilon . g$. hear- 
ing organ, it is most highly specialized. Its group is an interesting one, and has been but little studied.

The $E_{e l}$ (Fig. I 80) might well be taken as one of the

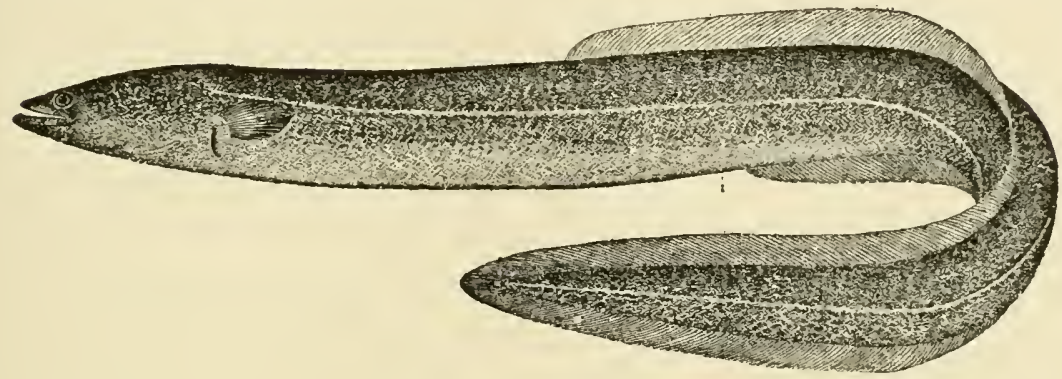

Fig. 180. - The eel, Anguilla vulgaris, Turton. $\times \frac{1}{4}$. (After GoodE in U.S. F. C.) Europe, South Asia, North Africa, North America.

fish forms evolved by special environment. Living in soft river bottoms, a serpent-like movement in progression has gradually been acquired; its form has, therefore, become elongated and rounded, and the internal structures correspondingly modified. Fin structures have accordingly been

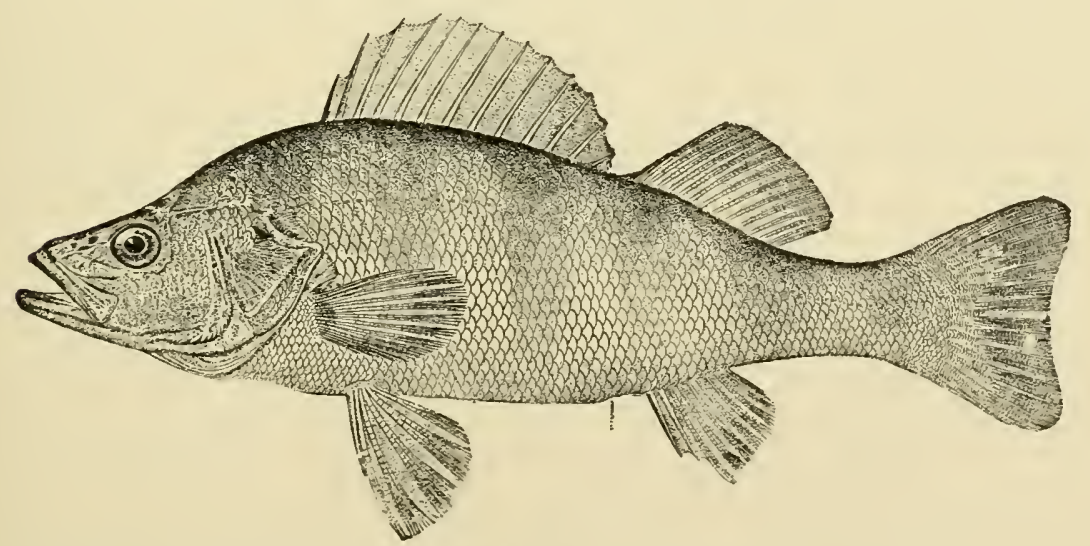

Fig. I8I. - The perch, Perca americana (= fuviatilis?), Schrank. $\times \frac{1}{2}$. (After GOODE in U.S. F. C.)

metamorphosed, ventral fins lost, tail degenerated, and a continuous dorsal and ventral secondarily evolved; scales have become reduced in size, supplanted by mucous layers. 
Similarity in eel-like form, e.g. as of Murena, is not in itself indicative of direct kinship. (Apodes.)

The Perch (Fig. I8I) has long been taken as a representative Teleost. Perfect in its "lines," its compact, wedge-like shape cleaves the water by vigorous thrusts of a strong broad caudal; its fins are stout, supported by spinous rays; its dermal armouring light, smooth, and flexible; its colour is brilliant under its transparent scales. So adapted is it to its environment that its organ of static equilibrium, the air-bladder, has lost its valvular connection with the gullet. Of existing fishes about one-half are essentially percoid. (Acanthopterygii.)

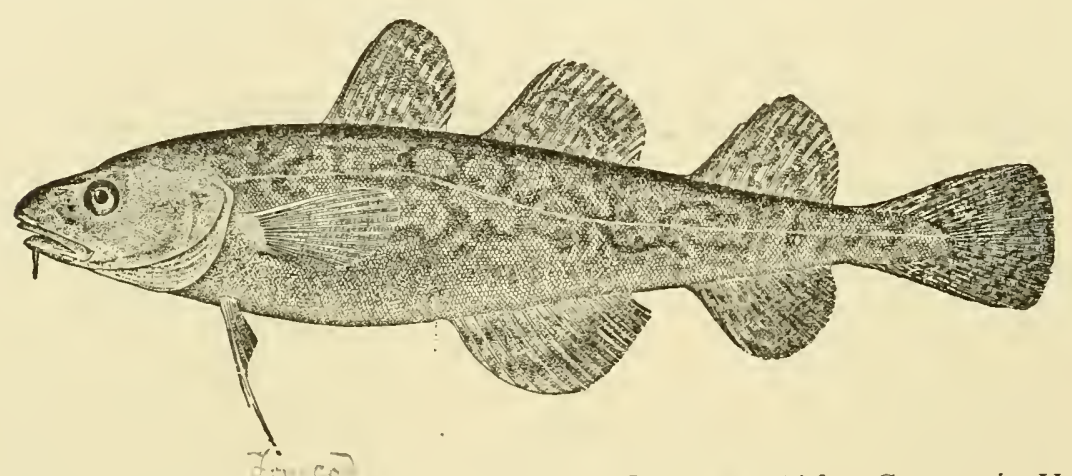

Fig. 182. - The codfish, Gadus morrhua, L. $\times \frac{1}{6}$. (After GoodE in U. S. F. C.) North Atlantic.

The Cod (Fig. I 82) is scarcely less important as a representative Teleost. Its structural differences may perhaps represent the result of a competition less active than that of the perch in the struggle for survival. Heavy in body, its sluggish form has become blunted and rounded; its fins are depressed, their rays soft and yielding; its scales are reduced in size, colours less vivid; its swim-bladder loses its connection with the gullet. As many, perhaps, as one quarter of the existing genera of fishes may be assigned to this type. (Anacanthini.)

The Flounder (Fig. I 83) should be mentioned as a singu- 
lar instance of environmental evolution, its flattened body adapting itself both in shape and colour to its bottom living. Its entire side, - not the ventral region, as in the rays, - is flattened to the bottom. The unpaired fins now become of especial value; they increase in size, and their undulatory movements enable the fish to swim rapidly yet retain its one-sided position; ventral fins become useless, and degenerate. The further adaptations of the flat fish include its pigmentation only on the upper or light-exposed side, and the rotation of the eye from the blind to the upper

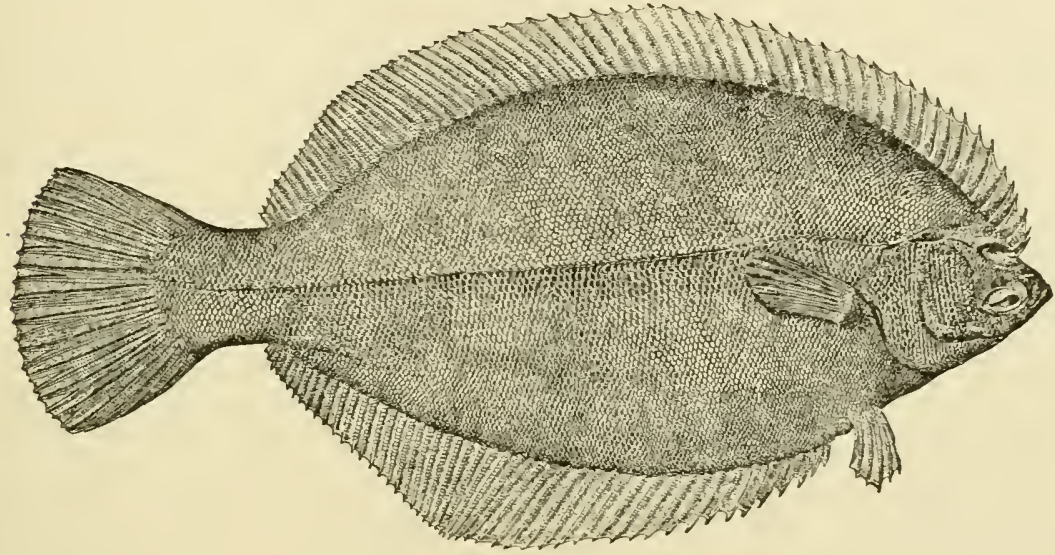

Fig. 183. - The winter flounder, Pseudopleuronectes americanus (Walb.), Gill. $\times \frac{1}{3}$. (After Goode in U. S. F. C.) North Atlantic.

side, - in this giving one of the most remarkable cases of adaptation known among vertebrates. (Heterosomata.)

The Porcupinc-fish (Fig. I 84) may be referred to as another singular result of environmental evolution. Its globular and inflatable form bespeaks slowness of motion and helplessness if exposed to changes of temperature or current. Its fins are reduced and feeble, suited, however, to its tranquil habitat; its fused jaws, parrot-like, show in how special a way its food is best secured. It has evolved a protective casing of enormous needle-like scales, whose shape parallels that of the derm denticles 
of the shark. As a somewhat transition form to the more usual conditions of the Teleost, the Rabbit-fish has been figured (Fig. I $S_{4} A$ ). (Plectognathi.)

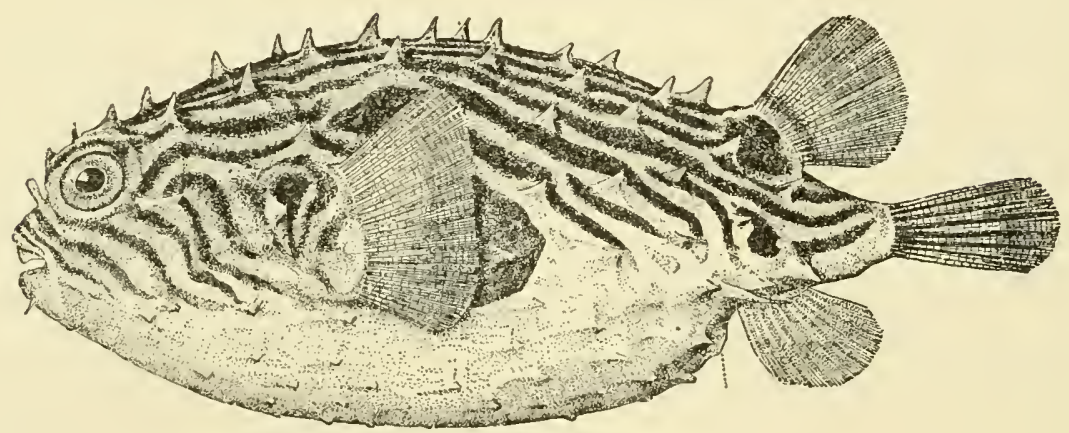

Fig. I84. - The porcupine-fish, ('hilomycterus geometricus (Schn.), Kaup. $\times \frac{2}{3}$. (After GoodE in U. S. F. C. report.) Warmer Atlantic.

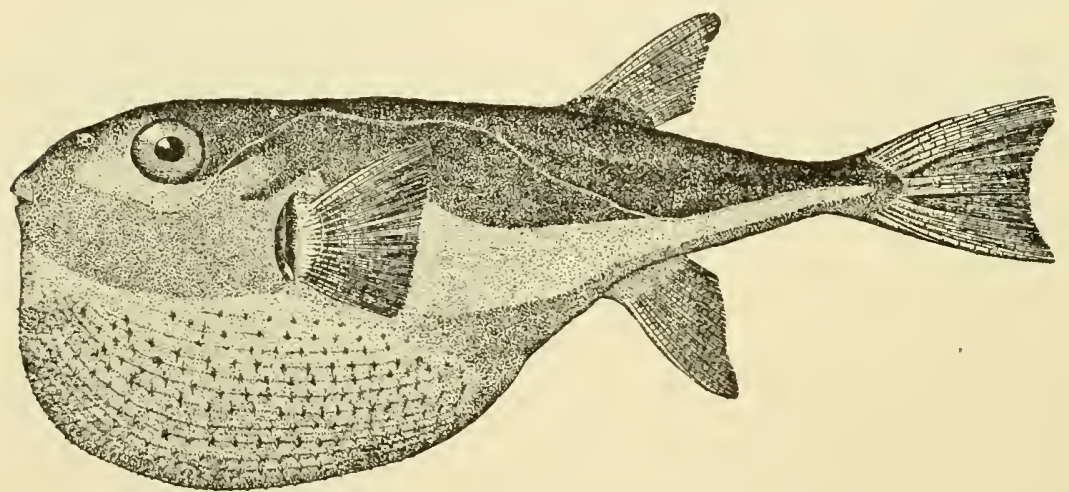

Fig. I84 A. - The rabbit-fish, Lagocephalus lavigatus (L.), Gill. $\times \frac{1}{2} . \quad$ (After Goode in U. S. F. C.) Northeast Atlantic.

A final, perhaps the most bizarre, instance of adaptation among Teleosts is that of the Sea-horse (Fig. I 85). In spite of its many structural oddities, its genetic kinship with the Sticklebacks (Hemibranchiates) cannot be doubted. Yet to have attained its present form its evolution must have been carried along a widely divergent path. It may, in the first place, have fused the lines of its metameral scales, dividing off the surface of its elongate body 
in sharp-edged rectangles, whose corners became produced as spines. At this stage of evolution its appearance might well be represented by (Fig. I $\&_{5} A$ ) the kindred Pipe-fish. To secure more perfect anchorage in its algous feedingground, its body terminal must now have discarded its fin membranes and become prchensile, - probably the most remarkable adaptation in the entire class of fishes, since it causes metameral organs to change the plane in which they function from a horizontal to a vertical one. As a probable development of prehensilism, three changes may nex $\imath$ have been wrought : the flexure of the neck region, the thickening of the trunk, and the metamorphosis of the fins. The first change may have been brought about by the normal position of the fish's axis becoming, as is well known, vertical; the head then assumes its normal horizontal plane and thus parallels mildly the cranial flexure of higher animals. The enlargement of the trunk region is evidently of static value. The alteration of the po-

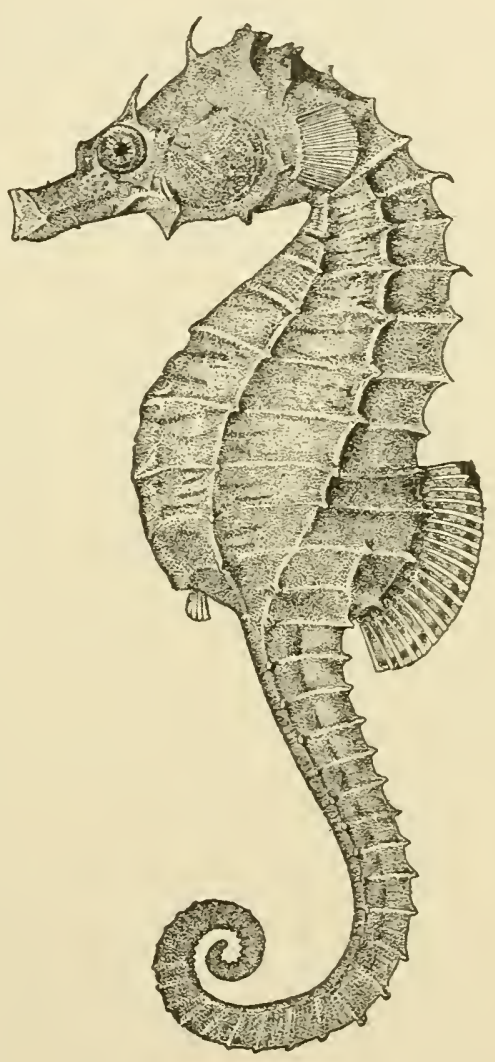

Fig. 185. - The sea-horse, Hippocampus heptagonus, Raf. $\times \frac{1}{2}$. (After Goone in U. S. F. C.) East coast of North America. sition, size, and degree of movement of the pectoral fins, the loss of the ventrals and the changed function, now one of propulsion, of the dorsal, appear clearly the result of the altered plane of the fish's motion. Further structural changes might with interest 
be followed, as in characters of viscera, gills, and endoskeleton. In its life habits mimicry is strongly evinced;

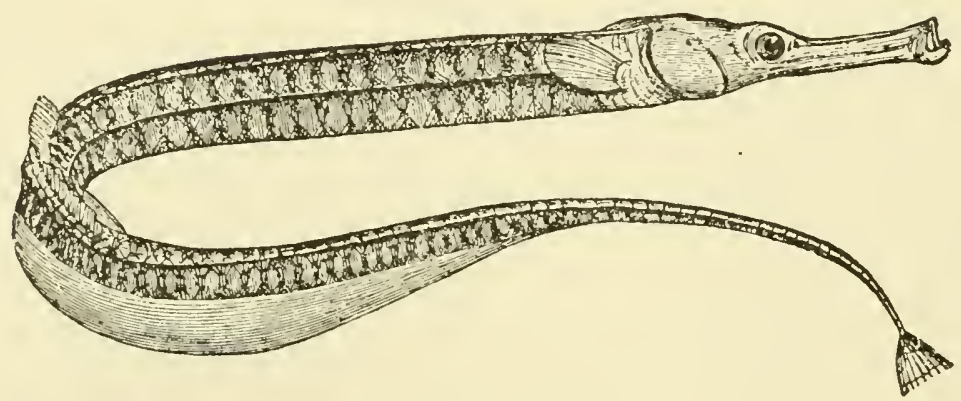

Fig. 185 A. - The pipe-fish, Syngnathus acus ơ, L., showing abdominal pouch. $X$ I. (After Günther.) Coasts of Europe and Africa.

the well-known genus Phyllopteryx; whose entire body surface develops pigmented appendages, is with difficulty to be distinguished from a rough-shaped seaweed. (Lophobranchii.) 


\section{VIII}

\section{THE DEVELOPMENT OF FISHES}

THE groups of fishes have hitherto been contrasted in the structures of their living and fossil forms. They should next be reviewed in the light of their mode of development; for the developmental stages of the Shark, Lung-fish, or Teleostome might be expected, according to time-honoured belief, to furnish important evidence as to their descent and interrelationships. The younger stages of the various forms of fishes should thus suggest their ancestral characters: the developing Teleost should approach the Ganoid; the Lung-fish and the Ganoid should resemble their supposed elasmobranchian ancestor.

But the embryology of fishes is in this regard very inconclusive, if at present in any important way suggestive. The majority of the forms, including some of the most important, are developmentally unknown; yet sufficient is known of the representative members of the groups to show the most perplexing characters. On the one hand, the developmental processes of forms which are regarded by the morphologist as closely akin seem often widely distinct; and, on the other hand, the fishes which should, a priori, exhibit an archaic mode of development actually present complex processes of early growth which can only be interpreted as highly specialized. In fact, there are far greater differences in the developmental plans 
of the closely related Ganoid and Teleost, than in those of a Reptile and a Bird; and even among the members of the single group, Teleosts, there are more striking embryological differences than those between Reptiles and Mammals. Adaptive characters have entered so largely into the plan of the development of fishes that they obscure many of the features which might otherwise be made of value for comparison. And until the controversies regarding some of the most fundamental principles in embryology - e.g. the importance of the loss or gain of food yolk - shall be decided, it seems impracticable to use the plan of development as in any strict sense a guide in phylogeny.

It is, accordingly, rather with the view of contrasting the groups of fishes, whose external features have hitherto been compared, that the present chapter seems of especial importance. They may briefly be reviewed in their (A) spawning habits, (B) the mode of fertilization of their eggs, (C) their embryonic, and (D) larval development.

\section{A. EGGS AND BREEDING HABITS}

The eggs of typical fishes in Figs. I86-I99, illustrate how wide a range occurs in their shapes and sizes. All are of about actual size, except Figs. I89-I9I, which have been reduced about two-thirds. From the figures the character of the egg membranes may also be contrasted.

Among Cyclostomes, which are usually looked upon as of close genetic kinship, there appears a striking difference in the characters of the eggs. Those of Bdellostoma and Myxine (Figs. i86, i 87) are large and bluntly spindle-shaped, encased in a horn-like capsule; those, on the other hand, of Petromyzon are minute, spherical, and enclosed in delicate and jelly-like membranes (Fig. I88). 
The eggs of Myxinoids are probably deposited at a single time; at first extruded by pressure of the body wall; then drawn out string-like, one egg following another, attached by hooked and thread-like processes (Figs. I $86 A$, I $87 A$ ). Little is known, however, of the actual breeding habits of Myxinoids, either as to locality, mode, or season; individuals of Myxine and Bdellostoma with ripe spawn have never been taken even in the most favourable regions. It is supposed that their spawning does not occur in the immediate neighbourhood of the shore, since detached eggs have been lredged in the deeper water. Their breeding time is probably in the early spring, although possibly intermittent spawning takes place. In Myxine, according to Putnam,* the bulk of the eggs may be deposited as late as the beginning of winter.

The spawning habits of Petromyzon, on the other hand, have been especially favourable for observation. The eggs are deposited in shallow and clear water and the movements of the fish may readily be followed. In the small stream at Princeton, $\dagger$ for example, the lampreys make their appearance about the middle of May and remain on the spawning grounds two or three weeks. Their "nests" are seen scattered thickly on the gravelly shoals, often but a few feet apart. Each will be occupied by several males and a single female, the latter conspicuous on account of greater size. When spawning, the lampreys press together and cause a flurry in the water at the moment when the eggs and milt are emitted. This portion of eggs will now

* As observed at Grand Menan. Pro. Bost. Soc. Nat. Hist. Feb. '74.

† Professor McClure and Dr. O. S. Strong have here repeatedly observed the spawning lampreys; it is to their account that the writer is here indebted. Compare, also, the excellent account given recently by Professor Gage. lief. p. 234 . 
be covered with a thin layer of sand or gravel, - the spawners always returning to the same nest, - and a second, third, and more tiers of eggs will be added. When the eggs have finally been deposited, the nest is fortified by a dome-like mass of pebbles and stones, which the lampreys carefully drag to the spot. The nest is thus marked out as well as protected, and is said to be made of partial use during the following season. The hatching of the eggs takes place within about a fortnight.

The eggs which Sharks and Rays deposit are usually enclosed in a stout, horn-like capsule; this is in general of oblong or rectangular outline, its surface smooth or ridged; the case of the egg of Scyllium (Fig. I89), shows threadlike terminal processes, while these in the ray ( $\mathrm{Fig}$. I $89 A$ ) are stout and spine-like. A great variation may exist in the size of the egg and in the character of its envelopes among the different groups of Elasmobranchs. The egg of the Port Jackson shark, Cestracion (Fig. I90), is of enormous size and possesses an extremely thick, spiral-rimmed, pear-shaped capsule ; that of the Greenland shark, Lamarguts, is said to be spherical and relatively small, and to be deposited unprotected by capsule.

The breeding habits of Elasmobranchs are but imperfectly known. With the exception, perhaps, of Læmargus, the sexes copulate.* The clasping appendages of the male are inserted either singly or together into the cloaca and oviduct of the female, and the eggs appear to be fertilized in the uppermost portion of the oviduct. The egg then becomes surrounded by a glairy albuminous envelope, and thereafter by the secretion of the oviducal gland, which in the lower oviduct hardens into the horny capsule. The

* The copulation of sharks has been but rarely observed (e.g. by Bolau in Hamburg; cf. Ref. on p. 24I). 
majority of sharks and rays are viviparous; the eggs are retained in the lowermost portion of the oviduct (uterus) and the embryo establishes a "placental" circulation, the vascular yolk sac becoming adherent to the walls of the uterus. Other sharks deposit their eggs, and their mode of oviposition has been observed. The egg (Fig. I89), when slightly protruded from the cloaca, is rubbed against brush-like objects, and when its terminal processes become finally entangled, the egg is withdrawn. The processes of the egg case which leave the body last, the longer ones, are often greatly straightened out when the egg is deposited; subsequently their elastic character causes them to curl tightly, and often to secure a firm attachment to neighbouring objects. The eggs of oviparous skates (Fig. I89 $A$ ) are said to be deposited on sand flats near the mark of low water. Mr. Vinal N. Edwards of Wood's Holl, Massachusetts, believes that they are implanted vertically in the sand, and, from the occurrence of "beds" of skate eggs, that the fishes are singularly local in their places of spawning. Eggs of Elasmobranchs* are often many months in hatching; the young fish finally escapes through a slit at the end of the egg case.

Nothing is known definitely of the breeding habits of Chimæroids. The mode of copulation of the sexes is doubtless similar to that of sharks. Their clasping organs are highly specialized sperm ducts, and the hook-bearing organs at the anterior margin of the ventral fin, and on the forehead of the male, function in all probability in retaining the female. The forehead spine could certainly prove of such service if the position of the fishes during mating was at all similar to that figured for Scyllium by

* In the case of Scyllium the eggs are deposited about six days after they have been fertilized; they then hatch in from 200 to 275 days. 
Bolau.* The egg case of Callorhynchus (Fig. I9I) is essentially shark-like; it is of spindle-shaped outline, and its broad, fringing margin gives it an almost seaweed-like appearance. The egg is believed to be deposited in deep water.

The spawning of but one of the three existing Lungfishes has been recorded. Ceratodus, according to Semon, has a spawning season extending over several months; it deposits its eggs in shallow water, scattering them broadcast. The female fish is attended by several males, and the emission of eggs and milt appears to be simultaneous. The egg (Fig. 192) lacks a horny capsule, but is amply protected by a thick, jelly-like hull. It hatches during the second week.

Eggs of Ganoids are shown in Figs. 193, I94. They are encased in a jelly-like envelope, especially viscid in the case of sturgeon. When deposited, they speedily adhere to whatever they touch, and often remain attached until the time of hatching. The spawning grounds are in shallow water; the fish occur in numbers during a few days of May and June, each female attended by several males: ova and milt are emitted simultaneously, at short intervals. The eggs develop rapidly, hatching in about a week.

The eggs of Teleosts present the utmost variety in number, form, membranes, and mode of deposition. In some forms (Embiotocids, Blenniids, Cyprinodonts) they may even develop within the ovarian tissue, establishing there a "placental" circulation. They have been fertilized within the fish, the anal fin spine of the male having in some cases been metamorphosed into a copulatory organ. The eggs of Siluroids (Fig. I95) are generally of large size, 
and somewhat adhesive; they are deposited in "nests," i.e. bowl-like depressions, and are attended by the male fish.* Other adhesive eggs are those of carp, Christiceps, Batrachus. Eggs of Salmonids are deposited loosely in "nests" on a clean, gravelly bottom; their membranes are thick and parchment-like. On the other hand, the majority of pelagic fishes produce eggs which float (Figs. I96, I97); of these the membranes are extremely hygroscopic and transparent, and an oil globule, located in the yolk region of the egg, serves to diminish its specific gravity. The egg membranes of a number of Teleosts, e.g. Blennies (Fig. I99), appear essentially shark-like; a horn-like capsule is evolved, whose terminal processes afford it a firm attachment. Aberrant modes of oviposition are not lacking; the South American Siluroid, Aspredo, as is well known, carries its eggs attached to its ventral surface; the pipe-fishes and sea-horses, Siphostoma, Solenostoma, Hippocampus, have specialized a pouch-like fold of the abdomen and of the ventral fins, which serves to retain the eggs and larvæ. It is curious to note that this remarkable condition occurs only in the male.

The breeding habits of Teleosts are in general like those of Ganoids; their spawning season is usually during the spring and summer, but is seldom of very brief duration. The hatching of the eggs depends largely upon water temperature, and may vary from a few days to several months (Salmo).

\section{B. THE FERTILIZATION PHENOMENA}

The processes of the maturation and fertilization of the egg have as yet shown but minor differences in the

* In several genera they are carried about in the gill chamber of the male, thus ensuring aëration. 
groups of fishes. In the forms which have thus far been studied* there have been few noteworthy variations from what appear the normal conditions of vertebrates. The sperm usually gains admission to the egg through a micropyle in the egg membranes which becomes formed immediately after the extrusion of the polar bodies. A sperm cell, invariably a single one, participates in the actual fertilization. This may occur directly by the formation of a single male pronucleus, as e.g. in Petromyzon, Teleosts; while in the sharks, on the other hand, Rückert describes a multiple fertilization (polyspermy), where many male pronuclei $\uparrow$ are formed, the one nearest in position fusing subsequently with the female pronucleus. An intermediate condition seems to be retained in the sturgeon, where several (six to nine) micropyles have been noted, although but a single one occurs in the kindred Ganoid, Lepidosteus (Mark, Ref. p. 249).

\section{THE EMPRIONIC DEVELOPMENT}

When the egg of a fish is deposited, it contains but the elements of a single cell. Its size and its enveloping membranes may vary widely, but its constituents are constant, - cytoplasm and nucleus. The size of the egg in different fishes varies with the amount of food material, or yolk, stored away in its cytoplasm; the enormous egg of the shark differs from the minute egg of the lamprey strikingly in this regard. But even in the minute lamprey egg there is a certain amount of yolk material present.

In every egg there can usually be distinguished at sight

* Lamprey by Kupffer and Böhm, and Calberla ; Sharks by Rückert ; Teleostomes by Hoffman, Agassiz and Whitman, Kupffer, Böhm, and others.

+ These appear later to undergo karyokinesis, and are thereafter to be regarded as supplemental merocytes (p. 195). 
an upper and a lower zone: the latter rich orange in colour, caused by the settling of the heavier yolk material; the former lighter in colour, containing the nucleus of the egg, and originating the growth processes.

The less the amount of yolk in the lower, or vegetative, region, the smaller is naturally the egg, and the more obscure becomes the limit of the upper zone, or germ, or animal pole, as it is indifferently called. In the yolkfilled egg of the shark, on the other hand, the upper zone becomes reduced to a mere "germ disc" on the surface of the egg (Fig. 2 I6, GD). If but little yolk is present, the early growth processes, i.e. the splitting of the germ cell, or egg, into many cells, or blastomeres, to give rise to the embryo, affect the entire egg. If, however, much yolk is present, the cells at first multiply only at the animal pole, and the yolk-filled region, remaining unsegmented, furnishes the nutriment for the cell growth above.

In the present outline of the development of fishes, the following types are reviewed :-

I. Petromyzon; II. Shark; III. Lung-fish; IV. Ganoid; V. Teleost.

\section{The Development of Petromyzon}

The egg of Petromyzon is of small size (Fig. I88), and is poorly provided with yolk material ; in surface view one can only distinguish the germinal from the yolk region by its slightly lighter colour. In the side view of the egg of Fig. 200, the beginning of the first cleavage plane is seen; a vertical plane, passing through the egg, completes the stage of the two blastomeres of Fig. 20I. The nuclei were at first close to the upper, or animal, pole, but they shortly take their position somewhat above the plane of the egg's equator. A second cleavage plane is again vertical, ap- 
FIG. 200

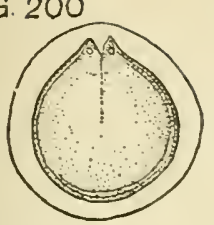

204

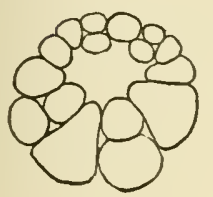

\section{EN

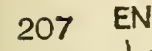

201

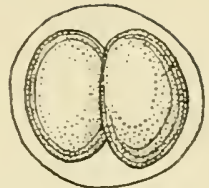

202

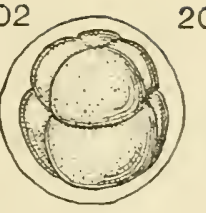

203

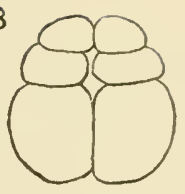

205

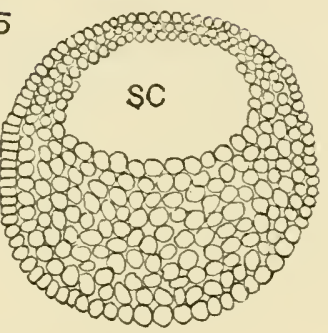

206

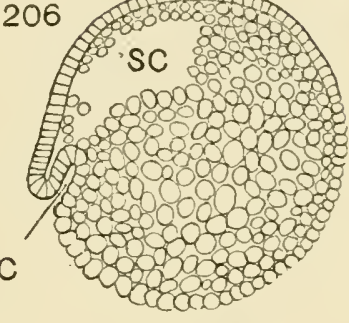

M

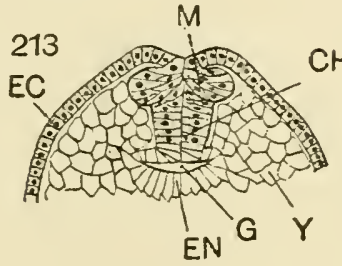

$\mathrm{BP}$

208
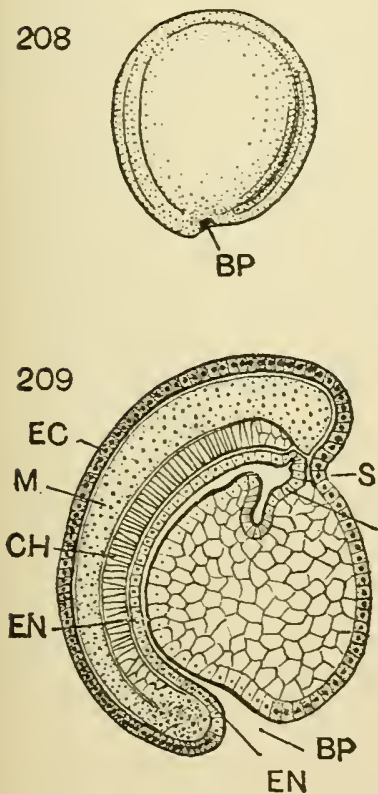
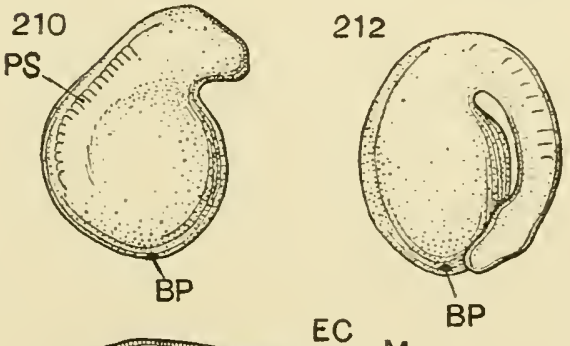

212

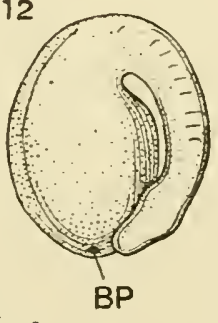

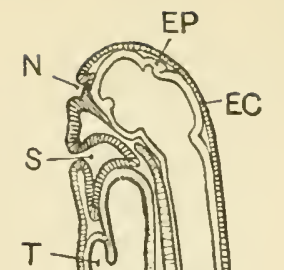
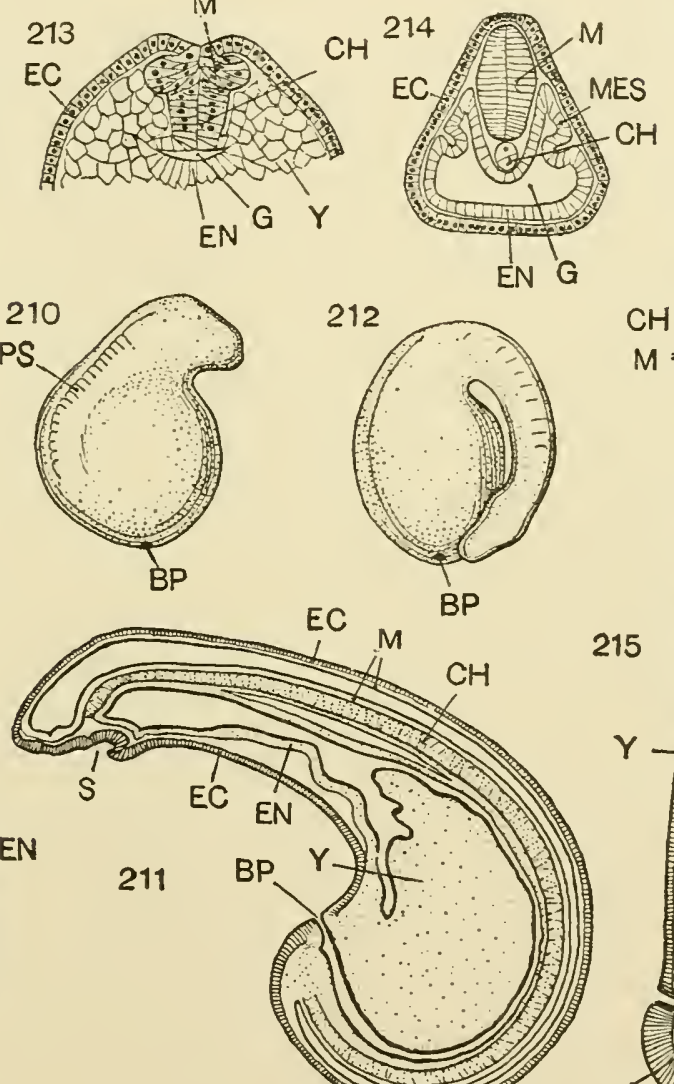

$\mathrm{CH}$

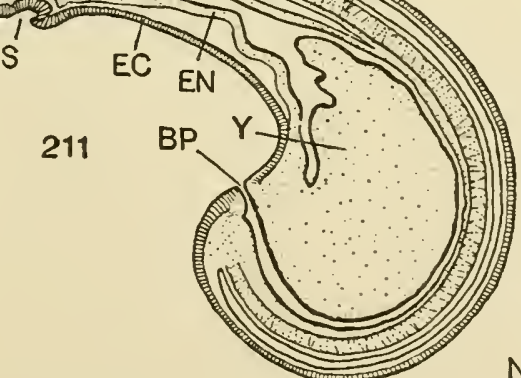

215

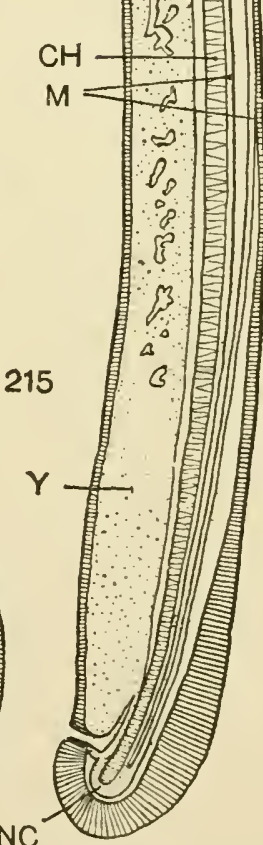

Figs. 200-215. - Development of lamprey, Petromyzon planeri. Figs. 200-204, 208-212 $\times$ 18, others $X$ about $30.200,201$. First cleavage, beginning and concluded. 202. Third cleavage. 203. Fourth cleavage, in section, showing beginning of segmentation cavity. 204, 205. Early and late blastulæ, in section. 206, 207. Early and late gastrulæ, in section. 208, 210, 212. Early embryos showing growth of head end. 209, 2II. Sagittal sections of early embryos showing differentiation of organs. 213, 2I4. Transverse sections of early embryos. 215. Sagittal section of newly hatched larva, Ammocœes. (Figs. 2I I, 215, after GOETTE, others after V. KUPFFER.)

BP. Blastopore. C. Cœlenteron. CH. Notochord. DL. Dorsal lip of blastopore. EC. Ectoderm. EN. Entoderm. EP. Epiphysis. G. Gut. H. Heart. M. Central nervous system. MES. Mesoblast. N. Nasal pit. NC. Neurenteric region. S. Mouth pit, stomodæum. SC. Segmentation cavity. T. Thyroid gland. $Y$. Yolk and yolk cells. 
proximately at right angles to the first; the third, which shortly appears, is horizontal (Fig. 202), giving rise to the stage of eight blastomeres; this plane, passing slightly above the equator, causes the upper blastomeres to be slightly smaller in size than those of the lower hemisphere. The amount of yolk in the egg, it is accordingly inferred, although not sufficient to prevent the passage of cleavage planes, is enough, nevertheless, to retard the nuclear cleavages in the region of the lower, or vegetative, pole. In Fig. 203, showing a vertical section of the following stage, another horizontal cleavage has been established in the upper part of the egg; the segmentation cavity is seen in the centre of the figure arising as the central space between the blastomeres. This is seen to have become greatly enlarged in Fig. 204, a slightly later stage where in vertical section is seen a greatly increased number of blastomeres. Repeated cleavage of all blastomeres now continues regularly, and results in the production of a blastula, a smooth-surfaced cell mass containing the segmentation cavity, SC (in section, Fig. 205); this is seen to be located in the region of the animal pole. In the next developmental stage, gastrula, seen in section in Fig. 206, the primitive digestive tract, colenteron, $C$, is appearing; it arises as an indentation of the side of the blastula. The colenteron, soon greatly increasing in depth, reduces in size and finally obliterates the segmentation cavity, taking the position, $C$, shown in section in Fig. 207. Here the segmentation cavity has practically disappeared; the surface opening of the coelenteron is the blastopore, $B P$; the cell layer of the gastrula's surface is the ectoderm, EC; the cell layer lining the colenteron is the entoderm, EN: the colenteron, it will be seen, is closely apposed to the ectoderm at the left of the figure, - the 
future dorsal region of the embryo; on this side the margin of the blastopore is known as the dorsal lip, $D L$, while to the right the ventral lip is seen greatly enlarged by the yolk-bearing cells, $Y$. A somewhat later stage (Fig. 208) shows the blastopore as a narrowly constricted opening, $B P$, whose dorsal lip is slightly raised at its lefthand margin. The head of the embryo is to arise near the opposite pole (as in Fig. 2IO), and is thence to elongate into neck and trunk (Fig. 2I2). A sagittal section of a stage, slightly older than Fig. 208, shows admirably the structures of the embryo that have thus far been differentiated (Fig. 209). Contrasting with Fig. 207, it will thus be seen that the colenteron, arising at $B P$, has become greatly elongated; at its blind end its lining membrane, entoderm, $E N$, is in contact with an indented portion of the ectoderm, at $S$, where later the opening of the mouth will be established; and that ventrally the colenteron has given off a pouch which passes into the yolk, and will later be differentiated as the liver. That the entire dorsal wall of the cœlenteron has become thickened, constitutes the main difference between the sections of Figs. 207 and 209; there have, in other words, arisen between the entoderm and ectoderm of Fig. 207 the central nervous system, or medullary cord, $M$, and the notochord, $C H$. The origin of these structures may best be traced in the cross-section of a slightly earlier stage (Fig. 2I3); the cœlenteron, or gut, is at $G$, the ectoderm at $E C$, the yolk cells intervening at $Y$; and the notochord and medullary cord, $C H$, and $M$, in the sagittal region immediately between the gut and the ectoderm. In the medullary region the ectoderm cells are seen pressed together, growing downward and sidewise, forming altogether a compact cell cord *

* As in Teleosts, but unlike other verteỏrates. 
passing down the back of the embryo ; the notochord is arising from the differentiating cells of the roof of the gut. In the cross-section shown in Fig. 2I4, the subsequent conditions of these structures may be seen; the medullary nerve cord, $M$, is now in section elliptical, separated dorsally from the ectoderm, and its cellular elements are of more uniform size, arranged with bilateral symmetry, its central lumen having not as yet appeared; the notochord, now constricted off from the wall of the gut, takes upon it its characteristic form and structure. It is, however, in the differentiation of the walls of the gut that this section is of especial interest; the gut is seen to have greatly enlarged, and at the expense of the yolk material; its lining membrane, entoderm, $E N$, is now directly apposed to the outer germ layer, ectoderm, $E C$. The middle germ layer, mesoderm, MES, - out of which cartilage, muscular and connective tissue, are formed, - is now seen taking its origin as paired evaginations of the dorsal wall of the gut. The mesoderm shortly loses its connection with the entoderm, and by the rapid increase of its cellular elements rapidly invests the remaining embryonic structures; its segmental character may be seen in the surface view shown in Fig. 2 IO, its dorsal portions appearing as the primitive segments.

Later developmental stages are shown in the sagittal sections, Figs. 2I I, 2I2. These may best be compared with Fig. 209. In Fig. 2 I I the head end of the body has greatly elongated, and with it the gut cavity has dilated; entoderm is now composed of very minute cells, whose nuclei are suggested by dots; the yolk has become more definitely restricted to the region of the hinder gut; the blastopore is still seen; at its lips the germ layers are alone fused. 


\section{The Development of the Shark}

On the side of embryology a shark presents many points of striking contrast to the lamprey; yet it may in many regards be looked upon as archaic in its developmental characters. Its contrasting structures (together with those of lung-fish, Ganoid, and Teleost) may best be reviewed in the table, p. 280.

The egg of the shark is of large size, richly provided with yolk material. When removed from its membranes, it is seen to be of a bright orange colour; its form is elongated, and the weight of its pasty substance causes it to assume a flattened ovoid (Fig. 2I6). At the upper pole of the egg is a small, light-coloured spot, the germ disc, $G D$, which figures prominently in the early stages of development. It would represent the lamprey's entire egg, if one could imagine a point of the lower pole of the latter hugely dilated with yolk. It is in the region of this germ disc alone that every process of development as far as gastrulation occurs.

The segmentation of the germ disc is shown in Figs. 2 I7-220. In the first of these (Fig. 2I 7) the germ is seen to be sharply marked off from the surrounding yolk by a circular band; two cleavages have traversed it in the form of narrow grooves separating the blastomeres. In Fig. 2 I 8 the fifth cleavage has been completed; the furrows dividing irregularly the surface of the germ disc fade away at its periphery. Fig. 2 I 9 represents a vertical section of the germ disc at this stage; the upper, finely dotted layer, thinning away at either side, is the germ disc ; the coarsely granular material below is the yolk; the depth of the cleavage furrows is seen, and it will be noted that up to this stage of development there have been no horizontal 
FIG. 216

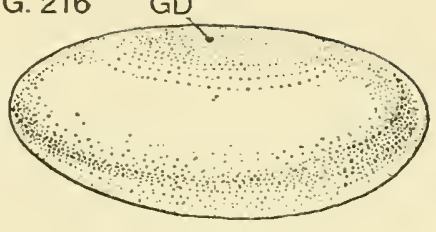

217

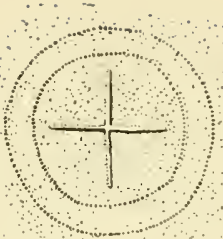

218

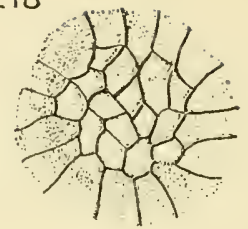

219
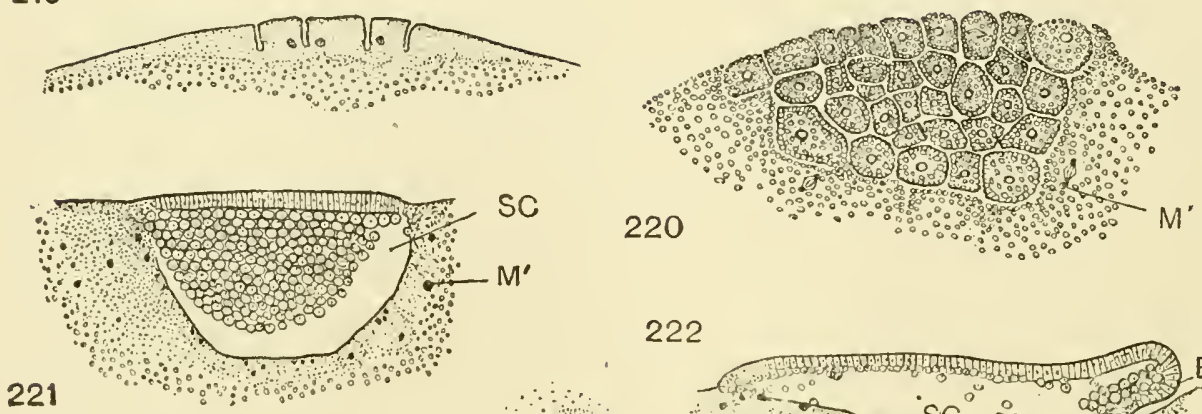

222

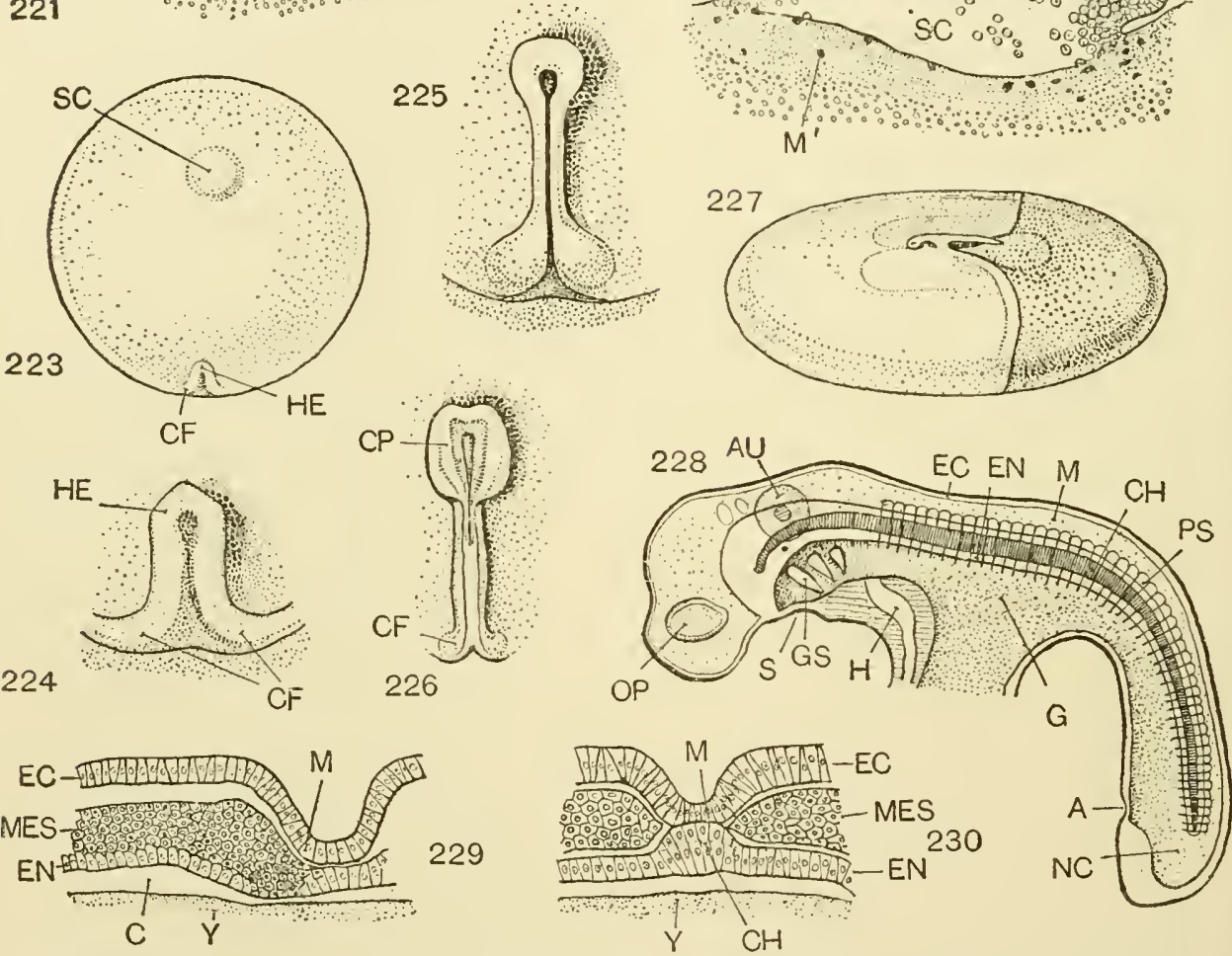

Figs. 2I6-230. - Development of shark, Scyllium (mainly). (All but 216 after BAL. FoUR.) 216. Egg freed from case showing germ disc $G D$. 217. Germ disc at second cleavage. 218. Germ disc at fifth (?) cleavage. 2I9. Vertical section of similar stage. 220. Vertical section of slightly older germ disc. 22I. Blastula. 222. Early gastrula. 223. Blastoderm showing early growth of embryo. 22t-226. Slightly later stages of growth of embryo. 227. Stage showing early embryo and mode in which the blastoderm surrounds yolk. 228. Early embryo viewed as a transparent object. 229, 230. Transverse sections of early embryo.

$A$. Anal invagination. $A U$. Auditory vesicle. $B P$. Dorsal lip of blastopore. $C$. Coelenteron. $C F$. Tail folds. $C H$. Notochord. $C P$. Cephalic plate. EC. Ectoderm. E.V. Entoderm. G. Gut. GD. Germ disc. GS. Gill slits. H. Heart. HE. Head eminence. $M$. Central nervous system. $M^{\prime}$. Yolk nuclei, merocytes. MES. Mesoblast. $N C$. Neurenteric canal. OP. Optic vesicle. PS. Primitive segments. S. Mouth pit, stomodæum. SC. Segmentation cavity. 
cleavages. A stage in which early horizontal cleavages are represented is shown in Fig. 220. This may well be compared with the last figure; the germ disc, while not increasing in diameter, is now seen to have multiplied its blastomeres by horizontal cleavages; it is converted into a plug-shaped mass of cells, sunken into the yolk material. At $M^{\prime}$ are cell nuclei, which have found their way into the adjacent yolk, and which there acquire a developmental importance. They become the so-called merocytes, or yolk nuclei.

The secticn of the germ shown in Fig. $22 \mathrm{I}$ represents a subsequent stage of development; the blastomeres, by continued subdivision, have become greatly reduced in size, and are clearly to be distinguished from the smooth-surfaced, yolk-like material lying beneath. Merocytes, $M^{\prime}$, are apparent in the superficial layer of the yolk; they are supposed to serve a twofold function, - on the one hand, to elaborate the yolk material and fit it for the embryo's use ; on the other, to supply the cells which are being continually added to the germ's margin. In the figure a large cavity is shown to exist between the yolk and the mass of blastomeres. This cavity has been identified as the segmentation cavity, SC, and the developmental stage as the blastula; it is as though the lower hemisphere of the lamprey's blastula (Fig. 205) had become enormously enlarged, and all traces of the cells in the floor of its segmentation cavity lost, except in the layer of the metamorphosed cells, the merocytes.

In the next growth process the extent of the germ area becomes greatly increased; the thick blastula is now thinned out into a surface layer of regular cells, an enlarging disc-like blastoderm, which will eventually grow around and enclose the entire egg. The blastoderm of 
Fig. 223 is a pale-coloured circular membrane of about a half inch in diameter lying on the surface of the egg. Sectioned at an earlier stage (Fig. 222) the blastoderm is seen to present the following contrast to the blastula of Fig. 22 I : the floor of the segmentation cavity has flattened, and a sharp rim forms the outline of the blastoderm; at one side this rim is seen to protrude over the yolk mass, leaving a narrow, fissure-like cavity between. This stage is identified as the gastrula; the fissure-like cavity, the cœlenteron; its marginal blastoderm, the dorsal lip of the blastopore; its ventral lip, the entire yolk mass.

The growth of the embryo's form takes its origin at the blastopore's dorsal lip. In Fig. 223 the rim of the blastoderm is seen indented near the point $C F$, and its thickening at this region becomes more and more marked in subsequent stages; on the other hand, the anterior portion of the blastoderm, growing continually on all sides, becomes excessively thin, flattening itself tightly to the yolk, and reducing the segmentation cavity to the small area indicated at $S C$. The growth of the embryo in the mid-region of the blastopore's dorsal lip may next be followed in the stages, Figs. 224, 225, 226. The indentation of the rim may thus be seen to assume a creeselike thickening, thrusting forward its blunt end, the head eminence, $H E$, over the blastoderm; at the points $C F$, the tail eminences, the rim of the blastoderm is thick, protruding, appearing to be pressing together in the median line, and causing the body of the embryo to be actually pushed into form and thrust above the level of the blastoderm. In Fig. 225 the sides of the embryo are separated dorsally by a deep groove, the medullary furrow, the future canal of the central nervous system. In Fig. 226 this is seen at a more advanced stage; its hinder 
portion has been roofed over by the coalesced sides, and the process of enclosing the groove is being continued anteriorly, although the head end of the embryo is now flattened out as the prominent cephalic plate.

In the stage figured in 227 , the form of the embryo has been acquired: the head in the manner already outlined, the tail by the coalescence and subsequent outgrowth of the tail folds, CF. The entire embryo now rises above the blastoderm, as this continues to enclose the yolk. In the figure the yolk has thus been more than half enclosed; its final appearance is seen in the oval space outlined by a dotted line behind the embryo.

The origin of the germ layers is not as readily traced as in the Cyclostome. Ectoderm is the most clearly marked; even in the blastula (Fig. 22I) it has appeared as an outer single-celled stratum clearly differentiated from the underlying cells. Entoderm is only to be seen on the dorsal wall of the cœlenteron: the ventral entoderm (cf. Fig. 222) is merged with the yolk. Mesoderm takes its origin from the inner layer on either side of the median line, but it arises as a solid cell mass instead of as the pouch-like diverticula in Petromyzon. Cross-sections of an embryo represented by Fig. 224 have been figured in Figs. 228 and 229; the former is of the hinder region and illustrates the mode of growth of the mesoderm, MES; the latter across the head region, shows that in this region the mesoderm is separated from the inner layer. Both sections show the simple character of the medullary groove, and the latter section the mode of origin of the notochord, $\mathrm{CH}$, i.e. as an axial thickening of the entoderm.

An embryo of about the stage of Fig. 227 is extremely delicate and may readily be viewed as a transparent object. 
By this time (Fig. 230) it will be seen that its prominent organs have already been differentiated. There are thus: medullary canal, $M$, with optic, $O P$, and auditory, $A U$, vesicles; gut with gill slits, $G S$, neurenteric canal, $N C$, and suggestion of mouth, $S$, and anus, $A$; notochord, $C H$; segmented mesoderm (primitive segments), $P S$, and heart, $H$. The medullary groove was converted into a canal, as has been already suggested, by the overroofing and fusion of the summits of the medullary ridges; its anterior dilatation is the brain; the gut, $G$, communicates freely below with the yolk mass; it is a cavity, a portion of the colenteron that has been constricted off with the embryo; its openings, the mouth, anus, and gill slits, are

- secondary, acquired after there have been established in these regions fusions of entoderm and ectoderm; the neurenteric canal, $N C$, a communication between medullary tube and gut, is a structure acquired in the stage of Fig. 226, where the hinder medullary groove was roofed over, allowing, in the region of the tail folds, a communication to exist between medullary canal and cœlenteron. The notochord has by this stage been completely separated from the entoderm; it already assumes a supporting function.

\section{The Development of Ceratodus}

The development of a Lung-fish has thus far been described (Semon) only from the outward appearance of the embryo. The egg of Ceratodus (Fig. 192) is seen without its covering membranes, enlarged, in Fig. 23 I. Its upper pole is distinguished by its fine covering of pigment. The first fine planes of cleavage are shown in Figs. 232-236; and from these it will be seen that the yolk material of the lower pole is not sufficient to prevent the egg's total seg- 

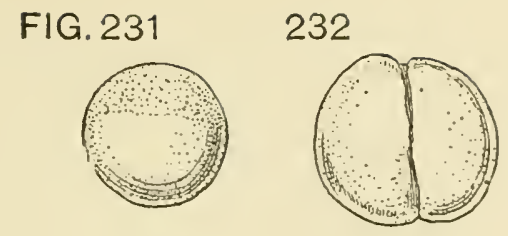

233
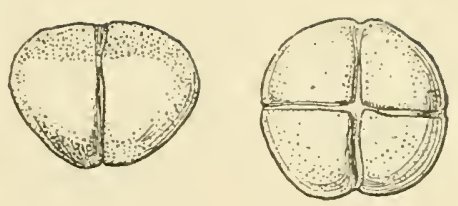

235

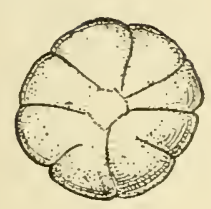

240

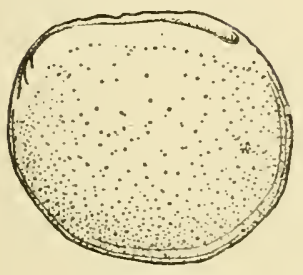

239

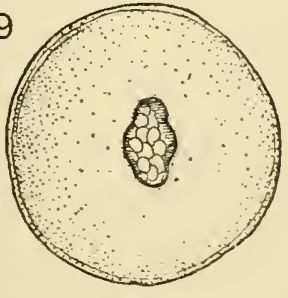

245

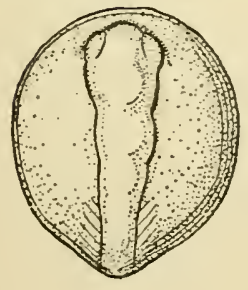

236

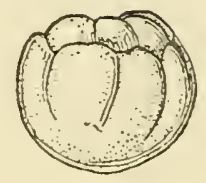

241

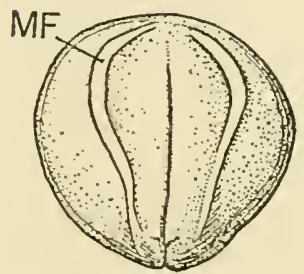

244

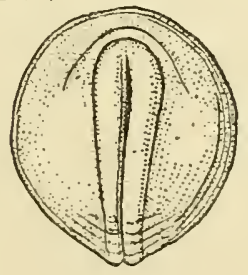

246

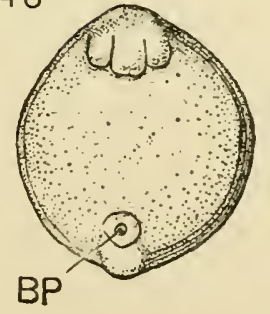

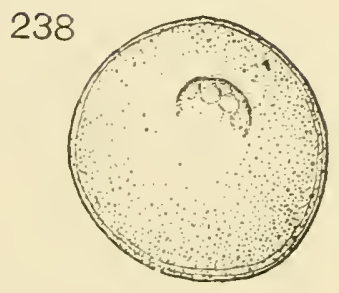
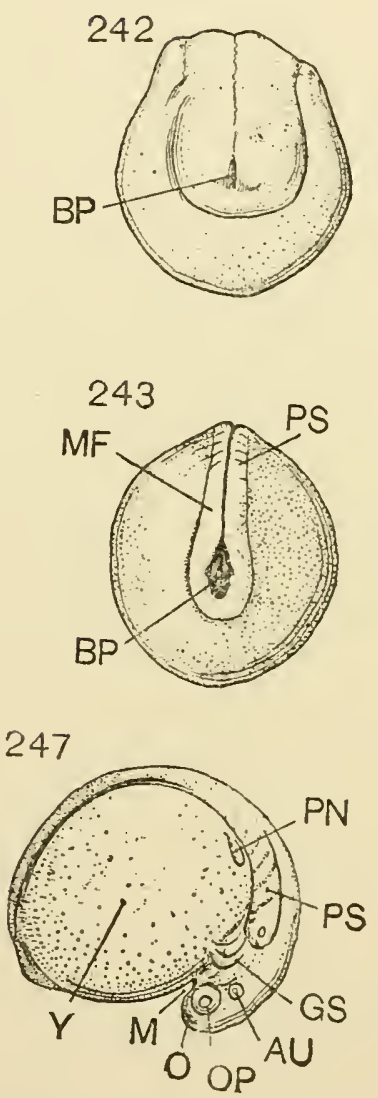

Figs. 23I-247. - Development of lung-fish, Ceratodus. (After SEMON.) $\times 4-7$. 23I. Egg immediately before cleavage. 232, 233. First cleavage, seen from above and from the side. 234. Second cleavage, seen from above. 235, 236. Third cleavage, seen from above and from the side. 237. Blastula. 238, 239. Gastrulæ showing closure of blastopore. 240. Early embryo, seen from the side. 24I. Early embryo showing medullary folds (head). 242. Tail region of same embryo. 243. Tail region of slightly later stage. 244. Head region of same embryo. 245-247. Later embryos. $A V$. Auditory vesicles. BP. Blastopore. $G S$. Gill slits. $M$. Mouth pit. $M F$. Medullary folds. $O$. Olfactory lobes. $O P$. Optic vesicles. $P N$. Primitive kidney, pronephros. PS. Primitive segments. $Y$. Yolk mass. 
mentation. The first plane of cleavage is a vertical one, passing down the side of the egg (Fig. 233) as a shallow surface furrow, not appearing to entirely separate the substance of the blastomeres, although traversing completely the lower hemisphere (Fig. 232). A second vertical furrow at right angles to the first is seen from the upper pole in Fig. 234; it is essentially similar to that of Fig. 233. The third cleavage of Fig. 235 is again a vertical one (as in all other fishes, but unlike Petromyzon), approximately meridional; its furrows appear less clearly marked than of earlier cleavages, and seem somewhat irregular in occurrence. The fourth cleavage is horizontal above the plane of the equator. Judging from Semon's figure (Fig. 236), at this stage the furrows of the lower pole seem to have become fainter, if not entirely lost. A blastula showing complete segmentation is seen in Fig. 237; the blastomeres of the upper hemisphere are the more finely subdivided; the conditions of the segmentation cavity may be expected to prove similar to those of Fig. 205. Two stages of the gastrula are shown in Figs. 238 and 239, showing a full view of the blastopore. In the earlier one (Fig. 238) the dorsal lip of the blastopore is crescent-like; in the later (239) the blastopore acquires its oblong outline, through which the yolk material is apparent; its conditions may later be compared to those of a Ganoid (Figs. 254, 255).

The growth of the embryo is illustrated in the remaining figures (Figs. 240-248). A side view of an early embryo is shown in Fig. 240; at the top of the egg to the right is the head region, to the left the blastopore and tail. The surface view of the head region (Fig. 24I), the medullary folds, $M F$, may be compared with those of Fig. 225, although they are low and widely separated; the axial seam is referred to by Semon as a demonstration of the 
theory of the embryo's concrescence. In the hinder region of the same embryo (Fig. 242) the blastopore is still apparent, $B P$, reduced to a narrow, fissure-like aperture; around it is the tail mass, corresponding generally to $C F$ of Fig. 226; and encircling all is the hinder continuation of the medullary folds.

The next change of the embryo is strikingly amphibianlike; the medullary folds rise above the egg's surface, and, arching over, fuse their edges in the median dorsal line. In Fig. 243, the tail region of a slightly older embryo, this process is clearly shown; the medullary folds, $M F$, are seen closely apposed in the median line; hindward, however, they are still separate, and through this opening the blastopore, $B P$, may yet be seen. At this stage primitive segments are shown at $P S$; in the brain region in Fig. 244 the medullary folds are still slightly separated (cf. $C P$, Fig. 226).

Two views of an older embryo are figured (Figs. 245 and 246), where the fishlike form may be recognized. The medullary folds have completely fused in the median line, and the

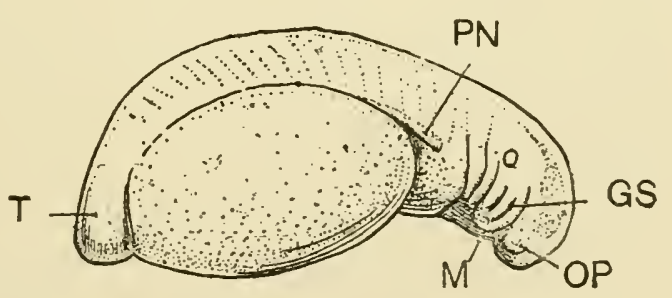

Fig. 248.- Embryo of Ceratodus, near the time of hatching.

GS. Gill slits. M. Mouth pit. OP. Optic vesicles. PN. Primitive kidney, pronephros. T. Tail eminence.

embryo is coming to acquire a ridge-like prominence; optic vesicles and primitive segments are apparent, and at $B P$ the blastopore appears to persist as the anus. The continued growth of the embryo above the yolk mass, $Y$, is apparent in Fig. 247; the head end has, however, grown the more rapidly, showing gill slits, $G S$, auditory, optic, and nasal vesicles, $A U, O P$, and $O$, at a time when 
the tail mass has hardly emerged from the surface. Pronephros has here appeared at $P N$ (cf. with Fig. 247, Fig. 2 Io). It is not until the stage of the late embryo of Fig. 248 that the hinder trunk region and tail come to be prominent. The embryo's axis elongates and becomes straighter; the yolk mass is now much reduced, acquiring a more and more oblong form, lying in front of the tail, $T$, in the region of the posterior gut (cf. Figs. 2 I I and 2 I2). The head, and even the region of the pronephros, $P N$, are clearly separate from the yolk sac; the mouth, $M$, is coming to be formed.

\section{The Development of Ganoids}

The development of Ganoids is next to be outlined. The eggs of the sturgeon and gar-pike are poorly provided with yolk. They have still, however, a greater amount than those of the lamprey or lung-fish, and in many regards of development suggest nearnesses to the Elasmobranchs.

The egg of the sturgeon shown in Fig. 249 shows clearly two distinct zones; the upper, blotched with pigment at the animal pole, is pale in colour; the lower, rich in yolk, is orange-coloured, well speckled with pigment. The early cleavages appear at first only in the upper palecoloured area which corresponds apparently with the germ disc of the shark's egg: In Fig. 250 there have been two cleavages, vertical and at right angles to each other; these have sharply traversed the germ area, the earlier one being now produced slightly into the yolk region of the egg-only, however, as a slight surface furrow. The third cleavage (Fig. 25I) presents a stage closely corresponding with that of Ceratodus of Fig. 235, its plane tending to pass parallel to the first cleavage: the germ disc 
FIG. 249

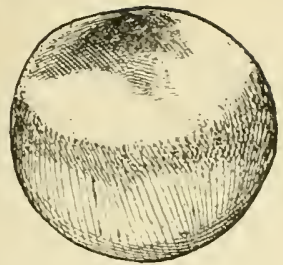

253

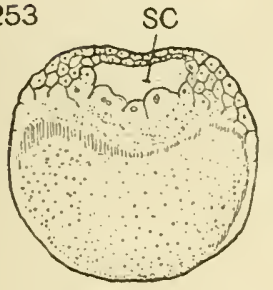

254
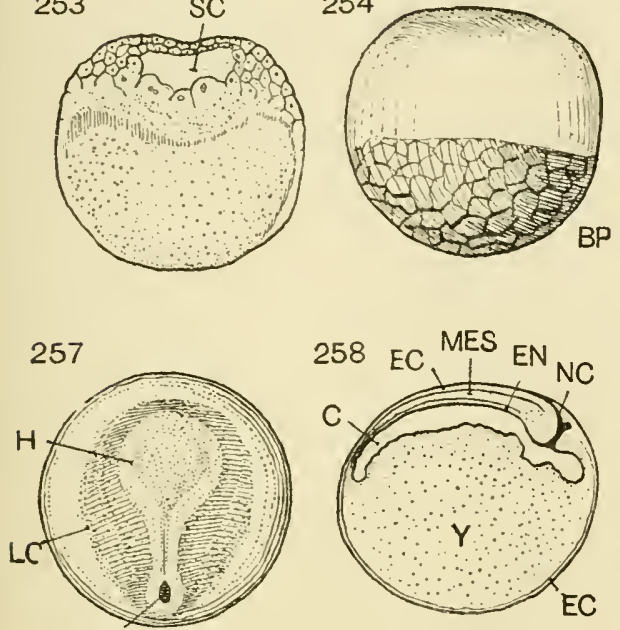

$\mathrm{BP}$
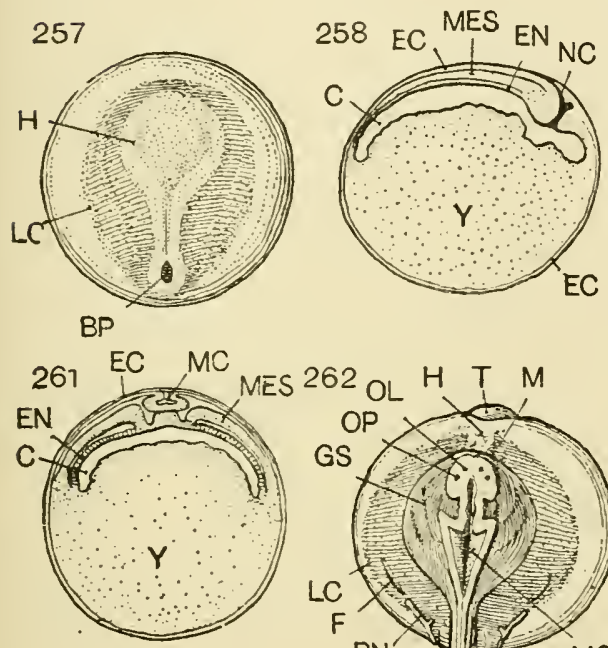

EC
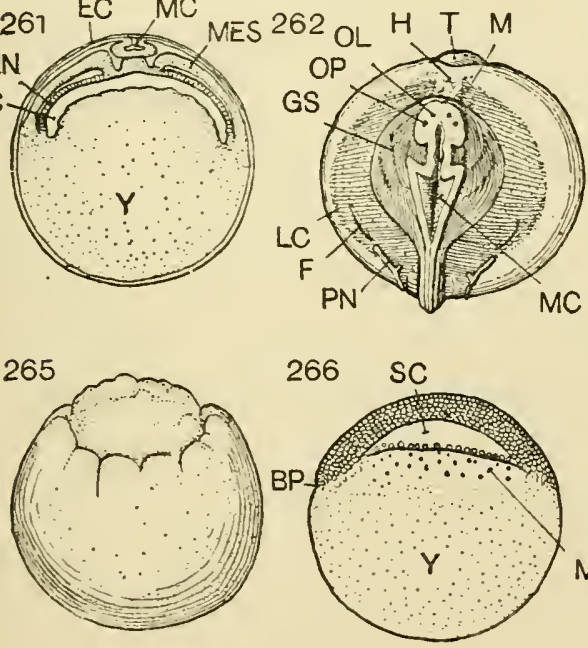
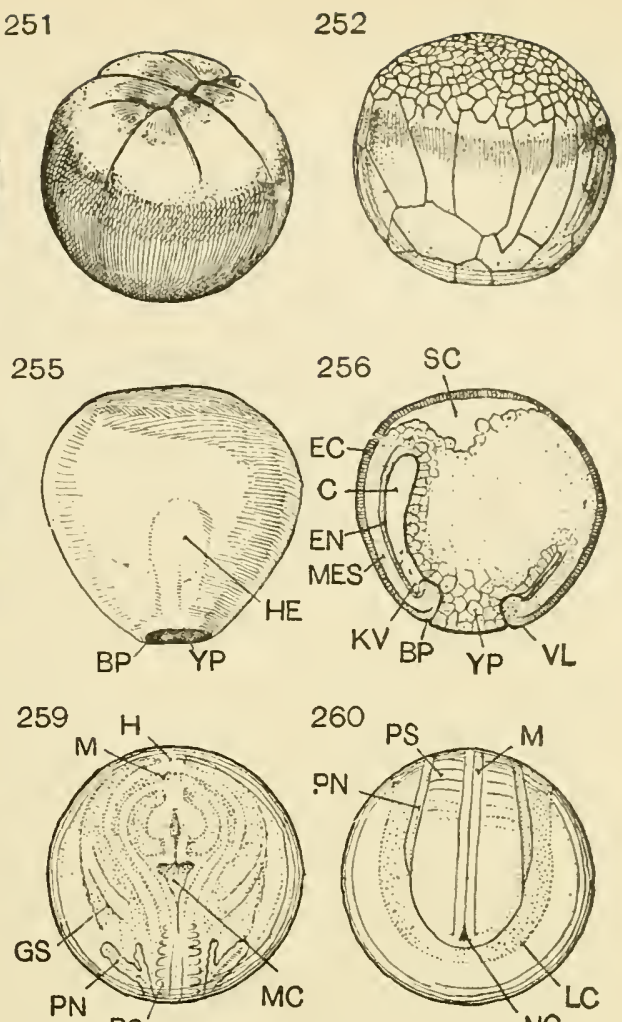

263

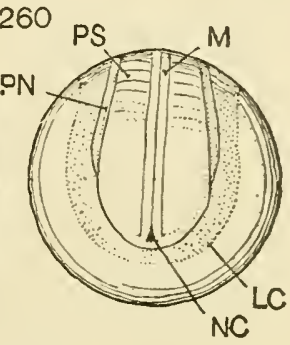

264
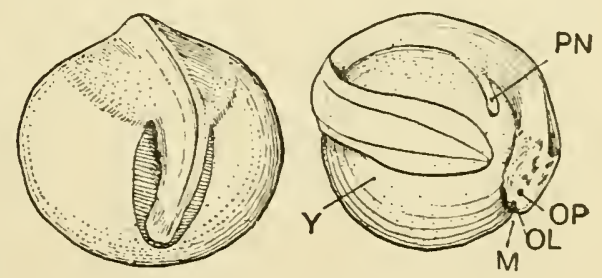

268

267
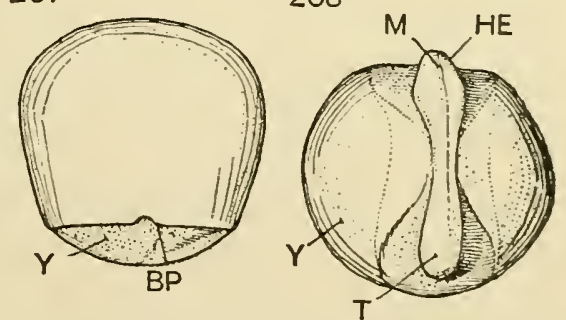

Figs. 249-268. - Development of Ganoids, Acipenser and (last four figures) Lepidosteus. $\times$ about 12. 249. Egg immediately before cleavage. 250. Second cleavage. 25I. Third cleavage. 252. Blastula. 253. Vertical section of blastula. 254. Early gastrula. 25. Late gastrula. 256. Vertical section of late gastrula. 257. Early embryo. 258. Sagittal section of same stage. 259, 260. Head and tail regions of slightly later embryo. 26r. 'Transverse body section of hinder body region of same stage. 262,263 . Head and tail regions of late embryo. 264. Embryo inmediately before hatching. 265. Lepidosteus' blastula. 266. Vertical section of early gastrula. 267. Late gastrula. 268. Embryo, showing mode of separation from yolk.

$B P$. Dorsal lip of blastopore. C. Coelenteron. EC. Ectoderm. EN. Entoderm. $F$. Pectoral fin. GS. Gill slits. $H$. Heart. $H E$. Head eminence. $K V$. Kupffer's vesicle. LC. Marginal limit of coelenteron. $M$. Mouth pit. MC. Medullary canal. MES. Mesoblast. NC. Neurenteric canal. OL. Olfactory pits. OP. Optic vesicles. $P N$. Primitive kidney, pronephros. $P S$. Primitive segments. $S C$. Segmentation cavity. T. Tail eminence. $V L$. Ventral lip of blastopore. $Y$. Yolk, yolk mass. $Y P$. Yolk plug. 
is deeply cut by the furrows ; the yolk area, however, only superficially; the shallow furrow of the first cleavage on the yolk hemisphere now passes through the lower pole; the second cleavage, passing downward, has made a shallow groove extending half-way between the rim of the germ area and the lower pole of the egg. It is the great amount of yolk in the lower hemisphere that retards the cleavage of the blastomeres. In Fig. 252 the entire germ area has become subdivided into a mass of small cells, while the large, irregular blastomeres of the yolk hemisphere are separated only by superficial furrows. This stage, the blastula, is seen in section in Fig. 253: the yolk, unsegmented, occupies the lower hemisphere; the germ area contains a segmentation cavity, SC, with a roofing of small cells, and a floor of irregular cells half engulfed in a deep, underlying zone transitional between germ and yolk.

An early gastrula is seen in Fig. 254: the more rapid multiplication of the cells of the germ region has given rise to a down-reaching cap of cells, whose boundary is here sharply marked off from the large and imperfect yolk cells of the lower hemisphere. At $B P$, the rim of the cell cap, or blastoderm, is sharply distinct from the yolk; it is the dorsal lip of the blastopore; the remaining portion of the rim is, generally speaking, the remainder of the rim of the blastopore; more accurately it is the circumcrescence margin of Hertwig. The late gastrula of Fig. 255 shows the greatly increased extent of the blastoderm: its margin is continually reducing the size of the blastopore, $B P$; on its dorsal lip at $H E$, the outline of the embryo is appearing. A sagittal section of this stage (Fig. 256) shows at $B P$ the dorsal, and at $V L$ the ventral, lip of the blastopore; at $Y P$ the yolk material appears at the egg's 
surface as a plug-like mass; at $S C$ is the segmentation cavity. The dorsal lip of the blastopore is seen to be far longer than the ventral lip; its rim is the more inflected, at $K V$ occurring a recessus which the writer compares to the Kupffer's vesicle of Teleost development; the cavity, $C$, colenteron, between the wall of the blastopore and the yolk mass is in this region the largest. The germ layers in this stage, EC, MES, EN, are seen to be confluent at the blastopore's rim; at the termination of the colenteron, entoderm and mesoderm are merged; the ectoderm forms the roof of the segmentation cavity.

The form of the embryo next becomes more definitely established. In Fig. 257 the blastopore, much reduced in size, is seen at $B P$; its thickened rim is whitish in colour; the darkened area, whose boundary is $L C$, is the coelenteron, seen faintly through the translucent margin of the blastopore; the embryo is the opaque area of the blastopore's dorsal lip, terminating anteriorly in the dilated tract, $H$, the head region. In a sagittal section of a slightly later stage (Fig. 258), the relations of germ layers, $E C, M E S, E N$, colenteron, $C$, and yolk mass, $Y$, may be compared with those of the section (Fig. 256), wherein the region $Y P$ corresponds to that of $N C$. A thin ectoderm will now be seen to have enclosed the entire egg; the segmentation cavity has disappeared; the rim of the blastopore, becoming continually constricted, causes the yolk material to recede from the surface, and leaves the blastopore disappearing, as the blunt diverticulum of $N C$. The neurenteric canal, $N C$, is the last communication between the surface of the egg and the collenteron; this has become established before the blastopore closes in the stage of Fig. 257 at its dorsal lip; 
the medullary furrow of the embryo has here been the deepest, and has been bridged over by a coalescence of its margins. At the anterior end of the embryo the inner, $E N$, and middle, $M E S$, germ layers become greatly thinned, in the region where the heart is shortly to arise.

The next stage of development is represented in Figs. 259, 260, showing front and hinder regions of the same embryo. The curiously flattened mode of growth characteristic of the sturgeon is here very apparent; the embryo has surrounded over three-fourths of thẹ egg's circumference, yet has not risen above its surface curvature; the head region is especially flattened; mouth, $M$, heart, $H$, gill slits, $G S$, brain, and optic vesicles are broadly spread out: the fourth ventricle at $M C$, the pronephros at $P N$, the primitive segments at $P S$. In the tail region the medullary folds appear at $M$, the pronephric duct at $P N$, the neurenteric canal at $N C$. A favourable section through the hinder body region of an early embryo is shown in Fig. 26I ; it illustrates the mode of origin of the following structures : the notochord as an axial thickening of entoderm, $E N$, immediately under $M C$; the medullary canal, as an infolding of (an under, or formative layer of) the ectoderm, its sides, folding over dorsally, coming to fuse in the median line; the mesoderm, MES, as in sharks, arising (partly) from the entoderm on either side of the notochord.

The later stage, shown in Figs. 262 and 263, may be contrasted with Figs. 259 and 260 ; the head region, though still greatly flattened out, is now rising above the surface; the trunk region is becoming prominent; the tail is budding out, and separating from the egg surface; sense organs are well outlined, and pectoral fins, $F$, elasmobran- 
chian in character, are appearing. An embryo shortly before hatching is next figured (Fig. 264); the head has now entirely lost its flattened character; the mouth invagination occurs at $M$; the tail, much elongated, is compressed laterally, and already presents the dermal embryonic fin; the yolk sac is attached along the anterior body region, in a position more nearly that of the shark than of the lung-fish.

Of the two Ganoids, sturgeon and gar-pike, the latter, as the writer has pointed out, * has the more shark-like developmental features. Its segmentation is incomplete, since the yolk pole of the egg is at no time traversed even by superficial furrows. The blastoderm, or cell cap, is early apparent, and is clearly marked off by a furrow from the irregular marginal blastomeres (Fig. 265). It resembles closely the segmented germ disc of an Elasmobranch, and the irregular marginal blastomeres may be compared to merocytes. The section of a late blastula of Fig. 266 does not differ widely from that of the shark of Fig. 22 I ; a segmentation cavity is present, whose floor is smooth, and contains a well-marked zone of merocytes, $M$; the smaller quantity and firmer consistency, perhaps, of the yolk do not, on the other hand, permit the blastula to occupy the sunken position of that of the shark. In the gastrula of the gar, further, a well-marked notch appears at the dorsal lip (as in this stage, Fig. 223, of the shark), representing the primitive blastopore. And, finally, the form of the embryo rises boldly from the surface, and early presents the well-marked head and tail eminences, $H E$ and $T$, of Fig. 268, comparable with Figs. 225 and 227. 
FIG. 269

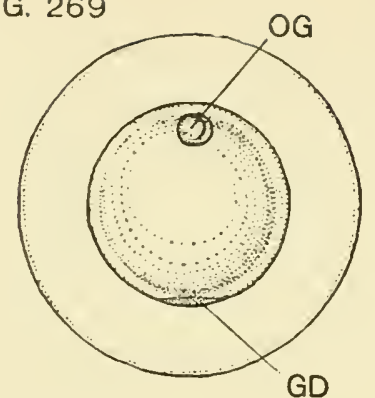

270
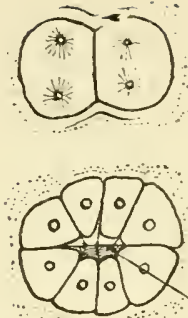

271
272
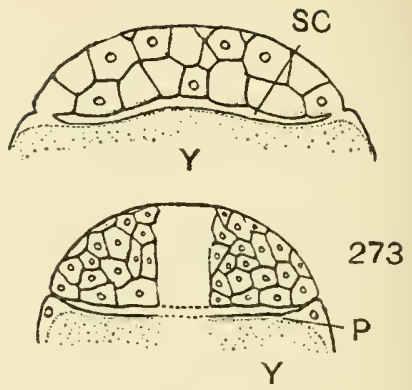
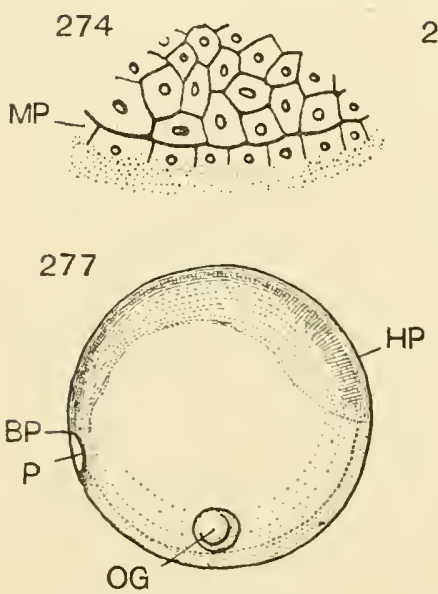

275
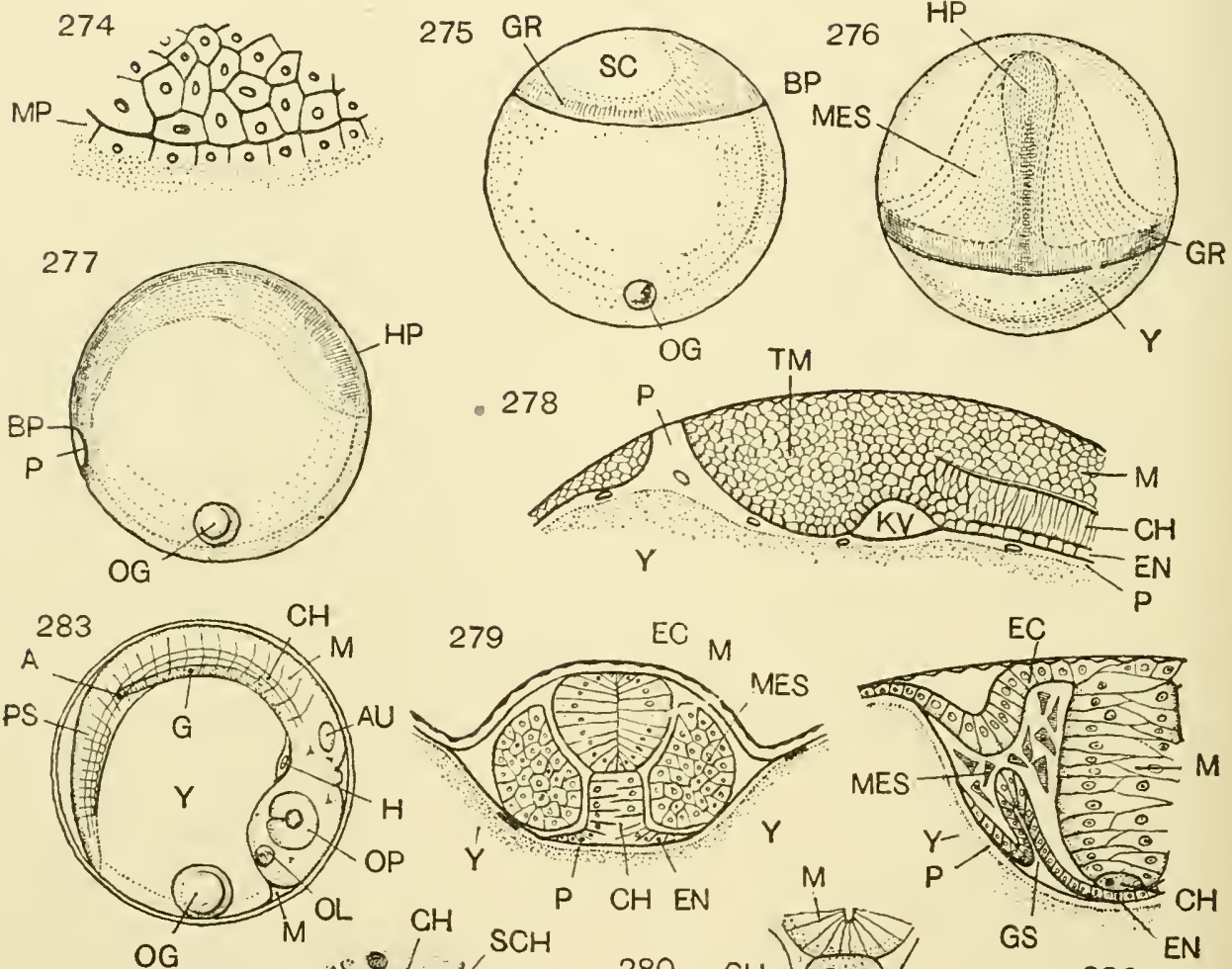

279

EC $M$

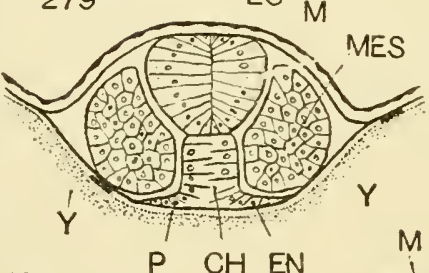

EC

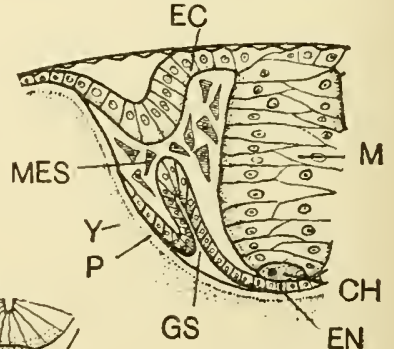

280
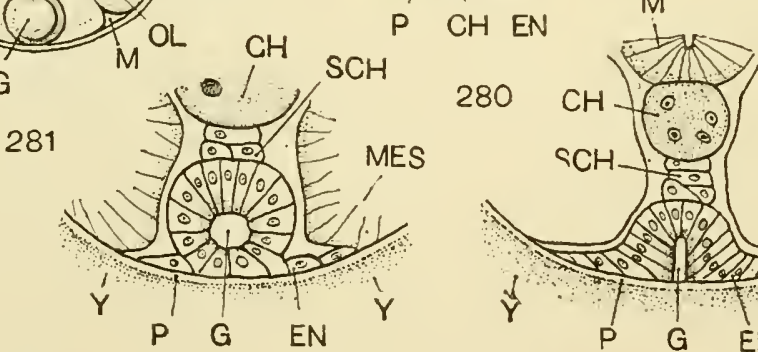

GS

282 EN

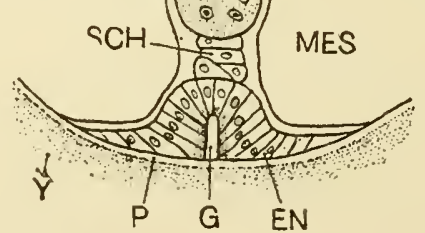

Figs. 269-283. - Development of Teleost, Serranus atrarius. (After H. V. WILSON.) Fig. $276 \times 25$. 269. Egg immediately prior to segmentation, showing position of germ disc and of oil globule. 270. Germ disc after first cleavage. 27I. Germ disc after third cleavage. 272. Vertical section of blastula. 273. Vertical section of blastula, showing origin of periblast. 274. View of marginal cells of blastula of similar stage. 275. Growth of blastoderm around yolk mass. 276. A slightly later stage, showing growth of embryo. 277. Continued growth of embryo and reduction in size of the blastopore. 278. Sagittal section of tail region of embryo of last figure. 279, 280, 28I. Cross-sections of embryos, showing successive stages in the development of notochord, gut, neuron, mesoblast. 282. Cross-section of young embryo, showing the mode of formation of gill slit. 283. Embryo shortly before hatching.

$A$. Anus. $A U$. Auditory vesicle. $B P$. Dorsal lip of blastopore. $C H$. Notochord. $E C$. Ectoderm. EN. Entoderm. G. Gut. GD. Germ disc. GR. Germ ring. GS. Gill slit. $H$. Heart. HP. Head process. $K T$. Kupffer's vesicle. $M$. Spinal nervous system. MES. Mesoblast. MP. Marginal periblast cells. OG. Oil globule. OL. Olfactory pit. $O P$. Optic capsule. $P$. Periblast. $P S$. Primitive segments. SC. Segmentation cavity. SCH. Subnotochordal rod. TM. Tail mass. $Y$. Yolk. 


\section{The Developinent of Teleost}

The mode of clevelopment of bony fishes cliffers in many and apparently important regards from that of their nearest kindred, the Ganoids. In their eggs a large amount of yolk is present, and its relations to the embryo have become widely specialized.

As a rule, the egg of a Teleost is small, perfectly spheri$\mathrm{cal}$, and enclosed in delicate but greatly distended membranes (Fig. 269). The germ disc, GD, is especially small, appearing on the surface as an almost transparent fleck; it may occupy the same position as in the other fishes, or, as in the figure, it may occur at the lowermost pole. Among the fishes whose eggs float at the surface during development, as of many pelagic Teleosts, e.g. the Sea-bass, Serranus atrarius, - to which all the accompanying figures refer, - the yolk is lighter in specific gravity than the germ; it is of fluid-like consistency, almost transparent. In the yolk at the upper pole of the egg an oil globule, $O G$, usually occurs; this serves to lighten the gravity of the entire egg, and from its position must aid materially in keeping this pole of the egg uppermost.

The early segmentation of the germ is seen in Figs. $270,27 \mathrm{I}$. In the former, the first cleavage plane is established, and the nuclear divisions have taken place for the second; in the latter, the third cleavage has been completed. As in other fishes these cleavages are vertical, the third parallel to the first. A segmentation cavity, $S C$, occurs as a central space between the blastomeres, as it does in the sturgeon and gar-pike.

Stages of late segmentation are seen in section in Figs. 272,273 . In both the segmentation cavity, $S C$, is greatly 
flattened, but extends to the marginal cells of the germ disc; in Fig. 272 its roof consists of two tiers of blastomeres, its floor a thin film of the unsegmented substance of the germ; the marginal blastomeres are continuous with both roof and floor of the cavity, and are produced into a thin film which passes downward, around the sides of the yolk. In Fig. 273 the segmentation cavity is still further flattened; its roof is now a dome-shaped mass of blastomeres; the marginal cells have multiplied, and their nuclei are seen in the layer of the germ, $P$, below the plane of the segmentation cavity. These are seen at MP in the surface view of the marginal cells of this stage (Fig. 274); they are separated by cell walls only at the sides; below they are continuous in the superficial downreaching layer of the germ. The marginal cells, $M P$, shortly lose all traces of having been separate; their nuclei, by continued division, spread into the layer of germ flooring the segmentation cavity, and into the delicate film of germ which now surrounds the entire yolk. Thus is formed the periblast of teleostean development, which from this point onward is to separate the embryo from the yolk; it is clearly the specialized inner part of the germ, which, becoming fluid-like, loses its cell walls, although retaining and multiplying its nuclei. It would accordingly correspond to that portion of the germ of the sturgeon in Fig. 253 which lies below the plane of the segmentation cavity, and which extends downward at the sides of the yolk; in this case, however, the surface outlines of the cells have not been lost. It will be seen from later figures (Figs. 278-282) that the periblast, $P$, comes into intimate relations with the growing embryo; it lies directly against it, and appears to receive cell increments from it at various regions; on the other hand, the nuclei of the periblast, 
from their intimate relations with the yolk, are supposed to subserve some function in its assimilation.

Aside from the question of periblast, the growth of the blastoderm appears not unlike that of the sturgeon. From the blastula stage of Fig. 273 to that of the early gastrula (Fig. 275), the changes have been but slight; the blastoderm has greatly flattened out as its margins grow downward, leaving the segmentation cavity apparent at $S C$. The rim of the blastoderm has become thickened, as the 'germ ring;' and immediately in front of $B P$, the dorsal lip of the blastopore, its thickening, as in Fig. 255, marks the appearance of the embryo. In Fig. 276 the germ ring, $G R$, continues to grow downward, and shows more prominently the outline of the embryo; this now terminates at $H P$, the head region; while on either side of this point spreads out tail-ward on either side the indefinite layer of outgrowing mesoderm, MES. In the. stage of Fig. 277 the closure of the blastopore, $B P$, is rapidly becoming completed; in front of it stretches the widened and elongated form of the embryo. A sagittal section through a late stage of the blastopore appears in Fig. 278; with it may be compared the corresponding region of the sturgeon of Fig. 256; the yolk plug, $Y P$, of the latter is now replaced by periblast, $P$, the dorsal lip at $B P$, by $T M$, the tail mass, or more accurately the dorsal section of the germ rim; the colenteron under the dorsal lip has here disappeared, on account of the close approximation of the embryo to the periblast; its last remnant, the Kupffer's vesicle, $K V$, is shortly to disappear. At $T M$, the germ layers become confluent as at $B P$ in Fig. 256 , but, unlike the sturgeon, the flattening of the dorsal germ ring, $T M$, does not permit the formation of a neurenteric canal. 
The process of the development of the germ layers in Teleosts appears an abbreviated one, although in many of its details it is but imperfectly known. In the development of the medullary groove, as an example, the following peculiarities exist: the medullary region at $H P$ (Fig. $276)$ is but an insunken mass of cells without a trace of the groove-like surface indentation of Fig. 26I or 229. Its condition is figured at $M$ in Fig. 282. It is only later, when becoming separate from the ectoderm, $E C$, that it acquires its rounded character (Fig. 279), $M$; its cellular elements then group themselves symmetrically with reference to a sagittal plane, where later by their disassociation (?) the canal of the spinal cord is formed (Fig. 280), $M$. The growth of the entoderm is another instance of specialized development. In the section of the embryo of Fig. 279, the entoderm exists in the axial region, its thickness tapering away abruptly on either side; its lower surface is closely apposed to the periblast; its clorsal thickening will shortly become separate as the notochord. In a following stage of development (Fig. 280), the entoderm is seen to arch upward in the median line as a preliminary stage in the formation of the cavity of the gut. Later, by the approximation of the entoderm cells in the median ventral line, the condition of Fig. 28I is reached, where the completed gut cavity exists at $G$.

The formation of the mesoderm in Teleosts is not definitely understood. It is usually said to arise as a process of 'delamination,' i.e. detaching itself in a mass from the entoderm. Its origin is, however, looked upon generally as of a specialized and secondary character.

The mode of formation of the gill slit of a Teleost does not differ from that in other groups; an evagination of the entoderm, GS (Fig. 282), coming in contact with an 
invaginated tract of ectoderm, $E C$, fuses, and at this point an opening is later established.

In Fig. 283 has been figured a late embryo. This may be compared with that of the sturgeon of Fig. 264. The Teleost, though of rounded form, is the more deeply implanted in the yolk sac; it is transparent, allowing notochord, primitive segments, heart, and sense organs to be readily distinguished; at about this stage both anus, $A$, and mouth, $M$, are making their appearance.

\section{THE LARVAL DEVELOPMENT OF FISHES}

When the young fish has freed itself from its egg membranes, it gives but little suggestion of its adult form. It enters upon a larval existence, which continues until maturity. The period of metamorphosis varies widely in the different groups of fishes - from a few weeks' to longer than a year's duration; and the extent of the changes that the larva undergoes are often surprisingly broad, investing every organ and tissue of the body, - the immature fish passing through a series of form stages which differ one from the other in a way strongly contrasting with the mode of growth of amniotes; since the chick, reptile, or mammal emerges from its embryonic membranes in nearly its adult form.

The fish may, in general, be said to begin its existence as a larva as soon as it emerges from its egg membranes. In some instances, however, it is difficult to decide at what point the larval stage is actually initiated: thus in sharks, the excessive amount of yolk material which has been provided for the growth of the larva renders unnecessary the emerging from the egg at an early stage; and the larval period is accordingly to be traced back to stages that are still enclosed in the egg membranes. In all cases the 
larval life may be said to begin when the following conditions have been fulfilled: the outward form of the larva must be well defined, separating it from the mass of yolk, its motions must be active, it must possess a continuous vertical fin fold passing dorsally from the head region to the body terminal, and thence ventrally as far as the yolk region; and the following structures, characteristic in outward appearance, must also be established, the sense organs, - eye, ear and nose, - mouth and anus, and one or more gill clefts.

Among the clifferent groups of fishes the larval changes are brought about in widely different ways. These larval peculiarities appear at first of far-reaching significance, but may ultimately be attributed, the writer believes, to changed environmental conditions, wherein one process may be lengthened, another shortened. So too the changes from one stage to another may occur with surprising abruptness. As a rule, it may be said the larval stage is of longest duration in (I) the Cyclostomes, and thence diminished in length in (II) Sharks, (III) Lungfishes, (IV) Ganoids, and (V) Teleosts; in the last-named group, a very much curtailed (i.e. precocious) larval life many often occur.

\section{Lamal Cyclostomes}

The Cyclostome larva is represented in a stage as early as that of Fig. 212: its form is here retort-shaped; the yolk material is concentrated in the ventral region immediately in front of the blastopore (the anus?), but is distributed in addition in the cells of other body regions. In the section of a slightly older larva (Fig. 2 I 5), in which the mouth is all but established, the form outline has become regular, the bulk of the yolk, $Y$, restricted to the 
cavity of the intestine, the only instance of this condition known among fishes (Ceratodus?), and, with but a single exception (Ichthyophis), * among all other vertebrates. The larval lamprey is by this time a quarter of an inch long, yellowish white in colour; its movements are sluggish, rarely more than to cause it to wriggle worm-like from the bottom. A few weeks later it has acquired its brownish grey colour, its fin fold is well marked, and its habit is active; it now feeds on muddy ooze rich in organic matter. It by this time possesses the essential characters of the well-grown larva, long looked upon as a distinct genus, Ammocetes. In its larval stage the lamprey appears to live a number of years; in Petromyzon planeri the adult stage is said to be sometimes deferred until the autumn of the fourth or fifth year. The transformation is then a surprisingly sudden one; the head attains its enlarged size, the mouth its ring-like and suctorial character, losing its more anterior position, and its lip-like flaps (cf. Fig. 72, $C, D$ ); teeth are developed in place of the numerous mouth papillæ; gills, formerly simpler in character, opening directly from neck surface to gullet, now enter the branchial chamber, a ventral diverticulum of the gullet; eyes become prominent, complete their development, and attain the head surface; unpaired fin, formerly of great extent, is now reduced to its adult position and proportions.

\section{Larval Sharks}

The larval history of Sharks has been summarized in Figs. 284-289: the younger of these stages (Figs. 284, $285,286)$ have not as yet escaped from their egg membranes. The hatching, in fact, of the young shark is

\footnotetext{
* The writer has not confirmed Salensky's observation upon the sturgeon.
} 
FIG. 284.
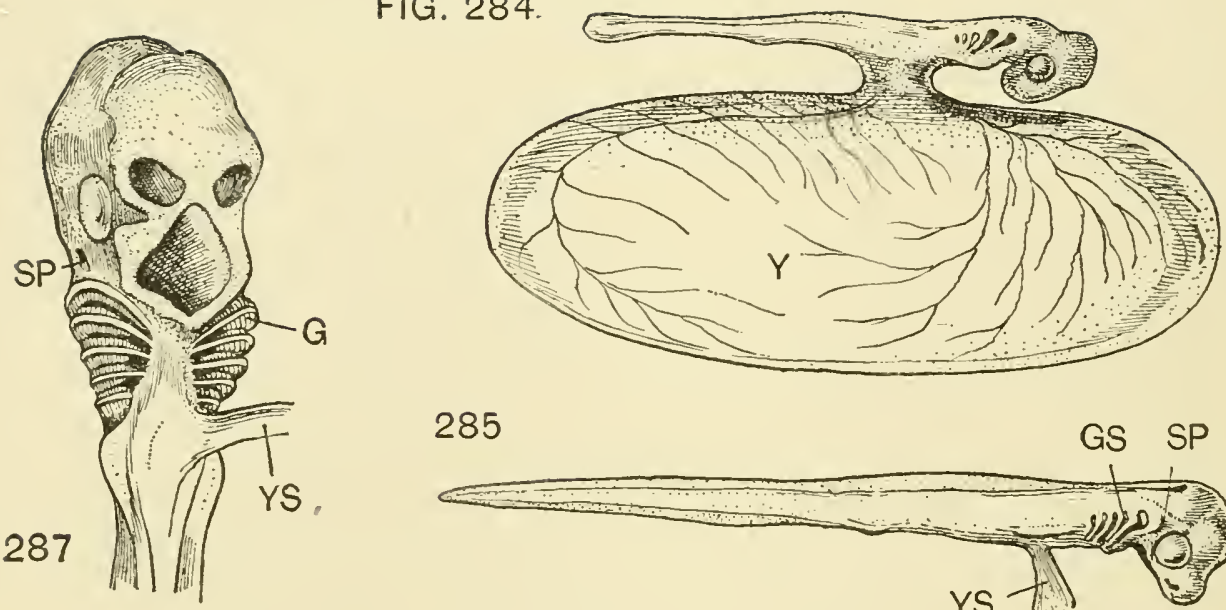

\section{5}
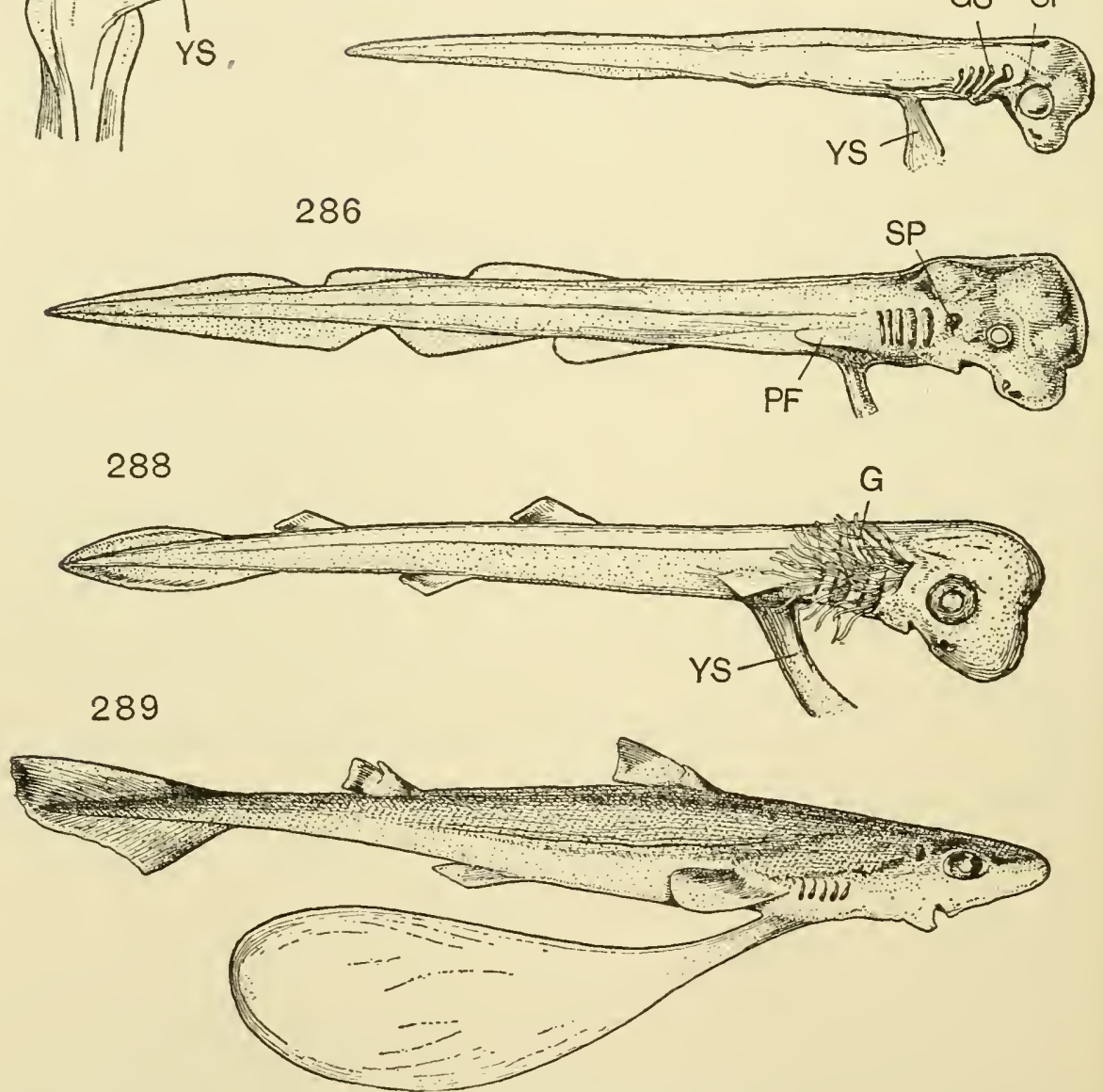

Figs. 284-289. - Larval sharks. (Figs. 284-287 after BALFOUR.) 284. Pristiurus $($ embryo, $\times 5$ ) with yolk sac $(\times 2) .285,286$. Larvæ of Scyllium. $\times 4.287$. Ventral view of head of larval Scyllium, slightly younger than that of last figure. $\times 8$. 288. Larva of Acanthias. $\times 4$. 289. Late larva of Acanthias. $\times \frac{2}{3}$.

G. Gills. GS. Gill slits. PF. Pectoral fin. SP. Spiracle. Y. Yolk sac. YS. Stalk of yolk sac. 
an exceedingly slow one; Pristiurus emerges from the egg in about nine months, Scyllium in about seven. And in consequence of the large amount of yolk stored in the yolk sac, the young shark, as in Fig. 289, has fully acquired its adult outward characters by the time the yolk is exhausted and its sac absorbed.

In Fig. 284 is figured a stage in the development of Pristiurus which may be regarded as either embryonic or larval; the form of the larva is well established; gill clefts, muscle-plates, mouth, and sense organs are present; but, on the other hand, unpaired fin and anus are lacking. There is shown the abrupt constriction, characteristic of Elasmobranchs, which separates the animal from the yolk sac, - a construction which in later stages becomes narrow and tubular. The relatively larger size of the yolk sac in later stages is, of course, the result of the bulkier elaboration of the yolk material.

The youngest stage (Fig. 284) shows prominently the great enlargement of the anterior end of the embryo, a marked cephalic flexure, large optic capsule, and irregular gill slits of graded sizes; a tubular tail end, bulbous at the terminal, where the neurenteric canal occurs; as yet the nasal pits are in close proximity to the mouth. In the next stage (Fig. 285), the elongated trunk has its unpaired fin, the neurenteric canal disappearing; the beginnings of the pectoral fins are noticeable; gill clefts are of more uniform size; and the anal region is indicated. In the stage of Fig. 286, further advances are seen in the constricting off of the unpaired fins, the appearance of the ventral and the continued growth of the pectoral fins; in the reduced foremost gill slit (spiracle); in the jaw region, and, in fact, in the entire shaping of the head; in the appearance of the lateral line. In the ventral head 
region (Fig. 287), is to be noted the prominence of the mouth cavity, and the enlarged gill arches, showing by this time the outbudding branchial filaments. In the stage of Fig. 288, the larva begins to appear shark-like; the fins are longer and more noticeable, the anus has appeared, and the branchial filaments by continued growth protrude at all gill openings. The external gills thus acquired are seen in a later stage (Fig. 289) to have disappeared; they have aided, however, as Beard, Turner, and others have shown, in absorbing nutriment, and must be looked upon as an especial organ of the larval life of the animal. Fig. 289 illustrates a final larval stage: in it there appear all of the structures of the adult outward form, e.g. shagreen, fin spines, nictitating membrane, anterior and posterior nasal openings. This larva has been estimated to be about a year older than that of Fig. 284.

\section{Larval Lung-fish}

The larval history of the lung-fish, Ceratodus, as recently described by Semon, seems to offer characters of exceptional interest, uniting features of Ganoids with those of Cyclostomes and Amphibians.

The newly hatched Ceratodus (Fig. 290) does not strikingly resemble the early larva of shark (Fig. 284). No yolk sac occurs, and the distribution of the yolk material in the ventral and especially the hinder ventral region is suggestive rather of lamprey or amphibian; it is, in fact, as though the quantum of yolk material had been so reduced that the body form had not been constricted off from it. The caudal tip in this stage appears, however, to resemble that of the shark, and as far as can be inferred from surface views a neurenteric canal persists. Like the shark there then exists no unpaired fin; the 

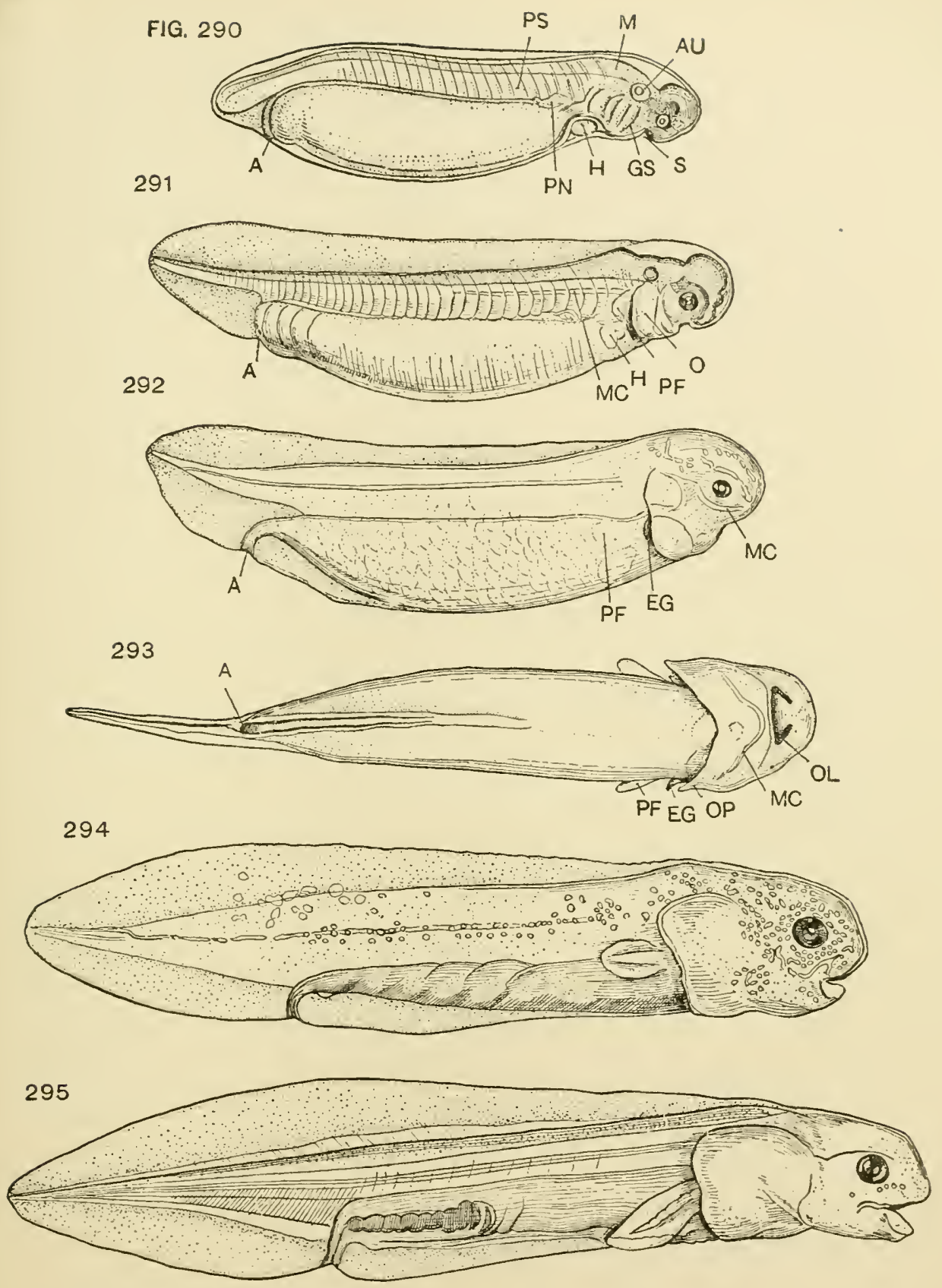

Figs. 290-295. - Larval lung-fishes, Ceratodus. (After Semon.) × 6. 290. Embryo at about the time of hatching. 29I. Young larva. 292. Larva of two weeks. 293. Larva of four weeks, ventral side. 294. Larva of six weeks. 295. Larva of ten weeks.

$A$. Anus. $A U$. Auditory vesicle. EG. External gills. GS. Gill slits. H. Heart. $M$. Central nervous system. $M C$. Mucous canals. O. Opercular flap. OL. Olfactory organ. $P F$. Pectoral fin. $P N$. Pronephros. $P S$. Primitive segments. S. Mouth pit, stomodæum. 
gill slits, five (?), $G S$, are well separated, and there is an abrupt cephalic flexure. In this stage pronephros and primitive segments, $P S$, are well marked, and are outwardly similar to those structures in Ganoid; the mouth, $S$, is on the point of forming its connection with the digestive cavity; the anus is the persistent blastopore; the heart, well established, takes a position, as in Cyclostomes, immediately in front of the yolk material.

In a later stage the unpaired fin has become perfectly established, the tail increasing in length; the gill slits have now been almost entirely concealed by a surrounding dermal outgrowth, the embryonic operculum; a trace of the pectoral fin, $P F$, appears; the lateral line is seen proceeding down the side of the body; near the anal region the intestine ${ }^{*}$ becomes narrower and the beginnings of the spiral valve appear. In a larva of two weeks (Fig. 292), a number of developmental advances are noticed: the fish has become opaque, the primitive segments are no longer seen; the size of the yolk mass is reduced; the anal fin fold appears; sensory canals are prominent in the head region; lateral line is completely established; the rectum becomes narrowed; and the cycloidal body scales are already outlined. Gill filaments may still be seen beyond the rim of the outgrowing operculum. In the ventral view of a somewhat later larva (Fig. 293), the following structures are to be noted : the pectoral fins which have now suddenly budded out, $\uparrow$ remincling one in their late appearance of the mode of

* The yolk appears to be contained in the digestive cavity as in Ichthyophis and lamprey.

t The abbreviated mode of development of the fins is most interesting; from the earliest stage they assume outwardly the archipterygial form ; the retarded development of the limbs seems curiously amphibian-like; the pectorals do not properly appear until about the third week, the ventrals not until after the tenth. 
origin of the anterior extremity of urodele; the greatly enlarged size of the opercular flap; external gills, still prominent ; the internal nares, $O L$, becoming constricted off into the mouth cavity by the dermal fold of the anterior lip (as in some sharks); and finally (as in Protopterus and some batrachian larvæ) the one-sided position of the anus.

The larva of six weeks (Fig. 294) suggests the outline of the mature fish; head and sides show the various openings of the tubules of the insunken sensory canals; and the 'archipterygium' of the pectoral fin is well defined. The oldest larva figured (Fig. 295) is ten weeks old; its operculum and pectoral fin show an increased size; the tubular mucous openings, becoming finely subdivided, are no longer noticeable; and although the basal supports of the remaining fins are coming to be established, there is as yet little more than a trace of the ventrals.

\section{Larval Ganoids}

The larval forms of a Ganoid, Acipenser (Figs. 296302), resemble far more closely those of the shark than of the lung-fish. When newly hatched, the young sturgeon (Figs. 296, 297) is attached to the well-rounded yolk sac situated in the throat region, in exactly the position one would expect the yolk stalk to be situated if the yolk mass were larger; it resembles the shark larva of Fig. 295 in its unpaired fin, in gill slits, in olfactory, $O L$, optic, $O P$, and auditory, $A U$, organs, and in the fact that it possesses even at this stage a trace of the neurenteric canal; on the other hand, it suggests the Ceratodus larva of Fig. 29I in its stout trunk region, prominent muscle segments, pronephros, $P N$, and anus, $A$; at the foremost corner of the yolk sac are mouth pit (stomodaum, $S$ ) and heart. A larva of the second day resembles in many features the 

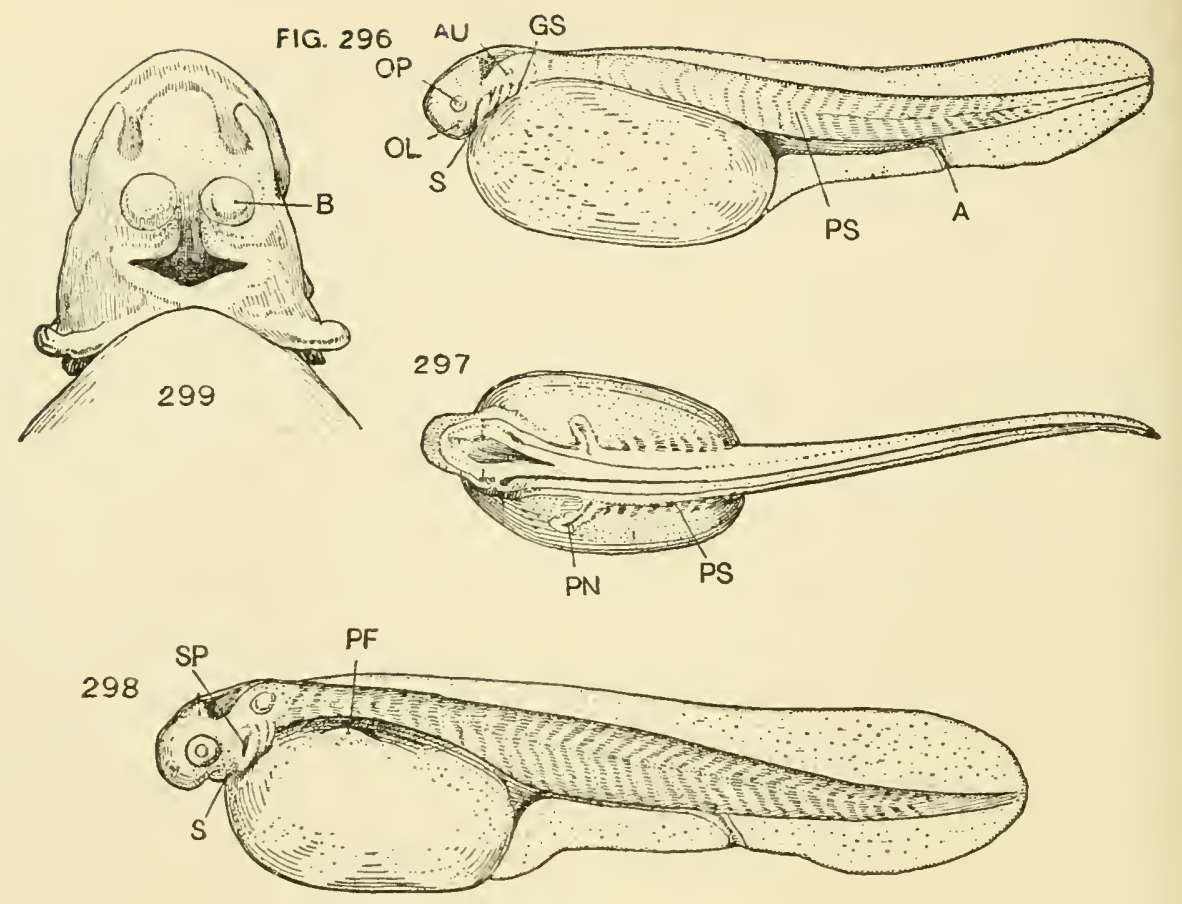

300

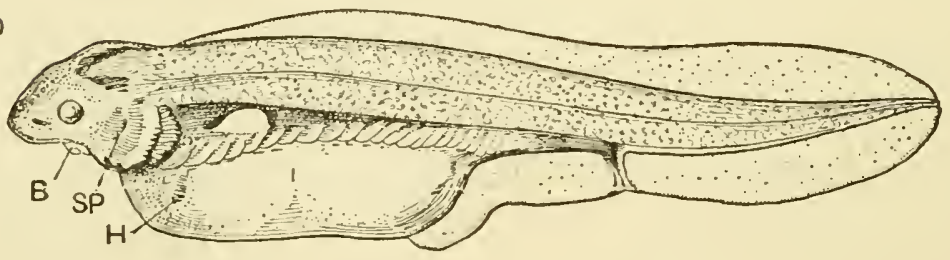

301
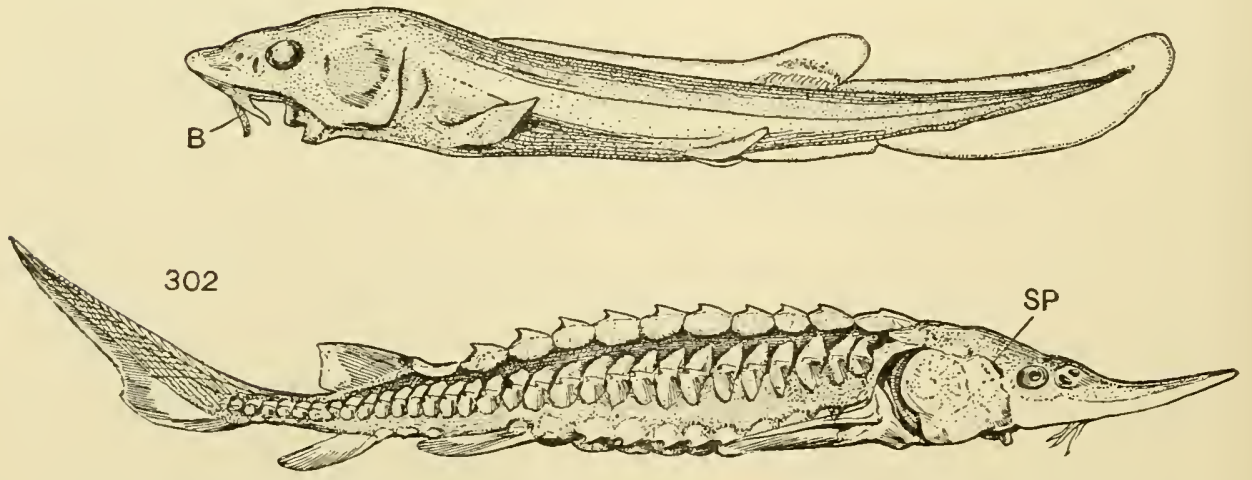

Figs. 296-302. - Larval sturgeons. (All but Fig. 302 after KUPFFER.) Fig. 299, X 18; 296-300, $\times$ I0; 301, $\times 8$; 302, $\times \frac{1}{2}$. (Enlargement approximate.) 296, 297. Larvæ shortly after hatching. 298. Larva two days old. 299. Mouth region of larva of third day. 300. Larva of fourth dav. 30r. Larva of twenty-eight days. 302. Sturgeon of twelve months.

A. Anus. $A U$. Auditory vesicle. B. Barbel. GS. Gill slit. H. Heart. OL. Olfactory pit. $O P$. Optic vesicle. $P F$. Pectoral fin. $P$ V. Pronephros. $S$. Mouth pit. $S P$. Spiracle. 
shark larva of Fig. 286: clorsal, caudal, and anal regions are outlined in the unpaired fin; a pectoral fin of a fin-fold character, $P F$, has appeared; the spiracle, $S P$, is becoming established. The mouth region is more clearly indicated in this stage, $S$, but may better be seen in ventral view in a slightly later larva; here (Fig. 299) the posterior lip is constricted off from the yolk region, and the anterior lip is budding off near the median line a pair of the tactile barbels; the dermal fold (operculum) enclosing the gills is in a condition very similar to that of Ceratodus in Fig. 293. A larva of the fourth day (Fig. 300) shows well-marked advances : the snout is elongated; the opercle is enclosing the gills, which are now seen to protrude as external branchial; the pectoral fin elongates and is tending to protrude its fin axis; body segments and heart are encroaching into the region of the now elongate yolk sac; the lateral line has been formed. In a larva of four weeks (Fig. 30I), the essential outlines of the sturgeon may be recognized, although the head appears of strikingly larger proportions: barbels, nares, mouth, operculum, and spiracle are as in the adult; fins, of the mature outlines, are wanting in all save basal supports; yolk material has long since been exhausted. A very late larva (Fig. 302), supposed to be twelve months old, differs outwardly from the sexually mature form in but its colouring and dermal plates: those of the regular rows are of great size, conspicuous in their abrupt spines and well-roughened borders; and those of the remaining trunk integument are remarkably prominent; the tail of the larva shows clearly its palæoniscoid character.

\section{Larval Teleosts}

The metamorphoses of the newly hatched Teleost must finally be reviewed; they are certainly the most 

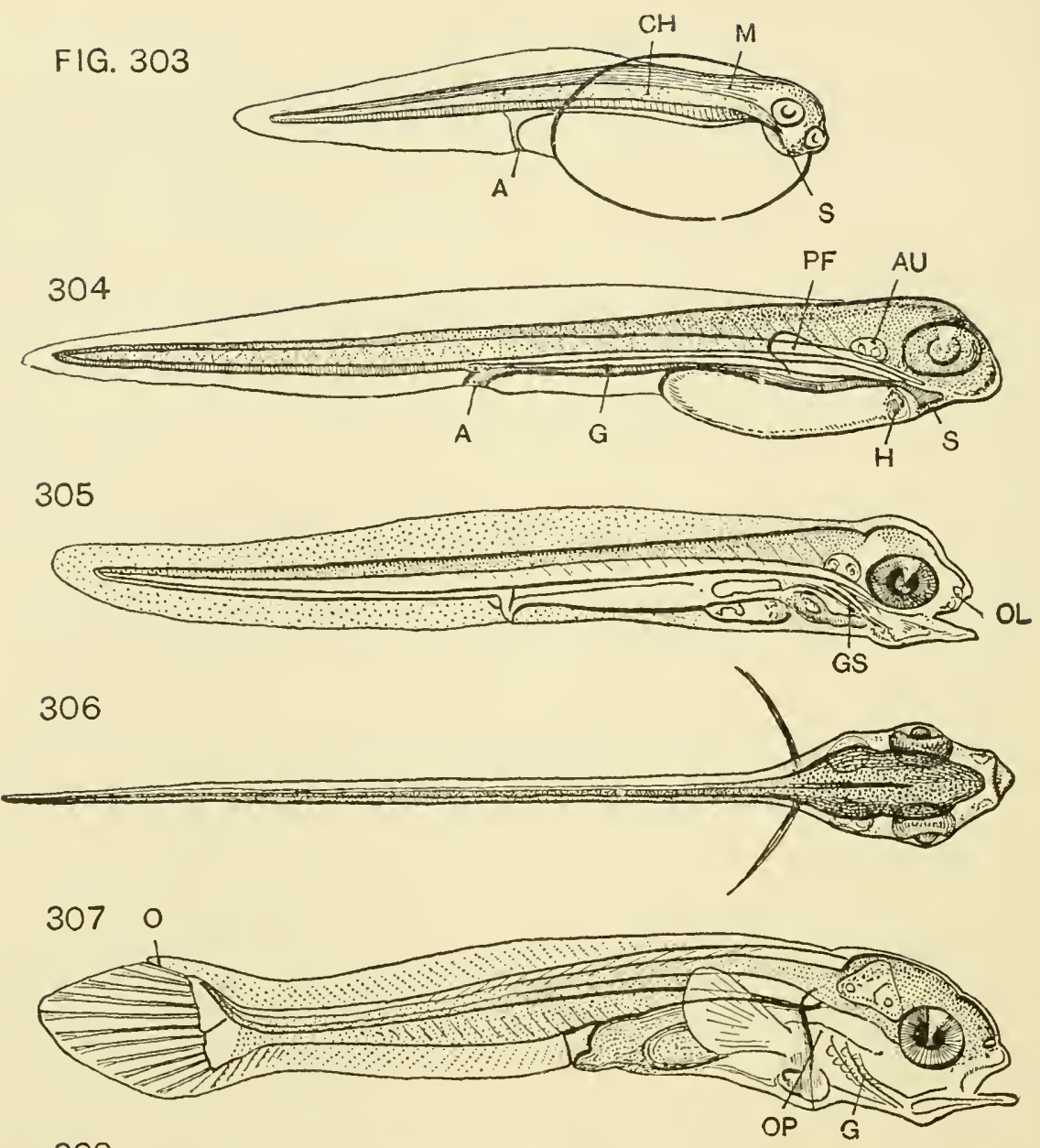

308

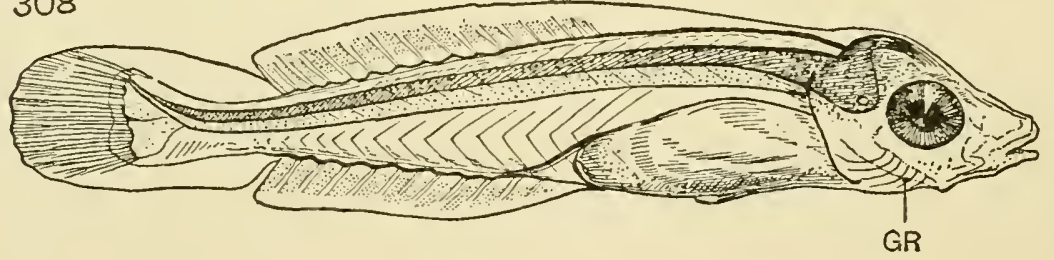

309

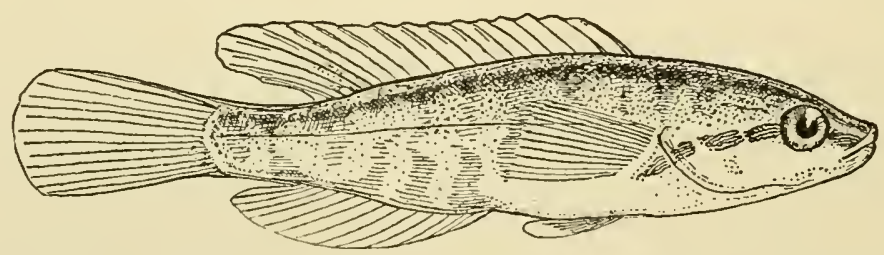

Figs. 303-309. - Larvæ of Teleost, Ctenolabrus. (After A. AgAssiz.) Fig. $309 \times$ about 7 , other figures $\times$ about $\mathrm{I}_{4}$. 303. Larva shortly after hatching. 304, 305. Larvæ of first few days. 306, 307. Larva of one week. 308. Larva of two weeks (?). 309. Final larval stage, four (?) weeks.

$A$. Anus. $A U$. Auditory vesicle. $C H$. Notochord. GR. Gill protecting dermal rays. $H$. Heart. $M$. Central nervous system. $O L$. Olfactory capsule. $O P$. Optic vesicle. $P F$. Pectoral fin. S. Stomodæum. 
varied and striking of all larval fishes, and, singularly enough, appear to be crowded into the briefest space of time; the young fish, hatched often as early as on the fourth day, is then of the most immature character; it is transparent, delicate, inactive, easily injured; within a month, however, it may have assumed almost every detail of its mature form. A form hatching three millemetres in length may acquire the adult form before it becomes much longer than a centimetre.

The larval life of the common Sea-bream, or Cunner, Ctcnolabrus comuleus, has been admirably figured by $\mathrm{A}$. Agassiz. The newly hatched fish (Fig. 303) has the yolk sac appended at the throat, as a large, transparent, if slightly tinted, globule; save for its great delicacy and transparency, it may generally be compared to the corresponding larva of Acipenser (Fig. 296). By the third day (Fig. 304), the yolk sac has become greatly reduced, the trunk elongated, the fin fold less conspicuous; primitive segments have appeared; the pectoral fin has arisen, but is not of the elasmobranch form of the similar stage (Fig. 298) of sturgeon; it is long, thin, transparent, and its rapid growth indicates its metamorphosed character. The mouth, $S$, is in this stage on the point of formation. In a slightly older larva (Fig. 305), the yolk has almost disappeared; its gill slits, $G S$, and mouth have now been formed, and with the latter the nasal apertures. In a following stage (Figs. 306, 307), a well-marked opercular fold makes its appearance; pectoral fins acquire their completed outline and the fin fold undergoes changes: anteriorly it acquires supporting actinotrichia, posteriorly the dermal supports of the caudal fin appear and at their bases the coalesced radio-basals; a ganoidean heterocercy is here apparent, its distal tip the membranous opisthure, 0 . 
The later larva (Fig. 308) is characterized by the appearance of abundant pigment masses (not shown in the figure) in all regions of the trunk; branchiostegal rays, $G R$, and traces of pelvic fins are noted; the caudal fin has become separated from the dorsal and anal elements. And finally, in the stage of Fig. 309, the fish, although still of very small size, has acquired almost perfectly its mature features; the outward differences are only those of pigmentation and fin proportions. 


\section{LIST OF DERIVATIONS OF PROPER NAMES}

Acanthodes, åkav $\theta \dot{\omega} \delta \eta s$, provided with spines.

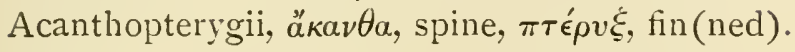

Acipenser, $\dot{\alpha} \kappa \iota \pi \dot{\eta} \sigma \iota \iota^{\circ}$, classic name of sturgeon.

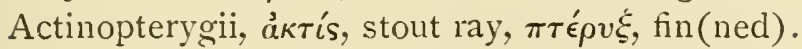

Alopias, $\dot{a} \lambda \omega \pi \epsilon \kappa^{\prime} \alpha s$, classic name of the fox shark.

Amia, $\dot{a} \mu i a$, classic name of tunny(?).

Amiurus, ảuía, Amia, ớpá, tail(ed).

Ammocœes, ă $\mu \mu$ os, sand, кoí $\eta$, (a bed) abider.

Anacanthini, ảvá, without, $a ̈ \kappa \alpha \nu \theta \alpha$, spine.

Anguilla, classic name of eel.

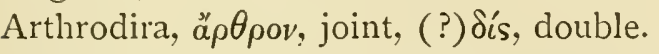

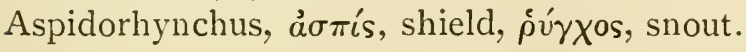

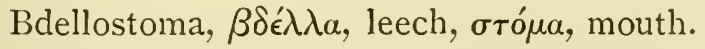

Belonorhynchus, $\beta \epsilon \lambda o ́ v \eta$, classic name of gar-fish, ṕv $\gamma \chi \chi_{0}$, snout.

Calamoichthys, calamus, a reed, i $\chi$ $\theta$ śs, fish.

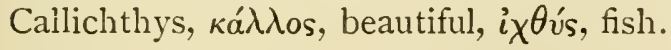

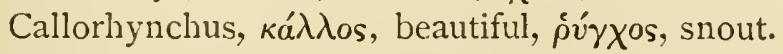

Carassius, $\chi a ́ p \alpha \xi$, classic name of (sea)fish.

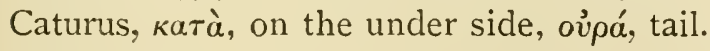

Cephalaspis, $\kappa \epsilon \phi \alpha \lambda \dot{\eta}$, head, $\dot{a} \sigma \pi i i^{\prime}$, shield.

Ceratodus, ќ́pas, horn, ỏdov́s, tooth(ed).

Cestracion, $\kappa \epsilon ́ \sigma \tau \rho \alpha$, classic name of (pavement-toothed) sea-fish.

Cheirodus, $\chi \epsilon i p$, hand, ỏoov's, tooth(ed).

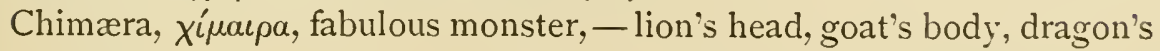
tail.

Chlamydoselache, $\chi \lambda a \mu v \delta o ́ s$, frilled, $\sigma \in \lambda a ́ x \eta$, shark.

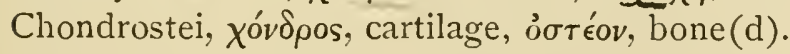

Cladoselache, for Cladodonto-selache, $\kappa \lambda a ́ \delta 0$ s, branch, ỏoovis, tooth(ed), $\sigma \in \lambda \alpha ́ \chi \eta$, shark.

Climatius, $\kappa \lambda i \mu a$, a gradation (in allusion, perhaps, to the graded row of fin spines). 
Coccosteus, ко́ккоs, rough like a berry, ó $\sigma \tau \in \operatorname{cov}$, bone.

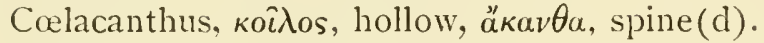

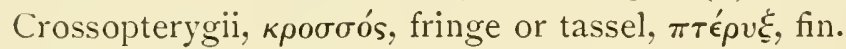

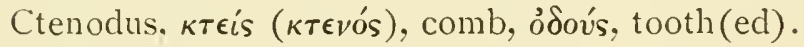

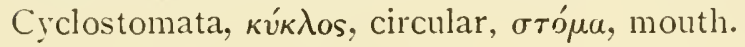

Dinichthys, $\delta \epsilon \iota v o ́ s$, terrible, ¿ $\chi \theta$ ús. fish.

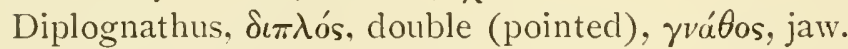

Diplurus, $\delta \iota \pi \lambda$ ós. double. oủpá, tail(ed).

Dipnoi, dípvoos, double breathing.

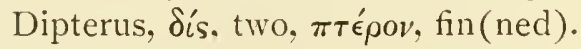

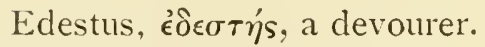

Elasmobranchii, é $\lambda a \sigma \mu o ́ s, ~ s t r a p-l i k e . ~ \beta \rho a ́ \gamma \chi \iota \iota$, gill(ed).

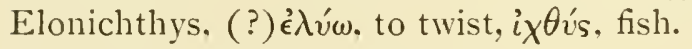

Erythrinus, ép $\imath$ epós, red-coloured.

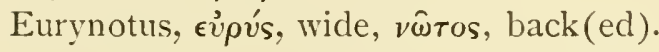

Eusthenopteron, $\epsilon \dot{v} \sigma \theta \epsilon v \dot{\eta} \boldsymbol{s}$, strong, $\pi \tau \epsilon \rho o ́ v$, firr.

Fierasfer, derivation of Cuvier uncertain, perhaps from proper name.

Gadus, classic name of cod.

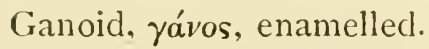

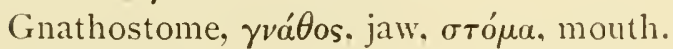

Gyroptychius, $\gamma \hat{v} \rho o s$, a circle, $\pi \tau \dot{x} \chi \chi_{0}$, folded (referring to the tooth enamel).

Harriotta, from the proper name Harriott.

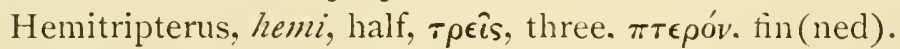

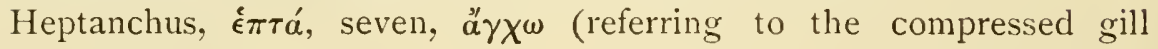
openings).

Hippocampus, classic name, "sea-horse."

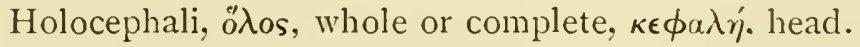

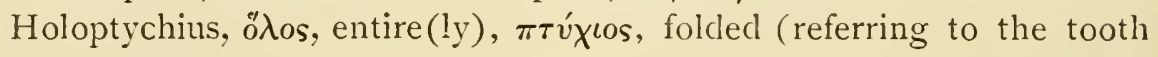
enamel).

Hybodus, v̋os, hump, ódovis, tooth.

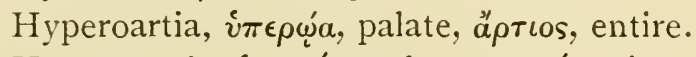

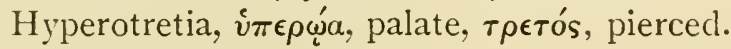

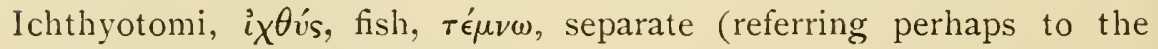
distinctness of this group).

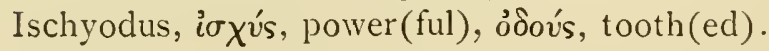


Læmargus, classic name of a shark.

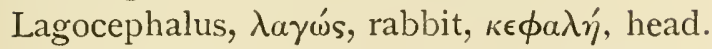

Lamna, $\lambda \alpha ́ \mu \nu \alpha$, classic name for a shark.

Lepidosiren, $\lambda \epsilon \pi i s$, scale (d), siren, salamander.

Lepidosteus, $\lambda \epsilon \pi i$ s, scale, ỏoréov, bone.

Leptolepis, $\lambda \epsilon \pi \tau$ ós, smooth or delicate, $\lambda \epsilon \pi i s$, scale $(\mathrm{d})$.

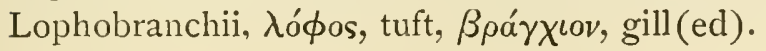

Marsipobranchii, $\mu \alpha \rho \sigma i ́ \pi \iota v$, pouch, $\beta \rho a ́ \gamma \chi \iota \alpha$, gills.

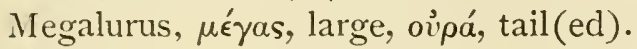

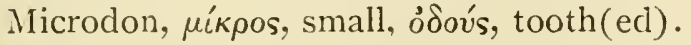

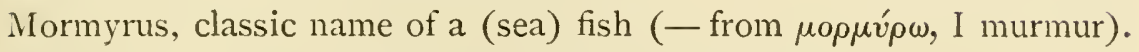

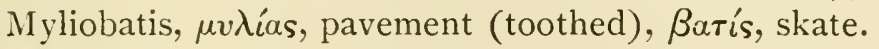

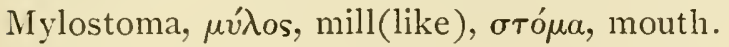

Myriacanthus, $\mu v \rho \iota a ́ s$, ten thousand, äkav $\theta a$, spine.

Myxine, $\mu \nu \xi \hat{\imath} \iota \nu s$, slimy-fish.

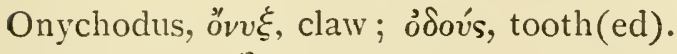

Ophidium, ỏ $\phi \hat{\imath} \iota \iota v$, a snake.

Osteolepis, ó $\sigma \tau \epsilon \dot{o v}$, bone, $\lambda \epsilon \pi i$ s, scale(d).

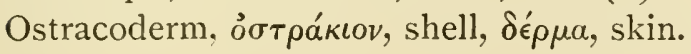

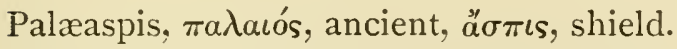

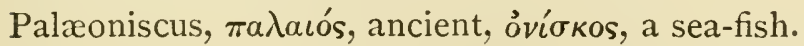

Palæospondylus, $\pi a \lambda a \iota o ́ s, ~ a n c i e n t, ~ \sigma \pi o ́ v \delta v \lambda o s$, vertebræ.

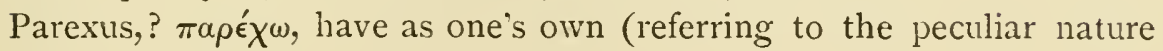
of the fish?).

Perca, classic name of fish.

Petromyzon, $\pi \dot{\varepsilon} \tau \rho o s$, stone, $\mu \nu \zeta \alpha$ '́ $\omega$, to suck.

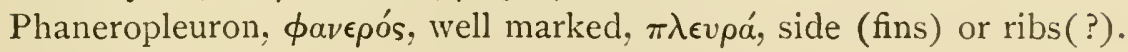

Pisces, fishes.

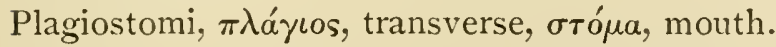

Plectognathi, $\pi \lambda \epsilon \kappa \tau o ́ s, ~ t w i s t e d, ~ \gamma v a ́ \theta o s$, jaw.

Pleuracanthus, $\pi \lambda \epsilon v \rho a ́$, side, åkav $\theta a$, spine.

Pleuropterygii, $\pi \lambda \epsilon v \rho a ́$, side, $\pi \tau \hat{\tau} \rho v \xi$, fin(ned).

Pogonias, $\pi \omega \gamma \omega v i a s$, bearded.

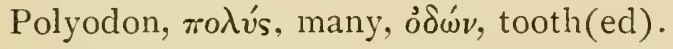

Polypterus, $\pi$ odv́s, many, $\pi \tau \epsilon \rho o ́ v$, fin(ned).

Prionotus, $\pi \rho i \omega v$, saw, vîtos, back.

Pristiophorus, $\pi \rho i \sigma \tau \iota s$, a saw, $\phi \circ \rho \dot{\epsilon} \omega$, to carry.

Pristis, $\pi \rho i \sigma \tau \iota s$, a saw-fish.

Protopterus, $\pi \rho \hat{\omega} \tau o s$, ancient, $\pi \tau \epsilon \rho o ́ v$, fin(ned). 


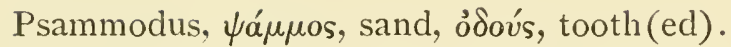

Psephurus, $\psi \hat{\eta} \phi o s$, a little stone, oủpá, tail.

Pseudopleuronectes, $\psi \epsilon \hat{v} \delta o s$, false, $\pi \lambda \epsilon v \rho o ́ v$, side, $\nu \eta \dot{\kappa} \tau \eta s$, swimmer.

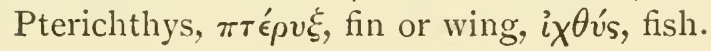

Raja, classic name of skate.

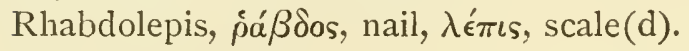

Rhina, ீív $\eta$, a rasp.

Rhinobatus, 'ீiva, Rhina, $\beta a \tau i s$, skate.

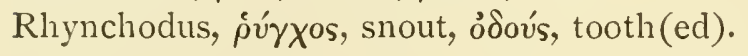

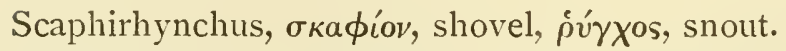

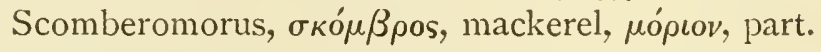

Scyllium, $\sigma \kappa u ́ \lambda \iota v v$, classic name of this shark.

Selachii, $\sigma \epsilon \lambda \alpha ́ \chi \eta$, shark.

Semionotus, $\sigma \eta \mu \epsilon \hat{\imath} o v$, a standard, $\nu \hat{\omega} \tau o s$, back.

Silurus, classic name of fish.

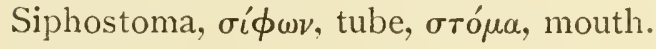

Sirenoidei, siren, salamander, oỉos, like.

Squaloraja, squalus, shark, raja, skate.

Squalus, classic name of a shark.

Squatina, a classic name of a sea-fish.

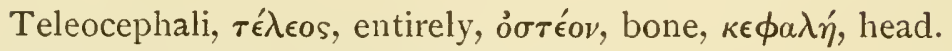

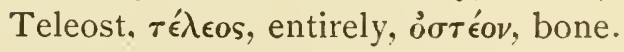

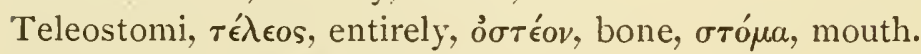

Titanichthys, titan, giant, ix$\theta$ v́s, fish.

Torpedo, classic name (from the root of Torpor, stupefy).

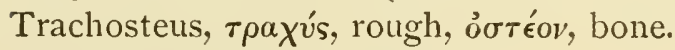

Trygon, т $\rho \dot{\gamma} \gamma \omega \nu$, the thorny ray.

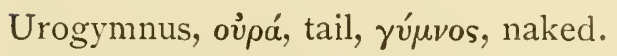

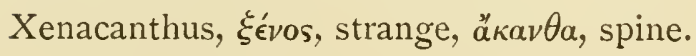




\section{BIBLIOGRAPHY}

In the following list the writer aims to present the more recent and more important works relating to the general subject of fishes. Titles have been classified, and most of the references give more or less complete bibliographies of their special subjects. Of the journals in which papers occur the principal abbreviations are as follows :-

\begin{tabular}{|c|c|c|}
\hline $\begin{array}{l}\mathrm{A} \cdot \\
\mathrm{AH}\end{array}$ & $\begin{array}{l}\text { Archiv (or Archives). } \\
\text { Abhandlungen. }\end{array}$ & $\begin{array}{l}\text { Q.J.M.S Quarterly Journal of } \\
\text { Microscopical Science. }\end{array}$ \\
\hline Ann. N.H & $\begin{array}{l}\text { Annals and Magazine } \\
\text { of Natural History. }\end{array}$ & $\begin{array}{l}\text { P. . . Proceedings. } \\
\text { R. . . Report. }\end{array}$ \\
\hline B & Bulletin. & Society. \\
\hline $\mathrm{R}$ & Contes rendus. & Sitzungsberichte. \\
\hline S . & Denkschriften. & Science, or Scientific. \\
\hline & Journal & Transactions. \\
\hline & $\begin{array}{l}\text { Jahrbuch } \\
\text { Jahreshefte }\end{array}$ & $\begin{array}{c}\text { U.S.F.C United States Fishery } \\
\text { Commission. }\end{array}$ \\
\hline J.R. & $\begin{array}{l}\text { Journal of the Royal Mi- } \\
\text { croscopical Society. } \\
\text { Mittheilungen }\end{array}$ & $\begin{array}{l}\text { Verhandlungen. } \\
\text { Zeitschrift. }\end{array}$ \\
\hline
\end{tabular}

The Roman numerals denote the number of the volume, the Arabic numerals the pages.

\section{WORKS ON THE GENERAL SUBJECT, FISHES}

Woodward, A. Smith Catalogue of Fossil Fishes in the British Museum. Vols. I, II (and III).

London, I8S9-(95).

Günther, A. . . Catalogue of the Fishes in the British Museum. Vols. I-VIII. London, I859-70.

Günther, A. . . . An Introduction to the Study of Fishes. 8vo. pp. 720. Illustrated. Edinburgh, I880.

Günther, A. . . Fishes: Challenger Reports. Vol. I, pt. VI, Vol. XXXI, pt. LXXVIII.

London, 1880-89.

GiLl, T. . . . Fishes: Standard Natural History. 
Goode, G. Brown . . Fishery Industries of U. S. U. S. F. C.

Washington, I884.

Dumeril, A. . . Histoire naturelle des Poissons. Vols. I-II (Sharks, Chimæroids, Lung-fishes, Ganoids, Lophobranchs). Paris, I890.

Agassiz, L. . . . Recherches sur les Poissons Fossiles. Vols. $\mathrm{I}-\mathrm{V}$, with Atlas volumes.

Neuchâtel, 1833-43.

Zittel, K. v. Handbuch der Palaeontologie. Fische. Munich, I887.

Rolleston, G. . . . Forms of Animal Life. Second edition. Oxford, I888: Huxler, T. . . Manual of the Comparative Anatomy of Vertebrated Animals. New York, I872. Jordan and Guilbert Manual of the Vertebrates of Eastern N. A. McClurg. Last edition.

SKeleton. - '86 Baur, G., Squamosum, Anat. Anz. '87 Ribs, Am. Nat. xxi, 942-945. '86 Cope, E. D., Caudal vertebræ, Am. Phil. Soc. 243. ' 93 Boulenger, G. A., Hæmapophyses, Ann. N.H. xii, 6o-6r. '92 Dol.lo, L., Ribs, vertebræ, B. Sci. Fr. Belg. xxiv. '87 Gegenbaur, Occipital region, Kölliker Festschr. I-33. '79 Goette, A., Wirbelsäule, A. mikr. Anat. xvi, 428. ' 89 HaTSCHEK, Rippen, VH. Anat. Gesell. Berl. (Jena). '78 Ihering, H., Wirbelverdoppelung, Zool. Anz. I, 72-74. 93 Jordax, D. S., Temperature and vertebræ. Wilder Quarter Century Book, Ithaca, I3-37. '93 Klaatsch, H. (Vertebræ). Morph. JB. xix, 649680, and xx, I43-I86. '68 KLEIN. Schädel, Würt. Nat. JH. 7 II7 I, and ('81) xxxvii, 326-360. '87 LuofF, B. (Chorda and Sheath), B. S. Mosc. 227-342 (442-482, German). '77 PARker and Bettany, Morph. of the Skull, London, pp. I4-9o. 89 Pouchet and Beauregard, Traité de Ostéol. Comp. Paris, 398-451. '87 Strecker, C. (Condyles), A. Anat. Phys. Anat. Abth. $30 \mathrm{I}-33$.

Integument, TEETH. - '92 Agassiz, A., Chromatophores, B. Mus. Comp. Zool. xxiii, I89-193. '82 Baume, A., Odont. Forsch. Leip. 4I-52. '77 Hertwig, O., Hautskelet, Morph. JB. II, 328-395, and v ('79), I-2I. 90 Klaatsch, H., Schuppen, op. cit., 97-202 and 209-258. '45 Owex, Odontography, London. '93 Ryder, J. A., Mechanical genesis of Scales, Ann. N. H., xi, 243-248. '82 Tomes, C., Dental Anat. Ed. 2. 
FINS. - '90 Cope, Homologies, Am. Nat. 40i-423. '79 Davinoff, M., Pelvics, Morph. JB. v' 450-520, vi ('80), I25-1 28, 433-468. '87 Enery, C., Homologies, Zool. Anz.x, i 85-189. '65 GeGexBAUR, C., Brust Flosse, Leip. 4to, pp. i76. '70 Jen. Z., v, and (73) Archipterygium, vii. '79 Morph. JB., v, 52 I-525. '94 Op. cit. xxi, I I9-I60. '89 Hatschek (Paired), VH. Anat. Gesell. Berl. 82-90. '68 PARker, W. K., Shoulder girdle, Ray' Society, Lond. pp. 237. '83 Rauterfeld, E. V., Ventrals, Dorpat ('82), 48 pp. ' 79 Rrder, J. A., Bilateral symmetry, Am. Nat. xiii, 4I-43. '85 Unpaired fins, op. cit. xix, 90-97. '86 Embryol. of fins, R. U.S. F. C., 98 I-Io86. ' 86 Fin rays and degeneration, P. U. S. Nat. Mus. 7I-82. $\mathbf{8 7}$ Homologies, P. Acad. Philadel. 344-368. '77 Thacher, J., Homologies, Tr. Conn. Acad. III. '92 Wiedersheir, R., Gliedmassenskelet, Jena, 266 pp. ' 92 Woodward, A. S., Evolution, Nat. Sci. 28-35.

VISCERA, GLANDS, CiRCUlATORY. - '84 Ayers, H., Pori abdominales, Morph. JB. x, 344-349. ' 89 Carotids, B. Mus. Comp. Zool. xvii. ' 82 Balfour, F. M., Head kidney, Q.J. M. S. xxx, I2-I6. '87 BoAs, J. E. V., Arterienbogen, Morph. JB. xiii, I I5-I I8. '79 BRIdge, T., Pori abdominales, J. Anat. Phys. xiv, 8I-IO2. '85 Cleland, J., Spiracle, R. Br. Ass. I069. '87 Евеrтн, C. J., Blutplättchen, Kölliker Festschrift, 37-48. '66 Gegenbaur, Bulbus, Jen. Z. ii, 365-375. ' 84 Abdominal poren, Morph. JB. x, 462-464. '91 Conus, op. cit. xvii, 596, 6ro.' '85 Grosglik, S., Kopfniere, Zool. Anz. viii, 605-6i I. '90 Howes, G. B., Intestinal canal and blood supply, J. Linn. S. xxiii, 38I-4Io. '64 Hyrtl, J. (Hepatic and portal), SB. Acad. Wiss. Wien, 167-I75. '85 Phisalix, C., Rate, Paris, 8vo. '90 Röse, C., Herz, Morph. JB. xvi, 27-96. '82 Solger, B., Niere, A. H. Gesell. Halle, xv, 405-444. '84 Weldon, W. F. R., Suprarenals, P. Roy. S. xxxvii, 422-425.

SWIM-BLADDER. - '86 Albrecht, P., Non-homologie des poumons, Paris and Brux, 44 pp. '80 DAY, F., Zool. 97-IO4. '66 Gouriet, E., Ann. Sci. Nat. vi, 369-382. '73 Hasse, C., Anat. Studien, I, Heft 4. '90 Liebreich, O., A. Anat. Phy's. Phys. Suppt. I42-161, 360-363. '85 Morris, C., P. Acad. Nat. Sci. Philadel. 124-I35, Anat. Anz. ('85) xxvi, 975-986.

NERVOUS SYSTEM AND END ORGANS. - '83 BAUDELOT, E., fol. Paris, 178 pp. 88 BAteson, Sense organs, J. Mar. Biol. Ass. I, No. 2. ' 85 BEARD, J., Branchial sense organs, Q. J. M.S. xxvi. '82 Berger, E. (Eye), Morph. JB. viii, 97-I68. '84 Blaue, J. (Nasal membrane), A. Anat. Phys. 331-362. '83 
Canestrini, Otoliths, Atti. Soc. Pad. viii, 280-339. 86 Hearing organ, op. cit. ix, 256-282. '91 Chevrel, R., Sympathetic, Thèse faculté des sciences, Paris. '79 Dercus, F., Lateral line, P. Acad. Phil. I 52-I54. '70 FÉE, F., Système lateral, Mem. S. Sci. Nat. Strasb. vi, I29-20I. 73 HAsse, C., Gehörorgan, Anat. Stud. I, Heft 3. ' 88 Julin, C., Epiphysis, B. Sci. Nord. x, 55-65. '90 ? Kokes, E., Otoliths, Z. geol. Gesell. xliii, 154. '91 Owsjannikow, P. (Pineal eye), Rev. S. Nat. St. Petersb. I00-III. ' 81 Retzius, G., Gehörorgan, Stockholm, fol. 222 pp. 71 Schultze, F. E., Seitenlinie, A. mikr. Anat. vi, 62. '70 StiedA, L., Centralnervensystem, Z. wiss. Zool. xxi, 273-456.

EMBRYOLOGY. - '85 HaAcke, W., Uterinaler Brutpflege, Zool. Anz. viii, 488-490. Halbertsina, H. J., Normal en abnormal Hermaphroditismus, Tijd. Nied. Dier. Ver. Amst. '87 НоснStetter, F., Venensystem, Morph. JB. xiii. I I9-172. '86 HoffMas, C. K., Urogenital, Z. wiss. Zool. xliv, 570-643. '91 KupfFer, C. v., Kopfniere, VH. Anat. Gesell. 22-55. '90 Laguesse, E., Rate, J. de l'Anat. Phys. xxvi, 345-406 and 425-495. '77 Lankester, E. Ray. Germ layers, Q. J. M. S. xrii. '93 Lwoff, B., Keimblätterbildung, Biol. Centralb. xiii, 40-50, 76-8I. '79 MARTExs, E. V., Hermaphroditische Fische. Naturf. I I6. '80 NussBaUm, M., Differenzirung d. Geschlechts, A. mikr. Anat. xviii, I-I2I. 89 Schwarz, D., Schwanzende, Z. wiss. Zool. xlix, I9I-223. '92 Virchow, H., Dotterorgan, Z. wiss. Zool. liii, Suppl. 16I-206.

\section{THE CYCLOSTOMES}

GENERAL. -'93 Ayers, H., Bdellostoma, Woods Holl Lectures, I25-I6I. '92 BeARd, J., Lampreys and Hags, Anat. Anz. viii, 59-60. '91 Bujor, P., La metamorphose de l'Ammocœtes, Rev. Biol. du Nord de la France, iii, pp. 97. '93 GAGE, Lake and Brook Lampreys, Wilder Quarter Century Book, Ithaca, 421-493. '91 Howes, G. B., Lamprey's affinities and relationships, P. Tr. Liverpool Biol. Soc. vi, I 22-147. '89 JuLin, C., Morphologie de l'Ammocœte, B. Sci. France et Belge, 28I-282. '90 KaExsche, C. C., Metamorphose des Ammocœtes, Schneider's Zool. Beiträge, II, 219-250.

AnATOMY, GENERAL.-86 Cunningham, J. T., Critique of Dohrn's views of Cyclostome morphology, Q. J. M. S. xxvii, 265284. '88 Julin, C., Anatomie de l'Ammocœtes, B. Sci. du Nord de la France, x, 265-295. '75 Langerhass, P., Untersuchungen i. Petromyzon, VH. d. n. Gesell. Friburg, XI, Heft 3. '37 
Müller, J., Vergleich. Anat. d. Myxinoiden, AH. K. Akad. Wiss. Berlin, 6j-340, 9 pls. '79 Schneider, A., Beiträge zur vergleich. Anat. 4 to, pp. 164 , Berlin.

SKELETON. - '92 Burne, R., Branchial Basket in Myxine, P. Zool.

S. 706-708. '69 Gegenbaur, C., Sketelgewebe, Jen. Z. V. '93 Hasse, C., Wirbel. Z. wiss. Zool. 290-305. '76 HuXlex, T. H., Craniofacial Apparatus, J. Anat. Phys. x, 412-429. ('84) PARker, W. K., Monograph of Skeleton of Petrom. and Myxine, P. Roy. S., '82, 439-443 and Phil. Tr. Roy. S., '83, 373457. '78 PÉrÉpelkine, K., Structure de la Notochorde, B. Mosc. liii, I07-108. '92 Retzius, G., Caudalskelet der Myxine, Biol. Fören. iii, 8I-84.

MUSCUlATURE. - '75 Fürbringer, P., Muskulatur des Kopfskelets, Jen. Z. ix, N. F. II. '67 Grenacher, H., Muskulatur, Z. wiss. Zool. xvii. '59 Keferstein (Histological), Du Bois R's. A. f. Anat. 548. '82 Schneider, A., ü. d. Rectus, Zool. Anz. N. Io7, p. I64. '52 Stannius, H. (Heart fibres), Z. wiss. Zool. iv, 252. '52 (Histology), L'Institut, xx, I32-134, and Göttin. Nachricht. '51, 225-235. '82 Steindachner, A., ii. d. Rectus. Zool. Anz. v, 660.

FinS. - 85 Cleland, J., Tail of Myxine, R. Br. Ass. Adv. Sci. Io69. InTEGUMENT, TEETH. - '88 Beard, J., Teeth of Myxinoids, Nature, xxxvii, 499, and Anat. Anz. iii, 169-172. '91 Behrens, Hornzähne v. Myxine, Zool. Anz. xiv, 83-87. '82 Blomfield, S. E., Thread. cells of Epidermis of Myx. Q. J. M. S. xxii, 355-36r. '76 Foettinger, A., Structure de l'Epiderme, B. Acad. roy. d. Belge. ix́, No. 3. '94 Jacoby, M., Hornzähne, A. mikr. Anat. I 17-I48. '60 Kölliker, Inhalt d. Schleimsäcke d. Epidermis, Würzb. naturwiss. Zeitschr. i, I-IO. '64 MÜLler, H., Epidermis, Würzb. naturwiss. Zeitschr. v, 43-53. '89 PogojefF, L., Haut, A. mikr. Anat. xxxiv, 106-122. '61 Schultze, M., Kolbenförmig Gebilde, A. Anat. u. Phys.

VISCERA, GLANDS, CIRCULATORY.-'46 Duvernoy, G. L., Sinus veineux génital, C. R. xxii, 662. '76 Ewart, T. C., Abdom. pores, J. Anat. and Phys. x. '78 Vascular peribranchial spaces, J. Anat. and Phys. xii, 232-236. ' 89 GAGE, S. H., Blood, P. Am. S. Micros. x, 77-83, and J. R. M. S. 494. '17 Hone (Gills), Isis, 25-35. '93 Howes, G. B., Abnormal gill clefts in Pet. and Myx. P. Zool. S. 730-733. ' '87 Julin, Ch. (Two anterior gill slits), B. Acad. Roy. Sci. Brux. xiii, 275-293. '88 Appareil vasculaire, Zool. Anz. xi, 567-568. '94 Kerkaldy, J. W., Head-kidney of Myx. Q. J. 
M. S. 353-359. '90 Klinckowströм, A., Darm-u. Lebervenen b. Myx. Biol. Fören. 62-67. '93 Kupffer, C. v., Pankreas, SB. Morph. Gesell. Mün. ix, 37-59. '82 Legouis, P. S., Pancreas, C. R. xcv, 305-308, and Ann. S. Sci. Brux. viii, I87-304. 132 Mayer, C., milz. Gror. Nat. xxxiv, i65-166. '76 Meyer, F., Nieren, Centr. f. d. medicin. Wiss. No. 2. '39 Müller, J., Gefässe : Wundernetze, Monatsheft, Berlin, I84-186, and 272-292. '39 Lymphgefässe, AH. d. Berl. Akad. '73 Müller, W., Unniere b. Myx. Jen. Z. vii. '75 Urogenital system, AH. d. Ak. d. Wiss. Berl. ix. '2l Oken, J. (Gills), Isis, 27I-272, and '29 VH. Gesell. Natur. Berl. I, I33-I4I. '46 Robin, C., Système veineux, L'Inst. xiv, I20-123. '87 Thompson, D'A. W., Blood, Ann. N. H. xx, 23I-233, and Anat. Anz. ii, 630-632. '84 Weldon, W. F., Head-kidney of Bdell. Q. J. M. S. xxiv, I7I-I82.

NERVOUS SYSTEM, END ORGANS.-'82 Ahlborn, F., Götting. Nachr. 677-682. '83 Z. wiss. Zool. xxxix, I9I-294. '84 Hirnnerven, Z. wiss. Zool. xl, 286-308. '88-'89 BEARD, J., Parietal eye, Nature, xxxvi, 246-298, and 340-34I, also Q. J. M. S. xxix, 55-73. $\quad 77$ FrEUD, S., Nervenwurzeln im Rückenmark, SB. Ak. Wien, lxxv. '78 Spinalganglien, SB. Ak. Wien, lxxviii. '78 Goette, A., Spinalganglien, A. mikr. Anat. xv, 332-338. '72 HAsse, Auditory organ, Anat. Studien, I, Heft 3, and Ketel, ibid. 489-54I. '79 Jéténef, A. (Cerebellum), B. Pétersb. xxv, 333-345. '86 Julin, C. (Sy'mpathetic), A. Zool. exper. vi, and Anat. Anz. '87, I92-20I. '87 Nerfs latéral, B. Acad. R. Brux. xiii, 300-309. '92 Kohl, C., D. Auge v. Pet. u. Myx. Leip. Reudnitz. br. '37 Müller, J., Gehörorgan, Abh. Berl. Acad. '38 Nervensystem d. Myx. Berl. Monatsber, I6-20. '85 Nansen, F.. Aarsber. Berg. Mus. 55-78 (trans. in Ann. N. H. xviii, 209-226. '64 Owsjannikow, P., Gehör. Mém. Acad. St. Pétersb. viii. '83 (Sympathetic), Arb. Naturf. Gesell. xiv, and '84 B. Acad. St. Pétersb. xxviii, 439-448. '88 (Pineal eye), Mém. Acad. St. Pétersb. xxxvi. '86 Ransom, W. and Thompson, D'A., Spinal and visceral nerves, Zool. Anz. ix, 42I. '80 Retzius, G., Riechepithel. A. f. Anat. u. Phys. '90 (Myxine: caudal heart, nerve and sub-cutaneous ganglion cells), Biol. Untersuch. Neue Folge, Stockholm, Fol. '92 Nervenendungen in der Haut, des Pet., op. cit. (2) III, 37-40, and (tail structures), op. cit. iv, 36-41. '93 Gelirn-Auge v., Myx. op. cit. v, 27-30. And Geschmacksknospen bei Pet. op. cit., 69-70. '82 Rohon, J. V., Ursprung d. acusticus. SB. Ak. Wien, lxxxv, 245-267. '84 SACсні, T. (Neuroglia of retina), Arch. Ital. Biol. vi, 76-96. 
'80 Schneider, A., Nerven, Zool. Anz. 330. '71 Schultze, M., Retina, SB. nieder-rhein Gesell. 6 Nov. 79 Seleneff, A. (Cerebellum). B. Acad. St. Pétersb. xxv, 333-343, and ' 80 Mélanges Biol. St. Pétersb. x, 307-325. '88 Whitwell, J. R., Epiphysis, J. Anat. Phys. xxii, 502-504. 79 Wiedershem (Brain and nerves), Zool. Anz. 589-592 and ' 80 in Jen. Z. xiv, $1-24$.

\section{EMBRYOLOGY.}

I. General. '88 Goette, A., Zool. Anz. xi, I60-163 and '90 in AH. 3, Entwicklungesch. d. Thiere, 5 Heft. 88 Kupffer, C. v., Sỉ. bayer. Akad. I, 70-79, and '90 in A. mikr. Anat. xxxv, 469-558. '90 Nestler, Zool. Anz. xiii. 81 Nuel, J. B., A. d. Biol. i, and '82 ii, 403-454; also J. R. M. S. ii, 26-27. '70 OWSJANNIKOW, B. Acad. St. Pétersb. xiv, 325 and '89, xxxii, 83-95, and '91 Mél. Biol. xiii, 55-67 and B. Acad. St. Pétersb. 13-55, and '93 Ann. N. H. xi, 30-43. 81 Sсотт, W. B., O. J. M. S. xxi, 146-153, Zool. Anz. ('80) 422, and Morph. JB. vii. Also '82, A. Zool. expér. ix, and (pituitary body and teeth) Science, ii, I84-186, 731-732. Also '88 J. of Morph. i, 253-310. '87 Shipler, A. E., Q. J. M. S. xxvii, 325-370, and A. Zool. expér. i. Also Stud. Morph. Lab. Camb. iii.

II. Onary, Sperm, Fertilization. '93 BEARd, J., Testes with ora. Anat. Anz. viii, 59-60. '87 Böнı, A. A., Befruchtung, SB. bayer. Akad. 8 Feb., and A. mikr. Anat. xxxii. 77 CAlberla, E., Befruchtungsvorgang. Z. wiss. Zool. xxx, 437-486. '87 CunvingHan, T., Ova of Bdell. Tr. Roy. S. Edinb. xxx, 247-250, (Myxine) Zool. Anz. 390-392, and Q. J. M. S. xxvii, 49-76. 91 Spermatogenesis of Myx. Q. J. M. S. xxxiii, I69-186, and Zool. Anz. xiv, 22-27. '83 FERRY, L. (Internal fecundation), CR. Ixxxxvi, 721-722, and Ann. N. H. xi, 388 . '75 Gulliver, Spermatozoa, P. Zool. S. 336. '78 Kupfrer, C. v., u. Benecke, Befruchtung. Festschr. Th. Schwann Königsberg. '86 NANSEN (Protandric), Myxine, Zool. Anz. 676, '87 in Bergens Mus. Aarsber, pp. 34, and '89 (Q. J. M. S. I88-189) Zool. Anz. 261. '80 Nussbauni, M. (Eggs and spawning), A. mikr. Anat. xviii, I-I2I. 89 RetziUs, Entwick. d. Myx. Biol. For. i, 22-28, Anhang. 50-5I (Dec. '88). 63 Steenstrup, J. (Egg of Myxine), Oversigt. o. d. K. danske Videnskabernes Selskabs Forh.' 233-239. '87 IVeber, M. (Reply to Cunningham), Zool. Anz. 318-321. Geslachtsorganen v. Myx. Ned. Dierkd. Vereen, 4 pp. D. I. Af. 3-4.

III. Organogeny. 77 Calberla, E., Medullarrohr, Morph. JB. iii. '82 Dohrs, Hypophysis, Zool. Anz. 587-588, '83 in MT. z. Stat. Neapel, iv, I72-I89. '84 Visceralbogen, op. cit. V, I52-189. 
'86 Thyreoidea, op. cit. vi. 87 (Thyroid, Spiracle, Pseudobranch), op. cit. vii, 30I-337. ' 88 Nerven u. Gefässe, op. cit. viii, 233. '92 HatтA, S., Germinal Layers, J. Coll. Sci. Japan, v, 129-I 47. '84 Herms, E., Nervus acusticus, SB. math. nat. Acad. Münch. 333-354. '93 MCClure, Early stages, Zool. Anz. xvi, 429. ' 85 Shipley, A. C., Mesoblast and blastopore, P. Roy. S. Lond. xxxix, 244-248. 86 Nervous system, P. Camb. Phil. S. v, 374. '79 Wiedersheim, Brain and spinal nerves, Zool. Anz. ii, 589-592.

\section{THE OSTRACODERMS AND PALAOSPONDYLUS}

\section{(Cf. Smith Woodward's Cat. Foss. Fishes.)}

'85 Cope, E. D., Position of Pterichthys, Am. Nat. xix, 289-29I. '92 Claypole, E. W., Pteraspidian family, Q. J. Geol. S. xlviii, 542-562. '90 PAtтex. W., Q. J. M. S. xxxi, 359-365. 94 Limulus and Pteraspis, Anat. Anz. '94 Rohon, J. V. (Metamerism of Cephalaspids), Zool. Anz. 5I. '88 TraQUAIR, R. H., Asterolepids, Ann. N. H. ii, 485-504, and ('89) P. Phys. Soc. Edinb. 23-46. '90 Palæospondylus. Ann. N. H. vi, 485, and '93 in P. Roy. Phys. Soc. Edinb. xii, $87-94$, and ' 94 op. cit. xii, 312-321. '92 Silth Woodward, Forerunners of Backboned Animals, Nat. Sci. i, 596-602.

\section{THE SHARKS}

GENERAL. - 65 DumÉril, A, Hist. nat. d. poissons, Tome I (Sharks, Skates, and Chimæra), pp. 720, Paris. '79-'80 MiklouhoMACLAY, Plagiostomes of the Pacific, i, ii, iii (Anat. notes: Dentition of young Cestracionts), P. Linn. S. N. S. Wales, iii, 306-326. ' 41 Müller, u. Henle, Syst. Beschr. d. Plagiost. folio, 60 pls. Berlin.

ANATOMY, GENERAL. - '85 Garuan, Chlamydoselache, B. Mus. Comp. Zool. (cf. Günther in Challenger report). 90 JAEkEL, O., Kiemenstellung u. System. d. Sel. (?) Berlin. '91 Pristiophorus, A. f. Naturges, 15-48. LeuckART, R., Bildung d. Körpergestalt b. Rochen. Z. wiss. Zool. ii, 258. ' 93 MAREY (Swimming movements of Ray), C. R., cxvi, 77-8I. '92 MARShall and Hurst, Practical Zoölogy (Dog-fish), Putnam, N. Y. '84 Parker, T. J., Zoötomy (Skate), Macmillan. '84 Wils, H. B., Squatina. Lugd. Bat.

SKELETON. - '85 DoHRN (Visceral arches of Skate), MT. z. Stat. 
Neapel, vi. '72 Gegenbaur, Kopfskelet, 4to, Leip. '78 Hasse, C. (Vertebræ, Morph. JB. iv, 2 I4-268, and op. cit. Supplt. 43-58, and Berl. Verh. Naturw. I73-I74 (Zool. Anz. i, I44-I48 and I67I 7 I). Also '85, 4to, 27 pp. Leip. '84 HAswell, IV. A., P. Linn. S. N. S. Wales, ix, 7i-I I7. '78 Hubrecht, Bronn's Klassen u. Ordnungen. '64 Kölliker, Wirbel, Senkenb. Naturf. Gesell. v, 5I-99. Also 4to. Frankfurt. '90 PARker, T. J., Sternum in Notidanus, Nature, xilii, I42. '78 PARkER, W. K., Skuli (with develop.) of shark and skate, Tr. Zool. S. x, I84-234. '84 RosENBERG, E., Occiput, Festschr. Dorpat. 4to, 20 pp. And ' 87 in SB. Gesell. Dorp. viii, 3I-34. '73 Steenstrup, J. (Gill rakers of Selache), Overs. Dan. Selsk. No. I. '90 White, P. J., Skull and visc. skelet. of Læmargus, Anat. Anz. v, 259-26r .

FINS AND GIRDLES. - '81 BALFour, Skates, P. Zool. S. 70 Gegenbaur, Skel. of, Jen. Z. v, 397-447, also (claspers) 448-458. '90 Howes, Batoid and Squaloraja, P. Zool. S. 675-68S. '8.5 Mayer, P., Unpaaren Flos. MT. z. Stat. Neap. vi, 217-2S5. '79 Metschnikoff, O. (Morph. of girdles), Z. wiss. Zool. xxriii, 423438. '79 Mivart, ST. G., T. Zool. S. x, 439-484. ' 92 Mollier, S. (Entwickelung), Vorl. MT. Anat. Anz. vii, 35 I-365, also '77 Thacher, J., Tr. Connec. Acad. iii.

INTEGUMENT AND TEETH. - '44 AGAssiz, L., Dents et rayons, 4to, Neuchâtel. ' 68 Hawnover, A., Écailles. (?). Harless, E., Zahnbau v. Myliobates, 4to (?). '74 HerTwig. O. (also development), Jen. Z. viii. '72 RAvviER, L., Étranglements annulaire (Rays), C. R. I I29-I I32.

VISCERA. VESSELS, GLANDS. - '92 AntipA, G., Thymus, Anat. Anz. vii, 690-692. '88 Ayres, H., Carotids (Chlamydosel.), B. Mus. Comp. Zool. xvii, I9I-224. '78 Blanchard, R.. Superanal gland, J. de l'Anat. Phys. xiv, 442-450, and B. S. Zool. Fr. vii, 399-40I. '79 Bridge, Pori abdominales. J. Anat. Phys. ' 82 Dröscher, WV. (Histol. of gills), A. f. Nat. xlviii, I20-I77. '90 Ewart, J. C., Spiracle of Lamna, J. Anat. Phys. xxiv, 227-229. '78 Furbringer, Excretory system. Morph. JB, 49-56. '91 Gegenbaur, Cöcalanhänge v. Mitteldarm, Jen. Z. (?). I8o-I 84 . '90 Howes, Kidney of Raja, J. Anat. Phys. xxiv, 407-422. 90 Visceral anat. of Hypnos, P. Zool. S. 669-675. '72 Hyrte, J., Kopfarterien, DS. Ak. Wiss. Wien, xxxii. 263-275. 85 List, J. H., Cloakenepithel, SB. Akad. Wien (?), and Anat. Anz. vii, 545-546. ' 80 PARker, T. J., Spiral valve of Ray. T. Zool. S. xi, 49-6I, and Venous system, Tr. N. Zeal. Ins. xiii, 4I3-4IS. '86 On the vessels of Mustelus, and ('87) on Carcharodon, P. Zool. 
S. (?). '90 Pilliet, A. (Histol. of liver), C. R. Soc. Biol. ii, 690-694. ' 82 Pouchet, G., Termin. vascul. d. la Rate, J. de l'Anat. Phys. xviii, 498-502. '88 RüCKERT, J., Excretions-organe, A. Anat. Phys. (Anat.), 205-278. '77 STohr (Valves in arterial conus), Morph. JB. ii, I97-228. '79 Trois, E. F. (Carotids of Oxyrhina), Atti del Inst. Ven. and $\mathbf{8 3}$ (Of Alopecias), op. cit. '73 Turner, W., Visceral Anat. of Læmargus, J. Anat. Phys. 233. '75 Spiny Shark, op. cit. 79 Pori abdominales, op. cit. xiv, IOI-IO2. 81 Teeth and gill-rakers of Selache, op. cit. xiv, 273-286. '93 Virchow, H., Spritzlochkieme, SB. Gesell. n. Freunde, Berl. I77-I82; Augengefässe (90) A. Anat. Phys. (Phys.), I69-173. '67 MikluCHO-MAClay, Schwimmblasenrudiment. Jen. Z. iii, $448-453$.

NERVOUS SYSTEM AND END ORGANS. - '92 BRAUS, H., Rami ventrales d. vord. Spinalnerven. Inaug. Diss. 35 pp. Jena. '83 Cattie, J. F., Epiphysis, Z. wiss. Zoöl. xxxix, 720-722, and A. Biol. iii, IoI-I96. '90 Cherrel, R., Sympathetic, A. Zool. expér. v, I96 pp. '91 Coggi, A.. Vésicules de Savi (Torpedo), A. Ital. Biol. xvi, 2 I6-224. '92 Edinger, L., Zwischenhirn, AH. Senck. Gesell. xviii, 55 pp. (and Anat. Anz. vii, 472-476). '78 Ehlers, E., Gehirn u. Epiphyse, Z. wiss. Zool. xxx, Suppl. 607. '90 Ewart, J. C., Cran. nerves of Torpedo, P. Roy. S. xlvii, 240-291. 92 Electric organ of Skate, Phil. Trans. clxxxiii, 389-420 (Abs. in P. Roy. S. 474-476). '92 Sensory canals of Læmargus, and Skate, Tr. Roy. S. Edinb. Nos. 5-6 (Abs. in Zool. Anz.xv), i I6-1 20. ' 88 Fritsch, G., Bedeuting d. Kanalsyst. SB. Ak. Berl. 273-306. '88-89 GARMAN, Lateral line (figures many forms), B. Mus. Comp. Zool. xvii, No. 2. '71 Gegenbaur, Kopfnerven v. Hexanchus, Jen. Z. 497-560. '75 JACkson, W. H., and Clarke, Brain and nerves, J. Anat. Phys. x, 75-197. 87 LÉger, M., Cervelet d'un Alopias, B. S. Philom. xi, I60-163. '81 Marshall, A. M.. Head cavities and nerves, Q. J. M. S. xxi, 72, and (with SPENCER) 469-499. 80 Merkel, Sens. nerven in d. Haut. Rostock. '70 Miklucho-Maclay, Gehirn, 4to, 74 pp. Leip. '78 Retzius, G., Memb. Gehörlabyr. A. Anat. Phys. (Anat.), 83-105. '91 Rex, H. (Morph. of cran. nerves), Morph. JB. xvii, 4I7-466. '78 Rоном, J. (Brain), DS. Ak. Wien, xxxviii, 43-108. '86 Sanders, A., Phil. Trans. clxxvii, 733-764, and P. R. S. xl. '89 Shore, T. W., Vagus, J. Anat. Phys. iii, 428-45 I. '80 Solger (Organs of lateral line), A. mikr. Anat. xvii. '73 StiedA, L., Riickenmark, Z. wiss. Zool. xxiii, 435-442. '73 TodAro, F. (Gustatory buds and branch. membr.), Récherche 
lab. univers. Roma. (Abs. in A. Zool. expér.) 534-558. '91 Valenti, G., Histogenesis, A. Ital. Biol. xvi, 247-252. '76 Viault, F., Histology, A. Zool. expér. v, 44I-528. '83 Vignal, Sys. ganglionaire (Ray), op. cit. i, xvii.

EMBRYOLOGY, GENERAL. - '76 BALFour, G. M., in Q. J. M. S. xiv, and Camb. J. Anat. Phys. xi, pt. I. Also '78 Monograph, Macmillan, London. '90 Beard, J., Skate, R. Fish. Board, Edin. 89 Eigenmann, C. H. and R. S., Young stages, West Am. Nat. vi, I 50-I 51. ' 85 Haswell, W. A., Young Pristiophorus, P. Linn. S. N. S. Wales, ix, 680-68I. '77 His, W., Ueb. d. Bildung v. Haifishembryonen, Z. wiss. Zool. ii, I08-I24. '81 Hoffuan,, C. K. (?), Harlem. '88 Kastschenko, N., Anat. Anz. iii, 445467. '70 Kowalewsky, A. (Russian), Trans. Kiew. Soc. of Nat. i. '52 Leydig, F., Mikr. Rochen u. Haie, Leip. Englemann, iv, I27 pp. '76 MALı, A. W., Kongl. vet. akad. förhand. Stockholm. '42 MÜller, J. (Emb. differences of Shark and Ray), fol. Berlin. '86 Perenyi, J., Torpedo, Zool. Anz. ix, No. 227, 433-436. '77 Schultz, A., A. mikr. Anat. '92 Sedgwick, A., Q. J. M. S. xxxiii, 559-586. '64, Wyuan, Raja, Mem. Am. Acad. Arts and Sciences, ix.

I. Breeding, Gestation. - '73 Agassiz, A., P. Bost. Soc. xiv, 339. '90 Alcock, A., J. A. Soc. Bombay, lix, 5I-56. (Of Rays) '92 Ann. N. H. ix, 4I7-427, and x, I-8. '79 BolaU, H. (Of Scyllium), VH. Ver. Hamb. iii, I22-I 30 and ('81) Z. wiss. Zool. xxxv. '67 Coste (Of Scyllium), C. R. 99-100, and Ann. M. N. H. xix, 227. '70 Hone, E., Oroviviparous Sharks.'68 Macdonald, J. D., and Barron, Ch., Heptanchus, P. Zool. S. 37I-373. '85 Matthews, J. D.. Oviduct of Skate, J. Anat. Phys. xix, I 44-I 49. '90 Mehrdorf, C. (Gestation), Rostock, 5 I pp. '72 Meyer (Scyllium), Zool. Gart. 37I. '85 Oerley, L. (Gestation), Term. füzetek. ix, 293-309. 90 PARker, T. J., Mustelus, Tr. N. Zeal. Inst. xxii, 33I-333. 77 Petri, K. R., Copulationsorgane, Z. wiss. Zool. xxx, 288-385. '75 Schenk, S. L., Kiemenfäder, SB. Akad. Wien, I 2 pp. '79 Schmidtlein, R., MT. z. Stat. Neap. 1, 6r. 91 Wood-Mason and Alcock, Gestation of Pteroplatæa, P. Roy. S. xlix, 359-367, and 1, 202-209. '67 Trors, E. F. (Acanthias' gestation), Atti. Inst. Ven. I7 I-I 76. '77 (Gestation of Myliobatis and Centrina), op. cit. ii, 429. '77 Turner, W., Læmargus' oviducts, J. Anat. Phys. xii, 604607, and ('85) op. cit. xix, $22 \mathrm{I}-222$.

II. Egg, Gastrulation. - '92 Dohrx, Schwann'schen Kerne, Anat. Anz. vii, 348-35I. '72 Gerbe, Z., Segmentation, J. de l'Anat. 
Phys. '81 Herrmand, G., Spermatogenèse, C. R. xciii, 858-860, and '83 J. l'Anat. Phys. xviii, 373-432. '83 Hertwig, O. (Middle germ layer), Jen. Z. xvi, 287-290. ' 83 Hoffmann, C. K. (Middle germ layer), Arch. Neerland. xviii, 24I. '92 Endothelial Anlage d. Herzens, Anat. Anz. vii, 270-273, and '93 in Morph. JB. xix, 592-648. '88 Kastschenko, Dotterkerne, Anat. Anz. '90 (Early develop. and muscles), Zool. Beitr. ii, 25 I-266. '86 Kollidan, Fürchung (C. R. '84), Congr. pér. internat. d. sc. méd. Copenhague, i, Sect. d'Anat. 50-52, and VH. d. Natur. Gesell. Basle, Th. viii, Heft I. '78 La VAllette, St. George. A., Spermatosomatum, Bonn, 4to, 9 pp. 79 Lutken, Læmargus' eggs, oviduct, Vid. Medd. ('80) 56-6r. '84 Perravex, M. E. (Egg case), C. R. xcix, I080-I082.' '89 Ostroumoff, A., Blastoporus u. Schwanzdarm, Zool. Anz. xii, 364-366. '85 Rückert, J., Keimblattbildung, SB. Gesell. Morph. München, i, 48-104, and '89 in Anat. Anz. iv, 353-374. '86 Gastrulation (and middle germ layer), Anat. Anz. 286-287, and '87 op. cit. 97-II2 and I5I-I74. '91 Befruchtung, Anat. Anz. vi, 308-322. '92 Ovarialei, vii, I07-I58, Chromosomen, viii, 44-52. '86 RYDER, Segmentation, Am. Nat. xx, 470-473, and B. U. S. F C. 8-Io. '82 Sabatier, A., Spermatogenèse, C. R. xciv, I097-I099. '75 Schultz, A. (Ovogenesis), A. mikr. Anat. xi, 569-582. '73 Schenk, S. L. (Egg and oviduct), SB. Akad. Wien, Ixxiii. 74 Dotterstrang, op. cit. lxix, 30I-308. '90 SCHNEIDER, A. (Gastrula-muscles), Zool. Beitr. ii, 25I-266. ' 85 Swaen, A. (Germ layers and blood). B. Acad. roy. Belgique, ix, and ' 86 in A. de Biol. vii, 537-585. '83 Trois, E. F., Spermatozoi, Atti. Inst. Ven. and J. Microgr. vii, I93-I96. '84 VAILlant, L., Orientation des œufs dans l'utérus, B. Soc. Philom. viii, I78-i79. '88 ZIEGLER (Mesenchyme), A. mikr. Anat. xxxii. '92 Ziegler, H. E. and F. (Early development), A. mikr. Anat. xxxix, 56-102.

III. Integument, Skeleton. - '81 BENDA, C., Dentinbildung, A. mikr. Anat. xx, 246-270. '79 HASSE, C., Knorpel, Zool. Anz. ii, 325-329, 35I-355, and 37I-374. '82 Wirbelsäule, Jena ('79), 4to. '92 Wirbelsäule, Z. wiss. Zool. lv, 5 I9-531. '60 KöLliker, A., Chorda u. Wirbel. Würz. 87 Perenyı, J., Chorda, perichordal. Math. u. Naturwiss. Ber. a. Ungarn, iv, 2I4-2I 7, and ('89) in 2I8-24I. '93 Platt, Julia B., Ectodermic cartilage, Anat. Anz. 506. '78 Reichert, Vordere Ende d. Chorda, AH. Ak. Berl. 49-I I3. '84 Rosenberg, E., Occipitalregion, Festschrift, Dorpat, 26 pp. 4 to.

IV. Viscera. - '87 BEARd, J., Segmental duct, Anat. Anz. ii, 646-652. 
'85 Bemmelen, J. F. r. (Rudimentary gill slits), MT. z. Stat. Neap. vi, I65-184. '79 BlanchaRD, R., Fingerförmigen Druise, MT. Emb. Inst. Schenk, iii, I79-192, and ('77) J. de l'Anat. xlv, 442-450. '84 Dohrs, Kiemenbogen, Flossen, MT. z. Stat. Neap. v, IO2-189. '87 MaYer, P. (Circulatory), op. cit. vii, 338-370, and ('88) viii, 307-373. Also Anat. Anz. ix, 185-192. 77 MaYer, F., Urogenitalsys. SB. Gesell. Leip. ('76), 38-44. '92 Rabl, C., Venensys. Leuckart Festschr. 228-235. '92 RAFFAELE, F., Sist. vascolare, MT. z. Stat. Neap. x, 44I-479. ' 88 RÜCKert, J., Endothel. Anlagen d. Herzens, Biol. Centralbl. viii. '89 Excretionssys. Zool. Anz. xii, i 5-22. 75 Semper. C., Urogenitalsys. Arb. a. d. Zool. Zoot. Inst. Wuirz. ii. 88 Wijhe, J. W. v., Excretionsorgane, Zool. Anz. xi, 539-540, and Anat. Anz. iii. 74-76, and 89 in A. mikr. Anat. xxxiii, 46I-516.

V. Nervous System and End Organs. - '85 BEARD, J., Cranial ganglia, Zool. Anz. viii, 220-223, Anat. Anz. iii, 874-905, and op. cit. '92, 19I-206. '91 Killias. Metamerie, VH. Anat. Gesell. 85-107. '88 Dohrs (Motor fibres), MT. z. Stat. Neap. viii, 44I-462. '91 Augenmuskelnerven, op. cit. x. I-40. '91 Froriep, Kopfnerven, VH. Anat. Gesell. 55-65. '92 LeNhossÉK, M. v. (Spinal ganglia and cord), Anat. Anz. vii, 5I9-539. 85 Oxodr, A. (Nerve roots), Ber. Math. Nat. Ungarn, ii, 3Io-336. '89 Ostrounoff, A., Froriep'schen Ganglien, Zool. Anz. xii, 363-364. '90 Platt, J. B., Anterior head cavities, Zool. Anz. xiii, 239, and ' 91 J. of Morph. v, 79-106, and Anat. Anz. vi, 25 I-265. '96 Punis, G. C., Pineal eye, P. Phys. Soc. Edinb. 62-67. '92 Rabl. C., Metamerie, VH. Anat. Gesell. I04-135. '80 RablRÜCKhardt (Metamerism), Morph. JB. vi, 535-570. '93 Lobus olf. impar. Anat. Anz. Sep. I5. '83 VigNaL, W., Système ganglionaire, A. Zool. expér. i, I7-20. '83 VAx Wijhe (Metamerism), VH. Akad. Wiss. Amsterdam. '76 Wilder, B. G.. Anterior brain mass, Am. J. Sci. xii, I03-106.

MORPHOLOGY OF FOSSIL SHARKS. - V. ref. in S. Woodward's Catalogue, also in present writer's article on Cladoselache, '94 J. of Morph. ix, i i2. In addition, '88 Brogniart et SaUvage, Études sur le Terrain Houiller de Commentry, Liv. iii, B. de la S. d. l'Indus. minér. ii. I-39. '93 Claypole, E. W., Cladodonts, Am. Geol. 325-33I, and ('95) op. cit. Jan. '93 Cope. Cladodonts, Am. Nat. Sept. Also '94 J. Am. N. S. Phila. ix, 427-44I. '92-'94 Davis, J. W., Pleuracantlis, Acanthodians, Tr. Dub. Roy. S. ' 94 Dean, B., Cladodont, Tr. N. Y. Acad. Sci. II 5-I I9. ' 92 JAEkel, O. (Eocene sharks), SB. Gesell. Nat. Fr. Berlin, p. 61, 
and Cladodus, l.c. I56-I58. '95 Smith IVoodward, Primæval sharks, Nat. Sci. vi, 38-44.

\section{THE CHIMÆROIDS}

(Cf. esp. Duméril, Ref. p. 238.)

'94 Beax, T. H., Harriotta, P. U. S. Nat. Mus. xvii, 47I-473. 52 Costa (Anatomy), Faun. regno Napoli. 51 Leydig, F., Anat. and Hist. Miil. A. f. Anat. Phys. xviii, 24I-27I. '76 Hubrecht, A., Kopfskelet, Nied. A. Zool. iii, 255-276, and '77 in Morph. JB. iii, 280-282. 86 PARkER, T. J., Claspers of Callorhynchus, Nat. xxxix, 635. '75 Solger, B. (Visceral skeleton), Morph. JB. I, H. I. 37 Duvernoy, G. Z. (Heart and vessels), Ann. d. Sc. Nat. I-I6. '78 LAnkester, E. R.. Heart, P. Zool. S. 634, and '79 in Tr. Zool. S. x, 493-506. 42 Müller, J. (Nerves and heart, critique of Valentin), A. f. Anat. ('43) ccliii. ' 89 GArman, S., Lateral line, Mus. Comp. Zool. xvii. 70 Miklucho-Maclay (Brain), Jen. Z. v, I32. 79 Solger. B. (Lateral line), A. mikr. Anat. xvii, 95-I I3. '42 VAlextin (Brain and Nebenherzen), A. mikr. Anat. 25-45. 77 Wilder, Brain, P. Philadel. Acad. Sci. 219-250. '90 AlCOCK, Egg capsule of Callorhynchus, Ann. N. H. viii, 22. '71 Cunningham, Callorhynchus' egg, Notes on the N. H. of the Straits of Magellan, 340. 89 Günther, Chimæra's egg, A. N. H. iv, 275-2So.

For literature of Fossil Chimæroids v. Smith WoOdward's Catalogue.

\section{THE LUNG-FISHES}

GENERAL (NATURAL HISTORY). - '94 Bohls, Fang u. Lebensweise v. Lepidosiren. Nachr. Gesell. Göttingen, 80-83. '76 CAStlenau, F., Ceratodus, C. R. lxxxiii, I034. '92 Dubois, R., Respiration, "hibernation," Ann. S. Linn. Lyon, xxxix, 65-72. '66 Dunéril, A. M. C., C. R. 97-100, and Ann. N. H. xvii, i6o. '70 (Swim-bladder, etc.), Angers?' 94 Ehlers, E., Lepid, n. s. Nachr. Gesell. Göttingen. Fritsch, A. (Living and Fossil Lungfishes and their affinities), Prag. 4to. 87 Giglioli (Rediscovery of Lepidosiren), Nat. xxxv, 343, and '88, Nat. xxxviii, II2. '56 Gray, J. E., "Lepidosiren," P. Zool. S. Lon. 342. '88 Howes, Rediscovery of Lep. Nat. xxxviii, 126. '41 JARDine, W., Ann. N. H. vii, 24. '64 Krauss, F., Protopterus, Würt. n't'rwiss. Jahresber. I26-I33. '70 KREFFt, Ceratodus, P. Zool. S. 22I- 
224, and Ann. N. H. 22I-224, and (71) P. Roy. S. 377. '91 Lachinas, H., Protop. Zool. Gart. xxxii, I29. '73 Marno, E., Protop. Zool. Gart. 44. '58-'59 McDonnell, R., Protop. Z. wiss. Zool.x. 37 Natterer, J., Lepid. Ann. Wien. Mus. II. '94 Natural Science, Lepid. 324-325. 39-'41 Owen, Lepidosiren annectans, Tr. Linn. S. xviii. '45 Peters, W., Protop. Muil. A. 76 Raisey, E. P., Cerat. P. Zool. S. 698. Schneltz, Cerat. J. Mus. Godeffr. viii, I38. '66 Sclater and Bates, Lepid. P. Zool. S. 34. 92 Spencer, IV. B., Cerat. Vict. Natural. Melb. June Io, and. P. Roy. S. Vict. iv, 8I-S4. 89 Stuhlmax, F., Cerat. SB. Akad. Wiss. Berl. 32. $\mathbf{8 7}$ Wiedersheim, Protop. Anat. Anz. ii, 707-7I3, and R. Br. Ass. 738-740.

ANATOMy, General. - $\mathbf{8 5}$ Ayers, H., Jen. Z. Naturwiss. xviii, 479-527. ' 87 BAUR, G., Lepid. Zool. JB. ii, 575. ' 40 Bischoff, T., Lepid. Leip. '7I Günther, Ceratodus, Ann. N. H. vii, 227 and Phil. Trans. (72) clxi, 5II-57I, and P. Roy. S. 377-379, Nat. Nos. 99. Iо0, 102. 76 Huxley, Ceratodus, P. Zool. S. 24-58. '64 Klein, Protop. Wuirt. n't'rwiss. Jahresber. I34-I 44. '78 Miall, L., Cerat. and Protop. Palæont. S. xxxii, I-32. '88 Parker, W. N., Ber. d. Naturforsch. Gesell. Friburg, VB. iv, H. 3, Nat. xxxix, 9-2I, and Tr. Cardiff Nat. S. xx. 91 Protop. P. Roy. S. xlix, 549-554. '92 Protop. (Large memoir), Tr. R. Irish Acad. xxx, 115-227. '66 Peters, Monatsber. Ak. Wiss. Berl. I2-13.

SKELETON. - 93 KLAatsch, H., Wirbel, VH. Anat. Gesell, I3O132. 91 Teller, F., Skull of Ceratodus, AH. Geol. Reichanst. xv. H. 3 .

MUSCleS. - '72 Humphrey, G. M., Ceratodus and Protop. J. Anat. and Phys. vi.

FINS AND GIRDLES. - 86 Albrecht, P., Protop. Fin forked, SB. Ak. Berl. 545-546. '91 Boulenger, Protop. Renewed pectoral. '83 Davidoff, M., Cerat. Pelvic fin. '84 Gill, T., Shoulder girdle, Ann. N. H. xi, 173-178. '83 Haswell, W. A., Cerat. Paired fins, P. Linn. S. N. S. Wales, vii, 2-I I. 91 Hopley, C., Protop. Renewed pectoral, Am. Nat. xxv, 487. '87 Howes, G. B.. Cerat. Paired fins compared with sharks', P. Zool. S. 3. 94 Lankester, E. Ray, Lepid. Villous processes of hind limbs, Nat. Apr. 12. '86 Schneider, A., Zool. Anz. ix, 52I-524, and (87) Zool. Beitr. ii, 97-105. '71 Traquair, R. H., Protop. Tail restored, Br. Ass. R. ' 90 Vanhöffen, Cerat. VH. Gesell. D. Naturf. ii, I34. 
INTEGUMent AND TeETH. - ' $\mathbf{8 7}$ Böcklen, H., Cerat. Dentition, JH. Ver. Würt. xliii, 76-8I. '60-'61 Kölliker, A., Protop. Histol. of Skin, Z. Naturwiss. Würzb. i. '65 Paulson, M., Protop. Histol. of epidermis, B. Acad. Sci. St. Pétersb. viii, I 4I-I 45. '92 Röse, C., Zahnbau u. Zahnwechsel, Anat. Anz. vii, 82I-839. ' 89 Walther, G., Prot. Skin, Z. f. Phys. Chem. xiii, H. 5. 80 Wiedersheim. R.. Scales, A. mikr. Anat. xviii.

VISCERA, VESSELS, GLANDS. - 80 BOAS, E. V. (Heart and arteries), Morph. JB. vii. 32I-354. '78 Fürbringer (Excretory), Morph. JB. iv, 6o. '76 Huxler, Anterior nares, P. Zool. S. I8o. '45 Hyrtl, J., Lepid. AH. d. böhm Gesell. Prag. '78 Lankester, E. R., Heart, P. Zool. S. 634, and ('79) Tr. Zool. S. x, 493-506. '89 PARker. W. N., Veins (L. cardinal), P. Zool. S. I45-15I. '94 Spencer, IV. B., Cerat. Vessels (complete memoir), Macleay Mem. Vol. Linn. S. N. S. Wales, 2-32.

NERVOUS SYSTEM, END ORGANS. --'82 Beauregard, H. (Cranial), J. de l'Anat. Phys. xvii. 230-242. '91 Burckhardt, R., Zirbel. Anat. Anz. vi, 348-349. 92 Cent. nerv. sys. Berlin, 64 pp. Also Zool. Gesell. ii, 92-95. and SB. Nat. Fr. Berl. 23-25. '94 (Zwischenhirndach), Anat. Anz. I52. '86 FuLLiquet, G. (Brain), A. Sci. Naturelles, xv, 94-96, and Rec. Zool. Suisse, iii, I-I 30. ' 94 Pinkus, F. (Undescribed nerve), Anat. Anz. ix, 562-566, and (Cranial nerves of Protop.) Morph. Arb. (Schwalbe), 275-346. ' 89 Sanders, A., Cent. nerv. sys. Cerat. Ann. N. H. iii, I57-188. '80 Wiedershem, Skel. and cent. nerv. sys. Jen. Z. xir, and Morph. Stud. Heft I, Jena. '82 Wijhe, J. W. van, Visceralskel. u. d. Nerven. Cerat. Nied. A. Zool. v, 207-320. ' 87 Wilder, B., Brain, Am. Nat. xxi, 544-548.

EMBRYOLOGY. - 86 Beddard, F. E., Ovarian ovum, P. Zool. S. 272-292, and Zool. Anz. ix, 635-637. '84 Caldwell, W. H., (Preliminary), J. and P. Roy. S. N. S. W. xviii, and ('87) in Phil. Trans. clxxviii. '93 Hasse, C., Wirbelsäule, Z. wiss. Zool. lv, 533-542. '93 Semon, R. (Habits and development-surface views of eggs and larvæ), DS. d. Med. Nat. Gesell. Z. Jena, pp. 50.

\section{THE GANOIDS}

GENERAL (NATURAL HiSTORY).-'70 Duméril, Aug. Tome ii, pp. 625, Roret, Paris. 35 Heckel, J., Scaphirhynchus, SB. Akad. Wien. '71 Lütkex (Classification), Transl. in Ann. N. H. 329-339. ' 85 OrR, H. (Phylogeny) Inaug. Dissert. Jena, 37 pp. '65-'66 Suith, J. A.. Calamoichthy's, P. Roy. S. Edinb. v, 654- 
659, and ('66) +57-479. 69 Steindachner. F.. Polypterus, SB. Wien. Akad. lx.

GENERAL ANATOMY. - 87 Twanzow, N., Scaphirhynchus, B. S. Mosc. I-4I. '54 LeYdig (Histology of Polypterus), Z. wiss. Zool. v. '50 Littany, M.. Acipenser, B. S. Mosc. xxiii, 389-445. '44 Müller, J., Bau u Grenzen, A. f. Anat. and ('46) AH. d. Berl. Akad. d. Wiss. 92 Pollard, H. B., Polypterus, Anat. and phylogeny, Morph. JB. V, 387-428, and preliminary in (91) Anat. Anz. vi, 338-343. 48 Wagner, A., de Spatulariarum Anat. Inaug. Diss. Berol. 75 WildDer, B., Notes on Am. Gan, I. Respir. of Lepid. and Amia. II. Tail formation of Lepid. III. Pect. fin formation of Lepid. IV. Brains of Amia, Lepid., Acip., and Polyod. P. Am. Ass. Adv. Sci. xxiv, 15I-193. 76 Brains, Philadel. Acad. P. xxxviii, 5I-53. 78 Amia and Lepid. rudimentary spiracle, P. Am. Ass. (unpub'd), and Am. Nat. xix, I92. And in the respiration of Amia, P. Am. Ass. 306313. ' 85 Wright, R. R., Notes on anat. of fishes: A. Cutansense organs. B. Spiracular cleft of Amia and Lepid. C. Aud. organ of Hypophthalmus, Am. Nat. xix, 187-190 and 513. D. Hyomand. clefts and pseudobranchs of Amia and Lepid. and Amia, J. Anat. Phy's. xix, 477-497. E. Amia's serrated appendages, Sci. iv, 5II. 87 ZografF, N., Monograph (Russians) on Sturgeon, Tr. S. Nat. Mosc. lii, pp. 72. 87 Affinities of ganoids, Nat. xxxvii, 70 .

Skeleton. - 77 Bridge, T., Cranium Amia J. Anat. Phys. xi, 605-622. '78 Polyodon, Phil. Trans. clxix, 683-734. 89 Cranial anat. Polypterus, P. Birmingham, Phil. S. vi, I I 8-i zo. '83 Cafauek, F. (Prag.). 47 Franque, H., Amia, Folio, Berolini. 78 Goette, A., Wirbelsäule, A. mikr. Anat. x, 44264I. 93 Hasse, C., Wirbelsäule, Z. Wiss. Zool. 76-90. 60 Kölliker, Ende d. Wirbelsäule, Leip. 20 Kuhl u. Hasselt Ost. of Sturgeon, Kuhl's Beitr. Zool. in Vergl. Anat. 2 Abth. I88-202. '51 Molin, R., Scheletro dell. Acipenser, SB. Acad. Wien, vii, 357-378. '82 PARKER, W. K., Skull (and develop.) of Acip. P. Roy. S. I42-I45, of Lepidos. 443-49I. '83 Sagemehl, M. (Skull of Amia), Morph. JB. ix, I77-227. '92 Sснмidt, L. (Vertebræ of Amia), Z. wiss. Zool. liv, 748-764. '85 SHufelnt, R. W., Amia, R. U. S. F. C. ('83) 747-834. '70 Traquair, R. H., Calamoichthys, J. Dub. Geol. Soc. June 8. '70 Skull of Polypterus, J. Anat. Phys. v, I66-183. '82 Wijhe, J. W. vax, Visceralskelet (u. Nerven) - includes Ceratodus, - Nied. A. Zool. v, 207-320. 
MUSClES. - '85 McMurrich, J. P., Head of Amia. Stud. Biol. Lab. J. Hop. Univ. iii, I2I-I53. '82 Schneider, H., Augenmuskeln, Jen. Z. $x v, 215^{-242}$.

IntEgument, TEETH. -'78 Barkas, W., Teeth of Lepid. Tr. Roy. S. N. S. Wales, xi, 203-207. '77 Mackintosh, H. W., Scale of Amia. (?). ' 80 Pawlow, H., Teeth of Sturgeon, Arb. St. Pétersb. Nat. Gesell. No. 9, 494-508. '59 Reissner, Schuppen v. Polyp. and Lepid. A. f. Anat. ' 87 Zograff, N., Zähne d, Knorp. gan. Biol. Centralb. vii, I78-I 83 and 224.

ViscerA. - '86 Cattaneo, G., Glandula gastriche nell' Acip. Rend. Inst. Lomb. xix, 676-682. '78 FÜRBRINGER, Excretory sys. Morph. JB. iv, 56-60. '72 Hertwig, R., Lymph. Drüsen d. Störherzens, A. mikr. Anat. ix, 62-79. Hoeven. J. v. D. (Air-bladder of Lepid.) 4to. (?). '91 Hopkins, G. S., Structure of stomach of Amia, P. Am. Micr. S. xxii, 165-169. '92 Diges. tracts of N. A. Gan. P. Am. Ass. xli, i97. '69 Hyrtl. J., Blutgefässe d. aus. Kiemendeckel-Kieme v. Polyp. SB. Ak. Wien, lx, I09-I I3. '86 Macallum, A. B., Diges. tract and pancreas of Acip., Amia, Lepid. J. Anat. Phys. xx, 604-636. '91 Senox, R., Zusammenhang d. Harn- und Geschlechtsorgane, Morph. JB. xvii, 623-635. '77 SтӧнR (Valves in conus - compares sharks'), Morph. JB. ii, I97-228. '90 Virchow, H., Spritzlochkieme v. Acip. A. Anat. Phys. (Phys. Abt.) 586-588. ' 86 WILDER, Serrated appendages of Amia, P. Am. Ass. xxxiv, 313-315.

FinS.-'94 Gegenbaur, Flossenskelet d. Crossopterygier, Morph. JB. xxi, I I9-I60. '82 Rautenfeld, E. V., Skel. hint. Gliedmassen, Inaug. Diss. Dorpat, 47 pp. '77 Thacher, J., Ventral fins, Tr. Connec. Acad. iv, 233-242. '80 Davidoff, M. V., Skel. d. hint. Gliedmassen, Morph. JB. vi, I26-I28 and 433-468. '66 Huxley, Illus. of struc. of Crossopt. 4to, Lon.

NERVOUS SYSTEM, END ORGANS. - '89 ALLis, Lateral line of Amia. J. of Morph. '83 Cattie, J. T., Epiphysis, Z. wiss. Zool. xxxix, 720-722, and A. de Biol. iii, IoI-196. '94 CoLLinge, W. E., Sensory canals, of Polypterus, P. Birmingh. S. viii, 255-262 ; of Lepid. op. cit. 263-272; of Polyodon Q. J. M. S. xxxvi, 499-437. ' 83 Dogiel, A., Retina, A. mikr. Anat. xxii, 4I9472, and '84 Naturf. Ges. Kasan, xi, I 24 pp. ' 86 Geruchsorgan, Tr. Kasan. Univ. xvi, 82 pp. '88 Retina, Anat. Anz. iii, I33-I43. '79 Gisow, A., Gehörorgan, Bonn. ' 81 Gisow, A., Gehörorgan, A. mikr. Anat. xviii, 484-519. '88 Goronowitsch, N., Gehirn u. Cranialnerven v. Acip. Morph. JB. xiii, 427-5I4. 
Miklucho-Maclay, N. v., Mittelhirn, Leip. 4to, pp. 74. 181 Retzius, Gehörorgan v. Polyp. Stockh. '81 Schxeider, H., Augenmuskelnerven, Jen. Z. viii, 2i 5-242. '87 WALdschum, J., Centr. nerv. u. Geruchsorg. v. Polyp. Anat. Anz. ii, 308-322.

DEvElopment. - 78 Agassiz, A. (Larvæ of Lepid.), P. Am. Acad. A. and Sc. xiii, 65-76. '89 Allis, E. P.. Lateral line, Amia, J. of Morph. ' 81 BALFOUR and PARkER, Str. and devel. of Lepid. P. Roy. S. xxiii, I I 2-I I9, and ' 82 in Phil. Trans. (large memoir). '89 BEARD, J., Early devel. of Lepid. P. R. S. xlvi, I08-I 8. '95 DEAx, B., Early devel. gar and sturgeon, J. Morph. xi, No. I, I-62. ' 82 Dunbar, G., Breeding of Lepid. Am. Nat. May. '94 Fülleborn, F. (Breed. habits Amia and Leipd.), SB. Akad. Wiss. Berl. xl, I-14. '67 Gegenbaur, Wirbelsäule d. Lepid. Jen. Z. iii, 359-414. '93 Jungersen, H. F. E., Embryonalniere d. Störs, Zool. Anz. 464, and ('94), Amia, op. cit. No. 45I. '70 Kowalewsky, Owsjannikow, U. Wagner, Stör, B. Acad. St. Pétersb. xiv, 287-325, and Mél. Biol. du B. Acad. St. Pétersb. vii, I7I-183. '91 Kupffer, K. v., Kopf. v. Acip. SB. Gesell. Morph. Muinchen, 107-123, and ('93) memoir, Lehman, München. ' 90 MARk, E. L., B. Mus. Comp. Zool. xix, I-I27. '82 PARker, W. K., Skull of Lepid. and Acip. P. Roy. S. '87 Peltsai, E. D., Segmentation (Russian), MT. Gesell. Mosc. Univ. I, Heft I, and Protocolle d. SB. Zool. Sect. Mosc. ('86) I, Heft I, 206. '89 Ryder, J. A., Sturgeon, Am. Nat. xxii, 659-660, and ('90) B. U. S. F. C. viii, 23I-28I. '78 Salensky, W., Sturgeon, SB. Gesell. Nat. Kasan ('77), 34 (Russian). Also Post-Emb. Entwickel op. cit. ('78) 2 I (Russian). (Segmentation) Zool. Anz. ('78) 243-245, and (Skeleton) 266-269, 288-29I. (General) Mém. S. Nat. Univ. Kasan, vii I-226 (Russian). ' 80 Pt. II, Post-Emb. and Organogeny, op. cit. $\mathrm{x}, 227-545$. Abstract in HofMAN and SCHWALBE's JB. vii. 2I3, 2I7-225. ' 81 (French), A. de Biol. ii, 233-278.

\section{THE TELEOSTS}

(Literature greatly summarized.)

GENERAL ANATOMY. - '93 PARKer, T. J., Zoötomy (Cod). '88 Rolleston, Forms of animal life, $8_{3}-102$, and '95 VOGT and Jung, Anatomie comparée, Vol. II. '80 Euerl, C., Fierasfer, Fauna u. Flora d. Golfes v. Neapel, ii.

SKELETON. - '83 Brooks, H. S., Haddock, P. Roy. S. Dub. iv, I66-I96. '90 Gill, T., Skeleton. notes, P. U. S. Nat. Mus. xiii, 
I 57-170, 23I-242, 377-380.

79 Goette, A., Wirbelsäule u. Anhänge, A. mikr. Anat. xvi, II7-I42. '84 Göldi, E. A. (Derm bones of Catfish, Balistes, Acipenser), Jen. Z. xvii, 40I-447. ' 82 Kostler, M., Knochenverdickungen, Z. wiss. Zool. xxxvii, 429456. '73 Vkolik, A., Verknöckerung, Nied. Arch. Zool. 219-3I4. TEETH, INTEGUMENT. -78 BOAS, J. E. V. (Scarid dentition), Z. wiss. Zool. xxxii, I89-215. '78 Carlet, M., Écailles, Ann. Sci. Naturelle, viii, Art. 8. '86 SchäFF, E.. Lophobranchier, Inaug. Diss. Kiel.

VISCERA, GLANDS, CIRCULATORY. - '80 BOAS, J. E. V., Conus, Morph. JB. vi, 527-533. ' 87 BRock, J., Urogenital, Z. wiss. Zool. xlv, 532-54I. 91 CALderwood, W. L., Head kidney, J. Mar. Biol. Ass. ii, 43-46. '82 Emery, C. (Kidney), A. Ital. Biol. ii, 135-I44, Atti. Acc. Rom. xiii, 43-49, ('85) Zool. Anz. viii, 742-744. '77 FürRRINGER (Excretory), Morph. JB. iv, 4349. '83 Maurer, F., Pseudobranchien, op. cit. ix, 229-25 r. ' 86 Thymus, op. cit. xi, I29-172. '86 WEBER, M., Abdominalporen (Geschlechtsorgane), op. cit. xii, 366-406.

SWIM-BLADDER. - '90 BRIDGe, T. W., P. Birm. Phil. S. vii, I44I87. '89 Bridge and Haddon, A. C., Siluroids, P. Roy. S. xlvi, 309-328, Phil. Trans. ('93) clxxxiv, 65-333. '88 Corning, H. K., Wundernetz, Morph. JB. xiv, I-53.

NERVOUS SYSTEM, END ORGANS. - 82 Cattie, J. T., Epiphysis, A. Biol. iii, Ior-196. 88 Chevrel, R.. Sympathetic, C. R. cvii, 530-53I. '91 Guitel, F., Ligne latérale, A. Zool. expér. ix, 125-190, 67I-697. '92 Herrick, C. L., Fore-brain, Am. Nat. xxvi, I I 2-120, and Anat. Anz. vii, 422-431. '87 LENDENFELD, R. V., Phosphorescent organs, Challenger, xxii, 277329. '81 Mayser, P., Gehirn, Z. wiss. Zool. xxxvi, 259-364. ' '84 SÉdE dE Lreoux, P. DE, Ligne latérale, Paris, I $15 \mathrm{pp}$.

EMBRYOlOGY, GENERAL. - '91 Wilson, H. V., Sea-bass, U.S. F. C. B. ix, 209-277 (with references). '81-'91 RYDER, J. A., U.S. F. C. R. and B. Larval Teleosts: '77 Agassiz, A., P. Am. Acad. v, II7-I26, ('78) xiv, pp. 25, ('82) 27I-303, and Mem. Mus. Comp. Zool. xiv, I-56. '87 Cunningham, J. T., Tr. Roy. S. Edinb. xxxiii, 97-136, ('91) J. Mar. Biol. Ass. ii. ' 83 HILGENDORF, SB. Nat. Fr. 43-45. '90 Holt, E. W. L., Sci. Tr. R. Dub. S. 432-474. '80 Lütken, C., Dan. Selsk. xii, 4r3-6r3. '91 Mclintosh, W. C., R. Fish. Scot. ix, 317-342. '90 McIntosh and Prince, Edinburgh, 4to. ' 87 Raffaele, F., MT. z. Stat. Neap. viii, $\mathrm{I}-84$, ('90) ix, 305-329. 
HERMAPHRODITISM. - 91 Howes, G. B., J. Linn. S. xxiii, 539558. ' 67 Jä́ckel, H., AH. Nat. Gesell. Nürn. iii, 245. '76 Mala, A. W., E. v. Ak. Förh. Stockholm. 67 Smith, J. A., P. Roy. S. Edinb. '64 '65, 300-302, ('70) J. Anat. Phys. iv, 256-258. 91 Simth, W. R., R. Fish. Scot. ix, 352. '84 Weber, M.. Ned. Tijdschr. Amst. 2I-43, ('87) I 28-I34.

VIVIPAROUS DEVELOPMENT. - 85 Ryder, P. U. S. Nat. Mus. viii, I28-I 56 (with references). 


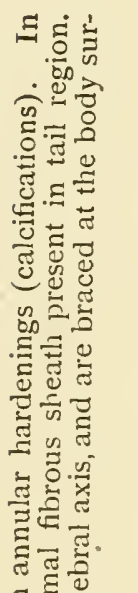

2n $\sum \sum \Phi$

ก

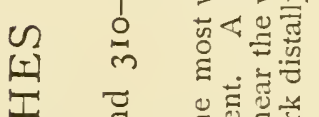

I

[I,

$\frac{1}{0} \stackrel{0}{\square}$

늘 กิ

$>\quad \dot{s}$

는

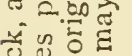

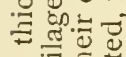

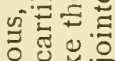

를

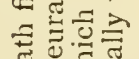

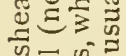

जै का बे

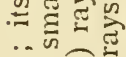

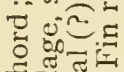

돌

ํㅠㅀ웛

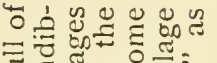

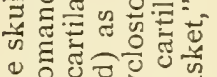

ॠ远宁

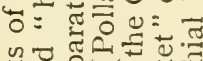

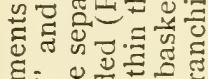

:

元

ป气

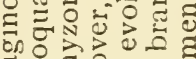

의을

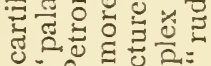

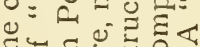

ङ

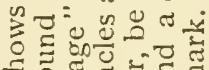

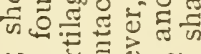

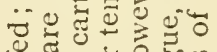

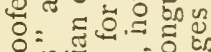

원

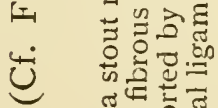

ऽ宁

है도 올

है छ जक

ป云结。

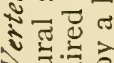

家

๘

焉恶

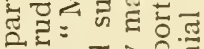

:

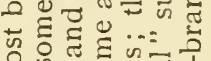

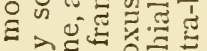

๑ิ

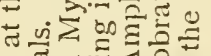

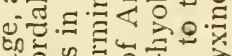

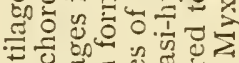

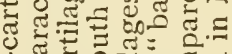

เ

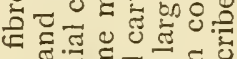

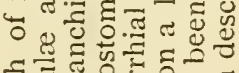

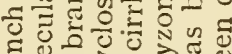

는

๙

$\approx$ 出

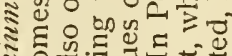

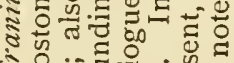

نㅇ..

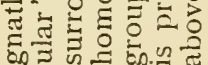

:

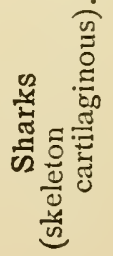

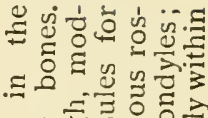

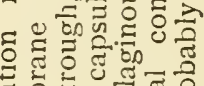

ฮ

论 次

ॐ

फै

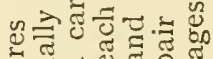

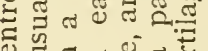

ฮั छี

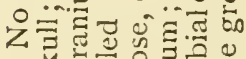

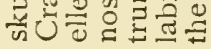

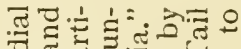

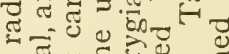

ปั

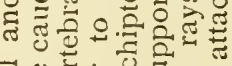

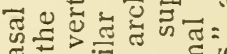

ऽ。

引 उ. जै:

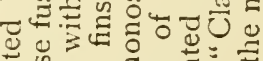

记

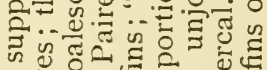

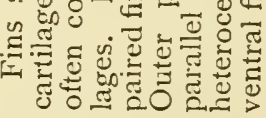

รี่

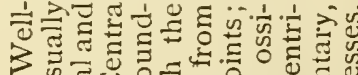

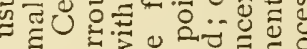

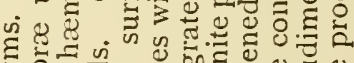
¿ 0 o

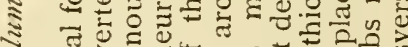

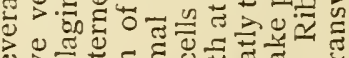

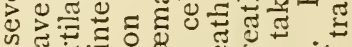

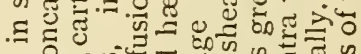
క.

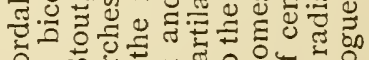

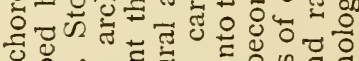

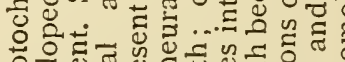

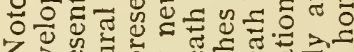

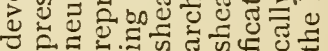




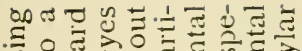

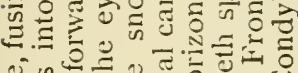

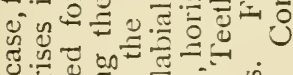

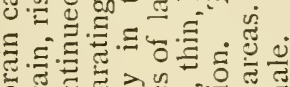

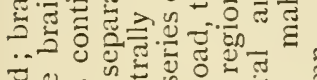
总导.

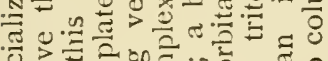

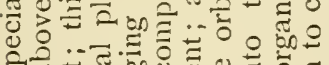

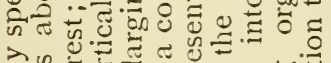

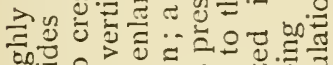

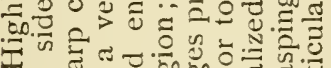
.

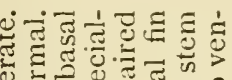

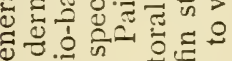

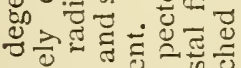

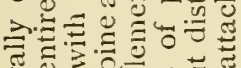
茯

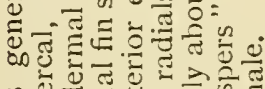
थ प⿺辶寸

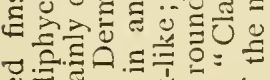
己.

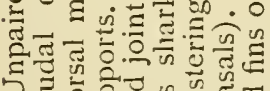

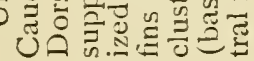

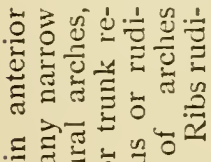

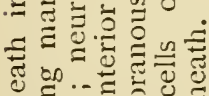

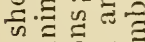

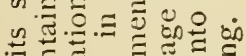

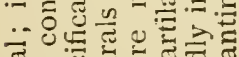

宛 ०.원 仓ुญ

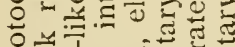

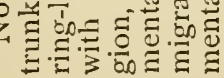

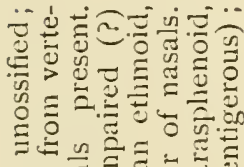

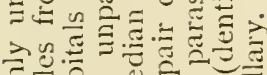

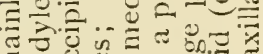

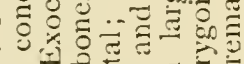
हn or. ฮี

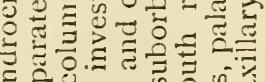

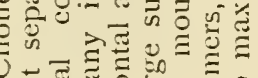

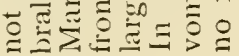

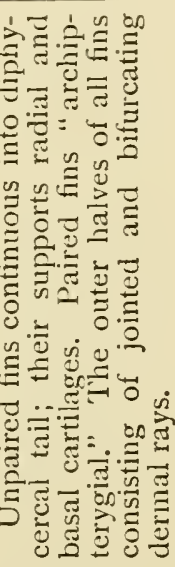

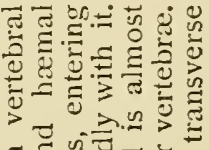

를

$\Rightarrow$ 苛

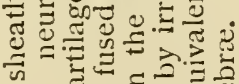

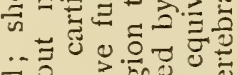

콜

可

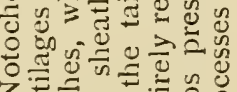

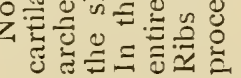

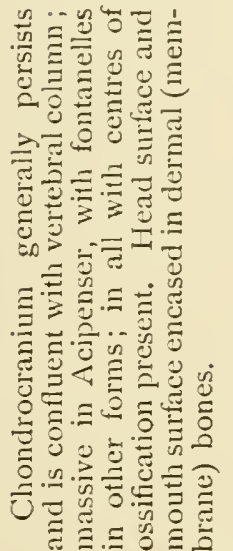

츠를

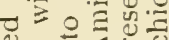

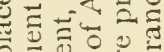

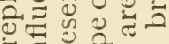

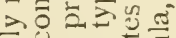

约至

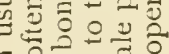

ह 궁ำ

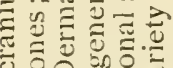

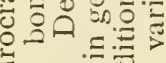

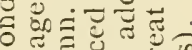

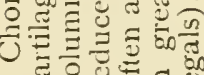
ฮु

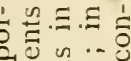

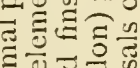

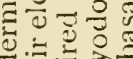

을.

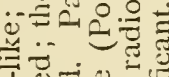

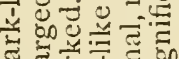

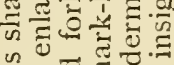

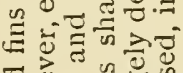

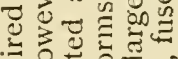

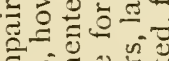

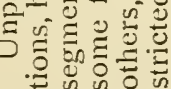

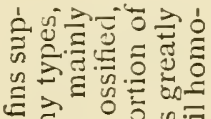

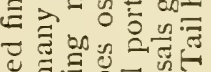

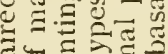

สై

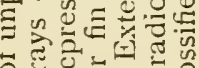

。ี

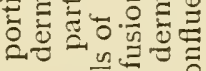

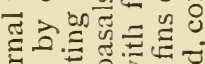

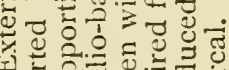

વ

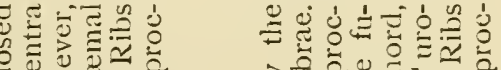

$\circlearrowleft \circlearrowright$

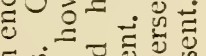

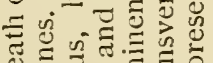

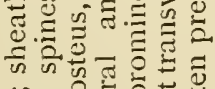

크류

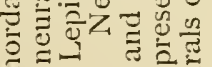

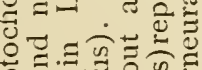

อ

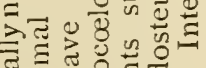

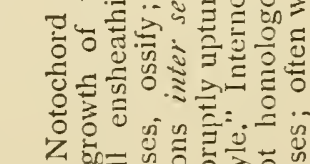

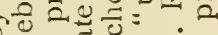

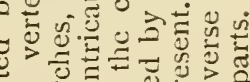

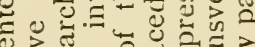

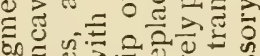

论

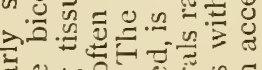

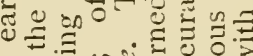
.
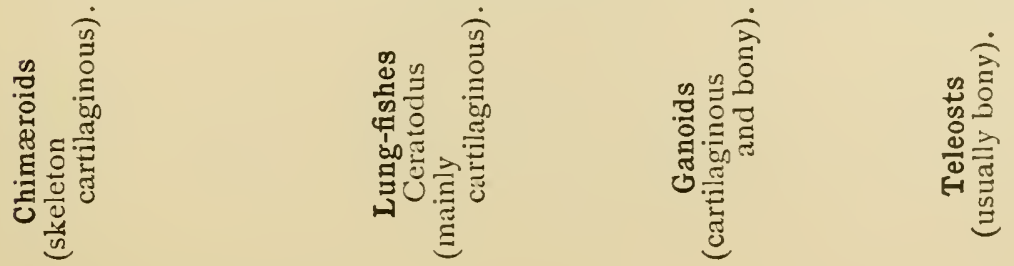

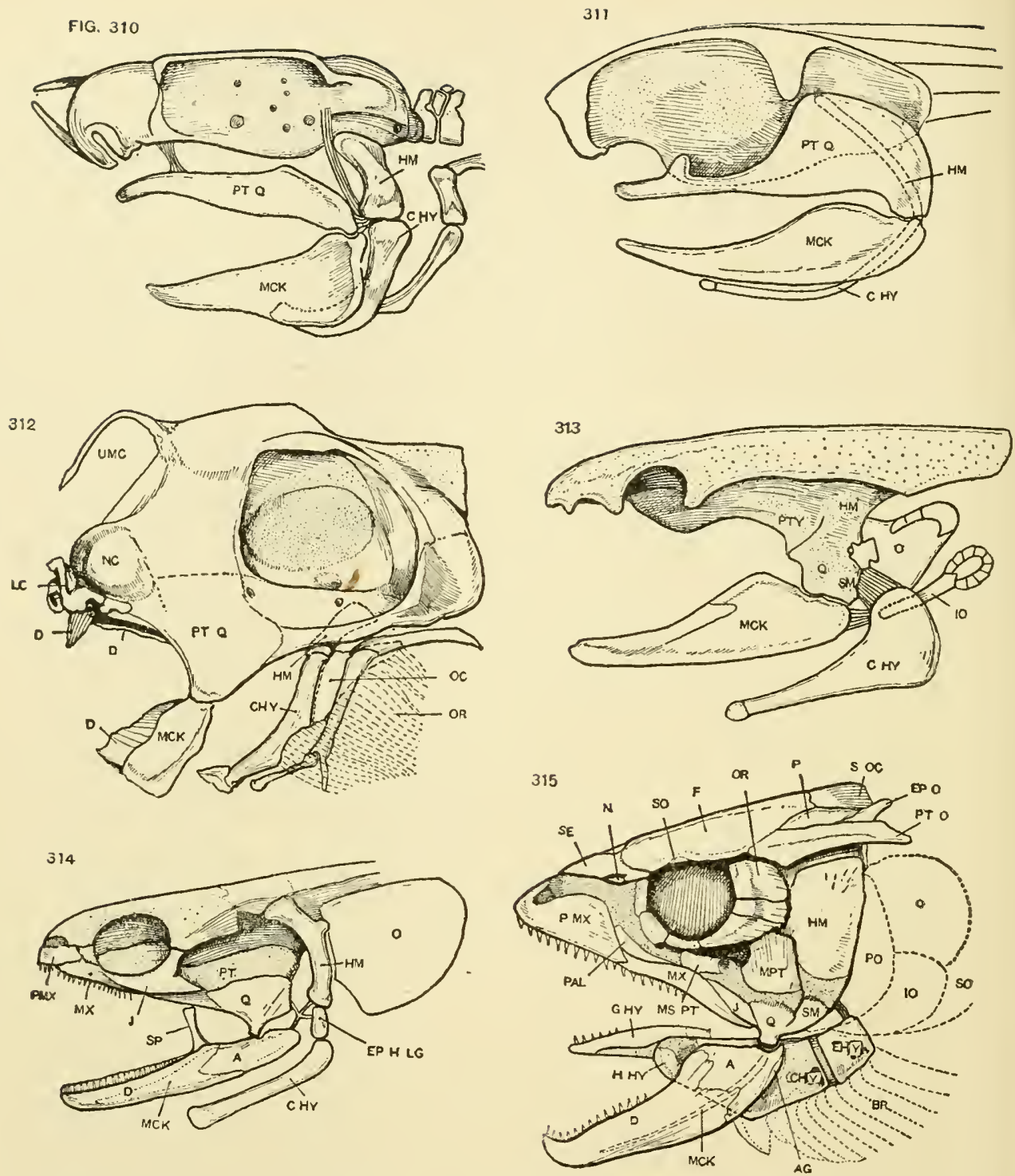

Figs. 310-315. - Skulls of fishes, to illustrate the mode of articulation of jaws and branchial arches. 310. Skull of Scyllium. (After Marshall and Hurst.) 3II. Heptanchus (Notidanus). (After HuxLey.) 312. Chimara. 9 313. Ceratodus. (Slightly modified after Huxley.) 3I4. Polypterus. 315. Salmon. (After PARKER.)

$A$. Articular. $A G$. Angular. $B R$. Branchiostegal rays. $C H Y$. Ceratohyal. $D$. Dentary. EHY. Epihyal. EPH, LG. Epihyal ligament. EPO. Epiotic. F. Frontal. GHY. Glossohyal. HHY. Hypohyal. HM. Hyomandibular. IO. Interoperculum. 7. Jugal. LC. Labial cartilages. MCK. Meckel's cartilage. MPT. Metapterygoid, MSPT. Mesopterygoid. MX. Maxillary. N. Nasal. NC. Nasal capsule. O. Operculum. $O C$. Opercular cartilage. OR. Suborbital ring. P. Parietal. PAL. Palatine. P.MX. Premaxillary. PO. Preoperculum. PTO. Pterotic. PTQ. Palatoquadrate. PTY. Palatopterygoid. Q. Quadrate. SQC. Supraoccipital. SE. Supra-ethmoid. SM. Symplectic. SO. Supraorbital. SP. Splenial. UMC. Upper median cartilage (not frontal spine of male).

Figs. 3IO, 3I4, $3 \mathrm{I} 5$ are regarded by HUXLEY as "hyostylic" (i.e. the hyoid element, $H M$, attached by ligaments to the jaw hinge, taking an important part in the suspension of the jaw; 3II, a modified hyostylic condition; the hinder upper margin of $P T Q$ becoming greatly enlarged, and attached by ligaments to the skull, is spoken of as "amphistylic"; 312-313, were "autostylic," i.e. the upper jaw element fused with the skull. 


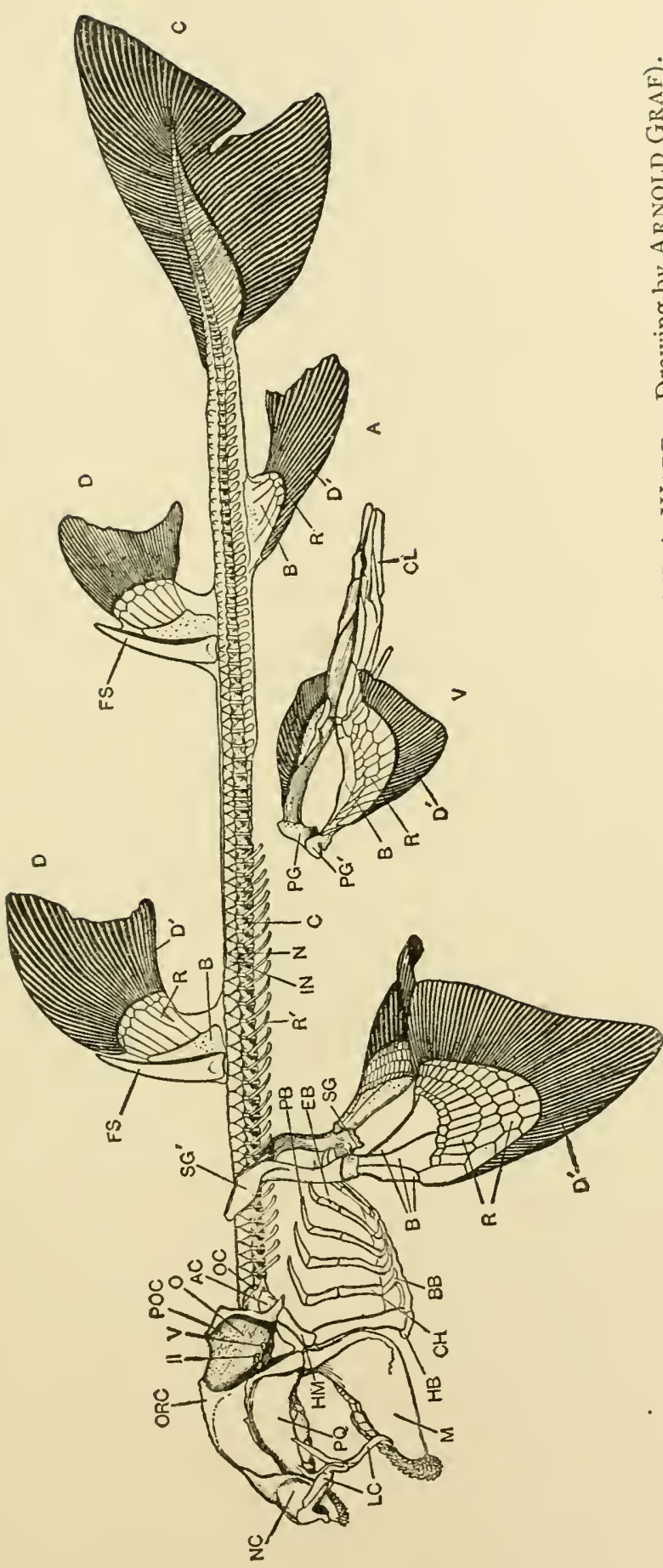

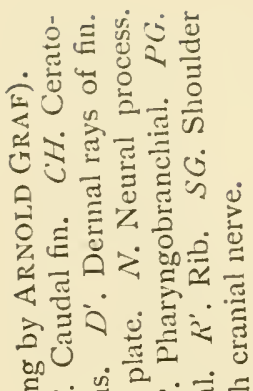

记焉完焉

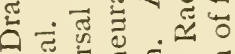

.

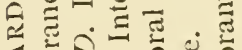

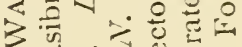

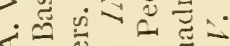

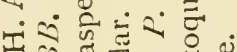

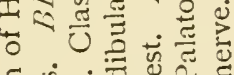

ฮิ

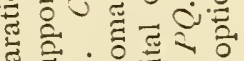

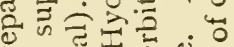

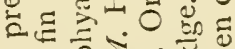

引웡

记

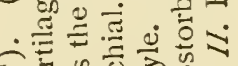

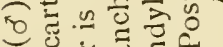

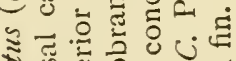
ปั है. है.

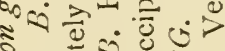
ن

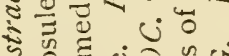

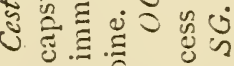

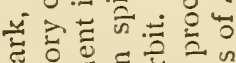

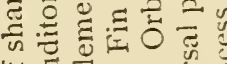

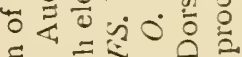
원 ए ह ऊै

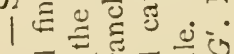

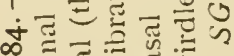

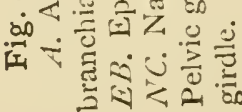




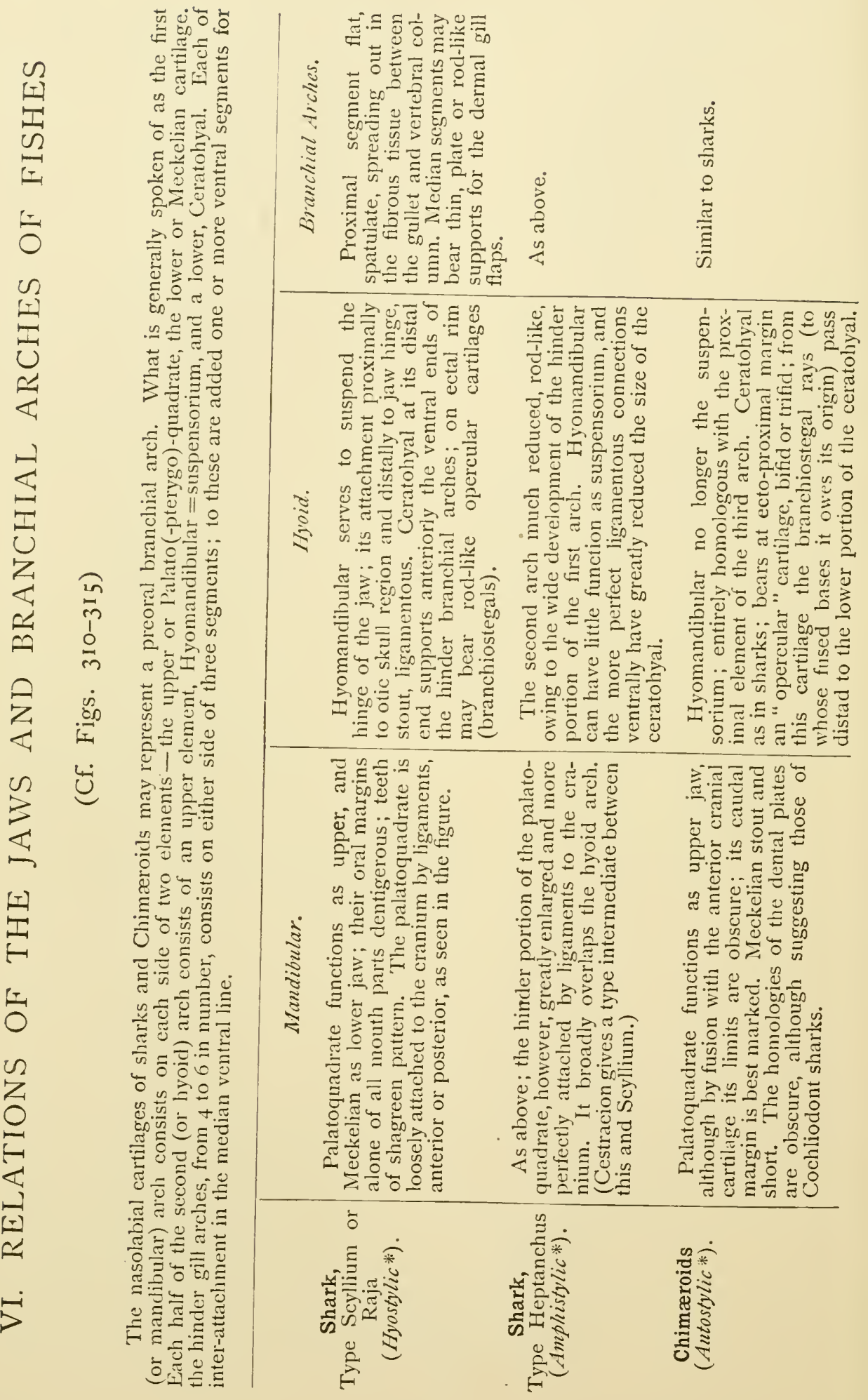



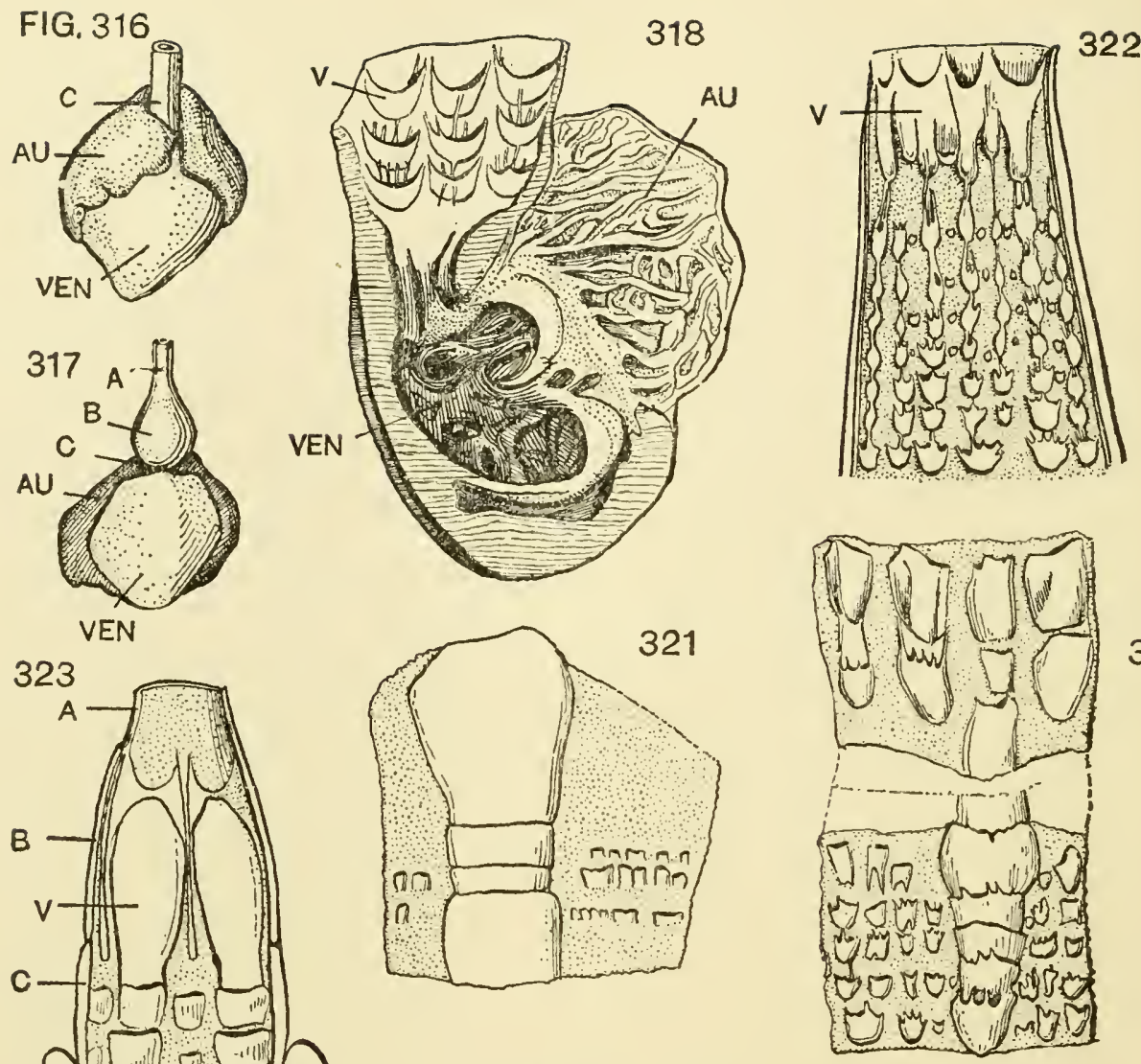

320
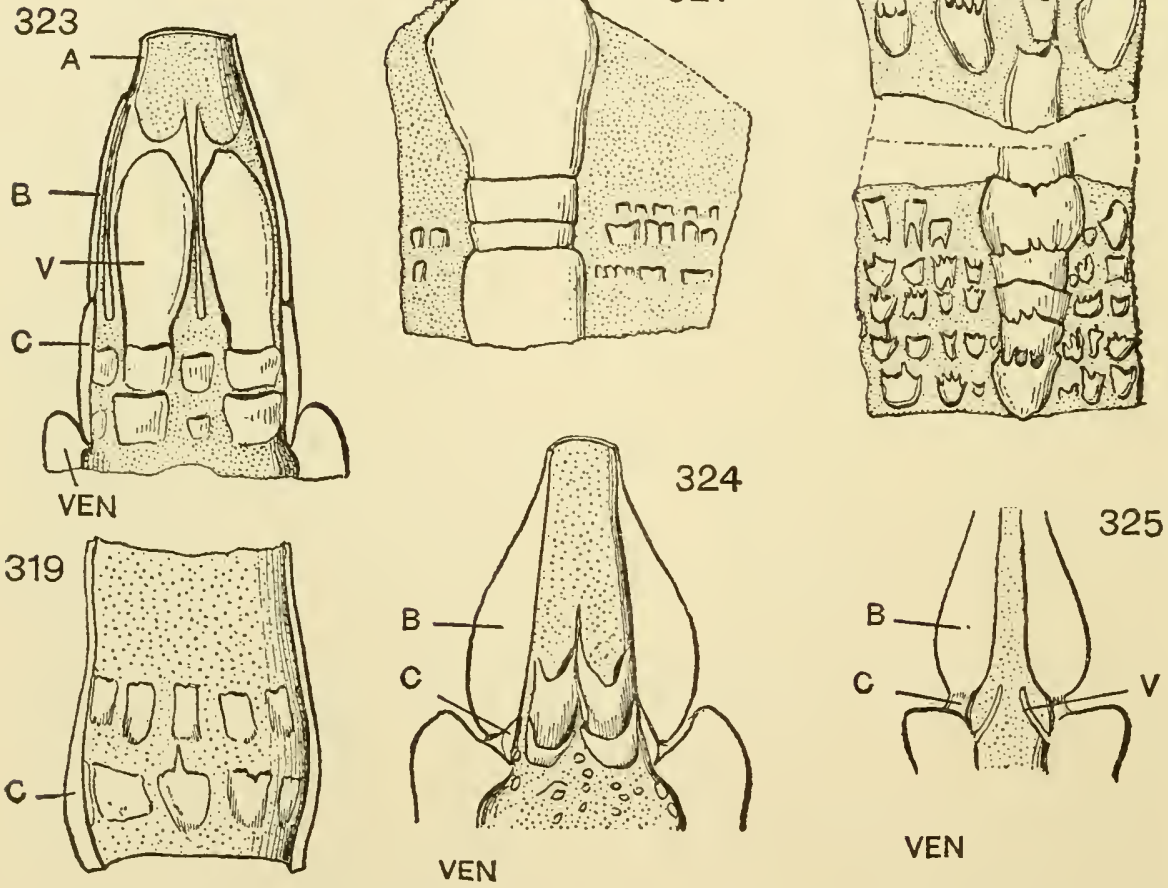

Figs. 316-325. - Heart and arterial cone of fishes. 316. Heart of shark; 317, Heart of catfish, Silurus glanis; 318, Heart of shark, shown opened at the side. 319. Conus arteriosus (innerr view) of Chimcera. 320. Conus of Ceratodus. 321. Conus of Protopterus. 322. Conus of Lepidosteus. 323. Conus of Amia. 324. Conus and bulbus of the Teleost, Butrinus. 325. Conus and bulbus of the Teleost, Clupea. (Figs. 316-318 after WiEderSHEIM, 320-325 after BOAS.)

A. Aorta. $A U$. Auricle. B. Bulbus. C. Conus. $V$. Valves. VEN. Ventricle. $25^{8}$ 

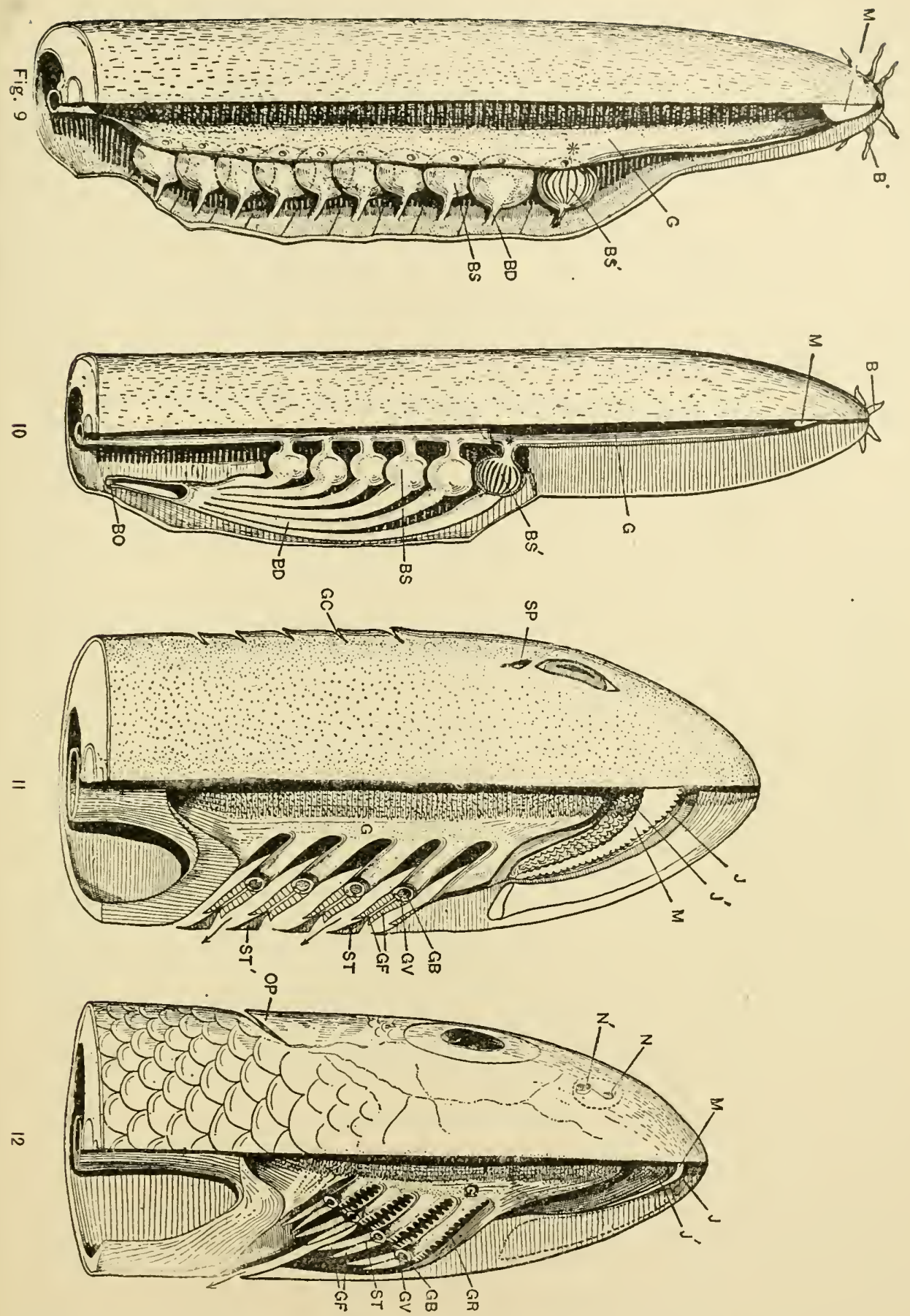

Figs. 9-12. - Arrangement of gills of Bdellostoma (9), Myxine (ro), Shark (rr), and Teleost (12). In each figure the surface of the head region is shown at the left.

$B$. Barbels. $B D$. Outer duct from gill chamber, $B S$. $B O$. Common opening of outer ducts from gill chambers. . $B S$. Branchial sac, or gill chamber. $B S^{\prime}$. Branchial sac, sectioned so as to show the folds of its lining membrane. $G$. Lining membrane of gullet. $G B$. Gill bar, supporting vessels and filaments of gills. $G C$. Outer opening of gill cleft. $G F$. Gill filament. GR. Gill rakers. $G V$. Vessels of gill. $\mathcal{F}, \mathcal{F}^{\prime}$. Upper and lower jaw. $M$. Mouth opening. $N, N^{\prime}$. Anterior and posterior opening of nasal chamber. OP. Operculum. SP. Spiracle. ST. Tendinous septum between anterior and posterior gill filaments. * Denotes the inner branchial opening; $\rightarrow$, the direction of the water current. 


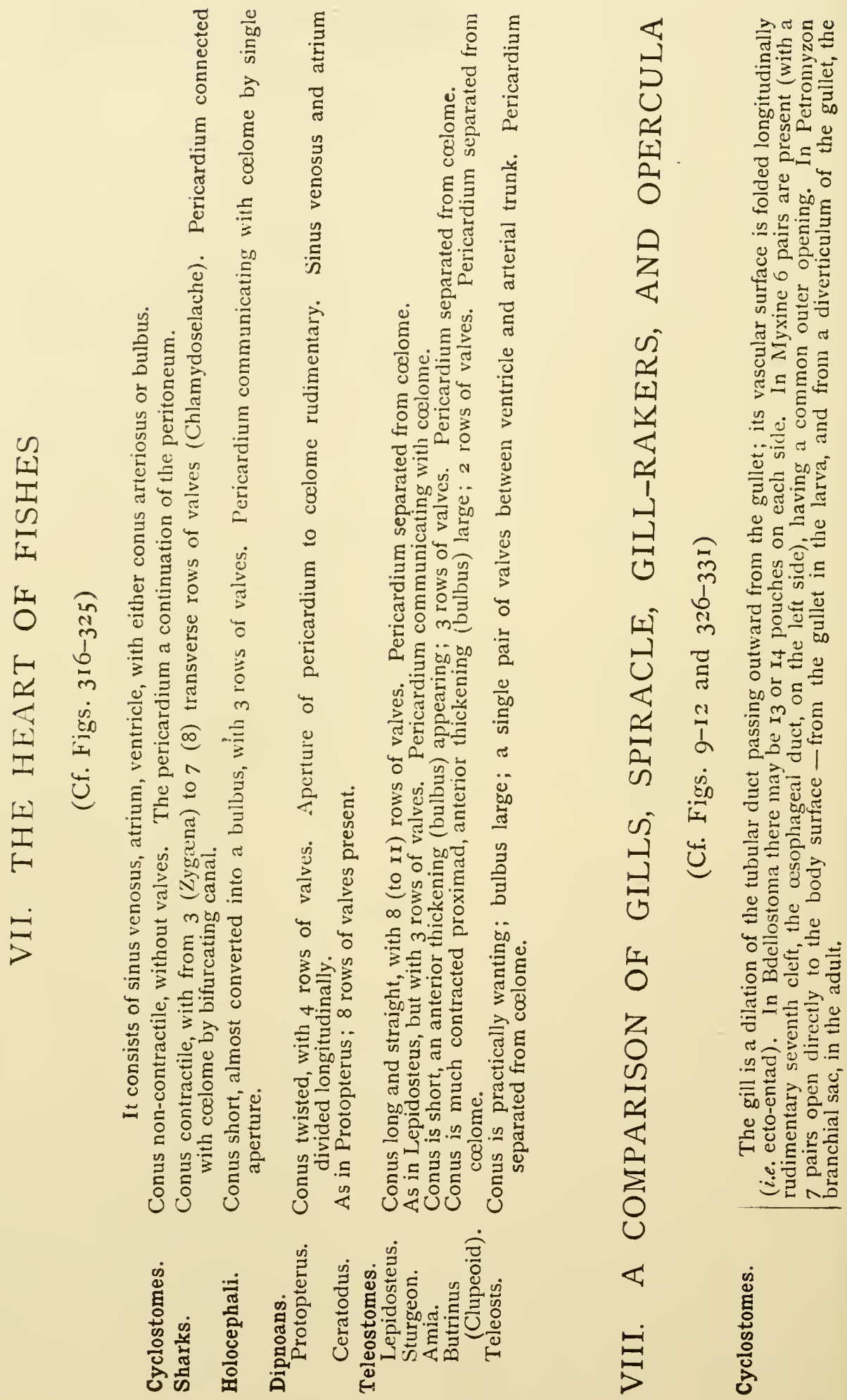




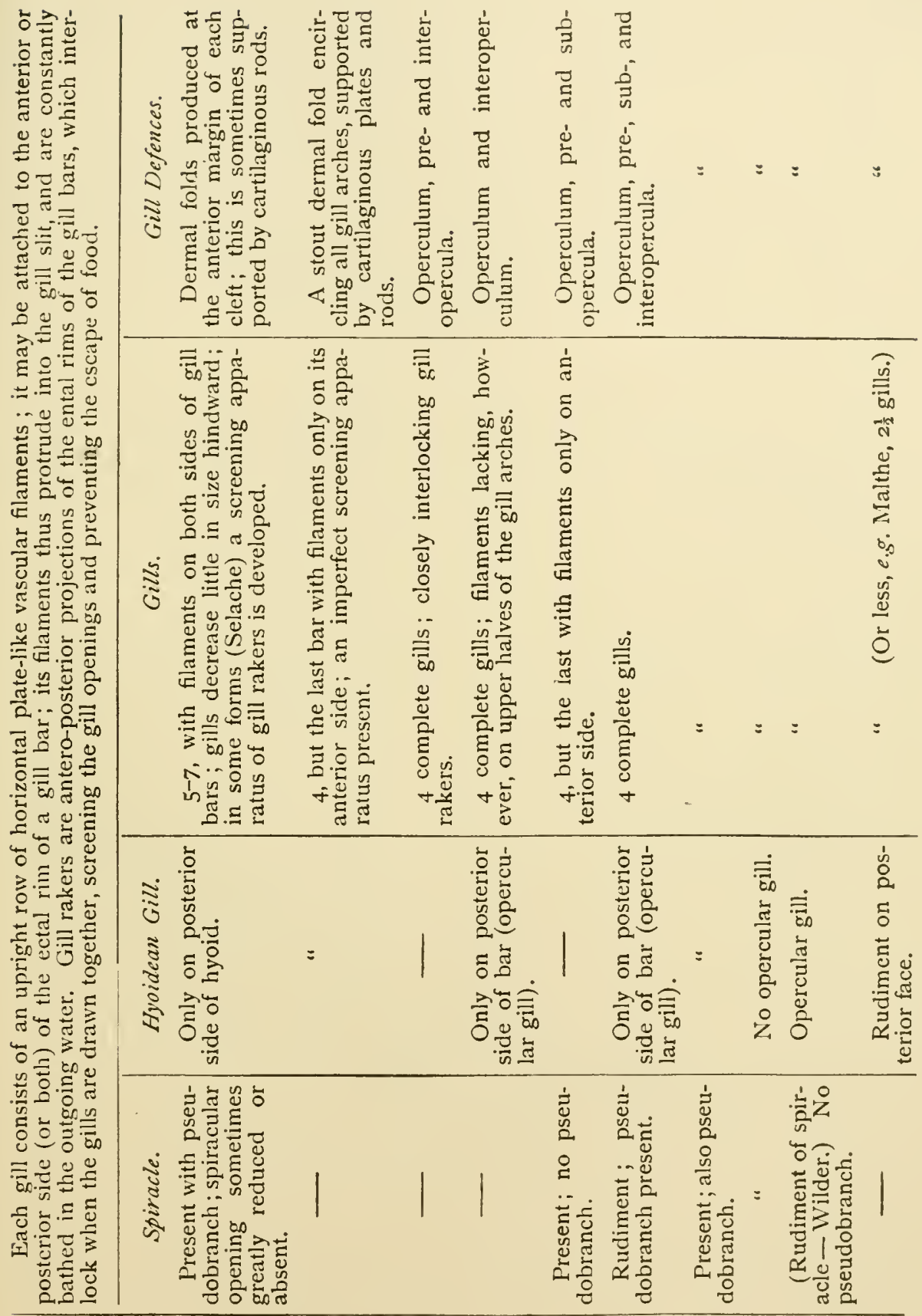

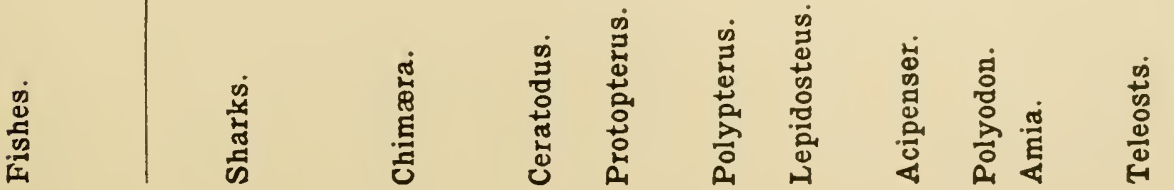



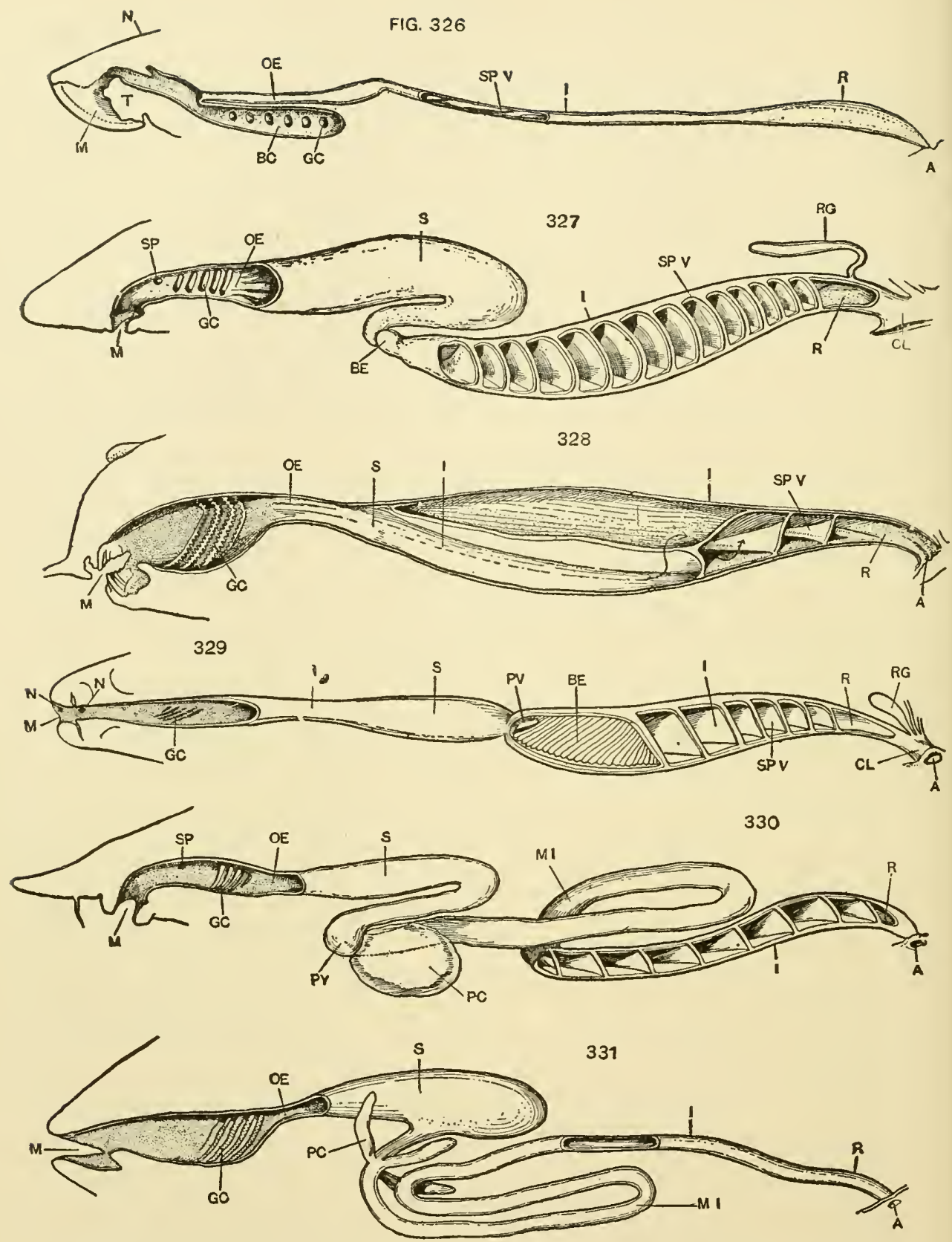

Figs. 326-331. - Digestive tracts of fishes. 326. Cyclostome, Petromyzon. 327. Shark. 328. Chimæroid, Callorhynchus. 329. Lung-fish, Protopterus. (After W. N. PARker.) 330. Ganoid, Acipenser sturio. 33I. Perch. (After Wiedersheim.)

$A$. Anus. BC. Branchial chamber. BE. Bursa entiana (duodenum). $C L$. Cloaca. $G C$. Gill openings. $I$. Intestine. $M$. Mouth. $M I$. Mid-gut. $N N^{\prime}$. Anterior and posterior nares. $O E$. Gullet. $P C$. Pyloric cœca (pancreas). $P Y$. Pyloric end of stomach. $R$. Rectum. $R G$. Rectal gland. $S$. Stomach. $S P$. Spiracle. $S P . V$. Spiral intestinal valve. 


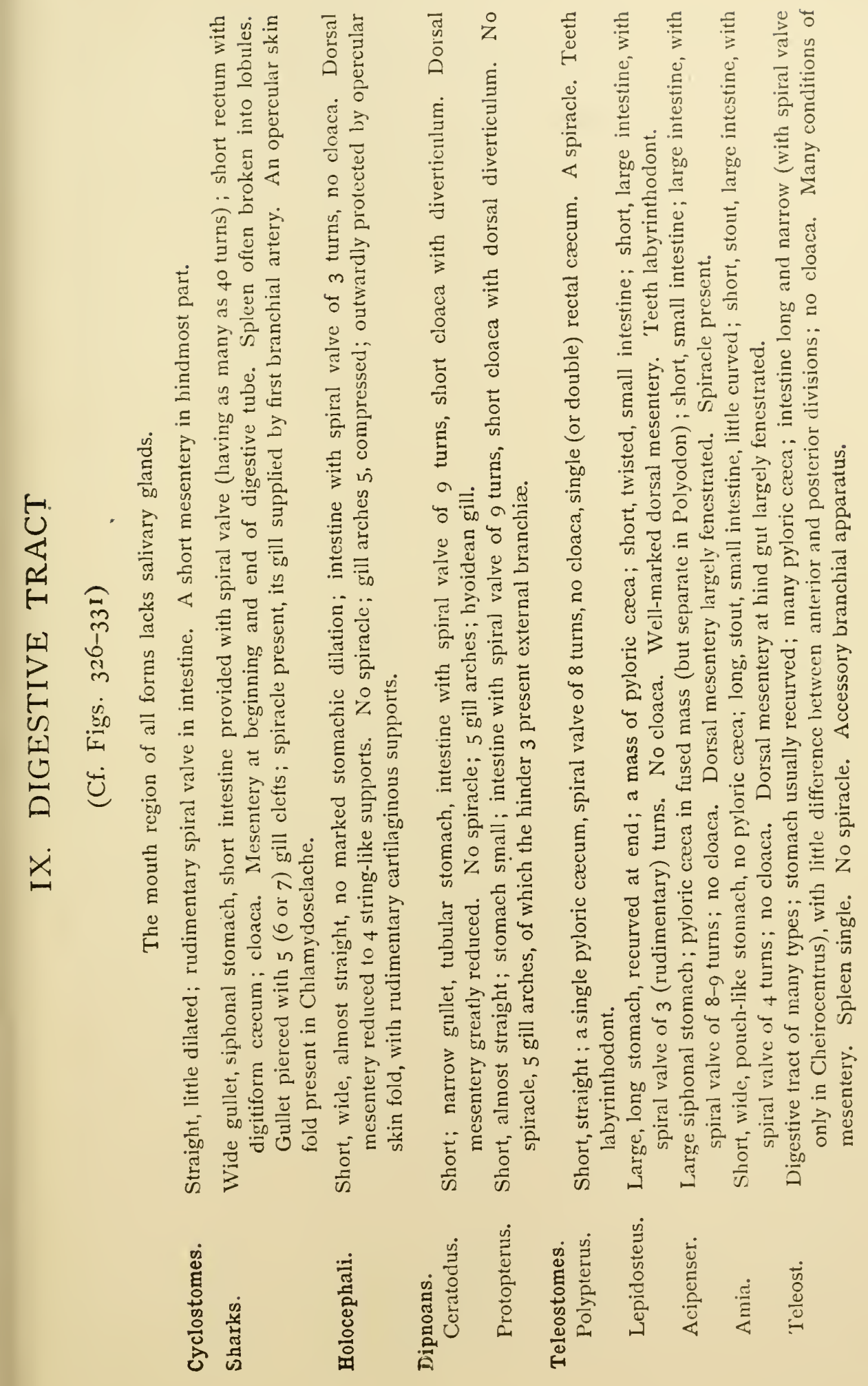




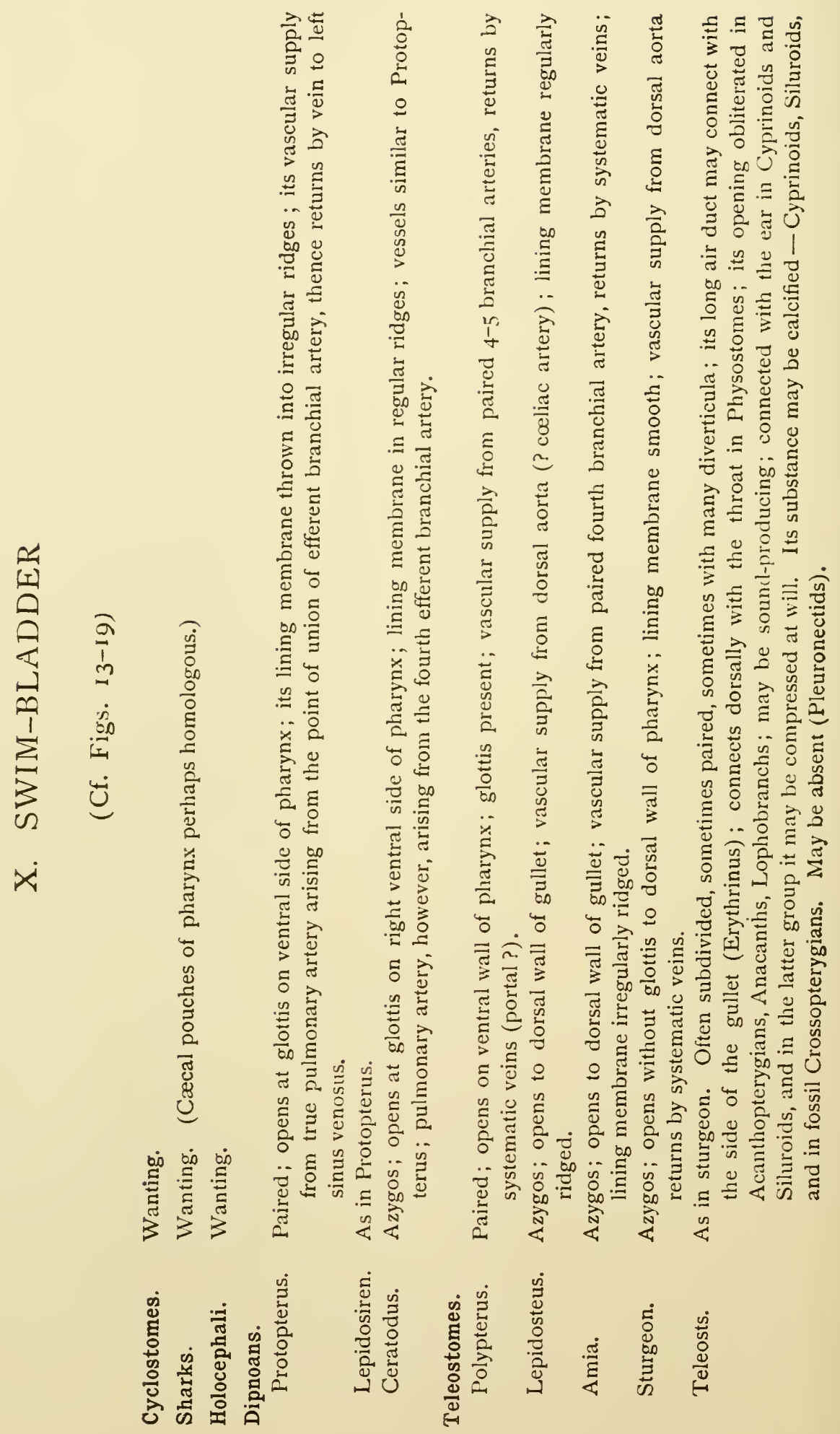


FIG. 13

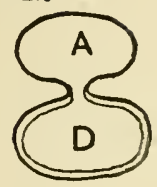

14

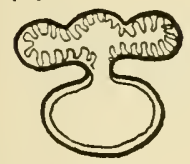

15

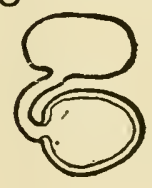

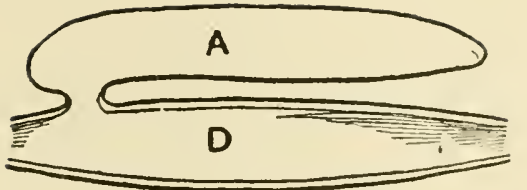
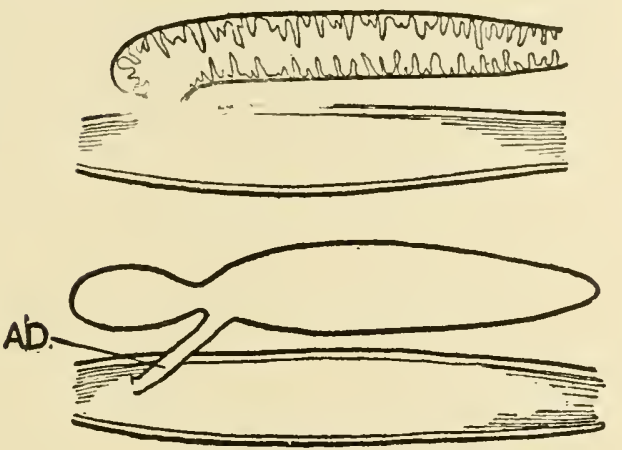

16
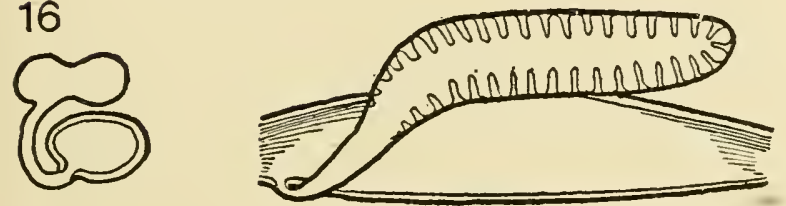

STURGEON

AND MANY

TELEOSTS

LEPIDOSTEUS

AND AMIA

ERYTHRINUS

CERATODUS
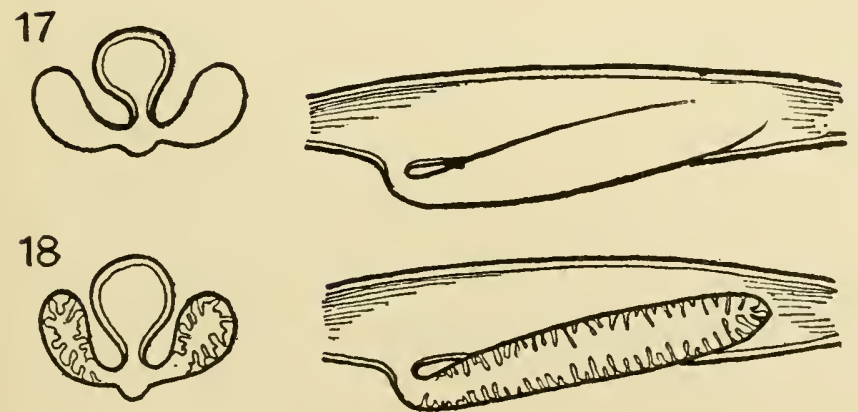

POLYPTERUS

AND

CALAMOICHTHYS
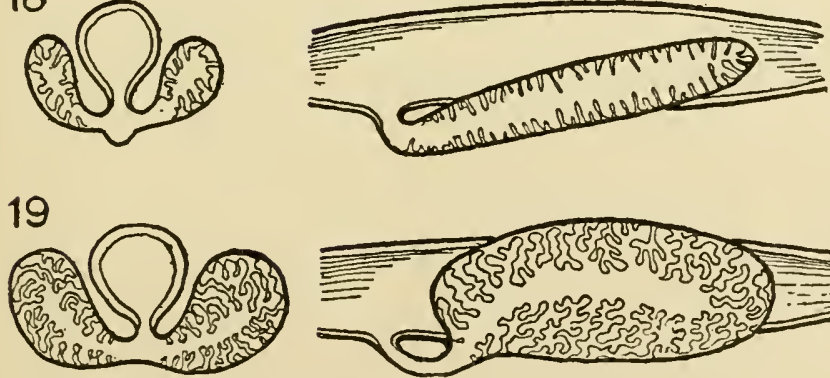

LEPIDOSIREN
AND
PROTOPTERUS

Figs. 13-19. - Air-bladder of fishes, shown from the front and sides. Cf. p. 264. A. Air-or swim-bladder. $A D$. Air duct. $D$. Digestive tube. (After WILDER.) 13. Sturgeon and many Teleosts. I4. Amia and Lepidosteus. 15. Erythrinus, a Cyprinoid Teleost. I6. Ceratodus. I7. Polypterus and Calamoichthys. I8. Lepidosiren and Protopterus. I9. Reptiles, birds, and mammals. The diagrams illustrate the paired or impaired character of the organ, its varied mode of attachment to the digestive tube, and the smooth or convoluted condition of its lining membrane. 


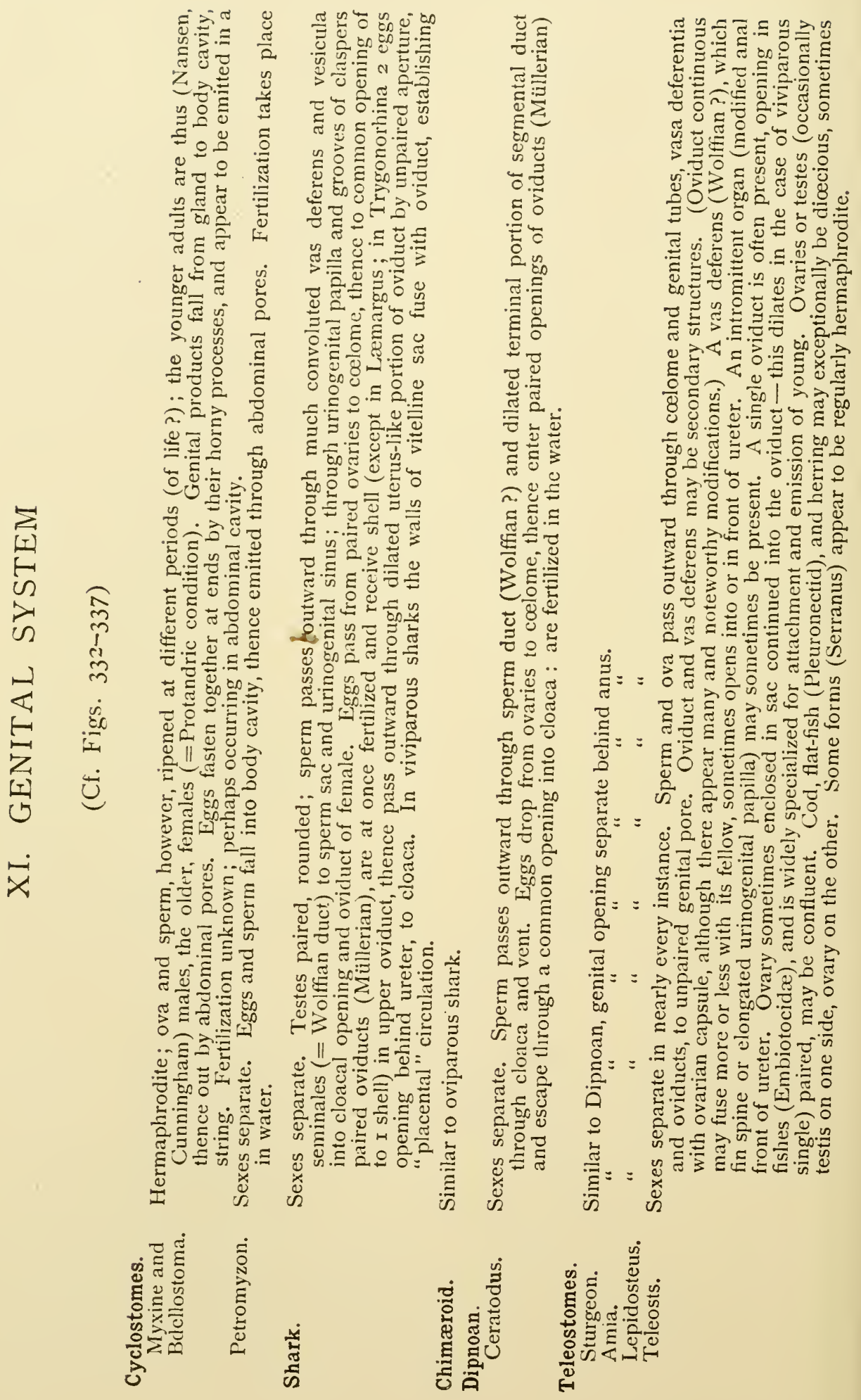


FIG. 332
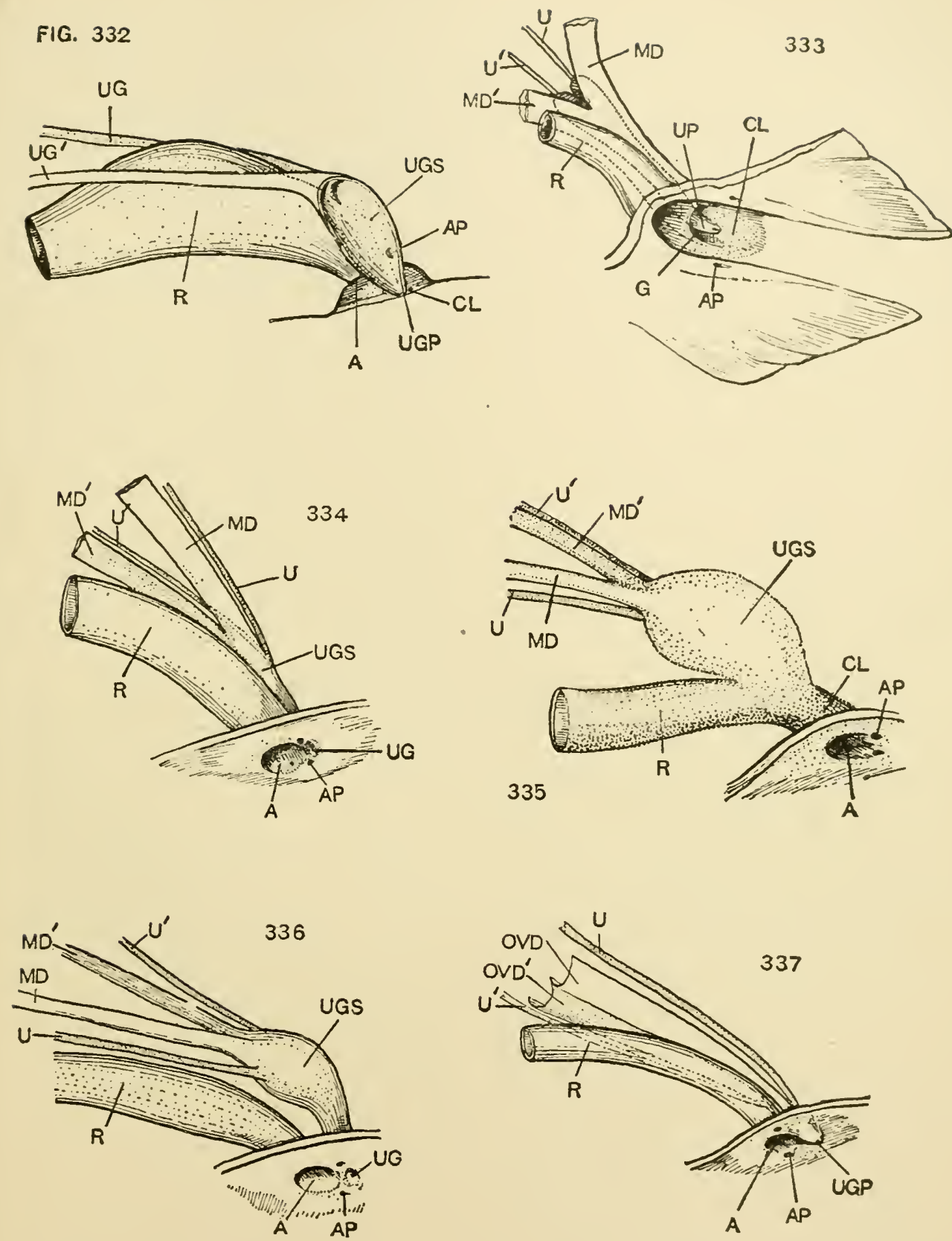

Figs. 332-337. - Urinogenital ducts and their external openings. 332. Cyclostome, Petromyzon. (After W. K. PARker.) 333. Shark, \&. 334. Chimæroid, juv. @. 335. Ceratodus. 336. Ganoid, 9. 337. Teleost (Salmonoid), 9. (After BoAs.)

$A$. Anus. $A P$. Abdominal pore. $C L$. Cloaca. G. Genital opening. $M D, M D^{\prime}$. Left and right Müllerian ducts. $O V D, O V D^{\prime}$. Left and right oviducts (not Müllerian ducts). $R$. Rectum. $U, U^{\prime}$. Left and right ureters. $U G$. Urinogenital opening. $U G^{\prime}$, $U G^{\prime \prime}$. Left and right urinogenital ducts. $U G P$. Urinogenital papilla, showing distal opening. UGS. Urinogenital sinus. UP. Urinary papilla. 


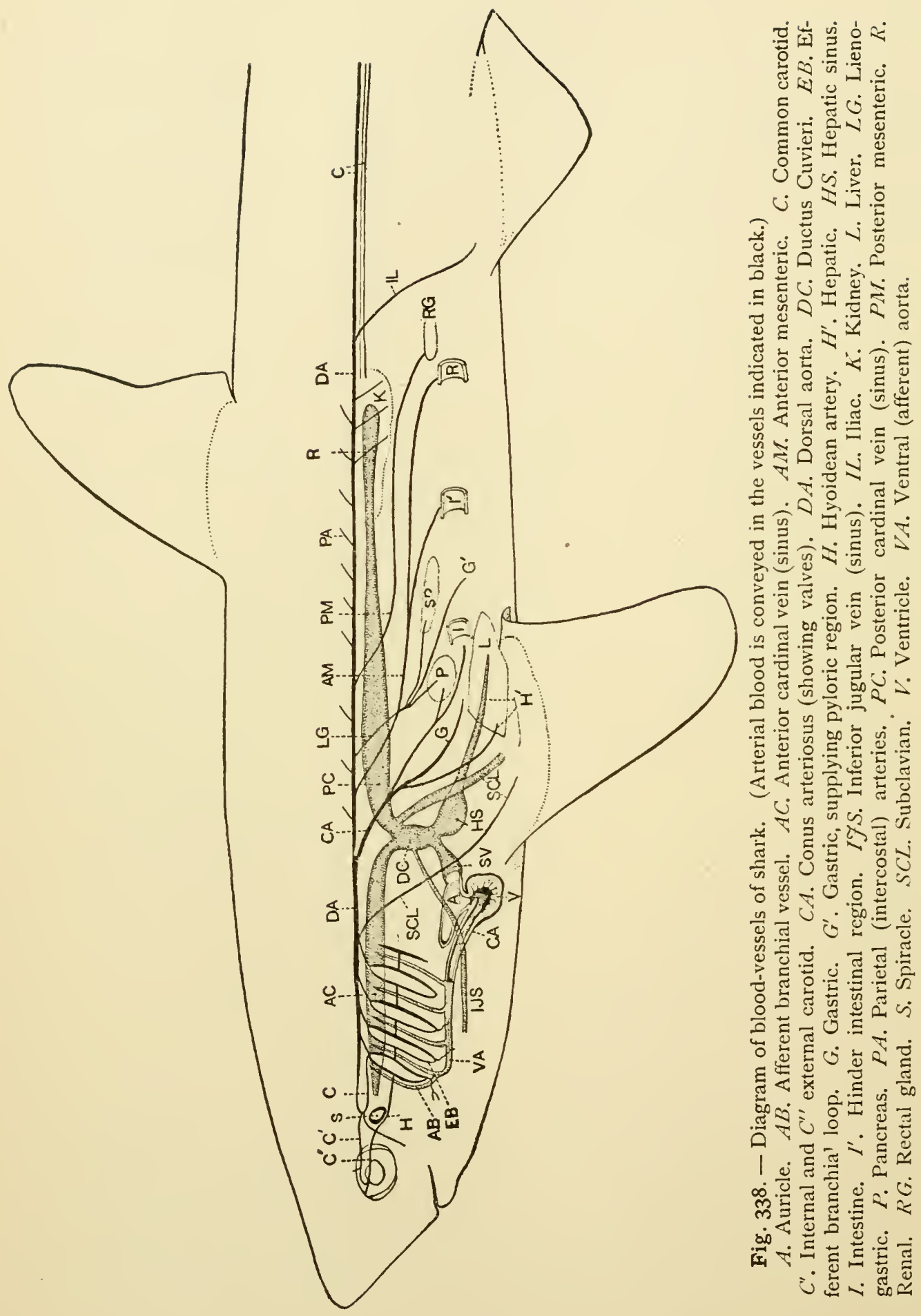




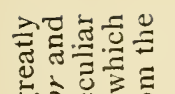

เo.

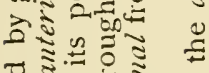

mंग

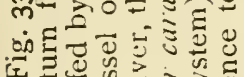

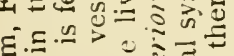

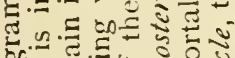

สำ

万.

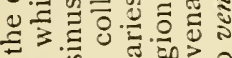

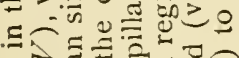
हैं

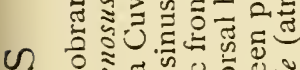

(I) ลี ส

正

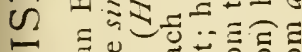

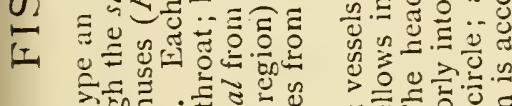

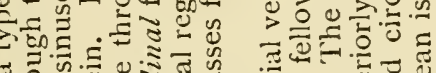

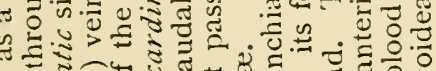

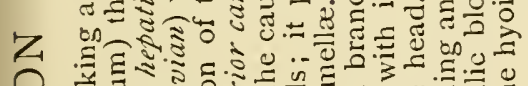

○

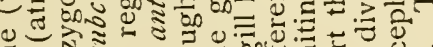

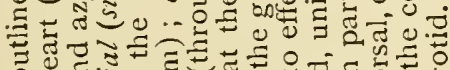

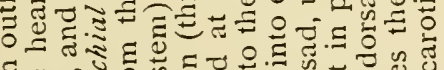
$\Xi$ -

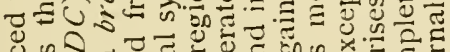

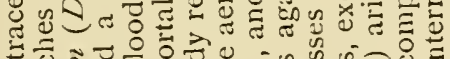
ป

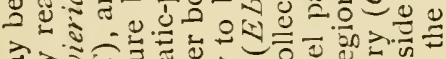

$\ddot{x}$ y

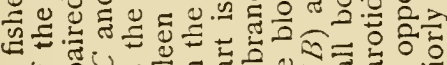

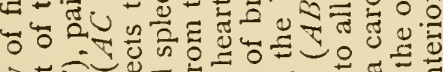

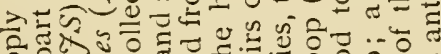

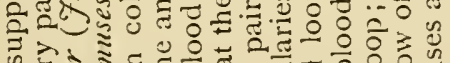
के यें ठ己

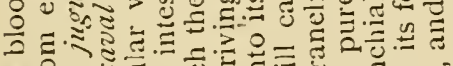

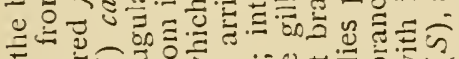

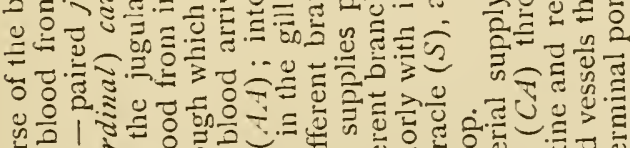
n O.气

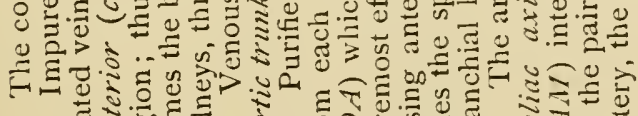

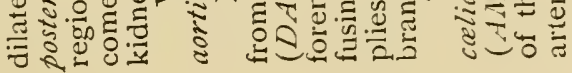

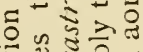

$80,50 \frac{1}{2}$

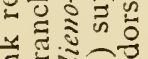

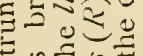

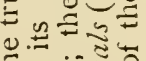

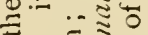

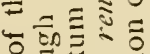

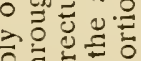

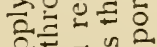

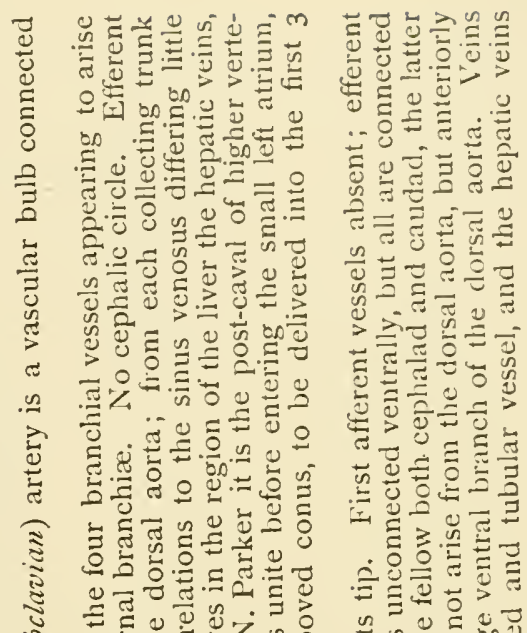

츨

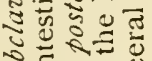

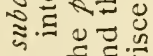

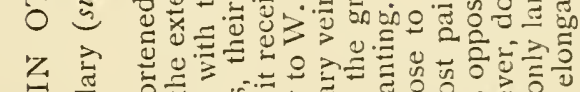

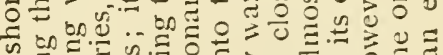

..

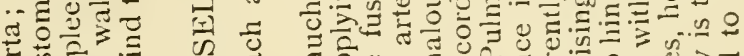

需.

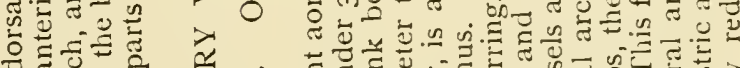
政雪 的分 हृ:

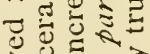

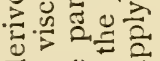

$>$ ำ

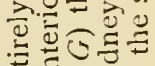

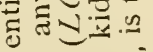

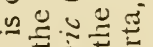

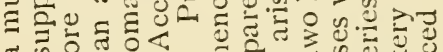

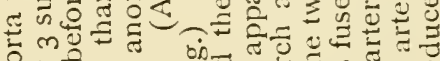

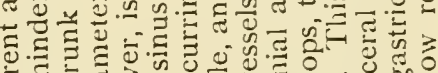

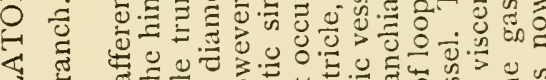
出 U

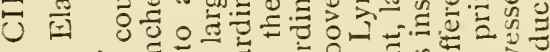
디

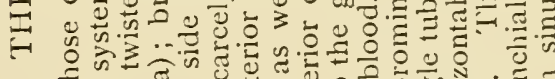

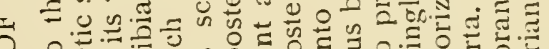

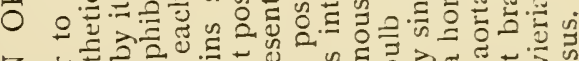

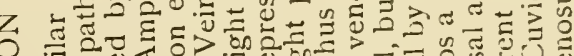
O

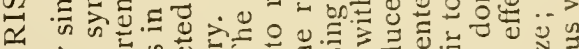

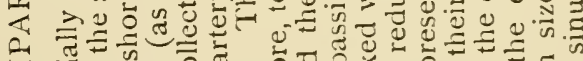
5. O

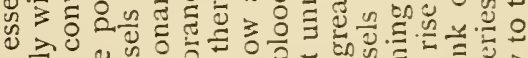

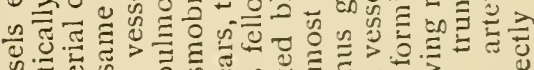

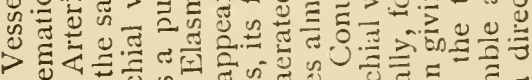

总

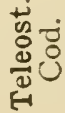




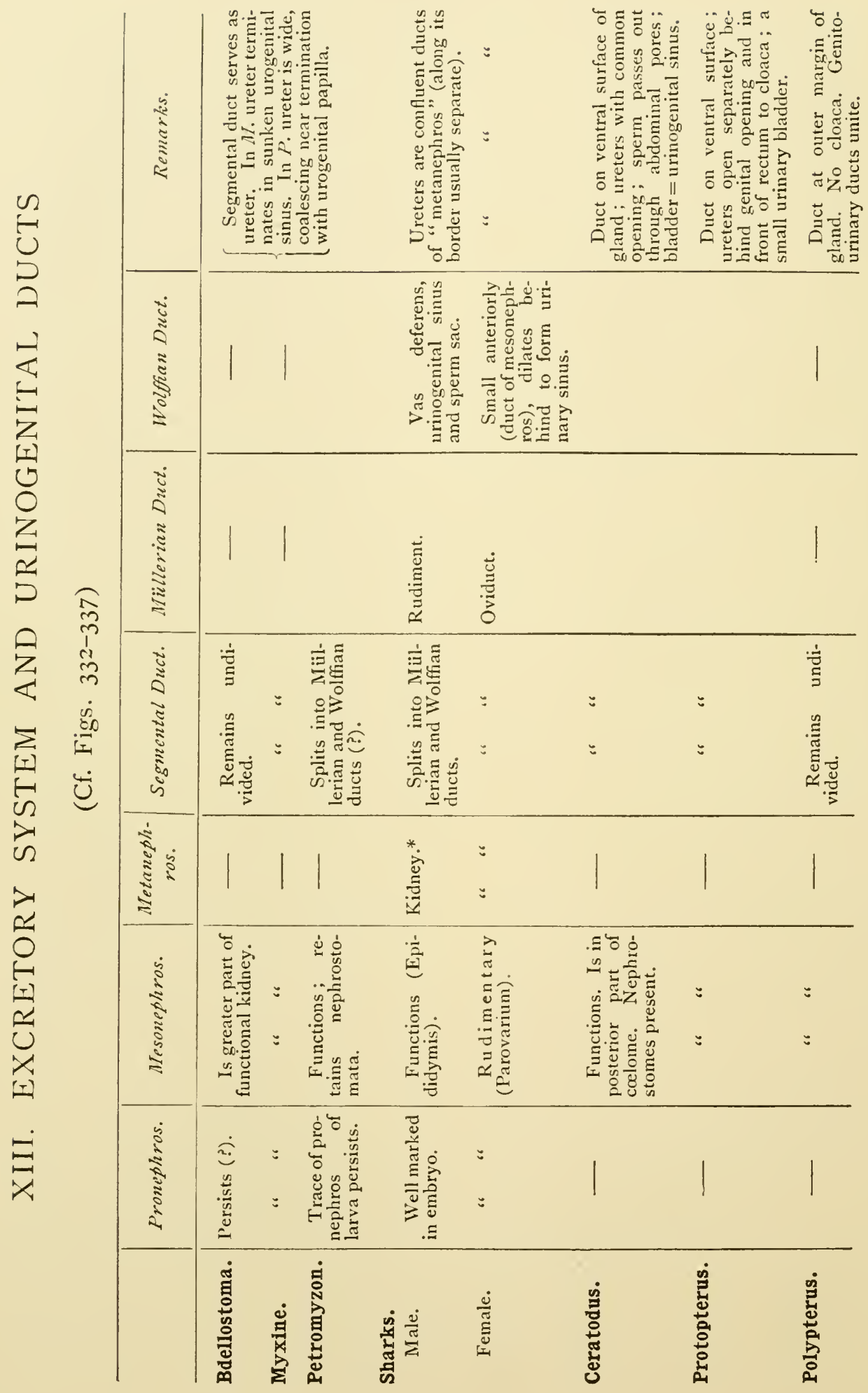



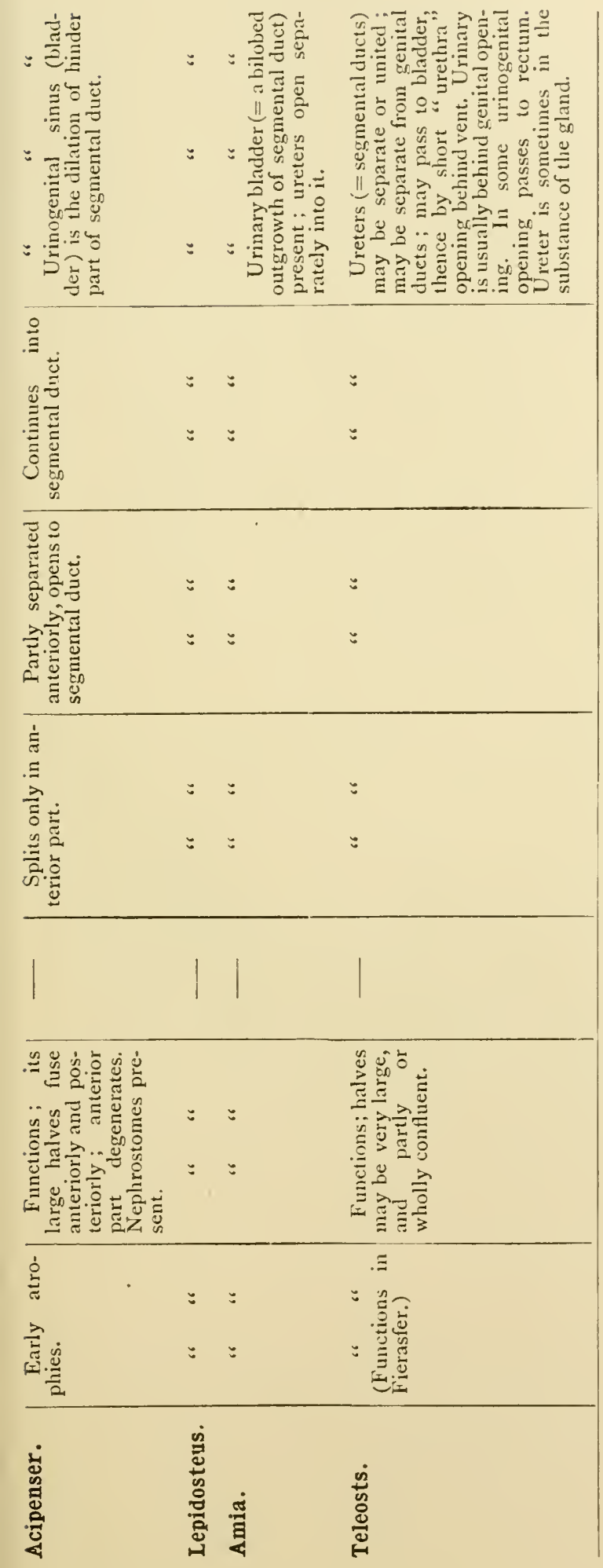

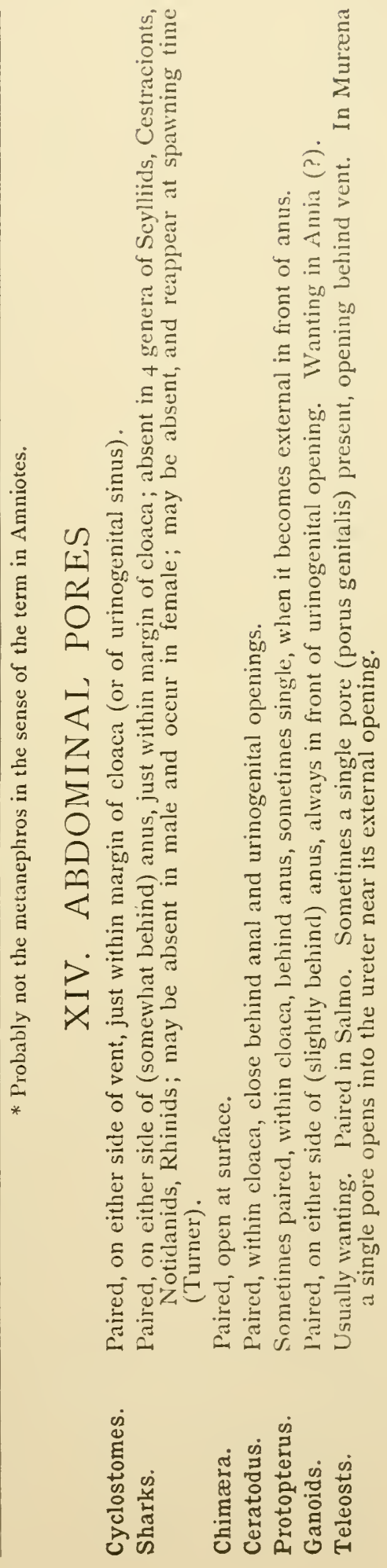


FIG. 339
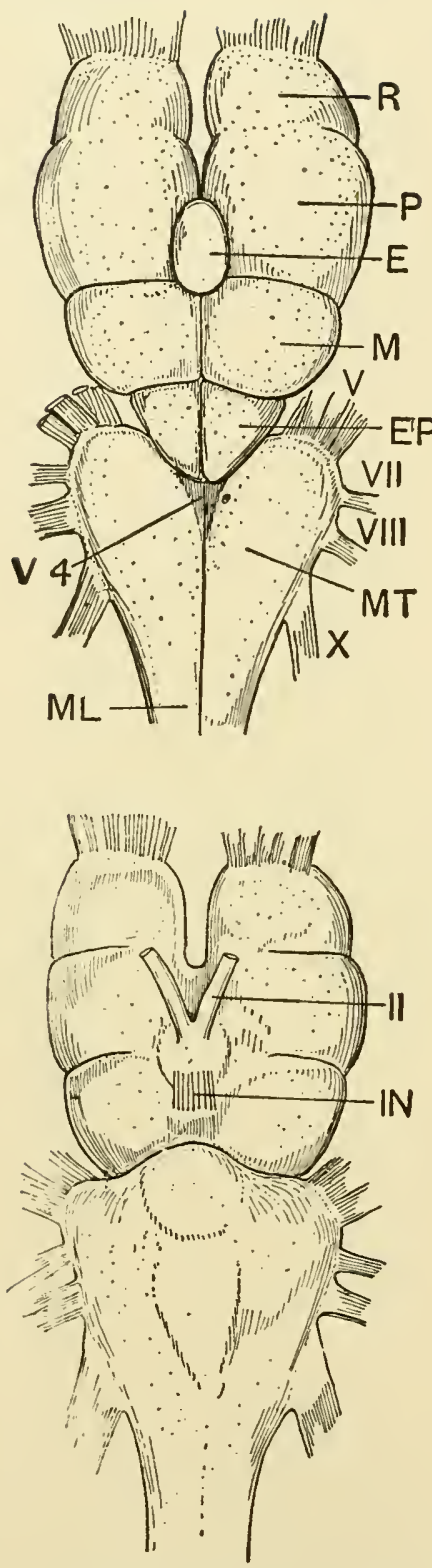
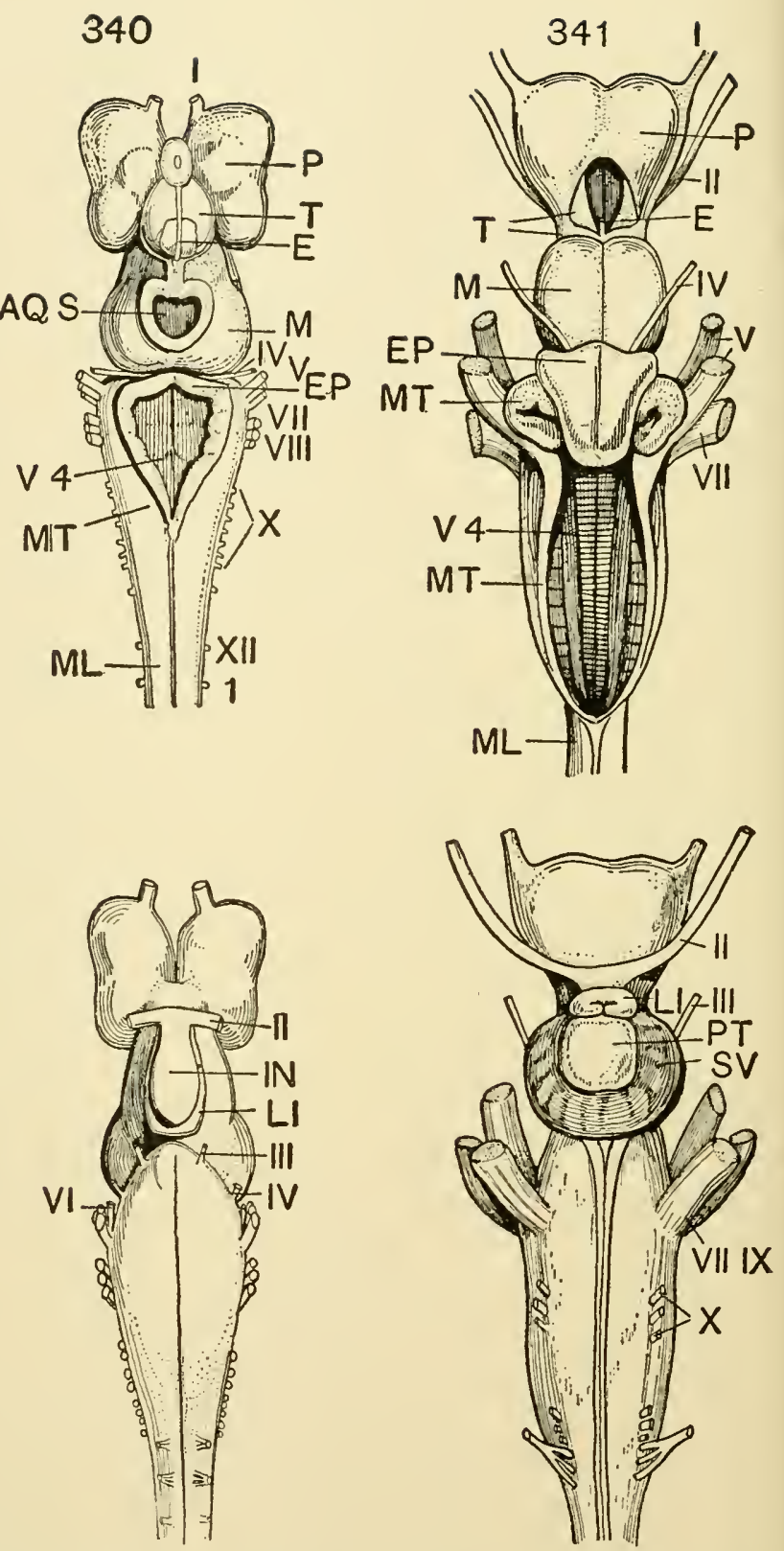

Figs. 339-344. - The brain of fishes. The dorsal view of each brain is shown in the upper figure, the ventral view immediately below. 339. Bdellostoma. (After JoH. Müller.) 340. Petromyzon (Ammocates stage). (After Ziegler's model.) 34I. Shark (angel-fish, Squatina). (After Duméril.) 342. Chimara. (After Wilder.) 343. Lung-fish, Protopterus. (After BurckhardT.) 344. Perch, Perca. (After T. J. PARKER.)

$A Q S$. Aqueduct of Sylvius. DSE. Diverticula of saccus endolymphaticus. $E$. 

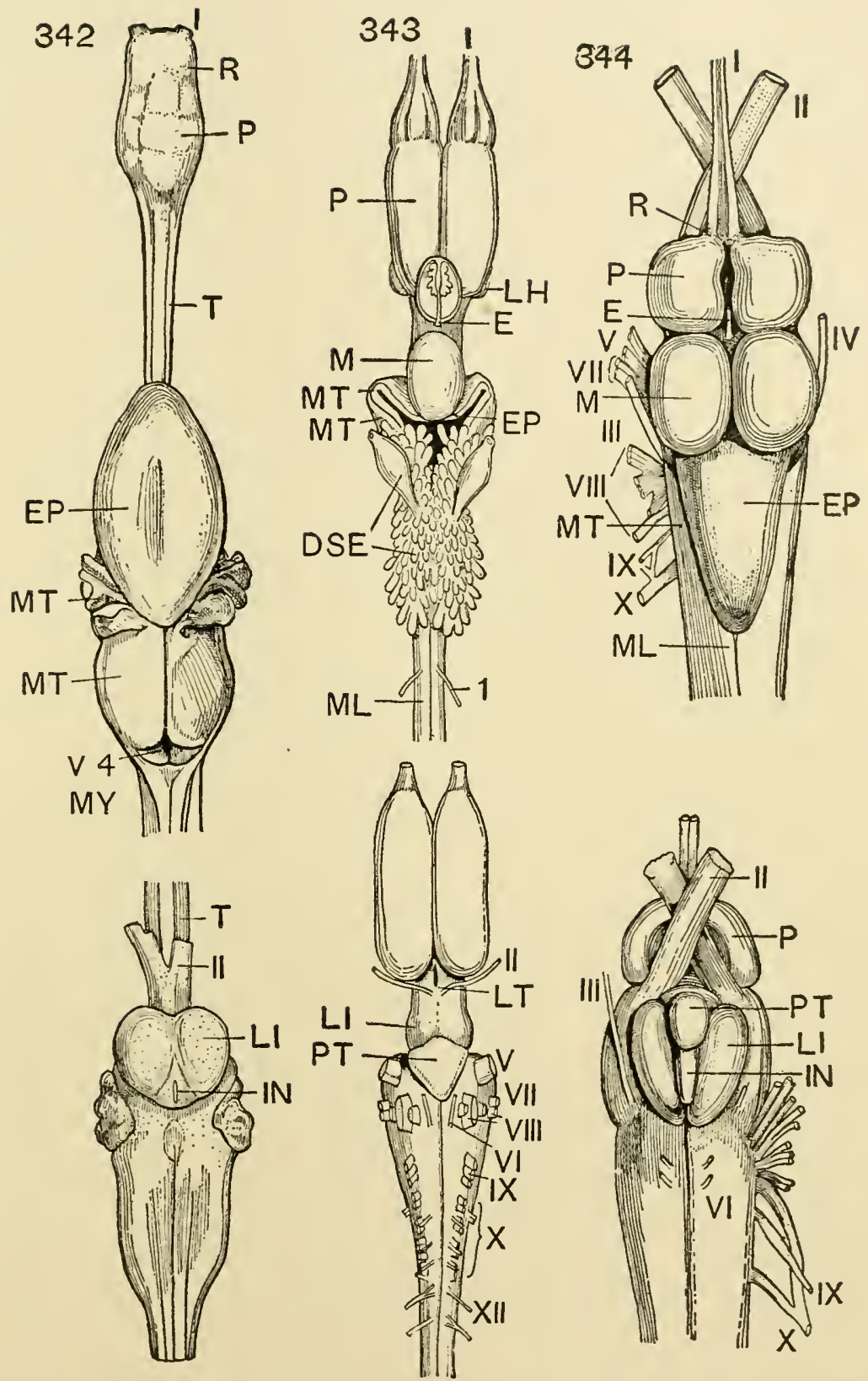

Epiphysis. EP. Epencephalon. IN. Infundibulum. LH. Lobus hippocampi. LI. Lobi inferiores. $L T$. Lamina terminalis. $M$. Mesencephalon (optic lobes). $M L$. Myelencephalon (spinal cord). MT. Metencephalon (medulla). $M T$. Anterolateral lobes of metencephalon. $P$. Prosencephalon (cerebral hemispheres). $P^{\prime} T$. Pituitary body. $R$. Olfactory lobes. $S V$. Saccus vasculosus. $T$. Thalamencephalon. $V 4$. Fourth ventricle. Numbers $I-X$. Cranial nerves. $I$. First spinal nerve. 


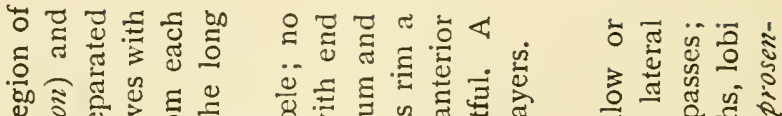

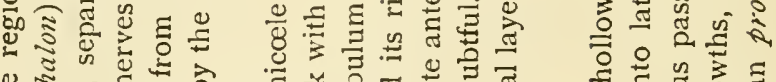

量

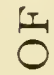

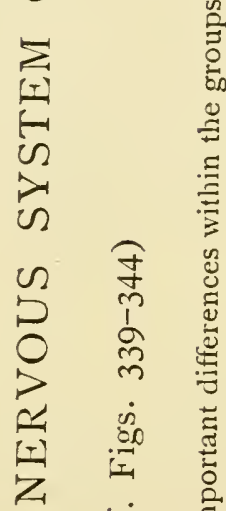
州

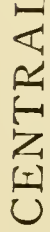

空

突

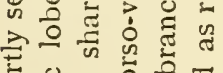

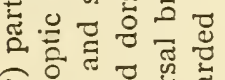

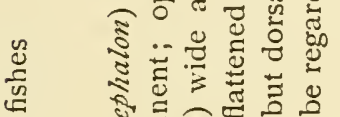

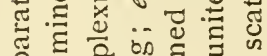

S잉.

荡

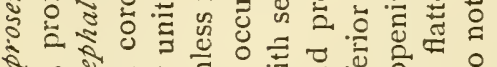

잉

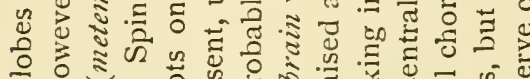

을

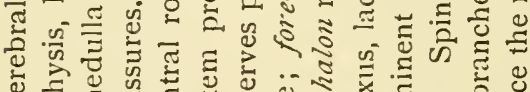

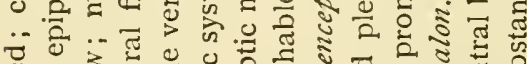

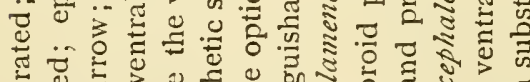

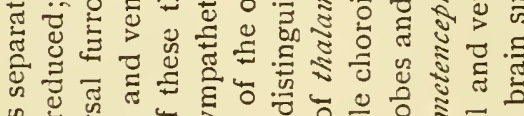

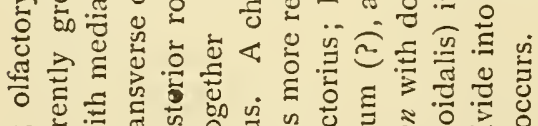

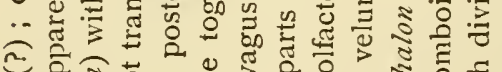

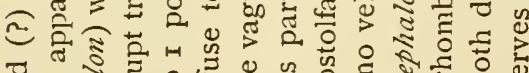

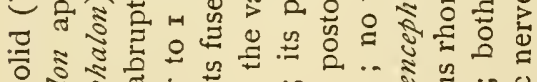

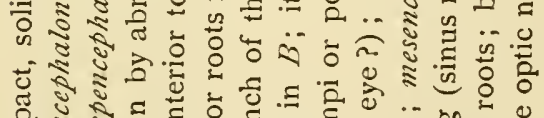

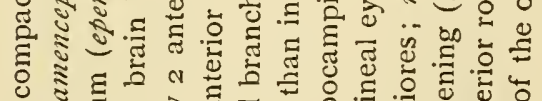

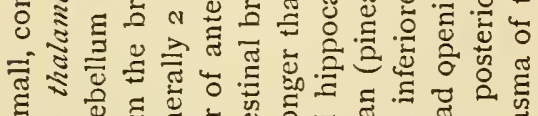
๘ ช :

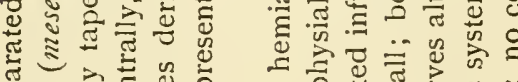

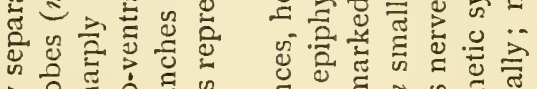

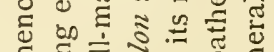

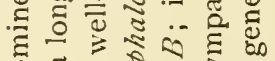

일

0

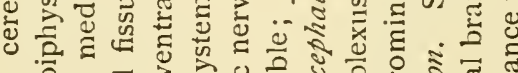

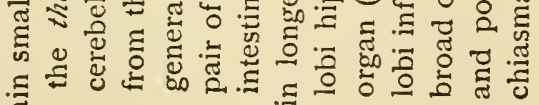

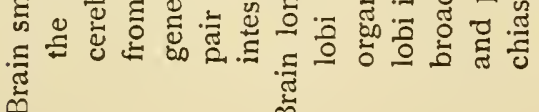

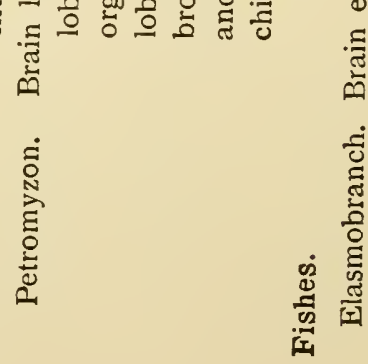

ज. 플

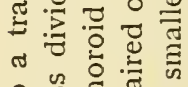
올

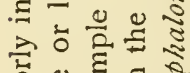
일 ह 与 응

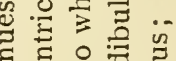

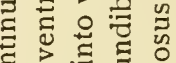
8. 응

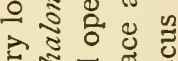
응

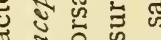
잉 مे

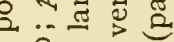

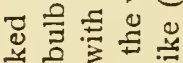
क्षे 施 政 칠 妾 잉 을 ㅎํ의

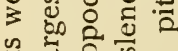

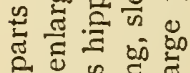

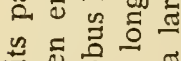
을

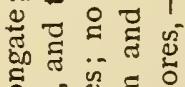
空

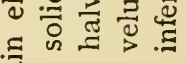
윰

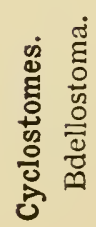

(1) 


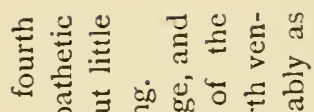

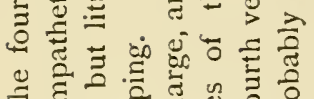

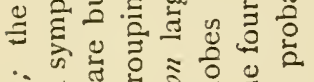

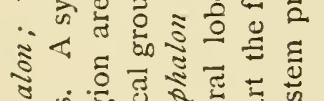

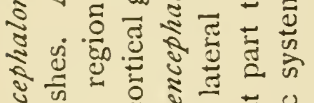

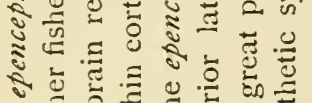

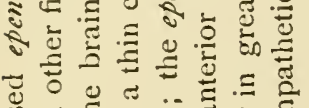

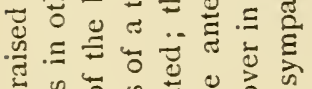

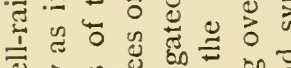

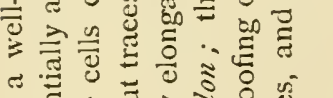

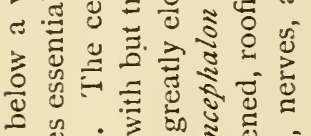

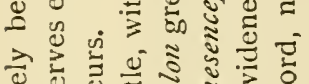

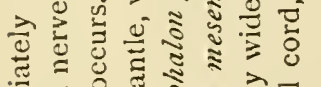

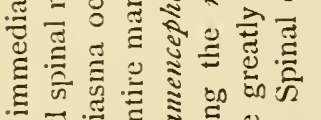

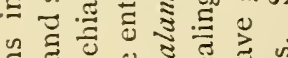

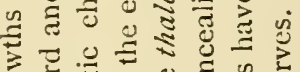

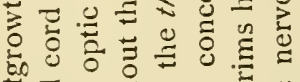

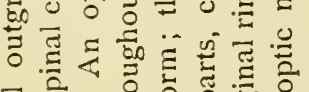
ब家 잉

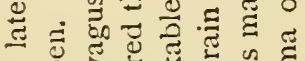

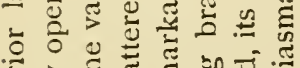

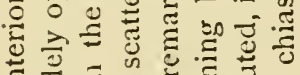

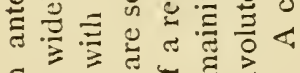

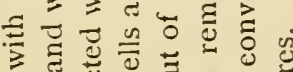
s.

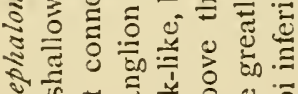

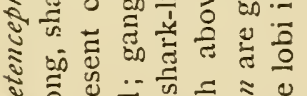

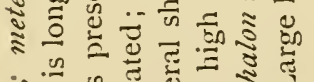

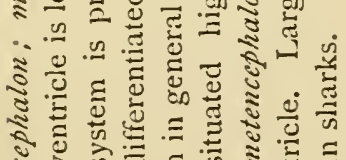

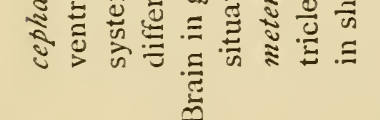

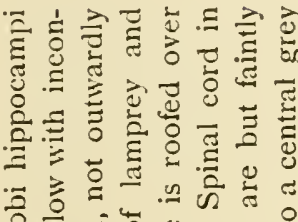
을 ஸे กิ 은

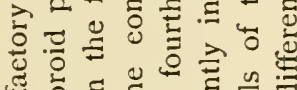

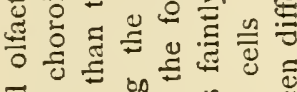

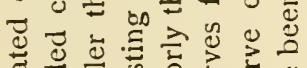

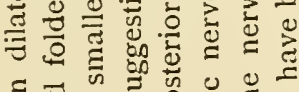

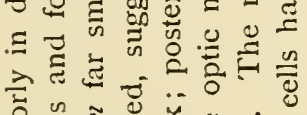

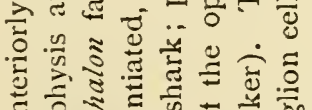

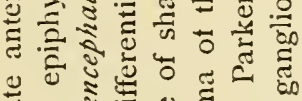
岕

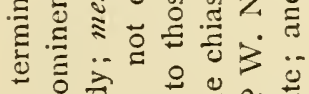

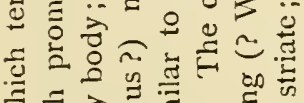

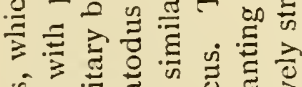

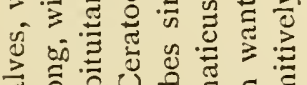

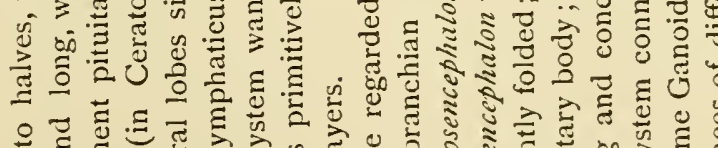

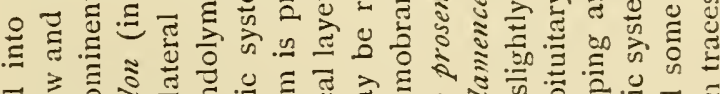
을

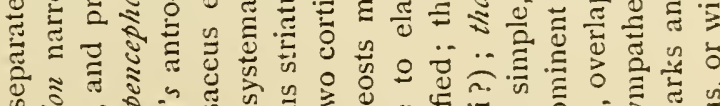

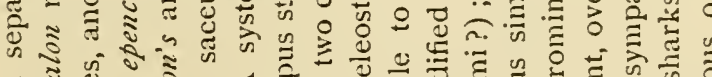

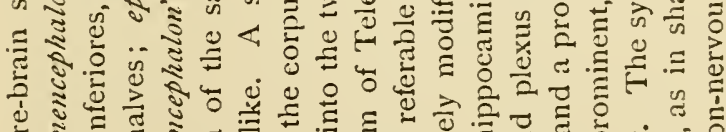

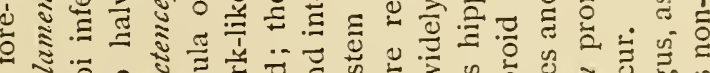

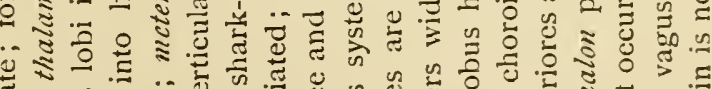

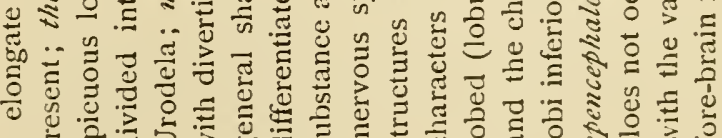

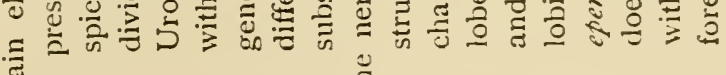
的

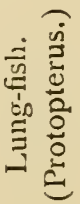

气

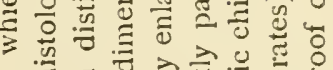

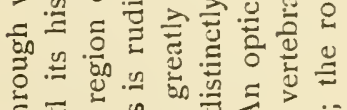

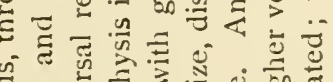

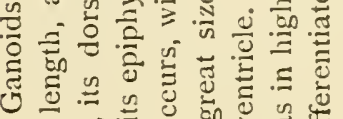
$\triangleq \equiv \overline{0}$ ¿

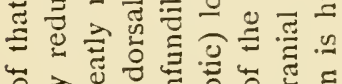

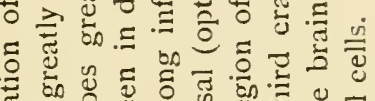

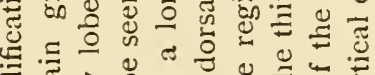

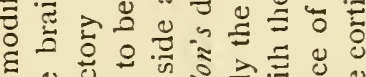

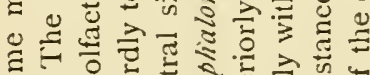
気

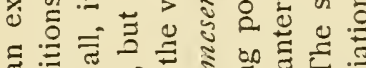
ने

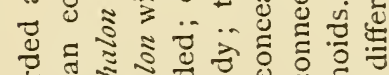
$\underset{\dot{0}}{\stackrel{0}{0}}$ 


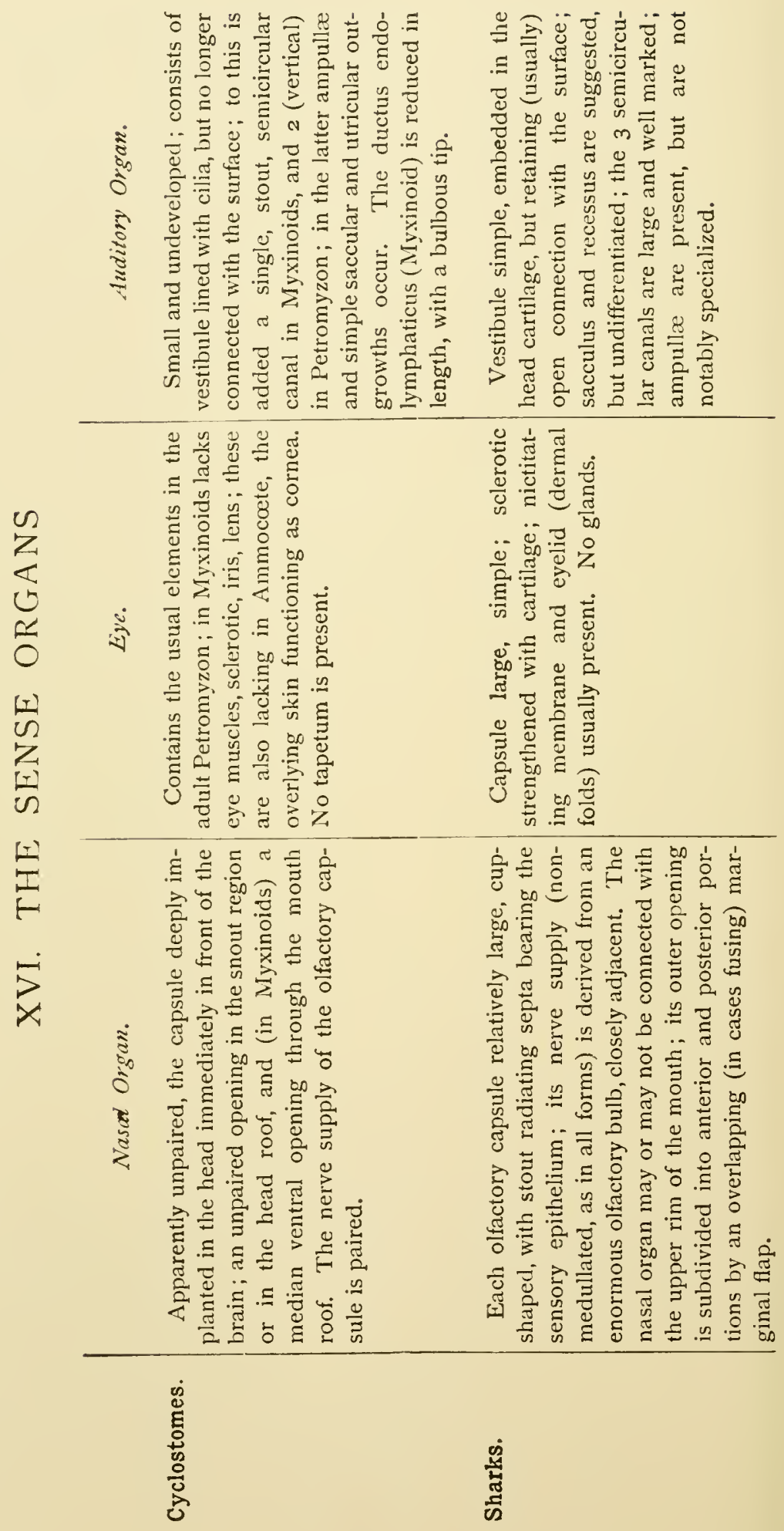




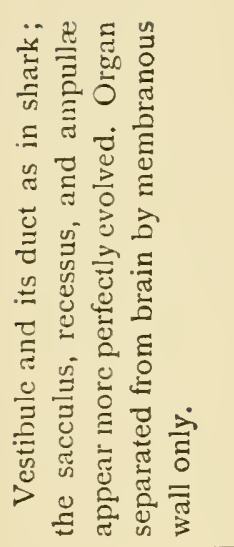

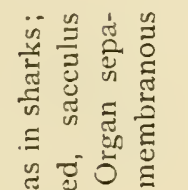

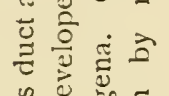

$\cong$ 을

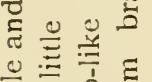

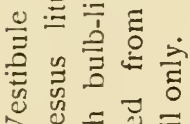

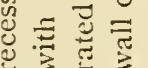

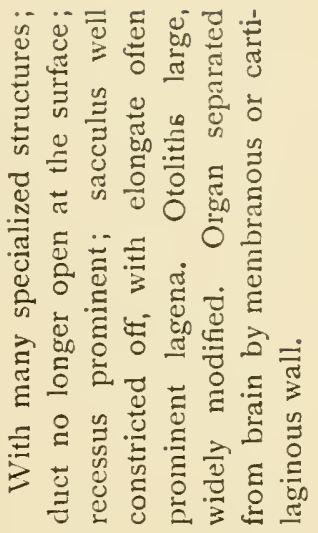

\begin{tabular}{|c|c|c|}
\hline 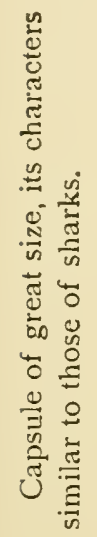 & 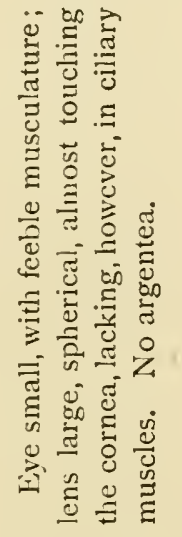 & 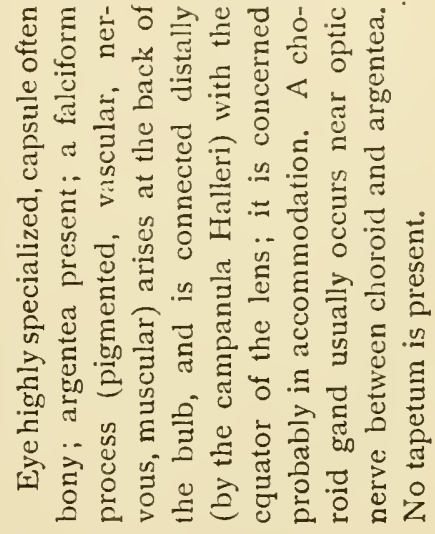 \\
\hline
\end{tabular}

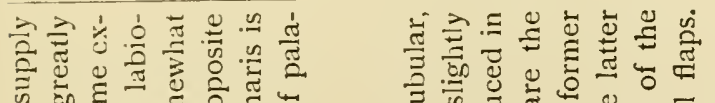

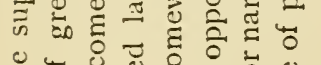
ن

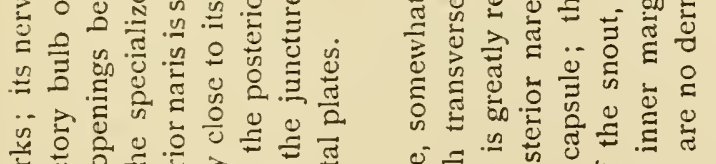

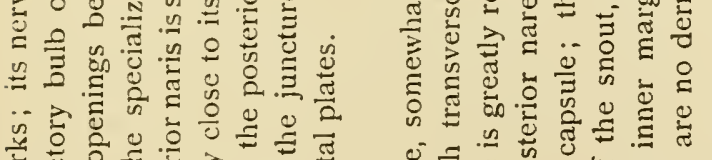

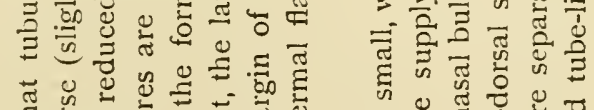

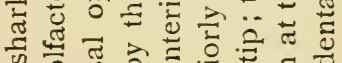

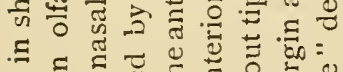

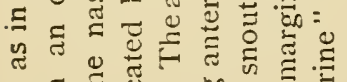
$\cong \Xi \cong$.

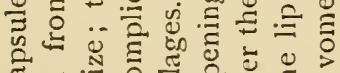
ปี एँ

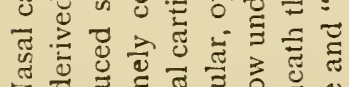

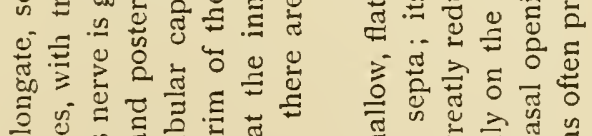

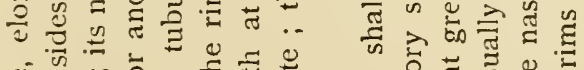
v

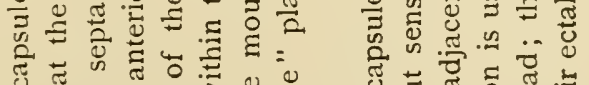
हैं

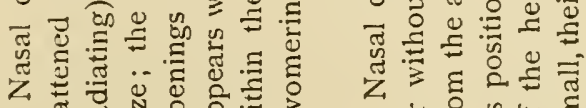
乙

:

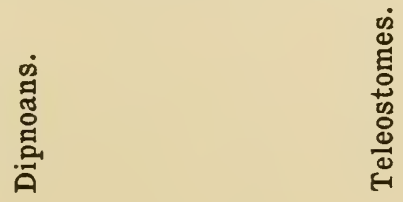




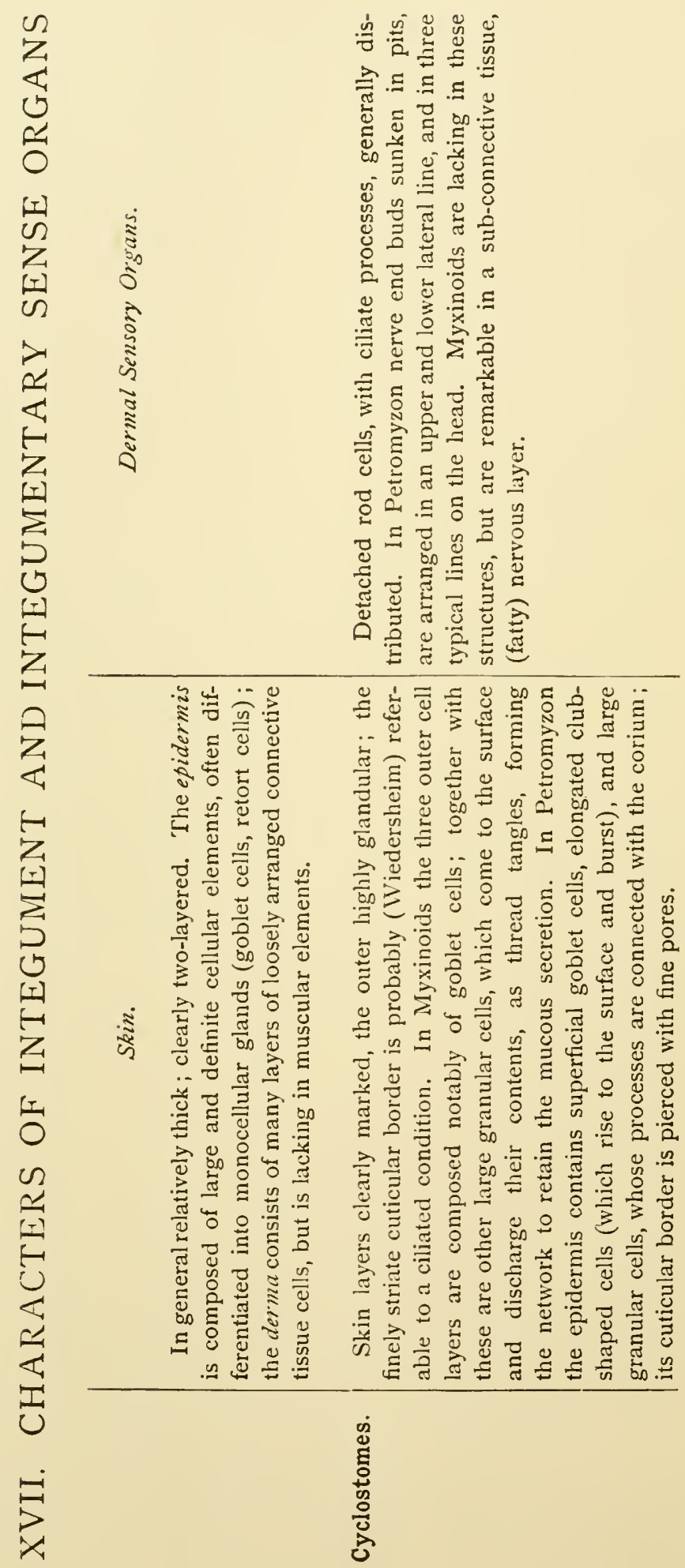




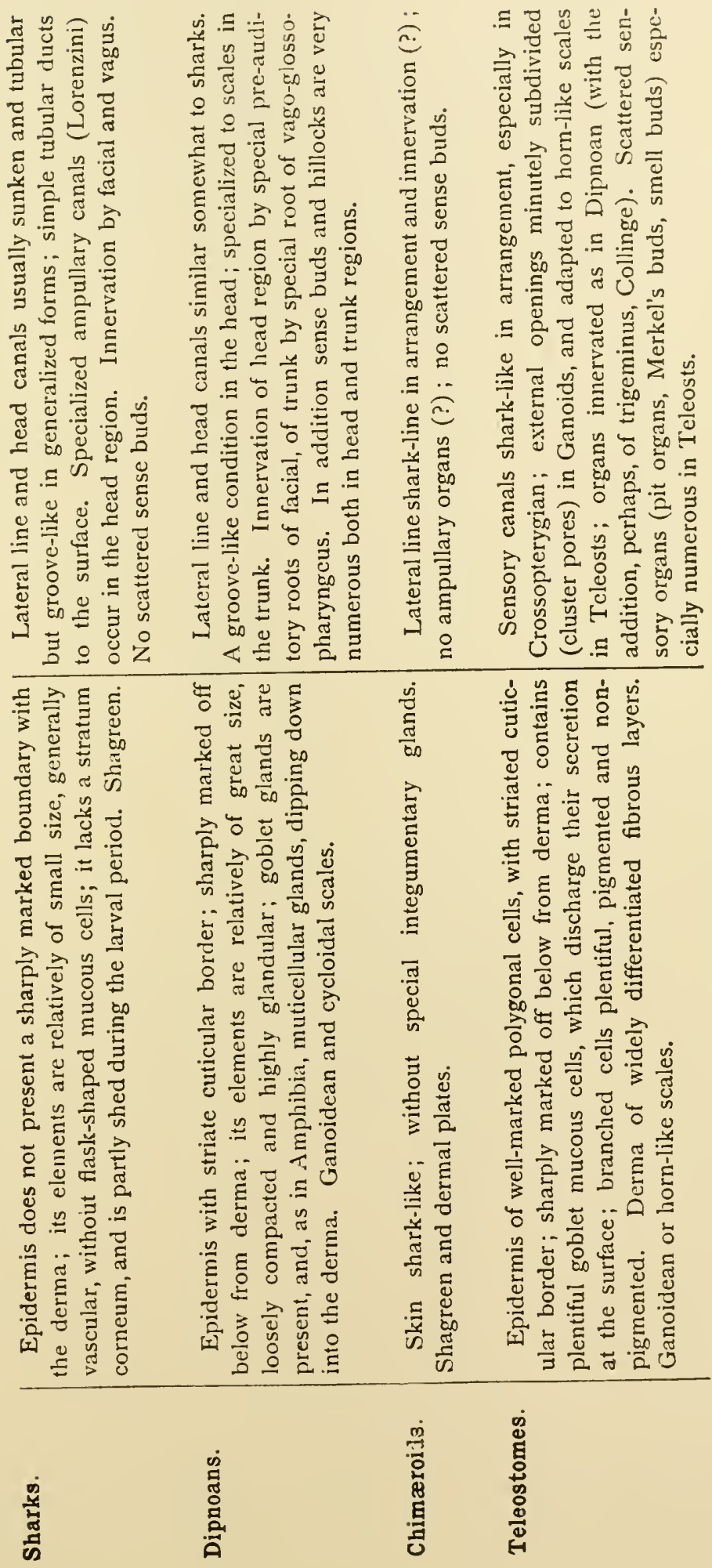




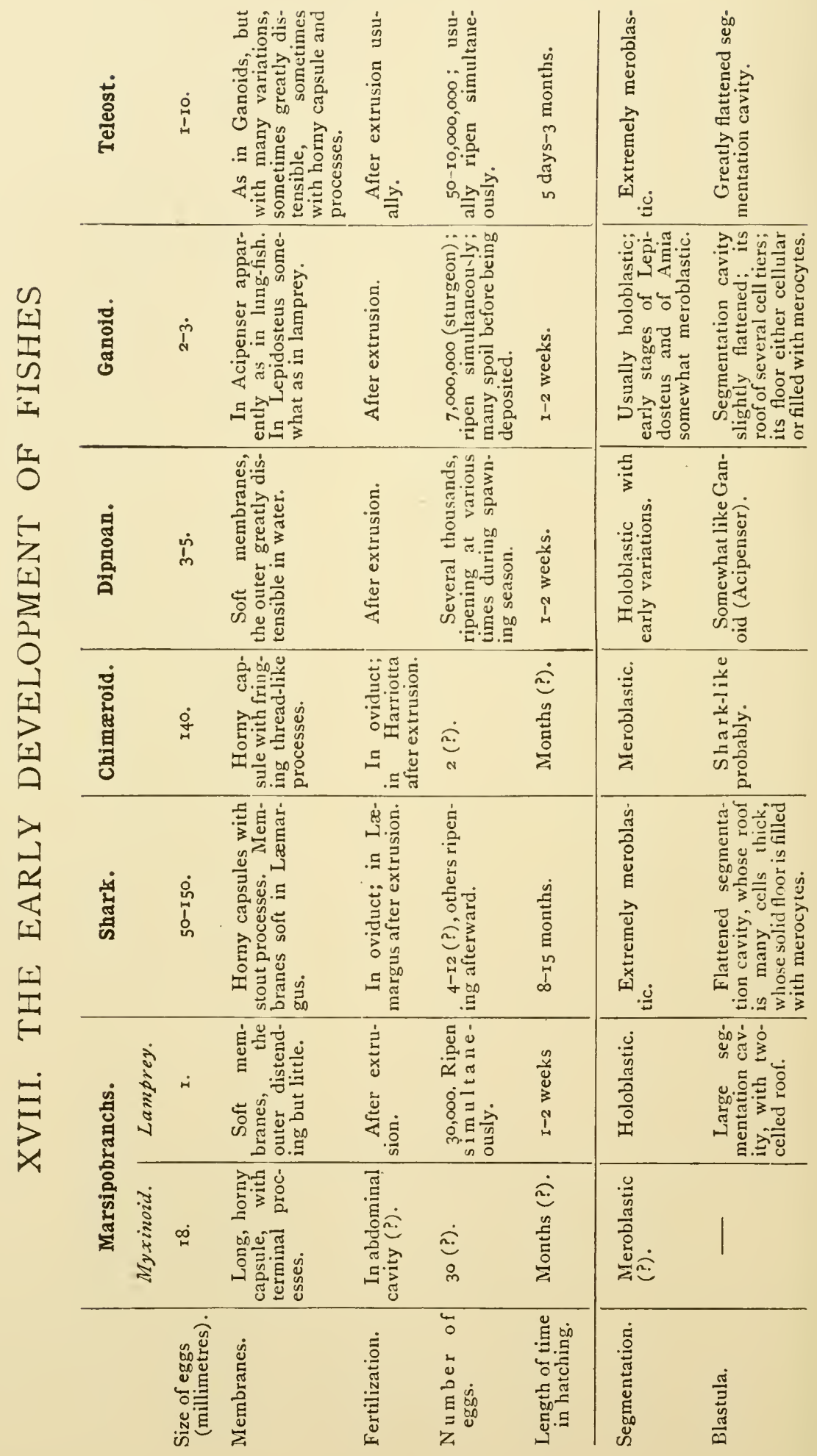




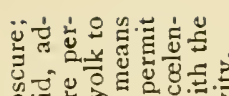

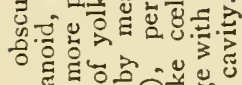

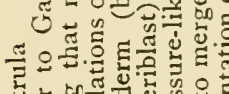

o.

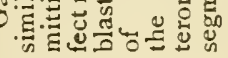

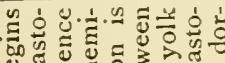

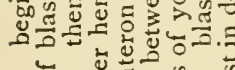

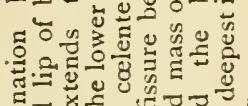

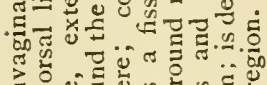

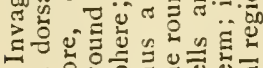

ส้

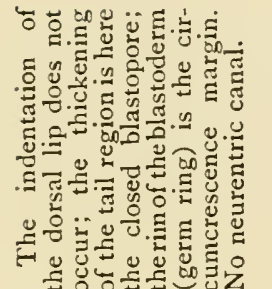

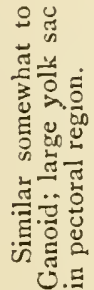

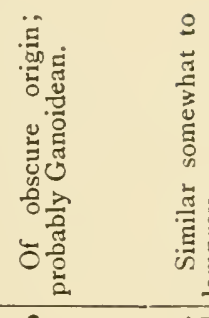

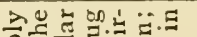

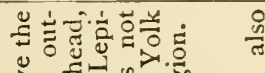

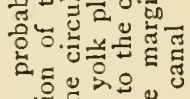

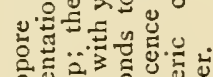

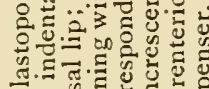

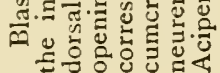

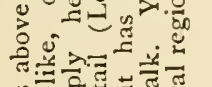

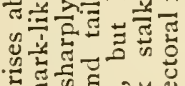

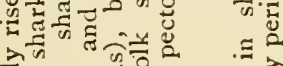

กั

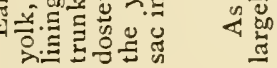

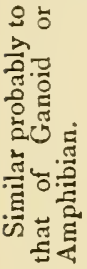

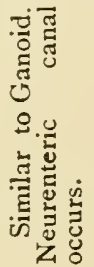

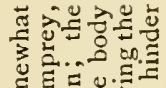

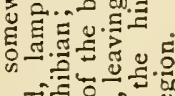

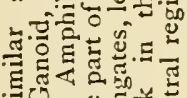

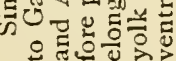

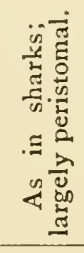

实卷

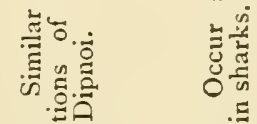

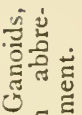

ఏ 등

बै है

दूव

․ㅗㅇ

(1)

त्

造

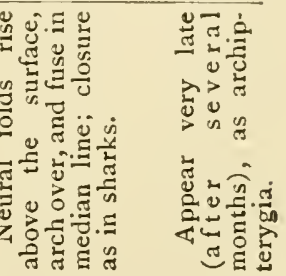
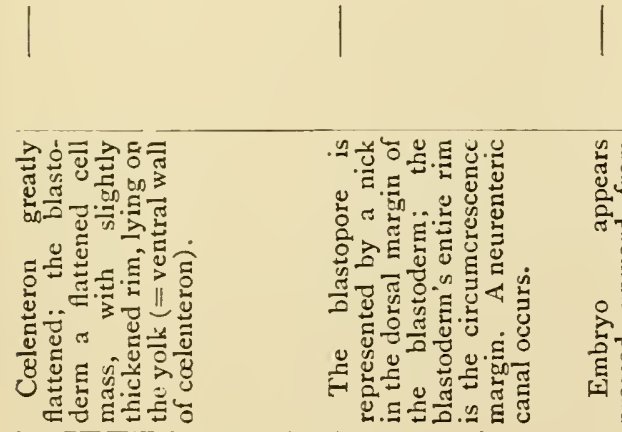

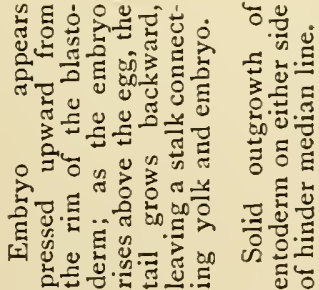

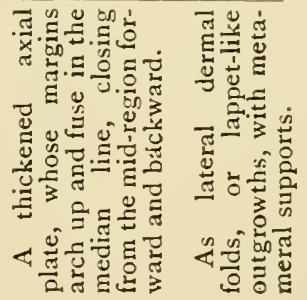

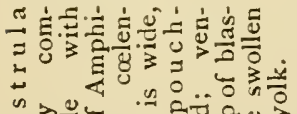

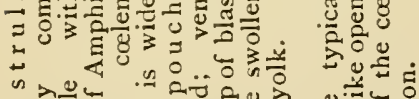

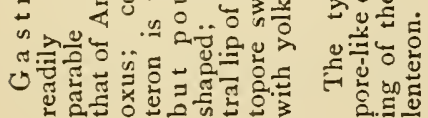
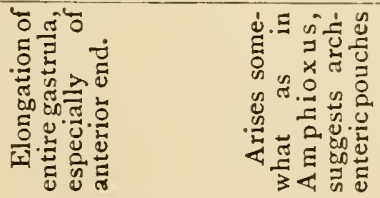

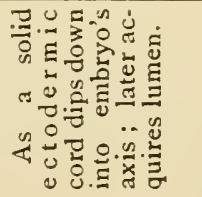

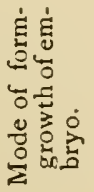

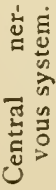




\section{THE SUPPOSED DESCENT}

Interrelationships and lines of descent as suggested by a number of noted on each scheme. * Denotes that the diagram is the present writer's

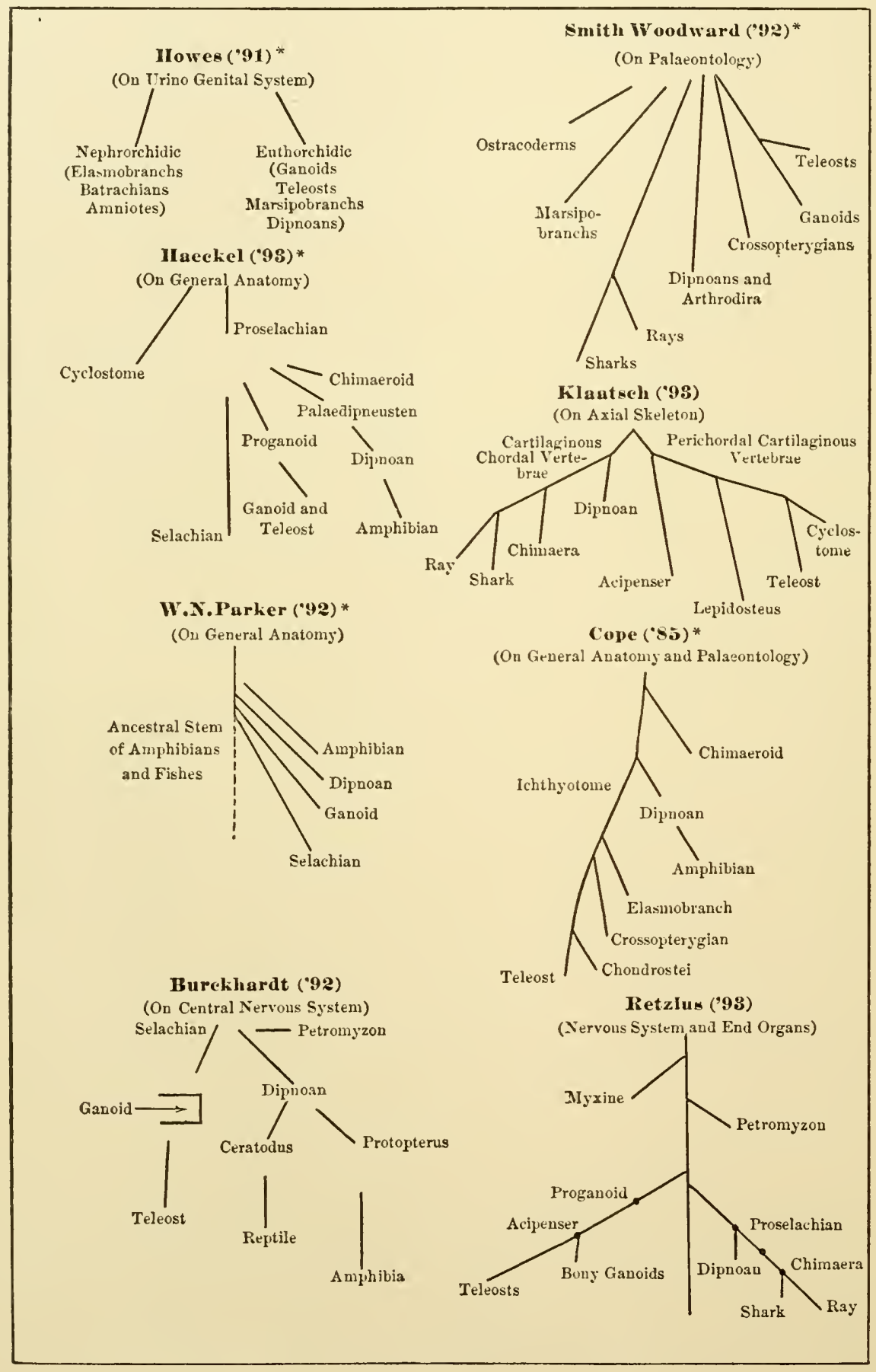




\section{OF THE GROUPS OF FISHES}

observers; their views have been based on the different lines of investigation interpretation of the text of the author cited.

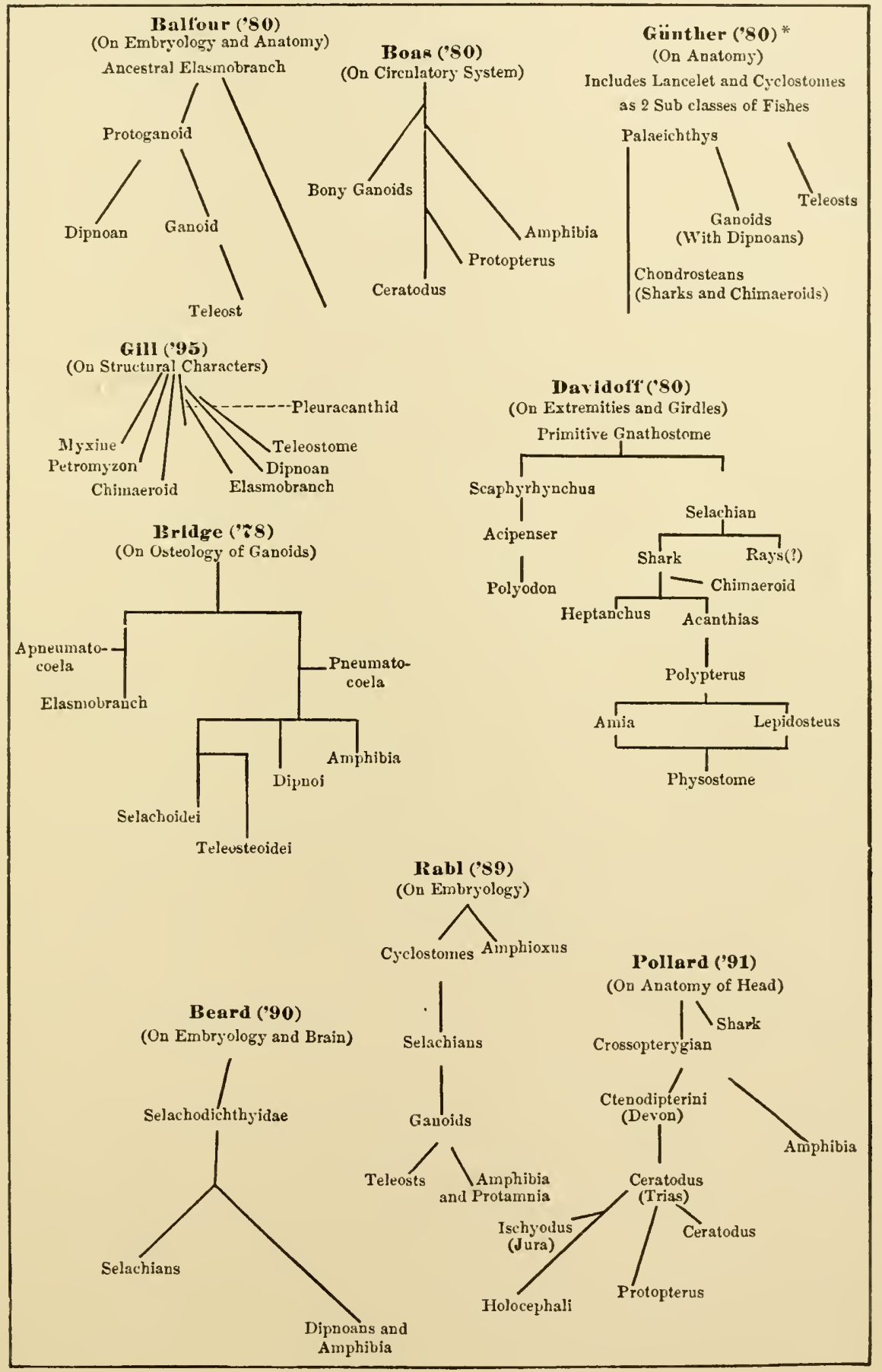





\section{INDEX}

Abdominal pores, $27 \mathbf{I}$.

Acanthias, larva of, 216 (Figs. 288, 289).

Acantinodes, gill shields, 20; a fossil shark of the Coal Measures, 79; structure of, $80,8 \mathrm{I} ; A$. wardii, $8 \mathrm{I}$ (Fig. $S_{7}$ ); shagreen and denticle of A. gracilis, 8I (Fig. SS); affinities of, 95 ; diagram of affinities, $9 S$ (Fig. I03); gill arches, I I 4 .

Acanthodians, antiquity of, 9; fin spine and pectoral fin, 28, 29 (Fig. 32); pectoral fin of Parexus, 42 (Fig. 5 I), 44.

Acanthodopsis wordii, teeth of, 82 (Fig. $88 \mathrm{~A}$ ).

Acanthopterygian, I66 (Fig. I 7 I $A$ ). ACANTHOPTERYGII, in classification, 9; as a subdivision of Teleocephali, I 74 . Acipenser, in classification, 8 ; antiquity of, 9, I 66 (Fig. I 7 I $A$ ); sivim-bladder of, 22 (Fig. I3); description of, I 59-161 ; A. sturio, 160 (Fig. 165);

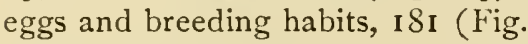
I94), I 85; fertilization, I 87 ; development of eggs, 203 (Figs. 249264), 207; larval development of, 22I-223 (Figs. 296-302); heart, conus and bulbus arteriosus, tables, 260; gills, spiracle, gill rakers and opercula, tables, 26I ; digestive tract, tables, 262 (Figs. 326-33I); swimbladder, tables, 264, 265 (Fig. I3); genital system, tables, 266; urinogenital ducts and external openings, tables, 267 (Figs. 332-337); excretory system and urinogenital ducts, tables, 27 I.
ACTINOPTERYGII, in classification, 8 , I 47; description of, $155^{-1} 78$ (Figs. I57-I $85 A$ ); Chondrosteans (Ganoids), I55; fossil forms, I 55-I 59 (Figs. I 5S-164); living types, I 59I 78 (Figs. $165-18_{5} \mathrm{~A}$ ).

Actinotrichia, 3I, 33 (Fig. 39).

Etheolepis, ganoid plates of, 24 (Fig. 25), 25 .

Agassiz, L., 37, 66, 107, I I .

Agassiz, A., 224.

Air-bladder, v. Swim-bladder.

Allis, E. P., 50, 51 .

Alopias, 89; A.vulpes (thrasher shark), 89 (Fig. 95).

Alosa, eggs and breeding habits, I $8 \mathbf{I}$ (Fig. I97), I 86.

American Arthrodirans, I 30.

American Geologist, So.

Amia, in classification, 8 ; antiquity of, 9, I66 (Fig. I 7 I $A$ ); swim-bladder of, 21, 22 (Fig. I4); sensory tracts in head dermal plates, and scales of, 50-52 (Figs. 64-68); $A$. calva, 5 I note; a Ganoid with herring-like scales, I45; description of, 163-165 (Figs. 167, I68); Mesozoic forms, I64, I65 (Figs. I69-I 7I); heart, conus and bulbus arteriosus, tables, 260; gills, spiracle, gill rakers, and opercula, tables, $26 \mathrm{I}$; digestive tract, tables, 263; swim-bladder, tables, 264, 265 (Fig. I4); genital system, tables, 266; excretory system and urinogenital ducts, tables, $27 \mathrm{I}$.

Amiurus, barbels of, 46, 47 (Fig. 58). Ammocates, head of, 61 (Fig. $72 \mathrm{C}$ ), 285 
62; development of egg, I89 (Fig. 215).

Amphibian affinities of the shark, 98 (Fig. $10_{3}$ ).

Amphioxus, in classification, 7; gills of, 16.

AnaCanthini, 174 .

Anal fins, v. Fins.

Anatomy, v. Shark, Cladoselache, Acanthodes, Climatius, Pleuracanthus, Chondrenchelys, Chimara, Dipnoan, etc.

Angel-fish, v. Rhina.

Anguilla, v. Eel.

APODES, I 73 .

Aquatic breathing, 16-23; modes of, 20.

Archipterygium, 39.

Arius, eggs and breeding habits, I8I

(Fig. 195), I $\$ 5$, I $\$ 6$.

Armour plates, 23; evolution of, 25.

ARTHRODIRA, in classification, $S$; described, 1 29-1 38 (Figs. 130-144); geological position of, 9, 129; associated with Pterichthys by Traquair, 130; American, described by Newberry and by Claypole, I 30 ; Din. ichthys, I30 (Frontispiece and Figs. 133-137); varying size of, 136 ; dentition, jaws, and mandibles, I 36, I 37 (Figs. 138-144); affinities, $136-138$; differing from lung-fishes and from sharks, 136 note.

Aspidorhynchus, 157; A. acutirostris, 158 (Fig. 162).

Aspredo, eggs and breeding habits, 186.

Authors, comparison of phylogenetic tables of, 282, 283; v. Bibliography.

Ayers, H., 57, 60, 181 .

Balfour, F. M., 40, 193, 216; phylogenetic table of, compared, 283 .

Barbels, 46-48 (Figs. 55-60).

Basking shark, v. Cetorhinus.

Bass, striped, numerical lines of, 5 (Fig. 8).

Bathyonus compressus, 168 (Fig. 172). Batrachus, eggs of, 186.
Bdellostoma, gills of, I7 (Fig. 9); anatomy and gencral description of B. dombeyi, 57, $5^{8}$ (Fig. 69 A), 59, 60 (Fig. 70), 61 (Fig. $72 A$ ); eggs of, ISo, I I I (Fig. IS6); genital system, tables, 266; excretory system and urinogenital ducts, tables, 270 ; brain of, tables, 272 (Fig. 339); central nervous system, tables, 274 .

Bean, T. H., I03, I08, 110.

Beard, J., 57, 61, I46, 217 ; phylogenetic table of, compared, $28_{3}$.

Berycids, antiquity of, 9 .

Bibliography, 23I-25I.

Blenniids, eggs of, I85 (Figs. I98199), 186.

Blenny, v. Blenniids.

Blood-vessels, v. Fishes, circulation in, Heart, Chimæ oids, etc.

Boas, J. E. V., phylogenetic table of, compared, 283 .

Böhm, A. A., 187 .

Bolau, H., I $\$ 5$.

Bony fishes, v. Teleosts.

Bow-fin, v. Amia calva.

Brain, of Chimæroids and sharks, II 4 ; resemblances between lung-fishes and Elasmobranchs, 128; comparison tables of, 272 (Figs. 339-341), 273 (Figs. 342-344), 274-275.

Branchial arches, table of relations of, 254 (Figs. 310-315), 256-257.

Breathing, aquatic, $16-23$.

Breeding habits, I So-1 86 ; table of the early development of fishes, 280-281.

Brevoortia (menhaden), gills of, 20.

Bridge, T., phylogenetic tables of, compared, 283.

Bulbus arteriosus, comparative tables of, $25^{8}$ (Figs. 316-325), 260.

Bull-head, v. Catfish.

Burkhardt, R., 12S; phylogenetic table of, compared, 282 .

Butrinus, heart, conus and bulbus arteriosus, 258 (Fig. 323); comparison tables of, 260 .

Calamoichthys, swim-bladder of, 22 
(Fig. I7); median fins of, $3 \mathbf{I}$; antiquity of, I48; described, I5O; C. calabaricus, 147, 150 (Fig. 150). Calberla, E., 187 .

Caldwell, IV. H., I 25.

Callichthys, respiration of, 20; ganoid plates of, 24 (Fig. 26), 26; origin of dermal cusps, 30; C. armatus, 172 (Fig. I 78 ); eggs and breeding habits, I 86 .

Callorhynchus, lateral line lost, 49; description of, I04, I09; mandibular, IO6 (Fig. I IO); bottle-nosed Chimæra, IO9 (Fig. II 8 ); eggs and breeding habits of, I $8 \mathbf{I}$ (Fig. 191), r $8_{5}$.

Canals, v. Lateral line.

Carassius auratus, I 70 (Fig. I 76).

Carp, scales of, 26 (Fig. 3I $A$ ); eggs of, I $S_{7}$.

Catfish, barbels of, 46,47 (Fig. $5^{8}$ ); description of, I7I, I72; Amiurus melas, I 7 I (Fig. I 77).

Cattie, J. T., 54.

Caturus, I64-165; C. furcatus, 164 (Fig. I69); Mesozoic caturid, I 66 (Fig. I7I $A$ ).

Caudal fins, 35; evolution of, 35-39 (Figs. 44-48).

Central nervous system, v. Nervous system.

Cephalaspis, antiquity of, 9 ; described, 67 ; C. lyelli, 66 (Figs. 78, 79).

Cephaloptera, v. Dicerobatis.

Ceratodus, antiquity of, 9, 10; swimbladder of, 22 (Fig. I6); archipterygial pectoral fin of, 39, 40, 42 (Fig. 54), 44, 45; description of, 123 (Fig. 127), I 24; skeleton of, I 23 (Fig. I 28); skull of, I24 (Fig. $128 \mathrm{~A}$ ); embryonic stages, I25; eggs and breeding habits, I 8 I (Fig. 192), I85; development of egg, 198-202 (Figs. 23I-248); larva of, 218-221 (Figs. 290-295); skeleton of, tables, 253; jaw's and branchial arches, tables, 254 (Fig. 3I3), 257; heart, conus and bulbus arteriosus, tables, 258 (Fig. 320); comparison tables of heart, etc., 260; gills, spiracle, gill raliers, and opercula, tables, 26I; digestive tract, tables, 263; swim-bladder, tables, 264, 265 (Fig. I6); genital system, tables, 266; urinogenital ducts and external openings, tables, 267 (Fig. 335); excretory system and urinogenital ducts, tables, 270; abdominal pores, tables, 27 I.

Cestracion, antiquity of, Io; jaw of, 24 (Fig. 27); caudal fin, 36, 37 (Fig. 45), 38 ; anatomy of, 85 (Fig. 9I), 86; Port Jackson shark, I8 I (Fig. I90), I83.

Cestraciont, antiquity of, 9, I0; gills of, 16 note; anatomy of, 85,86 ; dentition of, 86; affinities of, 95 , 96; dental evolution, I 12.

Cetacean, fish-like form of, 5 (Fig. 7), 6.

Cetorhinus, 90 (Fig. $96 A$ ).

Challenger report, quoted, $87,103$.

Characteristic structure of fishes, 14.

Cheirodus, I57; C. granulosus, 157 (Fig. I60).

Cheiropterygium, 39.

Chilomycterus geometricus, I 75, I 76 (Fig. I 84).

Chimara, sensory canals of the head, 30; lateral line of, 49,51 note; affinities to shark, 98 (Fig. I03); anatomy of, 99-IOI (Fig. IO4); skeleton of, IOI-IO3; skeleton of C. monstrosa, I02 (Fig. I05); genus, I04; mandibular, I06 (Fig. I09); palatine plate, Io6 (Fig. I09 $A$ ); clasping spine of forehead, IO7 (Fig. II3); ventral fin and clasping organ, I07 (Figs. I I6, I I 7); bottle-nosed Chimæra, Io9 (Fig. I I 8); general description, I IO (Fig. I I 9), I I I (Fig. 120); dermal plates, I 13 (Fig. I04); comparison tables of skeleton of, 253; jaws and branchial arches, tables, 254 (Fig. 312), 256; urinogenital ducts and external openings, 
tables, 267 (Figs. 332-337); abdominal pores, tables, $27 \mathrm{I}$; brain of, 273 (Fig. 342).

Chimeroids, in classification, 7,8 ; antiquity of, 9, I0; gill shields, 20; affinities to shark, 96; general description of, 99-II5 (Figs. 104I20); anatomy of, 99-IOI (Fig. IO4); skeleton of, IOI-IO3 (Fig. I05); embryology and larval history of, 103; fossil Chimæroids, I03, IO4 (Fig. I05 $A$ ); living Chimæroids, description of, IO4-II I (Figs. I I 7-I 2O); spines and clasping organs, IO7 (Figs. II3-II6); affinities, I I I-I I 5; dental plates, I I I (Fig. I I I); history of fossil forms, I I 2; dental evolution, I I 2; structural affinities to shark, I I 2I 5 ; divergences from elasmobranchian structure, I I3; skull and mandible of, I 3 ; fins and fin spines, I 3 ; skin defences and teeth, I I3; gill arches, I I4; brain of, I I4; lateral line, I I4; clasping spine, I I4; descent of, II5; diphycercal tail compared with that of sharks, II 5 ; separated from Arthrodirans, 136; eggs and breeding habits, I8I (Fig. I9I ), I $8_{4}$, I $_{5}$; list of authors and works on the Chimæroids, 244; gills, spiracle, gill rakers, and opercula, tables, 27r; genital system, tables, 266; circulation in, tables, 269; central nervous system, tables, 275; sense organs of, tables, 277; integument and integumentary sense organs, 279; early development of, tables, 280$2 S$ I.

Chlamydoselache, antiquity of, ro; gill snields, 20; lateral line, 49, 50 (Fig. 6I); C. anguineus, 87 (Fig. 92); affinities to shark, etc., 96; gill arches, II 4 .

Chondrenchelys, 78; anatomy of, 85 .

Chondrostei, in classification, 8 , $161,162$.
Chondrosteus, 161, 162;C. acipenseroides, I6I (Fig. I65

Chordates, ancestors of, I 6 note; description of, 63-65.

Christiceps, eggs of, I $\$ 6$.

Circulatory characters in Dipnoans, I 29.

Cladodus, teeth of, So (Fig. $\$ 6 B$ ).

Cladoselache, in classification, 8; antiquity of, 9; gill slits, I6; gill shields, 20; dorsal fins of, 33 (Fig. 4I); caudal fin of, 36, 37 (Fig. 46), $3 S$; pectoral and ventral fins of, 42 (Figs. 49, 50), 43-46; a primitive form of, $7 \delta$; description of, 79 ; anatomy of, 79 (Figs. 86 and $\$ 6 \mathrm{~A}$ and $\$ 6 B$ ); dentition of, $S 6$; affinities of, 95, 98 (Fig. 103); gill arches, II4.

Clark, IV., r30, I 33 note, Frontispiece.

Clasping spine of Chimæroids, II4; absence of, in Dipnoans, $\mathbf{1} 29$.

Claypole, E. W., 66, 67, 71, 8o, I30. Climatius, anatomy of, 82 (Fig. 89 ).

Clupeoid, antiquity of, 9 ; heart, conus and bulbus arteriosus, 258 (Fig. $320)$; heart, etc., comparison tables of, 260 .

Coccosteus, in classification, 8; localities, I30; anatomy of $C$. decipiens, 13I-I33 (Figs. I3O-I32); dermal and ventral plates of, 132 (Figs. 131, 132); lateral line in, 135; eyes of, 135 .

Cochliodonts, 86; dental evolution of, I 2.

Cod, barbels of, 46, 47 (Fig. 55), I $7 \mathbf{I}$; description of Gadus morrhua, I 74 (Fig. 182); circulation in, tables of, 269.

Calacanthus, in classification, 8; dorsal fin of, 33, 34 (Fig. 43), 43; description of, 87 (Fig. 92), 153; as a Crossopterygian, 147 ; C. elegans, I 53 (Fig. I 55).

Columbia College Museum, I30, I35, Frontispiece.

Conus arteriosus, comparison tables of, 
258 (Figs. 316-325), 260; v. Sharks, etc.

Cope, E. D., 8, ro; phylogenetic table of, compared, 282 .

Cricotus, 54; parietal foramen of, 54 . Crossopterygil, in classification, 8; antiquity of, 9; unpaired fins of, 33 (Fig. 43); affinities to shark, 96; included in the term Ganoid, I39; ancestry of, 147 ; a group of Teleostomes, I47; description of, I48I 55 (Figs. I $48-156 \mathrm{~A}$ ); habits of living and breeding, I50; fossil forms, I 50-I 55 (Figs. I 5 I-I $56 \mathrm{~A}$ ); palzozic, r66 (Fig. I 7 I $A$ ).

Ctenodus, in classification, 8; median foramen of, 55; affinity to Ceratodus, 122, 124; ancestry of, 147.

Ctenolabrus coruleus, larval development of, 224 (Figs. 303-309), 225.

Curves of fishes, 5,6 .

Cusk, barbels of, 46, 47 (Fig. 55).

Cusps, v. Derm cusps.

Cyclostomes, in classification, 7,8 ; antiquity of, 9; metamerism in, 14I6; gills of, I8; lampreys, 57-63; their affinities, $63-65$; palæichthyic affinities, 70; eggs and breeding habits of, I 80, I 8 I (Figs. 186, I 87 ); fertilization of eggs, 187 note; larval development, 2I4, 2I 5 (Figs. 2I 2, 2 I 5, p. IS9, and 72, p. 60); names of authors and works, list of, 234-238; skeleton of, tables, 252; heart, conus, and bulbus arteriosus, tables, 260; gills, spiracles, gill rakers, and opercula, tables, 260; digestive tract, tables, 262 (Fig. 326), 263; swimbladder, tables, 264; genital system, tables, 266; urinogenital ducts and external openings, tables, 266,267 (Fig. 332); abdominal pores, tables, 27 I, 272 (Fig. 340); central nervous system, tables, 274 ; sense organs, tables, 276; integument and integumentary sense organs, tables, 278.

Cyprinodonts, eggs of, 185 .
Davidoff, M., phylogenetic table of, compared, 283.

Davis, J. W., 84 .

Dean, B., 8, 78, I 28, I 32 .

Deep-sea fishes, lateral line in, 49.

Defences, v. Dermal and Teeth.

Dental plate, of Sandalodus, 24 (Fig. 28), 28; of sting-ray, 24 (Fig. 29); of eagle-ray, 24 (Fig. 30), 27; of Arthrodirans, I 36, 137 (Figs. 138I44); of Dinichthys, I36-I38.

Denticle, v. Dermal defences.

Dentine, v. Shark, skin of.

Derm cusps, origin of, 30 .

Dermal defences of fishes, 23-30; of shark, 23, 24 (Figs. 30, 3I); evolution of, 24 (Figs. 24-26), 25; of Chimæroids, II 3 ; of Coccosteus decipiens, 132 (Fig. 13I); v. Fin spines.

Dermal sense organs, v. Sensory organs, integumentary.

Development, v. Fishes, Eggs, larval, etc.; comparison table of early, 280, $28 \mathrm{I}$.

Devil ray or mantis, v. Dicerobatis.

Dicerobatis, 95, 96 (Fig. I02 $A$ ).

Digestive tract, comparison tables of, 263 (Figs. 326-33I).

Dinichthys, Frontispiece; pineal funnel, 55; general description, I30I38; type specimens in Columbia College Museum, I30 (Frontispiece and Figs. 133-137); fin and fin spine, I3I ; D. intermedius, restoration of by Newberry, I33 (Fig. I33 and Frontispiece); elater-joint of, I34; dermal, ventral, and pineal plates of, I 33 note; dorsal plates in Columbia College Museum, I35; jaws of, I36, 137 (Figs. I38-144); inter movement of dental plates of, 138 .

Diphycercal-shaped fin, 35, 37 (Fig. 47).

Diplognathus, jaw of, 136,137 (Figs. I41-143).

Diplurus, 147, I 53, I 54; D. longicaudatus, 154 (Fig. 156 ). 
DipNoans, in classification, 7,8 ; antiquity of, 9, 10, 147; swim-bladder of, 2 I ; affinities to shark, 96, 98 (Fig. 103); general description of, 116-129 (Figs. 121-129); structural characters and general anatomy of, 116-120 (Fig. 12I); skeleton of, I18 (Fig. I22), I19; fossil forms, 120-124 (Figs. 123-126); living forms, 123-127 (Figs. 127-I $29 A$ ); relationships, 127-129; amphibian characters of, 127, I29; kinship to sharks, 127; the advancing structures of, I 29; the Arthrodiran lungfishes, 129-138 (Figs. 130-144); arthrodiran affinities, 136 ; eggs and breeding habits, 181 (Fig. 192), 185; larval development of, 2I8221 (Figs. 290-295); names of authors and works on, list of, 244246; comparison tables of skeleton, 253; skeleton of Protopterus annectans, 119 (Fig. 122); skull and branchial arches, table of relations of, 257; heart, conus and bulbus arteriosus, tables of, 258 (Figs. 320 , $32 \mathrm{I}$ ); comparison tables of heart, etc., 260; digestive tract, 262 (Fig. 329); comparison tables of digestive tract, 263; genital system, tables, 266; urinogenital ducts and external openings, tables, 267 (Figs. 332337); circulation in, tables, 269; brain, 272 (Fig. 343); central nervous system, tables, 275 ; sense organs, tables, 277; integument and integumentary sense organs, tables, 279; early development of, comparison tables, $2 \mathrm{SO}-2 \mathrm{SI}$.

Dipterus, in classification, 8; antiquity of, 9; description of, I2I (Figs. 123-125), 122.

Dohrn, A., 40, 63 .

Dolphin, fish-like form of, 6 .

Dorsal fin, v. Fins.

Drum-fish, barbels of, 46,47 (Fig. 56).

Dugong, fish-like form of, 6 .
Eagle-ray (Myliobatis), dental plates of, 24 (Fig. 30), 27.

Early development, v. Development.

Edestus heinrichsii, fin spine of, 28-30 (Figs. 35-38).

Edinburgh Society, Transactions of, quoted, 70.

Edwards, V. N., I 84.

Eel, movement of, 2 (Fig. 2); gills of, I8; median fins of, 31 ; description of Anguilla wulgaris, I 7 I, I 73 (Fig. I80).

Eggs of fishes, rSo-I86 (Figs. IS6199), v. Comparison tables of the early development of fishes, 280 .

Elasmobranchir, in classification, 8, 9; antiquity of, 9; description of, 72-97 (Figs. $\mathrm{S}_{3}-\mathrm{IO} 2$ ); affinities of, 95; resemblances to lung-fishes, $12 S$, 129; to Athrodirans, I 36, v. Shark; eggs and breeding habits of, $1 \delta_{3}$, 184 (Figs. $189,189 A$ ); circulation in, 268 (Fig. 338), 269; central nervous system, tables of, 274,275 .

Elonichthys, 156; E. (Rhabdolepis) macropterus, 156 (Fig. I58).

Embiotocids, eggs of, 185 .

Emery, C., I69, 170.

Enamel of shark skin, 23, 24 (Fig. 20); enamel organ of shark, 23, 24 (Fig. 20).

Entering angle of fishes, 5, 6 .

Environment, changes due to, $167-$ 169 (Figs. 172-1 74).

Erythrinus, swim-bladder of, 22 (Fig. I 5).

Eurynotus, 157; E. crenatus, 156 (Fig. 159).

Eusthenopteron, I5I-153; E. foordi, I 52 (Fig. I 54).

Evolution, of fishes, slowness of, 11 ; of fins, 30-46; of unpaired fins, 31 39 (Figs. 39-43) ; of paired fins, 3946 (Figs. 49-54).

Excretory system, tables of, 270, 271 (Figs. 332-337, p. 267).

Exoskeletal specializations of Dipnoans, 129. 
Eye, v. Pineal eye.

Feeling, sense of, 46-48.

Fertilization phenomena, $\mathbf{8} 86, \mathbf{I} S_{7}$, v. comparison tables of the early development of fishes, 280 .

Fierasfer, 169, I70; F. acus, I69 (Fig. I 75).

Fins, location of, 3, 4; evolution of, 30-46 (Figs. 39-54); unpaired, 3 I39 (Figs. 39-43); dorsal and anal, 3I-35 (Figs. 39-43); caudal, 3539 (Figs. 44-48); paired, 39-46 (Figs. 49-54); pectoral, 4I-43 (Figs. 49, 5I-54); ventral, 4I-43 (Fig. 50); of Chimæroids, I I 3 ; primitive dermal, $3 \mathrm{I}$; of Cladoselache, 33 (Fig. 4I); of Calacanthus, 34 (Fig. 43); of Crossopterygian (Holoptychizus), 33 (Fig. 43).

Fin spines, 23; description of, 28-30 (Figs. 32-38); of Acanthodian, 29 (Fig. 32); of Hybodus, 29 (Fig. 33); of sting-ray, 28, 29 (Fig. 34); of Edestus heinrichsii, 28, 29 (Figs. $35-38)$; of Chimæroids, 113.

Fishes, defined, I ; movement of, I, 2 (Figs. 1, 2); type of swift swimming fish, 3, 4 (Fig. 3); balanced in water, 1,4 ; symmetry of, 4 ; numerical lines of, 5, 6 (Figs. 5-8); effect of environment of, 7 ; classification of, 7,8 ; geological distribution of, 9; importance of group, IO; permanence of, IO; evolution of, I I ; generalized, 12; characteristic structure of, 14-56 (Figs. 9-6o); metamerism, I4-16; aquatic breathing, gills, etc., I6-23 (Figs. 9-19); dermal defences of, 23-30 (Figs. 20$38)$; teeth in highly modified fishes, 28; development of, I 79-225 (Figs. I 86-309); embryology of, I 79; eggs and breeding habits of, I80-1 86 (Figs. I 86-199); fertilization of eggs of, I86, I87; development of eggs of, I $87-214$ (Figs. 200-283); larval development of, 213-225
(Figs. 284-309); names of authors and works, on the general subject, 23I-234; skeletons, table of, 252, 253 (Figs. 69, 84, 105, I 22, I 46, 147, and 3IO-315); skull, jaw, and branchial arches, tables, 254 (Figs. 3IO-3I5); heart of, 258 (Figs. 3I6-325), 260; comparison tables of heart of, 260; gills, spiracles, gill rakers, and opercula, tables, 259 (Figs. 9-I2), 260, 26I ; digestive tract, tables, 262 (Figs. 326331), 263; swim-bladder, tables, 264, 265 (Figs. 1 3-19); genital system, tables, 266, 267 (Figs. 332337); circulation in, tables, 268 (Fig. 338), 269; excretory system and urinogenital ducts, 270, $27 \mathrm{I}$ (Figs. $332-337$, p. 267); abdominal pores, 27 I ; brain of, 272 (Figs. 33934I), 273 (Figs. 342-344); central nervous system, tables, 274, 275; sense organs, tables of, 276,277 ; characters of integument and integumentary sense organs, 278 , 279; early development, comparison tables of, $280,28 \mathrm{r}$.

Flounder, I II; description of, 174 , 175; Pseudopleuronectes americanus, I 72 (Fig. $1 S_{3}$ ).

Fossil forms, v. Sharks, Chimæroids, etc.

Fraas, I 57.

Fric, IO2, I 19.

Frilled shark, v. Chlamydoselache, etc. Fritsch, A., 42, 83 .

Gadoid, 9.

Gadus, v. Cod.

Gage, S., I 82.

Ganoid plates, in Etheolepis, 24 (Fig. 25); in Lepidosteus, 24 (Fig. 24); in Callichthys, 24 (Fig. 26).

GaNoIDs, in classification, 8,148 ; antiquity of, 9; dermal plates, 24 (Fig. 25), 25; Ganoid includes the Crossopterygians, I39. note; the term "Ganoid" used in the popular sense to denote the Teleostomes, I39; con- 
trasted with Teleost, I 44 (Fig. I 47); air-bladder like that of a Dipnoan, 145; J. Müller as to structural differences between Ganoids and Teleosts, I45; recent Ganoids, I59; Mesozoic, I66 (Fig. I 7 I $A$ ); eggs and breeding habits, I $S_{1}$ (Figs. I93, 194); fertilization of eggs of, $1 S_{7}$; development of eggs of, 202-207 (Figs. 249-268) ; larval development, 21 1-223 (Figs. 296-302); names of authors and works on, 246-249; skeleton, tables of, 253 ; skeleton of Polypterus hichir, I44 (Fig. I47); digestive tract, tables, 262 (Figs. 326-33I); urinogenital ducts and external openings, tables, 266, 267 (Figs. 332-337); abdominal pores, tables, 27I; tables of early development, 28o, 28 r.

Ganoine, I 66 note.

Garman, '87, 93, I09, I Iо.

Gar-pike, v. Lepidosteus.

Gegenbaur, C., 39, 40, 42, I46.

Generalized fishes, defined, I 2.

Genital system, comparison tables of, 266 (Figs. 332-337), 270, 271.

Geological distribution of fishes, 9 .

Geologist, American, quoted, 80.

Gill, T., I10; phylogenetic table of, compared, 283 .

Gill rakers, 20; comparison tables of, 260.

Gill shields, 2o; v. Sharks, Chimæroids, etc.

Gills, 16-23; evolution of, I8; of Amphioxus, I6; of Bdellostoma, I 7 (Fig. 9); of Myxine, I 7 (Fig. Io); of shark, I7 (Fig. II); of Teleost, I 7 (Fig. I2); of Cyclostomes, I8; of Heptanchus, I6, I9; of mullet, 20; of Brevoortia (menhaden), 20; of Selache, 20; number of gill slits, I6, note; table of comparison of, 260, 26r (Figs. 9-1 2, p. 259).

Goette, A., 189.

Goldfish, I 70; Carassius auratus, I 70 (Fig. I 76 ).
Goode, G. B., 3, 47, 89, 90, 92, 94, 95 , 103, I08, I 55, I60, I62, I63, I 7 I, $173^{-1} 77$.

Graf, A., 75, I02, I 19.

Greenland shark, v. Lamargus.

Guitel, F, ISI.

Gunn, M., 70.

Günther, A., 60, 90, 96, 103, 1 23, I 25, 146, I62, I6S, I70, I 72, I 7S, I81 ; phylogenetic table of, compared, 283.

Gurnard, v. Prionotus.

Gyroptychius, I5O, I5I (Fig. I5I).

Haeckel, I46; phylogenetic table, compared, 282 .

Hagfish, in classification, S; v. Myxine. Harriotta, 103, 104, IOS (Fig. II 7); clasping spine of, I I 5 .

Heart, v. Sharks, etc.

Henibranchiates, I 76 .

Hemitripterus, barbels of, 46, 47 (Fig. 57).

Heptabranchias, v. Notidanus.

Heptanchus, v. Notidanus.

Hertwig, O., 54, 204.

Heterocercal caudal fin, 35, 37 (Figs. $45,46)$.

HETEROSOMATA, I 75 .

Hippocampus, I76; H. heptagonus, I 77 (Fig. 185); eggs and breeding habits, I 86.

Hofer, B., 24 .

Hoffman, I 87 note.

Holocephal, v. Chimæroids; heart, conus and bulbus arteriosus, tables, 260; digestive tract, tables, 263; swim-bladder, tables, 264.

Holoptychize, in classification, 8; unpaired fins of, 33 (Fig. 33); ancestry of, 147; description of, 150; $H$. andersoni, I $5 \mathrm{I}$ (Fig. I53).

Homocercal caudal fin, 35, 37 (Fig.48).

Howes, G. B., 42; phylogenetic table of, compared, 282.

Huxley, I3I, 257.

Hybodus, number of gill slits, I 6 note; fin spines of, 28, 29 (Fig. 33). 
Hydrolagus colliei, general anatomy of, IOO (Fig. IO4), I IO.

Hyperorartia, 62.

Iснтнуом, in classification, 8 .

Innes, W., I 49.

Integument, v. Shark, sense organs, etc.

Intestine, v. Digestive tract.

Ischyodus, I03 (Fig. I06); mandibular of, I06 (Figs. I I I, I I 2), I I 2.

Jaekel, O., 92, I I 3.

Janassa, 86.

Jaws of fishes, 24, 27; of Port Jackson shark, 24 (Fig. 27), 27; table of relations of, 254 (Figs. 310-3I5), $256,257$.

Journal of Morphology, quoted, 5 I note, 160.

Kepler, IV., I 30.

Klaatsch, phylogenetic table of, compared, 282.

Kner, 82.

Kreft, 125.

Kupffer, K. v., I87 note, I89, 222.

Labrax lineatus, v. Bass.

Lamargus, shagreen denticle of, 24 (Fig. 21), 25; described, 90 (Fig. $96 \mathrm{~B}$ ); breeding habits of, 183 and note.

Lagocephalus, description of L. lavigatus, I 76 (1 $84 A)$.

Lamna, 89, 90 (Fig. 96).

Lamprey, classified, 8; metamerism in, 14-16; gills of, I 7; v. Petromyzon, Cyclostomes, etc.

Lampreys, v. Cyclostomes, etc.; comparison table of the early development of, $280,28 \mathrm{I}$.

Lankester, E. R., 66.

Larva, v. Fishes, larval development of.

Lateral line, 48-53 (Figs. 6I-68); of Chimeroids and shark, $\mathrm{I}_{14}$; in Coccosteus, I 35 .
Lepidosiren, in classification, 8; swimbladder of, 22 (Fig. 18); account of, I 25 (Fig. 129), I 26; swimbladder, tables of, 264, 265 (Fig. I8).

Lepidosteus, in classification, 8; antiquity of, 9, I66 (Fig. I 7 I $A$ ); swim-bladder of, 21, 22 (Fig. I4); ganoid dermal plates of, 24, 25 (Fig. 24); especial interest of gar-pike in connecting the Ganoids with the Crossopterygians, I 59; gar-pike, $L$. platystom us, described, I 59-I60 (Fig. I57); eggs and breeding habits of, I 8 I (Fig. I93), I85; fertilization of, I 87 ; development of egg of, 203 (Figs. 265-268), 207; heart, conus and bulbus arteriosus, 258 (Fig. 322); comparison tables of heart, etc., 260; gills, spiracle, gill rakers, and opercula, tables, 26I ; digestive tract, tables, 263; swim-bladder, tables, 264, 265 (Fig. I4); genital system, tables, 266; excretory system and urinogenital ducts, 27 I.

Leptolepis, $165 ;$ L. sprattiformis, 165 (Fig. I 70).

Leydig, F., 5 I note.

Limb structure in Dipnoans, I 29.

List of names of authors and of their works, $23 \mathrm{I}-25 \mathrm{I}$.

List of the derivations of proper names, 227-230.

LOPHOBRANCHI, I66 (Fig. I 7 I $A$ ), 178.

Lung-fishes, v. Dipnoans.

Lungs, v. Swim-bladder.

Mackerel shark, v. Lamna.

Mackerel, Spanish, movement and fins of, 2, 3 (Fig. 3); front view of, 4 (Fig. 4); lines of, 5 (Fig. 6).

Macropetalichthys, eyes of, 135 .

Manatee, fish-like form of, 6 .

Mandibles of Chimæroids, $1_{13}$; articulation of in Dipnoans, I 29.

Mantis, or devil-ray, v. Dicerobatis.

Marey, 2. 
Marsipobranchs, v. Cyclostomes; tables of the early development of, 28o, $28 \mathrm{I}$.

McClure, I 82.

Mechanical adaptation of the fish's form, 5,6 .

Median fins, v. Fins.

Megalurus, I65; M. elegantissimus, I 65 (Fig. I 7 I).

Megaptera, v. Whale; $M$. longimana, numerical lines of, 5 (Fig. 7), 6I.

Menaspis, skin defences of, I I 3 .

Menhaden, v. Brevootia.

Metamerism, vertebrate, of fishes, 1416; of lampreys, I5; of sharks, 16.

Miall, L., 126.

Microdon, I57; M. wagneri, 158 (Fig. I63).

Mivart, St. G., 40

Mordern fishes, v. Teleostomes.

Mollier, S., 39.

Monk-fish, v. Rhina.

Mormyrus, I 71, I 72; M. oxyrhynchus, 172 (Fig. 179).

Morphology, Journal of, quoted, 5 I note.

Mouth of fishes, v. Jaws, Teeth, etc.; of catfish (a Teleostome), 64 note.

Movement in water, I, 2 (Figs. I and 2).

Mucous canal system, v. Lateral line.

Müller, Johannes, 145.

Mullet, gills of, 20 .

Murena, 173 .

Myliobatis, v. Eagle-ray.

Mylostomids, in classification, 8; trunk of, I36; jaws of Mylostoma variabilis, 136, 137 (Fig. 138).

Myriacanthus, in classification, $S$; restoration of, 104; head region of, I05 (Fig. I06); dermal plates of head and snout, I05 (Figs. I06, $A$ and B), I I3; mandibular, I06 (Fig. 107); dorsal spine, I07 (Fig. I14); dental evolution, I I2; shagreen tubercles and dermal bones and plates, 105 (Fig. I06), 107 (Fig. I I4), I I3.
Myxine, classification, 8; gills of, I7 (Fig. Io), IS; general description, of $M$. glutinosa, 59, 6o (Fig. 7I), 61 (Fig. $72 B$ ); eggs of, I 80-182 (Fig. I87); genital system, tables of, 266; excretory system and urinogenital ducts, 270 .

Myxinoid, Californian, gills of, I8; teeth of, 57; eggs of, I 82 (Figs. I 86 $A$ and $187 A$ ); comparison tables of the early development, $280,28 \mathrm{I}$.

Names, list of authors and their works, 23I-25I.

Names, list of derivations of, 227-2jo.

Nares, in Dipnoans, 129.

Natterer, J., I 25.

Necturus, swim-bladder of, $2 \mathrm{I}$.

Nervous system, central, 272 (Figs. 339-341), 273 (Figs. 342-344), 274,275 .

Newberry, J. IV., 78, 106, I 20, I 30, I3 I, I32, I 36.

Newton, 106.

Nicholson, H. A., 125.

Notacanthus sexspinis, I68 (Fig. I 74).

Notidanus, antiquity of, 9; gill slits, 16, 19; pectoral fin, 40-42 (Fig. 52), 44, 45; described, 87-89 (Fig. 93); affinities, 96; skull, jaws, and branchial arches of, 254 (Fig. 3II).

Numerical lines of fishes, 5, 6 (Figs. $5^{-8)}$.

Onychodus, in classification, 8.

Operculum of Teleosts, 19 ; comparison tables of, 260.

Ophidium, barbels of, 46, 47 (Fig. 55).

Opisthure, I I I.

Osteolepis, in classification, 8; description of, I5O, I5I (Fig. I52).

Ostracoderis, classified, 8 ; antiquity of, 9; description of, 65-71; types of, 67 ; affinities of, 66 (Fig. 77), 70 ; list of authors and works on Ostracoderms, 238. 
Paddle-tish, v. Polyodon.

Palcaspis americana, 67 (Fig. 75); paired fins or spines, 7 I note.

Palcadaphus, median foramen, 55 .

Palconiscus, in classification, $157,{ }_{5} 8$

(Fig. I64); Palæozic, I66 (Fig. I 7 I $A$ ).

Palcospondylus, in classification, 8; antiquity of, 9, 7I; P. gunni, 65 (Fig. 73), 70; palæichthyic affinities, 70; list of authors and their works on Palcospondylus, 238.

Pander, I2I, I 5 I.

Paraliparis bathybius, 168 (Fig. I72). Parexus, pectoral fin of, 42 (Fig. 5I), 44.

Parker, IV. N., 7, II 7, I27, I28.

- - T. J., 4 I, $5^{8 .}$

Parsons, 5, 6.

Perca, v. Perch.

Perch, antiquity of, 9; scales of, 25 (Fig. 3I A), 26, I 7I; described, 174; Perca americana (= fuviatalis?), I73 (Fig. ISI); digestive tract, tables of, 262 (Figs. 326-33I).

Petalodonts, 86.

Petromyzon, 6I ; P. marinus, 60 (Fig. 72), 61 (Fig. D), 62; skeleton of, ${ }_{5}^{8}$ (Fig. 69); eggs of, I80-1 83 ; eggs of $P$. marimus, $18 \mathrm{I}$ (Fig. 188); fertilization of eggs, I 87 ; development of, ISS-192; development of $P$. planeri, I 89 (Figs. 200214); digestive tract, tables of, 262 (Fig. 326); genital system, tables of, 266; urinogenital ducts and external openings, 267 (Fig. 332); excretory system and urinogenital ducts, 270; brain of, 272 (Fig. 340); central nervous system, 274.

Phaneropleuron, in classification, 8; description of, I 22 (Fig. I26).

Phocana lineata, v. Porpoise.

Phylogeny, tables of, 98 (Fig. I03), I66 (Fig. I 7 I $A$ ); comparison of the phylogenetic tables of the different authors, $282,283$.

Phyllopteryx, I 78 .
Physostome, 166 ( I 7 I $A$ ).

Pineal eye, 53-56.

Pipe-fish, v. Syngnathus.

PIsces, v. Fishes.

Plectognathi, i 76.

Pleuracanthus, in classification, 8; gill slits, I6; a fossil shark, 78 ; anatomy and skeleton of, $\delta_{3}$ (Fig. 90); dermal bones of head roof, 84 (Fig. $90 A$ ); teeth of, 84 (Fig. $90 B$ ); affinities of, 95,98 (Fig. I03); anterior spine of dorsal fin, I I4; tail of, II 5; Coccosteus compared with, I $3 \mathbf{I}$.

Pleuropterygil, in classification, 8.

Pogonias, v. Drum-fish.

Pollard, H. B., 64, I I 3, I 32.

Polyodon, barbels of, 46, 47 (Fig. 59), 48; described, I60-163; P. spatula, I62 (Fig. I66 B); gills, spiracle, gill rakers, and opercula, tables of, 261.

Polypterus, swim-bladder of, 21, 22 (Fig. I 7); origin of derm cusps, 30; caudal fin of, 36,37 (Fig. 47); tail of, II 5 ; skeleton of $P$. bichir, I44, I47 (Fig. I47); contrasted with Teleosts, I44; $P$. bichir described, I48 (Fig. I48), I 49 note; $P$. lapradei, 149 (Fig. I49); in table of phylogeny, I66 (Fig. I 7 I $A$ ); skull and branchial arches, 254 (Fig. 314); table of relations of skull and branchial arches, 257; comparison tables of gills, spiracle, gill rakers, and opercula, 26I ; digestive tract, tables, 263; swim-bladder, tables, 264,265 (Fig. I 7); excretory system and urinogenital ducts, tables, 270.

Porcupine-fish, v. Chilomycterus.

Porpoise, striped, lines of, 5 (Fig. 5). Port Jackson shark, v. Cestracion.

Powrie, S2.

Prionotus, barbels of, 46, 47 (Fig. 6o), 48.

Pristiophorus, antiquity of, 9; description of, 92 (Fig. 99); affinities of, 96-98 (Fig. I03). 
Pristis, antiquity of, 9; description of, 9I (Figs. 38 and $98 A$ ); affinities of, 96-98 (Fig. 103).

Pristiurus, larval development of, 215 , 2 I 6 (Fig. 284).

Protocercy, 35 .

Protopterus, swim-bladder of, 22 (Fig. I8); anatomy of, II6 (Fig. 12I); paired fin structure, I 8 (Fig. I22), II9; jaws and skull, II9 (Fig. $122 A$ ); account of, I26 (Fig. $129 A$ ); Coccosteus compared with, I3I; heart, conus and bulbus arteriosus, 285 (Fig. 325); comparison tables of heart, etc., 260 ; gills, spiracle, gill rakers, and opercula, tables, 26I ; digestive tract, tables, 262 (Fig. 329), 263; swim-bladder, tables, 264, 265 (Fig. I8); circulation in, tables, 269; excretory system and urinogenital ducts, 270; abdominal pores, $27 \mathrm{I}$; brain of, 273 (Fig. 343); central nervous system tables, 275.

Psammodus, dentition, 86 .

Psephurus, 160-163; P. gladius, I62 (Fig. I66 $A$ ).

Pseudopleuronectes, v. Flounder.

Pteraspis, antiquity of, 9; described, 67 (Figs. 74, 76, 77).

Pterichthys, antiquity of, 9; described, 69 (Figs. 80-82) ; Arthrodira associated with by Traquair, 130 .

Putnam, I82.

Pycnodont, $157,15^{8}$.

Rabbit-fish, v. Lagocephalus.

Rabl, C., I46; phylogenetic table of, compared, $28_{3}$.

Raja, v. Ray.

Rat-fish, v. Chimera.

RAY, in classification, 8; antiquity of, 9; shagreen of, 24 (Fig. 23); description of, 93-95 (Figs. IO0-102); barn-door skate (R. lavis), 94 (Fig. IOI); affinities, 95, 96, 98 (Fig. I03); eggs and breeding habits, I 81 (Fig. $189 A$ ), 183,184 .
Recent sharks, v. Sharks.

Relationships, v. Affinities, under the family and species.

Respiration, v. Aquatic breathing.

Retzius, G., phylogenetic table of, compared, 282.

Rhina, 91 (Fig. 97); affinities to shark, 96, 98 (Fig. 103); brain of, tables of, 272 (Fig. 34I).

Rhinobatus, antiquity of, 9; description of, 93 (Fig. IOO); affinities to shark, 98 (Fig. I03).

Rhyncodus, mandibular of, Io6 (Fig. I I I ), III.

Rückert, J., I $S_{7}$.

Ryder, J. A., 3I, 37, I I 5 .

Salensky, IV., 2 I 4 note.

Salmonid, antiquity of, 9; eggs and breeding habits, I86; skull and branchial arches, table of, 254 (Fig. 3I5), 257.

Sandalodus, dental plates of, 24 (Fig. 28), 28.

Scales, 23; of Teleost, 24 (Fig. 3I); degeneration of, 26.

Scaphaspis, 66 (Fig. 77), 67.

Scaphirhynchus, 160; S. platyrhyncus, I62 (Fig. I66).

Scomberomorus maculatus, 2, 3 (Fig.

3 ); front view of, 4 (Fig. 4); lines of, 5 (Fig. 6).

Sculpin, barbels of, 46,47 (Fig. 57).

Scyllizm, shagreen of, 24 (Fig. 22), 25, 90; eggs of, I8I (Fig. I89), I 83, I 84 and note; development of egg of, I93 (Figs. 216-230); larvæ of, 2I 5, 2 I 6 (Figs. 285-287); skull, jaw, and branchial arches of, 254 (Fig. 310), 256.

Sea-bass, v. Serranus.

Sea-cat, v. Chimara and Callorhynchuss.

Sea-horse, v. Hippocampus.

Sea-raven, v. Hemitripterus.

Sea-robin, v. Prionotus.

Seal, fish-like form of, 6 .

Selache, gills of, 20 . 
SelaChiI, in classification, 8 .

Semionotus, 157; S. kapffi, I57 (Fig. I6I).

Semon, R., I 25, r81, I99, 200, 219.

Sense organs, characters of, $46-56$; tables of, 276-277; integument and integumentary sense organs, tables of, $278,279$.

Sense of feeling, 46-48.

Sensory canals in head of Chimæra, 30.

Sensory tubules, v. Lateral line.

Serranus, eggs of, I8I (Fig. I96), I S6́; development of egg of $S$. atrarius, 208 (Figs. 269-283).

Shad, v. Alosa.

Shagreen denticle of shark, 23-25 (Figs. 20-22); of sting-ray, 24 (Fig. 23), 25 .

SHARKS, movement of, 2 ; in classification, 7,8 ; antiquity of, 9 , 10, 72 ; gills of, I7 (Fig. II), I9; spiracle of, I9; gill shields of, 20; skin, enamel, and dermal denticle of, 2326 (Figs. 20-22); shagreen denticle of the Greenland shark (Lemargus), 24 (Fig. 21); jaw of Port Jackson shark (Cestracion), 24 (Fig. 27), 27 ; evolution of the dermal armouring, 25, 26 (Figs. 25, 26); unpaired fins of, 33, 34 (Figs. 39-43); caudal fin of, 36-39 (Figs. 45-47); lateral line of, 49, 50 (Figs. 61, 62), 51, 76; description of, 72-98 (Figs. 83-103); position of, 72 ; general anatomy of, 73 (Fig. 83); skeleton of, $74-76$ (Fig. 84); sub-notochordal rod in skeleton, 76 (Fig. 85); integument of, 76 ; brain of, 76 ; nasal organ, eye, and ear, 76; renal and reproductive system of, 76 ; digestive tube, viscera, 77; heart, 77; claspers, 77; fossil sharks described, 7786 (Figs. 86-9I) ; teeth of fossil, 86; recent sharks, 87-95 (Figs. 92-IOI); affinities of, 95-98 (Fig. I03); eggs and breeding habits, I 8 I (Figs. I 89190), I $\delta_{3}, \mathrm{I} 8_{4}$; fertilization of eggs,
I 87 note; development of egg of, 194-198 (Figs. 216-230); larval development of, 215-218 (Figs. 284289); list of authors and their works on sharks, 238-244; comparison tables of the skeleton of, 252 ; skeleton of Cestracion galeatus, 75 (Fig. 84), 255; skull, jaws, and branchial arches, tables, 256; heart, tables, 258 (Fig. 3 I 7), 260; gills, spiracle, gill rakers, and opercula, tables, 262 (Fig. I I, p. 259); swim-bladder, tables, 264; genital system, tables, 266; urinogenital ducts and external openings, 267 (Fig. 333), and tables, 270; plan of circulation in, tables, 268 (Fig. 338), 269; abdominal pores, tables, $27 \mathrm{I}$; brain of, 272 (Fig. 34I); sense organs of, tables, 276; integument and integumentary sense organs, tables, 279; comparison tables of the early development of, $280,28 \mathrm{I}$.

Siluroid, antiquity of, 9; affinity and phylogeny of, I47, I66 (I7I $A$ ), I 7 I South American Siluroid ( $\mathrm{Cal}$ lichthy's armatus), I72 (Fig. I78); eggs and breeding habits of, I8I (Fig. I95), I 85, I 86 and note; heart, conus and bulbus arteriosus, tables of, 258 (Fig. 318 ).

Siphostoma, eggs and breeding habits of, I 86.

SiRENOIDEI, in classification, 8.

Skates, description of, 93-95 (Figs. 100-102) v. Ray.

Skeleton, v. Shark, Pleuracanthus, Chimæroid, Dipnoan, Ceratodus, etc.

Skin defences, v. Dermal and Teeth.

Skull of fishes, dermal bones of head root of Pleuracanthus, 84 (Fig. 90 $A)$; of Chimæroids, II 3 ; resemblances of skull of lung-fishes to Elasmobranchs, I28; of Dinichthy's intermedius, I 33 (Fig. I 33 and Frontispiece); table of relations of skull, jaws, and branchial arches of, 254 (Figs. 310-315), 256. 
Smithsonian Iustitution, Heptanchus, 88 (Fig. 93).

Solenostoma, eggs and breeding habits, 186.

South American lung-fish, v. Lepidosiren.

South American Siluroid, v. Callichthys. Spatularia, v. Polyodon.

Specialized fishes, defined, I 2.

Spines, 23; v. Fin spines, Clasping spines.

Spiracle of shark, I8; comparison tables of, 260.

Spook-fish, v. Chimæra and Chimæroids.

Spoon-bill sturgeon, v. Polyodon.

Squaloraja, in classification, 8; affinities of, 98 (Fig. 103); restoration of, 104, 105 (Fig. $106 A$ ); mandibular of, I06 (Fig. 108); frontal spine of, IO7 (Fig. I I 5); dental evolution of, I 12 ; skin defences of, I 13 .

Squalus, 89 (Fig. 94).

Squatina, v. Rhina.

Steindachner, F., r 49, 150.

Sticklebacks, v. Hemibranchiates.

Sting-ray, shagreen of, 24 (Fig. 23); dental plates of jaw, 24 (Fig. 29), 25; fin spine of, 28, 29 (Fig. 34).

Stomach, v. Digestive tract.

Strong, O. S., I I 2.

Structure, characteristic, of fishes, 14.

Sturgeon, v. Acipenser; spoon-bill sturgeon, v. Polyodon and Psephurus; shovel-nose sturgeon, v. Scaphirhyncus; a Liassic sturgeon, v. Chondrosteus.

Swim-bladder, hydrostatic, I, 2r, 22 (Figs. 13-19); of Amia, 21, 22 (Fig. 14); of gar-pike, 21, 22 (Fig. 14); of Dipnoans, 2I ; of Polypterus and Calamoichthys, 21, 22 (Fig. 17); of Necturus, 2I; of sturgeon, 22 (Fig. 13); of Teleosts, 22 (Fig. 13); of Erythrinus, 22 (Fig. 15); of Ceratodus, 22 (Fig. I6); of Lepidosiren. 22 (Fig. I8); of Protopterus, 22 (Fig. 18); of Dipnoans, 129 ; compared with reptiles, birds, and mammals, 20 (Fig. 19); comparison tables, 264, 265 (Figs. 1 3-19).

Swimming: eel, shark, mackerel, 2.

Symmetry of fishes, 4 .

Synechodus, dentition of, 86.

Syngnathus, I66 (Fig. I7I A) ; description of, 177, I $78 ; S$. acus, I 78 (Fig. $185 A$ ); eggs and breeding habits of, I 86 .

Tail, v. Caudal fins.

Teeth, general, 23, 24 (Figs. 27-30); description and evolution of, 27,28 ; of Port Jackson shark, 24 (Fig. 27), 27,86 ; of highly modified fishes, 28; of Myxinoids, 57; of Cladodus, 80 (Fig. $86 B$ ); of Acanthodopsis, 82 (Fig. $88 A$ ); of Pleuracanthus, 84 (Fig. $90 B$ ); of fossil sharks, 86 ; of Chimæroids, II3; resemblances of lung-fishes to Elasmobranchs as to teeth, I28.

Teleocephal, included in Actinopterygians, 8, 148; description and phylogeny of, 165,166 (Fig. $171 . A$ ). TELEOST, antiquity of, 9, I47; gills of, 17 (Fig. 12), 19; operculum of, 19; gill rakers of, 20; swim-bladder of, 22 (Fig. 13); swim-bladder of Erythrinus, 22 (Fig. I 5); scales of, 24 (Fig. 31); caudal fin of, 36,37 (Fig. 48); the term "Teleost" used in the popular sense to denote the modern "bony fish," 139; the perch a convenient type, I39; general anatomy of, I4I-I 45 (Figs. I45, 146); skeleton of Perca fuviatilis, 142 (Fig. 146); relationship and descent, I45-147; description and phylogeny of, 165, 166 (Fig. I $11 A$ ); modified conditions of, 167-17I; eggs and breeding habits, I 8 I (Figs. 196-199), 185, 186; fertilization of, 187 and note; development of egg, 207-212 (Figs. 260-283); larval development, 223-225 (Figs. 303309); list of authors and their 
works, 249-25I ; comparison tables of the skeleton of, 253; heart, conus and bulbus arteriosus, tables, $25^{8}$ (Figs. 324, 325), 260; digestive tract, tables, 262 (Fig. 331), 263; urinogenital ducts and external openings, 267 (Fig. 337), and tables, 27I; circulation in, tables, 269; abdominal pores, tables, $27 \mathrm{I}$; brain of, 273 (Fig. 344); central nervous system, tables, 275; comparison table of the early development of, $28 \mathrm{o}, 28 \mathrm{I}$.

Teleostomes, in classification, 7,8 ; antiquity of, 9, I0; mouth of, 64 note; opercular apparatus of, II4; tail of, I I 5 ; affinities to Arthrodirans, I36; general description of, I39I 78 (Figs. I 45-I $85 \mathrm{~A}$ ); skeleton of, I 4I-I43 (Fig. I46); visceral parts of, I43; contrasted with Ganoids, I44 (Fig. I47); Teleosts and Ganoids merged into one group by Prof. Owen, I46; descent of, I46; affinities with the Dipnoans generally admitted, I46; Rabl derives them from a selachian stem, I46; Beard and Woodward as to their descent, I46; two principal subdivisions of, 147; phylogeny, scheme of, 165, I66 (Fig. I7 I $A$ ); comparison tables of skeleton of, 253; table of relation of skull, jaws, and branchial arches, 257; heart, conus and bulbus arteriosus, tables, 260; gills, spiracle, gill rakers, and opercula, tables, 26I ; digestive tract, tables, 263; swim-bladder, tables, 264, 265 (Fig. I3); genital system, tables, 266; sense organs, tables, 277; integument and integumentary sense organs, tables, 279 .

Telescope-fish, v. Carassius.

Terrell, J., I 30.

Thacher, J., 40.

Thiollière, 58 .

Thrasher shark, v. Alopias.

Tissues, cellular elements of, in Dipnoans, $\mathbf{1 2 9 .}$.
Titanichthy's, pineal foramen of, 55, 56,135 ; size and localities of, 130 ; lip-like mandibles of, 136 ; mandibles of $T$. clarki, I36, I37 (Fig. I39).

Torpedo, 95 (Fig. I02).

Trachosteus, jaws of, 136, I37 (Fig. I 40).

Transactions of Edinburgh Society, quoted, 70.

Traquair, R. H., 65, 68, 70, 71, 78, I 28, I 30, I 32, I 56, I 57, I 59 .

Trygon, dental plates of jaw of, 24 (Fig. 29); fin spine of, 28, 29 (Fig. 34).

Turner, IV., 217.

Undina, I47, I 53; U. gulo, 154 (Fig. $5_{5} 6$ ).

United States Fish Commission Reports, quoted, 3, 89, 90, 92, 94, 95, 155, I60, I62, I63, I 7 I, I 73-1 77.

United States National Museum, Proceedings of, quoted, I03.

Urinogenital system, comparison tables of, 266, 267 (Figs. 332-337), 270, $27 \mathrm{I}$.

Urogymnus, shagreen of, 24 (Fig. 23).

Ventral plates of Coccosteus decipiens, I32 (Fig. I32).

Vertebral axis of lung-fishes, resemblance to Elasmobranchs, I 28.

Vienna collection, 149 note.

Visceral characters, resemblance between lung-fishes and Elasmobranchs, I28; of Teleost, I43; of Ganoids, 145 .

Walcott, 65 .

Ward, H. A., 75.

Whale, fish-like form of, 6 .

Whale, humplack, numerical lines of, 5 (Fig. 7).

Whiteaves, $\mathbf{1} 5 \mathbf{2}$.

Whitman, C. O., I87 note.

Wiedersheim, R., 40, II3.

Willey, A., I6. 
Wilson, H. V., 208.

Woodward, A. S., 8, 10, 24, 25, 33, $42,66,68-71,80,81,106,107$, I I 2, I 21, I27, I29, I3I, I 32, I35, $136,146,151,154,161,164,165$; phylogenetic table, compared, 282 . Works on the general subject, fishes, 231-234; on the Cyclostomes, 234238 ; on the Ostracoderms and Palcoospondylus, 238; on the sharks, 238-244; on the Chimæroids, 244; on the lung-fishes, $244-246$; on the
Ganoids, 246-249; on the Teleosts, 249-25I.

Xenacanthus, pectoral fin of, 39, 40 , 42 (Fig. 53), 45; v. Pleuracanthus.

Zittel, K. v., table of geological distribution of fishes, 9; quoted, $\mathrm{S} \mathrm{I}$, 82 , I04, I 24, I 57, I58, I64, 165.

Zoölogical Society, Proceedings of, 257 note. 


\section{Columbia University Biological Series.}

EDITED BY

\section{HENRY FAIRFIELD OSBORN,}

Da Costa Professor of Biology in Columbia College.

This series is founded upon a course of popular University lectures given during the winter of $1892-3$, in connection with the opening of the new department of Biology in Columbia College. The lectures are in a measure consecutive in character, illustrating phases in the discovery and application of the theory of Evolution. 'Thus the first course outlined the development of the Descent theory; the second, the application of this theory to the problem of the ancestry of the Vertebrates, largely based upon embryological data; the third, the application of the Descent theory to the interpretation of the structure and phylogeny of the Fishes or lowest Vertebrates, chiefly based upon comparative anatomy ; the fourth, upon the problems of individual development and Inheritance, chiefly based upon the structure and functions of the cell.

Since their original delivery the lectures have been carefully rewritten and illustrated so as to adapt them to the use of College and University students and of general readers. The volumes as at present arranged for include:

I. From the Greeks to Darwin. By Henry Fairfield OsBors.

II. Amphioxus and the Ancestry of the Vertebrates. By Arthur Willey.

III. Fishes, Living and Fossil. By Bashford Dear.

IV. The Cell in Development and Inheritance. By EdMund B. Wilson.

Two other volumes are in preparation.

$$
\text { MACMILLAN \& CO., }
$$




\section{FROM THE GREEKS TO DARWIN.}

THE DEVELOPMENT OF THE EVOLUTION IDEA.

BY

HENRY FAIRFIELD OSBORN, SC.D. PRINCETON,

Da Costa Professor of Biology in Columbia College.

Ready in September.

'This opening volume, "From the Greeks to Darwin," is an ontline of the development from the earliest times of the idea of the origin of life by evolution. It brings together in a continuous treatment the progress of this idea from the Greek philosopher 'Thales (640 B.c.) to Darwin and Wallace. It is based partly upon critical studies of the original authorities, partly upon the studies of Zeller, Perrier, Quatrefages, Martin, and other writers less known to English readers.

'This history differs from the outlines which have been previously published, in attempting to establish a complete continuity of thought in the growth of the various elements in the Evolution idea, and especially in the more critical and exact study of the pre-Darwinian writers, such as Buffon, Goethe, Erasmus Darwin, Treviranus, Lamarck, and St. Hilaire, about whose actual share in the establishment of the Evolution theory vague ideas are still current.

\section{TABLE OF CONTENTA}

I. The Anticipation and Interpretation of Nature.

II. Among the Greeks.

III. 'The Theologians and Natural Philosophers.

IV. 'T'he Evolutionists of the Eighteenth Century.

V. From Lamarch to St. Hilaire.

VI. The First Half-century and Darwin.

In the opening chapter the elements and environment of the Evolution idea are discussed, and in the second chapter the remarkable parallelism between the growth of this idea in Greece and in modern times is pointed out. In the succeeding chapters the various periods of European thought on the subject are covered, concluding with the first half of the present century, especially with the development of the Evolution idea in the mind of Darwin. 


\section{AMPHIOXUS AND THE ANCESTRY OF THE VERTEBRATES.}

$\mathbf{B P}$

ARTHUR WILLEY, B.SC. LOND.,

Tutor in Biology, Columbia College: Balfour Student of the University of Cumbridge.

Ready in September.

The purpose of this volume is to consider the problem of the ancestry of the Vertebrates from the standpoint of the anatomy and development of Amphioxus and other members of the group Protochordata. The work opens with an Introduction, in which is given a brief historical sketch of the speculations of the celebrated anatomists and embryologists, from Étienne Geoffroy St. Hilaire down to our own day, upon this problem. 'The remainder of the first and the whole of the second chapter is devoted to a detailed account of the anatomy of Amphioxus as compared with that of higher Vertebrates. The third chapter deals with the embryonic and larval development of Amphioxus, while the fourth deals more briefly with the anatomy, embryology, and relationships of the Ascidians; then the other allied forms, Balanoglossus, Cephalodiscus, are described.

The work concludes with a series of discussions touching the problem proposed in the Introduction, in which it is attempted to define certain general principles of Evolution by which the descent of the Vertebrates from Invertebrate ancestors may be supposed to have taken place.

The work contains an extensive bibliography, full notes, and 135 illustrations.

TABLE OF CONTENTS.

INTRODUCTION.

Chapter I. Anatomy of Amphioxus.

II. Ditto.

III. Development of Amphioxus.

IV. 'The Ascidians.

V. The Protochordata in their Relation to the Problem of Vertebrate Descent. 


\section{FISHES, LIVING AND FOSSIL.}

AN INTRODUCTORY STUDY.

BY

BASHFORD DEAN, PH.D. COLUMBIA,

Instructor in Biology, Columbia College.

This work has been prepared to meet the needs of the general student for a concise knowledge of the Fishes. It contains a review of the four larger groups of the strictly fishlike forms, Sharks, Chimaeroids, Teleostomes, and the Dipnoans, and adds to this a chapter on the Lampreys. It presents in figures the prominent members, living and fossil, of each group; illustrates characteristic structures; adds notes upon the important phases of development, and formulates the views of investigators as to relationships and descent.

The recent contributions to the knowledge of extinct Fishes are taken into special account in the treatment of the entire subject, and restorations have been attempted, as of Dinichthys, Ctenodus, and Cladoselache.

'The writer has also indicated diagrammatically, as far as generally accepted, the genetic relationships of fossil and living forms.

The aim of the book has been mainly to furnish the student with a well-marked ground-plan of Ichthyology, to enable him to better understand special works, such as those of Smith Woodward and Günther. 'The work is fully illustrated, mainly from the writer's original pen-drawings.

\section{TABLE OF CON'TENTS.}

CHAPTER

I. Fishes. Their Essential Characters. Sharks, Chimaeroids, Teleostomes, and Lung-tishes. Their Appearance in Time and their Distribution.

II. The Lampreys. Their Position with Reference to Fishes. Bdellostoma, Myxine, Petromyzon, Palaeospondylus.

III. The Shark Group. Anatomical Characters. Its Extinct Members, Acauthodian, Cladoselachid, Xenacanthid, Cestracionts.

IV. Chimaeroids. Structures of Callorhynchus and Chimaera. Squaloraja and Myriacanthus. Life-habits and Probable Relationships.

V. Teleostomes. The Forms of Recent "Ganoids." Habits and Distribution. The Relations of Prominent Extinct Forms. Crossopterygiaus. Typical "Bony Fishes."

VI. The Evolution of the Groups of Fishes. Aquatic Metamerism. Numerical Lines. Evolution of Gill-cleft Characters, Paired and Unpaired Fins, Aquatic Sense-organs.

VII. The Development of Fishes. Prominent Features in Embryonic and Larval Development of Members of each Group. Summaries. 






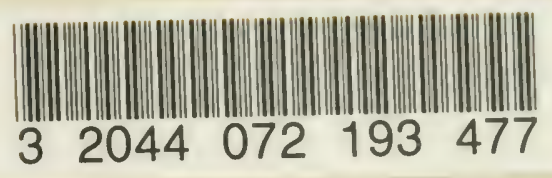


(15)

(⿻)

3.39
3 